Rohit Jain

Kosmopolitische Pioniere

Kultur und soziale Praxis 
Rohit Jain, geb. 1978, ist assoziierter Forscher am Institut für Sozialanthropologie und Empirische Kulturwissenschaft der Universität Zürich und arbeitet zur politischen Ästhetik transnationaler Öffentlichkeiten. Weitere Forschungsschwerpunkte sind Rassismus und Humor im Kontext von Anti-Political Correctness sowie postkoloniale Amnesie in Europa. Nach der Verteidigung der Dissertation an der Universität Zürich war er wissenschaftlicher Koordinator am »nccr - on the move«, dem Schweizer Forschungsschwerpunkt zu Migration und Mobilität (2014-2016). Seither ist er Geschäftsführer beim postmigrantischen Think \& Act Tank Institut Neue Schweiz (INES). 
Rohit JaIN

\section{Kosmopolitische Pioniere}

"Inder_innen der zweiten Generation" aus der Schweiz

zwischen Assimilation, Exotik und globaler Moderne 
Die vorliegende Arbeit wurde von der Philosophischen Fakultät der Universität Zürich im Herbstsemester 2014 auf Antrag von Prof. Dr. Shalini Randeria, Prof. em. Dr. Claudia Honegger und Prof. Dr. Gianni D’Amato als Dissertation angenommen.

Publiziert mit Unterstützung des Schweizerischen Nationalfonds zur Förderung wissenschaftlicher Forschung.

Forschung und Publikation wurden durch den Universitären Forschungsschwerpunkt Asien und Europa Zürich und das Asien-Orient-Institut der Unversität Zürich gefördert.

\section{(c) $(1) \Theta \Theta$}

Dieses Werk ist lizenziert unter der Creative Commons Attribution-NonCommercial-NoDerivs 4.0 Lizenz (BY-NC-ND). Diese Lizenz erlaubt die private Nutzung, gestattet aber keine Bearbeitung und keine kommerzielle Nutzung. Weitere Informationen finden Sie unter https://creativecommons.org/licenses/by-nc-nd/4.o/deed.de/.

Um Genehmigungen für Adaptionen, Übersetzungen, Derivate oder Wiederverwendung zu kommerziellen Zwecken einzuholen, wenden Sie sich bitte an rights@transcript-verlag.de

\section{(C) 2018 transcript Verlag, Bielefeld}

\section{Bibliografische Information der Deutschen Nationalbibliothek}

Die Deutsche Nationalbibliothek verzeichnet diese Publikation in der Deutschen Nationalbibliografie; detaillierte bibliografische Daten sind im Internet über http://dnb.d-nb.de abrufbar.

Umschlaggestaltung: Maria Arndt, Bielefeld

Umschlagabbildung: rashidinquilabgraphics, Karachi/Zürich, 2018

Druck: docupoint GmbH, Magdeburg

Print-ISBN 978-3-8376-4133-2

PDF-ISBN 978-3-8394-4133-6

Gedruckt auf alterungsbeständigem Papier mit chlorfrei gebleichtem Zellstoff. Besuchen Sie uns im Internet: http://www.transcript-verlag.de

Bitte fordern Sie unser Gesamtverzeichnis und andere Broschüren an unter: info@transcript-verlag.de 


\section{Inhalt}

Abkürzungsverzeichnis $\mid 9$

Vorwort und Danksagung | 11

1. Einleitung $\mid 17$

1.1 Verflechtungsgeschichtliche Skizze der indischen Migration in die Schweiz | 21 1850-1946: Kolonialer Handel, Lebensreformbewegung und Warenrassismus | 23

1947-1990: Nehruvianische Modernisierung, postkolonialer Braindrain, Assimilationspolitik und Hippiebewegung | 26

Ab 1990: Dezentralisierung des globalen Kapitalismus, IT und Bollywood $\mid 29$

1.2 Kosmopolitische Pioniere - eine Ethnografie von „Inder_innen der zweiten Generation" aus der Schweiz $\mid 32$

Die „neue zweite Generation“, globale indische Diaspora und die Nachkriegsmigration nach Europa und Nordamerika | 33

Die „zweite Generation“ in der Schweiz und im deutschsprachigen Raum $\mid 36$

Postkoloniale Amnesie und „unmögliche Subjekte“ | 39

1.3 Macht, Subjektivierung und Alterität: Eine Kritik der generationellen Rationalität | 41

Soziale Konstruktion von „Generationen“| 42

Genealogie: „Generation“ als doppelte Subjektivierung im Nationalstaat | 43

1.4 Transnationale Subjektivierungsprozesse in einer globalen Sozialtheorie $\mid 48$

Neue Perspektiven: Transnationalismus, kulturelle Globalisierung,

Diasporaforschung $\mid 48$

Transnationale Genealogie: Subjekte und Macht im dezentralen globalen Kapitalismus $\mid 51$

1.5 Methodik: Biografie, Ethnografie und Diskurse im transnationalen Feld | 54

Forschungsprozess und Sampling $\mid 56$

1.6 Aufbau $\mid 58$ 


\section{Teil A: Assimilation und „Leben zwischen den Welten“}

2. Die Geburt der "zweiten Generation“ im Assimilationismus | 65

2.1 „Assimilation“ und „Generation“ als biopolitische Technologien im modernen Nationalstaat | 67

Exkurs: Naturalisierung der „Zweiten Generation“ in der sozialwissenschaftlichen Migrationsforschung der Chicago School | 73

2.2 Schweizer nation building und Assimilationismus $\mid 78$

Die „zweite Generation“ als politische Größe | 78

Die Ethnisierung und Rassialisierung des Überfremdungsdiskurses $\mid 80$

Die biopolitische Neuordnung der Migrationspolitik nach dem Ersten Weltkrieg | 83

Der Assimilationismus der 1960er und 1970er Jahre als Subjektivierungsregime $\mid 85$

2.3 Fazit: Die assimilatorische Subjektivierungslogik der „zweiten Generation“| 95

3. "Zwischen den Welten"? - die "Migrationsfamilie" als semantischer Topos und soziale Arena | 99

3.1 Aftab: Die intellektuelle Suche nach eigenen Worten | 102

3.2 Maya: Wider den „Kulturkonflikt“| 106

3.3 Sonia: Verhandeln von Spielräumen im Familienidiom | 111

Exkurs: „Emigrationsfamilie“, Gender und Nation in transnationalen

Diskursen der indischen Mittelschicht | 115

3.4 „Arrangierte Heirat" und der assimilatorische Wille zum Wissen | 121

3.5 Raj: Der abwesende Vater und die „Suche nach den Wurzeln“ | 125

3.6 Fazit: Biografisch-ethische Projekte des Andersseins | 130

\section{Teil B: Exotik und globale indische Moderne}

\section{4. "Grüezi India“ - warenförmige Anerkennung und Exotisierung Indiens in der urbanen Schweiz | 137}

4.1 Kurze Genealogie eines kommerziellen Multikulturalismus in der (urbanen) Schweiz | 145

Zaghafte Ansätze eines politischen Multikulturalismus in der Schweiz | 148

Zürichs Aufstieg zur „Weltstadt“, Mediterranisierung des öffentlichen Raums und Indienhype $\mid 151$ „Showcase India“ - warenförmige Anerkennung in der urbanen Schweiz | 157 
4.2 Das „neue Indien“ im Schweizer Blick: Exotisierung zwischen ökonomischer Expansion und postkolonialer Verunsicherung | 162

Exkurs: Bollywood und Indiens Anspruch auf

den globalen Kapitalismus | 163

Hybride Formensprache indischer Exotik und Aneignung

von Globalisierung | 167

„Der Aufstieg des indischen Elefanten“ - zur Ambivalenz des neuen

Indiendiskurses in der Schweiz $\mid 171$

4.3 Fazit: Die Spaltung der „Zweiten Generation“ in „kosmopolitische

Exot_innen“ und „unassimilierbare Andere“| 174

\section{Yoga, Bollywood und IT - ethnic entrepreneurship,} Identitätskonsum und neue Gemeinschaften | 179

5.1 Sonia: „Globale indische Frau“ und kosmopolitischer Lebensstil | 184 „Indian brain“ und weibliche Respektabilität in der Bankenwelt | 185

Zwischen Diasporakultur und kosmopolitischem Lifestyle | 187

Exkurs: Das Scheitern indischer Wunschbiografien, amor fati und die Kontinuität des „Lebens zwischen den Welten“| 189

5.2 Maya: Selbstverwirklichung und kulturelle Übersetzung im Yoga-Boom | 192

Chancen und Grenzen des Yoga-Universalismus | 193

Die Konstruktion kultureller Übersetzung als Expertise und die Krise der Repräsentation | 196

5.3 Raj: Offenbarung, Identitätskonsum und Ironie unter „Indian brotha's and sista's"| 199

„Indian sista's and brotha's“: Offenbarung, Intimität und

performative Vergemeinschaftung | 201

Identitätskonsum und Ambivalenz der Kommerzialisierung | 202

Ironie und Parodie: Chancen und Tücken

experimenteller Authentizität | 204

5.4 Aftab: Das Management „interkultureller Probleme“ im globalen Kapitalismus | 207

Von der Biografie zum Geschäftsmodell an den Schnittstellen des globalen Kapitalismus | 208

Rationale Expertise über die Irrationalität Indiens $\mid 210$

Markteintritt als postkoloniales Abenteuer und ironische Kritik

des Eurozentrismus $\mid 212$

Authentifikation und Verdacht | 214

5.5. Fazit: (Un-)Doing „Indianness“ - Anerkennung, Nostalgie und Authentizität | 216 


\section{6. "Swiss Indian Dreams" - diasporische Subjektivitäten, globaler Kapitalismus und soziale Ungleichheit im "neuen Indien“ | 223}

6.1 „The global Indian family“ - die Subjektivierung der „Zweiten Generation“ im „neuen Indien“| 229

Die neuen Mittelschichten als Trägerschaft der hegemonialen

Konstruktion eines ,neuen Indiens“ | 230

„Diasporaisierung" und globale indische Moderne | 232

Bollywood als Leitmedium der globalen indischen Moderne:

Diasporische Narrative von Rückkehr und Konsum | 235

"The sun never sets on the Indian diaspora" - die Nation und ihre Diaspora $\mid 241$

6.2 Akash: Karriere, Nostalgie und Freiheit als „Swiss Indian Dream“| 248

Das letzte gemeinsame Diwali? - Feier der transnationalen indischen Familie | 251

Konsum, Bildung und Distinktion - das Ethos des kapitalistischen

Kosmopoliten | 253

Armut und Macht im NRI-Zirkel | 255

6.3 „Incredible India“ - ein familiäres Bildungsprojekt: Raj und Krish | 258

Indien - ein intergenerationelles Bildungsprojekt | 259

Kumta: Das „echte Indien“ zwischen Paradies und Armut $\mid 260$

Fabindia und Arundhati Roy: zwischen Teilhabe, Sozialkritik und Nostalgie | 264

6.4 Sonia, Gayatri und Asha: Verwerfungen von Geschlecht und Klasse in der "globalen patrilinaren Familie“ 267

Sonia: Kinderwunsch und Karriere | 268

Gayatri: Promotion, familiäre Solidarität und Sozialkritik im „neuen Indien“| 270

Asha: Weibliche Flexibilität zwischen neoliberaler Ressource und konservativer Disziplinierung | 274

6.5 Fazit: Privilegien und Ungleichheit im „neuen Indien“| 277

\section{Schlusswort: Kosmopolitische Ethiken in einem dezentralen globalen Kapitalismus | 281}

7.1 Kosmopolitische Subjekte: Zwischen Aspiration und Disziplinierung | 285

7.2 Das „Kosmopolitische“als hegemoniale Signatur eines dezentralen Kapitalismus | 288

7.3 Postkoloniale Verwerfungen: Ausblick auf Repräsentationspolitik und Ethik in einer globalen Ära | 291

8 Bibliografie | 295 


\section{Abkürzungsverzeichnis}

ANAG Bundesgesetz über Aufenthalt und Niederlassung vom 26. März 1931. Am 16. Dezember 2005 wurde es durch das Bundesgesetz über die Ausländerinnen und Ausländer (AuG) ersetzt.

BfS Bundesamt für Statistik der Schweiz.

BJP Bhartiya Janata Party (Indische Volkspartei), rechtsnationalistische indische Partei, 1980 gegründet, hat sich seit den 1990er Jahren als zweite staatstragende Partei neben der Kongresspartei etabliert.

BRIC Bezeichnung für die aufsteigenden regionalen Wirtschaftsmächte Brasilien, Russland, Indien und China (ehemals Schwellenländer), Begriff aus der Finanzanalyse (Jim O’Neill, Chef Volkswirt Goldmann Sachs).

DDLJ In Indien gängige Abkürzung für den Film „Dilwale Dhulania Le Jayenge“ („Der Beherzte gewinnt die Braut“, 1995), Bollywood-Blockbuster von Aditya Chopra.

EKA Eidgenössische Kommission für Ausländerprobleme (1983 aus der Eidgenössischen Konsultativkommission für das Ausländerproblem von 1973 entstanden). Heute EKM (Eidgenössische Migrationskommision).

IAZ Indian Association Zurich, gegründet 1954 von indischen Studierenden der Eidgenössischen Technischen Hochschule in Zürich (ETH).

NRI Non-Resident Indian, staatlicher Begriff aus den 1970er Jahren für Auslandsinder_innen im Westen.

OCI Overseas Citizens of India, seit 2003 Staatsbürgerschaftskategorie, gewährt alle staatsbürgerlichen Rechte ausser den politischen.

PIO Person of Indian Origin, seit 2003 Staatsbürgerschaftskategorie, die erleichterte Einreisebedingungen gewährt, 2015 abgeschafft.

RSS Rashtriya Swayamsevak Sanghatam (Nationale Freiwilligenorganisation), hindunationalistische Bewegung, gegründet 1925.

SVP Schweizerische Volkspartei, rechtsnationalistische Schweizer Partei, die sich seit den 1990er Jahren zur stärksten parlamentarischen Kraft entwickelt hat.

VB Volkart Brothers, Handelshaus Gebrüder Volkart, gegründet 1851 in Winterthur. 



\section{Vorwort und Danksagung}

Dieses Buch handelt von „unmöglichen Subjekten“, die zu kosmopolitischen Pionier_innen wurden. Und es handelt auch von der Verschiebung in den postkolonialen Verhältnissen zwischen der Schweiz und Indien, die zwischen den 1990er und 2010er Jahren stattfand, als sich kapitalistische Strukturen zunehmend dezentralisierten. Das Buch nimmt eine bestimmte Perspektive auf diese machtvollen, vielstimmigen Prozesse ein, die mit sozialem Wandel im Kontext von Migration, Kolonialismus und Globalisierung verbunden sind.

Die ethnografische Forschung zu diesem Buch fand zwischen 2007 und 2014 in einem bestimmten historischen Zeitfenster statt, das einen privilegierten Blick auf das Innenleben dieses sowohl brachialen als auch subtilen Werdens eröffnete:

Während die Wirtschaftskrise Europa - vor allem die südeuropäischen Länder - hart getroffen hatte, vermochte Indien diesen Schock als Wirtschaft mit dem zweitgrößten Wachstum relativ gut zu überstehen. Es waren geradezu Boomjahre in Indien und die wachsende Mittelschicht jubelte voller Stolz, als der britische Film „Slumdog Millionnaire“, der in Indien spielt, acht Oscars gewann - unter anderem für die beste Filmmusik des Bollywood-Komponisten A. R. Rahman. Davon wird in diesem Buch noch die Rede sein. Manmohan Singh von der Kongresspartei, der als Finanzminister die Liberalisierungsreform in den 1990er Jahren eingeleitet hatte, war nun Ministerpräsident und konsolidierte den indischen Anspruch wachsender Mittelschichten auf den Kapitalismus - was wiederum die Ungleichheit im Lande verstärkte. Der indische Kapitalismus war aber immer noch im Werden und die Erinnerungen an die Zeiten vor der Liberalisierung - sowie an Werte wie Säkularismus, Gandhi'sche Mäßigung und Nehru'sche Solidarität - lagen noch in der Luft.

Die Schweiz wiederum war von der Wirtschaftskrise nur gestreift worden. Es herrschte zwar - wie generell im „alten Europa“ - Katerstimmung und die rechtspopulistische Schweizerische Volkspartei ging seit 9/11 mit antiislamischen Parolen auf Stimmenfang. Immer noch herrschte eine gewisse Desorientierung nach dem Kalten Krieg, wenn auch der „Krieg gegen den Terror“ und neoliberale Ideologie Halt und Perspektive versprachen. Gleichzeitig wurden die Städte multikultureller und die nationale Schweizer Öffentlichkeit musste sich der Globalisierung 
stellen. Während die Populärkultur das indische Bollywood-Kino schon entdeckte hatte, wurden nun auch Staat, Medien, Forschung und Wirtschaft auf die Dynamik Indiens, namentlich auf dessen Märkte aufmerksam. Während die dezentrale Globalisierung dem Schweizer Modernisierungsmodell neue Möglichkeiten eröffnete, irritierte die Präsenz von selbstbewussten indischen IT-Ingenieur_innen und Tourist_innen die gewachsenen postkolonialen Identitäten.

Die Feldforschung in diesem Zeitfenster erlaubte auf den Spuren von „Inder_ innen der zweiten Generation" aus der Schweiz, mehr über das institutionelle und diskursive Werden dieses dezentralen Kapitalismus zu erfahren. Gleichzeitig war es eine Zeit, in der sich für „Inder_innen der zweiten Generation“ aus der Schweiz viele neue Optionen zwischen Assimilation, kommerziellem Multikulturalismus und globaler indischer Moderne eröffneten: Waren Kindheit und Jugend in den 1970er und 1980er Jahren geprägt von Assimilationsdruck und dem Gefühl „Zwischen zwei Welten zu leben“, fanden ihre Erfahrungen von kultureller Übersetzung, transnationaler Lebenswelt und Vielstimmigkeit im Kontext der intensiven Globalisierung sowohl in der Schweiz als auch in Indien zunehmend soziale Entsprechung und Anerkennung. Imaginäre Geografien, die zwischen dem „Westen“ und dem „Rest“, zwischen „Nord“ und „Süd“ unterschieden und damit immer auch eurozentrische Kategorien von „Moderne“ und „Tradition“ implizierten, brachen langsam auf, kamen in Bewegung.

Die heutige Zeit ist anders. Die Erinnerung an den 11. September 2001 als Ursprung eines „Kampfes gegen den Terror“ ist verblasst; antiislamischer Rassismus ist heute einfach Realität. Genauso wird Kapitalismus in Indien nicht mehr als Werden wahrgenommen, in einem Land, in dem über 50 Prozent der Bevölkerung nach 1990 geboren sind. Die postkolonialen Verhältnisse sind gekippt und wir leben in einer multipolaren Welt, in der die Dichotomie vom „Westen“ und dem „Rest“ offensichtlich nicht mehr gilt, auch wenn das nicht alle wahrhaben wollen. Der selbstverständliche Revisionismus eines Donald Trump, der unhinterfragte wirtschaftsnationalistische Chauvinismus von Narendra Modi oder der Aufstieg rechtsextremer europäischer Parteien wie der Alternative für Deutschland (AfD) sind in den je lokalen Zusammenhängen Reaktionen auf die Folgen der Dezentralisierung des Kapitalismus. Konnte man ab dem Millenniumswechsel noch zusehen, wie diese reaktionären Prozesse stattfanden, sind sie heute Realität, ohne dass ihr Werden noch einfach erinnert oder infrage gestellt werden könnte. Wenn sich die Zeit zwischen den 1990er Jahre bis in die frühen 2010er Jahren mit der Marx'schen und Engel'schen Wendung „Alles was fest ist, schmilzt in die Luft“ („All that is solid melts into air“) charakterisieren lässt, müssen wir uns heute eher an Gramsci orientieren: „Die alte Welt liegt im Sterben, die neue ist noch nicht geboren: Es ist die Zeit der Monster“. Schien die Zeit zwischen den 1990er und den frühen 2010er Jahre also geprägt von der Entkoppelung und dem Verflüssigen überkommener Strukturen, Diskurse und Imaginationen, hat seither das Arrangement des Neuen, die Institutionalisierung des Kommenden solidere Züge angenommen. 
Der genealogische Fokus auf Subjektivierungsprozesse von „Inder_innen der zweiten Generation“ zwischen Assimilation, Exotik und globaler indischer Moderne ermöglicht eine historische Tiefenschärfe, mit der die strukturellen Prozesse hinter den schnell wechselnden politischen Debatten und individuellen Lebenssituationen sichtbar gemacht und analysiert werden können. Damit war die bewusste Entscheidung verbunden, Personen in die Forschung einzubeziehen, die zwischen 30 und 50 Jahren alt sind. Denn in ihren Biografien waren sowohl Erfahrungen der Assimilationspolitik als auch die Erfahrungen der aufkommenden Globalisierung, des indischen Entwicklungsstaates wie der Liberalisierung eingeschrieben, ja gespeichert. Wenn auch die Leben von jugendlichen „Inder_innen der zweiten Generation“ - oder von Jugendlichen der „zweiten Generation“ generell - in der Schweiz sich heute anders abspielen mögen als diejenigen der Protagonist_innen in diesem Buch, so argumentiere ich, dass die historisch-genealogischen Logiken von "Assimilation“, „Exotik“ und „globaler indischer Moderne“ weiterhin wirken, in bestimmten Konfigurationen der Gleichzeitigkeit und individuellen Überlappung.

Nicht nur ist der Gegenstand dieses Buches das Werden, auch der ethnografische Forschungsprozess, auf dem es basiert, ist davon geprägt sowie die darin involvierten Personen. In den lehrreichen Wanderjahren der Forschung habe ich in unzähligen Begegnungen, Gesprächen und Momenten zwischen Europa und Asien inspirierende Menschen getroffen, von denen ich gelernt habe, Wissenschaftler $\mathrm{zu}$ sein, das heißt wissenschaftlich zu schreiben und zu sprechen. Ich habe aber gleichzeitig eine soziale Position in einer postkolonialen Welt gefunden sowie eine kosmopolitische Ethik entwickeln können.

Ich möchte zu allererst den Personen hinter den Pseudonymen Aftab, Akash, Anil, Asha, Gayatri, Jasmin, Maya, Raj, Sonia, Sunil, Sushma und Tara danken, die die Protagonist_innen dieses Buches sind. Auch Dutzenden anderen „Inder_innen der zweiten Generation“ möchte ich danken, die zu den Erkenntnissen in diesem Buch beigetragen haben, auch wenn sie aus dramaturgischen Gründen nicht als Vorbilder für Figuren in diesem Buch dienten. Sie alle haben ihre Zeit, ihre Geschichten, ihre Erinnerungen - und zum Teil auch Unsicherheiten - mit mir geteilt. Einige von ihnen haben mir zudem auf gemeinsamen Reisen, Abenteuern, Festen oder Mittagessen tiefere Einblicke in ihre Lebenswelten, in ihre Familien, ihren Arbeitsalltag, ihre Freizeit und in ihre persönlichen Aspirationen gewährt. Mir ist bewusst, dass die Teilnahme an einer ethnografischen Forschung gerade für Menschen, die als (undefinierbare) Grenzgänger_innen oder gar als „Fremde“ früh gelernt hatten, ihre Innenwelt vor äußerlichen Zugriffen und Zuschreibungen zu schützen, nicht selbstverständlich ist - geschweige denn ein risikofreies Unterfangen. Es bedeutete eine Auseinandersetzung mit Routinen und Selbstbildern, mit Bewältigungsstrategien, Tabus, ja in einigen Fällen auch Traumata. Ich hoffe, ich bin mit dem Vertrauen, das mir entgegengebracht wurde, behutsam umgegangen. Ansonsten möchte ich mich entschuldigen. Ich hoffe zudem, dass meine 
Gesprächspartner_innen vom Austausch über Fremdsein und Transnationalität, über Assimilation und Exotik sowie über Gott und die Welt auch profitieren konnten - so wie ich. Dabei ist es wichtig zu betonen, dass die Figuren in diesem Buch insofern "fiktiv“ sind, als ihnen zwar bestimmte Personen als Vorbilder dienten, aber ich keinen Anspruch darauf erhebe, die Wahrheit über die dahinterstehenden Personen zu schreiben. Gegenstand dieses Buches sind nicht diese Personen selbst, sondern die Subjektivierungsprozesse, die sie prägen und die ich anhand der Charaktere dieser Ethnografie gemäß wissenschaftlicher Regeln analysiere und beschreibe. Dabei ist die ethnografische Sicht eine andere als eine von Freunden, Eltern oder gar die eigene auf sich selbst. Und natürlich ist die hier präsentierte Perspektive nicht abschließend, sondern unbedingt offen für Diskussion und Kritik.

In den ethnografischen Begegnungen haben mich besonders diejenigen Beteuerungen von einigen Gesprächspartner_innen berührt, dass sie während der Forschung über gewisse (gute oder schlechte) Erfahrungen in ihrer Biografie zum ersten Mal gesprochen haben respektive etwas über sich selbst und die Welt, in der wir leben, gelernt haben. Dies erhoffe ich mir auch von diesem Buch. Die Stimmen, Erfahrungen und Geschichten in dieser Ethnografie sind Teil der Wirklichkeit, ein Teil eines unterschwelligen Archivs von Wissen, von (Gegen-)Geschichten und von Utopien, die jedoch nur zu oft unter dem machtvollen Common Sense des „Eigenen“ und des „Anderen“ verborgen liegen. Dies gilt sowohl in den nationalen Öffentlichkeiten in der Schweiz und in Indien als auch in institutionellen Teil- und Suböffentlichkeiten wie in Unternehmen, Familien oder Vereinen.

Ziel dieser Ethnografie ist es, diesen Stimmen Gehör zu verschaffen, nicht weil sie per se wahr oder authentisch wären, sondern weil sie als gespeicherte Erfahrungen Teil der sozialen und politischen Wirklichkeit sind, aber in deren Konstruktion kaum anerkannt werden, geschweige denn adäquat daran teilhaben. Ich würde sogar behaupten, dass diese und andere Stimmen, gerade weil sie sich an Rändern und in Zwischenräumen der Gesellschaft entwickelt haben, einen kritische Perspektive auf die Normen und Strukturen werfen, die uns tagtäglich dominieren sowie Ungerechtigkeit hervorbringen und Freiheit verhindern.

Bedanken möchte ich mich auch bei meinen Kolleg_innen des Universitären Forschungsschwerpunkt (UFSP) Asien und Europa der Universität Zürich, mit denen ich das Graduiertenkolleg von 2007 bis 2010 bestritten habe, sowie bei den Fachvertreter_innen, die uns ein spannendes Programm geboten haben. Gemeinsam mit ihnen habe ich erfahren, dass interdisziplinäre Forschungszusammenhänge einen wichtigen intellektuellen Nährboden bieten, und auch, dass Wissenschaft ein Beruf ist. Die vielen Debatten zu „multiplen Modernen“ oder „kultureller Übersetzung“ mit Sinolog_innen, Historiker_innen oder Archäolog_innen sind zweifellos in diese Ethnografie eingeflossen. Mit einer gewissen Nostalgie denke ich an die intellektuelle Kultur am Lehrstuhl Randeria des Ethnologischen Seminars der Universität Zürich zwischen 2007 und 2014 zurück, in 
der ich vom Soziologiestudenten zum Sozialanthropologen wurde. In Kolloquien, Kaffeepausen, Seminaren und Retreats habe ich die postkoloniale Imagination, das ethnografische Handwerk und die theoretische Innovation kennengelernt, die die Sozialanthropologie als Disziplin und Ethik in unserer globalen Ära unersetzlich macht. Die Erfahrung des kritischen Austausches mit Gerhard Anders, Carlo Caduff, Anila Daulatzai, Evangelos Karagiannis, Tobias Rees, Stefanie Strulik, Roger Begrich, Nikolas Kosmatopoulos, Claudia Nef, Juliane Neuhaus, Matthäus Rest und mit den vielen anderen Studierenden, Doktorand_innen, Assistent_innen und internationalen Gästen am Lehrstuhl bleibt mir unvergessen und ist wohl der Hauptgrund, warum ich mich heute als Anthropologe bezeichnen kann.

Während mehrerer akademischer Gastaufenthalte, auf Kongressen und in Seminaren konnte ich meine Gedanken und Texte im Austausch mit vielen wunderbaren Forscher_innen schärfen. Besonders wichtig für das Verständnis einer rassismuskritischen Migrationsforschung in der Anfangszeit der Forschung waren die intensiven Gespräche mit Paul Mecheril, Urmila Goel und Michael Bommes sowie später mit Manuela Bojadžijev, Naika Foroutan, Kien Ngi Ha, Regina Römhild und Vassilis Tsianos. Ich möchte mich auch bei meinen Kolleg_innen aus dem informellen Forschungsnetzwerk zur postkolonialen Schweiz danken, namentlich Bernhard Schär, Francesca Falk, Barbara Lüthi, Res Zangger und vor allem Patricia Purtschert. Am Max-Planck-Institut in Göttingen hatte ich das Glück, inspirierende Gespräche mit Boris Nieswand, Ayse Caglar und Peter van der Veer zu führen. Aus der Feldforschung in Indien wird der Austausch mit Daniel Naujoks und Helen Schwenken rund um die Feierlichkeiten des Indischen Diasporatags 2010 in New Delhi unvergessen bleiben. Ich danke auch Patricia Uberoi, Rajni Palriwala, Ravi Sundaram und Meenakshi Thapan, dass sie für die Diskussion meiner Forschung ihre wertvolle Zeit geopfert haben.

Mein ganz herzlicher Dank richtet sich an meine „Doktormütter“ Shalini Randeria und Claudia Honegger, die mir Geist und Handwerk sozial- und kulturwissenschaftlicher Forschung vermittelt haben. Sie haben mich stets auf meinen intellektuellen Irrwegen unterstützt - mit dem Wissen, dass eigenständige intuitive Entscheidungen grundlegende Bedingungen für solide Forschung, kritisches Denken und gutes Leben sind. Mit der Unterstützung von Claudia Honegger habe ich mich eigenwillig in die Gefilde der postkolonialen Studien ,aufgemacht“, die heute meine intellektuelle Heimat geworden sind. Shalini Randeria hatte mich gleich beim ersten Gespräch überzeugt, dass die ethnografische Methode und die Anthropologie notwendig waren für meine Forschungsinteressen, und mir dadurch gleichzeitig den Zugang zu einer intellektuell-affektiven Haltung erlaubt, um in einer postkolonialen Welt engagiert zu sein.

Auch viele Erfahrungen seit dem Abschluss der Dissertation haben sich produktiv in diesem Buch niedergeschlagen. Ich danke dem Team und der Community des nccr - on the move an der Universität Neuchâtel, und insbesondere dem Direktor Gianni D’Amato, für die zwei Jahre als Scientific Officer, die mir 
erlaubt haben, meine Kenntnisse der internationalen Migrations- und Mobilitätsforschung zu erweitern. Besonders wichtig für den Geist dieses Buches war zudem meine Involvierung in ein wachsendes Netzwerk von Forschenden, Aktivist_innen und Kulturschaffenden zu einem großen Teil - aber nicht nur - mit Migrationshintergrund und of color, das in den letzten Jahren rassismuskritische und postmigrantische Debatten in der Schweiz lanciert hat. Die Mitwirkung an Projekten wie „Die Ganze Welt in Zürich“ zu Urban Citizenship sowie an „Laugh Up. Stand Up! Rassismuskritisches Humorfestival" in der Shedhalle Zürich, am Berner Rassismusstammtisch, am Salon Bastarde in Zürich oder am postmigrantischen Think \& Act Tank Institut Neue Schweiz bewiesen mir nicht nur die gesellschaftliche Relevanz akademischer Forschung, sondern auch das große Potenzial von migrantischem und postkolonialem Gegenwissen für eine gerechte, gesellschaftliche Transformation. Neben den vielen Mitstreiter_innen möchte ich ganz besonders Katharina Morawek, Kijan Espahangizi, Noémi Michel, Said Adrus und Tarek Naguib danken, die meine Perspektive auf die machtvolle Praxis von Wissensproduktion an den Schnittstellen von Forschung, Politik und Kultur maßgeblich verändert haben.

Die Zeit seit dem Beginn der Forschung 2007 waren nicht nur wissenschaftliche Lehrjahre sondern, auch private. Unterstützt auf diesem Weg haben mich stets meine Eltern und mein Bruder sowie meine Verwandten in Indien, in den USA, Grossbritannien und Hong Kong. Meine „Migrationsfamilie“ war meine erste Heimat, wenn sie auch im Kontext von Assimilation als exterritoriales Gebiet galt. In ihr habe ich die ersten Erfahrungen von kultureller Übersetzung, von Fremdsein und von kosmopolitischer Selbstsorge gemacht; Themen, die dieses Buch behandelt und die mich und diese heutige Welt weiterhin prägen. So gesehen ist dieses Buch auch Ausdruck meiner eigenen Aspiration eines guten Lebens zwischen Assimilation, Exotik und globaler indischer Moderne.

Der allergrößte Dank geht an Bea Glaser und meine Töchter Mina und Rani, die mich während dieser Zeit nicht nur stets inspiriert haben, sondern auch erduldet. Sie zeigen mir durch Kritik, Geduld, Liebe und viel Spaß, worum es in einem guten Leben gehen muss.

Schließlich möchte meiner Lektorin Anna E. Wilkens und dem Grafiker Roland Regner danken, die dem Rohmaterial sprachlich und visuell den notwendigen Schliff verpasst haben und ohne deren geduldige und engagierte Arbeit dieses Buch nie zustande gekommen wäre. 


\section{Einleitung}

My object has been to create a history of the different modes by which, in our culture, human beings are made subjects.

(Michel Foucault 1986a:208)

Wurzeln! Sehe ich aus wie ein Mangobaum?

(Bruno Ziauddin, 2010:15)

Das obige Zitat von Bruno Ziauddin stammt aus dem Buch „Curry-Connection. Wie ich zu fünf Tanten, 34 Cousins und einem neuen Namen kam“, das im Jahr 2010 im Rowohlt-Verlag erschienen ist. Darin erzählt der schweizerisch-indische Journalist, wie er im Jahr 2004 zum ersten Mal nach Indien reiste, um die Familie seines Vaters kennenzulernen - drei Jahre nach dessen Tod: Der Vater des Autor-Erzählers stammte aus einem ärmlichen muslimischen Dorf in Südindien und absolvierte in den 1950er Jahren dank eines Stipendiums eine Ausbildung am Royal Engineering College in London. Er arbeitete mehrere Jahre als Staudammexperte in Ghana und lernte auf einer Europareise seine spätere Ehepartnerin, eine Schweizer Krankenschwester kennen. Sie heirateten in Ghana und lebten vier Jahre im mondänen Alltag der britischen Kolonialelite. In den 1960er Jahren ließen sie sich in der Schweiz nieder, wo 1965 ihr Sohn Bruno zur Welt kam. Der Vater liebte die moderne europäische Hochkultur - insbesondere die britische - und hatte sich diese seit seinem Studium in London sukzessive angeeignet. Er hatte Beethoven in der Royal Albert Hall gehört, trank Scotch und las Rudyard Kipling. Auch den Assimilationsforderungen aus der Zeit der „Schweizermacher ${ }^{\text {“1 }}$ war der Vater gemäß der Wahrnehmung seines Sohnes nachgekommen und hatte die

1 | "Die Schweizermacher" ist ein Film von Rolf Lyssy aus dem Jahre 1978. Der Film schildert auf satirische Weise die Arbeit zweier Fremdenpolizisten, die gemäß der Schweizer Assimilationspolitik der 1960er und 1970er Jahre "Ausländer" hinsichtlich ihre kulturellen Eignung für eine Einbürgerung kontrollierten (s. Kapitel 2). Diese oft willkürlichen Kontrollen werden im Falle von binationalen Eheschliessungen bis heute durchgeführt, um so genannte "Scheinehen" zu identifizieren. 
Bezüge zu Indien aus dem familiären Alltag ausgeblendet. Bruno versuchte sich daher während Kindheit und Jugend - trotz einschneidender Erfahrungen von rassistischen Äußerungen gegenüber dem Vater in der Schweizer Öffentlichkeit als waschechten Schweizer wahrzunehmen. Fragen nach seiner Herkunft, die ihm aufgrund seines Namens und seiner hellbraunen Haut gestellt wurden, stellten den selbstverständlich erscheinenden Anspruch auf eine legitime Zugehörigkeit zur Schweiz sowie den Wunsch, nicht aufzufallen, infrage: „Wurzeln! Sehe ich aus wie ein Mangobaum?“, war eines seiner Mottos, um Zuschreibungen des Andersseins abzuwehren und um sich als „in der Schweiz geborener Schweizer“ zu legitimieren (Ziauddin 2010:73). Nach dem Tod des Vaters im Jahr 2001 realisierte Bruno auf schockartige Weise, dass der Vater zeitlebens viel engere Beziehungen zu seiner indischen Familie gepflegt hatte, als er offenbart hatte. Entgegen dessen Beteuerung, Tamilisch verlernt zu haben, hatte dieser regelmäßig mit seiner Familie in Indien korrespondiert und seinen Angehörigen jährlich Geld gesandt. Der Tod des Vaters und die Entdeckung des väterlichen „Geheimnisses“ lösten in Bruno eine existenzielle Auseinandersetzung mit der Geschichte seines Vaters, seiner Herkunft und mit sich selbst aus. In einer Mischung von Reisebericht, Autobiografie und culture clash comedy schildert Bruno Ziauddin im Buch „Curry-Connection“ diese (familien-)biografische Spurensuche. Im Zentrum steht seine erste Reise nach Indien, in der Bruno nicht nur das Herkunftsland seines Vaters kennenlernt, sondern auch Beziehungen zu seinen indischen Verwandten aufbaut. Aus der Perspektive des Kulturschocks - voller exotisierender Stereotypen, autobiografischer Selbstironie sowie persönlichen und politischen Reflexionen über Migrationsdiskurs und Rassismus in der Schweiz - offenbart "Curry-Connection“ die Verschiebung in Brunos subjektiver Erfahrung von Zugehörigkeit und Herkunft.

Ich war mitten in der Feldforschung, als ich auf „Curry-Connection“ stieß. Das Buch wurde in den Medien breit rezipiert und sehr positiv aufgenommen, im Feuilleton, in Gratiszeitungen und sogar in Talkshows. Mich berührte einerseits die Ehrlichkeit der Erzählung. Anderseits war ich erstaunt darüber, wie bekannt mir viele Erfahrungen, sprachliche Wendungen, aber auch Bilder erschienen, die in "Curry-Connection“ - aber auch in der medialen Rezeption - vorkamen. In der Präsenz des Buches, in der darin erzählten Geschichte und im kommerziellen Rahmen von dessen Rezeption verdichteten sich interessanterweise diejenigen Momente, die sich in der bisherigen Forschung über die transnationale Lebensführung von „Inder_innen der zweite Generation“" aus der Schweiz als die wesentlichen Kräfte herauskristallisiert hatten: Assimilation, Exotik und globale Moderne. Die Geschichte im und um das Buch bietet daher einen guten Ausgangspunkt für das Unterfangen dieser Ethnografie, „Inder_innen der zweiten Generation“ aus der Schweiz als kosmopolitische Pioniere zu verstehen:

1. „Curry-Connection“ schildert den Wandel in Brunos subjektiver Erfahrung von Zugehörigkeit nach dem Tod des Vaters und nach der Reise nach Indien. Versuchte 
er sich davor als „schweizerischer Schweizer“ zu definieren und seine Andersheit zu relativieren, muss er nach dem Tod seines Vaters die verschwiegene transnationale Verbindung im Zentrum seines Lebens akzeptieren und aushandeln. Markant zeigt sich der Wandel in Brunos Repräsentationspraxis, also zwischen dem im Buch beschriebenen assimilatorischen Wunsch, nicht aufzufallen und der performativen Selbstrepräsentation als schweizerisch-indischer Secondo, ${ }^{2}$ die mit der Publikation des Buches öffentlich manifest wurde. Dieser autobiografische Bericht wiederum ordnete sich durch eine stereotypisierende Bild- und Textlogik - wie sie etwa in Titel und Covergestaltung deutlich wird - in das Genre der culture clash comedy ein, wie es in Großbritannien etwa mit „Bend it Like Beckham“ (2002) oder in Deutschland mit „Kebab Connection“ (2005) breitenwirksam etabliert wurde.

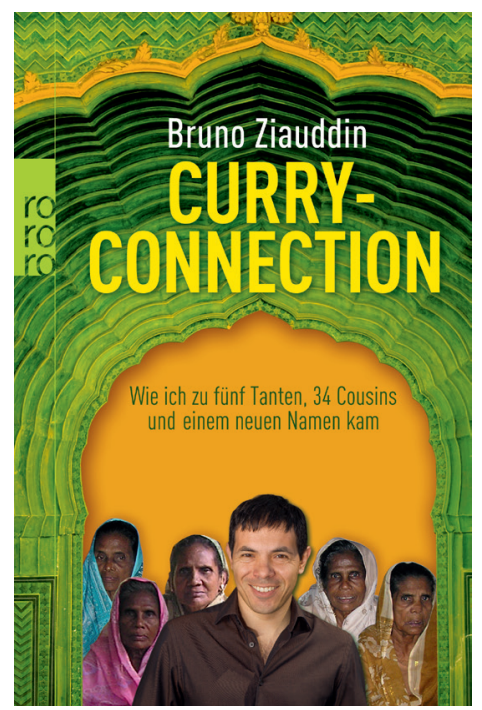

Abbildung 1: Buch-Cover von "Curry-Connection" verbindet autobiografische Selbstrepräsentation mit Ironie und Exotisierung (Quelle: www.rowohlt.de)

2 | Der Begriff Second@ wurde ursprünglich durch italienische Migrant_innen für ihre Nachfolgegenerationen geprägt. Seither ist Second@s in der Schweiz zu einem öffentlichen Begriff geworden, der zwischen politischer migrantischer Selbstrepräsentation, Diffamierung und Kommerzialisierung oszilliert (s. Kapitel 4). Der Begriff wird hier als feldimmanente Markierung der politischen Selbstrepräsentation von Mehrfachzugehörigkeit verwendet - und nicht als analytische Kategorie. Auch ist "Inder_innen der zweiten Generation" in Anführungszeichen gesetzt, um darauf hinzuweisen, dass dieser Begriff selbst im Feld von Fremd- und Selbstrepräsentation ausgehandelt wird (zur genauen generationentheoretischen und methodischen Konzipierung des Begriffs s. weiter unten in dieser Einleitung)." 
Aus anthropologischer Sicht stellt sich daher die Frage: Welche diskursiven und institutionellen Bedingungen regulierten Brunos Erfahrungen des Andersseins - sein Schweigen über sich selbst und seine Herkunft einerseits und seine öffentliche Selbstrepräsentation darüber andererseits - im biografischen Verlauf? Wie die folgenden Kapitel zeigen werden, entsprachen Menschen indischer Herkunft, die in der Schweiz aufgewachsen waren, nie vollständig den hegemonialen kulturellen Normen in der Schweiz. Sie wuchsen auf unterschiedliche Weise als „unmögliche Subjekte“ auf, für die kaum Vorbilder, kulturelle Erzählungen und öffentliche Räume existierten. Eingebettet in vielfältige - oft ambivalente - Subjektivierungslogiken, mussten - und konnten - sie sich eine "fragwürdige“ und „erklärungsbedürftige“ Zwischenposition sinnhaft ausbedingen und aneignen. So gelesen, schildert „Curry-Connection“ die spannungsvolle Sozialisation inmitten eines Schweizer Rassismus, der „anders“ macht, und des gleichzeitigen assimilatorischen Wunsches, darin nicht aufzufallen. Gleichzeitig beweist die Publikation des Buches Jahrzehnte später das Bedürfnis, diese „unerhörten Erfahrungen“ des Andersseins zu äußern, aber auch den plötzlichen Marktwert des Sprechens über kulturelle Differenz - insbesondere von „Indianness“ - im Kontext eines kommerziellen Multikulturalismus sowie angesichts des Aufstiegs Indiens zu einer regionalen Supermacht. Auf den folgenden Seiten soll untersucht werden, wie Subjektivierungsprozesse von „Inder_innen der zweiten Generation“ zwischen biografischer Eigenlogik und dem Wandel diskursiv-institutioneller Machtverhältnisse ausgehandelt wurden.

2. Das Buch „Curry-Connection“ zeigt zudem exemplarisch auf, wie schweizerisch-indische Migrationsbiografien und deren intergenerationelle Aushandlungen in transnationale Verflechtungsgeschichten eingebettet sind, die vom Kolonialismus bis in die heutigen Verhältnisse eines flexibilisierten, de-zentralen Kapitalismus reichen. Die Assimilation des Vaters an die britische Hochkultur ist genauso eingebettet in koloniale Zugehörigkeitslogiken wie die europäische und schweizerische Nachfrage nach indischen Ingenieuren in spezifische politisch-ökonomische Beziehungen der kolonialen und postkolonialen Arbeitsteilung. Wir können nicht verstehen, was in der Schweiz und Europa im Kontext von Migration und Globalisierung passiert, wenn wir diese Zusammenhänge ausblenden. Genauso wie Bruno Ziauddin für seine im Buch beschriebene Spurensuche den assimilationistischen „Container“ der Schweiz - sowohl räumlich als auch epistemisch - verlassen musste, um sich und seine Geschichte zu verstehen, muss auch die Erforschung dieser Prozesse selbst in einem globalen Rahmen stattfinden. Dadurch sollen „Inder_innen der zweiten Generation“ aus dem voraussetzungsvollen Blick der Migrationsforschung herausgelöst werden. Stattdessen sollen sie als Subjekte in Prozessen und Strukturen einer sich ausbildenden postkolonialen, globalen Moderne betrachtet werden. Wie in einem Prisma erscheinen sie als kosmopolitische Pionier_innen, deren Ethnografie aufzeigt, wie heutige Subjektivi- 
täten zwischen Nationalstaat und dezentralem Kapitalismus, zwischen lokalen Erfahrungen und transnationalen Lebenswelten, zwischen Eurozentrismus und postkolonialen Horizonten konstruiert und ausgehandelt werden. Die vorliegende Ethnografie ist somit auch ein theoretischer, methodischer und empirischer Versuch, transnationale Migrationsforschung mit Ansätzen aus den Postcolonial Studies und der Anthropologie der Globalisierung in Verbindung zu bringen, um zur Konturierung einer „globalisierten Sozialtheorie“ beizutragen (Randeria 1999b:373; Bhambra 2014).

Diese Einleitung steckt den Rahmen der Untersuchung ab: Zuerst wird die indische Migration in die Schweiz in eine kurze verflechtungsgeschichtliche Skizze der Beziehungen zwischen Indien und der Schweiz eingebettet. Im Rahmen der historischen Bewegungen von Menschen, Ideen, Geldern, Gütern und Objekten wurden die Protagonist_innen und die Statist_innen dieses Buches zu den Subjekten, die sie wurden und die sie noch werden können. Danach wird anhand bestehender Forschungen über die „Zweite Generation“ in Nordamerika und Europa sowie über die indische Diaspora die empirische und theoretische Spezifität von „Inder_innen der zweiten Generation“ aus der Schweiz als postkoloniale Pionier_innen herausgearbeitet. Weiter folgt eine theoretisch-kritische Reflexion über den Begriff der Generation im Spannungsfeld von biopolitischer Technologie und Lebensführung. Sie dient dazu, den klassisch soziologischen Begriff der (zweiten) Generation aus den politisch-epistemologischen Voraussetzungen des Nationalstaates (und damit auch der Migrationsforschung) zu lösen, das heisst aus einer Sicht auf die Realität von Migration und Mehrfachzugehörigkeit, die stark von politischen Annahmen und Interessen geprägt ist. Daraus eröffnet sich die Möglichkeit, sich Subjektivierungsprozessen von „Inder_innen der zweiten Generation“ über eine transnationale Genealogie zu nähern, wonach diese eingelassen sind in ein machtvolles globales Netz staatlicher Gouvernementalität, familiärer Disziplinierung und kapitalistischer Akkumulation. Schließlich werden verwendete Methoden und der Forschungsprozess kurz dargestellt.

\subsection{VerflechtungsgeschichtLiche SkizZe DER INDISCHEN MIGRATION IN DIE SCHWEIZ}

Wie das Beispiel von Bruno Ziauddins Familienbiografie zeigt, sind schweizerisch-indische Migrationsgeschichten sowie die damit verbundenen Subjektivierungsprozesse von „Inder_innen der zweiten Generation“ in transnationale Verflechtungsgeschichten eingebettet. Shalini Randeria hat mit den Begriffen der „geteilten Geschichten“ (Randeria 1999a, 1999b; Conrad/Randeria 2002) und der „entangled histories“ (Randeria 2002) eine relationale Perspektive benannt, um 
kulturelle und soziale Prozesse in machtvolle postkoloniale Beziehungen einzuordnen.

Einerseits kann man die Entstehung und Entwicklung der modernen Welt als „gemeinsame Geschichte“ lesen, in der verschiedene Kulturen und Gesellschaften eine Reihe zentraler Erfahrungen teilten und durch ihre Interaktionen und Interdependenz die moderne Welt gemeinsam konstituierten. Andererseits brachte die zunehmende Zirkulation von Gütern, Menschen und Ideen nicht nur Gemeinsamkeiten, sondern zugleich Abgrenzungen hervor, das Bedürfnis nach Partikularität und die Hypostasierung dichotomischer Strukturen, die das verbreitete Geschichtsbild nach wie vor dominieren. (Conrad/Randeria 2002:17)

Diese - von globalgeschichtlichen und postkolonialen Ansätzen beeinflusste Perspektive erfordert, die angeblichen Dichotomien zwischen dem „Westen“ und dem „Rest“ sowie zwischen „Moderne“ und „Tradition“, die die „imaginativen Geografien“" (Said 1978) seit dem Kolonialismus dominieren, nicht als analytische Grundlage, sondern als empirische Produkte von historischen Verflechtungen und Hierarchien zu untersuchen. Gemäß diesem relationalen Modell „verwobener Modernen“ (Randeria 1999a, 1999b) konnte das bürgerliche Europa erst im Kontext der kolonialen Verflechtungen sowohl die technologischen und wissenschaftlichen Mittel, die ökonomische Überlegenheit als auch das kulturelle und moralische Selbstverständnis hervorbringen, um sich in Abgrenzung zur „Tradition“ oder zur „Primitivität“ der „Anderen“ als Quelle und Inbegriff von Modernität zu definieren (exemplarisch für die vielen theoretischen und empirischen Studien aus dem Feld der postkolonialen Forschung: Conrad/Randeria 2002; Bhambra 2007). Gleichzeitig entstanden im Zusammenspiel globaler Begegnung und lokaler Bedingungen außerhalb Europas andere Konfiguration der Moderne, wenn auch die europäische Konfiguration lange eine Definitionsmacht beanspruchte und als hegemonialer Referenzrahmen akzeptiert wurde (Randeria et al. 2004). Diese verflechtungsgeschichtliche Fragestellung eröffnet eine neue Betrachtungsweise auf gegenwärtige globale Prozesse:

Wird der Blick erst einmal auf die Variationen der lokalen Produktion der Moderne gelenkt, öffnet sich die Möglichkeit, diese ethnographisch und auch vergleichend zu untersuchen. [...] Damit rückt das Handeln verschiedener Gruppen von Akteuren, die an diesen komplexen Prozessen der Interpretation, Übertragung, Aneignung und Aushandlung der Moderne unter sehr ungleichen Machtbedingungen beteiligt sind, sowie das im Interaktionsprozess hervortretende Neue in den Mittelpunkt der Betrachtung. (Randeria 1999b:379) 
Aus einer verflechtungsgeschichtlichen Perspektive lässt sich die indische Migration in die Schweiz in einem Raum verorten, der Kolonialismus und flexibilisierten Kapitalismus sowie Asien und Europa verbindet. Obwohl die Schweiz als Nationalstaat formal keine Kolonien besaß, waren die Beziehungen zwischen der Schweiz, der Welt und Indien geprägt vom europäischen Kolonialismus als hierarchischem Rahmen politischer, kultureller und ökonomischer Herrschaft. Schweizer Händler, Financiers, Missionare, Wissenschaftler und zum Teil auch Soldaten waren involviert in die europäische Expansion in Südasien und anderen Regionen der Welt. Dieses koloniale Engagement hat nicht nur zur Herausbildung von Industrie und Massenkonsum von Kolonialwaren in der Schweiz beigetragen. Die öffentliche Identifikation mit Aspekten der kolonialen Mission Europas brachte in der Schweiz das Selbstbild einer modernen europäischen Nation hervor (Purtschert et al. 2012; Zangger 2011). Die indische Migration in die Schweiz ist dementsprechend eingebettet in koloniale wirtschaftliche Beziehungen, in Muster internationaler Arbeitsteilung, in normative kulturelle Diskurse über das „Eigene“ und das "Andere" sowie in transnationale soziale Netzwerke, die die damit verbundenen Subjektivierungsprozesse prägen. Dies aufzuzeigen, ist ein wichtiges Ziel dieses Buches.

\section{0-1946: Kolonialer Handel, Lebensreformbewegung und Warenrassismus}

Das schweizerische koloniale Engagement in Indien bestand zu Beginn vor allem im Handel und in der Mission. Schweizer Firmen waren schon vom 18. Jahrhundert an beteiligt am lukrativen Handel mit bedruckten und bemalten Textilien aus Indien, sogenannten indiennes, aus dem sich im 19. Jahrhundert die schweizerische Textil- und Maschinenindustrie herausbildete (Imhasly 2008b). Ab 1834 war die Basler Mission, die durch die Basler Elite aus geistlichen und kommerziellen Motiven gegründet worden war, im kolonialen Indien präsent (Jenkins 1998). Ab Mitte des 19. Jahrhunderts konnte die Handelsfirma Volkart Brothers (VB) aus Winterthur vom britischen Regime des kolonialen Freihandels profitieren und übte als Quasi-Monopolistin im Baumwollhandel einen enormen Einfluss auf die schweizerisch-indischen Bewegungen von Menschen, Gütern, Bildern, Geldern und Ideen aus (Dejung 2013; Imhasly 2008b). Vor dem Ersten Weltkrieg waren fast alle großen Schweizer Unternehmen im indischen Markt präsent, wobei die meisten - wie Ciba-Geigy, Rieter, Sulzer oder BBC - von VB vertreten wurden. Bis zum Zweiten Weltkrieg waren die Schweizer mit 1500 Personen zur drittgrößten Emigrantengemeinschaft in Indien angewachsen (Schweizer 2008). Das Indienbild in der Schweiz wurde durch Erzählungen, Fotografien, Publikationen sowie durch Sammlertätigkeiten und Einfuhr von Souvenirs dieser Auslandschweizer_innen stark beeinflusst (Falk/Jenni 2012; Dejung 2013). 


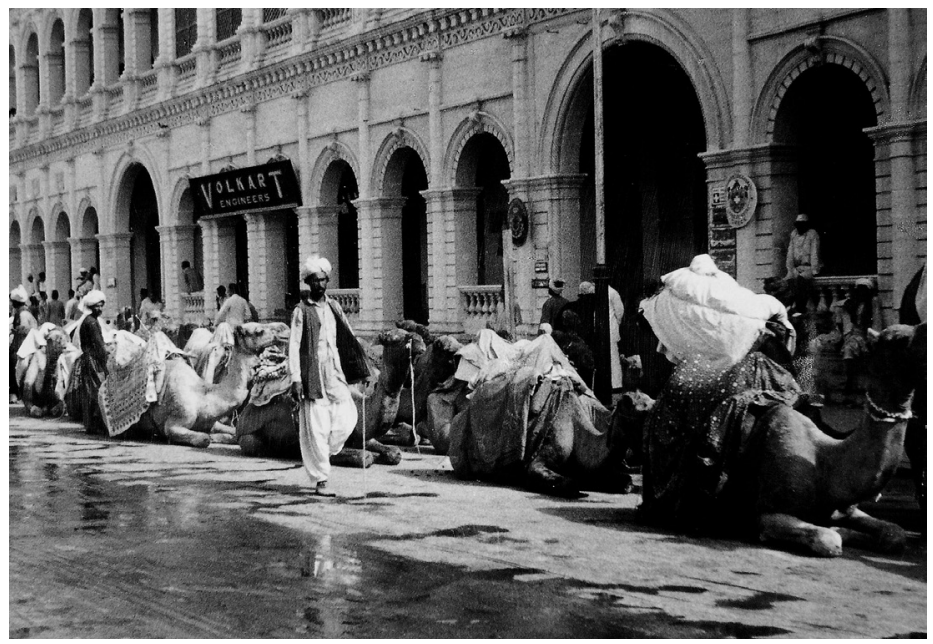

Abbildung 2: Die Handelsfirma Volkart Borthers verkörperte die koloniale Verflechtung zwischen Schweiz und Indien. Baumwollhändler vor dem Volkart-Gebäude in Karachi 1938 (Quelle: Stadtarchiv Winterthur)

Angesichts der engen kolonialen Verflechtungen zwischen Europa und Südasien waren in den wachsenden Städten spätestens im Fin de Siècle komplexe „colonial contact-zones" (Pratt 1992) entstanden, in denen ein Sammelsurium von Menschen, Gütern und Ideen aus aller Welt aufeinandertrafen. In den kosmopolitischen Räumen der Schweizer Städte bewegten sich indische Migrantinnen und Migranten oder temporäre Aufenthalter wie etwa indische Unabhängigkeitskämpfer (Fischer-Tiné 2014), indische Geschäftspartner, „Schausteller“ in Völkerschauen (Brändle 2013), Yogis, Diplomaten oder (andere) Angehörige der anglofonen indischen Oberschicht, die Urlaub machten, Kuren absolvierten oder Internate besuchten. ${ }^{3}$ Jedoch kann für diese Zeit nicht von einer eigentlich indischen oder südasiatischen Migrationsbewegung in die Schweiz gesprochen werden.

Ausgehend von diesen Kontaktzonen etablierte sich eine bis heute nachwirkende populäre Konstruktion eines imaginären Indiens, das zwischen den Bildern und Narrativen eines romantischen Orientalismus und eines evolutionistischen Kolonialrassismus oszilliert:

3 | Für die Zwischenkriegszeit hat Vikram Seth in "Two Lives" (2005) Urlaubspraktiken seines indischen Onkels beschrieben, der in Großbritannien studierte. Von Nehru ist bekannt, dass er sich 1926/27 mehrmals in der Schweiz aufhielt, weil seine Frau Kamla wegen Tuberkulose behandelt wurde (Schweizer 2008). Kamla starb 1936 in einen Sanatorium in Lausanne. Nehrus Tochter Indira, die später Premierministerin Indiens wurde, besuchte zu dieser Zeit ein Schweizer Mädcheninternat. 
1. Zum einen hatte sich etwa der Tessiner Monte Verità zum Zentrum für Mitglieder oder Sympathisanten der deutschen Lebensreformbewegung entwickelt, deren non-konformistische Lebensweisen und Weltanschauungen wie etwa Vegetarismus, Naturismus, Anthroposophie, Ausdruckstanz oder Pazifismus oft um die ästhetische Konstruktion des Orients und insbesondere Indiens als schöpferische Quelle kreisten (Schwab 2003; Museo d'Arte della Svizzera Italiana 2017). In der Tradition der deutschen Romantik versprach der gegenmoderne, schwärmerische Indiendiskurs einer bildungsbürgerlichen europäischen Bohème den Ausbruch aus dem „eisernen Käfig" der Rationalisierung und die politische, kulturelle und spirituelle Erneuerung Europas (Gandhi 2006). Verknüpft damit waren etwa die Gründungen der Theosophischen Gesellschaft in Genf, der ersten Schweizer Organisation moderner indischer Spiritualität oder des ersten vegetarischen Restaurants Hiltl im Jahr 1897, das ab 1952 indisches Essen anbot (allenfalls als erstes Restaurant in der Schweiz). Auch auf dieser Bewegung beruht die Institutionalisierung von Yoga in der Schweiz, die auf den Inder Selvarajan Yesudian und seine ungarische Partnerin Elisabeth Haich im Jahr 1949 zurückgeht.

2. Zum anderen verankerten Massenkonsum von indischen Kolonialwaren, populäre Völkerschauen, aber auch orientalistische Filme wie etwa Franz Ostens „Die Leuchte Asiens“ (1925) das imaginäre Indien seit dem Fin de Siècle in der öffentlichen Populärkultur. Parallel zur utopischen Schwärmerei der Lebensreformbewegung erlaubte ein „Warenrassismus“ der wachsenden Masse der Konsumenten, die exotisierende Faszination mit einer ostentativen zivilisatorischen Überlegenheit gegenüber traditionellen und heidnischen „Anderen“ $\mathrm{zu}$ verbinden (McClintock 1995). Besonders beliebt waren Völkerschauen, die das angeblich authentische Alltagsleben von außereuropäischen Menschen und exotischen Tieren als kommerzielles Bildungsspektakel für Hundertausende von zahlenden Gästen darboten (Brändle 2013). 1885 fand Hagenbecks berühmte "Singhalesen-Ausstellung“ statt. 1898 waren Hagenbecks „Indische Fakire“ zu besichtigen. 1900 folgte eine Schau über „Ceylon-Insulaner“ und zwei weitere Indien-Spektakel von 1905 und 1926/27. Mit ihnen fanden Elefanten den Weg in die Schweiz und erhielten dadurch ihren Platz als populärkulturelle Ikonen dieser frühen Globalisierung (s. Abbildung 3).

Sowohl die Utopie der Lebensreformbewegung als auch die rassistische Kommodifizierung indischer Exotik konstruierten Indien als "Spektakel des Anderen“ (Hall 1997) außerhalb der modernen europäischen Zeit und prägen das Indienbild bis heute. 


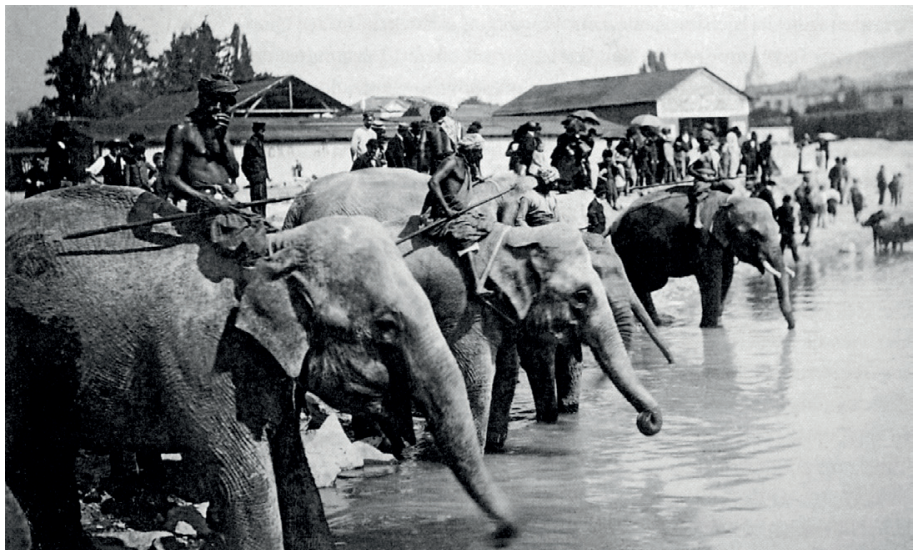

Abb. 3: Völkerschauen popularisierten das Bild Indiens zwischen Exotik und Primitivität. Schausteller und Elefanten in einer Werbeaktion für die "Singhalesen-Ausstellung" 1885 in Zürich (Quelle: Staatsarchiv Aargau).

\section{7-1990: Nehruvianische Modernisierung, postkolonialer Braindrain, Assimilationspolitik und Hippiebewegung}

Mit der Unabhängigkeit Indiens im Jahr 1947 verschoben sich die kolonialen Machtverhältnisse zwischen der Schweiz und Indien. Indien nationalisierte die Wirtschaft und ließ nur noch Joint Ventures mit indischer Mehrheit zu, um die durch den Kolonialismus geschwächte lokale Industrie zu stützen. Mit einem schweizerisch-indischen Freundschaftsvertrag konnte die Schweiz im Jahr 1948 die Doktrin der Neutralität institutionalisieren, und damit die wirtschaftlichen Interessen ihrer Unternehmen - vor allem von VB - schützen (Schweizer 2008, s. Kapitel 4.2). ${ }^{4}$ Mit der Unabhängigkeit Indiens hatte sich also die Schweizer Position von einem kolonialen Junior-Partner der Briten in das Narrativ einer paternalistischen Freundschaft gegenüber dem sich modernisierenden Indien verschoben (Jain 2015). Ab den 1950er Jahren wurde Indien in das Programm der schweizerischen Entwicklungshilfe aufgenommen, später sogar als Schwerpunktland. Der humanitäre Diskurs von Armut, Unterentwicklung und Kastenwesen prägt die Schweizer Imagination Indiens bis heute. Diese Verflechtungen erklären wohl

4 | Auch dem ersten Premierminister Indiens, Jawaharlal Nehru, kam diese diplomatische und wirtschaftliche Beziehung entgegen. Gemäß seiner antikolonialen Doktrin sollte das unabhängige Indien eine nachholende Modernisierung vollziehen, ohne seine kulturelle Unabhängigkeit oder politische Souveränität zu verlieren: Die Schweiz war für Beziehungen mit Indien geeignet, war sie doch demokratisch und neutral sowie wirtschaftlich und technologisch stark. Zudem wurde dem kaschmirischen Brahmanen und Harrow-Schüler Nehru eine Schwäche für die Schweizer Berge nachgesagt. 
auch die langjährige Rolle Indiens als eines der wichtigsten außereuropäischen Partnerländer für Adoptionen in die Schweiz.

In dieser Zeit begann die eigentliche indische Migration in die Schweiz: Nehrus Politik hatte im Hinblick auf sein Projekt der Modernisierung die Hochschulbildung und insbesondere die Ingenieurswissenschaften gefördert, gleichzeitig aber den Abgängern aus den Mittelschichten nur wenig berufliche Perspektive geboten. Die Schweiz wiederum bildete seit jeher - und bis heute - zu wenig technische Experten aus und war schon damals auf ausländische Fachleute angewiesen. $\mathrm{Ab}$ den 1950er Jahren schickten Familien aus unterschiedlichen Segmenten der indischen Ober- und Mittelschichten ihre Söhne - und in einzelnen Fällen auch ihre Töchter - in die Schweiz. ${ }^{5}$ Die Emigration war für die meisten indischen Migranten eine Strategie der transnationalen sozialen Mobilität innerhalb einer hierarchischen postkolonialen Arbeitsteilung, wie sie Angehörige aus der Oberschicht - wie etwa Nehru oder auch Gandhi - schon während der Kolonialzeit praktiziert hatten. Vor diesem Hintergrund lässt sich die indische Migration in die Schweiz als Nebenfluss des Braindrains verstehen, der in den Jahrzehnten nach der Unabhängigkeit Indiens Millionen von Inderinnen und Indern aus der Mittelschicht in die USA, nach Großbritannien, Europa, Australien und Kanada führte (zur Übersicht Brown 2006). Während Schweizer Firmen und Universitäten indische Ingenieure oder Studierende direkt oder über Austauschprogramme rekrutierten, verfügten einzelne Familien aus der Kolonialzeit über Kontakte zu Schweizer Universitäten und Unternehmen - wie etwa zu ETH, Ciba-Geigy oder BBC. Während in Basel die Chemie- und Pharmaindustrie indische Migranten beschäftigte, waren es in Genf die UNO, in Zürich die ETH und die Dienstleistungsbranche und im Großraum Zürich die Maschinenindustrie - in Baden zum Beispiel die BBC (heute ABB-Alstom). Die meisten indischen Migranten heirateten nach einigen Jahren in Indien und ließen sich mit ihren Ehegattinnen oft wieder in der Schweiz nieder, wogegen eine nicht unbeträchtliche Minderheit Schweizerinnen heiratete. Die wenigen indischen Migrantinnen, von denen ich während der Forschung erfuhr, heirateten Schweizer Männer und ließen sich in der Schweiz nieder. 1980 lebten gemäß Bundesamt für Statistik 2229 Personen indischer Herkunft in der

5 | Die moderne indische Mittelschicht war ab Mitte des 19. Jahrhunderts aus der Nachfrage der Kolonialadministration und aus dem politischen Kalkül der Kolonialherren entstanden (Joshi 2001). Es sollte eine lokale Schicht von Inder_innen geschaffen werden, die die britische Sprache und Kultur und die europäischen modernen Errungenschaften verinnerlicht hatte und dadurch die koloniale Herrschaft über die "Rassengrenze" hinweg verkörpern würde, so die Taktik. Während es oft gerade diese Schichten waren, die die koloniale indische Moderne verkörperten und die Unabhängigkeitsbewegung mittrugen, hatten sie kaum traditionelle Privilegien wie Großgrundbesitzer, Aristokraten, Industrielle oder Geistliche und setzten primär auf (britische) Bildung und Familienzusammenhalt, um ihre sozialstrukturelle Position auszumarchen. 
Schweiz, 1990 waren es $5770 .{ }^{6}$ Von Anfang an war die indische Gemeinschaft in der Schweiz regional, religiös und sprachlich heterogen und geografisch verstreut. Seit den 1950er Jahren gründeten die Migrantinnen und Migranten neben informellen Netzwerken von ethnischen und religiösen Gemeinschaften auch pan-indische Kulturvereine, um religiöse und kulturelle Feste zu feiern, sich zu treffen und sich gegenseitig im Alltag zu unterstützen.

Diese erste Phase indischer Migration in den 1960er und 1970er Jahren fand statt, als die Schweiz ihr Wachstumsmodell der Nachkriegszeit neu regulieren musste. Eine De-Industrialisierung hatte begonnen, Arbeitsstellen in der Industrie wurden ausgelagert, wogegen die Tertiarisierung zunahm und neue Fachkräfte erforderte. Gleichzeitig etablierte sich die sogenannte „Überfremdungsbewegung“ von James Schwarzenbach, die die Reduktion des Ausländeranteils auf zehn Prozent forderte, was die Abschiebung von Hunderttausenden von südeuropäischen, vor allem italienischen Arbeitnehmerinnen und -nehmern aus dem Bau- und Gastronomiegewerbe sowie der Industrie - und wohl auch von indischen Migrant_ innen - zur Folge gehabt hätte. Um diese Forderung abzuschmettern, die dem Wachstum der Schweizer Wirtschaft geschadet hätten, etablierte der Bundesrat eine Assimilationspolitik, die eine Einbürgerung von „kulturell gut angepassten“ Individuen ermöglichte (s. Kapitel 2 und 3). Indische Migrantinnen und Migranten aus der Mittelschicht nahmen in dieser Konstellation eine einzigartige, aber auch widersprüchliche Position ein. Einerseits unterschieden sie sich in den meisten Fällen sozialstrukturell von nicht oder wenig qualifizierten südeuropäischen Arbeitsmigrant_innen. Ihre Legitimation als qualifizierte Fachleute schien nicht existenziell infrage gestellt - wenn auch in Indien erworbene Bildungsabschlüsse oft nicht anerkannt wurden.

Andererseits waren sie besonders von der gesellschaftlichen Assimilationsforderung betroffen, wonach sie als rassialisierte, außereuropäische „Andere“ als besonders unassimilierbar galten. Parallel erwachte das orientalisierende Indienbild durch die Hippiebewegung ab 1968 als gegenmoderne Projektionsfläche für Bestrebungen nach persönlicher und gesellschaftlicher Transformation zu neuem Leben. Indische klassische Musik, Yoga und hinduistische Heilslehren fanden Eingang in die Ikonografie der bürgerlichen Populärkultur und verbreitete ambivalente, exotisierende Subjektpositionen für indische Migrantinnen.

6 | Diese Daten stammen aus der Tabelle „Personen indischer Herkunft nach Geschlecht und Beruf, 1970-2000" des Bundesamtes für Statistik, basierend auf den Volkszählungen 1970-2000. Im Wert für 1990 sind auch eingebürgerte Personen indischer Herkunft einbezogen; die Einbürgerungen wurden erst ab 1981 statistisch erfasst. 


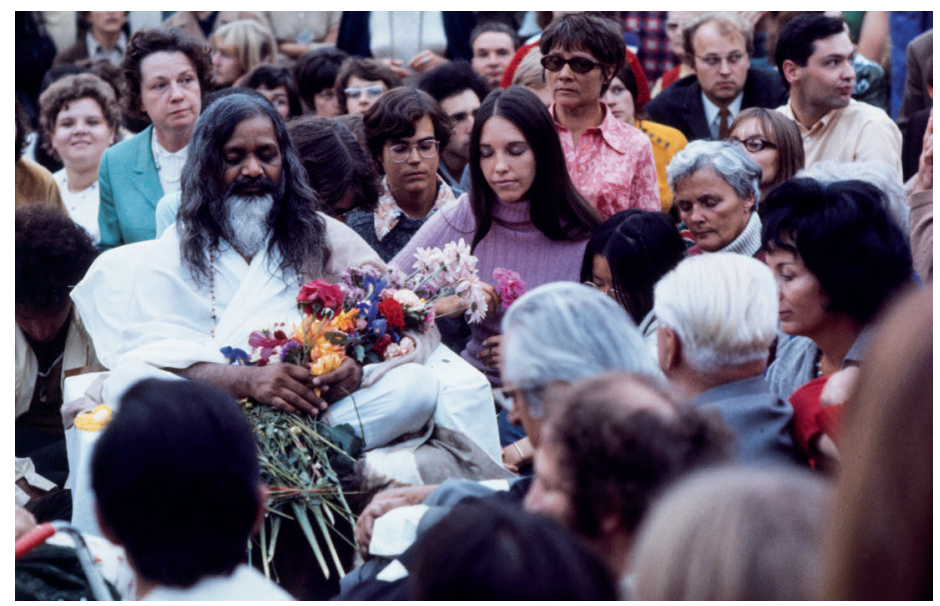

Abbildung 4: Indische Spiritualität fasziniert Hippies und die mediale Öffentlichkeit zugleich. Der indische Guru Maharishi Mahesh Yogi inmitten seiner Anhänger_innen in Seelisberg 1970 (Quelle: ETH Bildarchiv)

\section{Ab 1990: Dezentralisierung des globalen Kapitalismus, IT und Bollywood}

Ab den 1990er Jahren haben die Verflechtungen zwischen Indien und der Schweiz im Zuge der spezifischen Integration der beiden Länder in den wachsenden Weltmarkt weiter zugenommen. Schweizer Städteregionen wie Zürich, Genf oder Basel haben sich seither von fordistischen Industriestädten zu Knotenpunkten in einem globalen Dienstleistungskapitalismus umstrukturiert, in denen sich ein kommerzieller Multikulturalismus entwickelt hat (s. Kapitel 4). Indien wiederum leitete ab 1991 in einen einschneidenden Liberalisierungsprozess ein und hat sich nach der Nehruvianischen Planwirtschaft stärker in den globalen Markt integriert und eine pulsierende, urbane Konsumkultur entwickelt (s. Kapitel 6). Vor dem Hintergrund eines dezentralen Kapitalismus haben sich die Machtverhältnisse, die politisch-ökonomischen Beziehungen, die kulturellen Diskurse des „Eigenen“ und des „Anderen“ erneut verschoben. 

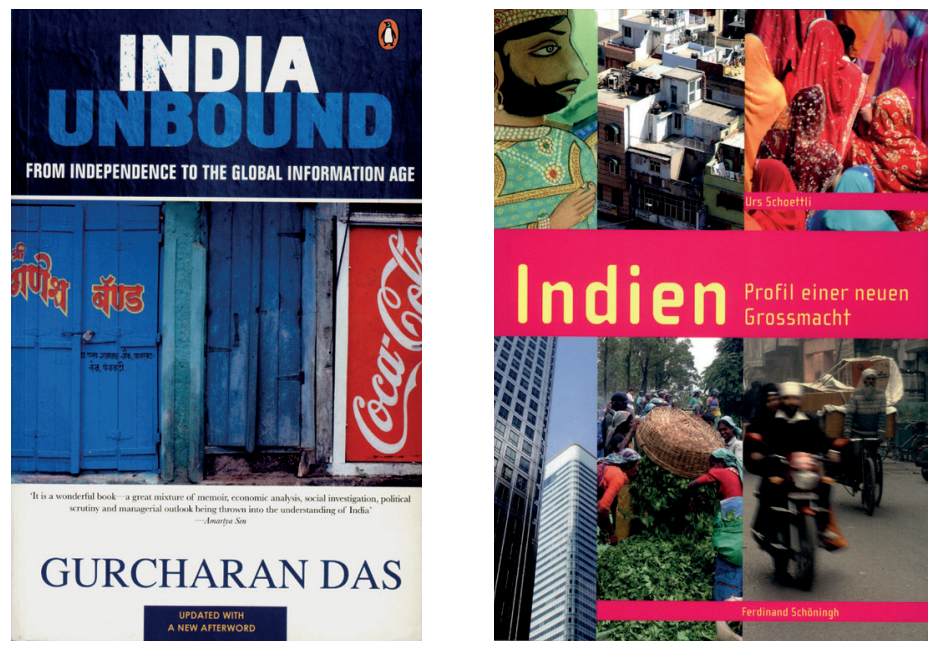

Abbildung 5a und 5b: Grossmachtphantasien in der Schweiz und Indien. Neue Bilder und Diskurse eines Indiens zwischen Tradition und globalem Kapitalismus (Quelle: Das 2000; Schöttli: 2009)

Atomwaffen, eine wachsende Mittelschicht, neue Märkte haben Indien von einem „Entwicklungsland“ in eine politische und ökonomische Regionalmacht verwandelt, was mit einem neuen Selbstbewusstsein, um nicht zu sagen: Chauvinismus einhergeht. Während Schweizer Staat und Unternehmen die neuen indischen Märkte anvisieren, bildet Indien seinerseits immer mehr hochqualifizierte Fachkräfte - etwa im IT-Sektor - aus. In dieser globalen Konstellation hat eine zweite Welle indischer Migration in die Schweiz stattgefunden. Die Rekrutierung von IT-Fachleuten, die in den 1990er Jahren noch vereinzelt geschah, hat ab dem Millenniumswechsel stark zugenommen, wobei immer mehr temporäre Projektteams mit Kurzaufenthaltsbewilligung engagiert werden. Auch die Präsenz von anderen professionellen Fachkräften - etwa aus dem Finanzwesen -, von Studierenden und wissenschaftlichem Personal hat zugenommen. Ab den 1980er Jahren wurden zudem Pflegefachfrauen aus Kerala, die davor oft in Österreich oder Deutschland gearbeitet hatten, mit Spezialbewilligungen in die Schweiz geholt, um den Arbeitskräftemangel im Intensivpflegebereich zu kompensieren (Gschwend 2007). ${ }^{7}$ Obwohl die Schweiz die Immigration Ungelernter von außerhalb Europas durch Selektion, nämlich mit einem Regime des sogenannten Drei- und später des Zweikreisemodells, verhindern wollte, hat ab den 1980er Jahren über Asylkanäle, Familiennachzug sowie mit Ausnahmebewilligungen, etwa für Mitarbeiter indischer

7 | Die Malayali bilden mit knapp 2000 Personen nicht nur die größte regionale indische Gemeinschaft der Schweiz, sondern wahrscheinlich auch die einzige sozial relativ homogene und eng vernetzte. 
Restaurants, eine zunehmende Migration von Menschen aus ländlichen, nordindischen Regionen, etwa aus Punjab, stattgefunden. Laut den Angaben des Bundesamtes für Statistik weilten 2015 ca. 22250 Personen indischer Herkunft in der Schweiz, davon ca. 20000 als Teil der ständigen Wohnbevölkerung (Staatsangehörige, Aufenthalter und Niedergelassene) und 2263 als Kurzaufenthalter oder Asylsuchende (mit Aufenthaltsdauer von bis zu zwölf Monaten). ${ }^{8}$

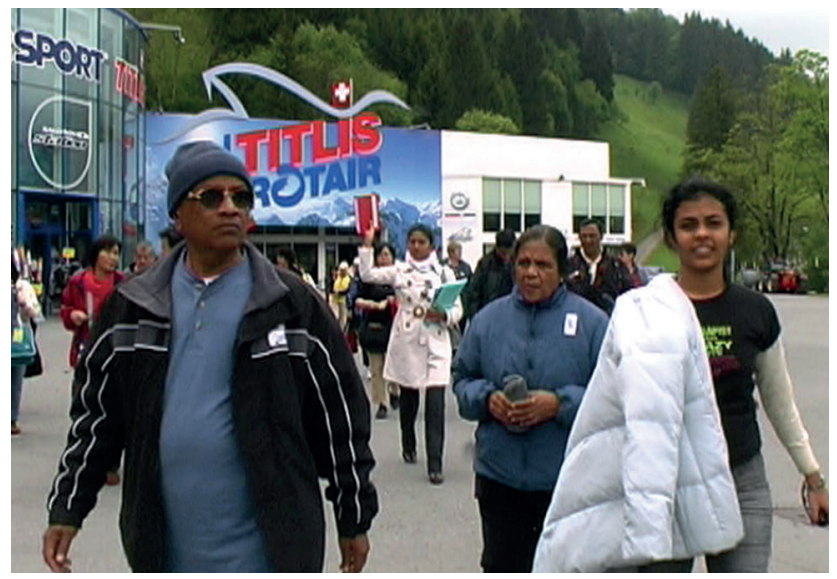

Abbildung 6: Indische Tourist_innen erobern die Schweizer Alpen. Videostill aus dem Film „Amazing Europe“ von 2007 in Engelberg (Quelle: Angela Sanders)

Neben diesen beruflichen und familiären Migrationsmustern hat zudem der Tourismus stark zugenommen und zur Präsenz von Personen indischer Herkunft in urbanen und touristischen Zentren geführt. Im Jahr 2000 betrugen die Logiernächte indischer Touristen und Touristinnen 179629 und hatten seit 1992 um 167,8 Prozent zugenommen (Keller 2002). Seither ist der Tourismus aus Indien weiter angewachsen und die Zahl der Logiernächte betrug 2016 gemäß Bundesamt für Statistik 599 062, womit der Tourismus aus Indien an 7. Stelle rangiert. ${ }^{9}$ Der

8 | Die Angaben basieren auf STAT-TAB „Wohnbevölkerung nach Jahr, Kanton, Geschlecht, Anwesenheitsbewilligung, Altersklasse, Bevölkerungstyp und Staatsangehörigkeit" (px-x-0103010000_115, basierend auf der Erhebung STATPOP des Bundesamtes für Statistik). Die approximative Angabe beruht darauf, dass die 6466 einbezogenen Einbürgerungen indischer Personen den Zeitraum von 1981 und 2015 abdecken (gemäß „Erwerb der Schweizer Bürgerrechte nach früherer Staatsangehörigkeit, 19812016", su-d-01.05.01.06) - aber davor auch Personen eingebürgert worden waren.

9 | Quelle ist die Tabelle „Hotels und Kurbetriebe: Ankünfte und Logiernächte in der Schweiz nach Gästeherkunftsland" (Januar-Dezember, cc-d-10.03.DD-04, basierend auf der Beherbungsstatistik HESTA des BfS)". 
Tourismus in die Schweiz war nicht zuletzt durch die Produktion von Sequenzen und Filmen des Bollywood-Kinos in den 1990er Jahren in den Alpen ausgelöst worden, in denen die Schweiz als romantisches Phantasma konstruiert wurde (Schneider 2002).

Die Präsenz indischer Tourist_innen und IT-Ingenieur_innen, aber auch von Bollywood-Filmen hat das Bild Indiens maßgeblich verschoben. Dadurch wurden Indiens Anspruch als aufstrebende Regionalmacht sowie die Dynamik eines dezentralisierten Kapitalismus sichtbar (Jain 2015, Kapitel 4).

\subsection{Kosmopolitische Pioniere - eine Ethnografie VON „INDER _ INNEN DER ZWEITEN GENERATION“ AUS DER SCHWEIZ}

Von den oben beschriebenen indischen Migrant_innen der „ersten Welle“, die zwischen den 1950er und 1980er Jahren in die Schweiz kamen, stammen die Protagonist_innen dieses Buches ab, wenn auch in sehr unterschiedlichen familienbiografischen Konstellationen. ${ }^{10}$ Einige von ihnen waren über ihre Eltern in indische Netzwerke eingebunden oder besuchten Anlässe der indischen Vereine. Andere haben nur wenig über ihre kulturelle Herkunft erfahren - so wie etwa Bruno Ziauddin. Da die Gemeinschaft sehr klein und zerstreut sowie ethnisch und religiös heterogen war, waren die Beziehungen unter Angehörigen der „zweiten Generation“ locker, die Netzwerke verzweigt und Treffen fanden unregelmäßig an Wochenenden statt. Ab der Adoleszenz wurden Bekanntschaften aus der Schule oder der Nachbarschaft wichtiger und Netzwerke unter „Inder_innen der zweiten Generation“ wurden nur selten gepflegt. Wie die Kapitel 2 und 3 ausführlich zeigen, existierten im Schweizer Assimilationismus kaum öffentliche Räume, in denen kulturelle Mehrfachzugehörigkeiten als legitim anerkannt wurden, geschweige denn nicht-weiße, außereuropäische Subjekte. Angesichts dieser sozialstrukturellen und soziokulturellen Voraussetzungen waren „Inder_innen der zweiten Generation“ in der postkolonialen Schweiz vor die Aufgabe gestellt, die an sie gestellten Fragen von Herkunft und Zugehörigkeit in intimen biografischen Prozessen selbst zu verhandeln.

10 | Da ich mich für den Einfluss von Biografien und diskursivem Wandel auf die Subjektivierung interessiere, beschränke ich mich in meinem Sample auf erwachsene "Inder_innen der zweiten Generation“. Das Sample berücksichtigt Personen, die ein oder zwei indische Elternteile haben, die im heutigen Indien (oder in einzelnen Fällen als koloniale Subjekte einer ehemaligen britischen Kolonie) geboren sind, und umfasst ca. 600 bis 800 Personen. 
Im Folgenden versuche ich einen kursorischen und gezielten Überblick über den für diese Ethnografie relevanten Forschungsstand zu geben um zu erläutern, wie und warum die Fallstudie zu transnationaler Lebensführung von „Inder_innen der zweiten Generation“ über den Einzelfall der Schweiz hinausgeht. Dies hat einerseits mit dem Schweizer Kontext selbst zu tun, aber auch mit der gewählten theoretischen und methodischen Rahmung der Ethnografie, die anstrebt, Debatten zu Migration, Vielfalt und Globalisierung durch einen explizit machtanalytischen und postkolonialen Rahmen weiterzuentwickeln.

Die Forschungslandschaft zur „zweiten Generation“ und namentlich zu „Inder_ innen der zweiten Generation“ ist alles andere als ein kohärentes Feld. Die „zweite Generation“ wird in der Migrationsforschung, in der Familiensoziologie, in der Analyse von citizenship, in critical race studies oder auch in Filmstudien zur Diaspora untersucht - um nur einige Zusammenhänge zu nennen. Diese Forschungstraditionen und -interessen wiederum sind selbst in die historischen Rahmenbedingungen eingebettet, welche die Kategorie einer „zweiten Generation“ im nation building der jeweiligen Länder und in deren bevölkerungspolitischen Umgang mit Migration, Rassismus und Vielfalt hervorgebracht haben. Diese interdisziplinären und transnationalen Bezüge sind für die vorliegende Ethnografie relevant, sowohl als empirischen Referenzen, als auch als Gegenstand einer kritischen, epistemologischen Reflexion.

\section{Die "neue zweite Generation“, globale indische Diaspora und die Nachkriegsmigration nach Europa und Nordamerika}

Die klassische Migrationsforschung ist eng verbunden mit der Chicago Schule der Soziologie, die zu Beginn des 20. Jahrhunderts die Transformation nordamerikanischer Städte und ihrer Bevölkerungen untersuchte. Angesichts der politischen Anlage als Siedler- und Immigrationsgesellschaft stand die Spannung von Pluralismus und Zusammenhalt im Zentrum des amerikanischen Nationalprojekts (s. ausführlich Kapitel 2). Bis in die 1960er und 1970er wurden in den USA in der Migrationsforschung grösstenteils Assimilation und Inkorporationsverläufe europäischer Immigrant_innen untersucht. Ab den 1970er Jahren nahmen die asiatische Migration in die USA und Kanada als Folge der Liberalisierung der Zuwanderungsgesetze sowie die illegalisierte Migration aus Mexiko und Mittelamerika als Folge der Weltwirtschaftskrise zu. In der Tradition der Assimilations- und Segmentationsforschung ist seither eine transatlantisches Forschungsfeld zu einer „neuen zweiten Generation“ entstanden, die die selektiven Inkorporationspfade von Migrationsbevölkerungen hinsichtlich sozialer Ungleichheit untersucht (Portes/Zhou 1993; Portes 1996; Crul/Vermeulen 2003; Thomson/Crul 2007). Parallel dazu entstand ab den 1990er Jahren eine spezifische Forschung zu den vielfältigen historischen und geografischen Mustern südasiatischer Migration (Peach et 
al. 1990; van der Veer 1995; Brah 1996; Petievich 1999; Bates 2001; Parekh et al. 2003; Brown 2006). ${ }^{11}$

Als Orientierungspunkt für die vorliegende Forschung boten sich in erster Linie die Studien über die Nachkommen indischer Nachkriegsmigration nach Europa und in die USA an (Ballard 1994; Gillespie 1995; Baumann 1996; Bacon 1996; Alexander 2000; Fagerlid 2001; Maira 2002; Hall 2002; Purkayastha 2005; Shankar 2008). Bei der postkolonialen südasiatischen Migration nach Großbritannien handelte es sich um Hunderttausende von - zu einem großen Teil - wenig qualifizierten Personen, die für die Industrie und nationale Dienstleistungsunternehmen im Rahmen des Wideraufbaus des kriegsgeschädigten, imperialen Zentrums rekrutiert wurden. Obwohl sie als ehemalige koloniale Subjekte Staatsbürger_innen des Commonwealth waren, lebten sie oft unter harschen rassistischen Bedingungen. In den 1970er Jahren kamen weiter ca. 300000 südasiatische Flüchtlinge aus Uganda nach Großbritannien, nachdem Idi Amin sie ausgebürgert hatte. Gemäß der aktuellen Volkszählung lebten 2011 1,41 Millionen Personen indischer Herkunft in Großbritannien (und über 3 Millionen Menschen südasiatischer Herkunft) und gehören demnach der größten ethnischen Minderheit an. Angesichts von strukturellem Rassismus, Kettenmigration und kolonialen Mustern haben sich soziokulturell, religiös und national ausdifferenzierte und räumlich tendenziell segregierte Gemeinschaften herausgebildet. Nachkommen dieser Migrant_innen wuchsen daher in diasporischen (Teil-)Öffentlichkeiten auf, die sich in Medien, Quartieren, religiösen Stätten, ethnischen Organisationen sowie an Schulen manifestierten. Durch antirassistische Kämpfe seit den 1950er Jahren und die daraus folgenden multikulturalistischen Politiken ab den 1980er Jahren wurden sie als British Asians von der Dominanzgesellschaft zunehmend als Teil der britischen Nation anerkannt, wenn auch die strukturelle Diskriminierung weiterhin anhält und die multikulturellen Errungenschaften mit der Zunahme von antiislamischem Rassismus seit 9/11 - und nun wegen der Brexit-Debatten - in die Defensive geraten sind (Vertovec/Wessendorf 2010).

Die indische respektive südasiatische Migration in die USA unterschied sich von den durch die Kolonialgeschichte geprägten Mustern im Falle Großbritanni-

11 Ab dem 19. Jahrhundert fand im Zuge des Kolonialismus eine Migration von Schuldknechten (indentured labour), Beamten und Händlern in die damals britischen Kolonien in der Karibik, in Süd- und Ostafrika, Fidschi und Mauritius statt (Bhachu 1985; Vertovec 2000; Niranjana 2006). Im Zeitraum nach der Unabhängigkeit Indiens lässt sich die Migration von größtenteils ungelernten bis wenig qualifizierten Personen in Golfstaaten (Gardner 2010; zur neuen Mittelschicht in Dubai, Vora 2013) und nach Südostasien einerseits und die Migration nach Europa, Nordamerika sowie nach Australien und Neuseeland andererseits unterscheiden, welche vor allem Angehörige der Mittelschicht umfasst - mit Ausnahme des Sonderfalles Großbritannien (z. B. Bhachu 1985; Leonard 1992; Lessinger 1995; Prashad 2000; Raj 2003; Shukla 2003). 
ens: Ab 1965 öffneten die USA die Grenzen für Migrant_innen aus Asien, nachdem die chinesische Einwanderung 1882 und die gesamtasiatische 1917 verboten worden waren (Leonard 1992). Seither wanderten zuerst vereinzelt und ab den 1980er Jahren mehrere Hunderttausend indische Angehörige der Mittelschicht als Studierende und professionelle Fachkräfte in die USA ein. Gemäß dem Zensus von 2013 lebten knapp 3 Millionen Menschen südasiatischer Herkunft in den USA. Wenn auch in den letzten Jahrzehnten die Zahl von wenig qualifizierten Migrantinnen und Migranten zugenommen hat - ein typisches Beispiel sind südasiatische Taxifahrer in New York -, so herrscht doch eine spezifisch mittelständische Konnotation von Inderinnen und Indern als model minority vor (Purkayastha 2005; Shankar 2008). Diese Zuschreibung hat im Falle der hinduistischen Mehrheit mit der Zunahme von antiislamischem Rassismus seit 9/11 noch stärker zugenommen, wogegen die muslimische Minderheit zunehmend Stigmatisierung ausgesetzt ist (Therwat 2007). Der Vergleich südasiatischer Migration in die USA mit der Schweizer Situation ist insbesondere hinsichtlich der Nachkommen der hochqualifizierten indischen Migrant_innen aus den 1960er und 1970er Jahren interessant. Diese verbrachten ihre Kindheit und Jugend oft in weißen, anglo-konformen Vorstädten, bis sie mit dem Wechsel ins College multikulturalistische Milieus kennen lernten (Bacon 1996; Purkayastha 2005; Shankar 2008). Trotzdem unterscheidet sich die Situation in den USA von derjenigen in der Schweiz nicht nur wegen des schieren Umfangs und der soziokulturellen und religiösen Ausdifferenzierung der südasiatischen Migrationsgemeinschaften, sondern auch wegen der unterschiedlichen politischen und sozialen Inkorporationslogik. Die starke Rassialisierung der US-amerikanischen Sozialstruktur und politischen Kultur führt einerseits $\mathrm{zu}$ einer starken (in einem gewissen Maße immer auch legitimen) Präsenz von Differenz in der Öffentlichkeit und der Populärkultur, aber auch zu expliziteren Formen von Rassismus. Andererseits hat der Widerstand gegen strukturellen Rassismus im civil rights movement in den 1960er Jahren zu einer Verankerung multikulturalistischer Politiken und von Antidiskriminierungsprogrammen sowie zu entsprechenden Debatte in Medien und Populärkultur geführt.

Die indische Gemeinschaft in der Schweiz war - im Gegensatz zu den großen südasiatischen Gemeinschaften in den USA und in Großbritannien - relativ klein, sozial heterogen und geografisch verstreut. Gleichzeitig herrschte ein starkes Assimilationsregime vor, das Migrantinnen und Migranten als nicht zugehörig markierte, von ihnen kulturelle Anpassung forderte und öffentliche ethnische Selbstrepräsentation sanktionierte. Es existierten daher kaum diasporische Öffentlichkeiten mit entsprechenden Quartieren, Medien und Netzwerken wie etwa zur gleichen Zeit in Großbritannien oder ab 1965 zunehmend auch in den USA oder Kanada. Des Weiteren existierten kaum öffentliche Räume oder Debatten, in denen Rassismus als gesellschaftliches Problem anerkannt und angegangen wurde oder in denen Selbstrepräsentationen von Mehrfachzugehörigkeit möglich waren. 
Das Zusammenspiel der historisch-sozialstrukturellen Konstellation der Migrationsströme mit den institutionell-diskursiven Inkorporationsregimes schaffte je spezifische Möglichkeitsbedingungen der Subjektivierung von „Inder_innen der zweiten Generation“.

\section{Die "zweite Generation" in der Schweiz und im deutschsprachigen Raum}

Die Schweiz ist ein Migrationsland - ohne dies anzuerkennen: Sie verzeichnet seit 1860 einen durchschnittlichen Ausländeranteil von knapp 11 Prozent und Ende 2016 einen Ausländeranteil von 24,96 Prozent an der ständigen Wohnbevölkerung. Dies hat jedoch nicht nur mit einer relativ hohen Migration zu tun, sondern auch mit einem der rigidesten Einbürgerungsregime Europas (s. Kapitel 2). Während die Schweiz als Binnenland mit starker Industrialisierung seit jeher auf Handel und Migration angewiesen war, wurde die Fremdenabwehr seit dem frühen 20. Jahrhundert bewusst erhöht (Kury 2003; Niederberger 2004; Argast 2007). Während es in der Schweiz für die französisch-, italienisch- und rätoromanischen regionalen Minderheiten eine multikulturelle Politik bezüglich Bildung und Kultur (Radio, Fernsehen, Kulturförderung) gibt, sind migrantische Minderheiten einem strikten Assimilationsregime unterworfen und verfügen über keinen anerkennungspolitischen Schutz. In stimmiger Weise wurde die Schweiz daher als „multikulturelles Land ohne multikulturelle Politik“ bezeichnet (D’Amato 2010). Zudem gilt die Schweiz seit der Schwarzenbach-Bewegung der 1960er und 1970er Jahren als eine Vorreiterin des europäischen Rechtspopulismus, wie bis heute in der gesamteuropäischen Wirkung der Schweizerischen Volkspartei (SVP) sichtbar wird (Buomberger 2004; Skenderovic/D'Amato 2008). Dies steht zum einen in einem Spannungsverhältnis dazu, dass die Schweiz in Bezug auf Wirtschafts-, Sozialund Fiskalpolitik eines der liberalsten Länder Europas mit geringer Arbeitslosigkeit ist, also die populistische Argumentation von Arbeitsmarktkonkurrenz oder Überlastung der Sozialausgaben den Daten nicht standhält (Staatsquote 2016: 33,1 Prozent, Erwerbslosenquote: 5 Prozent). Die rechtspopulistische Tradition steht zudem in einer Spannung mit der humanitären Rolle der Schweiz als Bewahrerin der Genfer Konventionen und als Gastgeberland für das Internationale Komitee vom Roten Kreuz. Diese Widersprüche zwischen wirtschaftlicher Nachfrage nach Migration, restriktivem Einbürgerungsregime, starkem Rechtspopulismus, und humanitärem Selbstverständnis zeichnen den „Sonderfall Schweiz“ als produktives Labor für die europäische Migrations- und Rassismusforschung aus.

Wenn auch die erste Studie zur Forschung über die „zweite Generation“ von Hoffmann-Nowotny aus dem Jahr 1985 den Grundstein legte (Hoffmann-Nowotny 1985), etablierte sich das aktuelle Forschungsfeldes über die „zweite Generation" in der Schweiz in den frühen 2000er Jahren. Ein Teil der Arbeiten (Bolzmann et al. 2003a, 2003b, Cattacin et al. 2016) bezieht sich auf die Tradition der 
nordamerikanischen Assimilations- und Segmentationstheorie. Theoretisch und methodisch davon abgesetzt existieren kultursoziologische Arbeiten in der Tradition der deutschsprachigen, rekonstruktiven Biografieforschung (Juhasz/Mey 2003) und der sozialanthropologischen Transnationalismus- und Ethnizitätsforschung (Wimmer 2003; Menet 2010; Allenbach 2011; Weißköppel 2011; Wessendorf 2013; Müller 2013; Dümmler 2014). Mit einigen Ausnahmen (Jain 2011, 2013; Goel 2011; Lauer 2013; Müller 2013) hat sich die Forschung zur „zweiten Generation" in der Schweiz mit Angehörigen der viel größeren Migrationsgemeinschaften aus Südeuropa, Südosteuropa und der Türkei beschäftigt, die sich größtenteils im Zuge der "Gastarbeitermigration“ in die Schweiz niederließen. Die meisten Studien fokussieren auf die klassenspezifische Rolle von sozialer Mobilität für das Verständnis von Inkorporationsverläufen, Netzwerkbildung und biografischen Aushandlungen (Bolzman et al. 2003a, 2003b; Juhasz/Mey 2003; Wessendorf 2007, 2008; OECD 2015): Bolzmann et al. 2003 stellen eine relativ überdurchschnittliche soziale Mobilität bei Angehörigen der „Zweiten Generation“ (im Vergleich zur Elterngeneration) fest. Gleichzeitig belegen aktuelle absolute Zahlen eine strukturelle Diskriminierung der „Zweiten Generation“ in Bildung und Arbeitsmarkt: Gemäß der OECD-Studie „Settling In“von 2015 haben 15-Jährige, die mindestens einen wenig qualifizierten ausländischen Elternteil haben, eine zweimal schlechtere Chance, sozial aufzusteigen, als ihre Peers mit in der Schweiz geborenen Eltern. 15- bis 34-Jährige mit mindestens einem ausländischen Elternteil sind dreimal so häufig ohne Ausbildung, Lehre oder Arbeit wie ihre Schweizer Peers (OECD 2015). Wie lässt sich diese Mobilitätsorientierung bei gleichzeitiger Diskriminierung deuten? Vor dem Hintergrund der Bourdieu'schen Klassentheorie argumentieren Juhasz/Mey, dass die Nachkommen von Migrantinnen und Migranten eine Aufstiegsorientierung als Teil eines intergenerationelles „Projektes der Mobilität" (Juhasz/Mey 2003:313) von den Eltern übernehmen, quasi um das von den Eltern für sie erbrachte „Opfer" auszugleichen. In der Tradition der biografischen Migrationsforschung (Apitzsch 1990; Breckner 2003) zeigen die Autorinnen weiter, dass ein erfolgreicher Aufstieg in die Mittelschicht - im Sinne einer unbeabsichtigten Nebenwirkung - zu einer soziokulturellen Distanzierung zwischen den Generationen führen kann, die jedoch oft als „Kulturkonflikt“ gedeutet wird. Zusammenfassend lässt sich von einer Aufstiegsorientierung sprechen, wobei gleichzeitig die kulturelle und strukturelle Segmentation zunimmt: Nicht nur ist der soziale Aufstieg von hohen Hürden in Bildung und Arbeitsmarkt geprägt (und beinhaltet daher oft den Weg langjähriger Weiterbildungen). Zudem geht der Eintritt in die mittelständische Dominanzgesellschaft mit einer stärkeren Inkorporation assimilationistischer Normen einher. Angehörige der „zweiten Generation“, die durch Tradierung elterlicher Ressourcen oder durch intergenerationelle soziale Mobilität eine Mittelschichtszugehörigkeit aufweisen, identifizieren sich etwa stärker mit der Schweiz, was sich etwa in der relativ höheren Naturalisierungsquote zeigt (Bolzmann et al. 2003). Weniger mobile Individuen hingegen identifizieren sich 
stattdessen weniger mit der Schweiz mutmaßlich als Folge der Diskriminierungserfahrung und aufgrund einer restriktiven Einbürgerungspolitik. Wessendorf bestätigt diese Diagnose in ihrem ethnografischen Argument, dass sozial mobile Angehörige der „Zweiten Generation“ eher einen mittelständischen Lebensstil pflegen und politische Partizipation einfordern als nicht-mobile Individuen, die stärker in ethnischen Subkulturen und Netzwerken leben (Wessendorf 2007, 2008). Des Weiteren belegen anthropologische Studien, wie soziale Ungleichheit unter Jugendlichen durch symbolische Grenzziehungen anhand von Ethnizität und Religion verstärkt wird (Müller 2013; Dümmler 2014). Angesichts wenig öffentlicher Debatten und Maßnahmen über Diskriminierung lässt sich die These vertreten, dass eine individuelle, assimilatorische Bildungsstrategie ein häufiger Weg ist, um das Damoklesschwert von Diskriminierung und Segmentation auszubalancieren. Dagegen bietet sich angesichts alltäglicher Stigmatisierung eine subkulturelle Ethnisierung als Coping-Strategie an. Keine der beiden Strategien erlaubt es jedoch, öffentliche Anerkennung für Mehrfachzugehörigkeit als lebensweltliche Realität zu gewinnen, respektive alltäglichen oder strukturellen Rassismus aktiv in Frage zu stellen.

Während der Schweizer Forschungsstand zur „Zweiten Generation“ Hypothesen zu Segmentation und sozialer Ungleichheit zulässt, sind die Hinweise auf eine postkoloniale Spezifität schweizerisch-indischer Second@s selten. Einerseits existiert kaum Forschung zu außereuropäischen, nicht-weißen Angehörigen der „Zweiten Generation“, zweitens existieren in der Schweiz kaum rassismuskritischen oder postkolonialen Positionen in diesem Forschungsfeld, geschweige denn kritische öffentliche Debatten.

Die Situation in der Schweiz lässt sich auf fruchtbare Weise mit Deutschland vergleichen, das ab der Nachkriegszeit eine ähnliche assimilationspolitische Logik im Rahmen eines ius sanguinis aufwies. Wie in der Schweiz basierte die Nachkriegsmigration in Deutschland auf dem Gastarbeitersystem. Jedoch war das ius sanguinis noch stärker ausgestaltet, sodass Einbürgerungen kaum möglich waren. Migrantische Kämpfe seit den 1970er Jahren hatten jedoch vor dem Hintergrund neonazistischer Pogrome in den frühen 1990er Jahren eine neue Generation von Menschen mit Migrationshintergrund mobilisiert. Parallel dazu führte die Arbeit der Süssmuth-Kommission 2001 zur offiziellen Anerkennung Deutschlands als Einwanderungsland und zu einer Teileinführung eines ius soli. Diese Faktoren haben die wissenschaftlichen und öffentlichen Debatten bezüglich der Konstruktion der Nation verändert. Spätestens seit der Sarrazin-Debatte hat sich eine Schicht junger Professioneller der „Zweiten Generation“ etabliert, die in den 1980ern und 1990ern aufgewachsen war und die sich nun in Medien und Kultur öffentlich gegen Rassismus äußert. Im wissenschaftlichen Kontext sind eine rassismuskritische Migrationsforschung, das Konzept der „Autonomie der Migration“ sowie die Debatten um Postkolonialismus, die „postmigrantische Gesellschaft“ und „Interkultur“ zu erwähnen, die diese Veränderungen reflektieren (Mecheril 2003, Terkes- 
sidis 2004; Terkessidis 2010; Foroutan 2014, 2015, 2016; Karakayali/Tsianos 2014; Bojadzijev/Römhild 2014; El-Tayeb 2015). Migration wird in diesen Ansätzen als transformative und formende Kraft in einer Gesellschaft verstanden, die gleichzeitig weiterhin auf einer rassialisierten Unterscheidung zwischen Nation und Migration fußt. In der Spannung zwischen institutionellem Rassismus und interkultureller Öffnung müsse sich die postmigrantische deutsche Gesellschaft selbst reflektieren und verändern. Symptomatisch dafür steht die Debatte um „Inder statt Kinder“ aus dem Jahr 2000, in der der CDU-Politiker Jürgen Rüttgers forderte, Deutsche Kinder zu fördern, statt IT-Ingenieure aus Indien zu rekrutieren. Zwischen neoliberaler Nachfrage nach indischen IT-Ingenieuren und neovölkischem Populismus setzte sich hier die Dominanzgesellschaft mit der Frage von Migration und Vielfalt auseinander. Als postmigrantische (und postkoloniale) Antwort darauf kann das Buch „InderKinder. Über das Aufwachsen und Leben in Deutschland“ von 2012 verstanden werden, in dem „neue Deutsche“ indischer Herkunft in autobiografischen Porträts und wissenschaftlichen Essays eigene Stimmen und Geschichten in der „weißen“ öffentlichen Debatte beanspruchten (Goel et al. 2012).

Es stellt sich im Sinne eines Vergleichs die Frage, warum rassismuskritische, postkoloniale oder postmigrantische Debatten zu Migration und Teilhabe in der Schweiz noch wenig etabliert sind, und warum angesichts des hohen Anteils von Angehörigen der „Zweiten Generation“ diese sich nicht stärker in wissenschaftlichen und öffentlichen Debatten zu Migration und Rassismus zu Wort melden (zu postmigrantischen Debatten in der Schweiz: Espahangizi/Pinto de Magalhães 2014 ; Espahangizi 2016). Ein Ziel dieser Ethnografie ist es daher, kritische Ansätze in der Schweizer Debatte anzustoßen und mit der deutschsprachigen Forschungslandschaft in Verbindung zu bringen. Umgekehrt soll ein postkolonialer Einblick in den „Sonderfall Schweiz“ einen Beitrag zur Stärkung dieser Debatten im deutschsprachigen Raum leisten.

\section{Postkoloniale Amnesie und „unmögliche Subjekte“}

Das ethnografisch Spezifische an der vorliegenden Fallstudie besteht darin, dass "Inder_innen der zweiten Generation“ insofern als Pionier_innen (Juhasz/Mey 2003:314) betrachtet werden sollen, als sie angesichts schwacher diasporischer Vorbilder und starker Assimilationsforderungen vor der biografischen Aufgabe standen, eigene Sprachen und Praktiken zu entwickeln, um die Erfahrungen des Andersseins sinnhaft zu bearbeiten. Diese Ausgangslage als „unmögliche Subjekte“ wird durch die besondere Positionierung der indischen Migrant_innen in der Schweiz bezüglich Klasse, Rassifizierung und Geschlecht weiter spezifiziert. Zwar herrschte in der Nachkriegszeit ein starker institutioneller und alläglicher Rassismus gegenüber südeuropäischen, vor allem italienischen Migrantinnen und Migranten (Maiolino 2011). Indische Migrant_innen und ihre Nachkommen waren jedoch kolonialen Diskursen einer geschlechtsspezifischen Rassialisierung 
- etwa durch Evolutionismus oder Exotismus - ausgesetzt, die sie nicht nur als national „Andere" in Europa, sondern als postkoloniale Grenzgänger der europäischen Moderne platzier(t)en. Angesichts einer schwachen Auseinandersetzung der Schweizer Öffentlichkeit mit Alltagsrassismus bedeutete dies die Sozialisierung in einen „weißen“ ̈̈ffentlichen Raum ohne eine anerkannte Sprache der Selbstrepräsentation (Michel 2015). Der Begriff der „Pioniere“ soll dabei nicht bedeuten, dass die Situation von „InderInnen der zweiten Generation“ aus der Schweiz einzigartig war. Wie Fatima El-Tayeb schildert, war es für junge People of Colour in Europa angesichts eines „Rassismus ohne Rassen“ seit dem Zweiten Weltkrieg (Goldberg 2009) nur durch widerständische Praktiken möglich war, sich als ,anders europäisch " zu sozialisieren (El-Tayeb 2015). Die vorliegende ethnografisch-transnationale Fallstudie schließt an diese wichtigen postkolonialen Debatten über Rassismus und Dekolonisierung Europas an. Dabei ist der „Sonderfall Schweiz“ besonders spannend, weil das Land noch kaum mit der moralischen und politischen Aufgabe konfrontiert war, sich mit der eigenen Geschichte der Gewalt im Kontext von Migration und kolonialer Komplizität auseinanderzusetzen, wie etwa Deutschland sich mit dem Holocaust, oder andere europäische Länder sich mit Faschismus, Kollaboration oder Kolonialismus (Gilroy 2006, Loftsdóttir/Jensen 2012; Michel 2014; Wekker 2015) auseinandergesetzt haben. Zwischen Assimilationsdruck und humanitärem Selbstverständnis in der Dominanzgesellschaft, zwischen diffusen oder konkreten Erfahrungen des Andersseins und einer (öffentlichen) postkolonialen „Amnesie“ (Purtschert 2013) wuchsen „Inder_innen der zweiten Generation“ in der Schweiz auf. Statt jedoch den Fokus auf aktivistische, repräsentationspolitische Interventionen in der Schweiz oder Europa zu beschränken, eröffnet der Blick auf „Inder_innen der zweiten Generation“ eine weitere spannende Perspektive. Die Transformation Indiens von einem Entwicklungsland zu einem global player in den letzten vierzig Jahren hat die postkolonialen Beziehungen, Hierarchien und Diskurse des „Eigenen“ und des „Anderen“ zwischen der Schweiz - ja, dem Westen - und Indien beträchtlich verändert. Angesichts der neuen Macht Indiens in der dezentralisierten Globalisierung der letzten Jahre, nehmen „InderInnen der zweiten Generation" eine spezifische Position in der Aushandlung neuer Narrative, ethischer Räume und Subjektivitäten im Kontext dieser postkolonialen Verschiebungen ein. Waren die Stimmen und Lebenswelten der Protagonist_innen vor zwanzig oder dreißig Jahren am Rande der Gesellschaft angesiedelt, stehen sie heute im besonderen Rampenlicht der Umbrüche unserer Zeit.

Vor dem Hintergrund dieser spezifischen Positionierung von „Inder_innen der zweiten Generation" aus der Schweiz als postkoloniale Pionier_innen möchte ich hier zwei theoretische Aspekte diskutieren, die in der Forschungslandschaft bisher zu wenig beachtet wurden. Der erste Kritikpunkt betrifft die kaum vorhandene Theoretisierung des Generationenbegriffs, weshalb die machtvolle gesellschaftliche Konstruktion der „Zweiten Generation“ als politische und wissenschaftliche Kategorie im nationalstaatlichen Rassismus und im Kontext des postkolonialen 
Europas kaum reflektiert wird. Zweitens existieren erstaunlich wenige Studien über transnationale Praktiken und Erfahrungen von Migrationsnachfolgegenerationen, die ethnografisch und machtanalytisch arbeiten. ${ }^{12}$ Entsprechend werde ich in den folgenden drei Abschnitten versuchen, einige theoretische und methodologische Ansätze einer transnationalen Genealogie zu entwickeln, die diese Ethnografie anleiten.

\subsection{Macht, Subjektivierung Und Alterität: EINe Kritik deR generationellen Rationalität}

In den meisten sozialwissenschaftlichen Studien zur „zweiten Generation“ wird der Generationenbegriff selbst zwar diskutiert und operationalisiert, aber kaum explizit theoretisiert.

Unter zweiter Generation werden hier jene Kinder und Jugendlichen ausländischer Herkunft verstanden, welche in der Schweiz geboren oder als Kleinkinder in die Schweiz gekommen sind. Zudem wenden wir den Begriff nur auf jene Personen an, bei welchen beide Eltern im Ausland geboren sind. (Juhasz/Mey 2003:18)

Durch diese geradezu kanonische Definition wird die „zweite Generation“ als relevante analytische, ethnische Kategorie gesetzt und erscheint als soziale Tatsache. Diese Definition ist exemplarisch dafür, dass die Fragestellungen vieler Studien auf mehr oder weniger unhinterfragten Annahmen der Assimilationstheorie, der Familiensoziologie und der Sozialisationstheorie basieren. Nicht nur werden diese Annahmen der Komplexität von Migrationsgesellschaften kaum gerecht, schliessen sie doch zirkuläre Migration, binationale Ehen, die Rolle digitaler Medien in transnationalen Familien oder Mehrgenerationshaushalte aus dem Blick aus. Es fehlt zudem ein Instrumentarium, um die machtvolle rassialisierte Konstruktion der institutionellen Kategorie einerseits und der Erfahrung der „zweiten Generation" andererseits angemessen zu reflektieren. Auf der einen Seite wird in diesem Forschungsfeld „Kultur“, respektive Ethnizität oder Rassismus - im Sinne einer strukturfunktionalistischen oder marxistischen Dichotomie - oft als Verzerrung oder als „falsches Bewusstsein“ verstanden und der wissenschaftlichen und historischen Objektivität von struktureller Ungleichheit gegenübergestellt (z. B. Juhasz/

12 | Während Wessendorf (2013) eine spannende transnationale Ethnografie vorlegt, ohne jedoch die Machtverhältnisse systematisch zu untersuchen, diskutieren Maira (2002) und Purkayastha (2005) die transnational-postkolonialen Aspekte der machtvollen Zuschreibungen in den lokalen Verhältnissen, ohne auf ethnografisches Material zurückzugreifen. 
Mey 2003; Bolzman et al. 2003). Diese Privilegierung von „Struktur“ gegenüber „Kultur“ ist jedoch erklärungsbedürftig, da kulturelle, rassialisierte Differenz sowohl als Zuschreibung in Prozessen institutioneller Diskriminierung sowie als subjektive Erfahrung von Zugehörigkeit oder Ausschluss praktisch wirksam ist. Auf der anderen Seite besteht die epistemologische Problematik in der Forschung über Migration, ethnische Kategorie des „Anderen“ im Forschungsgegenstand essentialistisch zu verstärken, was als Kritik an einer „ethnic lens“ oder an einer Migrantologie formuliert wurde (Glick Schiller 2006; Römhild/Bojadžijev 2014; Dahinden 2016).

Stattdessen wäre es wichtig, die Verquickung von Alterität und Generation systematisch zu untersuchen, die sowohl die Erfahrungen der Subjekte als auch die politischen und wissenschaftlichen Migrationsdiskurse im Nationalstaat reguliert (Mecheril 2003; Riegel 2004; Terkessidis 2004; Riegel/Giesen 2007; Goel et al. 2012; Jain 2013; El-Tayeb 2015). ${ }^{13}$ Die Erforschung der „Zweiten Generation“ erfordert demnach einen theoretischen Rahmen, der die Konstruktion kultureller und rassialisierter Differenz als machtvolle Praxis und als subjektive Erfahrung von Generationalität aufzeigt und ernstnimmt.

\section{Soziale Konstruktion von "Generationen"}

Der Wissens- und Kultursoziologe Karl Mannheim hat in seinem klassischen Aufsatz „Das Problem der Generationen“ (2009 [1928]) begonnen, Generationen als sinnhaft ausgehandelte soziale Entitäten im Rahmen von Geschichte und sozialem Wandel zu konzipieren. Mit dem Aufsatz strebte er an, eine soziologisch fundierte und empirisch erforschbare Kategorie der „Generation“ zu entwickeln, die zwischen dem Verständnis einer biologisch-quantitativen Generationenabfolge (im Positivismus) und der rein subjektiven Erfahrung einer historischen Gemeinschaft (im Historizismus) vermitteln könnte. Generationen als historisch-soziale Größen konstituieren sich laut Mannheim durch die

spezifische Lagerung der durch sie betroffenen Individuen im gesellschaftlich-historischen Lebensraum, [die] diese Individuen auf einen bestimmten Spielraum möglichen Geschehens beschränk[t] und damit eine spezifische Art des Erlebens und Denkens, Fühlens und Handelns, eine spezifische Weise des Eingreifens in den historischen Prozess nahelegt. (Mannheim 2009 [1928]:136)

13 | Des Weiteren kann eine nicht auf Differenz sensibilisierte Migrationsforschung keine normativen Hinweise auf eine "Politik der Differenz" (Young 1990) oder auf Kämpfe der Anerkennung (Honneth 1992) geben, die eine liberale Utopie der Indifferenz, ja der "Color-blindness", infrage stellen könnten (Bonilla-Silva 2006). 
Mannheim argumentierte, die ähnliche Schichtung von älteren und neueren Erfahrungen und Wissensfragmenten („Erlebnis-Schichtung“) im Zuge der Sozialisation und des Lebenslaufes schaffe bei gleichaltrigen Individuen das Potenzial, sowohl sich miteinander zu identifizieren („Generationenzusammenhang“) als auch sich sozial oder politisch zu vergemeinschaften („Generationeneinheit“). Im analytisch offenen Sinne eines „generation building“ (Jureit 2006:87) erlaubt Mannheims Generationenverständnis, die gesellschaftlichen Prozesse in den Blick zu nehmen, die allfällige gemeinsame subjektive Erfahrungen, kulturelle Praktiken oder politische Formationen einer Generation hervorbringen.

Die gesellschaftliche Herstellung der Kategorie, der Erfahrungen, ja, der Gruppe von „Inder_innen der zweiten Generation“ muss also angesichts der kleinen, sozial heterogenen Migrationsgemeinschaft und des assimilationistischen Kontexts selbst zum Thema der Analyse gemacht werden. Ist „Inder_innen der zweiten Generation" eine wissenschaftliche oder politische Zuschreibung? Oder teilen die Subjekte spezifische Erfahrungen? Wenn ja, woraus entstanden diese gemeinsamen Erfahrungen? Aus politischen Diskursen, ethnischen Netzwerken, populärkulturellen Artefakten oder familienbiografischen Erzählungen?

Dieses theoretische Verständnis von „Generation“ als eines feldimmanenten sozialen Konstrukts verschiebt die Forschungshaltung. Es dezentriert den Blick von den Forschungssubjekten selbst auf die gesellschaftlichen Bedingungen, die sozial relevante generationelle Erfahrungen und soziale Praktiken hervorbringen und regulieren. Es verschiebt aber auch insofern die methodische Herangehensweise - etwa das Sampling -, als die Kategorie der „zweiten Generation“ nicht als analytische, sondern als empirische Größe mit untersucht werden muss. Im Zentrum der Forschung stehen demnach die Aushandlungen zwischen den historisch-institutionellen Zuweisungen, ein Subjekt der „zweiten Generation“ zu sein, und der subjektiven Verhandlung, Teil der „Zweiten Generation“ zu sein (oder nicht).

\section{Genealogie: "Generation" als doppelte Subjektivierung im Nationalstaat}

Die Komplexität des modernen Generationenbegriffs wird weiter deutlich, wenn wir das Verständnis von Generation in der Migrationsforschung und bei Mannheim vergleichen. Während Mannheim den Begriff auf eine Gleichzeitigkeit der Erfahrung im Rahmen einer historisch-sozialen Gemeinschaft bezieht, verweist der Begriff der „Zweiten Generation“ im Migrationskontext auf die zeitlichen Abfolge in der Reproduktion einer Familie. Das sind aber nur auf den ersten Blick zwei verschiedene Zusammenhänge. Neuere wissenschaftshistorische und postkoloniale Forschungen haben eine Genealogie des Generationenbegriffs angestoßen, die ich - in Anlehnung an Michel Foucault - als „biopolitische“ bezeichnen möchte (Foucault 1977; Young 1995; Parnes et al. 2008). Der Generationenbegriff 
war in der Moderne demnach nicht nur grundlegend für die Hervorbringung eines modernen Verständnisses von Geschichte, wie Mannheim argumentiert, sondern auch eng verflochten mit der Imagination und dem Aufbau nationaler und kolonialer Gesellschaften und mit der damit verbundenen hierarchischen Logik bei der Definition von Bevölkerungen. Die Begründung von Nation und Volk als moderne politische Konzepte ist eng verbunden mit der Metapher der Familie und dem darin eingeschriebenen Prinzip einer "Kette von Generationen“ (Parnes et al. 2008). Nicht nur konnte die Nation mit der Metapher der Familie als Gemeinschaft von eng verbundenen Individuen gedacht werden, auch war es möglich, die historische Reproduktion dieser neuen politischen Gemeinschaft durch die Abfolge von Generationen zu konzipieren. Als epistemische Folie dieser neuen politischen Gemeinschaft diente das Konzept des Organismus als lebendige, sich eigenständig, wandelnde Einheit, das die moderne Zellbiologie und Genetik hervorgebracht hatten. Vor diesem Hintergrund wurde der Generationswechsel im nation building und im Kolonialismus - und dies insbesondere in der Variante der „Vermischung“ (Hybridität) - zu einem strategischen Feld der politischen und wissenschaftlichen Herstellung und Regulierung reiner, nationaler und rassialisierter Bevölkerungen (Foucault 1977, 1999; Stoler 1995; Young 1995).

Vor diesem Hintergrund verknüpft das Konzept der "nationalen Grenze“ den Mannheim'schen Generationenbegriff und den der „Zweiten Generation“ in der Migrationsforschung. Die mediale Konstruktion einer nationalen Öffentlichkeit im Rahmen einer absoluten globalen Zeitrechnung (Anderson 1996 [1983]), die administrative, pädagogische und rechtliche Etablierung des Staates (Smith 1986; Foucault 1999) sowie die Humanwissenschaften (Foucault 1999) haben die Mannheim'sche „Gesellschaft" als „historisch-sozialen Lebensraum“ erst hervorgebracht. Indem Mannheim den „historisch-sozialen Lebensraum“, innerhalb dessen generationelle Zusammenhänge entstehen, implizit (wenn auch nicht ausschließlich) als nationalen annimmt, unterschätzt er die Konstruktion der von ihm untersuchten „Gesellschaft" im Rahmen eines politischen und insbesondere nationalstaatlichen Projektes. Das heisst konkret, dass Migrantinnen und Migranten in diesen politischen Projekten mehr oder weniger außerhalb der „historischen Lebensgemeinschaft" angesiedelt und sozialisiert wurden, innerhalb derer eine gemeinsame Erfahrung möglich gewesen wäre. Die gemeinsame Erlebnisschichtung, die Generationen innerhalb der Nation hervorbringt, findet also unter den konstitutiven Bedingungen der Konstruktion von Alterität statt. ${ }^{14}$

14 | Es ist daher symptomatisch, dass Mannheim im Aufsatz schreibt: „Es wird niemand behaupten wollen, die chinesische und die deutsche Jugend um 1800 hätten sich in einer ähnlichen Lagerung befunden" (Mannheim 2009 [1928]:142). Es ist nicht ausgeschlossen, dass diese sich in einem gemeinsamen "historisch-sozialen Lebensraum" im Mannheim'schen Sinne befinden könnten. Ein solcher, der im Vergleich zu $1800 \mathrm{im}$ Kontext der aktuellen Globalisierungsprozesse schon viel näher liegt, könnte im Sinne 
Im Kapitel 2 werde ich im Detail darlegen, wie die Begriffe der Generation und der Assimilation, die in der sozialwissenschaftlichen Migrationsforschung sowie der Migrationspolitik des 20. Jahrhunderts zentral sind, in eine politische Epistemologie innerhalb des nation building und der kolonialen Rassenanthropologie verstrickt sind. Die wissenschaftliche Forschung über die „zweite Generation“ muss die Produktionsbedingungen selbst reflektieren, in die ihre Kategorien, Konzepte und Fragestellungen eingebunden sind. ${ }^{15}$

In Anlehnung an Michel Foucaults Kritik der Biopolitik schlage ich ein genealogisches Verständnis von „Generation“ vor, um die institutionellen und diskursiven Bedingungen sowie die historischen Machtverhältnisse in den Blick zu nehmen, die „Migration“ und insbesondere die „zweite Generation“ als politische Felder, wissenschaftliche Kategorien, ökonomische Dispositive oder populärkulturelle Narrative in modernen Nationalstaaten generier(t)en. Unter Genealogie verstehe ich eine Methodologie, mit der die Konstituierung von Subjekten innerhalb historischer Konfigurationen von Macht und Wissen analysiert werden kann (Foucault 1980:117). Demnach ist „Subjektivität gerahmt und ermöglicht von strukturierenden diskursiven Bedingungen, über die sie nicht verfügt. [...] Damit tauchen auf der historischen Bühne verschiedene Subjektfiguren auf, legitime und mögliche Weisen, als Subjekt im Diskurs bzw. Objekt des Diskurses sprechen bzw. thematisiert werden zu können." (Saar 2007:180) Gegenstand der Genealogie sind dabei nicht die Subjekte selbst, sondern Subjektivierungslogiken, die - eingebettet in Diskurse, Institutionen, Objekte, Körper und Räume - spezifische Erfahrungen, Praktiken und Zugehörigkeiten hervorbringen, verknüpfen oder verhindern (Rose 1996:130). Die objektivierte Evidenz und die subjektiven Erfahrungen von „Inder_innen der zweiten Generation“ werden demnach innerhalb von Prozessen politischer Regulierung, ökonomischer Verwertbarkeit, wissenschaftlicher Ob-

einer Weiterführung von Mannheims Argument jedoch erst durch die Reflexion über postkoloniale Positionen innerhalb dieser Beziehungen theoretisch konzipiert werden. 15 | Sozialanthropologische Arbeiten zur "zweiten Generation", die sich theoretisch in diese Tradition der Ethnizitätsforschung (Weber 1972 [1921]; Barth 1969; Baumann 1996; Jenkins 1997; Brubaker 2004) einordnen, stellen explizit die ethnischen Grenzziehungsprozesse ins Zentrum der Analyse (Menet 2010; Allenbach 2011; Wessendorf 2013; Müller 2013; Dümmler 2014). Dadurch werden die Aushandlungen von Zugehörigkeit und das Verständnis von Alterität als essenzialistische oder als konstruierte GröBen selbst zum Thema subjektiver und sozialer Prozesse. Diese spannenden Studien vermögen Ethnizität als Spur im Konzept und in der Erfahrung von Generationalität - als umkämpfte und markierte Größe gesellschaftlicher Erfahrung und Struktur - zu untersuchen. Jedoch vermag auch die Ethnizitätsforschung - im Hinblick auf den bei Weber und Barth angelegten methodologischen Individualismus - nicht zu theoretisieren, wie Konstruktion der Alterität in diskursiv-institutionelle Machtverhältnisse eingeschrieben ist und daher die Grenzziehungsprozesse reguliert. 
jektivierung, populärkultureller Repräsentation konstruiert und ausgehandelt, die empirisch untersucht werden können. "[Subjectivities] are never unified and increasingly fragmented and fractured; never singular but multiply constructed across different, often intersecting and antagonistic discourses, practices and positions." (Hall 1996:4).

Für die vorliegende Arbeit ist theoretisch und empirisch besonders fruchtbar, dass dem Subjektivierungsbegriff (frz. assujettisement) eine Doppelbedeutung innewohnt, die sowohl ein hegemoniales Regime biopolitischer Unterwerfung als auch ein subjektives Ethos der Lebensführung beschreibt, wie Foucault in seinen späteren Texten immer expliziter darlegt (Foucault 1986b, 1993).

This form of power applies itself to immediate everyday life which categorizes the individual, marks him [sic!] by his own individuality, attaches him to his own identity, imposes a law of truth on him which he must recognize and others have to recognize on him. It is a form of power, which makes individuals subjects. There are two meanings of the word subject: subject to someone else by control and dependence, and tied to his own identity by a conscience or self-knowledge. Both meanings suggest a form of power, which subjugates and makes subject to. (Foucault 1986a: 212)

Das eröffnet nicht nur den Blick auf die Konstruktion der „Zweiten Generation“ als politische, wissenschaftliche und soziale Kategorie, die sich aus der biopolitischen Problematisierung der „Migration“ im modernen Nationalstaat ergeben hat. Gleichzeitig können dadurch die subjektiven Aspirationen und eigenlogischen Lebensentwürfe von Angehörigen der „Zweiten Generation“ untersucht werden, die innerhalb dieser gesellschaftlichen Konstruktionen stattfinden. Subjekte konstituieren sich so verstanden als Produkte und Agenten in fragmentierten und komplexen Prozessen von machtvoller Zuschreibung und Aneignung. Judith Butler hat darauf aufmerksam gemacht, dass die Subjektivierung innerhalb hegemonialer Diskurse ermöglicht, Handlungsmacht, alternative Sprachen und Subjektivierungsprozesse freizusetzen: „Eine auf das Subjekt ausgeübte Macht, ist die Unterwerfung durch eine vom Subjekt angenommene Macht, eine Annahme, die das Instrument des Werdens dieses Subjekts ausmacht.“ (Butler 2001:16, Hervorhebungen R. J.) Butler versteht eine diskursive Formation als machtvoll, aber nicht als total, sondern voller Lücken und Widersprüche, da sie den Ausschluss der „unmöglichen Subjekte" stets performativ wiederholen muss, um sich angesichts einer offen Zukunft aufrechtzuerhalten. In diesem Momenten der Wiederholung öffnen sich Möglichkeiten der Verschiebung. "[A]nd yet, it is also by virtue of this reiteration that gaps and fissures are opened up as the constitutive instabilities in such constructions, as that which escapes or exceeds the norm, as that which cannot be wholly defined or fixed by the repetitive labor of the norm." (Butler 1993:10). 
Der doppelte Subjektbegriff in Foucaults Arbeiten eröffnet einen theoretischen Rahmen, um Subjektivierungsprozesse von „Inder_innen der zweiten Generation" sowohl als hegemoniale Disziplinierung als auch als eigenlogische Projekte der Lebensführung zu verstehen. Einerseits schreibt sich die strukturelle und diskursive Unmöglichkeit, die „zweite Generation“ als Teil der Nation zu verstehen und anzuerkennen, in die Subjektivierungsprozesse als Frage nach dem Anderssein ein, die immer aufs Neue beantwortet werden muss (Mecheril 2003). Genauso wie die Gesellschaft bemüht ist, „unmögliche Subjekte“ zu bearbeiten, müssen diese selbst Strategien finden, um die strukturellen Widersprüche in ihren Lebensentwürfen aufzulösen respektive zu re-artikulieren. Die Untersuchungsgruppe der „Inder_innen der zweiten Generation“ ist dabei sowohl empirisch als auch theoretisch keineswegs selbstevident, sondern wird in hegemonialen nationalstaatlich-wissenschaftlichen Subjektivierungsweisen und den dadurch produzierten geteilten Erfahrungen ausgehandelt. Die Identifikation mit dieser „Gruppe“ sowie die Aushandlung der damit verbundenen Grenzen sind Thema der Subjektivierungsprozesse und Teil einer „prekären Zugehörigkeit“ (Mecheril 2003). Deshalb verwende ich die Schreibweise „Inder_innen der zweiten Generation“ in Anführungszeichen, um auf die Konstruiertheit, die Polysemie und die Performativität der Kategorie und der Erfahrung in unterschiedlichen transnationalen Kontexten hinzuweisen.

Da die genealogische Analyse von Subjektivierungsprozessen, einen analytischen Rahmen öffnet, um Lebensentwürfe von „Inder_innen der zweiten Generation“ - als "projects for making oneself a certain person“ (Laidlaw 2010:374) - und institutionelle und diskursive Machtverhältnisse gemeinsam zu denken, werden Konstruktionen ethischer Räume zwischen dem „Eigenen“ und dem „Anderen“ sichtbar, in denen die Anerkennungsbeziehungen selbst ausgehandelt werden. Eine Fallstudie zu Subjektivierungsprozessen „InderInnen der zweiten Generation" bedeutet demnach nicht etwa eine ethnische Einengung der Fragestellung oder eine Fortschreibung einer Migrantologie (Glick Schiller, Caglar, Bojadzijev/ Römhild 2014; Dahinden 2017). Im Gegenteil stellt sie eine produktive Konkretisierung dar, um die Prozesse der Rassialisierung zwischen Struktur und Kultur, Disziplinierung und Lebensführung ethnografisch und transnational sichtbar zu machen und zu erforschen. Dieser Fokus erlaubt insbesondere die dichten, verflechtungsgeschichtlichen und postkolonialen Zusammenhänge in die Forschung einzubeziehen, zumal die intersektionale Konstruktion ethnischer, rassialisierter Zuschreibungen anhand der Ungleichheitsdimensionen von Geschlecht, Klasse und Religion methodisch und theoretisch reflektiert wird. 


\subsection{Transnationale Subjektivierungsprozesse IN EINER GLOBALEN SOZIALTHEORIE}

Wie das Beispiel von Bruno Ziauddins Familienbiografie am Anfang der Einleitung zeigte, überschreiten die Lebenswelten, kulturellen Orientierungsrahmen oder sozialen Mobilitätsmuster indischer Migrant_innen und ihrer Nachkommen nolens volens den nationalen Rahmen. Sie sind eingebettet in transnationale Diskurse, in wirtschaftliche und politische Verflechtungen sowie in intergenerationelle Familienbiografien zwischen Indien, dem Westen und anderen Regionen in der Diaspora. Nicht nur politisch, sondern auch wissenschaftlich wurde diese Evidenz transnationaler Verflechtungen wegen eines expliziten oder impliziten „methodologischen Nationalismus“ und eines Eurozentrismus in der Sozialtheorie lange kaum wahrgenommen (Conrad/Randeria 2002; Wimmer/Glick Schiller 2002; Bhambra 2014; Gutierérrez Rodríguez et al. 2010). Ab den 1990er Jahren wurden vor dem Hintergrund zunehmender Internationalisierung der Wissenschaft, aufgrund theoretischer Verschiebungen, neuer empirischer Studien und nicht zuletzt wegen politischer Kämpfe essenzialistische und eurozentrische Kategorien in den Sozial- und Kulturwissenschaften zunehmend kritisiert. ${ }^{16}$ Gegen die soziologische Migrations- als Assimilationsforschung sowie gegen die Modernisierungs- und Weltsystemtheorie wurden aus unterschiedlichen empirischen, theoretischen und disziplinären Richtungen Ansätze formuliert, die Grenzüberschreitungen, Pluralisierung, Fragmentierung und Dezentrierung von politisch-epistemologischen Kategorien in den Sozial- und Kulturwissenschaften forderten.

\section{Neue Perspektiven:}

\section{Transnationalismus, kulturelle Globalisierung, Diasporaforschung}

Neue Forschungsfelder wie die transnationale Migrationsforschung, die Anthropologie der Globalisierung und postkoloniale Studien eröffneten Perspektiven auf grenzüberschreitende Lebenswelten, Netzwerke, Institutionen und Diskurse im Kontext von Migration und Globalisierung.

16 | In Großbritannien war die Wissensproduktion der postkolonialen Forschung etwa im Falle von Stuart Hall oder Paul Gilroy am Birmingham Center for Cultural Studies oder im British Asian Movement (Sharma et al. 1996; Kalra 1998), eng verknüpft mit der antirassistischen Bewegung und mit kulturpolitischen Interventionen. Auch in Deutschland prägen migrantische Forscherinnen aus dem aktivistischen Zusammenhang von Kanak Attak die rassismuskritische Migrations- und Grenzregimeforschung (Bojadzijev 2008). Zur epistemischen Teilhabe von Migrant_innen in der Schweizer Migrationsforschung: Espahangizi 2017. 
1. Ausgehend von sozialanthropologischen Fallstudien entstand die transnationale Migrationsforschung als empirische und theoretische Kritik an der gängigen Migrations- als Assimilationsforschung (Portes et al. 1999; Vertovec 1999; Levitt/ Glick Schiller 2004; Bauböck/Faist 2010). Paradigmatisch postulierten Glick Schiller et al.

Transmigrants develop and maintain relations - familial, economic, social, organizational, religious, and political that span borders. Transmigrants take actions, make decisions, and feel concerns, and develop identities within social networks that connect them to two or more societies simultaneously. (Glick Schiller et al. 1992:1 f.)

Die transnationale Migrationsforschung machte insbesondere durch empirische Fallstudien auf die soziokulturellen Prozesse und Netzwerke sowie auf Momente der Handlungsmacht aufmerksam, die globale Prozesse innerhalb politisch-ökonomischer und institutioneller Strukturen vorantrieben. Im Zuge ihrer Systematisierung wurde die transnationale Migrationsforschung auch auf die „zweite Generation“" angewendet (Levitt/Waters 2002; Morawska 2003; Bommes 2005; Wessendorf 2013). Jedoch wurde der in den Gründungstexten formulierte und in den frühen Fallstudien sichtbare theoretische Anspruch nicht erfüllt, eine Analyse von transnationaler Migration mit der Kritik eines globalen Kapitalismus und hegemonialer Diskurse zu verbinden (Rouse 1991; Glick Schiller et al. 1992; Basch et al. 1994; Smith/Guarnizo 1998).

2. Auch ab den frühen 1990er Jahren intervenierten vor allem Sozialanthropolog_innen und Kulturgeograf_innen im aufkommenden Globalisierungsdiskurs mit dem Fokus auf kulturelle Globalisierung (Friedman 1990; Massey 1994, Appadurai 1996; Hannerz 1996). Gegen Thesen der kulturellen Homogenisierung (z. B. McDonaldisierung) und der globalen Modernisierung konnten sie aufzeigen, dass globale Prozesse gemäß lokaler kultureller Logiken angeeignet, reinterpretiert und indigenisiert werden und dadurch alternative Konfigurationen von Modernität entstehen (Appadurai/Breckenridge 1995; Randeria et al. 2004). Durch diese Interventionen wurden die Momente der Multiperspektivität und Fragmentierung innerhalb sich globalisierender Modernen in der breiten Globalisierungsdebatte stark gemacht und die empirische Forschung globaler Öffentlichkeit etabliert.

3. Eng mit dieser Debatte verknüpft, entstand ab den späten 1980er Jahren das neue Feld der Diasporaforschung. Ausgehend von den poststrukturalistischen Ansätzen der British Cultural Studies und der Postcolonial Studies wurde darin der Diasporabegriff reartikuliert, der bis dahin die Erfahrung gewalttätiger Vertreibung aus einer ursprünglichen Heimat bezeichnete, wie sie paradigmatisch für die jüdische und seit dem 20. Jahrhundert auch für die armenische und palästi- 
nensische Geschichte beschrieben wurde (Hall 1990; Tölölyan 1991; Safran 1991; Clifford 1994; Cohen 1997). Eine neue, offenere Verwendung des Diasporabegriffs versprach, die im Kontext von Globalisierung und Migration zunehmenden, deterritorialisierten Formen von Vergemeinschaftung und Zugehörigkeit sichtbar zu machen, zu erforschen und aufzuwerten, die nicht durch eindeutige, essenzialistische Herkunft konstituiert waren. So schrieb etwa Stuart Hall:

The diaspora experience as I intend it here is defined, not by essence or purity, but by the recognition of a necessary heterogeneity and diversity; by a conception of "identity" which lives with and through, not despite, difference; by hybridity. Diaspora identities are those which are constantly producing and reproducing themselves anew, through transformation and difference. (Hall 1990: 235, Hervorhebung im Original)

Während die Diasporastudien kulturelle Konstruktionen von Narrativen und Subjektivitäten marginalisierter und rassialisierter Gruppen und die Konstruktion von Hybridität als kritische Praxis gegenüber hegemonialer Repräsentationspolitik etablierten (Bhabha/Rutherford 1990), barg der theoretisch-methodische Fokus auf kulturwissenschaftliche Diskursanalyse auch Nachteile. Dadurch wurden erstens diasporische Subjekte und ihre hybriden Praktiken oft per se als widerständige Akteure konstruiert, ohne deren Spielräume innerhalb institutioneller und politisch-ökonomischer Zwänge empirisch und analytisch zu verorten (Anthias 1998, 2001; Brubaker 2005). Zweitens richteten die Diasporastudien ihren empirischen Fokus oft auf westliche Dominanzgesellschaften. Dadurch blendeten sie die Position diasporischer Subjekte und Gemeinschaften in der ökonomischen internationalen Arbeitsteilung aus (Dhawan 2007).

Trotz neuer Forschungsperspektiven und spannender Fallstudien wurden in den drei skizzierten Feldern - aus je unterschiedlichen theoretischen und methodischen Gründen - wenig analytische Instrumentarien entwickelt, um die neu eröffneten Phänomene transnationaler Mobilität, hybrider, populärkultureller Praktiken oder diasporischer Subjektivitäten als Teil global wirksamer Institutionen, Strukturen und Machtverhältnisse systematisch und empirisch zu untersuchen. Besonders bedeutsam mag dafür die starke Präsenz poststrukturalistischer Theorien gewesen sein, mit deren Annahmen Weltsystem- und Modernisierungstheorie dezentriert werden konnten. Der diskurs- und kulturanalytische Fokus in den Leitdisziplinen der Cultural Studies oder auch Postcolonial Studies hat jedoch die Funktion von sozialen Institutionen, von Materialitäten und von politisch-ökonomischen Strukturen für die historische Ausprägung von Diskursen, Subjektivitäten und Machtverhältnissen unterschätzt (Ahmad 1994; Parry 2004; Mezzadra 2011; Chibber 2013). Von dieser materialistischen Kritik angeleitet, stellt sich an dieser Stelle die konkrete, ethnografische Frage: Wie lassen sich die Reflexion und empirische Untersuchung global zirkulierender und hybrider Narrative und 
Subjektivierungsweisen stärker in diskursiv-institutionelle Strukturen sowie politisch-ökonomische Machtverhältnisse einbetten - und umgekehrt?

\section{Transnationale Genealogie: Subjekte und Macht im dezentralen globalen Kapitalismus}

Die vorliegende Ethnografie schließt an die transnationale Migrationsforschung sowie an die kulturelle Globalisierungs- und Diasporaforschung an, indem die darin eingesetzten Konzepte und die damit bezeichneten Prozesse, Praktiken und Subjektivitäten selbst als Elemente in verflechtungsgeschichtlichen Konfigurationen von Strukturen, Diskursen, Institutionen, Netzwerken und Praktiken untersucht werden: Wie das Konzept der „Zweiten Generation“ sollen auch die Konzepte „Diaspora“, „Hybridität“ und „Kosmopolitismus“ nicht als neutrale wissenschaftliche Kategorien verwendet werden. Stattdessen sollen sie als Wissensbestände in einem Netz staatlicher Regierungstechniken, ökonomischer Verwertungslogiken und populärkultureller Narrative untersucht werden. Während also die indische Regierung ab den 1990er Jahren eine neue Diasporapolitik einführte (Kapitel 6), bot ein kommerzieller Multikulturalismus im urbanen Zürich Räume, um hybride kulturelle Formen wie das Bollywood-Kino als Lifestyle zu konsumieren und dabei kosmopolitische Aspirationen zu pflegen (Kapitel 4). Als Rahmen versuche ich, die im obigen Unterkapitel skizzierte genealogische Herangehensweise auf eine globale Ebene zu heben. Dazu werde ich Ansätze zur Kritik des postfordistischen Kapitalismus mit Ansätzen aus einer Anthropologie der Globalisierung zu verbinden, und dadurch postkoloniale und kapitalismuskritische Perspektiven zu kombinieren suchen (Ong 1999; Coronil 2000; Comaroff/Comaroff 2001, 2009; Mezzadra/Neillson 2013).

Mit Konzepten wie „flexibilisierte Akkumulation“ (Harvey 1990a), „unorganisierter Kapitalismus“ (Lash/Urry 1987) oder Postfordismus (Hirsch/Roth 1986) wurden Verschiebungen in den räumlichen, technologischen und sozialen Produktions- und Reproduktionsbedingungen des Kapitalismus seit den 1970er Jahren - konkret seit der Ölkrise 1973 - beschrieben. Damit verbunden waren unter anderem Deindustrialisierung und die Zunahme des Dienstleistungssektors in den westlichen Metropolen, die Stärkung globaler Finanzmärkte, die Intensivierung, Differenzierung und Fragmentierung internationaler Arbeitsteilung (Sklair 2001), die Zunahme internationaler Arbeitsmigration, räumliche Konzentration von Macht in global cities (Sassen 1991), Flexibilisierung und Digitalisierung von organisatorischen Prozessen (Castells 1996), die Verschiebung von einer produktions- zu einer konsumorientierten Wertschöpfung und die Kommodifikation von Kultur, Wissen, Bildern, Emotionen und Identitäten (Lash/Urry 1994). Wie Jameson und Harvey argumentieren, waren diese politisch-ökonomischen Verschiebungen und eine raumzeitliche Verdichtung im postfordistischen Kapitalismus verflochten mit der Entstehung einer Postmoderne als „kultureller Logik des 
Spätkapitalismus“, wonach etwa Wiederholungen, Kopien, Pastiche, Remix und Retro-Nostalgie zuerst die künstlerische Produktion und dann die öffentliche Kultur zu prägen begannen (Jameson 1991; Harvey 1990a). Mit Harvey und Jameson lässt sich die postmoderne (und die poststrukturalistische) Logik der Fragmentierung und der Dezentrierung selbst als kulturelle Hegemonie in einem flexibilisierten Kapitalismus analysieren, die ihre politisch-ökonomischen Bedingungen verdeckt.

Through the experience of everything from food, to culinary habits, music, television, entertainment, and cinema, it is now possible to experience the world's geography vicariously, as a simulacrum. The interweaving of simulacra in daily life brings together different worlds (of commodities) in the same space and time. But it does so in such a way as to conceal almost perfectly any trace of origin, of the labour processes that produced them, or of the social relations implicated in their production. (Harvey 1990a:300)

Diese Kritik am postfordistischen Kapitalismus vermag zwar sowohl die politische Ökonomie mit der postmodernen Kulturananalyse zu verbinden, als auch die historische Flexibilisierung des Kapitalismus - oder gar das „Konglomerat unterschiedlicher Kapitalismen“ (Dirlik 2003:282) - zu erforschen. Jedoch erwähnen diese im weitesten Sinne ideologiekritischen Ansätze zum Wandel des globalen Kapitalismus kaum Verschiebungen in den postkolonialen Hierarchien (Ong 1999; Coronil 2000; Dirlik 2003) oder die Kommodifizierung und Hybridisierung von Ethnizität im globalen Kapitalismus (Hall 1991; Chow 2002; Ha 2005; Comaroff/Comaroff 2009). Zudem bleibt offen, wie in dieser kapitalistischen Kulturanalyse spezifische transnationale Subjektivierungsprozesse als „situated cultural practices" genealogisch untersucht werden sollen (Ong 1999:17 ff.).

Aihwa Ongs Buch „Flexible Citizenship“ (1999) über den chinesischen Diasporakapitalismus verbindet theoretisch auf paradigmatische Weise die Stärken einer Kapitalismuskritik mit einer Genealogie transnationaler Subjektivität. In Anlehnung an Michel Foucaults Verständnis von Macht und Wissen als Geflecht von Disziplinierungen und Subjektivierung analysiert Ong die Konstruktion der chinesischen Diaspora in einem transnationalen und machtvollen Netz von staatlicher Gouvernementalität, familiärer Disziplinierung und kapitalistischer Akkumulation.

Indeed, even under conditions of transnationality, political rationality and cultural mechanisms continue to deploy, discipline, regulate, or civilize subjects in place or on the move. Although increasingly able to escape localization by state authorities, [transnational] subjects are never free of regulations set by state power, market options, or kinship norms. (Ong 1999: 19 f.) 
In ihrer genealogisch-ethnografischen Spurensuche entdeckt sie flexible Staatsbürgerschaftsregelungen, globale populärkulturelle Öffentlichkeiten, hybride nationale Ideologien und transnationale familiäre Organisationsformen, die eine eigenwillige globale Konfiguration der chinesischen Moderne hervorgebracht haben. Ongs Fallstudie verweist auf die transnationale kulturelle Logik eines „dezentrierten globalen Kapitalismus“ (Dirlik 2003), respektive eines „Globalozentrismus" (Coronil 2000). Nach Arif Dirlik hat die kapitalistische Expansion eine globale Moderne hervorgebracht, jedoch nicht etwa die teleologische Erfüllung der westlichen Moderne - im Sinne des „Endes der Geschichte“ -, sondern eine umkämpfte globale Moderne mit neuen Hierarchien und Widersprüchen.

This new situation is a product of modernity, but it needs to be recognized nevertheless for the kinds of contradictions it presents, which differentiate it from a period of Eurocentric modernity. Global modernity unifies and divides the globe in new ways. (Dirlik 2003:277)

In dieser umkämpften globalen Moderne zirkulieren koloniale und kulturelle Differenzen als Waren, als sinnhafte Imaginationen und als ordnende geopolitische Markierungen, durch deren Aneignung sich Staaten, Unternehmen sowie Subjekte je nach Klasse, Geschlecht und Lokalität innerhalb eines postkolonialen Systems von Status und Ungleichheit positionieren können. Diese Perspektive eröffnet den Blick auf die politischen, kulturellen und sozialen Formen und Widersprüche, mit denen auch Indien aus der kolonialen Vergangenheit heraustritt und einen „Anspruch auf den globalen Kapitalismus“ erhebt (Dirlik 2003:278). Die Integration in den globalen Kapitalismus seit den Liberalisierungsreformen ab den 1980er Jahren hat die Beziehung von Indien zum Westen sowie zwischen Moderne und Tradition, wie sie seit der Unabhängigkeit etabliert wurden verschoben. Wie in Kapitel 6 gezeigt werden wird, werden seither für die „neuen Mittelschichten“ in neuen urbanen und medialen Konsumräumen in Indien sowie in transnationalen, diasporischen Netzwerken kulturelle Narrative und Subjektivitäten konstruiert, in denen etwa Konsum, Sexualität oder Individualismus nun nicht mehr als westliche Dekadenz oder Mimikry, sondern als selbstbewusster Teil einer globalen indischen Moderne verstanden werden.

Durch den Blick auf die Subjektivierungsprozesse von „Inder_innen der zweiten Generation" beschreibt die vorliegende transnational-genealogische Ethnografie die Umbrüche und Widersprüche in der Schweiz und Indien, die die postkoloniale dezentrale Globalisierung seit den 1960er Jahren befördern. Sie erlaubt, den gesellschaftlichen Wandel im Kontext von Migration und Globalisierung on the ground zu analysieren. 


\subsection{Methodik: Biografie, Ethnografie UND DiskurSe IM TRANSNATIONALEN FELD}

Die vorliegende Ethnografie ist das Ergebnis einer explorativen Spurensuche in einem transnationalen und machtvollen Netz von politischen Regulierungen, ökonomischen Verwertungszwängen, populärkulturellen Narrativen, familiären Solidaritäten und biografischen Projekten der Lebensführung, innerhalb derer die Subjektivierungen von „InderInnen der zweiten Generation“ stattfanden und weiterhin stattfinden. Als methodischer Rahmen bot sich eine „multi-sited ethnography“ an (Marcus 1995; Falzon 2009; Coleman/Hellerman 2011). Damit wird nicht eine konkrete Methode bezeichnet, sondern eine Forschungshaltung. Statt ein ethnografisches Feld, im Sinne der Isomorphie von Ort, Gemeinschaft und Kultur (Gupta/Ferguson 1992) aufzusuchen, müssen Anthropolog_innen ihr „Feld“ im Kontext des „Weltsystems“ als Konglomerat unterschiedlicher Arenen in globalen Prozessen, Institutionen und Diskursen konstruieren (z. B. Fox 1991; Augé 1994; Marcus 1998). Eine „multi-sited ethnography“ wirft jedoch angesichts der Komplexität der aktuellen Globalisierungsprozesse zwangsläufig Fragen auf und beleuchtet Phänomene, die methodisch und theoretisch nicht rigoros zu klären sind. Gemäß Marcus bedeutet „multi-sited ethnography“ daher nicht die rein physische Ausweitung des Feldes angesichts einer zunehmenden transnationalen Verflechtung kultureller und institutioneller Zusammenhänge. Sie ist eine theoretisch geleitete und ethnografisch-explorative Spurensuche, in der die Konstruktion und Analyse des gewählten multilokalen Feldes stets auch eine Fallstudie des sich wandelnden „Weltsystems“ darstellt.

Just as this mode [of mobile ethnography] investigates and ethnographically constructs the lifeworlds of variously situated subjects, it also constructs aspects of the system itself through the associations and connections it suggests among sites [...] For ethnography this means that the world system is not the theoretically constructed holistic frame that gives context to the contemporary study of peoples or local subjects closely observed by ethnographers, but it becomes, in a piecemeal way, integral to and embedded in discontinous, multi-sited objects of study. (Marcus 1995:96 f. Hervorhebung im Original)

Die „multi-sited ethnography“ gibt jedoch selbst noch keine methodischen Vorgaben. Die Forschung, aus der dieses Buch resultierte, beruht auf einer Verbindung von Biografieanalyse (Rosenthal 2005), Diskursanalyse (Jäger 2004) und teilnehmender Beobachtung (Spradley 1980; Dewalt/Dewalt 2002). Diese Kombination versprach dem doppelten Verständnis von Subjektivierungsprozessen als diskursiv-institutionelle Disziplinierung und als eigenlogische Lebensführung sowie der transnationalen Ausrichtung der Forschung gerecht zu werden. 
Die rekonstruktive Biografieforschung nimmt an, dass in der (westlichen) Moderne die Biografie als relativ stabile kulturelle Norm entstanden ist, um subjektive Erfahrungen entlang eines individuellen Lebenslaufes zu organisieren, zu beschreiben und zu vermitteln sowie um dadurch die eigene Individualität und Authentizität zu bestätigen (Hahn 2000). Demnach schichten Individuen Erlebnisse im Lebenszyklus auf eine spezifische Weise als subjektive Erfahrungen auf, die wiederum eine spezifische Art der Erinnerung und der Erzählung generiert (Hahn 2000; Rosenthal 2005). Ziel der Biografieforschung ist es, die „biografischen Codes“, verstanden als generative Strukturen von Handlungsmustern und Selbstauslegung, $\mathrm{zu}$ untersuchen, die sich eigenlogisch und prozesshaft in der Lebensgeschichte eines Menschen entwickeln (Breckner 2005). Das Foucault'sche Argument einer Produktion von Subjekten in machtvollen historischen Prozessen stellt den phänomenologischen und handlungstheoretischen Kern der Biografieforschung infrage, die die Herstellung von Sinn letzten Endes im Subjekt ansiedelt. Deshalb soll hier Biografieanalyse stärker mit einer Subjektkritik konfrontiert sowie mit diskursanalytischen und ethnografischen Methoden kombiniert werden (Völter/ Schäfer 2005; Dausien/Keller 2005). Damit erscheinen Biografien zusammengesetzt aus einer „Vielfalt von subjektiven Handlungs- und Deutungsstrukturen bzw. von lebensgeschichtlichen oder biografischen Elementen und Diskursen“ (Völter/ Schäfer 2005:177). Darin lassen sich empirisch die Aushandlungen von Subjektivierungsweisen im Rahmen eines eigenlogischen, wenn auch nicht zwangsläufig kohärenten Lebensentwurfes rekonstruieren. Das doppelte Verständnis von Subjektivierung als Lebensführung und gesellschaftliche Disziplinierung erlaubt, Biografien als Produkte von Diskursen zu verstehen, ohne die eigenlogische Qualität "generativer biografischer Strukturen“ oder Momente von Handlungsmacht und sozialer Imagination aufzugeben. Artikulationen subjektiver Erfahrungen können stattdessen sogar als „biografische Arbeit“ in unterschiedlichen diskursiven, institutionellen, transnationalen Kontexten verstanden werden (Hall 1996). Im Sinne eines „doing biography“ (Dausien/Keller 2005:200 ff.) kann ethnografisch untersucht werden, wie biografische Markierungen in unterschiedlichen interaktiven und institutionellen Prozessen strategisch eingesetzt oder eingefordert werden: Die paradigmatische, assimilationistische Frage „Woher kommst du?“ fordert etwa von „Inder_innen der zweiten Generation“ eine (familien-)biografische Selbstrepräsentation ein. Dadurch werden sie als „Andere“ im Gegensatz zu Angehörigen einer Norm markiert, die nicht erklärt werden muss und unsichtbar bleibt. Umgekehrt kann die autonome Erzählung der Biografie bei „Inder_innen der zweiten Generation" eine Strategie der Offenbarung in einem selbst gewählten Kontext darstellen, um Erfahrungen des Andersseins jenseits von Scham und Unsicherheit zu äußern und zu teilen. Als soziale Praxis wird die Biografie zur ethischen Ressource in Aushandlungen nicht-normativer Subjektivität in einer transnationalen Repräsentationspolitik. Die Publikation von Bruno Ziauddins autobiografischem Buch „Curry-Connection“ erscheint so gesehen sowohl als kommerzielles Produkt 
als auch als sozioethische Anerkennungspraxis im Spannungsfeld von Assimilation, kommerziellem Multikulturalismus und globaler indischer Moderne.

\section{Forschungsprozess und Sampling}

Die Feldforschung zur vorliegenden Studie fand vom Winter 2008 bis Winter 2012 in der Schweiz und - davon ein knappes halbes Jahr - in Indien statt.

Um mir ein Bild von der Geschichte, der Sozialstruktur und der Organisation der indischen Migrationsgemeinschaft in der Schweiz zu machen, habe ich Expert_inneninterviews mit Gatekeepern aus den indischen Kulturvereinen sowie der indischen Botschaft durchgeführt sowie Veranstaltungen dieser Kulturvereine, besucht. Im Laufe der Feldforschung haben des Weiteren biografisch-narrative Interviews mit 33 Personen stattgefunden (Rosenthal 2005; Küsters 2009). Die Auswahl der Interviewten basierte insofern auf einem theoretischen Sampling (Strauss 1991), als ich Personen vor dem Hintergrund der laufenden Kategorienbildung im Forschungsprozess ausgewählt habe, die neue biografische Verläufe, Thematiken oder transnationale Verflechtungen versprachen oder sich maximal oder minimal von bisherigen Fällen unterschieden.

1. Die erste theoretisch bedingte Entscheidung war es, vor allem Personen auszuwählen, die älter als 30 Jahre waren - mit einigen bewussten Ausnahmen als Vergleichpersonen. Dieser Fokus erlaubte es - im Gegensatz zu vielen Jugendstudien zur „zweiten Generation“ -, die historische Verschiebung der Subjektivierungslogiken zwischen Assimilation, kommerziellem Multikulturalismus und globaler indischer Moderne zu untersuchen. Aus biografietheoretischen Überlegungen erschien es zudem sinnvoll, Personen zu wählen, die gewisse biografische Entscheidungen etwa in Bezug auf Ausbildung und Partnerschaft getroffen hatten. Diese Themen waren in Bezug auf die intergenerationelle und assimilatorische Aushandlung von Geschlechternormen und sozialer Mobilität zentral (s. Kapitel 3).

2. Der zweite wichtige Punkt beim Sampling war es, dass auch Personen einbezogen wurden, die sich an den Grenzen der Kategorie „Inder_innen der zweiten Generation" positionierten oder die von anderen Personen an eben diesen Grenzen positioniert wurden. Damit sollte im Sinne der Ethnizitätsforschung ein Kategorienfehler vermieden werden und ein doing generation als umkämpfte Repräsentationspolitik untersucht werden. Daher wurden 13 Personen mit binationalen Eltern einbezogen. Zudem haben zwei Personen an der Forschung teilgenommen, die von Schweizer Eltern adoptiert wurden. Schließlich habe ich drei Personen interviewt, die als Angehörige der „Zweiten Generation“ in der indischen Diaspora - im einen Fall in den USA, in einem anderen Fall in Australien und in einem weiteren in Uganda - aufgewachsen waren und zu einem späteren Zeitpunkt ihres Lebens in die Schweiz kamen. 
3. Drittens habe ich versucht, im Sampling (sowie natürlich in der Analyse) die Verteilung nach Geschlecht, Schichtzugehörigkeit, regionaler Herkunft und Religionszugehörigkeit in Indien und in der Schweiz im Sinne intersektioneller Ansätze abzubilden und zu analysieren (Crenshaw 1991; Knapp 2005). Kastenzugehörigkeit war, soweit ich eruieren konnte, außer in einigen Brahmanenfamilien in der „Zweiten Generation“ kein explizites Thema, sondern wurde implizit auf der Ebene von Klasse verhandelt, wie es gerade in den „neuen Mittelschichten“ oft geschieht, um Kastendiskriminierung zu verharmlosen (Sheth 1999). Auch die Thematik der queerness, die im indischen Diasporakontext zweifellos sehr spannend wäre (Gopinath 2005), konnte ich nicht bearbeiten, da ich erst von queeren „Inder_innen der zweiten Generation“ erfahren hatte, als die Feldforschung schon abgeschlossen war. Auch dies verweist auf spannende feldimmanente Prozesse, wie Heteronormativität und queere Leben zwischen Assimilation und Diaspora ausgehandelt werden, die in weiteren Forschungen untersucht werden sollten.

Dies hat eine Grundgesamtheit von etwa 600 bis 800 Personen innerhalb der gewählten Kohorte ergeben. Im Laufe der ethnografischen Feldforschung in der Schweiz habe ich aus den 33 Interviews etwa ein Dutzend Fälle vertieft. Ich habe die Biografien dieser Forschungsteilnehmenden gemäß einer rekonstruktiven Analyse ausgewertet (Rosenthal 2005). Zudem habe ich sie möglichst oft im Alltag und in der Freizeit begleitet, habe Freunde, Arbeitskolleginnen und Familienmitglieder getroffen und zum Teil auch interviewt. Dadurch konnte ich Repräsentationspraktiken meiner Gesprächspartner_innen in unterschiedlichen Kontexten miterleben sowie informelle Gespräche über biografische Erfahrungen führen und diese in Form von Feldnotizen festhalten. Diskursive Materialien wie akademische Arbeiten, berufliche Dokumente, Flyer, Fotografien oder berufliche Websites, die mir zur Verfügung gestellt wurden oder öffentlich waren, boten weitere Einblicke. Um Einsichten in die Konstruktion von Schweizer Indiendiskursen zu gewinnen, besuchte ich - allein oder mit Forschungsteilnehmenden - Veranstaltungen über Indien, über Migration oder einfach was gerade anstand: literarische Lesungen von indischen Autorinnen und Autoren, Bollywood-Vorführungen in Kinos, $\mathrm{Mu}$ seumsführungen und multikulturelle Festivals. Dabei habe ich Einblicke in soziale und ethnische Zusammensetzungen von Trägerschaften sowie Publikum gewonnen sowie Interviews und informelle Gespräche mit Gatekeepern geführt - etwa in Bezug auf die Lancierung des Bollywood-Booms in der Schweiz. Schließlich untersuchte ich Zeitungsberichte, Bücher, Filme, populärkulturelle Artefakte über Indien, Migration und die „Zweite Generation“ sowie Statistiken und politische Dokumente in Bezug auf die Konstruktion von Migration und der „zweiten Generation“.

Zwischen September 2009 und März 2010 fand eine Feldforschungsphase in Indien statt. Im Zentrum stand die ethnografische Begleitung von sechs Forschungsteilnehmenden während ihrer Aufenthalte in Indien, die unterschiedlich motiviert 
waren: Familienreisen, Praktika, berufliche Projekte bis zu mehrjähriger Remigration. Während dieser Zeit habe ich die Forschungsteilnehmenden im Alltag, zu beruflichen und privaten Anlässen begleitet, Freunde und Familienmitglieder kennengelernt und wenn möglich interviewt. In Gesprächen und durch gemeinsame Erlebnisse sowie durch Beobachtungen in urbanen Räumen und durch die Analyse populärkultureller Artefakte wie Filme, Bücher, Flyer oder Geschenke konnte ich Material zu vielfältigen Narrativen über „Indien“ und den „Westen“ sowie über die "neue Mittelschicht" sammeln. Schließlich bot der Pravasi Bhartiya Divas (PBD) 2010 in New Delhi, der offizielle „Tag der Indischen Diaspora“, zu dem die indische Regierung seit 2003 lädt, eine gutes ethnografisches Feld für die Erforschung der neuen indischen Diasporapolitik. In diesem Zusammenhang habe ich Expert_inneninterviews mit Beamten geführt sowie staatliche Dokumente, Magazine und Werbematerial gesichtet.

Meine Gesprächspartnerinnen und Gesprächspartner habe ich anonymisiert und ihre Namen in den Fallanalysen durch Pseudonyme ersetzt. Persönlichkeiten oder Expert_innen, die kraft ihres Amtes öffentliche Aussagen machten oder Handlungen in der Öffentlichkeit vollzogen, habe ich namentlich erwähnt. In beiden Fällen sind Aussagen in dieser Dissertation auf „Fälle“ im Sinne wissenschaftlicher Modellierungen gesellschaftlicher Prozesse bezogen und nicht auf die individuellen Personen (Mecheril 2003).

\subsection{Aufbau}

Die Ethnografie ist historisch entlang der Konstituierung der drei gesellschaftlichen Subjektivierungslogiken Assimilation, multikulturelle Exotik und globale indische Moderne aufgebaut. Diese Struktur erlaubt es, die gleichzeitige Konstruktion von Biografien und diskursiv-institutionellen Bedingungen zu verfolgen. Im Teil A, der die beiden ersten Kapitel umfasst, wird die assimilatorische Subjektivierungslogike diskutiert, die ab den 1960er Jahren die Kindheit und Jugend der hier vorgestellten Subjekten prägte. Teil B diskutiert die Subjektivierungslogik der multikulturellen Exotik und der globalen indischen Moderne, die ab den 1990er Jahren zunehmend an Macht gewannen. Die Abfolge im Text soll weder eine strenge Chronologie abbilden oder gar eine Teleologie suggerieren, noch sollen diese Subjektivierungslogiken vollständig unabhängig voneinander verstanden werden. Ich argumentiere zwar, dass die assimilatorische Subjektivierungslogik in der Schweiz zeitweise vorherrschend war und die Subjektivierungsprozesse von „Inder_innen der zweiten Generation“ zu konstituieren vermochte. Jedoch hat ab den 1990er Jahren eine Pluralisierung stattgefunden, wonach sich neben der Assimilation zunächst multikulturell-exotisierende und seit dem Beginn des neuen Millenniums zunehmend diasporische Subjektivierungen in einer globalen indischen Moderne etablieren konnten. Seither ist es gerade das Zusammenspiel dieser 
Logiken, das die individuellen Subjektivierungsprozesse bestimmt. Je nach situativem oder transnationalem Kontext und je nach biografischer Perspektive können Erfahrungen ähnlicher Phänomene unterschiedlichen oder mehreren Subjektivierungslogiken unterworfen sein. Gerade diese Polysemie und Ambivalenz verweist auf die fragilen und sehr persönlichen Erfahrungen des Andersseins, aber auch auf die Spielräume in den individuellen Subjektivierungsprozessen kosmopolitischer Pionierinnen und Pioniere. Ich habe zudem versucht, die Verflechtungen assimilatorischer, multikulturell-exotisierender und diasporischer Subjektivierung möglichst in den Fallanalysen aufzunehmen und zu thematisieren.

Im zweiten Kapitel leite zuerst ich die assimilatorische Subjektivierungslogik als Produkt der biopolitischen Konstruktion des Nationalstaates her. Ich zeige, wie die Kategorien „Assimilation“ und "Generation“ eine Herrschaftstechnologie in der Migrationspolitik aufspannten, die sich urspünglich um die Regulierung der nationalen und kolonialen Bevölkerung drehte und die in der politischen Epistemologie der Migrationsforschung eingeschrieben ist. In einer Genealogie der Konstruktion der „zweiten Generation“" und des Assimilationsparadigmas in der Schweizer Migrationspolitik des 20. Jahrhunderts wird deutlich, wie die „zweite Generation“ zu einer strategischen politischen Größe wurde, um zwischen „Überfremdung " und Wachstum abzuwägen. Diese assimilatorische Subjektivierungslogik verdichtet sich seit den Texten der Chicago School bis in den Schweizer Assimilationismus in der Metapher des „Lebens zwischen den Welten“.

Im dritten Kapitel zeige ich anhand von biografischen Fallstudien wie die assimilatorische Subjektivierungslogik eine sozialräumliche Hierarchie zwischen nationaler Öffentlichkeit und der „Migrationsfamilie“ herstellte. Die „Migrationsfamilie" wurde dadurch sowohl zur sozialen Arena als auch zum diskursiven Topos in Subjektivierungsprozessen von „Inder_innen der zweiten Generation“. Das „Leben zwischen den Welten“ wurde im Sinne einer selbsterfüllenden Prophezeiung zu einem machtvollen Deutungsmuster, das unterschiedliche familiäre und öffentliche Aushandlungen von Ethnizität, Geschlechterperformanz und sozialer Mobilität steuerte. Angesichts der Internalisierung assimilatorischer Macht sowie fehlender diasporischer Öffentlichkeiten und Netzwerke unter der „Zweiten Generation" schrieben sich die dadurch generierten, ambivalenten Erfahrungen des Andersseins als intime biografische Projekte in die Subjektivierungsprozesse ein.

Im vierten Kapitel beschreibe ich, wie Zürich als global city zu einem Knotenpunkt im globalen Kapitalismus wurde und dadurch eine Internationalisierung urbaner Räume in der Schweiz stattfand. Durch urbanes Standortmarketing, städtische Kulturpolitiken und Kommodifikation von Ethnizität entstand ein kommerzieller Multikulturalismus. In diesem Rahmen fand angesichts der Integration Indiens in den Kapitalismus ein Indienhype statt, in dem „Indianness" mitten in der Gesellschaft reexotisiert wurde. Die multikulturell-exotisierende Subjektivierung 
eröffnet „Inder_innen der zweiten Generation“ ambivalente Räume und Praktiken einer warenförmigen Anerkennung, die eine Selbstrepräsentation und Mehrfachzugehörigkeiten zulässt, wie etwa in Gesprächen über Bollywood-Kino oder indisches Essen oder gar in beruflichen Projekten - etwa als Yoga-Lehrerin oder in Forschungsprojekten. Jedoch offenbart sie auch eine strukturelle Spaltung in der Subjektivierung der „zweiten Generation“ im Zuge der Positionierung der Schweiz im globalen Kapitalismus. Während Angehörige der Unterschicht und dem Islam nur zu oft als "unassimilierbare Andere" angesehen werden und deshalb staatlicher Disziplinierung und gesellschaftlicher Diskriminierung ausgesetzt sind, gelten Angehörige der Mittelschicht mit überdurchschnittlicher Bildung als „kosmopolitische Exoten“ in einer weltoffenen, global orientierten Schweiz. „Inder_innen der zweiten Generation", die größtenteils der Mittelschicht angehören, können Räume warenförmiger Anerkennung nutzen, sind jedoch trotzdem nicht gefeit vor Exotisierung und wiederkehrenden Assimilationsforderungen.

Im fünften Kapitel zeige ich anhand von biografischen Fallstudien aus Kapitel 3, wie intime biografische Projekte des Andersseins in den ambivalenten Räumen eines kommerziellen Multikulturalismus ausgehandelt werden. Mit Fokus auf Identitätskonsum und ethnic entrepreneurship zeige ich auf, wie „Inder_innen der zweiten Generation" neue Anerkennungsräume und professionelle Optionen nutzen, um ihre Erfahrungen des Andersseins und Mehrfachzugehörigkeit äußern zu können und als Lebensentwürfe zu verwirklichen suchen, die nicht durch essenzialistische Annahmen eines Entweder-Oder eingeschränkt sind. Angesichts des gesellschaftlichen Begehrens nach Differenz bleiben die Protagonist_innen jedoch eingebettet in eine Politik der Authentizität, die zwischen Selbst-Orientalisierung und Anerkennung oszilliert. Die Strategien „Expertise“, „Offenbarung“ und „Ironie“ bieten einerseits die Möglichkeit, sich öffentlich selbst zu repräsentieren. Gleichzeitig wird in vielen Fällen eine intime, performative Strategie des Schweigens bevorzugt, die eine gewisse Autonomie verspricht - zum Preis fehlender Anerkennung.

Im sechsten Kapitel beschreibe ich die politische, ökonomische und kulturelle Repositionierung des indischen Unabhängigkeitsprojektes im globalen Kapitalismus ab den 1990er Jahren. Ich argumentiere, dass darin die im antikolonialen Programm Nehrus stiefmütterlich behandelte Diaspora als strategische, politische, soziale und kulturelle Plattform reartikuliert wurde, um eine globale indische Moderne zu etablieren, die indische Werte und westlichen Materialismus sinnhaft verbindet. In den urbanen und medialen Konsumräumen der aufstrebenden Mittelschichten, in Bollywood-Narrativen und in einer neuen Diasporapolitik entstanden auf der Projektionsfläche der Diaspora neue normative Subjektivitäten entlang der Konfigurationen von Geschlecht, Klasse und Nation. In drei Fallanalysen zeige ich, wie „Inder_innen der zweiten Generation“ in diesem Kontext ihre 
transnationalen Praktiken vertiefen und sich als Teil der indischen Nation als "globale indische Familie“ positionieren. An Beispielen wie Tourismus, professionellen Projekten und Heirat zeige ich die Ambivalenzen zwischen dem privilegierten Zugang zu den urbanen kosmopolitischen Sphären der „neuen Mittelschichten“ und den individuellen moralischen Aushandlungen angesichts von patriarchalen Geschlechternormen und der Zunahme von Ungleichheit und Armut im „neuen Indien".

Im letzten Kapitel versuche ich die Subjektivierungsprozesse von „InderInnen der zweiten Generation“ aus der Schweiz als Entwicklung kosmopolitischer Ethiken in einer postkolonialen globalen Moderne zu deuten. Der Begriff des Kosmopolitismus verweist sowohl auf die Aspirationen individuelle, nicht-essenzialistisch verstandene Lebensentwürfe zu verwirklichen, als auch auf eine Signatur im dezentralen globalen Kapitalismus, die den Zugang zu einer transnationalen Mittelschicht markiert, die sich unter Anderem durch flexible Staatsbürgerschaften und Narrative von Vielfalt auszeichnet. Diese kosmopolitische Logik ist in nationalstaatliche Regime, ökonomische Verwertungspraktiken und populärkulturelle Narrative eingeschrieben und markiert die Selektion zwischen Einschluss und Ausschluss, Privilegien und Ausbeutung, Anerkennung und Disziplinierung im Sinne neuer postkolonialer Ordnungen von Klasse, Geschlecht und Herkunft. 

TEIL A: ASSIMILATION UND

I

กI

$Z$

0

II

$\sum$

$\pi$

I

ח7

$Z$ 



\section{Die Geburt der „zweiten Generation“ im Assimilationismus}

Generations are perceived to be so obviously natural that they have become rather inconspicuous.

(Werner Sollors 1986:208)

Bei der gezielten Assimilationsförderung dürfen wir deshalb nur psychologisch geschickt vorgehen und nicht einen so starken Druck ausüben, dass der Ausländer glauben muss, seine mitgebrachte Eigenart sei nichts wert. Sie soll nicht gewaltsam zerstört werden, sondern durch unsere überblendet werden.

(Marc Virot 1968:33)

"Ich bin nur Halbinder“, „I try to take the best of both worlds“, „Wo sind eigentlich deine Wurzeln?" - Sätzen wie diesen bin ich während meiner Feldforschung oft begegnet. Für die meisten meiner Gesprächspartnerinnen und -partner waren es beiläufige und allägliche Floskeln, die kaum der Rede wert waren. Beim ethnografischen Zuhören und Zusehen erschienen sie jedoch auch als Indizes wirkungsmächtiger Normen von Herkunft und Zugehörigkeit. Nach Werner Sollors sind alltägliche und wissenschaftliche Begriffe, die Herkunft und kulturelle Zugehörigkeit beschreiben, eher vage Metaphern denn erklärende Kategorien (Sollors 1986:5): „Ganz-“ versus „Halbinder“, in „Zwei Welten leben“, „Wurzeln“ oder „Zweite Generation“ sind diffuse semantische Konstruktionen, die jedoch als natürlich wahrgenommen werden und dadurch objektivierte Wirklichkeiten zu schaffen vermögen.

In diesem Kapitel wird diese sublime Naturalisierung von Herkunftsnormen aufgebrochen und in ihrem historischen und politischen Zusammenhang analysiert. Ausgehend von einem genealogischen Ansatz wird darin die Semantik und Politik der „Zweiten Generation“ im nationalstaatlichen Projekt der Assimilation beleuchtet.

- Was ist der historisch-politische Entstehungskontext des Begriffes der „Zweiten Generation"? 
- Unter welchen historischen und politischen Bedingungen gewann der Begriff seine Bedeutung und die Kraft, gesellschaftliche Probleme zu definieren oder zu lösen?

- Welche spezifischen Narrative und Praktiken sind mit dem Begriff verknüpft, die Menschen auf eine bestimmte Weise im sozialen Kontext positionieren und als Subjekte - eben als Angehörige der „Zweiten Generation“ - konstituieren?

Um diese Fragen zu beantworten, verorte ich zunächst den für die Migrationspolitik und -forschung des 20. Jahrhunderts zentralen Begriff der „Generation“ und den damit eng verknüpften der „Assimilation“ in der Biopolitik des entstehenden Nationalstaates des 19. Jahrhunderts. In dieser Konstellation wurde die Zusammensetzung der nationalen Bevölkerung als epistemische und politische problématique wahrgenommen, die sowohl der wissenschaftlichen Untersuchung als auch der staatlichen Regulation bedurfte. Vor diesem Hintergrund entstand Migration überhaupt als Phänomen und Problem, das eine Ordnung des national „Eigenen“ gefährden konnte und das deshalb durch biopolitische Intervention kontrolliert werden musste.

In einem zweiten Teil schildere ich die Entstehung der migrationspolitischen und -wissenschaftlichen Kategorie der „zweiten Generation“ im Assimilationsparadigma der US-amerikanischen Migrationsforschung anfangs des 20. Jahrhunderts. Das Assimilationsmodell hat den Umgang mit Migration und der „zweiten Generation“ in der Wissenschaft, der Populärkultur und der Politik in den USA, aber auch in Europa bis heute geprägt (Kazaal 1995; Sollors 1986; Brubaker 2001; Aumüller 2009). Die Analyse der ursprünglichen, wissenschaftlichen Narrative über die „zweite Generation“ offenbart die politischen und epistemischen Dilemmata in den Begriffen und Denkmustern des Assimilationismus, dem zentralen migrationswissenschaftlichen und -politischen Paradigma des 20. - und wie es aussieht auch des 21. - Jahrhunderts.

In einem dritten Teil zeichne ich die schweizerische Debatte $\mathrm{zu}$ „Überfremdung“, „Assimilation“ und der „Zweiten Generation“ im 20. Jahrhundert nach. Der Überfremdungsdiskurs entfesselte zum einen eine Ethnisierung und Rassialisierung des Nationalen in der Schweiz (Wimmer 2002). Zum anderen lieferte er die diskursiven Ressourcen, um ab dem Ersten Weltkrieg ein nationalstaatliches biopolitisches Regime zu errichten und die „Fremdenfrage“ mit bürokratischen, polizeilichen, rechtlichen und wissenschaftlichen Praktiken zu institutionalisieren. Diese Entwicklung mündete ab den 1960er Jahren in ein assimilatorisches Subjektivierungsregime, das den Alltag und die Persönlichkeit von Migrant_innen und der „zweiten Generation“ zum Gegenstand staatlicher und zivilgesellschaftlicher Imagination, Kontrolle und Intervention machte. In der assimilationistischen Subjektivierungslogik der Schweiz zwischen den 1960er und 1980er Jahren sind die Protagonistinnen und Protagonisten dieser Arbeit sozialisiert worden. 


\section{1 "ASSIMILATION" UND „GEneration" ALS BIOPOLITISCHE TECHNOLOGIEN IM MODERNEN NATIONALSTAAT}

Im späten 18. und im 19. Jahrhundert entstand mit der Nation eine neue politische Legitimation staatlichen Handelns. Die Definition, Gestaltung und Regulierung des nationalen „Eigenen“ gegenüber dem nicht-nationalen „Anderen“ war eine der konstitutiven und existenziellen Aufgaben des Nationalstaates. Die Begriffe „Generation“ und „Assimilation“ waren dafür grundlegend, wie ich im Folgenden zeigen werde. Als die globalen Migrationsbewegungen am Ende des 19. Jahrhunderts zunahmen (Wimmer/Glick Schiller 2002), waren die „Problematisierung“ dieser Migration, die assimilationistische Sprache, um darüber zu sprechen, sowie die politischen, technologischen und bürokratischen Maßnahmen, um diese „Krise“ anzugehen, folgerichtige Konsequenzen aus der biopolitischen Konstitution des Nationalstaates.

Michel Foucault prägte den Begriff der Biopolitik, um die Beziehung von Staat und Untertanen sowie die Begriffe und Praktiken zu analysieren, die „Bevölkerungen“ im 19. Jahrhundert als neue kollektive Objekte zur Regulierung und Optimierung von Leben hervorbrachten (Foucault 1977:135 ff., 1999). Im Rahmen der Geburt der Biopolitik bildeten sich neue wissenschaftliche Disziplinen wie Demografie, Statistik oder Epidemiologie und damit verbundene Techniken wie Hygiene, Eugenik oder Pädagogik heraus, die Bevölkerungen regulieren, vermessen und normieren sowie deren individuellen Körper disziplinieren und formen sollten. Spezifisch an der Biomacht war gemäß Foucault nicht nur der neue epistemische und politische Gegenstand der Bevölkerung als eine zu formende Masse von Individuen, sondern auch die spezifische Ausübung der Macht durch die Produktion von Leben statt der Androhung des Todes (1977:161ff.). Die Macht und Legitimität des frühneuzeitlichen Königs hatte auf der Möglichkeit gegründet, seine einzelnen Untertanen „sterben zu machen, oder leben zu lassen“. Sein Zugriff auf den einzelnen Körper bestand in der Möglichkeit der öffentlichen Tötung. Die Biopolitik fokussierte, so Foucault, stattdessen auf die Kenntnis, Erhaltung, Regulierung und Optimierung von Bevölkerungen - und damit verbunden auf gewaltvolle Prozesse der Selektion, Erziehung und Umformung. Sie hatte die „Macht, Leben zu ,machen und sterben zu ,lassen“" (Foucault 1999:284). Die biopolitische Verflechtung von staatlicher Praxis und wissenschaftlichem Wissen war aus Foucaults Sicht insofern produktiv (im beschreibenden, nicht im normativen Sinn), als innerhalb dieser Ordnung neue gesamtgesellschaftliche Wirklichkeiten, neue soziale Kategorien und Gruppen sowie neue Subjekte geschaffen wurden. Diese neue biopolitische Form der Macht im späten 18. und im 19. Jahrhundert war dabei eng verknüpft mit der Geburt der Nation als neuem historischem Subjekt und als Legitimation staatlichen Handelns. 
Die biopolitische Perspektive unterscheidet sich in der Erklärung der Konstitution von Nationalstaaten von den Klassikern der Nationalismusforschung. Darin wurde die Rolle des Staates als institutioneller Rahmen für die Konstruktion einer ethnischen Gemeinschaft betont (Smith 1986). Auch wurde die Bedeutung der nationalen Pädagogik sowie materieller und ritueller Technologien wie Museen, Karten, Hymnen oder Denkmäler beschrieben, die die nationale Ordnung in die soziale Wirklichkeit einschrieben (Anderson 1996 [1983]; Billig 1995). Die biopolitische Perspektive ergänzt die symbolisch-institutionelle „Erfindung der Nation“ um den Fokus auf die institutionelle und praktische Schaffung der nationalen und nicht-nationalen Bevölkerungen und Subjekte: Foucault leitet den modernen Nationalstaat aus einem Kampf politisch unterdrückter Gemeinschaften gegen die staatliche Macht von Eroberern seit der frühen Neuzeit in Frankreich (Gallier vs. Franken) sowie in England (Angelsachsen vs. Normannen) her (Foucault 1999). Diese Gemeinschaften stilisierten sich und ihre Eroberer als antagonistische „Rassen“ im Kampf um politische Macht. Jedoch beschrieb der Rassebegriff - der zu dieser Zeit mit dem der Nation oder des Volkes eng verknüpft war - nicht etwa homogene, biologisch konnotierte Populationen, sondern politische Gemeinschaften, die sich über eine gemeinsame Geschichte der Unterdrückung definierten. Die Entstehung der Nationalstaaten nach den Revolutionen des 17. und 18. Jahrhunderts bedeutete den Triumph dieser unterdrückten „Rassen“ über die Eroberer und bewirkte gleichzeitig die Rekonfiguration staatlicher Macht. Zunehmend lenkte der Staat mit der Biopolitik seine Macht auf die rassifizierte und kulturelle Homogenisierung seiner eigenen Bevölkerung anhand von Bevölkerungsstatistiken, volksmedizinischen Untersuchungen, ökonomischen Analysen und weiteren wissenschaftlichen und bürokratischen Technologien. Vor dem Hintergrund der kolonialen Herrschaft wurde die Biopolitik zunehmend zum wissenschaftlich-administrativen „Staatsrassismus“ gegen die eigene Bevölkerung und deren Subjekte zur Definition und Vergewisserung nationaler Einheit, und staatlicher Autorität (Foucault 1999:81).

Der Staat ist nicht das Instrument einer Rasse gegen eine andere, sondern ist und wird zum Beschützer der Integrität, der Überlegenheit und Reinheit der Rasse. Die Idee der Reinheit der Rasse mit allem, was sie zugleich an Monistischem, Staatlichem und Biologischem enthält, tritt an die Stelle des Rassenkampfes (Foucault 1999:101)

Erstaunlicherweise hat Foucault Phänomene der Mobilität und der Migration geschweige denn des Kolonialismus - nicht in seine Analyse der Biopolitik einbezogen. ${ }^{17}$ Dabei stellt die Verwaltung und Regulierung von mobilen Bevölkerungen

17 | Bei der Einführung der Biomacht erwähnt Foucault nur einmal ganz kurz "Wanderung und Siedlung" als neues Problem (Foucault 1977:167), geht aber in seiner Analy- 
insofern ein exemplarisches, wenn nicht gar konstitutives Feld biopolitischer Intervention dar, als darin die demografische, rassifizierte, legale Grenze der Gesamtbevölkerung definiert, kontrolliert und geschützt wird. ${ }^{18}$ Wie Zygmunt Bauman erläutert, war der Assimilationsbegriff maßgeblich für die Vorstellung und die praktische Umsetzung des nationalstaatlichen Bestrebens, eine Bevölkerung und ein Volk gemäß bestimmten Vorstellungen und Normen zu schaffen:

Assimilation ist, anders als Austausch und Mischung von Kulturen allgemein, ein typisch modernes Phänomen. Sie erhält ihren Charakter und ihre Bedeutung durch die moderne Nationalisierung des Staates, d. h. durch dessen Bestreben nach sprachlicher, kultureller und ideologischer Vereinheitlichung der Bevölkerung, die das Territorium seines Zuständigkeitsbereiches bewohnt. (Bauman 1998:41)

Die nationale Assimilation basierte auf der Stigmatisierung von lokalen, soziokulturellen Gemeinschaften sowie auf dem Ausschluss ethnisierter und rassifizierter „Anderer“ - oder, gemäß Foucaults Analyse auf der Disziplinierung angeblich ineffizienter, anomaler Bevölkerungssegmente. Gleichzeitig schuf Assimilation insofern neue nationale Subjekte, als den Individuen „angeboten“ wurde, „der stigmatisierten Klassifikation durch die Akzeptanz einer nichtstigmatisierten Lebensweise zu entgehen“ (Bauman 1998:39). Die Assimilationslogik erlaubte dem staatlichen Willen - und zwang ihn zugleich -, den nationalen Körper kontinuierlich zu definieren, zu bewerten, zu formen und zu schützen.

Der Assimilationsbegriff selbst reflektiert die (biopolitische) Verflechtung biologistischer Gesellschaftskonzepte mit dem nation building. Laut Aumüller (2009:27 ff.) wurde er ab dem späten 18. Jahrhundert aus der Hermeneutik in die Physiolo-

se nicht weiter darauf ein. Es ist überhaupt erstaunlich, dass Foucault "Staatsrassismus" unabhängig vom sozialdarwinistischen Wettbewerb der Nationen im kolonialen Kontext konzipieren konnte. Konsequenterweise konnte er den modernen Rassismus nur als "Survival" des vormodernen Gesetzes des Schwertes in die Moderne erklären (Foucault 1999:303).

18 | Als Beispiel kann die „Zigeunerfrage“ als eines der zentralen Probleme der europäischen Nationalstaaten im 19. Jahrhundert genannt werden. Die Sesshaftigkeit der nationalen Bevölkerung war nicht nur Ausdruck von Zivilisiertheit, sondern auch Garant der nationalstaatlichen Macht. In der Schweiz wurden 1850 als eine der ersten bundesstaatlichen Interventionen überhaupt "Heimatlose" zwangseingebürgert. 1899 wurde in Bayern die erste Zigeunerkartei gegründet. Die "Zigeunerplage“ war schließlich der Anlass zur Gründung der ersten supranationalen, europäischen Polizeiinstitution: der Internationalen Kriminalpolizeilichen Kommission 1923 in Wien, der Vorläuferin von Interpol. Analog zeigt sich die staatliche Problematik der Mobilität in der kolonialen Politik gegen die „population flottante“ (Falk 2011). 
gie übertragen. In metaphorischer Anlehnung an die Bedeutung einer geistigen Annäherung des Erkennenden an das Erkannte bezeichnete „Assimilation“ in der biologischen Terminologie die organische Einverleibung des Fremdartigen bis zu dessen Auflösung. Gleichzeitig wirkte die hermeneutische Bedeutung als ,geistige Nahrungsaufnahme" im Sinne der nationalen Erziehung und kulturellen Tradierung weiter. Die Wirksamkeit des Assimilationsbegriffes für das nationale Projekt basiert auf dieser semantischen Verflechtung von Natur und Kultur, Gesellschaft und Organismus. ${ }^{19}$ Die organische Metaphorik ermöglichte, die Nation als strikte territoriale, kulturelle und politische Einheit zu repräsentieren, da Organismen dank einflussreicher Entdeckungen in der Physiologie zunehmend als funktionale, abgeschlossene Einheiten betrachtet wurden. Die Natur repräsentierte den Genius, Neues zu schaffen, Vitalität, Individualität und Wachstum; Qualitäten, die sich direkt in die historische Mission der Nation übersetzen ließen (Berlin 1997 [1949]:590 ff.). Diese doppelte - kulturell-historische und biologische - Semantik der Assimilation wurde zum politisch-epistemischen Horizont, als die Grenze der Nation zum Problem wurde, als gefragt wurde, wer dazugehören sollte und wer nicht, welches Leben legitim und wertvoll sei und welches nicht. ${ }^{20}$

Eng mit dem Assimilationskonzept verknüpft ist auch der Generationenbegriff auf vielfältige Weise in die organische Metaphorik der Nation als politische Gemeinschaft eingeschrieben (Parnes et al. 2008). Bedeutete Generation im 18. Jahrhundert noch die individuelle Erzeugung eines neuen Menschen, verschob sich diese Bedeutung im 19. Jahrhundert auf eine kollektive Ebene im Sinne von naturhistorischer Reproduktion (Generationenwechsel). Am Anfang des 19. Jahrhunderts stand die moderne Biologie vor dem Problem, wie die Einheit einer Spezies und die individuelle Varianz (innerhalb dieser Spezies) erklärt werden konnten. Die Vorstellung des Generationenwechsels, als gesetzmäßige und naturhistorische Rekombination artspezifischer und individueller Eigenschaften bei der Fortpflan-

19 | Der moderne, soziologische Gesellschaftsbegriff entstand auch im Zuge dieser Imagination einer nationalen Bevölkerung (Lüdemann 2004). Dies erklärt auch die Verflechtung kulturalistischer, organischer und rassistischer Register in der klassischen Migrationsforschung und im Assimilationismus, (s. dazu Exkurs unten).

20 | Der Begriff der Assimilation wurde im deutschen Kontext der Emanzipation von Jüd_innen seit dem frühen 19. Jahrhundert geprägt und verwendet (Bauman 1998). Einerseits wurde die jüdische Assimilation von aufgeklärten deutschen Staatsbeamten und Gelehrten gefordert, um ein einheitliches "Staatsvolk" zu schaffen. Andererseits war Assimilation eine Strategie aufgeklärter Juden, um trotz endemischer Diskriminierung Zugang zur gesellschaftlichen Öffentlichkeit zu finden (Markell 2003; Aumüller 2009). Die Grenzen der Assimilation, die emanzipierte deutsche Juden spätestens im zunehmenden Antisemitismus nach dem Ersten Weltkrieg erfuhren, weisen auf die fundamentale Ambivalenz zwischen Einheit und Differenz hin, die in der politischen Genealogie von Assimilation eingeschrieben ist. 
zung des Individuums, ebnete dem modernen biologischen Konzept der Vererbung und schließlich der Evolutionstheorie den Weg.

Dieses Verständnis einer sich wandelnden Einheit verbundener Individuen floss über das Sinnbild der Familie in das neue politische Projekt der Nation. Angesichts der Revolutionen in den USA und Frankreich konnten in der Vorstellung einer familiären Abfolge von Generationen sowohl die Reproduktion der Nation als auch der historische Fortschritt vorgestellt werden. Die Verquickung von Familie und Organismus, Kultur und Natur spiegelt sich in der omnipräsenten nationalen Metaphorik des Baumes wider: Die visuelle Technik des Familienstammbaums, die im 18. Jahrhundert als Legitimation von monarchischen Dynastien diente, erlaubte es, die Nation als Familie vorzustellen und zu legitimieren (Bouquet 1996).

Gemäß Malkki verdichtete die pflanzliche Metapher der „Verwurzelung“ die Einheit von Nation, Territorium und Geschichte auf geradezu metaphysische Weise: "Each nation is a grand genealogical tree, rooted in the soil that nourishes it. By implication, it is impossible to be part of more than one tree. Such a tree evokes both temporal continuity of essence and territorial rootedness." (Malkki 1992:28) Die moderne Baum- und die Wurzelmetaphorik vermochte die Angehörigen einer Gruppe über Generationen hinweg durch einen eindeutigen gemeinsamen natürlichen Ursprung als Nation zu naturalisieren. Die Baummetapher- und ikonografie ist insbesondere in den jungen republikanischen Nationalstaaten Frankreichs und der USA wichtig, die ihre Legitimität nicht aus einem ethnischen Abstammungsmythos (ius sanguinis), sondern aus dem politischen Willen und einem gemeinsamen Territorium ableiten. Dort wird der Boden fast durchgehend als Mutter imaginiert, die die junge Nation von Brüdern geboren hat, die sich wiederum als historische Abfolge von Generationen reproduzieren. ${ }^{21}$ Das Territorium wird als generative Instanz angesehen, wonach die Naturalisierung (Einbürgerung) per Geburt auf dem Boden (ius soli) passiert.

21 | Sollors zeigt, wie die Enstehung der USA durch den Pocahontas-Mythos legitimiert wird (Sollors 1986). Demnach ist das indianische Mädchen Pocahontas der generative, mythische Boden, der die amerikanische Nation hervorgebracht hat und ihre Gründerväter nährt. Gemäß Bouquet knüpft die moderne botanische Metapher der Nation an die Stammbäume Jesu an, die seit dem 8. Jahrhundert als pädagogische Instrumente der christlichen Theologie dienen (Bouquet 1996). Darin wird impliziert, dass im genealogischen Baum das eine Blut fließe, aus dem die Menschheit gemäß christlicher Anthropologie stamme. So können Blut und Boden als eng verknüpfte Metaphoriken verstanden werden, in denen eine Nation als generative Einheit imaginiert und reguliert wird. Nach dieser Analyse stellt sich Frage, ob die analytische Unterscheidung von "ethnos" und "demos" als Nationentypen, respektive von ius sanguinis und ius soli als Typen der Staatsbürgerschaft, sinnvoll ist. Demnach wohnt auch republikanisch verfassten Nationen stets eine organische Legitimation und biopolitische Logik inne, die eine rassialisierte und heteronormative Regulierung erfordert. 
Während der Generationenbegriff ein modernes nationales Geschichtsverständnis von Fortschritt und Erneuerung ermöglicht, ist darin immer auch die krisenhafte Kehrseite der Degeneration eingeschrieben. Dieses Krisenszenario einer Biopolitik von Reinheit und Rassenvermischung spannt den Bogen zwischen den Kolonial- und Sklavenhaltergesellschaften des 19. Jahrhunderts und den modernen europäischen Nationalstaaten sowie der darin verankerten Eugenik in Europa im 20. Jahrhundert (Weingart et al. 1992; Young 1995). Die Generationenfolge markierte in den rassenanthropologischen Tableaus den Grad von Unfruchtbarkeit und Verfall, die angeblich durch Hybridität, das heisst Rassenvermischung, ausgelöst würden (Stocking 1987). Die Kontrolle der Generation wurde somit zur biopolitischen Grenztechnologie, mit der die Reproduktion der kolonialen Herrschaft imaginiert, gestaltet und geschützt werden konnte und die über „wissenschaftlichen Rassismus" und über gouvernementale Strategien in die Bildung der Nationalstaaten einfloss (Falk 2011). Die Sorge um die Reproduktion nationaler Bevölkerung war dabei stets eng verbunden mit der Konstruktion und der Kontrolle individueller weiblicher und männlicher Körper und damit der Normierung von Geschlechterperformanz und Familienformen (Sollors 1986; Yuval-Davis 1997; Schumann 2004). Die Metapher der Generation naturalisiert - verdichtet in der Wurzelmetapher - die legitime Abstammung eines Individuums aus einem nationalen, heteronormativen Ganzen und markiert gleichzeitig die existenzielle Gefahr der Transgression in der illegitimen Verbindung „eigener" Frauen und „anderer" Männer.

Die westliche Migrationsforschung und Migrationspolitik können als Produkt dieser politisch-epistemischen Logik der Assimilation im Nationalstaat verstanden werden. Transnationale Migration wurde als potenzielles „Problem“ für den Nationalstaat konstruiert. Das heißt nicht, dass „Andere“ in modernen Nationalstaaten immer ausgeschlossen werden müssen. Es besteht eine Bandbreite des politischen Umgangs mit der Frage des „Eigenen“ und des „Anderen“, von völkischer Einheit bis Pluralismus. Die Ambivalenz zwischen Einheit und Vielfalt in der Anlage des Nationalstaates kann jedoch nicht aufgelöst werden, weshalb darin stets die gewaltvolle Phantasie und Praxis der „Ausmerzung“ präsent ist (Bauman 1998). Die generationelle Reihe markiert dabei den „fremden“" ethnisch-rassialisierten, territorialen Ursprung, der dem migrantischen Subjekt im Nationalstaat eingeschrieben wird und es als Gegenstand wissenschaftlicher Erforschung und biopolitischer Regulierung und Disziplinierung konstituiert. 


\section{Exkurs: Naturalisierung der "zweiten Generation“ in der sozialwissenschaftlichen Migrationsforschung der Chicago School}

Der Begriff der „Zweiten Generation“ taucht schon in den frühen Texten der modernen US-amerikanischen Migrationsforschung am Ende des 19. Jahrhunderts auf. In seinem Aufsatz „Assimilation of Nationalities in the United States“ (1894a, 1894b) widmet sich der Ökonom und Statistiker Richmond Mayo-Smith einem der brennendsten politischen und wissenschaftlichen Themen der jungen US-amerikanischen Nation.

It is my purpose [...] to make some observations in regard to the character of the process of mixture of nationalities which is going on in the United States. By mixture I do not mean the actual mixture of blood, but an assimilation of institutions, character and customs by which these different elements shall gradually be fused into one nationality, or one body - the American people. (Mayo-Smith 1894a:431)

Die Gesellschaft der Vereinigten Staaten wandelte sich zu dieser Zeit massiv: DreiBig Jahre nach dem Sezessionskrieg war das Land geprägt von der Urbanisierung und Industrialisierung der Metropolen in den Nordstaaten, der Etablierung des Zentralstaates und der voranschreitenden Kolonisierung und Bewirtschaftung des Landes. Diese wirtschaftliche und politische Expansion wurde begleitet und ermöglicht durch eine massive Immigration aus Europa, die zwischen 1865 und 1918 über 25 Millionen Personen umfasste. Während die Einwanderer und Einwandererinnen in der „Neuen Welt“ einerseits als Arbeitskräfte und zukünftige Bürgerinnen und Bürger begrüßt wurden, machten sich andererseits zunehmend Ängste breit, ob und wie sich diese sozial, ethnisch und rassisch heterogene Gesellschaft als Nation konstituieren könne (Higham 1981). In diesem Zusammenhang prägt Mayo-Smith den Begriff der „zweiten Generation“ als Objekt der wissenschaftlichen Reflexion und der politischen Steuerung.

Next to these are the native-born of foreign parents. These are the second generation of the immigrants, so to speak. They are foreigners by extraction, but they are American by birth. They form an important element, over eighteen per cent of the total population, and more important still, they stand half-way, as it were, between the native and the foreign element. [...] They represent the process of assimilation in the act, as it were, and form a most interesting subject of study. For if by any means we can measure their social characteristics and character, we have some indication of the rapidity and completeness of the process [of assimilation] itself. (Mayo-Smith 1894a:437) 
Aus Mayo-Smiths soziodemografischer Perspektive fungiert Assimilation als lineare, intergenerationelle Passage von den ethnischen Bindungen der "Alten Welt“ in die homogene US-amerikanische Nation. Der „zweiten Generation“ kommt in diesem Prozess sowohl eine politische als auch eine epistemische Funktion zu: Sie vollzieht nicht nur die Assimilation in der Praxis, sondern erlaubt auch eine wissenschaftliche Beobachtung, Kontrolle und Messung dieses Prozesses.

Die Mitglieder der Chicago School um Robert Ezra Park vertieften „Assimilation“ und „Zweite Generation“ als politisch-epistemologische Kategorien der Migrationsforschung, indem sie eine wissenschaftliche Objektivierung anhand von Modellen, kausalen Zusammenhängen und Typologien vornahmen. Mit dieser Systematisierung beleuchteten sie die sozialen Zusammenhänge von städtischer Ökologie, sozialer Inklusion und Migration und etablierten die Assimilationsforschung als migrationssoziologisches Paradigma des 20. Jahrhunderts. Ein entscheidender Beitrag der Chicago School zur Migrationsforschung war die Modellierung des Assimilationsprozesses im sogenannten race relation cycle. Darin wendet Park seine Theorie zum quasi-naturgesetzlichen universellen Ablauf des Zusammentreffens von sozialen Gruppen auf das Phänomen der Migration an. Der race relation cycle beginnt mit ersten friedlichen Kontakten, geht über in die Phase des Wettbewerbs, wenn Auseinandersetzungen über knappe Ressourcen stattfinden, und kulminiert im offenen oder latenten Konflikt - in Form von Kriegen oder Diskriminierung. In der Phase der Akkommodation geht der Konflikt in einen symbiotischen Zustand über, in dem sich ein funktionales Arrangement bei gleichzeitiger Segregation etabliert. Schließlich findet die Assimilation statt, „the process of interpenetration and fusion, in which persons and groups acquire the memories, sentiments, and attitudes of other persons or groups, and, by sharing their experience and history, are incorporated with them in a common cultural life" (Park/Burgess 1970 [1921]:360). Mit dem race relation cycle wurde die Passage der Migration und der Assimilation in Begriffen reflektiert, in der die sozialevolutionistischen Stufenmodelle aus dem 19. Jahrhundert - wie zum Beispiel bei Herbert Spencer - nachklingen (Aumüller 2009): Zum Einen beschreibt der race relation cycle eine Naturgesetzmäßigkeit, die ebenso linear und unwiderruflich wie fortschrittlich ist. Zum Anderen verweist er in der Beschreibung abgeschlossener Systeme auf die organische Metaphorik des Evolutionismus. Der race relation cycle verbindet dadurch paradoxerweise die Imagination eines krisenhaften Prozess von Migration und Assimilation mit seiner geradezu naturgesetzlichen Aufhebung.

In der Migrationssoziologie von Robert Ezra Park und Everett Stonequist spiegelte sich die krisenhafte Assimilationsdramaturgie des race relation cycle auch als Mikronarrativ wider. Im klassischen Aufsatz „Human Migration and the Marginal Man“ (1928) versucht Park, die subjektive Erfahrungsebene des Menschen im kulturellen Wandel - des sogenannten marginal man - zu beleuchten. 
[A] sense of moral dichotomy and conflict is probably characteristic of every immigrant during the period of transition, when old habits are being discarded and new ones are not yet formed. It is inevitably a period of inner turmoil and intense self-consciousness. [...] In the case of the marginal man the period of crisis is relatively permanent. The result is that he tends to become a personality type. [...] It is in the mind of the marginal man that the moral turmoil, which new cultural contacts occasion manifests itself in the most obvious forms. (Park 1928:893)

Das Narrativ der Krise beim marginal man korrespondiert mit dem kulturalistischen Register der Entfremdung, das Park und Stonequist in Anlehnung an die deutschen Soziologen Ferdinand Tönnies (1855-1924) und Georg Simmel (18581918) verwenden, um Migration als Erfahrung des zivilisatorischen Umbruchs der Modernisierung zu konzipieren. So beginnt Everett Stonequist - die Migration aus den europäischen Nationen in die neue Welt vor Augen - seinen klassischen Essay „The Problem of the Marginal Man“ (1935) mit den Worten:

Probably the great majority of individuals in the world live and have their being within a single cultural system. Each individual is likely to be born, mature and die within the boundaries of one tribal or national tradition, learning to communicate in one tongue, developing loyalties to one sovereign government, conforming to the expectations of one moral code, believing in the way of life approved of one religion [...]. Migration has transplanted individuals and cultures to such an extent that nearly every land and every city is something of a melting-pot of races and nationalities. The individual who grows up in such a situation is likely to find himself faced, perhaps unexpectedly, with problems, conflicts, and decisions peculiar to the melting-pot. (Stonequist 1935: 1f., Hervorhebung R. J.)

Die Figur von Parks und Stonequists marginal man meint nicht eine eindeutige soziale Gruppe. Sie zielt auf eine bestimmte Persönlichkeitsstruktur, die entsteht, wenn Individuen „in zwei Welten leben“ (Park 1928:893; Stonequist 1935:3) und die exemplarisch bei emanzipierten Jüdinnen und Juden, Immigrantinnen und Immigranten, „Mischlingen“22 (mulattoes, racial hybrids) und eben bei der „Zweiten Generation“ anzutreffen ist. ${ }^{23}$ Migration, die Entstehung der Großstädte, ja, die

22 | Ich verwende hier den aus der Rassenanthropologie stammenden Begriff des "Mischlings", um einerseits möglichst nah am historischen Dokument zu bleiben. Andererseits macht der Begriff deutlich, wie eng rassialisierte und kulturalistische Register ineinandergreifen.

23 | Lindner (1990) erwähnt als weitere Inspiration für diese These des "Lebens zwischen den Welten" Parks eigenen Übergang aus dem puritanischen Milieu seiner Eltern 
Moderne selbst repräsentieren den Bruch mit den bekannten Bräuchen, Traditionen und Sitten, aber auch die Unmöglichkeit, die neuen kulturellen Repertoires $\mathrm{zu}$ entschlüsseln. Der marginal man verkörpert diese kulturelle Entfremdung im krisenhaften „Leben zwischen zwei Welten“. In den migrationssoziologischen Arbeiten von Park und Stonequist wird diese existenzielle Ambivalenz der „zweiten Generation“" noch dadurch verstärkt, dass die nationale Debatte der kulturellen Assimilation eng mit der damaligen Debatte um die Aufhebung der Rassentrennung verflochten ist. So analysiert Stonequist die „zweite Generation“ in Anlehnung und Abgrenzung von rassifizierten „Mischlingen“: "Beside the racial hybrid there is also the unmixed cultural hybrid.” (Stonequist 1935:9) Angesichts dieses Transfers des Hybriditätsbegriffes aus der Rassenpolitik in die Assimilationstheorie, von der Rasse in die Kultur, verweist der Diskurs über den krisenhaften „marginal man" auf die in den USA omnipräsenten rassentheoretischen Vorstellungen von Degeneration und vom zivilisatorischen Verfall angesichts der angenommenen biologischen Unfruchtbarkeit des „rassischen Mischlings“ ${ }^{24}$

Park und Stonequist sehen in dem beängstigenden Aufbrechen des „cake of custom“ (Park 1928:881) aber auch das Potenzial für eine kosmopolitische Gesellschaft, das in den USA in der Metaphorik des melting pot angelegt ist und das für sie durch den Simmel'schen Stadtmenschen verkörpert wird (Simmel 2006 [1903]). Die von Israel Zangwill in seinem Drama „The Melting-Pot“ von 1908 popularisierte Metapher stellte das Projekt der „Neuen Welt“ als republikanische Neukonzipierung von Nationalität dar. Während in der „Alten Welt“ Blut, Herkunft und Nationalismus vorherrschten (Mayo-Smith 1894a:426), versprach der US-amerikanische melting pot die rassischen, nationalen und politischen Bindungen aufzubrechen und in einer neuen, utopischen, kosmopolitischen Gemeinschaft wieder zu verbinden. Gelänge dies nicht, wäre nicht nur die junge Nation gescheitert, sondern auch das religiös-millennial aufgeladene Projekt der „Neuen Welt“ ${ }^{25}$

in das kosmopolitische Milieu der Chicagoer Intellektuellen sowie die Mobilität von ethnografisch Forschenden überhaupt.

24 | Während sich die "Assimilation" beim "cultural hybrid" und die "Amalgamation" beim "racial hybrid" in Dauer und Mechanismen unterscheiden mögen, so erscheinen beide Fälle als krisenhafter Prozess. Ich will nicht behaupten, dass die liberalen Soziologen Park und Stonequist diese Rassentheorien verfochten haben. Beide haben immer wieder betont, dass der Grund für die rassische Durchmischung vor allem wegen rassistischer Stereotype länger dauere als die kulturelle Assimilation der europäischen Einwanderer. Und Park schrieb, dass auch in einer multirassischen Gesellschaft früher oder später eine Durchmischung stattfinden werde. Jedoch argumentiere ich, dass sie ihre wissenschaftlichen Reflexionen nicht jenseits der rassentheoretischen Prämissen und Begriffe ansetzen konnten und daher immer wieder in Widersprüche gerieten.

25 | Wie Werner Sollors betont, beförderte die polysemische Offenheit der Metapher des melting pot neben einer kosmopolitischen Interpretation auch einen Anglo-Kon- 
In den Arbeiten der Chicago School manifestiert sich paradigmatisch die politisch-epistemische Krise des Assimilationismus, ja, des modernen Nationalstaates. Angesichts der Kombination, Übertragung und Konfusion organizistisch, kulturalistisch und rassistisch abgeschlossener Gesellschaftsbegriffe erscheint Migration bei Park und Stonequist als Transgression rassialisierter, ethnischer und kultureller Grenzen - wie die impliziten und expliziten Bezüge auf die Begriffe „Transplantation“, „Entfremdung“, „Kulturkonflikt“ oder „Rassenvermischung“ indizieren. Zwar erlauben sowohl der evolutionistische Automatismus des Assimilationsmodells als auch das modernisierungstheoretische Versprechen - im Sinne von Simmels kosmopolitischem Stadtmenschen - eine Überwindung dieser Krise. Die migrationswissenschaftlichen Reflexionen von Park und Stonequist dokumentieren jedoch auch die epistemologische Unmöglichkeit, Migration mit den bestehenden abgeschlossenen Gesellschaftsbegriffen zu fassen, die ihnen aus der deutschen Soziologie und dem Evolutionismus des 19. Jahrhunderts zur Verfügung standen (Lüdemann 2004). Die Arbeiten der Chicago School durchzieht daher eine starke Ambivalenz zwischen der Dystopie des marginal man und der Utopie der perfekten Assimilation, zwischen der Krise kultureller und rassischer Vermischung und dem Versprechen der Herstellung einer neuen republikanischen Ordnung und kosmopolitischen Haltung. ${ }^{26}$

Die Entstehung und die Praxis der klassischen Migrationsforschung in den USA am Ende des 19. Jahrhunderts reflektiert und reproduziert anhand wissenschaftlicher Objektivierungen die politische „Konstruktion“ der „Zweiten Generation“ im frühen US-amerikanischen Nationalstaat. Der Historiker Marcus Lee Hansen brachte in seinem klassischen Aufsatz „The Problem of the Third Generation Immigrant“ aus dem Jahr 1938 das notorische Leitmotiv für die „zweite Generation" auf den Punkt: "How to inhabit two worlds at the same time was the problem of the second generation." (Hansen 1996:204). ${ }^{27}$

formismus, wonach sich Migrant_innen an die Normen der protestantischen, weißen Mehrheit anpassen sollten. In dieser Ambivalenz von "consent and descent" seien nation building und Assimilation in den USA strukturiert (Sollors 1986).

26| Die darin eingeschriebene politisch-epistemologische Problematisierung der Migration und der Nation zeigte sich in der politischen Realität der USA am Ende des 19. Jahrhunderts und am Anfang des 20. Jahrhunderts, als im Zuge der expansiven Nationalstaatenbildung rassistische und kulturelle Kämpfe ausbrachen (Higham 1981). Der Bundesstaat verfolgte daraufhin eine Politik, welche die asiatische Migration einschränkte und die Ausgrenzung der schwarzen Bevölkerung legitimierte, um ein "weiBes", möglichst anglo-konformes Amerika sicherzustellen.

27 | Karakayali (2005) hat gezeigt, wie im 20. Jahrhundert in den USA ein eigenes literarisches Genre entstanden ist, in dem die Bewältigung "des Lebens zwischen den zwei Welten" thematisiert wird. 


\subsection{SCHWEIZER NATION BUILDING UND ASSIMILATIONISMUS}

In der Schweizer Migrationsgeschichte erscheint der Begriff der „Zweiten Generation" wie auch in den USA im Rahmen einer Krise des Nationalstaates um die vorletzte Jahrhundertwende (Argast 2007:174 ff.). Angesichts der boomenden Industrialisierung der Schweiz, des Aufbaus der modernen Infrastruktur und des Hochschulsystems in der zweiten Hälfte des 19. Jahrhunderts gewährten die liberale schweizerische Gesetzgebung und internationale Niederlassungsverträge mit den Nachbarstaaten eine umfassende Bewegungs- und Niederlassungsfreiheit für Ausländerinnen und Ausländer. Zwischen 1860 und 1900 wuchs die ausländische Bevölkerung von 114983 auf 383424 Personen, was einen Anstieg von 4,58 Prozent auf 11,56 Prozent an der Gesamtbevölkerung bedeutete.

\section{Die „zweite Generation“ als politische Größe}

Im Hinblick auf diesen Anstieg der ausländischen Bevölkerung richtete der St. Galler Journalist und Nationalrat der Demokraten Carl Theodor Curti am 9. Dezember 1898 ein Postulat an den Bundesrat, das eine für die Schweiz des 20. Jahrhunderts zentrale Debatte über „Assimilation“ lancieren sollte und in der die „Zweite Generation“ als politisches Objekt enstand.

Die bedenkliche Erscheinung, dass zufolge der letzten Volkszählung [von 1888, R. J.] in der Schweiz rund eine Viertelmillion Ausländer dauernd sich aufhalten und dass, zumal in den Grenzstädten, die ausländische Bevölkerung die einheimische nachgerade zu überflügeln drohe, lasse auf Mittel und Wege zur Abhülfe denken. [...] Das einzige zulässige und zweckmäßige Mittel zur Abhülfe sei wohl das, durch Erleichterung der Bürgerrechtsaufnahme die sich dazu überhaupt eignenden Elemente der schweizerischen Nation zu assimilieren. Man sollte insbesondere danach trachten, in der Schweiz geborene Kinder von Ausländern zu naturalisieren [...]. (Bundesrat 1899:438 f., Hervorhebung R. J.)

In ungleich schärferem Ton beklagt sich der Vorsteher der Zürcher Armenfürsorge Dr. Carl A. Schmid in einem Pamphlet mit dem Titel „Unsere Fremdenfrage“ (1900), „dass unter den gegebenen Rechtszuständen und Niederlassungsverhältnissen bei der geradezu riesigen Anziehungskraft der schweizerischen Großstädte (Zürich, Basel, Genf) in absehbarer Zeit eine so hochgradige Überfremdung der Schweiz stattfindet, dass ihre nationale Existenz nur durch ein Wunder denkbar ist." (Schmid 1900:4 f.) Schmid fordert vom Bundesrat daher auch eine sofortige Einbürgerungsreform, die erlaube diese „Gefahr“ zu beheben. 
Die Argumentation von Curti und Schmid war jedoch - aus heutiger Sicht erstaunlicherweise - grösstenteils eine staatspolitische, nicht etwa eine ethnische. ${ }^{28}$ Gemäß dem führenden liberalen Juristen Carl Hilty (1833-1909) basierte die republikanische „Willensnation“ Schweiz auf dem Zusammenschluss williger, wehrhafter, christlicher Männer, was zwar explizit Frauen und Juden ausschloss, aber nicht explizit mit einer gemeinsamen Ethnizität oder Kultur begründet wurde (Argast 2007:100). So schrieb der Bundesrat im „Bericht über den Entwurf einer Bundesverfassung“ vom 8. April 1848: „Wenn man will, dass die Schweiz eine Nation, die Eidgenossenschaft eine Familie von Brüdern sei, so muss man die Gleichheit der Rechte der Eidgenossen als Prinzip aufstellen“ (zit. nach Argast 2007:99, Hervorhebung R. J). ${ }^{29}$ Curti und Schmid gründeten ihre Argumentation um 1900 darauf, dass Ausländer und Schweizer nicht gleiche Rechte hatten. Erstere hatten keine politischen Rechte, wogegen nur letztere Militärdienst leisten und Armensteuern bezahlen mussten. Die zweite staatspolitische Problematik bestand darin, dass Ausländer in der Schweiz in gewissen Bereichen dem Recht ihrer Heimstaaten unterstanden und insbesondere zum Militärdienst eingezogen werden konnten. Dies bedeutete eine Einbusse der staatlichen Souveränität auf dem eigenen Territorium. Im kriegstreiberischen Klima des Hochimperialismus drohte laut Schmid ein potenzieller Loyalitätskonflikt für Ausländer in der Schweiz. Assimilation bedeutete für Curti und Schmid primär die Einbürgerung als politische Teilhabe an der Nation und nicht etwa eine Anpassung an kulturelle Werte oder Sitten. ${ }^{30}$

28 | Eine Nostalgie gegenüber einer progressiven, liberalen Ära in der Migrationspolitik ist jedoch kaum angebracht. Es fanden wegen des Widerstands der Kantone und Gemeinden, die die Armenfürsorge leisteten und keine weiteren potenziellen Empfänger wünschten, nur sehr wenige Einbürgerungen statt (Studer et al. 2008). Auch geben Analysen der politischen Diskurse allein keine Auskunft über öffentliche und alltägliche Einschluss- und Ausschlussprozesse. Die unüberblickbaren Folgen des Föderalismus in der Frage der Staatsbürgerschaft war ein wichtiger Grund für die politische Intervention in den Überfremdungsdiskurs, die dem Bund mehr steuernde Vollmacht übertragen sollte.

29 | Der republikanische Nationendiskurs der Schweiz bot zweifellos schon Ansatzpunkte für eine ethnische Reartikulation. Nicht nur entstand in der republikanischen Bewegung des 19. Jahrhunderts der Mythos des Schweizer Alpenvolkes mitsamt der Erfindung der traditionellen Volksfeste (Marchal/Mattioli 1992; Schär 2012). Auch bot die helvetische patriarchale Familienmetaphorik durchaus ein anschlussfähiges Fundament. Der staatsbürgerliche Ausschluss jüdischer Menschen verweist ebenso auf einen strukturellen Antisemitismus wie die erste Volksinitiative von 1893, die das Schächten von Tieren verbot.

30 | In den folgenden Jahren gewann Schmids Engagement entsprechend der gesamtgesellschaftlichen Trendwende patriotisch-paranoide Schlagseite: Gleich zu Beginn seines Pamphlets etablierte Schmid das Schicksal des Burenstaates Transvaal, der nach 
Die schnelle Einbürgerung und die politische Teilhabe der niedergelassenen Immigrant_innen, oder zumindest der in der Schweiz geborenen Kinder der Eingewanderten, würden Bedingung für eine innige patriotische Beziehung der ehemaligen Ausländer zum neuen Vaterland schaffen und den politisch-pädagogischen Einfluss des Staates auf sie vergrößern. Die „zweite Generation“ war um 1900 in der Schweiz als staatspolitisch strategisches Objekt etabliert, das versprach, eine nationale Krise zu überwinden.

\section{Die Ethnisierung und Rassialisierung des Überfremdungsdiskurses}

Innert weniger Jahre wuchs diese Debatte unter Staatsrechtlern, kantonalen Regierungen, Nationalräten und führenden Beamten zu einem regelrechten „Überfremdungsdiskurs“ an, in dem demografische Analysen, rechtliche Lösungen, historische Narrative und semantische Register als neue Elemente der Argumentation und der Evidenz etabliert wurden (Kury 2003). In dieser kurzen Zeit lässt sich eine einschneidende diskursive Verschiebung von einem staatspolitischen zu einem ethnischen Verständnis von Assimilation feststellen. 1909 diskutiert Edmond Boissier, Genfer Großrat und Mitglied der prominenten interkantonalen Neunerkommission betreffend Maßnahmen gegen die Überfremdung in der Schweiz, in einer Denkschrift folgende Frage: „1. Ist die starke Einwanderung der Ausländer, welche sich in der Schweiz niederlassen ohne sich einbürgern zu lassen oder zu assimilieren, eine Gefahr für das moralische und nationale Fortbestehn unseres Vaterlandes?" (Boissier 1909:1) In dieser Formulierung ist von einer republikanischen Argumentation einer rechtlichen Gleichstellung und der Legitimation von Demokratie kaum mehr etwas zu spüren. Stattdessen glaubt Boissier festzustellen, dass eine „Entnationalisierung“ der Schweiz stattfinde, weil „die von auswärts kommenden Elemente einen entscheidenden Einfluss auf die Sitten und den Geist der Bevölkerung ausüben. [Diese] verliert nach und nach ihren nationalen Charakter, ihre Originalität, ihr eigenes Ideal, zuletzt das Recht, als unabhängiges und autonomes Volk zu existieren." (Boissier 1909:4) In der einführenden Frage von Boissiers Denkschrift ist das Problem der Überfremdung von der Vorstellung eines nationalen Volkes gerahmt, das durch seinen eigenständigen Charakter und seine geistige Stärke sich erst gegen andere Nationen durchsetzen kann und daraus seinen Sinn und seine Existenzberechtigung zieht. Die „geistige Überfremdung“ erschien als Ausdruck einer kulturell-moralischen Krise und Fanal des Untergangs des Schweizer Volkes. Boissiers Denkschrift markiert die plötzliche Ethnisierung

zunehmender Ansiedelung von Briten im Zweiten Burenkrieg von Großbritannien annektiert wurde, als neuen Topos im Überfremdungsdiskurs. In seinem Aufsatz "Die Schweiz im Jahre 2000" von 1912 schildert er als Gefahr, dass Frankreich, Deutschland und Italien durch ihre wirtschaftliche und politische Macht in den Ausländerkolonien in der Schweiz den Kleinstaat de facto unter sich aufteilen könnten (Schmid 1912). 
des Begriffes der Assimilation im Schweizer Kontext. Assimilation bedeutete nicht mehr die republikanische Aufnahme der Ausländer in die politische Nation der Schweiz, sondern die notwendige kulturelle Anpassung der Ausländer an die Sitten und Gebräuche der Schweizer - an deren „Nationalcharakter“ eben (ebd.:5). Dabei impliziert Assimilation hier im Gegensatz zu Curtis Postulat von 1898 eine qualitative Selektion, wonach „nur die Aufnahme solcher Elemente in unser Volk zu verstehen sei, welche gute Schweizer abgeben können und sich gänzlich unseren Gebräuchen, Sitten und Prinzipien anpassen“ (ebd.:6).

Dieser plötzlich omnipräsente Topos einer national-moralischen Erneuerung ging auf den Einfluss einer „reaktionären Avantgarde“ zurück, wenn auch deren Exponenten nur am Rande am politischen „Überfremdungsdiskurs“ teilnahmen (Jost 1992).$^{31} \mathrm{Ab}$ den 1890er Jahren propagierten katholisch-konservative, aristokratische und ländlich-handwerkliche Kreise eine „Krise des Liberalismus“, die sie zum Anlass nahmen, revisionistische und nationalkonservative Gegenprojekte der Schweiz zu entwickeln. Gemeinsam war der heterogenen konservativen Bewegung die Kritik am liberalen Projekt als sinnlosem, materialistischem Treiben, das schliesslich in den national-moralischen Untergang führen würde: Die historischen Städte wucherten aufs Land hinaus, die Hygieneverhältnisse waren katastrophal, die Arbeiterbewegung gewann an Boden, der Erste Weltkrieg kündigte sich an - kurz: Die soziale Ordnung der Schweiz schien ihnen aus den Fugen geraten zu sein. Der konservative Ruf nach moralischer Ordnung stieß auch bei der politischen Elite, dem Bürgertum und der entstehenden unteren Mittelschicht angesichts des Drucks von der Strasse auf offene politische Ohren und so setzten sich innert weniger Jahre konservative Narrative und Motive im „Überfremdungsdiskurs“ durch. Gleichzeitig manifestierte sich im „Überfremdungsdiskurs“ - gerade in radikalen Kreisen - ein völkisch-sozialdarwinistischer und rassistischer Diskurs aus Deutschland und Großbritannien, der äußerst anschlussfähig war an den Antisemitismus und den Chauvinismus der „Neuen Rechten“. So sinniert der durchaus liberale Berner Staatsrechtsprofessor Walther Burckhard im Jahr 1913:

Man wird es vielleicht später als einen Fehler einsehen, nicht mehr Gewicht auf die Erhaltung unserer Rasse gelegt zu haben. [...] Man braucht sich nicht einzubilden, der eigene Volksschlag sei der beste und verdiene a priori den Vorzug vor den anderen, und kann es doch berechtigt finden, dass jeder Volksstamm sich selbst bleiben wolle, d. h. sich fremde Rassen fernhalte, so-

31 | Viele Texte des "Überfremdungsdiskurses" entstanden als Referate im Rahmen der Neuen Helvetischen Gesellschaft oder wurden in der Zeitschrift "Wissen und Leben" publiziert. Die Neue Helvetische Gesellschaft wurde vom starken Mann der "Neuen Rechten" Gonzague de Reynold gegründet, "Wissen und Leben“ wurde von Ernest Bovet herausgegeben, der auch in der "Semaine Littéraire" schrieb, einem Leitmedium der "Neuen Rechten". 
lange er sich als lebenskräftig erweist; es sollte jedenfalls nicht dem Spiel des Zufalles überlassen werden, ob sich heute Hunderte und Tausende von Polen, morgen ebenso viele Russen oder Juden, und übermorgen vielleicht Chinesen und Malayen ansiedeln. Diesem Zufall steht aber der Staat gegenwärtig machtlos gegenüber, ein Unternehmer oder ein Vermittler kann gewerbsmäßig solche Leute kommen lassen, um billige Lohnarbeiter zu erhalten oder anderen anzubieten. (Burckhardt 1913:21)

Das rassistisch gefärbte Zitat zeigt, wie leicht Rassentheorien in den „Überfremdungsdiskurs" Eingang fanden, um die sogenannte "Qualität" der Assimilation abzuschätzen - auch bei freisinnigen Exponenten wie Burckhardt. ${ }^{32}$ Wenn sich auch eine explizit völkisch legitimierte Migrationspolitik in der Schweiz nicht etablierte, blieb die implizite völkische Angst vor der Unassimilierbarkeit von als graduell fremd wahrgenommenen „Rassen“ für das gesamte 20. Jahrhundert bedeutsam - und hielt sich in Konzepten wie „kulturelle Distanz“ oder im sogenannten Dreikreisemodell bis 1998 und implizit im heutigen dualen Zulassungssystem das Freizügigkeit für Europäische Staatsbürger und Drittstaatenangehörige unterscheidet, bis heute.

Zusammenfassend lässt sich feststellen, dass der Überfremdungsdiskurs angesichts der krisengetränkten Zeitdiagnose am Anfang des 20. Jahrhunderts und nur wenige Jahre vor dem Ersten Weltkrieg eine ideale Plattform darstellte, um die sehr offene Semantik der Nation umzudeuten. Durch den Fokus auf die ethnische Qualität der Assimilation entstand eine politische Grenztopologie, in der anhand von staatsrechtlichem, demografischem, historischem und rassentheoretischem Wissen die graduelle Imagination und Vermessung des Grenzraumes zwischen dem „nationalen Eigenen“ und dem „ausländischen Anderen“ vorgenommen wurde. So schien die „Zweite Generation“ besser in der Lage, sich zu assimilieren, als ältere Migrantinnen und Migranten, Norditaliener besser geeignet für die Assimilation als Süditaliener, und diese wieder um besser als „Malayen“, während gewisse Rassengrenzen unüberwindbar blieben. Dieser Ruf nach einer explizit ethnischen und rassifizierten Qualifizierung der Nation öffnete die Tore für die biopolitische Etablierung einer Migrations- und Ausländerpolitik.

32 | Die in der Debatte auffallend rassenanthropologisch geprägten Texte des Ingenieurs Max Koller haben das Argument der Unassimilierbarkeit von fremden Rassen zweifellos mitbeeinflusst: „Schließlich bleiben noch die vollständig fremden Elemente wie Spanier, Slaven, Türken, Orientalen aller Art usw. Diese wären nun alle grundsätzlich von jeder Einbürgerung auszuschließen, denn es ist undenkbar, dass sie sich in absehbarer Zeit wirklich assimilieren können." (Koller 1915:28) 


\section{Die biopolitische Neuordnung der Migrationspolitik nach dem Ersten Weltkrieg}

Die Krisensituation des Ersten Weltkriegs beförderte die Institutionalisierung des Überfremdungsdiskurses auf Bundesebene, nachdem ab der Jahrhundertwende - mit der Gründung des Schweizerischen Heimatschutzes (1904) und des Schweizerischen Bundes für Naturschutz (1909) - schon eine nationale Kulturpolitik entstanden war. 1917 wurde per Notverordnung die Eidgenössische Fremdenpolizei gegründet, die Grenzübertritte mittels eines Bewilligungs- und Visasystems regulieren sollte. 1919 wurde das Notrecht in ordentliches Recht überführt und der Ausnahmezustand normalisiert. Die kriegsbedingte Zentralisierung der Überfremdungsabwehr bedeutete das Ende des jahrzehntelangen Seilziehens zwischen der Bundesbehörde und den Kantonen, die zwar rechtlich für die Einbürgerungen zuständig waren, aber aus föderalistischen und finanziellen Gründen nur wenige Einbürgerungen zuließen, respektive Reformen blockierten. Nun existierte eine zentrale staatliche Institution, die sowohl das Personal als auch die finanziellen, technologischen und rechtlichen Mittel sowie die politische Legitimation hatte, eine effiziente „Überfremdungsabwehr“ einzuführen. Der Ausländeranteil war während des Krieges auf fünf Prozent gesunken, weil viele niedergelassene Ausländer in ihre Heimatländer zurückgekehrt waren, etwa um Kriegsdienst zu leisten. Im Zentrum stand nun die im Krieg eingeübte selektive Aufenthalts- und Niederlassungspolitik, die sicherstellen sollte, dass nur Personen in die Schweiz kommen, die mittelfristig auch assimiliert und eingebürgert werden konnten und sollten. Als besondere Gefahr wurden sogenannte Deserteure, Refraktäre, Kriegsgewinnler und Schleichhändler sowie potenzielle Spione genannt. Die Wohnsitzfrist für Einbürgerung wurde von zwei auf sechs Jahre erhöht, um sicherzustellen, dass diese kriegsbedingten Immigrantinnen und Immigranten nicht eingebürgert wurden. Öffentlich wurde argumentiert, dass diese nur aus Gründen der Zweckmäßigkeit oder des persönlichen Vorteils in der Schweiz weilten, ohne Absicht und Potenzial „innerlich Schweizer“ zu werden. Oft waren dies indes nur Vorwände der Fremdenpolizei, um aus antisemitischen Beweggründen die Abschiebung von ostjüdischen Flüchtlingen voranzutreiben (Kury 2003; Argast 2007). Ernst Delaquis, Strafrechtsprofessor und zwischen 1919 und 1929 Leiter der Polizeiabteilung des Eidgenössischen Justizdepartements, dem auch die Fremdenpolizei unterstellt war, vertrat diese Politik prägnant nach außen:

Man will in Zukunft, wenn ich so sagen darf, den Ausländer, bevor er sich in unserem Land niederlässt, daraufhin prüfen können, ob er „anpassungsfähig“ ist. [...] Wir müssen den fremden Ankömmling auf Herz und Nieren prüfen können. Reiht er sich in unser politisches, wirtschaftliches, soziales Gefüge? Ist er hygienisch akzeptabel? Überschreitet seine ethnische Struktur das Maß zulässiger Inadäquanz? Die Antwort wird von Fall zu Fall verschie- 
den lauten; doch wird sie wieder generell Angehörigen gewisser uns stärker homogener Rassen, uns geistig und nachbarlich naher Bevölkerungskreise günstiger sein als jenen anderen Milieus, die uns in Rasse, Religion, Sitte ferner stehen. Es wird notwendig sein zu unterscheiden! (Delaquis 1921:17 f.)

Delaquis' Rede verkörpert die autoritäre Praxis der staatlichen Biomacht, die zwischen technologischer Utopie, bürokratischer Präzision und polizeilichem Misstrauen oszilliert. Das Misstrauen des biopolitischen Staates zeigt sich auch in Bezug auf die „Zweite Generation“. Waren noch für Boissier und seine Zeitgenossen die nationale Erziehung in der Schule und im Militärdienst Garantie für eine wirksame Assimilation der „zweiten Generation“, hegte Delaquis Zweifel:

Der Einfluss der Schule und des Milieus können durch die Luft des Elternhauses paralysiert werden. [...] Haben wir nicht häufig erlebt, dass Jungens, die bei uns die Schulen durchgemacht haben, scheinbar die unseren waren, ja auch schon wirklich Naturalisierte, nicht wieder zu erkennen waren, nachdem ihr alter Heimatstaat in diese Katastrophe hereingezogen war? Das Blut der Väter regt sich in ihnen. Der Kern des Jünglings ist ausländisch geblieben, die Furnitur war schweizerisch und prallte beim ersten Anprall ab. (Delaquis 1921 zit. nach Kury 2003:136)

1931 wurde das biopolitische System der Selektion, des Misstrauens und der Kontrolle im „Bundesgesetz über Aufenthalt und Niederlassung von Ausländern“ (ANAG) verankert, das bis Ende 2005 gelten sollte. Vor dem Hintergrund des kulturpolitischen, nationalistischen Programmes der "Geistigen Landesverteidigung" in der Zwischenkriegszeit zeigte sich der Wille des Schweizer Staates, die Bevölkerung nach seinen Vorstellungen und Bewertungen einer möglichst homogenen ethnischen Nation zu regulieren und zu formen (Wimmer 2002). Die Entwicklung des "helvetischen Migrationskomplexes" als institutionelles, diskursives und affektives Dispositiv versprach, die sozialen und politischen Krisen des liberalen Modernisierungsmodells zu kitten, die in der Form von Arbeiterbewegung, Verstädterung und Massenkultur als Gefahr für eine bürgerlich-konservative Ordnung angesehen wurden (Jain/Randeria 2014). Die biopolitische Abgrenzung gegen fremde Bevölkerungen erlaubte es freisinnigen, konservativen und sozialdemokratischen Kräften einen gemeinsamen nationalen, fordistischen Konsens zu schaffen, der die Schweiz als eine Mischung von alpiner Romantik, industriellem Wachstum und sozialer Wohlfahrt neu erfand. ${ }^{33}$ Im Zuge der Neujustierung des

33 | Paradigmatisch dafür war die berühmte Landesausstellung von 1939, die nicht nur den alpinen Mythos der Schweiz in Form von dörflichen und alpinen Traditionen popularisierte, sondern auch die Leistungen der Schweiz als industrielle, arbeitsame und wehrhafte Gemeinschaft feierte (Kreis 1989). 
Schweizerischen Modernisierungsmodells war „Überfremdung“ zu einem kontextübergreifenden Code geworden, der erlaubte, neue politische Felder wie die Regulierung des Arbeitsmarkts, innere Sicherheit, Volksmedizin und Bevölkerungspolitik zu etablieren und zu einem nationalen Projekt der Normalisierung der Gesellschaft zu verknüpfen, das durchaus eugenische Züge beinhaltete (Kury 2003:79). ${ }^{34}$ Angesichts der Kuppelung von Geistiger Landesverteidigung und "Migrationskomplex“ lässt sich argumentieren, dass die diskursive und personelle Kontinuität in der latent antisemitischen Fremdenpolizei zur tödlichen „Boot-istvoll“-Politik beitrug, die im Zweiten Weltkrieg Tausende von Menschen jüdischer Herkunft von der Schweizer Grenze in den sicheren Tod schickte.

\section{Der Assimilationismus der 1960er und 1970er Jahre als Subjektivierungsregime}

Nach dem Zweiten Weltkrieg war die Zahl der Ausländer_innen kriegsbedingt wieder massiv gefallen. Deshalb konzentrierte sich die schweizerische Ausländerpolitik auf die Rekrutierung von Arbeitskräften (Niederberger 2004). Diese war neben dem Wirtschaftsboom auch deshalb nötig geworden, weil die im Krieg größtenteils berufstätigen Frauen sich gemäß der bürgerlich-patriarchalen Geschlechternormen der Nachkriegsjahre zur unbezahlten Haus- und Familienarbeit gedrängt sahen - oder sich danach sehnten. Um der Nachfrage nach Arbeitskräften im Baugewerbe, der Industrie, dem Tourismus, der Pflege und der Gastronomie nachzukommen, etablierte die Schweiz aufbauend auf dem ANAG von 1931 und bilateralen Abkommen - insbesondere mit Italien - ein komplexes Rekrutierungs-, Bewilligungs- und Verwaltungssystem ausländischer Arbeitskräfte. Mit dem Ziel, die fremdländischen Arbeitnehmer und -nehmerinnen nicht längerfristig aufzunehmen, wurden ihnen nur jährliche oder saisonale Arbeitsbewilligungen unter Patronage von Unternehmen erteilt sowie Familiennachzug verboten. Nach getaner Arbeit mussten sie wieder ausreisen und es wurden möglichst neue Arbeitskräfte gesucht. Dieses sogenannte Rotationssystem bezweckte, sowohl die wirtschaftliche Nachfrage zu stillen als auch die Ansiedelung der ausländischen

34 | Diese Normalisierung war eingebettet in ein Netzwerk staatlicher, wissenschaftlicher und sozialpolitischer Akteure, die unterschiedliche Bevölkerungsgruppen, die als "minderwertig" betrachtet wurden, erforschten, behandelten und disziplinierten. Diese biopolitische Logik manifestierte sich etwa in Zwangssterilisierung von als "Zigeuner" markierten Menschen oder in administrativen Anstaltsversorgungen von als "arbeitsscheu" und "liederlich" angesehenen Menschen (Unabhängige Expertenkommission 2001; Rietmann 2013), wobei letzteres oft Frauen betraf und mit der Fremdplatzierung ihrer Kinder verbunden war. Wie Rassifizierungen und migrantische Kategorisierungen in die administrativen Anstaltsversorgungen eingeschrieben waren, ist nicht erforscht. 
Arbeitnehmenden zu verhindern. Dem Rotationsmodell zum Trotz stieg die ausländische Bevölkerung aufgrund der wirtschaftlichen Nachfrage massiv an, während sich im restriktiven System nur wenige Arbeitsmigrantinnen und -migranten rechtlich niederlassen oder gar einbürgern lassen konnten. Das Rotationsmodell unter Verbot des Familiennachzugs hatte zur Folge, dass Tausende von Kindern illegalisiert mit der Angst vor der Deportation oder in Heimen in der Schweiz aufwuchsen. Die durch die Politik verursachte Entscheidung der Eltern, ihre Kinder entweder in Pflege zu geben oder sie heimlich bei sich zu haben, setzt vielen Familienbeziehungen bis heute zu. Trotzdem wurde die Thematik der sogenannten „Schrankkinder“ offiziell noch nicht aufgearbeitet (Frigerio 2014). Die gesamtgesellschaftliche Folge des Rotationsmodells war eine beträchtliche Segregation der schweizerischen Bevölkerung und der größtenteils italienischen Migrant_innen, deren Folgen heute als Integrationsproblem beklagt wird. In den frühen 1960er Jahren wurde in der Dominanzgesellschaft wieder die Klage über „Überfremdung" laut. Diesen erneuten Überfremdungsdiskurs konnte der Bundesrat nicht ignorieren, zumal der Rechtspopulist James Schwarzenbach mit seiner Nationalen Aktion gegen die Überfremdung von Volk und Heimat die öffentliche Stimmung beherrschte (Buomberger 2004). ${ }^{35}$ Das Eidgenössische Volkswirtschaftsdepartement reagierte, indem es 1961 eine Studienkommission beauftrage, „das Problem der ausländischen Arbeitskräfte“ zu behandeln. Deren Bericht aus dem Jahre 1964 bestätigte zwar eine „ausgesprochene Überfremdungsgefahr“, hielt jedoch am Bedarf nach ausländischen Arbeitskräften für die Schweizer Wirtschaft fest. „Die Lösung ist in der Richtung zu suchen, dass die Eingliederung der assimilationsfähigen Ausländer, die sich beruflich und persönlich bewährt haben, gefördert, die Zahl der unbeständigen Wanderarbeiter dagegen möglichst niedrig gehalten wird." (Studienkommission 1964:139) Durch eine rigorose Assimilationspolitik sollten die Bedingungen geschaffen werden, dass ausländische Arbeitskräfte sich einbürgern lassen konnten. So sollte sowohl die Arbeitskräftenachfrage gedeckt als auch die "geistige Überfremdung“ und der quantitative Ausländeranteil kontrolliert werden.

35 | James Schwarzenbach (1911-1994) stammte aus einer protestantischen Zürcher Industriellenfamilie. In jungen Jahren konvertierte er unter dem Patronat des Fribourger Erzkonservativen Gonzague de Reynolds zum Katholizismus. Sein politisch-ideologischer Fluchtpunkt blieb trotz seiner modernen politischen Strategie und Rhetorik der Ständestaat des Ancien Régime. Zwischen 1968 und 1977 reichten Schwarzenbach und seine Nationale Aktion fünf Volksinitiativen ein, die alle verloren gingen, aber die politische Agenda prägten und einen Rechtsrutsch in der Arbeiterbevölkerung besiegelten. Die Nationale Aktion wurde 1977 in Schweizer Demokraten umbenannt. Heute ist die Partei kaum mehr relevant, da ihr Gedankengut und ihre Basis größtenteils in der Schweizerischen Volkspartei (SVP) aufgegangen sind. 
Aber was bedeutete Assimilation in diesem Kontext? Wurde die Reartikulation des ethnischen Assimilations- und Nationenbegriffs in den 1910er und 1920er Jahren noch anhand unterschiedlicher völkischer und rassistischer Idiome vorgenommen, repräsentierte die Definition der „Überfremdung“ der Studienkommission einen seither historisch gewachsenen kulturalistischen Konsens:

Überfremdung [kann] umschrieben werden als der Einfluss von nicht oder ungenügend assimilierten Angehörigen fremder Kulturen - möglicherweise verstärkt durch unmittelbare Einflüsse aus dem Ausland infolge der Massenkommunikationsmittel -, der so stark ist, dass die wesentlichen und tragenden Vorstellungen, die der eigenen Kultur zugrunde liegen, durch fremde Vorstellungen überdeckt werden und die Bevölkerung ihre Lebensverhältnisse nicht mehr aufgrund ihrer eigenständigen Tradition gestaltet. (Studienkommission 1964:136, Hervorhebung R. J.)

Um dieser „Überfremdung“ Einhalt zu gebieten, forderte die Studienkommission: „Der Bewerber sollte bereits soweit assimiliert sein, dass er schweizerisch denkt und fühlt und dass ihm unsere Sitten und Gebräuche selbstverständlich geworden sind.“ (Studienkommission 1964:167, Hervorhebung R. J.). In dieser kulturalistischen Sprache sind die alten rassistischen Motive durchaus weiterhin präsent. Argast (2010) hat zurecht darauf hingewiesen, dass nach dem Zweiten Weltkrieg und dem Holocaust, als völkische und rassistische Idiome verpönt waren, sich im Schweizer Migrationsdiskurs (wie auch in Europa generell) zunehmend ein „Rassismus ohne Rassen“ etabliert hat (Balibar/Wallerstein 1990; Stolcke 1995; Goldberg 2009, Michel 2015). ${ }^{36}$ „Kultur“ wurde darin als monolithischer Block und kongruent mit Gesellschaft, Tradition und Nation, ja, sogar mit Bevölkerung wahrgenommen. „Rassismus ohne Rassen“ (auch Kulturrassismus oder Neorassismus) basiert nicht auf der biologisch legitimierten Hierarchie von Bevölkerungsgruppen, sondern auf der behaupteten graduellen Unvereinbarkeit von „verschiedenen Kulturen“. ${ }^{37}$ Die Grenze zwischen „Kulturen“ war zwar im Gegensatz

36 | Nachdem die UNESCO 1950 in ihrem Statement "The Race Question" die biologische Existenz von "Rassen" aufgrund genetischer Forschungen verneinte (UNESCO 1950), verschwand der Begriff zunehmend aus dem öffentlichen Gebrauch, ohne dass jedoch die Praxis und die Geschichte des Rassismus in Europa adäquat anerkannt und aufgearbeitet wurden.

37 | Der vor allem in der französischen "Neuen Rechten" der 1970er geförderte Ethnopluralismus führte das biologistische Element jedoch wieder ein, wenn dort argumentiert wird, dass eine zu starke kulturelle Durchmischung verhaltensbiologisch zu Stress und Aggressionen und schließlich zu sozialen Konflikten führen "muss" (Priester 2003). Viele kulturrassistische Narrative bilden die Grundlage der aktuellen rechtspopulistischen und neo-völkischen Bewegungen und Parteien in Europa, wie zum Beispiel der 
zu Rassengrenzen durch Assimilation theoretisch zu überwinden. Aber wie die Studienkommission beteuerte, „[ist] dieses eidgenössische Bewusstsein langsam über Jahrhunderte gewachsen und es braucht in der Regel Generationen, um es zu erwerben“" (Studienkommission 1964:138). ${ }^{38}$ Genauso selbstverständlich hielt die Studienkommission daran fest, dass sich „Arbeitskräfte aus anderen Kulturkreisen infolge der Verschiedenheit ihrer politischen, sozialen und religiösen Anschauungen und ihrer Lebensweise nur schwer an unsere Arbeits- und Lebensverhältnisse gewöhnen können“ (Studienkommission 1964:172), weshalb sie empfahl, auf deren Rekrutierung zu verzichten. Im offiziellen kulturalistischen Kontinuum der (Un-) Assimilierbarkeit fand sich also die rassialisierte, biopolitische Grenztopologie des ersten Überfremdungsdiskurses unreflektiert und als offiziell legitimierte Sprache wieder.

Eingebettet in die volkswirtschaftliche Wachstumslogik zeichnet sich der Assimilationismus der 1960er und 1970er Jahre statt durch eine volksgesundheitliche Logik - wie in der Zwischenkriegszeit - durch ein mechanisches Nutzendenken, eine pflichtbewusste Bürokratie sowie durch einen technokratischen Willen zur Sorgfalt und zur Gründlichkeit aus. Mit der angelsächsischen Migrationssoziologie, der Präventivmedizin und der Psychologie wurden zunehmend neue wissenschaftliche Konzepte rezipiert, mit denen Ausländer_innen im Gegensatz zum Zulassungsregime der Zwischenkriegszeit nicht mehr nur als bevölkerungspolitische „Fremdkörper“, sondern zunehmend als Individuen in einem gesamtgesellschaftlichen Kontext angesehen wurden. „Die Behörden müssen den ganzen Menschen ins Auge fassen und die demografischen und sozialen Folgen seiner Zulassung bedenken“" (Studienkommission 1964:172). In den 1960er und 1970er Jahre entwickelte sich ein „assimilatorischer Humanismus“, der sich im Detail für den Alltag und das Innenleben von Ausländer_innen und für deren praktischen Assimilationsprozess interessierte, dazu Wissen akkumulierte und Imagina-tionen schärfte - wenn auch im Hinblick auf die effektivere Abwehr der Überfremdung.

Besonders plastisch führt dies das Buch „Vom Anderssein zur Assimilation. Merkmale der Assimilationsreife der Ausländer in der Schweiz" (1968) des damaligen freisinnigen Vorstehers der Berner Fremdenpolizei Marc Virot vor. Seine

Begriff "Dichtestress", der die Ecopop-Debatte in der Schweiz um den Zusammenhang von Migration, Bevölkerungswachstum und Zersiedelung prägte (Glättli/Niklaus 2014). 38 | Diese notorische sprachliche Wendung geht auf Max Ruth zurück, der von 1920 bis 1944 als erster Adjunkt und von 1944 bis 1952 als Leiter der Rekurskommission in der Polizeiabteilung des Eidgenössischen Justizdepartements arbeitete (Ruth 1937). Ruth kann zweifellos als die graue Eminenz bezeichnet werden, der die diskursive und politische Kontinuität in der fremdenpolizeilichen Arbeit der Schweiz vom Ersten Weltkrieg bis in den Assimilationismus der Nachkriegszeit prägte. Als Beamter der betreffenden Kommissionen prägte er die schweizerische Flüchtlings- und Ausländerpolitik von den großen Zügen bis zum einzelnen Wortlaut (Kury 2003; Studer et al. 2008). 
Einleitung endet mit den salbungsvollen Worten: „Die fremden Arbeitskräfte sind weder statistische Einheiten, Manövriermassen, Reservoire, Sicherheitsventile, Puffer oder Arbeitsmaschinen, sondern vor allem und zuerst Menschen, mit individuellen Freuden und Problemen, mit Gefühlen und Seelen." (Virot 1968:6)

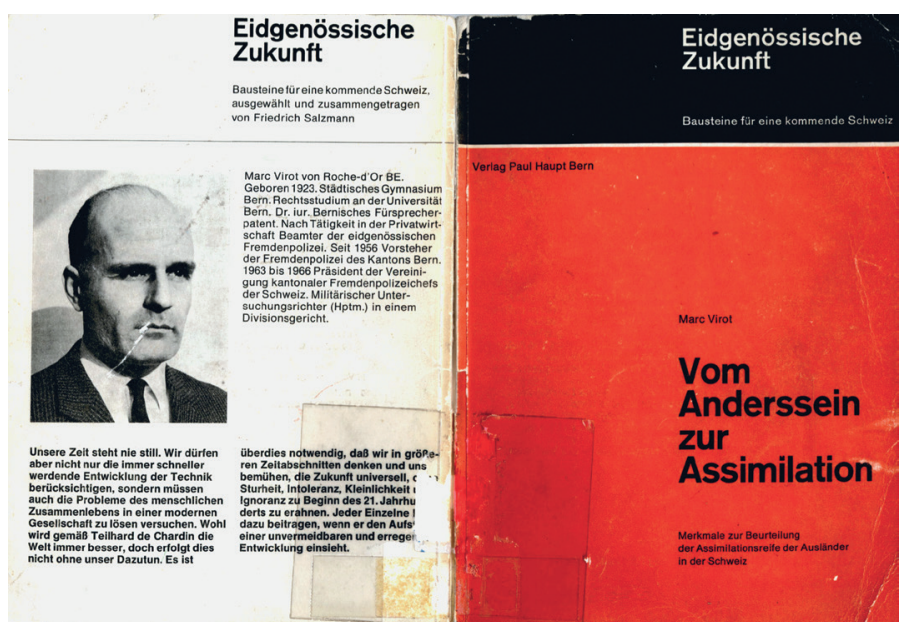

Abbildung 7: Der fremdenpolizeiliche Blick zwischen Präzision, Gelehrsamkeit, Misstrauen und Paternalismus. Marc Virots Assimilationsratgeber bietet Einblicke in den Schweizer "Migrationskomplex" (Quelle: Virot 1968)

Dieser Fokus auf den ganzen Menschen ist entgegen der Rhetorik jedoch nicht in erster Linie als ethische Sorge zu verstehen, sondern im Sinne einer objektiveren Prüfung, einer effizienteren Kontrolle und eines Willens zum präziseren Wissen. Gefangen zwischen dem Wunsch, die „innere Assimilation“ zu prüfen, und der Einschränkung, nur das äußere Verhalten objektiv beobachten zu können, listet Virot über vierzig Seiten Verhaltensweisen, Eigenschaften und Merkmale in allen Lebensbereichen auf, die Ausländer als nicht-assimiliert markieren. So schreibt er zum Beispiel:

Wir möchten ganz allgemein, dass sich die Ausländer anständig, gut erzogen und zivilisiert verhalten, also nicht grölen, sich betrinken und Skandal erregen, im Kino nicht alles laut kommentieren und mit Esswaren Lärm erzeugen, am Boxkampf keine Flaschen werfen, Frauen belästigen, die Straßen und Wohnungen nicht verunreinigen. (1968:38) 
Und weiter unten:

Mit zunehmender Anpassung sollte ein Ausländer den Frauen gegenüber nicht draufgängerischer sein als der vielleicht etwas biederere und leidenschaftslosere Schweizer. Die Ausländerinnen werden ebenfalls ihre Auffassung über die Bekanntschaft anpassen müssen und nicht ein allzu erotisches, überspitztes und abenteuerliches Gebaren zeigen dürfen. (1968: 65f.)

Oder:

Ein Ausländer, der in der Schweiz wohnt, braucht keinen Sport zu treiben, nicht zu kegeln, zu schiessen oder zu jassen und kann sich trotzdem assimilieren. Er darf aber nicht uns wesensfremde Spiele und Sportarten betreiben. (1968:76)

Dieser Katalog mit seinen minutiösen Beobachtungen und den strikten Forderungen manifestiert einen assimilationistischen Blick, der sowohl einen absoluten Anspruch erkennen lässt, das Andere zu definieren, zu kontrollieren und zu maßregeln, als auch das paternalistische Begehren und den Stolz, ihm nahe zu sein und es im Detail zu kennen. Im zwangsläufigen Scheitern, die Abweichung von der nationalen Eigenart objektiv messen und prüfen zu können, offenbart sich gleichzeitig ein geradezu paranoides Misstrauen und eine subtile, technokratische Gewalt. So lamentiert Virot:

Es wäre gut, wenn man die sogenannte Begeisterungsfähigkeit messen könnte, das heisst die Intensität des emotionalen Ansprechens eines Ausländers auf Slogans, Schlagworte und Begriffe wie Neutralität, Demokratie, Rotes Kreuz, Armee, General, Bundesfeier und so weiter. Die Erforschung des Unterbewusstseins ist praktisch undurchführbar. (1968:96)

Angesichts dieses Scheiterns propagiert Virot schließlich die Assimilationsprüfung als Kunstlehre, in der psychologisches Geschick potenzielle Schweizer_innen von Ausländer_innen, und das heisst auch: Wahrhaftigkeit von Verschlagenheit unterscheiden lässt. „Eine schematische Befragung des Ausländers mit einem noch so raffinierten Fragebogen kann kein persönliches Gespräch ersetzen. Der durchtriebene oder bloss intelligente Ausländer kommt hinter die Absicht, die in einer Frage steckt.“ (1968:113) Da auch das Einbürgerungsgespräch Lücken lässt, werden schließlich polizeiliche Methoden eingeführt, die das Leben von Hunderttausenden von Migrant_innen seither prägte - und im Film „Die Schweizermacher“ (1978) von Rolf Lyssy Eingang in die öffentliche Kultur fand. „In der Praxis wird man sich über die Assimilationsreife wohl nur ein Bild machen können, wenn man relativ viele Personen aus seiner Umgebung befragt, so dass Erkenntnisse 
durch Überschneidungen überprüft werden können, ohne dass man aber polizeistaatlichen Inquisitionsmethoden verfällt.“ (1968:114)
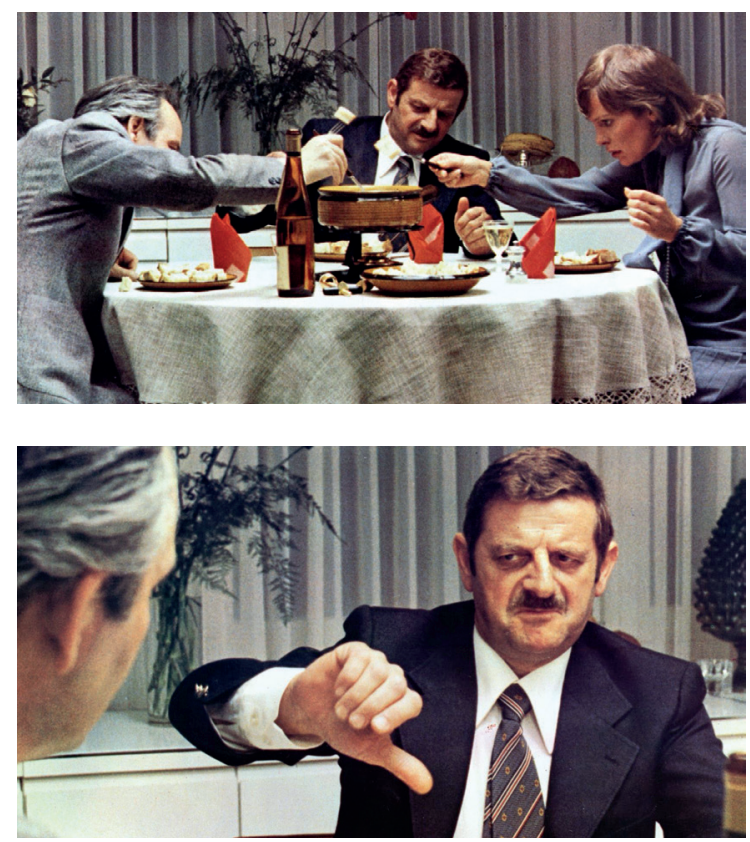

Abbildung 8a und 8b: Der Film "Die Schweizermacher" von Rolf Lyssy aus dem Jahr 1978 eröffnet der Dominanzgesellschaft auf ironische Weise, wie Einbürgerungsbeamte die Assimilationsreife von Ausländer_innen beurteilen (Quelle: Lyssy 1978)

Es war weiter symptomatisch für den staatlichen Assimilationismus der 1960er und 1970er Jahre, seine Bestrebungen auf die gesamte Gesellschaft auszudehnen. Fremdenfeindliche - in Virots Worten "primitive“ - Einstellungen und Verhaltensweisen der „einheimischen Bevölkerung" wurden explizit getadelt: Sie sollte stattdessen dazu erzogen werden, die Assimilation der Ausländer zu fördern und sie zum Nutzen der Nation als Menschen zu behandeln.

Heute leiden aber noch viele Ausländer unter dem Gefühl als „Mensch zweiter Klasse" zu gelten und isoliert zu sein. Was gelegentlich sogar zu körperlichen oder seelischen Störungen führt. Gegen die Geringachtung der Persönlichkeit des Ausländers, die gelegentlich noch anzutreffen ist, muss durch entsprechende Aufklärung angekämpft werden. Gleichzeitig ist aber auch die Erziehung vieler Ausländer zur bessern Anpassung an die hiesigen Sitten notwendig. Die Ausländer wären wohl im allgemeinen empfänglich für takt- 
voll erteilte Ratschläge, wie sie sich verhalten sollten, damit sie in der öffentlichen Meinung die gleiche soziale Achtung geniessen wir ihre schweizerische Umgebung. (Studienkommission 1964:194)

Die Aufklärung der einheimischen Bevölkerung war nicht nur im Sinne einer pädagogischen Hilfestellung zu verstehen, sondern auch als nationale Neudefinition angesichts einer Krise des Wachstumsprojektes der bürgerlichen Nachkriegsschweiz. Angesichts der Unterschichtung durch ausländische Fremdarbeiter und der zunehmenden Tertiarisierung entwickelte sich die lokale Schweizer Bevölkerung sozialstrukturell und in der öffentlichen Selbstwahrnehmung zunehmend zu einer ethnisch homogenen und patriarchalen Mittelschichtsgesellschaft. Als Schweizer Arbeiterfamilien auf Kosten - oder dank - der Arbeitsmigrant_innen in die neue Mittelschicht aufstiegen, bedeutete dies für Frauen und Mädchen eine Angleichung an die traditionellen, bürgerlichen Geschlechterrollen als Hausfrauen und Mütter, die in der Konsumgüterwerbung der 1950er Jahre zunehmend öffentlich als Zeichen der Nachkriegsmodernität zelebriert wurden. Die Abgrenzung von den insbesondere italienischen „Fremdarbeiter_innen“ erlaubte es, eine monolithische bürgerliche Kultur zu imaginieren, die gemäß Virot auf den Dogmen „Pünktlichkeit, Genauigkeit, Gründlichkeit, Ordnung, Perfektion, Ehrlichkeit, Sauberkeit, Ruhe, Gewissenhaftigkeit, Zucht, Disziplin, Bürgerlichkeit, Solidität, Verantwortungsbewusstsein und sozialer Friede" beruhte (Virot 1968:88). Diese richtete sich dabei in der Logik einer bürgerlichen Normalisierung nicht nur gegen Ausländer_innen :

Es gab und gibt sie bei uns auch, Extremisten, Asoziale, Dumme, Primitive, solche, die nur vegetieren, die aus Bequemlichkeit jede militärische Strapaze oder Beförderungsdienste ablehnen, jene, deren einzige Lektüre Boulevardblätter sind, und jene, die ihren Egoismus und ihre Interessen vor das Allgemeinwohl stellen. [...] [S]ie sind allerdings nicht maßgebend und nicht repräsentativ für die Eigenart. (Virot 1968:55)

Die Assimilationspolitik war verknüpft mit einem nationalen, vergeschlechtlichten Erneuerungsprojekt, das nicht nur die ausländische, sondern auch die schweizerische Bevölkerung disziplinierte und subjektivierte. Es erlaubte eine neue „Geistige Landesverteidigung" und eine Re-Imagination der "nationalen Eigenart" im Kontext des Kalten Krieges (Imhof 1996):

Alle Gebiete des schweizerischen Geisteslebens - Literatur, bildende Kunst, Theater, Film, Presse, Radio, Fernsehen, Erwachsenenbildung, Museen, Universitäten - haben zur Pflege der nationalen Eigenart ihren Teil beizutragen [...]. Schöpfer und Träger aller Kultur kann aber nur der einzelne Mensch sein, nicht der Staat. Deshalb ist nicht nur die Öffentlichkeit berufen, die na- 
tionale Eigenart zu pflegen; in letzter Linie kommt es auf die Haltung des einzelnen Bürgers an. (Studienkommission 1964:135f.)

Mit Blick auf den gesamten ausländischen Menschen nahm der Assimilationismus der 1960er und 1970er Jahre im Projekt der Nation eine geradezu totale Logik an. Er disziplinierte die ausländische Bevölkerung innerhalb eines Systems rechtlicher Bewilligung und alltagsspezifischer und persönlicher Eignungsprüfungen und imaginierte den Alltag der ausländischen Bevölkerung als Arena der praktischen Assimilation. Weiter wurde die einheimische Bevölkerung im Rahmen einer nationalen Erneuerung mobilisiert, um die ausländische Bevölkerung im Alltag zu überwachen und zu assimilieren. Die Forderung, nicht mehr aufzufallen und zu befremden, positionierte die ausländische Bevölkerung sowohl als staatliches als auch zivilgesellschaftliches Objekt misstrauischer Beobachtung und zwischenmenschlicher Willkür. Widerstand gegen diese hegemoniale Konstellation löste institutionalisierte Reflexe und dominanzgesellschaftliche Aggressionen aus - wie dies die italienische Protestbewegung gegen die Schwarzenbach-Initiative erlebte, die den Ausländeranteil auf 10\% reduzieren wollte und damit mehrere hunderttausend Menschen abschieben wollte (Maiolino 2011). Als italienische Gastarbeiter_innen sich den öffentlichen Raum als politische Subjekte aneigneten, wurden sie von staatlichen Institutionen sowie bürgerlichen Medien und Zivilgesellschaft behindert sowie nachhaltig mit Verachtung und Beleidigung überschüttet. Auch hier eröffnen die Worte Marc Virots einen paradigmatischen Einblick in den Assimilationismus jener Zeit:

Der Ausländer sollte nicht gegen die Strömung schwimmen. Wenn somit der Durchschnitt unserer Zeitungen und demzufolge die öffentliche Meinung nicht gegen die USA ist, hat er es auch nicht zu sein. Assimilation würde in diesem Sinn eine gewisse Gleichschaltung an eine Durchschnittsmeinung bedeuten. [...] Da wir rechthaberisch sind, darf er uns nicht widersprechen wenn wir einmal ein Urteil abgegeben haben. Dies kann sich äussern bei Streik, Verhalten gegenüber Minoritäten, bei Rivalitäten, Apartheid, Entwicklungshilfe, Flüchtlingspolitik, Löhnen und insbesondere bei der Frage der Überfremdung. Er soll uns ja nicht belehren wollen! (Virot 1968: 86)

Aber auch diejenigen Hunderttausende von Ausländer_innen, die nicht öffentlich protestierten, erlebten die Schwarzenbach-Abstimmung als existenzielle Machtdemonstration von Schweizer Staat und Öffentlichkeit. Die meisten von ihnen sassen am 7. Juni 1970 wohl vor dem Radio, weil sie nicht wussten, ob sie in der Schweiz bleiben konnten oder nicht. Und obwohl die Initiative mit 54\% abgelehnt wurde, hatte sie ihre Wirkung nicht verfehlt, zu zeigen, wer Herr im Haus war. Während im Verlaufe der 1970er Jahre eine Verbesserung der Rechtsstellung von Gastarbeiter_innen auf dem Arbeitsmarkt und im Familiennachzug stattfand, etablierte sich 
aber gleichzeitig auch das erwähnte Assimilationsregime. Wer sich also entschied, nach der Frist von 10 Jahren Aufenthalt einbürgern zu lassen, musste sich zum Teil mehrjährige Einbürgerungsprozedere inklusive Überwachungen der eigenen Familien über sich ergehen lassen. Die kaum greifbare und doch omnipräsente Gewalt des Assimilationsregimes mag erklären, warum öffentliche migrantische Kritik in der Schweiz seither kaum mehr stattgefunden hat.
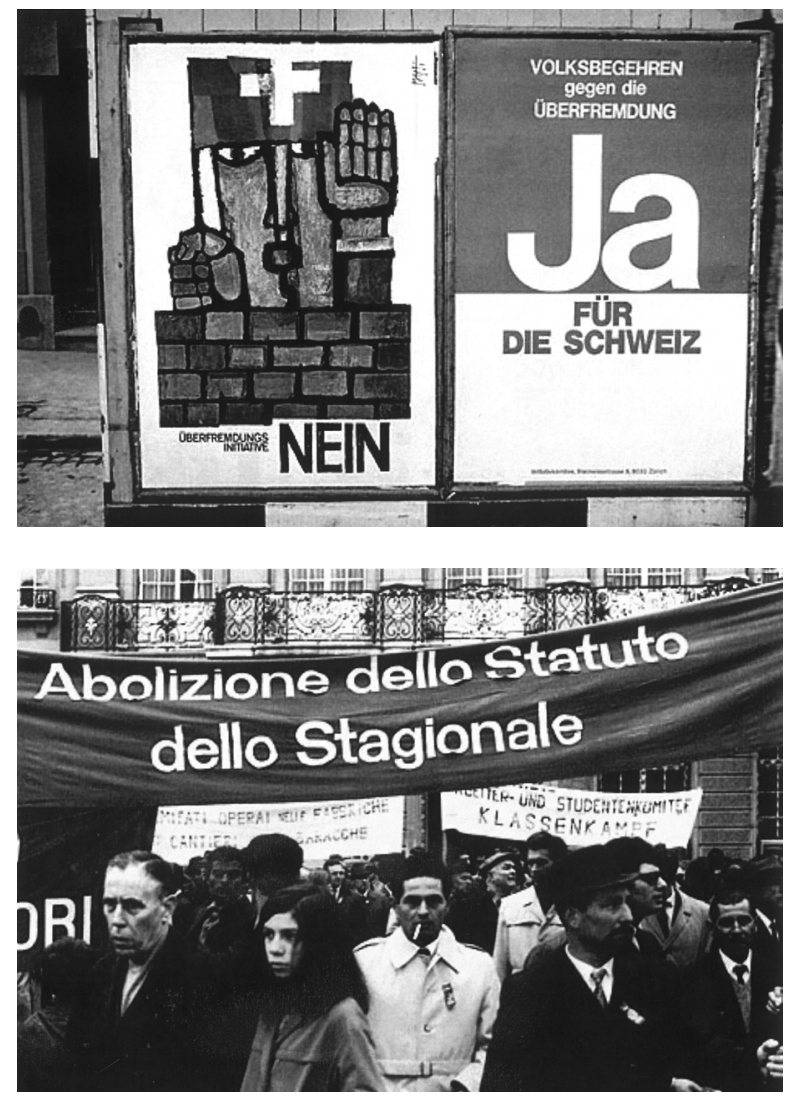

Abbildung 9a und 9b: Die Schwarzenbach-Initiative vom 7. Juni 1970 spaltete die Schweiz. Das aufgeheizte, fremdenfeindliche Klima und die über Jahrzehnte stattfindenden Proteste italienischer Gastarbeiter_innen haben die Erinnerungen von Migrant_innen und ihrer Familien geprägt, sind heute aber grösstenteils vergessen (Quelle: www.contaktSpuren.ch) 


\subsection{FAZIT: Die ASSIMILATORISCHE SUBJEKTIVIERUNGSLOGIK DER „ZWEITEN GENERATION"}

Der Assimilations- und der Generationenbegriff sind konstitutiver Teil nationalstaatlicher Projekte und finden spezifische Ausprägungen in historischen Kontexten. Das Schweizer Modernisierungsmodell verbindet seit dem frühen 20 . Jahrhundert die existenzielle wirtschaftliche Nachfrage nach Migration mit einer institutionalisierten Überfremdungsangst. Der „helvetische Migrationskomplex“ dreht sich nicht um völkische Grenzziehung, sondern primär um die Kontrolle über Arbeitskraft, politische Rechte und kulturelle Anerkennung (Jain/Randeria 2014). Der obsessive schweizerische Überfremdungsdiskurs operiert dabei anhand einer Grenztopologie, die im jeweiligen historischen Kontext immer aufs Neue erlaubt, die assimilatorische Passage vom migrantischen „Anderen“ zum nationalen „Eigenen“ - je nach Klasse, Rassifizierung und Herkunft, Religion und Geschlecht - neu zu bewerten, zu kontrollieren oder zu verhindern.

Die „Zweite Generation“ nahm in diesem „Migrationskomplex“ seit der Lancierung der „Fremdenfrage“ durch C. A. Schmid um 1900 eine wichtige Funktion ein. Sie erschien als Gruppe mit den größten Chancen auf Assimilation, wodurch sowohl das Arbeitskräfteangebot und das Wohlstandsmodell Schweiz gesichert als auch die „Überfremdungsangst“ gebannt werden könnte. Vor diesem Hintergrund wurde die „zweite Generation“ als strategische und hybride, politische Grösse konstruiert, die zwischen Assimilation und Anomie, zwischen Krise und Versprechen, zwischen Misstrauen und Sorge oszillierte. So formuliert die Eidgenössische Ausländerkommission 1989 die „Problematik der zweiten Generation“ in einem administrativen Ratgeber an die Gemeinden folgendermaßen:

Die zweite Ausländergeneration unterscheidet sich in ihrer Lebenssituation sowohl von der Einwanderergeneration [...] als auch von den gleichaltrigen Schweizern. Ihre Persönlichkeit orientiert sich nicht einseitig an den Wertvorstellungen und Verhaltensweisen der Schweiz oder des Heimatlandes. Der Jugendliche muss seinen Platz in der Gesellschaft unter dem Einfluss zweier Kulturen suchen, die sich stark voneinander unterscheiden können. Dieses Spannungsfeld wird durch die ausländische Familie und deren Umfeld einerseits sowie durch den Kindergarten andererseits bestimmt. Daneben wirken weitere Kräfte in die eine oder andere Richtung [...] Das Kind ausländischer Eltern wird stets zwischen Erwartungen, Bräuchen, Traditionen und Verhaltensmustern der einen oder anderen Seite hin- und hergezogen. Dieser Umstand kann zu einer Situation der Zerrissenheit führen. Der Jugendliche hat dadurch entsprechende Mühe, eine eigene Identität zu finden und ein Selbstwertgefühl zu entwickeln. (Schweizerischer Verband der Bürgergemeinden und Korporationen 1989:253 f., Hervorhebungen R. J.) 
Dieses Zitat konstruiert die Seele von Angehörigen der „zweiten Generation“ als krisenhafte Entität, die staatliche Unterstützung und paternalistische Sorge bedurfte. Während hier der Zugriff nicht durch Einbürgerungskontrollen stattfindet, sondern in der Sprache von Sorge und Verständnis, zeigt sich darin ein ähnlich gewaltvoller, staatlicher Zugriff auf die Subjekte wie bei der misstrauischen Fremdenpolizei. Beide Positionen verbinden sich in einem „assimilatorischen Humanismus“, der die sich im einseitigen und politisch-moralisch aufgeladenen Zugriff auf Angehörige der „Zweiten Generation“ sowie im Interesse manifestiert, deren Seelen zu kennen, ihr Verhalten zu kontrollieren und sie als Subjekte zu prägen.

Wie ausgeführt, ist die hier eingeschriebene Metaphorik eines „Lebens zwischen zwei Welten“ Ausdruck einer Subjektivierungslogik der „zweiten Generation“, die im biopolitischen Assimilationsprojekt der modernen Nation angelegt war und in der klassischen US-amerikanischen Migrationsforschung ihre explizite Ausformulierung fand.

Ich argumentiere, dass die „Zweite Generation“ in der Schweiz durch eine umfassende, vom Staat in den Alltag reichende assimilationistische Biomacht als spezifische Subjekte hervorgebracht wurde. Die alltägliche Konfrontation mit assimilatorischen Institutionen, Sprachen und Blicken und deren Aneignung machte sie zu Subjekten, die sich überhaupt als Angehörige der „zweiten Generation“ sehen, fühlen und verstehen können. Im dominanten Narrativ des „Kulturkonflikts“ wurden Angehörige der „Zweiten Generation“ als krisenhafte Existenzen zwischen den essenzialistischen Entitäten des nationalen „Eigenen“ und des „Anderen“ naturalisiert, die sich an der sozialräumlichen Grenze zwischen Öffentlichkeit und Privatheit, Familie und Schule manifestierten. In der Öffentlichkeit wurden Angehörige der „Zweiten Generation“ diszipliniert, nationale, bürgerliche Normen zu übernehmen, während ethnische Selbstrepräsentation weitgehend sanktioniert und delegitimiert wurden. Gleichzeitig wurden Ethnizität und Anderssein in den privaten Raum der „Migrationsfamilie“ und der Migrationsvereine projiziert.

Wie bereits in der Einleitung dargelegt, stammt die erste Kohorte von „Inder_ innen der zweiten Generation“ von indischen Migranten und Migrantinnen aus unterschiedlichen Segmenten der Mittelschicht ab, die ab den 1950er Jahren in die Schweiz kamen. Sie wuchsen in den 1960er, 1970er und 1980er Jahren im Kontext des Assimilationismus auf. Da die indische Gemeinschaft in den Jahren, in denen sich die Kindheit und Jugend von „Inder_innen der zweiten Generation“ abspielt, relativ klein, sozial heterogen und geografisch verstreut war, konnten subjektive Erfahrungen kaum in starken Netzwerken oder diasporischen Öffentlichkeiten verglichen und ausdifferenziert werden. Gleichzeitig existierten auch in der Öffentlichkeit nur lose Rollenmodelle oder Narrative, wie die Subjektivierung der „Zweiten Generation“ überhaupt stattfinden sollte. Diese sozialstrukturelle Konstellation hatte einen großen Einfluss auf die Logik der Subjektivierungsprozesse von „Inder_innen der zweiten Generation“. In dieser Situation standen „Inder_innen der zweiten Generation“ als „Pioniere“ (Juhasz/Mey 2003:314) vor der biogra- 
fischen Aufgabe, Sprachen und Praktiken zu finden, um die eigenen Erfahrungen des Andersseins sinnhaft zu bearbeiten.

Wie ich im folgenden Kapitel diskutieren möchte, wird die „Migrationsfamilie“ angesichts des verbreiteten Narrativ des „Lebens zwischen zwei Welten“ sowie der historischen und sozialstrukturellen Bedingungen der indischen Migration in die Schweiz sowohl zu einem prominenten Topos als auch zu einer zentralen Arena in den Subjektivierungsprozessen von „Inder_innen der zweiten Generation“ (Bacon 1997). Zum einen finden innerhalb der transnationalen, sozialen Mobilitätsprojekte innerfamiliäre moralische Aushandlungen statt, die sich um Normen kultureller und sozioökonomischer Reproduktion drehen. Zum anderen nehmen diese transnationalen innerfamiliären Aushandlungen Gestalt und Bedeutung in einer rassialisierten Konstruktion der „Migrationsfamilie“ an. Der Assimilationismus strukturiert die sozialmoralischen Aushandlungen von Solidarität und Zugehörigkeit in der „Migrationsfamilie“, er prägt innerfamiliäre Subjektivitäten und liefert Perspektiven auf das Familienleben. Die folgende Analyse von Subjektivierungsweisen in und um die Familie erlaubt es, sowohl die Funktionsweise des Assimilationsregimes zu analysieren als auch die biografischen und historischen Spielräume, die vielfältige und alternative Subjektivierungswege in Bezug auf $\mathrm{Zu}$ gehörigkeit, Geschlechterperformanz und soziale Mobilität eröffnen. 



\section{3. "Zwischen den Welten“? - die "Migrationsfamilie" als semantischer Topos und soziale Arena}

Children of immigrants do not literally live in two worlds, but they live in a world where the belief that there are only two worlds is omnipresent.

(Karakayali 2005:327)

Dieses Kapitel ist der Untersuchung der Familie als semantischer Topos und soziale Arena in den Subjektivierungsprozessen von „Inder_innen der zweiten Generation“ im schweizerischen Assimilationismus der 1960er bis in die frühen 1990er Jahre gewidmet. Die folgenden biografischen Fallanalysen dienen dazu, die vielfältige Wirkungsweise der assimilationistischen Subjektivierungslogik eines „Lebens zwischen Welten“ in diesem Zeitraum zu beleuchten und Aushandlungen alternativer Lebensführungen und Selbstrepräsentationen aufzuspüren.

Der Familie kam in der Migrationsforschung und insbesondere in der Forschung zur „zweiten Generation“ - implizit oder explizit - seit jeher eine wichtige Rolle zu. Die quantitative Assimilationsforschung versuchte, die sozialen und kulturellen Faktoren zu eruieren, die verschiedene Verläufe der Assimilation erklären (Esser 1990; Nauck et al. 1997; Hämmig 2000; Nauck 2005). Die „Migrationsfamilie“ figuriert in diesem Forschungsstrang als Black Box, innerhalb derer spezifische Mechanismen intergenerationeller sozialer Mobilität oder „Kulturkonflikte“ wirken, die assimilatorischen Erfolg oder Misserfolg ausmachen. Als Kritik dieses quantitativen Forschungsstrangs hat die biografisch-qualitative Migrationsforschung den Fokus auf die Aushandlung subjektiver Sinnkonstitution innerhalb des familiären Projektes der Migration gelenkt (Lutz 2000; Juhasz/ Mey 2003; Apitzsch 2006). Migration wird in der Biografieforschung als Familienprojekt mit einer eigenen Logik angesehen, in dem Aspirationen nach sozialer Mobilität, kulturelle Normen und spezifische Handlungskompetenzen vermittelt und ausgehandelt werden. Dies erlaubt - im Gegensatz zur „Außensicht aus der Sicht der Aufnahmegesellschaft“ (Lutz 2000:38), - die vielfältigen innerfamiliären Aushandlungsprozesse zu rekonstruieren (Apitzsch 2006), in der das Projekt 
der Migration als zukunftsoffener Prozess eingebettet ist. Aus der Kritik an der Assimilationsforschung ist auch die transnationale Familienforschung hervorgegangen (Foner 1997; Bryceson/Vuorela 2002; Olwig 2007). Die Familie wird darin als eigenlogisches System von soziomoralischen und affektiven Bindungen sowie Interessen betrachtet, das die methodologische Engführung auf das nationale Assimilations- und Inkorporationsregime sprengt. Der Fokus auf transnationale familiäre Netzwerke eröffnet den Blick auf die Aneignung und Aushandlung vielfältiger Zugehörigkeiten, Normen und Praktiken zwischen unterschiedlichen Kontexten.

Ich argumentiere, dass in diesen Ansätzen trotz wichtiger Erkenntnisse kaum thematisiert wird, warum und wie die Familie innerhalb spezifischer institutioneller und diskursiver Machtverhältnisse für unterschiedliche Akteure als relevanter Topos und zentrale soziale Aushandlungsstätte von Subjektivitätsprozessen entsteht. ${ }^{39}$ Ein weiterer Forschungsstrang zur Migrationsfamilie fordert deshalb, die "politicization of the family“ ins Zentrum der Analyse zu stellen (Grillo 2008:9). Familie wird hier nicht als selbstverständliche Einheit im Migrationsprozess verstanden, sondern als vielschichtig hergestellte soziale Wirklichkeit innerhalb spezifischer Machtverhältnisse.

The family is at once a social construct, a conceptional entity, a moral order, and a set of real social and cultural practices. Its investigation requires examining both the trope of family (including implicit and explicit definitions offered by informants, policymakers included), and the relationships (moral and practical) which it is thought to entail. (Grillo 2008:19)

Diese offene, sozialkonstruktivistische Herangehensweise verspricht, die Naturalisierung der Familie als konstitutive Einheit im Migrationsprozess zu hinterfragen. Sie erlaubt, die Familien als vielfältige Objekte politischer Steuerung, volkswirtschaftlicher Verwertung und moralischer Disziplinierung zu analysieren. Gleichzeitig erlaubt sie, Familien als transnationale Projekte der Mobilität zu verstehen, die in vielschichtigen familiären Idiomen und moralischen Beziehungen ausgehandelt werden.

Aus genealogischer Sicht gilt es, die epistemische Grenze zwischen innerfamiliären moralischen Beziehungen und öffentlichen, politischen Prozessen, zwischen „Innen“ und „Außen“ der Familie kritisch in den Blick zu nehmen. Es soll hier argumentiert werden, dass die Grenzziehung zwischen „Innen“ und „Außen“, „Eigenem“ und „Anderem“, „privat" und „öffentlich“ selbst Ausdruck einer politischen Konstruktion der „Migrationsfamilie“ im schweizerischen Assimilationismus ist, die die familiären Aushandlungen beeinflusste. In Anlehnung an Jacques

39 | Zu einer Weiterführung des biografischen Ansatzes in die hier vorgeschlagene Richtung siehe Lutz (2000, 2009). 
Donzelot ist hier unter „Migrationsfamilie“ nicht eine soziale Institution, sondern ein Mechanismus zu verstehen, mit dem der Staat auf seine Subjekte zugreift und sie einer assimilatorischen Norm unterwirft. Die Familie ist demnach nicht „als Ausgangspunkt, sondern als bewegliche Resultante, als unbeständige Form" $\mathrm{zu}$ verstehen, die eingebettet ist in „ein System der Beziehungen zwischen ihr und der sozio-politischen Entwicklung“(Donzelot 1980:15). Die „Migrationsfamilie“ wurde im Assimilationismus ab den 1960er Jahren Objekt bevölkerungspolitischer Regierung - wie schon im gesamten 20. Jahrhundert sozial marginalisierte Familien durch die Armenfürsorge (Ramsauer 2000) oder Familien von Fahrenden im Hilfswerk für die Kinder der Landstrasse (Leimgruber et al. 1998). „Migrationsfamilien" wurden als Hindernisse im intergenerationellen Assimilationsprozess angesehen, den Fremdenpolizei, Schule und Zivilgesellschaft überwachten und vorantrieben. Während die Fremdenpolizei den Familiennachzug regulierte und den Assimilationsgrad familiärer Praktiken bei der Einbürgerung überprüfte, vermittelte die Volksschule in Abgrenzung zur „Migrationsfamilie“ nationale Sprache und Werte. Diese „Regierung durch die ,Migrationsfamilie“", wie ich sie in Anlehnung an Donzelot nennen möchte (Donzelot 1980:104), war konstitutiv für die Macht der assimilatorischen Beziehung des Nationalstaates zu Migrantinnen und Migranten und ihren Nachkommen. Wie die Fallbeispiele zeigen werden, prägte diese Gouvernementalität direkt oder indirekt sozialmoralische Beziehungen innerhalb der Familien, Deutungsmuster des familiären Lebens und Aushandlungen von Normen der Solidarität und Zugehörigkeit. Sie naturalisierte das Leitnarrativ des „Lebens zwischen den Welten“ in einer sozioräumlichen Hierarchie, durch die „Ethnizität“ in die privaten Räume der „Migrationsfamilie“ und der Migrationsvereine projiziert wurde, wogegen in der Öffentlichkeit die unmarkierte Normalität der Nation herrschte. „Inder_innen der zweiten Generation“ wurden dadurch in ihrer Kindheit und Jugend öffentlich auf unterschiedliche Weise angerufen, ihre Familien im Gegensatz zur unsichtbaren schweizerischen Norm als Verkörperung ethnischer Differenz wahrzunehmen, wodurch die komplexen Beziehungen zwischen Familie und Gesellschaft und innerhalb Familie zumindest zeitweise essenzialisiert wurden. Die Form, aber auch die Grenzen dieser Macht und die darin sich vollziehenden widerspenstigen, hoffnungsvollen Prozesse der Lebensführung und sozialen Imagination sind Thema dieses Kapitels.

Die meisten meiner Gesprächspartnerinnen und -partner waren zwischen den 1960er und 1990er Jahren Kinder, Jugendliche oder junge Erwachsene. Zur gleichen Zeit, in der in Kindheit und Adoleszenz die wichtigsten sozialisatorischen Aushandlungen von Subjektivität in der Familie stattfinden, richtete sich der assimilatorische Blick stets auch auf eben diese. Die soziale Genese von „Inder_innen der zweiten Generation" als spezifische Subjekte bestand gerade auch darin, die diffusen Anrufungen des Andersseins zunehmend auf ihre „indische Migrationsfamilie" zu beziehen und dieses Anderssein auch in den soziomoralischen, familiären Beziehungen auszuhandeln. Es ist diese spezifische Verflechtung von biogra- 
fischer und historisch-politischer Konstellation, die in diesem Kapitel behandelt wird. Folgende Fragen leiten die Untersuchung:

- Wie wird die Grenzziehung zwischen „Migrationsfamilie“ und nationaler Öffentlichkeit konstruiert und ausgehandelt?

- Welche legitimen und illegitimen Subjekt- und Sprechpositionen werden für „Inder_innen der zweiten Generation“ dadurch etabliert?

- Wie handeln „Inder_innen der zweiten Generation“ innerhalb dieser hegemonialen Repräsentationspolitik alternative Formen des Sprechens und der Subjektivierung aus?

Zur Diskussion dieser Fragen stütze ich mich auf biografische Interviews, auf teilnehmende Beobachtung sowie auf die Analyse von staatlichen Dokumenten und populärkulturellen Quellen. Die Fallbeispiele dienen dazu, spezifische Subjektivierungsprozesse einerseits als hegemoniale Machteffekte zu analysieren. Angesichts von Widersprüchen, Brüchen und Kontingenzen in diesen Prozessen eröffneten sich andererseits auch Handlungsspielräume, innerhalb derer neue Sprechpositionen und alternative Subjektivitäten entstehen konnten. Subjektivierungsprozesse erscheinen dadurch sowohl als Ausdruck diskursiver und politischer Disziplinierung als auch als Aushandlungen neuer ethischer Räume und subjektiver Lebensentwürfe.

\subsection{Aftab: Die intellektuelle Suche nach EIGENEN WORTEN}

Aftab, ein 49-jähriger Unternehmensberater, stammt aus einer indisch-pakistanischen Familie und ist in Pakistan zur Welt gekommen. Als er drei Jahre alt war, nahm sein Vater einen Posten als Filialleiter eines südasiatischen Unternehmens in der Schweiz an und Aftab wuchs mit seinen beiden Brüdern und seinen Eltern in einer mittelständischen Agglomerationsgemeinde auf. Aftab kann sich noch gut an seine Einbürgerung erinnern:

Wir sind sehr wohlwollend behandelt worden. Aber das waren doch zwei Jahre gewesen, in denen wir uns intensiv mit unserem Ausländer-Sein beschäftigen mussten. Da sind Leute bei uns im Haus herumspaziert, die geklingelt haben bei den Nachbarn und gefragt haben, ja sind denn die Leute anständig, nicht zu laut, nicht dreckig, und so Sachen. Plötzlich sind auch zwei Einbürgerungsbeamte bei mir auf dem Schulhausplatz an einer Ecke aufgetaucht. Und dann bei der Einbürgerung an der Gemeindeversammlung war ich in einem abgesonderten Teil, weil ich nicht stimmberechtigt war, und da musstest du dich erheben, damit dich alle anschauen konnten und es wurde gefragt, ob 
jemand etwas gegen unsere Einbürgerung habe. Da wird einem das alles [das Ausländer-Sein] natürlich mit voller Wucht bewusst.

Das Einbürgerungsprozedere war eine minutiöse, gründliche, fremdenpolizeiliche Maßnahme, um die kulturelle Assimilation Aftabs und seiner Angehörigen zu prüfen und zu kontrollieren. Die Präsenz des institutionellen Misstrauens im Alltag sowie die erlebte Willkür und die Anrufung des Andersseins haben sich in Aftab geradezu körperlich festgeschrieben. Die Erinnerung zeugt von der moralischen Ambivalenz von Unterwerfung und Widerstand, wenn Aftab seine Erinnerung mit der Beteuerung beginnt, wohlwollend behandelt worden zu sein, und damit abschließt, wie er mit „voller Wucht“ sein „Ausländer-Sein“ spürte. Die paranoide Skepsis gegenüber Ausländer_innen und deren soziale und mentale Überwachung und Normierung war nicht nur Teil des behördlichen Einbürgerungsprozesses. Auch die Schweizer Bevölkerung achtete auf die alltägliche Lebensführung von als ausländisch markierten Menschen und sanktionierte die Abweichungen von der imaginierten Norm im öffentlichen Raum. So erinnert sich Aftab: „Ich weiß noch, als ich einmal am Fenster zusah, wie mein Vater nach Hause kam und einparkte, da öffnete ein Nachbar auf der anderen Seite des Hofes, der hinter dem Vorhang auch zugeschaut hatte, das Fenster und rief: ,Schräg eingeparkt!““ Trotz der abgeklärten und reflektierten Rekonstruktion dieser Erlebnisse lässt sich erahnen, dass Aftab als Kind ein intensives Gefühl des Andersseins entwickelte, wobei er nicht explizit benennen konnte, warum er als „anders“ galt. Durch die Wahrnehmung des assimilatorischen Blicks wie zum Beispiel des Nachbarn oder beim Einbürgerungsprozedere erlernte und internalisierte Aftab die hegemoniale Differenz zwischen dem „Eigenen“ und "Anderen“ als ordnende und sinnhafte Kategorien der sozialen Wirklichkeit. Der afrokaribische Psychoanalytiker Frantz Fanon hat die Macht einer „Urszene“ für die Subjektivierung beschrieben, in der ein weißes Kind in Paris beim Anblick von Fanon rief: "Mama, see the Negro! I'm frightened!" (Fanon 1967:112). In Fanon löste dies einen innerlichen Sturm der Wut und Verletzung hervor - doch äußerlich schwieg er. Sein Schweigen war in dem Sinne doppelt, als ihm - neben dem eigentlichen Nichts-Sagen - keine andere Sprache zur Verfügung stand als die des dominanten Repräsentationsregimes, die er größtenteils internalisiert und durch die er sich als Subjekt konstituiert hatte. Die Selbstrepräsentation von „Inder_innen der zweiten Generation“ in der Schweiz dieser Zeit basierte auch auf einer zumindest partiellen Internalisierung eines dominanten Blicks von Außen. Es ist gerade Teil des Assimilationsprozesses, diesen Blick in der eigenen Subjektivierung immer wieder fortzusetzen und auf sich selbst anzuwenden. Als Rationalisierung dieses Gefühls des Andersseins diente Aftab das Bild des „Lebens zwischen den Welten“, das die assimilationistische Repräsentationspolitik sozialräumlich und lebensweltlich erfahrbar macht. 
Ich habe lange noch gesagt, in unserer Wohnung sind wir in Indien, und wenn ich aus der Wohnung rausgehe, bin ich in der Schweiz. Und es ist eigentlich noch interessant gewesen, dass unsere Wohnungstür von der Innenseite weiß gestrichen war und außen rot (lacht). Also draußen bin ich dann wirklich in der Schweiz gewesen; es ist halbe-halbe gewesen, das war so eine Sache, und ich habe das lange so empfunden, es sind zwei verschiedene Welten gewesen.

Dieses Deutungsmuster eines „Lebens zwischen den Welten“ erlaubte ihm, die ambivalente Subjektivierung zwischen dem „Eigenen“ und dem „Anderen“ sinnhaft zu organisieren. Die assimilatorische Subjektivierungslogik forderte in der Öffentlichkeit, die unmarkiert „normalen“ Verhaltensweisen, Praktiken und Narrative zu verkörpern und ethnische Selbstrepräsentationen in der Öffentlichkeit zu unterlassen. Stattdessen wurde „Ethnizität“ in die Privatsphäre der Familie, in Migrantenvereine oder religiöse Stätten projiziert. Im Rahmen dieser sozialräumlichen und diskursiven Segregation versuchte Aftab aber auch einen öffentlichen Raum für Selbstrepräsentation von Differenz zu schaffen. Die folgenden Worte zeigen sowohl die konstitutive Macht der assimilatorischen Subjektivierungslogik als auch die biografisch-diskursiven Spielräume ihrer Reinterpretation:

Wie gesagt, es sind zwei verschiedene Welten gewesen, und die Welten haben sich erst dann angefangen zu öffnen, als vor allem ich - im Gegensatz zu meinen Brüdern - oft Kollegen von der Schule nach Hause brachte. Das hat die Grenze, die Abgrenzung durchlässiger gemacht, und meine Eltern haben das auch nie abgeklemmt. Dann sind diese Freunde gekommen und dann haben sie natürlich gefragt, warum riecht es bei euch anders, und deine Mutter, warum zieht sie an bestimmten Feiertagen komische, andere Kleider an, und ich habe diese Frage nie als Beleidigung oder Kritik oder Ähnliches empfunden, sondern als Interesse, also habe ich den Drang entwickelt, das irgendwie zu erklären.

Um sich selbst repräsentieren zu können und um verstanden zu werden, begann sich Aftab religiöses, historisches und politisches Wissen über Islam, Südasien und auch die Schweiz anzueignen. So hatte er intensiv seine Familienbiografie recherchiert, um sein Anderssein genealogisch möglichst genau zu verstehen und vermitteln zu können.

Meine Vorfahren stammen alle aus dem heutigen Bundesstaat Gujarat in Nordwestindien. Wie ich in Erfahrung gebracht habe, sind meine Vorfahren vor etwa drei, vielleicht vier Generationen vom Hinduismus zum Islam konvertiert. Es gibt verschiedene Theorien dazu. Zum Teil waren es erzwungene Konversionen durch muslimische Eroberer und so weiter. Zum Teil waren es aber auch freiwillige Konversionen vom Hinduismus zum Islam, zum Bud- 
dhismus oder zum Sikhismus, um dem Kastensystem zu entkommen. Auch da gibt es verschiedene Betrachtungsweisen, dass es vor allem niedrigkastige Hindus gewesen waren, aber es gab auch höherkastige Hindus, die konvertiert sind. Meine Vorfahren gehörten der zweitobersten Kaste der ksyhatriya, der Kriegerkaste, an. Unser Familienname war ursprünglich K., ein sehr, sehr alter Name, der vor allem in Gujarat und Südrajasthan verbreitet war. Väterlicherseits waren diese Vorfahren vor allem geschäftstüchtige Leute. Mütterlicherseits waren einige Vorfahren Anwälte und Richter, der Vater meiner Mutter war Politaktivist und Journalist.

Durch Gespräche mit Eltern und Verwandten sowie durch die Konsultation von wissenschaftlicher Literatur hat Aftab seinen genealogischen Ursprung festgemacht. Die intellektuelle Auseinandersetzung mit seinem als diffus erlebten Anderssein ermöglichte ihm, gegenüber seinen Peers die legitime Aushandlungsposition einer rationalen Expertise einzunehmen und eine eigene Sprache und ein eigenes Ethos zu entwickeln. In Erinnerung blieb Aftab das Unverständnis seiner Peers, dass er an Weihnachten keine Geschenke kriegte, worauf er konterte und ihnen den muslimischen Feiertagskalender rezitierte.

Ich habe immer versucht, es in etwas Anderes umzukehren und zu sagen, ich habe etwas, das mindestens genau so gut ist wie eures, vielleicht ist es sogar erhabener, denn ich muss zuerst fasten, bevor ich etwas kriege, und ich werde auch nicht überhäuft. Ihr müsst nichts machen und kriegt Berge von Geschenken. Das ist doch verlogen.

Wie in diesem Beispiel konnte Aftab durch trotzige Entgegnungen seinen unwissenden Peers Paroli und Antworten bieten. Er konnte dadurch eine kritische und oft auch ironische Position gegenüber seinen Peers einnehmen und Lücken und Widersprüche im hegemonialen Diskurs besetzen. Im Rückblick erscheint diese Strategie aber auch von einer aktiven Kompensation von Erfahrungen paternalistischer Stigmatisierung durchzogen, die er immer wieder zu spüren bekam.

Es hat natürlich auch Nachbarn gegeben, die sich meiner erbarmt hatten [lacht], und mich dann zwei, drei Mal an einem Heiligabend eingeladen haben und bei der Bescherung war dann auch etwas für mich dabei. Und ich bin ihnen heute dankbar dafür und es ist mir heute egal, ob sie einfach das arme "Negerkindli“ bemitleideten oder was ihre Beweggründe waren. Sie haben mir geholfen zu erfahren, wie wird da überhaupt Weihnachten gefeiert im privaten Rahmen und sie haben mir geholfen meine interkulturelle Kompetenz zu steigern. Für jemand anderen wäre das so eine Albert-Schweitzer-Geschichte gewesen. Ich habe das nie so empfunden. 
Aftab ist sich heute der Spannung von Exotisierung und Paternalismus bewusst, die ihm als Kind muslimischer Eltern entgegengebracht wurde - vielleicht war sie ihm auch schon als Kind auf diffuse Art bewusst gewesen. Er reagierte darauf, sich durch Wissen, Ironie und Rhetorik in der Dominanzgesellschaft sowohl Anerkennung - und auch ein erhabenes Gefühl der Überlegenheit - zu erkämpfen. Diese fragile Position als intellektueller Aufklärer, ironischer Kritiker und interkultureller Übersetzer prägte nicht nur Aftabs Subjektivierung im Kontext des Assimilationismus, sondern schreibt sich als Strategie in sein Leben ein - wie ich in Kapitel 5 weiter erläutern werde: Nach dem Abschluss der Handelsschule und nach mehreren Jahren in unterschiedlichen kaufmännischen und technischen Jobs arbeitete Aftab als unabhängiger Journalist zu Südasien und konnte so eine eigene Perspektive auf die Heimatregion seiner Eltern entwickeln. Heute ist Aftab selbstständig als interkultureller Unternehmensberater, der schweizerischen Klienten beim Einstieg in die wachsenden Märkte der neuen Supermacht Indien hilft. Mit dem Selbstverständnis des Selfmademans, der es trotz widriger Umstände zu etwas gebracht hat, meinte er im Gespräch stolz: „Ich mache immer noch das Gleiche, nur habe ich daraus ein Geschäftsmodell gemacht.“

Die Fallanalyse zeigt, wie sich ambivalente Erfahrungen eines „Lebens zwischen den Welten“ als Machteffekt des Assimilationsregimes in Aftabs Subjektivität einschrieben. Darin wurde die Familie zum Hort von ethnischem und rassialisiertem Anderssein gegenüber der unmarkierten Normalität im öffentlichen Raum. Als Reaktion auf assimilatorische Anrufungen entwickelte Aftab eine Form der öffentlichen Entgegnung. Durch Wissensakkumulation und eine Rhetorik der Aufklärung konnte er eine für sich moralisch überlegene Sprechposition gegenüber einer nur zu oft ignoranten Dominanzgesellschaft einnehmen. Damit konnte er sich eine legitime Gegenposition im öffentlichen Diskurs ausbedingen, ohne die ethnische und religiöse Zugehörigkeit seiner Familie zu leugnen.

\subsection{Maya: Wider DEN „KULtURKonflikt“}

Maya, eine 42-jährige Yoga-Lehrerin, wurde in der Schweiz geboren und wuchs in einer mittelständischen Deutschschweizer Agglomeration auf. Ihre Eltern stammen beide aus der indischen Beamtenschicht und migrierten in den späten 1960er Jahren mit der finanziellen Hilfe ihrer Verwandten in die Schweiz. Vor Mayas Geburt arbeitete ihr Vater als Elektromechaniker und bildete sich über die Jahre zum Informatikfachmann weiter. Ihre Mutter hatte in Indien einen Bachelor-Studiengang abgeschlossen und begann, als Maya in die Schule kam, als Englischlehrerin zu arbeiten. Eine prägende Erinnerung aus Mayas Kindheit zeigt die biografische Bedeutung der Familie als semantischer Topos und soziale Arena: 
Ich habe in der ersten oder zweiten Klasse einmal eine Party gemacht bei mir $z u$ Hause. Da war wirklich eine große Diskrepanz. Es sind so ein paar Mädchen zu mir gekommen und die sind dann alle so in Miniröcken aufgetaucht, ganz cool angezogen und haben sich ganz anders bewegt und ich bin so in meinem Prinzessinnenkleidli gewesen - so völlig in einem Traum.

Die Erzählung von den in Miniröcken gekleideten Peers, die in Mayas Welt „bei sich zu Hause" auftauchten, kann als klassisch Fanon'sche Urszene verstanden werden. Im geschlechterperformativen Kontrast ihres „Prinzessinnenkleids“ und der coolen Miniröcke der Schweizer Mädchen, die „sich ganz anders bewegten“, reflektiert Maya die plötzliche Erfahrung von Andersartigkeit. Durch die Übernahme des Blicks der anderen Mädchen sieht sie sich als verträumte „indische Prinzessin“. Ihre Subjektivität konstituiert sich von diesem Moment an im Spannungsfeld zwischen ihrer „weltfremden indischen Familie“ und ihren „coolen Schweizer Peers “. ${ }^{40}$ Maya schildert ihre Jugend als neugierige, sehnsüchtige Suche nach diesem nicht-familiären, das heisst dem nicht-indischen Anderen. Sie freundet sich in der dritten Klasse mit zwei Mädchen an, die sie „dann aufgeklärt [haben] bezüglich der Schweizer Kultur [...], darüber, wer Michael Jackson war und über alles, was cool war". Mit dem Eintritt in das Gymnasium nach der sechsten Klasse lässt Maya aus ihrer Sicht einen Lebensabschnitt hinter sich. Wieder erzählt Maya diese biografische Wende anhand des kulturellen Codes der „indischen Familie“. So meint Maya mit ironischer Distanz: „Bei mir war ja schon im Kindergarten klar, dass ich mal studieren würde, und ich war aber gar nicht so gut, aber sie haben es, sie haben wirklich gepusht" - womit sie die starke soziale Aufstiegsorientierung ihrer Eltern andeutet. Im Gymnasium versucht Maya sich zunehmend aus der gefühlten Abschottung und Außenseiterposition zu befreien.

Ich durfte zum Beispiel in langen Mittagspausen nicht in der Schule bleiben. Ich musste heimgehen. Ich durfte nie auf Parties gehen. Dann hat wirklich eine ganz schwierige Zeit mit meinen Eltern angefangen. Wir haben Dauerkrach gehabt, und ich habe mich dort einfach rebellisch verhalten müssen, um einigermaßen Anschluss zu finden an diese Kultur da.

40 Bezeichnenderweise hat auch Marc Virot in seinem Assimilationsratgeber von 1968 (s. Kapitel 2.2) die Kinderkleidung als assimilationsrelevant indiziert: „Bei der Kindermode bestehen gewisse Unterschiede. Unsere Kleinkinder sind meistens funktionell gekleidet, ohne viel Rüschen, Spitzen und Haarbänder." (Virot 1968: 60) Wenn Virot auch die italienische Mädchenmode im Blick hatte und nicht die indische und die 1980er Jahre noch in weiter Ferne lagen, so ist doch die Ähnlichkeit seiner assimilatorischen Forderung mit Mayas Urszene der Subjektivierung verblüffend. 
Mehrmals ist Maya von zu Hause abgehauen, weil sie dem dauernden Konflikt mit den Eltern ausweichen wollte. Im Nachhinein nimmt Maya eine distanzierte, psychologische Sicht auf das Verhalten der Eltern ein, das sie als Teenager jedoch nur als unverständlich und ungerecht erlebte. „Für meine Eltern ist das wirklich jenseits von Gut und Böse gewesen und sie haben extrem Angst gehabt, dass sich alles nur um Sex, Drogen und Rock 'n' Roll dreht“. Damals fühlte sich Maya jedoch in einem riesigen moralischen Dilemma, weil sie sich gegenüber den Eltern verpflichtet fühlte, von ihnen verstanden werden wollte und gleichzeitig den „Anschluss an diese Kultur da" suchte. Die Peers und deren Eltern, bei denen sie in dieser Zeit wohnte, wurden wichtige Ansprechpersonen in Bezug auf diesen Konflikt. Gemäß Maya fanden diese das „konservative Verhalten ihrer Eltern“ auch „jenseits von Gut und Böse“. Während Maya in diesen Beziehungen Geborgenheit und Verständnis fand, bestärkten und legitimierten sie auch ihren Widerstand gegen ihre „indische Familie“. Nach weiteren Konflikten zog Maya schließlich nach dem Gymnasium von zu Hause aus und grenzte sich vorübergehend sozial von den Eltern ab.

Ohne die Handlungen und Werte Mayas, ihrer Eltern oder ihrer Peers beurteilen $\mathrm{zu}$ wollen, stellt sich die Frage, welche institutionellen und diskursiven Bedingungen Mayas biografische Erzählung überhaupt möglich machten. Ich argumentiere, dass die Dichotomie zwischen der schweizerischen Öffentlichkeit und der „Migrationsfamilie“ und das daraus folgende Narrativ des „Kulturkonflikts“, das Maya verwendet, eingebettet waren in den hegemonialen Kontext des schweizerischen Assimilationsregimes dieser Zeit. Die „Migrationsfamilie“ oszillierte darin zwischen Potenzial der Assimilation und Gefahr der Überfremdung. Die Volksschule wurde dagegen zum Bollwerk von Fremdenabwehr und nationaler Erziehung der „zweiten Generation“, wie etwa der wegweisende Bericht der Studienkommission von 1964 festhielt: „In der gemeinsamen Erziehung und Bildung der ausländischen Kinder auf allen Schulstufen mit den einheimischen liegt die beste Gewähr für eine echte Assimilation." (Studienkommission 1964:147) Im technokratischen Eifer brachte der Bundesrat in seiner Botschaft zur zweiten Überfremdungsinitiative das assimilatorische Dilemma in Bezug auf die „zweite Generation" noch konkreter auf den Punkt:

Eine Assimilation der ausländischen Kinder durch die Schule setzt jedoch voraus, dass sich die Eltern ihrerseits unseren Verhältnissen anpassen, damit die Kinder nach Beendigung des Schulunterrichts nicht stets wieder in die andersartige und für uns fremde Umgebung ihrer Eltern zurückkehren und sich damit die für die Einbürgerung erforderliche Assimilation erst in der dritten Generation vollzieht. (Bundesrat 1967:103)

In der assimilatorischen Subjektivierungslogik wurden die Grenzen zwischen Familie/Schule, privat/öffentlich und indisch/schweizerisch gebündelt und als 
gefährliche Grenzzone im Kampf um die „zweite Generation“ - und damit für Wohlstand und Identität der Nation - konstruiert. Diese Grenzzone markierte zudem eine zivilisatorische Schwelle zwischen (westlicher) Moderne und Tradition, die sich konstitutiv in der Imagination der „patriarchalen Familie“ verdichtete. So schrieb der Zürcher Soziologe Oliver Hämmig im Jahr 2000:

Kulturkonflikte entstehen und begleiten die Einwanderer und deren Kinder, die Zweite Generation, mitunter auch im späteren Migrationsverlauf, nur dass sie sich dann als „innerfamiliärer Kulturkonflikt" zeigen. Zu dieser Kluft zwischen der ersten Generation (Eltern) und der Zweiten Generation (Kinder) kommt es nicht zuletzt aufgrund der durch den Kulturwechsel in Frage gestellten patriarchalen Familienstruktur und autoritären Erziehungspraxis, d. h. infolge der fehlenden oder mangelnden Unter- bzw. Einordnung der Kinder in das familiäre Autoritätsgefüge. (Hämmig 2000:147)

Dieses in Migrationspolitik und -forschung der 1980er und frühen 1990er Jahre vorherrschende paternalistische Argument, das die moralischen Dilemmata des angeblichen „Kulturkonflikts“ in die Migrationsfamilie projiziert, war angesichts des hegemonialen Assimilationsdiskurses in der Öffentlichkeit weit verbreitet. Der Beststeller „Nicht ohne meine Tochter“ von Betty Mahmoody, der 1988 in deutscher Übersetzung erschien war, popularisierte auch in der Schweiz, wie in anderen westlichen Industrieländern, das Narrativ der „patriarchalen orientalischen Familie“. Im Zusammenspiel staatlicher Autorität, wissenschaftlicher Objektivierung und populärkultureller Evidenz entstand eine kulturessenzialistische Hegemonie, in der sich intergenerationeller "Kulturkonflikt“ in der "patriarchalen Migrationsfamilie" als dominante, paternalistische Narration etablierte. Es kann mit Fug angenommen werden, dass dieses Deutungsmuster zu dieser Zeit so vorherrschend und selbstverständlich war, dass es auch Mayas Erfahrung und Selbstrepräsentation zu strukturieren vermochte.

Maya übernahm aber trotz des starken biografischen Deutungsmusters des „Kulturkonflikts" keineswegs eine vollständig assimilatorische Subjektposition, wonach sie etwa Indien und ihre Familie als traditionell und größtenteils unzivilisiert abgelehnt hätte oder wonach sie damit nichts zu tun hatte. Ein ehemaliger Schweizer Schüler der gleichen Kantonsschule konnte sich noch gut an die um einige Jahre ältere Maya erinnern. Er erzählte mir, dass sie mit den „Coolen“ rumgehangen habe, den Graffiti-Sprayern und den Rappern und selbst ein „Hippie“ war. Maya kleidete sich dezent in indische Kleider und Schmuck und erschien als exotische Schönheit, deren "Indianness“ ein orientalisches Flair in die provinzielle, bürgerliche Kleinstadt brachte. Maya empfand die beschriebene Jugendszene im Rückblick als Gruppe von „Freaks“, von außergewöhnlichen und non-konformen Persönlichkeiten, die von bürgerlichen Normen der Dominanzgesellschaft abwichen und alternative Lebensweisen pflegten. Diese gegenkulturelle Jugends- 
zene eröffnete Maya einen teilöffentlichen Raum, in dem sie mit einem Ethos des Andersseins und einer expressiven weiblichen Körperlichkeit experimentieren und das Bedürfnis und den Willen nach einem individuellen und autonomen Lebensentwurf entwickeln konnte. Diese gegenkulturelle Aushandlung des Andersseins war eng verflochten mit einer alternativen Repräsentation von „Indianness“, die im romantisch-orientalistischen Gegendiskurs der europäischen Moderne nicht als patriarchale, unzivilisierte Gesellschaft, sondern als das exotische „Andere“ einer rationalen, bürgerlichen Gesellschaft galt. In der Rolle als „exotischer Hippie“ konnte Maya sich einerseits von der aus ihrer Sicht strengen Erziehung und den rigiden Geschlechternormen ihrer „indischen Familie“ abgrenzen. Andererseits konnte sie gegen die bürgerlichen Normen des Assimilationismus aufbegehren und gleichzeitig - im Kontrast zu einer modernistischen Kritik - eine positive Identifikation mit Indien aufrechterhalten. Neben der kritischen Sicht auf die konservativen Werten ihrer Eltern erinnert sich Maya nostalgisch an die farbenfrohen, religiösen Feste des indischen Vereins, an die verspielte Ausgelassenheit des indischen Tanzes - und an das wunderbare Essen aus den Händen ihrer oft so strengen Mutter. Die Rolle als „exotischer Hippie“ eröffnete Maya zwar eine gestalterische Autonomie in ihrer Biografie, eine gegenkulturelle Position des Widerstandes und eine positive Selbstrepräsentation von „Indianness“. Gleichzeitig blieb sie einem dominanten, exotisierenden Blick in einem romantisch-orientalistischen Indiendiskurs unterworfen - der Kehrseite des Assimilationismus.

Auf einer Indienreise nach dem Gymnasium Mitte der 1990er Jahre entdeckte Maya Yoga als Körperpraxis und Lebensphilosophie und begann es während ihres Universitätsstudiums der Psychologie, Pädagogik und Ethnologie intensiv zu praktizieren. Die Entdeckung von Yoga war ein Schlüsselerlebnis in ihrer Biografie. Das körperliche, mentale und spirituelle System des Yoga lieferte Maya einen legitimen und sinnhaften Rahmen, um einen autonomen, individualistischen Lebensentwurf umzusetzen und ihre expressive Körperpraxis weiterzuentwickeln. Sie bildete sich nach dem Studium zur Yogalehrerin aus, vertiefte ihre persönliche Praxis und bereiste das Land, aus dem ihre Eltern stammten. Sie praktizierte Yoga am Fuße des Himalaya und an den Küsten Goas, reiste mit der Eisenbahn, redete mit den chaiwallahs (Teeverkäufern) und kreierte so - als Touristin, Yogini und Auslandsinderin - eine neue Perspektive auf Indien und auf sich selbst, wie ich in Kapitel 5 weiter erläutern werde. Im Laufe ihrer biografischen Erfahrungen, ihres Psychologie- und Pädagogikstudiums und der Yoga-Ausbildung hatte Maya schließlich eine neue, individuelle Sprache und Praxis der Selbstrepräsentation entwickelt, die ihre biografische Reflexion strukturiert. Sie zitierte auf ihrer Yoga-Website den US-Autor Neale Donald Walsch: „Das Leben ist ein niemals endender, fortlaufender Prozess der Kreation. Du kreierst Dich selbst immer und immer wieder nach dem höchsten Bild Deiner Selbst.“ Diese neue Sprache der Selbstverwirklichung erlaubte es Maya, das assimilatorische Kräftefeld zwischen „dieser Kultur da“ und ihrer „,indischen Familie“ zu verlassen und ihren persönli- 
chen Entwicklungsprozess zu reevaluieren. Vor diesem Hintergrund haben sie und ihre Eltern sich wieder angenähert und die moralischen Dilemmata zu bewältigen begonnen, die Mayas Jugend und Adoleszenz prägten. Der Fall von Maya verweist jedoch auf die gewaltvolle Paradoxie der assimilatorischen Subjektivierungslogik, dass anhand von kulturalistischen Geschlechternormen moralische Dilemmata in der "Migrationsfamilie“ verankert werden und dann die betroffenen Subjekte damit allein gelassen werden, diese intergenerationellen moralischen Konflikte zu lösen.

\subsection{SONIA: VERHANDELN VON SPIELRÄUMEN IM FAMILIENIDIOM}

Die Aushandlung der Konstruktion der „Migrationsfamilie“ und die sozialmoralischen Beziehungen innerhalb der familiären Arena zeigen keinesfalls eine einheitliche Dynamik. Aftab nutzte die Widersprüche im assimilationistischen Alltag - so etwa die Ignoranz seiner Peers -, um durch Wissen, Ironie und Rhetorik eine überlegene, aufklärerische Haltung und eine öffentliche Position der Selbstrepräsentation einzunehmen. Maya hatte die assimilatorische Anrufung internalisiert und ihre Jugend im Narrativ des „intergenerationellen Kulturkonflikts“ erfahren. Gleichzeitig hatte sie in einer jugendlichen Subkultur eine alternative Subjektivität entwickelt, in der sie ihre Erfahrung des Andersseins in einem radikal-individualistischen Lebensentwurf aushandelte. Im Folgenden möchte ich eine weitere Dynamik schildern, in der Erfahrungen des Andersseins stärker im Familienidiom ausgehandelt werden.

Sonia, eine 39-jährige Investmentbankerin, ist in Indien geboren. Ihre Familie immigrierte in die Schweiz, als sie sieben Jahre alt war, weil ihr Vater eine Stelle als Elektroingenieur bei einer Schweizer Firma antrat. Mit der Aufgabe konfrontiert, ihre Lebensgeschichte zu erzählen, sieht sich Sonia mit ihrer Unsicherheit sowohl bezüglich der Struktur wie des Subjekts dieser Narration konfrontiert.

Ok, gut ... [atmet ein] ... ich beginne mal chronologisch, als Bankerin musst du vielleicht mit Zahlen beginnen, ich weiß nicht. Also, ich bin auf die Welt gekommen in Mumbai, Indien, das war 1978, im November, ehm, wir sind damals, ehm, ich bin dort aufgewachsen, dort in die Schule, bis in die zweite Klasse, und bin mit sieben in die Schweiz gekommen, ehm, mein Vater hatte hier ein gutes Angebot bekommen. Und dann sind wir, ehm, zu viert in die Schweiz gekommen. Da habe ich angefangen in der Primarschule, und dann Sekundarschule, Gymnasium, Uni, alles hier dann abgeschlossen.

Sonia löst das Interaktionsproblem, ihre Lebensgeschichte zu erzählen, indem sie auf ihre Rolle als Bankerin Bezug nimmt und eine Zahlensemantik verwendet, die 
ihr Sicherheit und Eindeutigkeit verspricht. Aber auch als die Struktur der Narration geklärt ist, bleibt die Frage nach dem Subjekt der Erzählung unbeantwortet. Sonia oszilliert zwischen einer individuellen „Ich“-Perspektive und einer familienbiografischen „Wir“-Perspektive: Im Versuch, die kindliche Migrationserfahrung in ihrer Biografie zu erzählen, identifiziert sich Sonia unwiderruflich mit dem gemeinsamen familiären Migrationsprojekt. Sie liefert eigentlich zwei Versionen der Migration: Es ist sowohl ihre Geschichte als auch die ihrer Familie. Wie lässt sich diese stark oszillierende Subjektposition biografietheoretisch verstehen?

Wie Mecheril und Dausien argumentieren, stellt die familiäre Migrationsepisode angesichts der hiesigen biografischen Normerzählungen ein konstitutives Problem dar, das gelöst werden muss (Dausien/Mecheril 2006). Die Erfahrung der Andersartigkeit, die im Alltag, in der Schule, in öffentlichen Diskursen und staatlichen Praktiken durch rassialisierte Markierungen (z. B. Name, nicht-weisse Hautfarbe) stattfindet, schreibt Migration als konstitutive Abweichung in die Subjektivität der „zweiten Generation“ ein. Die narrative und identifikatorische Verflechtung der eigenen Biografie mit der Familie ist so gesehen ein Effekt der assimilatorischen Subjektivierungslogik, die Migration als anormale und erklärungsbedürftige Zugehörigkeit markiert. Zudem wird die Wichtigkeit der Familie in der migrationsbiografischen Erzählung dadurch verstärkt, dass der Migration in den meisten Fällen ein transnationales Projekt der sozialen Mobilität zugrundeliegt, innerhalb dessen gewisse Normen, Handlungskompetenzen und Ressourcen intergenerationell tradiert werden (Juhasz/Mey 2003:313 f.). Angehörige der „Zweiten Generation“ versuchen aus Verpflichtungsgefühl, Dankbarkeit oder Inspiration die Aufstiegsaspirationen der Eltern, die in der Migration eingeschrieben sind, zu erfüllen. Innerhalb dieses familiären Migrations- und Aufstiegsprojektes ist die Familienbiografie für Migrant_innen und ihre Nachkommen oft eine sinnhafte Ressource und ein Idiom, um Wandel und Kontinuität zu imaginieren und zu steuern, um innerfamiliäre Normen, Solidarität und Zugehörigkeit zu sichern oder/und infrage zu stellen (Lutz 2000; Olwig 2007). Aber nicht nur der Inhalt und die Struktur der unterschiedlichen Versionen der Familienbiografie, sondern überhaupt deren soziale Verfügbarkeit und Performanz drücken den Umgang einer Familie mit sozialem Wandel und kultureller Kontinuität, Zusammenhalt und Auseinandersetzung aus. Dies zeigt sich prägnant im Vergleich der Verknüpfung der individuellen Biografie mit der Familienbiografie bei Maya, Aftab und Sonia. Maya versucht sich in ihrer Erzählung von dem Familienprojekt und dem Familienidiom abzugrenzen und erzählt stattdessen eine individualistische Biografie. Es ist symptomatisch, dass sie sowohl in ihrer sehr detaillierten biografischen Erzählung als auch in den unzähligen Gesprächen und auf Nachfrage nur sehr wenig über ihre Familienbiografie zu erzählen wusste. Nichtsdestotrotz kommt sie nicht umhin, die migrationsbiografische Relevanz der Familie - indirekt - durch das prägende Narrativ des „Kulturkonflikts“ einzubeziehen. Aftab hatte seine biografische Erzählung mit einem langen und detaillierten Exkurs über die Familienge- 
schichte begonnen, die er im Laufe seines Lebens „recherchiert" hatte. Darin ist eine gewisse Identifikation mit dem familiären Projekt eingeschrieben, die jedoch durch die rationale und distanzierte Haltung der intellektuellen Expertise gebrochen wird. Sonia handelte ihre Biografie und Subjektivität viel stärker innerhalb des familiären Idioms aus als etwa Maya oder Aftab und identifiziert sich größtenteils mit dem familiären Projekt der Mobilität. In den Gesprächen mit Sonia zeigte sich, wie detailliert sie ihre Familienbiografie aus Erzählungen ihrer Eltern und Verwandten kennt und wie diese ihr als wichtige biografische Ressource und subjektive Orientierungshilfe dient:

Sonias Großeltern sowohl mütterlicher- als auch väterlicherseits lebten bis zur Teilung Britisch-Indiens 1947 in einer Provinz im heutigen Pakistan. Sonias Großvater väterlicherseits war Akademiker im staatlichen Dienst, die Vorfahren mütterlicherseits waren Großgrundbesitzer. Im Zuge der Teilung von Indien und Pakistan flohen sie - wie ein großer Teil der hinduistischen Minderheit - ins neu gegründete Indien. Beide Familien mussten wegen der Flucht ihr Vermögen, ihre sozialen Netzwerke und ihre kulturelle Verankerung aufgeben. Als Sonias Großvater väterlicherseits verstarb, musste Sonias damals 20-jähriger Vater, als älterer zweier Brüder, die Rolle des Familienoberhauptes übernehmen und wählte eine berufsorientierte Ausbildung zum Ingenieur. Mit 28 Jahren heiratete er eine von Bekannten vermittelte Frau aus der gleichen Gemeinschaft und konnte dadurch seinen Status als erwachsener Mann konsolidieren. Die Familie von Sonias Mutter hatte seit der Flucht durch Unternehmergeist und gute soziale Netzwerke ein lukratives Industrieunternehmen aufbauen können. Das junge Paar wohnte mit der Großmutter Sonias und ihrem Onkel, der in der Zwischenzeit ein Medizinstudium begonnen hatte, in einem Mittelstandsquartier einer indischen Metropole. In diese Phase der sozialen, ökonomischen und familiären Statuskonsolidierung fiel im Jahr 1978 die Geburt Sonias. Als Sonia sieben war, entschieden sich die Eltern in die Schweiz zu ziehen, da der Vater ein gutes Jobangebot einer Schweizer Partnerfirma seines Arbeitgebers erhalten hatte. In der Familienbiografie verweist Migration auf den schmerzhaften Verlust von Wohlstand, Status und kultureller Sicherheit nach der Flucht aus Pakistan. Gleichzeitig verheißt sie aber auch die Möglichkeit, durch individuellen Fleiss und Disziplin sowie durch die Solidarität in der Familie den verlorenen Status zu rehabilitieren. Während Sonias Großeltern als Flüchtlinge über wenig Handlungsmacht verfügten, konnte Sonias Vater mit der Migration in die Schweiz eine rationale, wenn auch emotional schwierige Entscheidung treffen, um das transnationale familiäre Projekt der Statusrehabilitation weiterzuführen. Die Familie zog in eine Hochhaussiedlung am Rande einer mittelländischen Schweizer Stadt, wo wegen der niedrigen Mieten vor allem ausländische Arbeitsmigrantinnen und -migranten wohnten. Die Migration in die Schweiz wurde für Sonia dadurch erleichtert, dass die Familie jedes Jahr in den Sommerferien nach Indien fuhr, wo Sonia die enge Beziehung zu ihrer Großmutter und auch Freundschaften zu ihren Peers aufrechterhalten konnte. Dieses Gefühl 
der Geborgenheit wurde jedoch getrübt, da sie während dieser Aufenthalte immer wieder erfuhr, dass sie in den Augen ihrer Peers als „Swiss girl“ galt. Diese Erfahrung der Nicht-Zugehörigkeit zwang Sonia, ihr nostalgisches Heimweh zu kontrollieren und sich stärker mit ihrer Migrationssituation zu identifizieren.

Gemäß der schon in Indien begonnenen Bildungsstrategie legten die Eltern großen Wert auf Sonias schulische Ausbildung. Nach dem achten Schuljahr schaffte sie den Übertritt ins Gymnasium, der - im Unterschied zum üblichen Vorgehen nach der neunten Klasse - nur nach einer strengen Prüfung möglich war. Bis zu dieser Zeit war Sonia, wie sie selbst sagt, den Werten und Interessen der Eltern gefolgt, ohne eine Alternative zu kennen oder in Betracht zu ziehen. Im Gymnasium traf sie nun auf Lehrpersonen, die aus Sonias Sicht im Gegensatz zu ihren Eltern liberale und geschlechteremanzipatorische Konzepte vertraten. Gleichzeitig freundete sie sich mit Peers an, die im Gegensatz zu ihr mehr Freiheiten in Ausbildungsentscheidungen, Freizeitgestaltung und Geschlechterperformanz hatten. Wie Maya konstruierte Sonia die Erfahrungen dieser neuen Subjektivitäten anhand des Topos der „indischen Familie“ - im Einklang mit dem Narrativ des „Lebens zwischen den Welten“.

Also, meine Eltern sind immer recht streng gewesen im Vergleich zu Eltern hier. Sie haben immer gesagt, dann sind deadlines, dann musst du zurück sein, dann darfst du etwas machen. Ich war vielleicht fünfzehn oder sechzehn gewesen, als ich zum ersten Mal mit meinen Freundinnen in die Ferien nach Spanien durfte. Es ist ein Riesenerlebnis gewesen. Du hast dich natürlich das erste Mal betrunken, das erste Mal - wirklich zum ersten Mal - richtig Spaß gehabt, hast die Eltern nicht immer dabei gehabt.“

Sonia kontrastierte in ihrer Erzählung dieses Teenager-Trips ihre strengen Eltern mit Individualismus, expressiver, weiblicher Körperlichkeit sowie Freiheit als Repräsentationen des Nicht-Indischen. Diese Semantik der "Strenge“ zeigt sich auch in den Erinnerungen an die innerfamiliäre Aushandlung ihrer Ausbildung und Erziehung.

Gymnasium, da habe ich gar keine Wahl gehabt, für meine Eltern ist klar gewesen, du wirst studieren, das ist wie vorgegeben gewesen. Und ich bin auch froh gewesen, weil wenn die Kinder jung sind, muss man sie fördern und ihnen gleichzeitig ein bisschen den Weg zeigen, das ist halt auch etwas sehr Indisches. Ich habe schon das Gefühl, dass man die Kinder ein bisschen pushen muss, weil viele gar nicht wissen, was sie wollen. Ich werde zu meinen Kindern sicher strenger sein als Schweizer Eltern.

Wie Maya konstruierte auch Sonia Kontrolle von Geschlechterperformanz und schulische Disziplinierung als intergenerationelle Aushandlung von „Indianness“ 
in einem „Leben zwischen den Welten“ - wenn auch die Bewertung sich unterscheiden mag. Die Eltern hatten strenge Geschlechternormen, „deadlines“ in der Freizeitgestaltung, und sie „pushten“ in der Ausbildung, insbesondere beim Übertritt ins Gymnasium.

\section{Exkurs: „Emigrationsfamilie“, Gender und Nation in transnationalen Diskursen der indischen Mittelschicht}

Sonia und Maya deuteten innerfamiliäre Idiome der sozialen Mobilität und Geschlechternormen auffällig oft als Ausdruck von „Indianness“. Diese Naturalisierung der ,indischen Migrationsfamilie“ ist, so argumentiere ich hier, einerseits auf diese assimilatorischen Subjektivierungslogik eines „Lebens zwischen den Welten" zurückzuführen. Anderseits kann sie nicht unabhängig von spezifischen Konstruktionen von Gender, Familie und Emigration in der indischen Mittelschicht aus der Zeit nach der Unabhängigkeit verstanden werden, in denen die sozialmoralischen Aushandlungen der transnationalen Familie stattfanden.

In der politischen Arena des Kolonialismus, der hinduistischen Reformbewegung und des frühen indischen Nationalismus im 19. Jahrhundert waren Geschlechterverhältnisse zu einem umkämpften Terrain unter transnationalen patriarchalen Vorzeichen geworden (Mani 1987; Chatterjee 1989; McClintock 1995). Ausschlag dafür gaben Kampagnen der britischen Kolonialadministration und reformhinduistischer Bewegungen gegen sogenannte Wittwenverbrennungen (sati). Mit dieser kulturpolitischen Reformbestrebungen verschob sich die koloniale Herrschaft zunehmend von einem Mittel zur ökonomischen Ausbeutung in ein Projekt der Zivilisierung, was den antikolonialen Widerstand in den aufstrebenden Mittelschichten antrieb. Während - wie Gayatri Spivak prägnant, aber vereinfacht formulierte - weiße Männer braune Frauen vor braunen Männern schützen wollten, versuchten wiederum braune Männer braune Frauen vor weißen Männern zu schützen (Spivak 1987). Mit der Verschärfung des Kolonialrassismus nach dem ersten Unabhängigkeitskrieg 1857 gewann die antikoloniale Imagination der indischen Nation als kulturelles Projekt einer neuen Mittelschicht zunehmend an Gestalt (Joshi 2001). Nach Partha Chatterjee basierte dieses Projekt auf der Aneignung des europäischen Konzepts der Nation unter kolonialen Vorzeichen (Chatterjee 1989, 1993). Angesichts der technologischen, ökonomischen und militärischen Stärke des Westens sollten diese Errungenschaften in einer sogenannten äußeren Sphäre angeeignet werden, um die Unabhängigkeit zu erreichen. Gleichzeitig erforderte der antikoloniale Nationalismus die identitäre Abgrenzung von westlichen Werten. Dies wurde in der sogenannten symbolischen und sozialen inneren Sphäre der Familie geleistet, in der die moralische und religiöse Überlegenheit einer antiken, indischen Zivilisation und spirituelle Wiege der Menschheit gepflegt werden sollte. 
The colonial state in other words, is kept out of the "inner" domain of national culture; but it is not as though this so-called spiritual domain is left unchanged. In fact, here nationalism launches its most powerful, creative, and historically significant project: to fashion a "modern" national culture, that is nevertheless not Western. (Chatterjee 1993:6)

Diese spirituelle Domäne wurde gemäß Chatterjee verkörpert durch eine „weibliche Respektabilität“, die sich durch Selbstdisziplin und hochkastige religiöse Werte sowohl von niederkastigen, indischen Frauen als auch von einer als dekadent geltenden, viktorianischen Weiblichkeit unterschied.

Mit der Unabhängigkeit Indiens 1947 wurde dieser antikoloniale Nationalismus - verkörpert durch die staatstragende obere Mittelschicht - zum Kern des Nehruvianischen Modernisierungsmodells. Westliche Standards in Industrialisierung, Forschung und Ausbildung sollten in einem teilsozialistischen Model übernommen werden, wogegen koloniale und kapitalistische Kultur, markiert durch dekadente Geschlechternormen und Konsumismus, weiterhin als das „Andere“ abgelehnt wurde. Innerhalb dieser Imagination von Nation, Familie und Gender nahmen Emigrantinnen und Emigranten, sogenannte Non-resident Indians (NRI) aus der Mittelschicht, die im Zuge des sogenannten Braindrains in den Westen auswanderten, eine zwiespältige Rolle ein. Die oft gut ausgebildeten Fachkräfte und Akademiker aus der Mittelschicht galten einerseits als „Fahnenflüchtige“, die sich aus eigennützigen Interessen der Aufgabe des Wiederaufbaus Indiens entzogen. NRI ließen sich von Konsum, fehlenden Familienwerten und sexueller Freizügigkeit im Westen korrumpieren und würden deshalb das kulturelle und religiöse Erbe und die Bindung zum Mutterland verlieren, so das Klischee. Gleichzeitig verfügten diese Auslandsinder über einen hohen sozialen Status, weil sie ökonomischen Erfolg und Reichtum im Westen repräsentierten. Paradigmatisch war die Narration der „indischen Emigrationsfamilie“ im Hindi-Kino bis in die 1980er Jahre von der dichotomen Gegenüberstellung des dekadenten, materialistischen Westens und des spirituell überlegenen und bescheidenen Indien geprägt. NRI erschienen in dieser narrativen Ordnung als moralisch orientierungslose „Abtrünnige“ oder als übermenschliche Verkörperungen von „Indianness“ (Thomas 1995; Brosius/Yazgi 2007). Exemplarisch dafür steht der Film „Purab aur Paschim“ („Ost und West“, 1970) von Manoj Kumar, in dem der Protagonist Bharat, Sohn eines indischen Widerstandskämpfers, nach London reist, um zu studieren. Dort wird er von Sharma empfangen, einem Freund seines Vaters, der sich um ihn kümmern soll. In der dominanten Lesart erscheinen Sharma und die Angehörigen von dessen Familie als national-moralische Grenzgänger, die von materiellen Aspirationen getrieben werden und jegliche kulturellen Werte verloren haben: Während sein Sohn als halbschlauer, clownesker Pseudo-Hippie dargestellt wird, erscheinen seine Tochter Preeti und seine britisch-indische Gattin als zigarettenrauchende Frauen in Miniröcken. Sharma selbst ist ein melancholischer Nostalgiker - ein 
verwestlichter indischer Mann in der Tradition der antikolonialen Satire des babu (z. B. Sartori 2009). Während Preeti und ihre Mutter die kulturellen, religiösen und familiären Werte und Praktiken der Nation verkörpern sollten, hat es Sharma versäumt, deren Ehre zu beschützen, so die dominante Lesart. Das geradezu mythische Dilemma zwischen „Indien“ und dem „Westen“ wird auf die Spitze getrieben, als Bharat sich in Preeti verliebt. Die Spannung wird aufgelöst, als Bharat die Aufgabe von Sharma übernimmt, die Ehre von dessen Tochter Preeti wiederherzustellen, indem er sie nach Indien bringt, wo sie ihre westlichen Laster ablegt und sie einander heiraten. In der Narration des Kassenschlagers „Purab aur Paschim“ wurde also die moralische Ambivalenz des Indiens der 1970er Jahre gegenüber dem Westen unauflösbar in die „indische Emigrationsfamilie“ eingeschrieben.

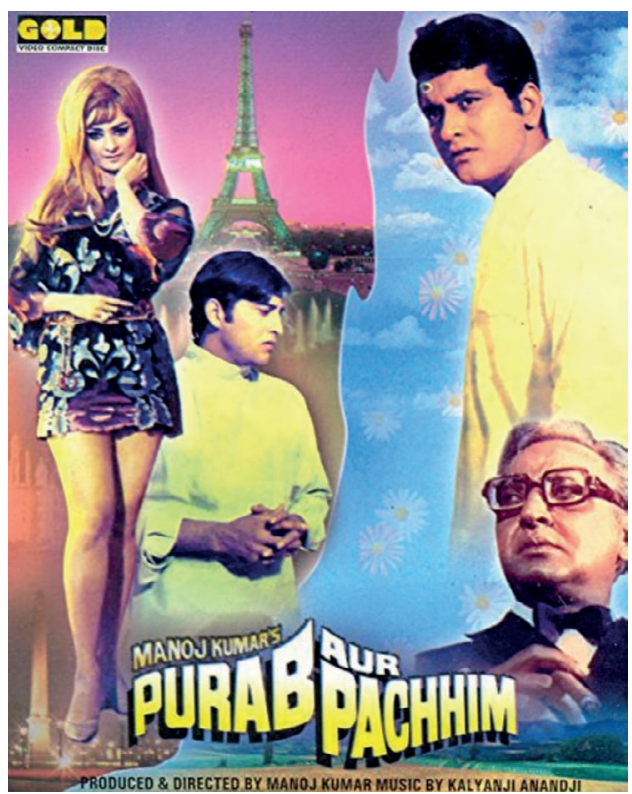

Abbildung 10: Postkoloniales, mythisches Drama zwischen "Indien“ und dem "Westen" an der Grenze von Gender, Klasse und Emigration. Cover Video-CD von „Purab Aur Paschim“ aus dem Jahr 1970 (Quelle: Autor)

National-moralische Narrative um Migration, Familie und Gender - wie sie in „Purab Aur Paschim“ verhandelt wurden -, bieten Einsichten darüber, mit welchen Aspirationen und innerhalb welcher Dilemmata indische Migrant_innen aus der Mittelschicht in dieser Zeit ihre familiären Mobilitätsprojekte verhandelten. Es ist in diesem Zusammenhang interessant, dass bei den größtenteils hochqualifizierten Migrant_innen, die ab 1965 in die USA reisten, schon von Anfang an die Fragen der kulturellen Kontinuität und der sozialen Mobilität im Zusammenhang 
mit der „zweiten Generation“ verhandelt wurde. Die Imagination des dekadenten, moralisch korrumpierten Westens war im Bewusstsein der NRI verankert und wurde schon früh von hindunationalistischen Organisationen befördert. In Ratgebern thematisierten sie den richtigen Umgang mit der „zweiten Generation“ und überlagerten dazu den Mythos der moralischen Reinheit der hinduistischen Familie mit dem US-amerikanischen Narrativ des „Lebens zwischen den Welten“ (Rajagopal 2001). In den indischen Mittelschichtsfamilien in den USA entwickelte sich eine culture of achievement, die gleichzeitig den individualistischen Leistungsprimat repräsentierte („du kannst es schaffen, wenn du hart arbeitest“) und ethnisch begründet wurde („wir Inder_innen arbeiten hart“) (Purkayastha 2005:97 ff.). Diese culture of achievement ist einerseits darauf zurückzuführen, dass Bildung historisch die fundamentale Strategie der indischen Mittelschichten war und ist, um sich sozioökonomisch zu positionieren und soziokulturell zu definieren (Joshi 2001). Andererseits war im indischen Narrativ über die „Emigrationsfamilie“ der Erfolg der transnationalen Mobilitätsstrategie die einzige Kompensation für die kulturelle Korruption im dekadenten Westen. Die indische community gewann mit diesem Bildungsstreben im Umfeld struktureller Diskriminierung in den USA zudem eine spezifische Konnotation als model minority, mit der sich indische Migrant_innen von anderen, weniger erfolgreichen Minderheiten abzugrenzen vermochten. ${ }^{41}$ Die wenigen Forschungen über die Diskurse und Lebenswelten von Emigrationsfamilien dieser Zeit deuten an, dass innerhalb transnationaler Netzwerke ab den 1960er Jahren wirkungsmächtige, wenn auch lose Normen sozialer Mobilität, sowie Ängste bezüglich der Erziehung der „zweiten Generation“, der Dekadenz des Westens und eines damit verbundenen „Kulturkonflikts“ existierten. Diese waren aber nicht ethnischen oder religiösen Ursprungs, sondern entwickelten sich in der Aushandlung einer schichtspezifische Statuslogik im Kontext einer postkolonialen Emigration unter den lokalen sozialstrukturellen, politischen und diskursiven Bedingungen der Inkorporation von Migration und „Rasse“ in den ehemaligen imperialen Zentren.

Indische Familien in der Schweiz stammten größtenteils auch aus der Mittelschicht und waren international stark vernetzt. Es ist daher wahrscheinlich, dass

41 Die culture of achievement (Purkayastha 2005:89ff.) in den indischen Mittelschichtsfamilien in den USA basiert auf der Übernahme des meritokratischen Ethos des liberalen Diskurses. Dies erlaubte ihnen, sich von den Migrant_innengruppen der Latinos sowie von afroamerikanischen und indigenen Gemeinschaften abzugrenzen, die schlechter ausgebildet sind und die im hegemonialen US-Diskurs anhand von Stereotypen fehlender Leistungsbereitschaft, Kriminalität oder gar mangelnder Intelligenz stigmatisiert werden. Dadurch wurde die indische Gemeinschaft als model minority konstruiert, die die liberale Ideologie der Meritokratie bestätigt und strukturelle Erklärungen der Diskriminierung disqualifiziert. Innerhalb der community wird diese Zuschreibung wiederum als culture of achievement ethnisiert. 
transnationale Narrative der ,indischen Migrationsfamilie“ in ihrer Aushandlung von Kontinuität und Wandel, Zugehörigkeit und Abgrenzung eine Rolle spielten. Jedoch wurden sie angesichts der individuellen Migrationsbiografien, der soziostrukturellen und historischen Bedingungen der indischen Migration in die Schweiz und angesichts der strikten sozioräumlichen und diskursiven Konstruktion der „Migrationsfamilie“ spezifisch gerahmt und befördert.

Vor diesem Hintergrund lässt sich verstehen, warum Maya und Sonia, gerade im provinziell-assimilatorischen Kontext der Schweiz die Erziehung ihrer Eltern bezüglich Geschlechternormen und Ausbildung als Spannung zwischen der schweizerischen Öffentlichkeit und der „indischen Migrationsfamilie“ wahrnahmen. Trotz der ähnlichen sozialen Lagerung haben sie jedoch sehr unterschiedliche Strategien im Umgang damit entwickelt. Da Sonia die Erfahrung des Andersseins innerhalb des familiären Idioms interpretierte und die elterlichen Erwartungen größtenteils internalisiert hatte, nahm Sonia im Gegensatz zu Maya kaum einen „Kulturkonflikt“ wahr. Stattdessen konnte sie sich im Rahmen des familiären Idioms einen Freiraum erarbeiten, ohne sich dem Willen der Eltern zu widersetzen. Diese Aushandlungsdynamik, die sich zum ersten Mal im Urlaub mit ihren Freundinnen gezeigt hatte, erlaubte ihr zunehmend, eine eigene Position im Rahmen des familiären Projektes der Mobilität einzunehmen: Während des Gymnasiums begann der Vater Sonia hartnäckig zu drängen, Informatik zu studieren, weil diese Branche während der 1990er Jahre in Indien als prestigereich und zukunftsträchtig galt. Sonia setzte sich jedoch durch, spezialisierte sich in Banking, da sie aus ihrer Sicht über eine Begabung für Zahlen verfügte. Trotz der Weigerung gegenüber dem Vater, Informatik zu studieren, wurde Sonia also der familiären Statusorientierung gerecht, ja, konnte diese angesichts des zunehmenden Glanzes der Bankenwelt ab den 1990er Jahren sogar dem Wandel der Zeit anpassen. Sie war dabei keinesfalls den elterlichen Direktiven ausgeliefert, sondern verschaffte sich innerhalb des familiären Projekts zunehmend Freiräume und eine eigene Position. Gleichzeitig hatte Sonia das intergenerationelle Projekt der Mobilität einer subtilen geschlechterspezifischen Reinterpretation unterzogen. So bedeutete ihre Karriere als Investmentbankerin aus ihrer Sicht nicht nur eine Reproduktion familiärer Statusorientierung, sondern auch eine Anknüpfung an einen Emanzipationsdiskurs, den sie sich im Gymnasium angeeignet hatte:

Also ich denke, in der Schweiz wirst du wirklich dazu erzogen für dich selbst zu schauen, also, ich weiß auch mit fünfzig, wenn irgendetwas ist, kann ich selbst zu mir schauen, also das, das können vielleicht nicht viele Inder von sich behaupten oder viele Cousinen oder Cousins von mir, also, sie sind so nicht selbstständig zum Teil, müssen eine Dienerin haben, die kocht und putzt, müssen einen Mann haben, der verdient, müssen ein Auto haben mit Chauffeur, sonst können sie nicht auf die Straße, also weißt du, aber das sind auch ein bisschen Probleme vom Geld, das sind auch ein bisschen die oberen 
Schichten, die ich da erwähne [...] ich denke, in der Schweiz wirst du viel tougher, wirst du viel mehr dazu trainiert, für dich selbst zu schauen.

Sonia konnte sich aus ihrer Sicht in der Schweiz - im Kontrast zu ihren nicht berufstätigen Cousinen in Indien - als selbstständige und „moderne indische Frau“ entwickeln, wie ich in Kapitel 5 und 6 weiter erläutern werde (Radhakrishnan 2008; Thapan 2004). Während zwar Sonias Eltern die Arbeitstätigkeit von Sonia förderten, sieht sie selbst in ihrer Karriere auch eine spezifische Eigenheit ihrer Migrationsbiografie. Gegenüber ihren indischen Peers geht ihr zwar eine gewisse indische Authentizität ab. Stattdessen kann sie sich dank der Migration als erfolgreiche, selbstständige Bankerin abgrenzen und behaupten.

Eine ähnliche Dynamik zeichnete sich bei Sonia in der Frage der familiären Reproduktion und der Aushandlung von Ehe, Liebe und Sexualität ab. Während des Gymnasiums hatte Sonia eine Liebesbeziehung zu einem Schweizer Klassenkameraden. Nach einem Jahr brach jedoch Sonia diese Beziehung ab, weil sie den Kontakt zu Rahul, einem indischen Kindheitsfreund, intensiviert hatte. Nach mehrjährigem E-Mail-Kontakt und einer mehrjährigen Fernbeziehung heirateten Sonia und Rahul noch während ihres Studiums. Damit entsprach Sonia zweifellos dem Wunsch ihrer Eltern nach einer standesgemäßen, endogamen Heirat, zumal sich die Familien kannten und Rahul der gleichen ethnischen Gemeinschaft angehörte. Dies vergrößerte Sonias Spielraum in der Aushandlung vorehelicher Mobilität. So durfte sie ihren zukünftigen Ehemann vor der Verlobung und vor der Hochzeit jeweils mehrere Wochen in den USA besuchen, bevor er eine Stelle als private banker in der Schweiz erhielt.

Und dann habe ich extrem Mühe gehabt mit meinen Eltern, das zuerst durchzubringen. Oh nein, du bist nicht einmal verlobt, bist nicht einmal verheiratet, jetzt gehst du einfach zu deinem Freund, übernachtest zwei, drei Wochen dort. Oh nein, da kann ja vieles passieren. Es hat ziemlich Überzeugung gebraucht, aber dann haben sie auch gefunden: Geh und genieße das Leben, du bist ja sicher.

Sonias Aushandlung von Beruf und Heirat innerhalb des familiären Idioms bewirkt, dass die Mutter die sexuelle Norm der Monogamie („Du bist ja sicher“) gegenüber derjenigen vorehelicher Jungfräulichkeit höher gewichtete. Die Aufrechterhaltung der moralischen Beziehungen und die Kontinuität des transnationalen Familienprojektes der Statusrehabilitation erforderte aus der Sicht der Eltern diese Anpassung der kulturellen Normen. Für Sonia wiederum erlaubte dieser innerfamiliäre Deal sowohl die Erfüllung der elterlichen Erwartungen als auch die Gestaltung eines emanzipatorischen Spielraums. Darin deutet sich bei ihr eine Subjektposition an, mit der sie sich Ende der 1990er Jahre als „moderne indische Frau“ repräsentieren kann, die geschickt im „Leben zwischen den Welten“ navi- 
giert, indem sie einerseits Karriere macht und gleichzeitig Familienwerte pflegt (s. Kapitel 5 und 6).

Trotz dieses subtilen Balanceakts vermochte sie die Widersprüche des Assimilationismus nicht vollständig aufzuheben, wie ich im Folgenden diskutieren möchte.

\section{4 "ARRANGIERTE HeIRAT“ UND DER ASSIMILATORISCHE WILLE ZUM WISSEN}

Unter ihren Schweizer Peers galt Sonia während des Gymnasiums als emanzipierte Seconda, die stets versuchte, gegenüber ihren strengen Eltern Urlaubsreise, Clubbing und anderes übliches Freizeitverhalten durchzusetzen. Die Heirat mit Rahul stieß deshalb auf Unverständnis bei vielen ehemaligen Schweizer Schulkolleginnen und -kollegen. Viele sahen in Sonias Heirat eine „arrangierten Ehe“, die sie selbst nicht wollte. Diese Gerüchte hielten sich, obwohl Sonia ihre Partnerwahl stets als romantische, schicksalshafte Liebesgeschichte erzählte:

Seine Schwester ist mit mir in die Schule, und wir haben uns jedes Jahr gesehen in den Ferien, im Sommer, und es ist irgendwie immer eine Chemie dagewesen zwischen uns. Aber wir haben nie irgendetwas gesagt, der andere hat das Gefühl gehabt, oh, sie liebt mich sowieso nicht, und ich habe auch das Gefühl gehabt, er will nichts von mir. Und dann ist irgendwie nichts daraus geworden, er hat damals eine Beziehung gehabt, er ist damals in London gewesen, er hat eine oder zwei Beziehungen gehabt und ich habe da eine Beziehung gehabt und da haben wir gefunden - dann war es irgendwie aus den Augen aus dem Sinn gewesen. Dann sind wir in Südeuropa an einer Hochzeit von einem gemeinsamen Freund gewesen, und dort hat es gefunkt. Also wir haben schon immer wieder ein bisschen gechattet und gemailt und so. Und ich habe schon das Gefühl gehabt, es könnte etwas sein. Dort hat er mich eingeladen gehabt zum Essen, und dort ist es dann passiert, dass er mich gefragt habe, ob ich ihn heiraten möchte. Das werde ich nie vergessen, das ist ein extrem schöner Moment gewesen.

Dieses romantische Narrativ wurde sowohl von Schweizer Peers als auch in der lokalen indischen Gemeinschaft, von anderen schweizerisch-indischen Second@s, infrage gestellt. Und auch ich war nach dem biografischen Interview mit Sonia mit der Frage beschäftigt, ob Sonia mir die Wahrheit erzählt hatte oder ob ihre Heirat nicht doch arrangiert war. Eine ethnografische Begegnung warf schließlich ein neues Licht auf diese (In-)Fragestellung: 
Einige Monate nach dem Interview mit Sonia traf ich mich mit der 37-jährigen Politologin Sushma in einer Bar. Wir sprachen über die Forschung, über ihre Familie, über ihre Jobsuche. Als wir nach zwei Stunden nach draußen gingen und uns verabschieden wollten, brachte Sushma plötzlich das Thema der arrangierten Heirat in der indischen Gemeinschaft auf. Sie war sich sicher, dass Sonia, die sie auch kannte, „verheiratet“ worden sei. Ihre Eltern hätten doch „jemanden für sie gesucht“. Sie habe ja noch einen Schweizer Freund gehabt, den sie dann habe verlassen müssen. Sushma betonte vehement, dass sie sich nie würde „verheiraten lassen“. Sie könne sich nicht vorstellen, dass jemand, die oder der hier aufgewachsen sei, sich freiwillig aufeine „Verheiratung“ einlasse. Natürlich könne man etwas den Eltern zuliebe machen, aber heiraten sei doch für das ganze Leben. Es erstaunte mich langsam, dass Sushma eine so normative dichotome Position in Bezug auf die Unterscheidung „Liebesheirat" oder „arrangierte Heirat" einnahm, um sich so stark von Sonia abzugrenzen. Denn auch sie kannte die intergenerationellen Aushandlungen von Liebe und Sexualität als Tochter in der, ,indischen Migrationsfamilie“. Hatte sie doch selbst aus Unsicherheit darüber, wie ihre Mutter reagieren würde, die Liebesbeziehung zu einem Schweizer Arbeitskollegen einige Monate verschwiegen. Und als sie einige Jahre danach zu ihrem Freund ziehen wollte, musste sie mit der Mutter lange diskutieren, um deren Einverständnis zu erlangen. Schließlich stellte auch Sushmas Mutter - wie Sonias Mutter - die Monogamie über die voreheliche Jungfräulichkeit und ließ ihre Tochter (aus-)ziehen.

Das moralisierende Gespräch mit Sushma und die performative Positionierung darin offenbarten, dass das Misstrauen gegenüber Sonias Heiratserzählung und die Gespräche anderer darüber für meine Forschung vielleicht aussagekräftiger waren als die Beantwortung der Frage, ob Sonia nun eine arrangierte Heirat hatte oder nicht. Was bedeutete es denn, dass unter Schweizer Peers und innerhalb der lokalen indischen Gemeinschaft eine solche Gerüchteküche darüber existierte, wie „Inder_innen der zweiten Generation“ heirateten? Was bedeutete es, dass diese Frage sowohl in der Schweizer Öffentlichkeit als auch von Angehörigen der „Zweiten Generation“ mit der dichotomen, moralisch aufgeladenen Kategorisierung „Liebesheirat“ und „arrangierte Heirat“ ausgehandelt wurde? Und was bedeutete es, dass nie jemand zugeben würde, „verheiratet“ worden zu sein, respektive dies $\mathrm{zu}$ tolerieren?

Einen Ansatzpunkt zum Verständnis dieser neuen Fragen lieferte ein Interview mit einer anderen Gesprächspartnerin, die vor etwa zehn Jahren explizit eine „arrangierte Heirat" einging, in der ihre Eltern mögliche Kandidaten vorschlugen, aus denen sie dann einen auswählte. Sie erzählte mir, dass sich viele ihrer Schweizer Freundinnen aus Enttäuschung von ihr abwandten, als sie davon erfuhren. Besonders verletzend für sie war, dass dieser Kontaktabbruch geschah, ohne dass sie selbst ihre Perspektive erklären konnte. Das Narrativ der „arrangierten Heirat", das die Migrationsfamilie in Kontrast zum schweizerischen Individualis- 
mus und das „orientalische Patriarchat“ als Gegensatz zur emanzipierten Schweiz darstellte, schloss den affektiven und ethischen Raum des freundschaftlichen Dialogs aus. ${ }^{42}$ Durch die "arrangierte Heirat" wurde sie in den Augen ihrer Freundinnen zu einem anderen Menschen, zu einer inkommensurablen „Fremden“. Diese krasse Sanktionierung deutet die Macht an, die dem Topos der ,arrangierten Heirat" in der moralischen Ordnung des Assimilationismus innewohnt. Die Gerüchte über die angeblich „arrangierte Heirat" Sonias dienten demnach vielen Akteuren als Plattform, damit sie sich selbst im Spektrum des „Eigenen“ und des "Anderen“ positionieren konnten: Sushma positionierte sich eindeutig innerhalb der Dichotomie von „Liebesheirat" und „arrangierte Heirat", die der lokale assimilatorische Diskurs zur Verfügung stellt. Ihre Selbstrepräsentation, sie würde sich nie „verheiraten“ lassen, ermöglicht ihr eine Subjektposition, die sie innerhalb des schweizerischen Kontexts als assimiliert, modern und selbstständig erscheinen liess. Die Schweizer Öffentlichkeit und Sonias ehemalige Schulkolleginnen und -kollegen wiederum deuteten Sonias Heirat in einem Narrativ, das die emanzipierte, individualistische Schweiz gegenüber der „patriarchalen Migrationsfamilie" als fortschrittlich und moralisch überlegen darstellte. In diesem geschlossenen Diskursraum spielten alternative Selbstrepräsentationen keine Rolle. Positionen jenseits der Dichotomie waren kaum vorstellbar und die hegemoniale moralische Ordnung blieb intakt.

Die dichotome Imagination zwischen "Liebesheirat" und „arrangierter Heirat" einerseits und die moralische Entrüstung gegenüber einer möglichen „arrangierten Heirat"waren im Rahmen des assimilationistischen Diskurses bis in die 1990er Jahre unhinterfragt und wirken gerade im Zusammenhang mit muslimischen und tamilischen Angehörigen der „Zweiten Generation“ bis heute weiter. In der assimilatorischen Subjektivierungslogik war es für „Inder_innen der zweiten Generation" kaum möglich, diese Dichotomie grundlegend infrage zu stellen. Während Sushma die „Kulturkonfliktthese“ übernommen hatte und sich öffentlich als modern positionierte, verwendete Sonia ein romantisches Narrativ der Liebesheirat. Beide bestätigten damit das hegemoniale, ethnisierende Erklärungsschema und mussten die moralischen Dilemmata austragen, die in die intergenerationelle As-

42 | Zur hegemonialen Konstruktion von "arrangierten Hochzeiten" in den USA siehe Shah (2004). Zur Aushandlung von elterlichen und hegemonialen Erwartungen an Partnerschaften siehe Purkayastha (2005:101 ff.) und Shankar (2008:157 ff.). Die Topoi und Aushandlungsweisen sind mit den hier beschriebenen vergleichbar. Jedoch strukturiert die Größe der südasiatischen Diaspora die ganze Thematik um Sexualität und Partnerschaft auf eine andere Weise. Einerseits existiert eine größere soziale Kontrolle, insbesondere von männlichen Angehörigen der "zweiten Generation“ gegenüber Frauen. Andererseits existieren größere Auswahl auf dem Partnerschaftsmarkt und größere Aushandlungsmöglichkeiten, um Ideale und Normen von Kindern, Eltern und der Dominanzgesellschaft in Bezug auf Partnerwahl zu verbinden. 
similationsforderung eingeschrieben sind. Erst in den letzten Jahren eigneten sich schweizerisch-indische Second@s öffentlich Repräsentationsweisen an, um dichotome Kategorisierungen, Moralisierungen und Ethnisierungen in Bezug auf Heirat und Ehe zu kritisieren. Nicht nur hatten sie durch ihre indischen Verwandten neue Perspektiven und Einblicke auf zeitgenössische Heiratsverhandlungen gewonnen, sondern auch die Präsenz von Partnerschaftsvermittlungen und insbesondere von Internet-Beziehungsbörsen in der Schweiz hatten die eindeutige Überlegenheit westlicher Liebesheiraten versus indischer arrangierten Heiraten ins Wanken gebracht (Illouz 1997). So reflektierte Sunil, ein 39-jähriger Eigentümer eines Musiklabels, der als Kind eines indischen Psychologen und einer schweizerischen Pflegerin aufwuchs, über die Heiratspraktiken seiner Cousins und Cousinen in der Schweiz und in Indien. Aus seiner Sicht existiere ein breites Kontinuum an Zwischen- und Mischformen von „arrangierten“ und „Liebesheiraten“, innerhalb dem die sozialen und emotionalen Bedürfnisse der Heiratenden und ihrer Eltern intergenerationell ausbalanciert würden. Innerhalb der innerfamiliären moralischen Verflechtung versuchten Eltern wie Kinder trotz asymmetrischer Machtbeziehungen die unterschiedlichen Erwartungen gegenseitig zu erfüllen. Diese nicht-dichotome Perspektive auf sogenannte ,arranged love marriages", die gerade in der indischen urbanen Mittelschicht verbreitet sind, wirft ein anderes Licht auf Sonias Partnerwahl.

The inspired indigenous solution to the dilemmas of romance and mate-selection - the contradiction between the impetuousness of youth and the wisdom of age, modernity and tradition, freedom of choice and social conformity - is the institution of "arranged love marriage", in one of its two well-recognized forms. Either a marriage is parentally arranged, and the engaged couple are thereafter allowed to go out together in a well-supervised approximation of romantic courtship; or else a young man and woman (appropriately matched by all the useful criteria) first fall in love, and then bring their parents into the picture to conduct the marriage as for a proper "arranged marriage". (Uberoi 2006:36)

Jenseits der Dichotomie „Liebesheirat" versus „arrangierte Heirat" hat Sonias Heiratsentscheidung wahrscheinlich in einem langjährigen Prozess stattgefunden, der elterliche Erwartungen und individuelle Entscheidungen, sowie familiäre Statuskriterien und romantische Liebesvorstellungen verband. Dies würde auch erklären, warum Sonia in ihrer Narration gleichzeitig eine Liebesheirat und eine standesgemäße Heirat beschreiben kann - weil es für sie trotz möglicher Widersprüche und Bedenken allenfalls tatsächlich beides war. In einer assimilationistischen Logik ließen sich diese transnationalen subjektiven Erfahrungen jedoch kaum legitim äußern. Stattdessen generierten die öffentliche Gerüchteküche, der politische Diskurs wie auch das wissenschaftliche Interview einen „Willen zum 
Wissen“, für den die reproduktive Grenze zwischen der "Migrationsfamilie“ und der Öffentlichkeit in bester fremdenpolizeilicher Manier zu einer gefährlichen nationalmoralischen Grenze zwischen „arrangierter Heirat" und „Liebesheirat“, „Eigenem" und „Fremden“, zwischen Wahrheit und Lüge wurde.

\subsection{Raj: Der abwesende Vater Und die „SUChe Nach DEN WURZELN"}

In den Subjektivierungsprozessen von Maya, Sonia und Aftab hat die assimilatorische Subjektivierungslogik die „indische Familie“ als prägenden Topos und als soziale Arena hervorgebracht. Die soziomoralischen Aushandlungen in der Familie gewannen ihre Bedeutung und Relevanz zu einem beträchtlichen Teil im Narrativ eines „Lebens zwischen den Welten“. Gleichzeitig habe ich gezeigt, wie Maya, Sonia und Aftab darin Räume, Lücken und Widersprüche nutzten, um alternative Subjektivierungsprozesse anzustoßen.

Der folgende Fall von Raj, einem 49-jährigen Pflegefachmann, unterscheidet sich dahingehend von Mayas, Sonias und Aftabs, als er seine Biografie nicht im Narrativ des „Lebens zwischen den Welten“ aushandelte. Trotzdem hat die assimilatorische Subjektivierungslogik seine Biografie geprägt. Rajs indischer Vater und seine Schweizer Mutter ließen sich früh scheiden und er wuchs unter prekären sozioökonomischen Bedingungen auf. In seiner Familiensituation wurden kaum kulturelle Praktiken vermittelt, weshalb er auf assimilatorische Anrufungen kaum intrinsische Erfahrungen oder Identifikationen aus der ,indischen Migrationsfamilie" entgegenhalten konnte. Stattdessen verknüpften sich für Raj Rassismuserfahrungen, Prekarität und die Abwesenheit des Vaters zu einer fluiden Erfahrung des Andersseins.

Raj wurde als zweites von drei Kindern einer Schweizer Hausfrau und eines indischen Maschinenmechanikers geboren. Rajs Vater stammt aus der unteren Mittelschicht aus einem ärmlichen Quartier in Kolkata, seine Mutter aus einer kleinbürgerlichen Schweizer Beamtenfamilie. Der Vater kam in den 1960er Jahren als junger Mann mit 23 Jahren aus Indien in die Schweiz, weil er mit einigen indischen Freunden zusammen von einer Schweizer Firma in der Maschinenindustrie rekrutiert worden war. In Rajs familienbiografischer Interpretation war sein Vater für seine Mutter der „indische Märchenprinz“, der ihr dazu verhalf, aus dem kleinbürgerlichen Leben auszubrechen. Binationale Beziehungen waren damals sehr verpönt und auch politisch sanktioniert, was sich etwa darin zeigt, dass Schweizer Frauen, die Ausländer heirateten, angesichts der patriarchalen Staatsbürgerschaftstradition der Schweiz noch bis 1953 ausgebürgert wurden (Studer et al. 2008). Und wie die damalige Verachtung für flirtende Italiener - etwa auch im Assimilationsratgeber Marc Virots (s. Kapitel 2) - andeuten mag, überschritten Frauen, die Beziehungen mit südländischen oder orientalischen Männern führten 
oder führen wollten, eine nationalmoralische Grenze. Gleichzeitig kündigten sich jedoch auch 1968 und der Aufbruch der europäischen Jugend an, der eng verknüpft war mit neuen Sexualitäts- und Geschlechternormen sowie mit einer orientalistischen Faszination für indische Weisheit und Spiritualität. Jedoch, so Raj, folgte auf die binationale Romanze der harte Alltag einer fünfköpfigen Familie. Seine Mutter hatte als Familienfrau kaum Zeit für ihre eigene Selbstverwirklichung. Rajs Vater arbeitete oft im Ausland auf Montage, um genügend Geld für den Lebensunterhalt zu verdienen. Er musste sich nach seinen regelmäßigen Abwesenheiten immer wieder in die Familie „einklinken“, wie Raj es nennt. Dies war stets ein krisenhafter Moment für die Familie und klappte oft nicht. Vermehrt kehrte der Vater, auch wenn er in der lokalen Fabrik arbeitete, wegen seiner zunehmenden Alkoholsucht am Abend nicht nach Hause zurück. Raj erinnert sich noch sehr plastisch an den leeren Stuhl am allabendlichen Esstisch und an seine Scham und Überforderung, als er den Vater in dessen Stammkneipen abholen musste. Obgleich der Vater zwar auch oft mit indischen Freunden verkehrte und die ganze Familie mehrmals nach Indien reiste, erinnert sich Raj an seinen Vater nicht primär anhand von als „indisch" markierten Praktiken oder Eigenschaften, sondern durch seine Abwesenheit und den regelmäßigen Streit der Eltern. In den frühen 1980er Jahren, als Raj zwölf Jahre alt war, ließen sich die Eltern scheiden und der Vater zog aus. In dieser schwierigen Zeit erlebten Raj und seine Geschwister in der Öffentlichkeit immer wieder rassistische Ausgrenzungen. Neben Beschimpfungen in der Nachbarschaft waren es prägende Erlebnisse in Institutionen wie der Schule oder bei Spielen des Fußballclubs. Die Mischung aus Rassismuserfahrung und Prekarität steigerten Rajs Wunsch, bei seinen Peers anerkannt zu werden. Mit Bubenstreichen, Schlägereien und als Leistungsträger im Fußballclub konnte er sich „natürliches Kapital“ aneignen und sich in der maskulinen Teenager-Hierarchie in seinem Quartier und seiner Szene positionieren (Juhasz/Mey 2003:318). Durch die Solidarität in dieser subkulturellen Gemeinschaft konnte Raj - im Gegensatz etwa zu seiner Schwester - die Ausgrenzungen bewältigen. Obwohl ihm seine Familie kaum kulturelle, ökonomische oder soziale Ressourcen vermittelt hatte, schaffte es Raj schließlich Mitte der 1990er Jahre durch Bildung, Willen, Kreativität und dank seines subkulturellen Sozialkapitals das Milieu seiner Familie zu verlassen und soziale Anerkennung zu gewinnen: Er schloss eine Ausbildung zum Pflegefachmann ab, war in der linksalternativen Szene verankert und lebte in einer Beziehung mit der Pflegefachfrau Rosa. Nach dem Millenniumswechsel kriegte das junge Paar einen Sohn und eine Tochter. Obwohl sich die Beziehung zum Vater gebessert hatte, war Raj froh, nach den zerrütteten Familienverhältnissen, in denen er aufgewachsen war, nun eine „eigene Familie“ zu haben. In seiner Rolle als Vater war ihm umso wichtiger, dass er seinen Kindern mehr Geborgenheit, Anleitung und Unterstützung bieten wollte, als seine Eltern ihm und seinen Geschwistern gegeben hatten.

Die sozioökonomische Prekarität, die Scheidung der binationalen Eltern und die Rassismuserfahrungen hatten sich in Rajs Erinnerungen von Jugend und Kind- 
heit zu einer diffusen Erfahrung des Andersseins und einer damit verbundenen Orientierungslosigkeit verbunden. Maya - im Vergleich - rationalisierte die Erfahrung des Andersseins in der Urszene des Kindergeburtstages bei sich zu Hause und später durch die Konflikte bezüglich Besuch von Parties und Schulleistungen eindeutig in Bezug auf ihre „indische Migrationsfamilie“. Ihr Anderssein beruhte aus ihrer Sicht auf der „realen“ kulturellen Differenz ihrer Familie von angeblichen Schweizer Werten in Bezug auf Erziehung und Geschlechternormen. Wenn auch Rajs Name, seine dunkle Hautfarbe und die schwarzen Locken assimilationistische Anrufungen provozierten, ließ Rajs Familienleben keine Aneignung des hegemonialen Deutungsmusters des „Lebens zwischen den Welten“ zu, um seine subjektiven Erfahrungen des Andersseins sinnhaft zu rahmen. Denn in seiner Familie fand kaum ein Transfer kultureller Praktiken oder kulturellen Wissens statt, das in der öffentlichen Wahrnehmung oder in der Familie als „indisch“ konnotiert war. Nicht nur konnte er auf stereotypen Fragen zu Indien kaum antworten geschweige, denn intrinsische Erfahrungen entgegenhalten. Auch gegenüber den indischen Gemeinschaften nahm er nur eine illegitime Zugehörigkeit ein. Wie viele Kinder binationaler Paare, mit einem Elternteil aus Indien, bezeichnete er sich als „Halbinder“ - in Abgrenzung zu „Ganzindern“. Wie eine Gesprächspartnerin, selbst Tochter aus einer binationalen Partnerschaft, mir gegenüber betonte, sollte ich „Halbinder_innen“ und "Ganzinder_innen“ keinesfalls gemeinsam in einer Forschung untersuchen. Diese seien wie Äpfel und Birnen, nicht zu vergleichen. In dieser verbreiteten naturalisierten Semantik, die auf die rassenanthropologische Angst vor Hybridität zurückgeht, ist eine tief verankerte Erfahrung illegitimer Zugehörigkeit von „Halbinder_innen“ in der lokalen indischen Gemeinschaft zu spüren, weil sie nicht über sprachliche Kompetenzen und Netzwerke verfügten oder Anforderungen an kulturelles Wissen oder Einhaltung von Normen nicht erfüllten. Vor dem Hintergrund dieser illegitimen und „prekären Zugehörigkeit“ (Mecheril 2003) kristallisierte sich bei Raj im Verlauf seiner Jugend angesichts des omnipräsenten Rätsels seiner Herkunft die Sehnsucht nach dem „anderen Teil in ihm" heraus, wie er es nennt. Und er begann seine diffusen Erfahrungen des Andersseins - neben der Suche nach einem guten Leben und einer „eigenen Familie" - auch durch die Auseinandersetzung mit der Herkunft seines Vaters auszuhandeln. In ihrer Arbeit über koptische Kinder von binationalen Paaren in der Schweiz hat Cordula Weißköppel argumentiert, dass Nicht-Schweizer Väter oft als innerfamiliäre „Andere“ konstruiert werden und also solche dann anhand spezifischer Neutralisierungsstrategien in die Familiendynamik eingebunden werden können (Weißköppel 2011). Da Rajs Vater aber kaum anwesend war und kaum kulturelle Praktiken vermittelte, die als „indisch“ gedeutet werden konnten, blieben für Raj der abwesende indische Vater und auch Indien ein Mysterium. Während sich also für Maya, Aftab und Sonia die assimilatorische Anrufung einer Ethnisierung der "Migrationsfamilie“ affirmativ einschrieb, hinterließ sie bei Raj das Bedauern, gerade „keine indische Familie“ zu haben, ja das Gefühl eines „Mangels 
an Kultur", das sich in der Figur des abwesenden indischen Vaters verdichtete. ${ }^{43}$ Durch die existenzielle Unfähigkeit, die äußere Anrufung des Andersseins zu erwidern, entstand eine nostalgische Sehnsucht nach dem „Anderen“, als das er im hegemonialen Diskurs galt.

Zwei Indienreisen, die Raj mit seinen Eltern und Geschwistern gemacht hatte, waren ein konstitutiver Anker seiner transnationalen Lebenswelt. Dadurch erhielt seine Erfahrung des Andersseins in der Schweiz ein sinnliches und emotionales Fundament, in dem sich ein nostalgisches Begehren entwickeln konnte. Für ihn baute sich die indische Familie - wie das Mysterium des „indischen Vaters“ - als faszinierende und vertraute Welt auf, zu der er jedoch keinen kognitiven und kulturellen Zugang hatte. Die faszinierenden Reisen zu seinen Verwandten väterlicherseits waren geprägt von der ambivalenten Erfahrung, in Indien vertraut $\mathrm{zu}$ sein und gleichzeitig außen vor zu bleiben. Als einzigen konkreten kulturellen Bezug von „Indianness“ nennt Raj die Erinnerung an seine Großmutter, die ihm einen taweez, einen Talisman, geschenkt hat, den er bis heute stolz am Oberarm trägt und nie abnimmt. Der taweez an seinem Körper markiert die imaginäre Spur der „Indianness“, die sich durch die Erfahrungen des Andersseins in seine Subjektivierungsprozesse eingeschrieben hat. Genauso wie ein Ton oder ein Lied, das in ihm bei der Assoziation mit Indien ,anklinge“, manifestiert der taweez das Unfassbare, Emotionale und Imaginäre seiner „Indianness“. In längeren Rucksack-Reisen als junger Tourist fand Raj eine legitime Form des Zugangs zu Indien. Im jungen Erwachsenenalter zwischen 1987 und 1998 reiste er drei Mal nach Indien - einmal sogar 10 Monate mit seiner damaligen Freundin und heutigen Ehefrau Rosa. Auf diesen individuellen Indienreisen, aber auch durch Bücher, Filme und Gespräche eignete sich Raj viel Wissen über Indien an und konnte durch diese subjektiven Erfahrungen den „Mangel an kultureller Authentizität“ auffüllen. In diesem nostalgischen und auch exotisierenden Bildungsprojekt konnte Raj auf legitime Weise seiner biografischen Aushandlung des Andersseins eine soziale Form geben und diese ausdifferenzieren. Obwohl er die "Suche nach den Wurzeln“ mit seinen Freunden und seiner Freundin teilen konnte, blieb Raj weitgehend allein in seiner Aushandlung des Andersseins. Für ihn blieb „Indianness“ das Andere, das ihn ausschloss, das ihn im Kontext des Assimilationismus aber gleichzeitig als Subjekt konstituierte.

Das Fallbeispiel von Raj offenbart die Macht des Imaginären in der assimilationistischen Ordnung des „Eigenen“ und des „Anderen“. Ohne explizite Vermittlung kultureller Praktiken, nur durch Anrufungen des Andersseins, schreibt sich „Indianness“ als imaginäre Spur in seine Subjektivierungsprozesse ein. Dabei

43 | Dieser Topos ist auch im Roman "Meine Väter" des Schweizer Autors Martin Dean aus dem Jahr 2003 zentral. Der Roman handelt von der Suche des Erzählers nach seinem biologischen Vater, einem Inder aus Trinidad. Auch Bruno Ziauddins Buch "Curry-Connection" kann als Suche nach dem unbekannten Vater gelesen werden. 
war Rajs eigentlich prägende Erfahrung eine diffuse Form des Ausschlusses, die seine Familie und ihn auf vielfältige Weise von der hegemonialen Norm der national-bürgerlichen Dominanzgesellschaft unterschied. In seinen Erinnerungen an Kindheit und Adoleszenz unterscheidet Raj nicht, ob dieses Anderssein von der sozioökonomischen Prekarität, der elterlichen Trennung, der binationalen Ehe der Eltern, der Rassismuserfahrung oder der indischen Herkunft des Vaters herrührte. Die kulturalistischen, assimilatorischen Anrufungen produzierten bei Raj nichtsdestotrotz eine lebenslange „Suche nach den Wurzeln“.

Auch der Journalist Bruno Ziauddin hatte in seiner schweizerisch-indischen Familie keine Vermittlung kultureller Praktiken und Symbole erfahren, und entwickelte durch Rassismuserfahrungen vielschichte Erfahrungen des Andersseins. Wie ich in der Einleitung dargelegt habe, widersetzte sich Bruno zwar Anrufungen des Andersseins. Auf die Frage „Wo sind deine Wurzeln?“ antwortete er trotzig: „Sehe ich aus wie ein Mangobaum?“ Mit seinem Widerstand gegen die Anrufungen versucht Bruno, seine subjektive Identifikation als „waschechter Schweizer“ in der binationalen Familie öffentlich zu repräsentieren. Angesichts des monolithischen Verständnisses des „Eigenen“ und des „Anderen“ konnte die vielschichtige Biografie Brunos jedoch kaum legitim abgebildet werden. Wie das Buch „Curry-Connection“ und die darin geschilderte Suche nach den „eigenen Wurzeln“ zeigen, sind in Brunos Anspruch auf wirkliche Assimilation Widersprüche eingeschrieben, die sich in der hiesigen rassialisierten Logik des „Eigenen“ und des "Anderen“ nicht auflösen lassen.

Es lässt sich festhalten, dass assimilatorische Anrufungen auch bei allen Subjekten, die nicht der rassialisierten und ethnisierten Norm entsprechen, Erfahrungen des Anderseins und einen moralischen Rechtfertigungsdruck produzieren, auf die sie reagieren müssen - ob sie wollen oder nicht und ob diese Anrufungen mit ihrem Leben zu tun haben oder nicht. Jedoch können die Bewältigungsstrategien variieren. Während Bruno versuchte, eine legitime Zugehörigkeit als Schweizer zu beanspruchen, schrieb sich die Projektion des Andersseins bei Raj seit der Jugend als nostalgische „Suche nach seinen Wurzeln“ ein. Diese empirische Feststellung macht deutlich, dass Erfahrungen des Andersseins weniger von „Kulturkonflikten“ herrühren, als von einem machtvollen Assimilationsregime, das die „Anderen“ zwar definiert, aber ihnen nicht die notwendigen kulturellen Ressourcen und öffentlichen Räume bietet, um für ihre Erfahrungen der Mehrfachzugehörigkeit Anerkennung zu gewinnen. 


\subsection{Fazit: Biografisch-ethische Projekte DES ANDERSSEINS}

Die vier Fallbeispiele in diesem Kapitel zeigen die vielfältigen Machteffekte und Aushandlungen einer assimilatorischen Subjektivierungslogik, die „Inder_innen der zweiten Generation“ in ihrer Kindheit und Jugend in der Schweiz erfahren haben.

Im Zusammenspiel von Assimilationspolitik und fremdenpolizeilicher Kontrolle, zivilgesellschaftlicher Disziplinierung und nationaler Erziehung in der Schule entstand eine relativ stabile sozioräumliche und diskursive Grenze zwischen nationaler Öffentlichkeit und „Migrationsfamilie“. In dieser Konstellation aufzuwachsen beförderte das Narrativ des „Lebens zwischen den Welten“ als einen sinnhaften Rahmen für die Subjektivierung von vielen „Inder_innen der zweiten Generation“ in der Schweiz. Da kaum Netzwerke innerhalb der „zweiten Generation" sowie kaum diasporische und antirassistische Öffentlichkeiten existierten, konnten „Inder_innen der zweiten Generation“ subjektive Erfahrungen nicht vergleichen und ausdifferenzieren und die eigene Familie wurde - außer bei Raj - zur Projektionsfläche von „Indianness“. Als „Pionier_innen“ standen sie vor der biografischen Aufgabe, eine Sprache und Lebensführung zu entwickeln, um die eigenen Erfahrungen des „postkolonialen Andersseins“ sinnhaft zu bearbeiten. Die Lücken und Widersprüche innerhalb der assimilationistischen Subjektivierungslogik sowie ihre transnationalen Lebenswelten boten ihnen Handlungsspielräume für unterschiedliche Aushandlungsstrategien.

Aftab hatte angesichts von Ausschlusserfahrungen angefangen, sich als ironischer und intellektueller Vermittler „zwischen den Welten“ zu inszenieren. Dadurch konnte er auf die öffentliche Ignoranz aufmerksam machen und eine legitime Position der Selbstrepräsentation einnehmen. Als Selfmademan hat er seine Biografie zum Beruf gemacht und konnte sich zum Journalisten mit Südasienfokus und später zum Unternehmensberater weiterentwickeln.

Maya hatte das vergeschlechtlichte Narrativ des „Kulturkonflikts“ zwischen konservativer Familie und Assimilationsforderungen biografisch stark internalisiert. Ihre Jugend schilderte sie als Suche nach einem Freiraum jenseits der Enge der indischen Familie und der bürgerlichen Assimilationsforderung. Mit der Ausbildung zur Yoga-Lehrerin fand sie schließlich eine Sprache und eine Praxis, um einen individualistischen Lebensentwurf jenseits des Kulturkonflikts zu rahmen.

Wie Maya hatte auch Sonia die elterlichen Erwartungen von Bildungserfolg und respektabler Geschlechterperformanz im Narrativ eines „Lebens zwischen den Welten" erfahren. Indem sie jedoch diese Forderungen im transnationalen Projekt der Statusrehabilitierung aushandelte, nahm sie kaum einen „Kulturkonflikt“ wahr. 
Stattdessen entwickelte sich Sonia durch eine Ausbildung zur Investmentbankerin und durch eine standesgemäße Heirat zu einer "modernen indischen Frau“.

Raj ist Sohn eines indischen Vaters und einer Schweizer Mutter und unter prekären sozioökonomischen Bedingungen aufgewachsen. Seine vielschichtigen Erfahrungen des Andersseins, die sich durch Prekarität, Rassismuserfahrungen und die Scheidung der Eltern ergaben, ließen sich nicht in einem Narrativ des „Lebens zwischen den Welten" rahmen. Nichtsdestotrotz begann Raj als Jugendlicher vor dem Hintergrund seines „abwesenden Vaters“ eine nostalgische „Suche nach seinen Wurzeln". Er eignete sich Wissen über Indien an und entwickelte in mehreren Rucksack-Reisen einen eigenen Zugang zum Herkunftsland seines Vaters, das er mit seinen Freunden und seiner Familie teilen kann. Nichtsdestotrotz erlebt Raj die Zugehörigkeit zu Indien weiterhin als illegitim, was sich in seiner Bezeichnung als „Halbinder" niederschlägt.

Die beschriebenen Aushandlungen der „Migrationsfamilie“ als semantischer Topos und soziale Arena waren in vielfältige transnationale Familienkonstellationen eingebettet. Im unabhängigen Indien wurde die Emigration in den postkolonialen Westen als ambivalente Praxis erlebt, die einerseits die Verbesserung von familiärem Status und Lebensstandard versprach, aber gleichzeitig die Gefahr bedeutete, die Bindung zur nationalen Gemeinschaft zu verlieren. Die moralische Last, Status, Kultur und Religion zu bewahren, war in der antikolonialen Konstruktion der Mittelschicht stark mit einem Ideal der „weiblichen Respektabilität“ verbunden. Das mag erklären, warum „Inderinnen der zweiten Generation“ wie Maya und Sonia in einem besonderen Maße mit der moralischen Last der Eltern oder eines Elternteils konfrontiert wurden, Indien verlassen zu haben. Im Kontext der Schweiz mussten sie versuchen, die komplexen innerfamiliären Aushandlungen von Migration und Geschlechternormen vor dem Hintergrund der dichotomen eurozentrischen Narrative von "modern“ und „traditionell“ und von „Liebesheirat" und „arrangierter Heirat" gerecht zu werden. Die assimilationistische Logik konfrontierte sie jedoch, pointiert formuliert, im Namen von Frauenrechten und Liberalismus mit einer kolonial-patriarchalen Logik, die auch auf die ersten britischen Interventionen gegen Witwenverbrennungen (sati) in Indien im 19. Jahrhundert zurückgeht (Mohanty 1986; Spivak 1987; Mohanty 2003). „Inder_innen der zweiten Generation" wie Sonia und Maya - aber auch Aftab und Raj - hatten diese normativen Narrative von "moderner Liebesheirat" und "traditioneller arrangierter Heirat" $\mathrm{zu}$ einem großen Teil internalisiert, weil es keine öffentlichen Debatten oder Räume gab, in denen die komplexen Fragen patriarchaler Geschlechternomen im postkolonialen Zusammenhang diskutiert und in denen ihre transnationalen Erfahrungen abgebildet werden konnten. Ohne öffentliche und institutionelle Räume einer vielschichten Aushandlung mussten sie sich nur zu oft zwischen den Schweizer Normen ihrer Peers und ihren Eltern entscheiden, eine 
Entscheidung, die für Kinder und Jugendliche ein unzumutbares moralisches Dilemma darstellt und Familienbeziehungen nachhaltig belastet. Die von Marc Virot geforderte „psychologisch geschickte“ Assimilationspolitik stellte so gesehen eine gleichermaßen systematische wie subtile Form der Gewalt dar, mit der die Dominanzgesellschaft die moralisch-politische Verantwortung abwälzte, pluralistische öffentliche Räume und Institutionen zu bereitzustellen, in denen die Anliegen und Lebenswirklichkeiten der gesamten Bevölkerung hätten anerkannt und ausgehandelt werden können.

Vor dem Hintergrund vielschichtiger transnationaler Aushandlungen von Zugehörigkeit, Klasse und Geschlecht erscheint das - implizit oder explizit - viel beschworene „Leben zwischen den Welten“ nicht als Ausdruck einer universellen condition migratoire, sondern als Effekt einer Assimilationsgesellschaft. Nedim Karakayali stellt in seiner Untersuchung von Autobiografien von Angehörigen der „Zweiten Generation“ in den USA und Kanada lapidar fest: "Children of immigrants do not literally live in two worlds, but they live in a world where the belief that there are only two worlds is omnipresent." (Karakayali 2005:327) Die nationale Normalität wurde sozialräumlich und diskursiv als so bindend und homogen konstruiert, dass legitime alternative Subjektpositionen kaum zugänglich waren und die fragilen, verwirrenden sowie leidvollen Erfahrungen des Andersseins bei „Inder_innen der zweiten Generation“ keinen Ausdruck fanden. Ihr Schweigen war, wie Frantz Fanon beschrieb, doppelt: Einerseits existierten kaum Kategorien und Worte jenseits des hegemonialen Diskurses, um die eigenen Erfahrungen auszudrücken. Andererseits existierten keine öffentlichen Räume, um sich selbst in einer eigenen Sprache zu äußern. Es war geradezu außergewöhnlich, dass Aftab sich an rassistische Erfahrungen wie etwa beim Einbürgerungsprozedere explizit erinnerte und sie intensiv diskutierte. Die meisten meiner Gesprächspartner und -partnerinnen sprachen nicht aus eigener Motivation über Ausschlusserfahrungen aufgrund ihrer Herkunft und ihrer Hautfarbe. Nach intensivem Nachfragen erinnerten sich jedoch fast alle an - zum Teil sehr extreme - Rassismuserfahrungen, auch wenn sie diese nie als solche bezeichneten und sie zu relativieren versuchten. In den Gesprächen wurde ein Mechanismus sichtbar, der zwischen Verleugnung und Bewältigung oszilliert und der die existenzielle Wirkungsweise von Assimilation reflektiert: Die intuitiven moralischen Anstrengungen, in der Kindheit und der Jugend als „normal“ zu gelten, waren in Fleisch und Blut übergegangen und schlugen sich grösstenteils auch in einer Identifikation als Schweizerinnen und Schweizer nieder. Die öffentliche Anerkennung von Rassismuserfahrung (oder explizite ethnische oder nicht-weisse Selbstrepräsentationen) würden einen Widerspruch zu dieser „erfolgreichen“ assimilatorischen Subjektivierung bedeuten. Die Erinnerung an Ausgrenzungserfahrungen würde auf schmerzhafte Weise die diffusen Erfahrungen des Andersseins in der Kindheit und der Jugend oder sogar die symbolische Gewalt der Assimilation als konstitutives Moment der eigenen Sub- 
jektivierung bewusst machen - und eine existenzielle, biografische Reevaluation erfordern. ${ }^{44}$

Wenn auch die Erfahrung der Assimilationsforderungen oft nicht in Worte gefasst oder gar nicht mehr erinnert werden kann, konnte der ethnografische $\mathrm{Zu}$ gang aufzeigen, wie sich die biopolitische Herstellung einer homogenen Nation sich in einer gewaltvollen Beziehung mit denjenigen Subjekten niederschlägt, die assimiliert werden sollen. Da im Assimilationssystem das eigentliche politische Projekt der Fremdenabwehr als „Kulturkonflikt" naturalisiert wurden, trugen Migrant_innen und ihre Nachkommen die Bürde, die gewaltvollen Widersprüche dieses Regimes innerhalb der Familie auszuhandeln. Ich argumentiere, dass „Inder_innen der zweiten Generation" solche postkolonialen Widersprüche als intime und biografische Auseinandersetzung mit ihrem Anderssein aushandelten. Es war konstitutiv für die assimilatorische Subjektivierungslogik, dass „Inder_innen der zweiten Generation" das angeworfene Anderssein nie ganz verstehen, erklären, attribuieren oder äußern konnten. Aber gerade weil es weder Kategorien noch öffentliche Anerkennung für dieses diffuse Gefühl des Andersseins gab, verschob und repetierte sich die Problematisierung des Selbst immer wieder und schrieb sich während der Kindheit und der Jugend in ihre Subjektivierungsprozesse ein. Die Fallbeispiele von Maya, Aftab, Raj und Sonia beschreiben paradigmatisch die Urszenen der Subjektivierung in eine moralische Ordnung des „Eigenen“ und des "Anderen" sowie auch ihre Suche nach Worten, nach Sprechpositionen und nach ethischen Räumen, um das ihnen angeworfene Anderssein zu verstehen und legitim zu äußern, eine Suche die ich als biografisch-ethische Projekte des Andersseins bezeichnen möchte.

Auf eine existenzielle Weise hat sich im Kontext des Assimilationismus die Erfahrung des Andersseins durch die Aushandlung von Mehrfachzugehörigkeit, Geschlechterperformanz und sozialer Mobilität in die biografischen Verläufe und die Lebensführung eingeschrieben, die nolens volens behandelt werden (müssen). Die meisten „Inder_innen der zweiten Generation“ haben versucht, diesen intimen, biografischen Aushandlungen des Andersseins eine (fragil bleibende) soziale Form innerhalb der legitimen Diskurse zu geben. Während der Feldforschung war ich verblüfft, wie viele meiner Informantinnen und Informanten entweder größere Rucksack-Reisen in Indien unternommen hatten, indische Hobbys wie klassischen Tanz, Gesang oder Yoga praktizierten, in der Schule oder im Beruf Projekte über Indien, Globalisierung oder Rassismus verfolgten, sich systematisch Wissen über Geschichte, Politik und Kultur Südasiens aneigneten, ihre Familiengeschichte aufarbeiteten oder sich in religiöse Texte vertieften - und dies alles aus der Motivation, die diffuse Erfahrung des Andersseins verstehen und äußern zu

44 | Velho (2010) hat im Zusammenhang mit Subjektivierungsprozessen im Kontext von Assimilationismus und Rassismus auch von der Möglichkeit eines "kumulativen Traumas" gesprochen. 
können und Anerkennung dafür zu finden. Es erscheint die paradoxe Essenz des groß angelegte Projekt der Assimilation zu sein, dass es ethnische und rassialisierte Differenz als spezifisches sinnhaftes und legitimes Raster des Andersseins auf existenzielle Weise verankert hat, statt diese aufzuheben. Gleichzeitig verweisen diese biografischen Projekte des Andersseins auf eine Suche nach ethischen Räumen des Zusammenlebens, in denen jenseits assimilatorischer Normen neue und widerspenstige Repräsentation von Mehrfachzugehörigkeiten und neue transnationale Aspirationen entwickelt werden können. 
TEIL B: EXOTIK UND

$\frac{9}{0}$

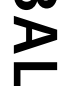

ก1

$\frac{7}{6}$

I

m

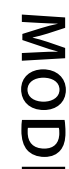

II

2

ก1 



\section{4. „Grüezi India“ - warenförmige Anerkennung und Exotisierung Indiens in der urbanen Schweiz}

Am 22. August 2008 reihten sich in der Zürcher Bahnhofshalle unzählige Marktstände aneinander. Dazwischen bahnten sich enge Gassen voller Menschen. Die Marktstände präsentierten kulinarische Köstlichkeiten aus unterschiedlichen Teilen Indiens. Frauen in Saris und weiß gekleidete Köche bereiteten in gusseisernen Pfannen Currys und Dosas zu und jonglierten Fladenbrote in Tandoori-Öfen. Banner und Menütafeln mit indisch anmutenden, aber auf Deutsch oder Englisch geschriebenen Schriftzügen priesen der flanierenden Kundschaft die Leckerbissen an. ${ }^{45}$ An einem Stand luden lebensgroße Kartonfiguren von Bollywood-Stars zum Kauf von DVDs der populären Hindi-Filmindustrie ein. In einem hell beleuchteten Marktstand hingen farbige Seidentücher und glitzerte filigraner Schmuck aus Silber und Halbedelsteinen. Darin saß konzentriert ein kleines Mädchen mit hellbraunem Teint und ließ sich von einer lachenden Inderin in Jeans ein Henna-Tattoo auf die Hand malen. In diesem Basar der vielfältigen Farben, Gerüche und Klänge waren aber auch einige weltlichere Stände zu finden: Intens, die Kuoni-Tochtergesellschaft für Indienreisen, die Swiss Cricket Association, die global tätige indische Softwarefirma Satyam, die Agentur Swiss Experience, die interkulturelle Coachings und Relocations Services für indische IT-Ingenieure anbot, und ein in der Schweiz ansässiges Hilfswerk für Kinder in Kerala informierten die Besucherschar über ihre Angebote. Neben der gelb-schwarzen Auto-Rikscha vor dem Basar blieben Passantinnen und Passanten stehen und beobachteten interessiert das bunte Treiben oder bahnten sich den Weg in den Markt. Auch viele Menschen indischer Herkunft waren aus der ganzen Schweiz nach Zürich angereist: Bisweilen voller Stolz, Neugier, aber auch mit Skepsis spazierten sie durch die Gassen. Auch „Inder_innen der zweiten Generation“waren vor Ort, um ein Teil dieses öffentlichen indischen Spektakels mitten in der Schweizer

45 | In den 1990er Jahren wurden verschiedene Schrifttypen - wie etwa Samarkan, Prakrta oder Devanagarish - kreiert, die der nordindischen Schrift Devanagari nachempfunden sind, jedoch in lateinischen Buchstaben geschrieben werden. 
Öffentlichkeit zu sein. Einige nahmen an kulturellen Darbietungen teil oder betreuten Marktstände. Andere waren mit Familie oder PartnerIn gekommen, um durch den Basar zu flanieren, Schmuck, Kleider und Filme zu ergattern, indische Snacks $z u$ degustieren oder um einfach ein bisschen indisches Flair zu erleben.

Auf einer großen Bühne mitten im Basar ertönten am späteren Nachmittag offizielle Reden: Der Vertreter der indischen Botschaft, Ajneesh Kumar, der Zürcher Stadtpräsident, Elmar Ledergerber, und die Bundespräsidentin und Vorsteherin des Departements für Auswärtige Angelegenheiten (EDA), Micheline Calmy-Rey, betonten die Bedeutung der schweizerisch-indischen Beziehungen und bekräftigten ihre Freude über die indische Präsenz in der Schweiz und im weltoffenen Zürich. Schließlich zündeten die Organisatoren und die Ehrengäste in einer hinduistisch anmutenden Zeremonie Kerzen in einem stehenden Kandelaber an, um dem Anlass - und den indisch-schweizerischen Beziehungen - gutes Gelingen zu wünschen. Im darauffolgenden kulturellen Programm präsentierten die renommierte Tänzerin Maitreyee Pahari und ihre Truppe Lokchhanda ein Medley klassischer und folkloristischer Tänze Indiens. Danach folgten Bollywood-Tanz-Shows einer schweizerisch-indischen sowie einer britisch-südasiatischen Tanztruppe. Die Bässe der Bollywood-Musik pumpten durch die Bahnhofshalle und Rauchschwaden des Trockeneises stiegen von der Bühne auf. Einige indische Studierende und IT-Ingenieure sowie einige "Inder_innen der zweiten Generation" und Schweizer_innen, die einen Bollywood-Tanzkurs besucht hatten, übten noch einige Choreografien, während sie auf die Disco warteten, die bis spät in die Nacht andauerte.

Die dreitägige Mega Mela am Bahnhof Zürich war der Höhepunkt des „Grüezi India Summer Festivals“, das der Indische Verein Zürich zum 60-jährigen Jubiläum des schweizerisch-indischen Freundschaftsvertrages vom 14. August 1948 organisierte (Imhasly 2008a). ${ }^{46}$ Neben der Mega Mela fanden in der Schweiz und in Indien unzählige kulturelle, politische, wissenschaftliche und ökonomische Veranstaltungen zur Feier dieses Jubiläums statt. Der schweizerisch-indische Freundschaftsvertrag von 1948 war der erste dieser Art, den die unabhängige Republik Indien geschlossen hatte. Während die Schweiz sich mit dieser diplomatischen Geste ihre ökonomischen Interessen im unabhängigen Indien zu sichern und ihre Neutralität zu verankern suchte, erhoffte sich Indien davon seine Bindungsfreiheit im aufkommenden Kalten Krieg zu demonstrieren und einen neutralen Partner für die Modernisierung des Landes zu gewinnen (Schweizer 2008; Dejung 2013; Jain 2015). Der Abschluss des schweizerisch-indischen Freundschaftsvertrages war - nota bene - bis anhin weder in der Schweiz noch in Indien gefeiert worden. Doch wie aus dem Nichts versammelte sich im Jahr 2008 eine Unzahl von staat-

46 | Mela (Hindi, Sanskrit: Treffen, Versammlung, Messe) bezeichnet in Nordindien eine Mischung aus Markt und Volksfest und kann religiöser, kommerzieller oder sozialer Natur sein. 
lichen Akteuren, Kulturvereinen und Kulturproduzent_innen, multinationalen Unternehmen, ethnic entrepreneurs sowie Privatpersonen indischer Herkunft und indophile Schweizer_innen, die das 60-jährige Jubiläum der offiziellen schweizerisch-indischen Beziehungen zum Anlass nahmen, um ihre Interessen und Imaginationen hinsichtlich Indien öffentlich zu manifestieren.
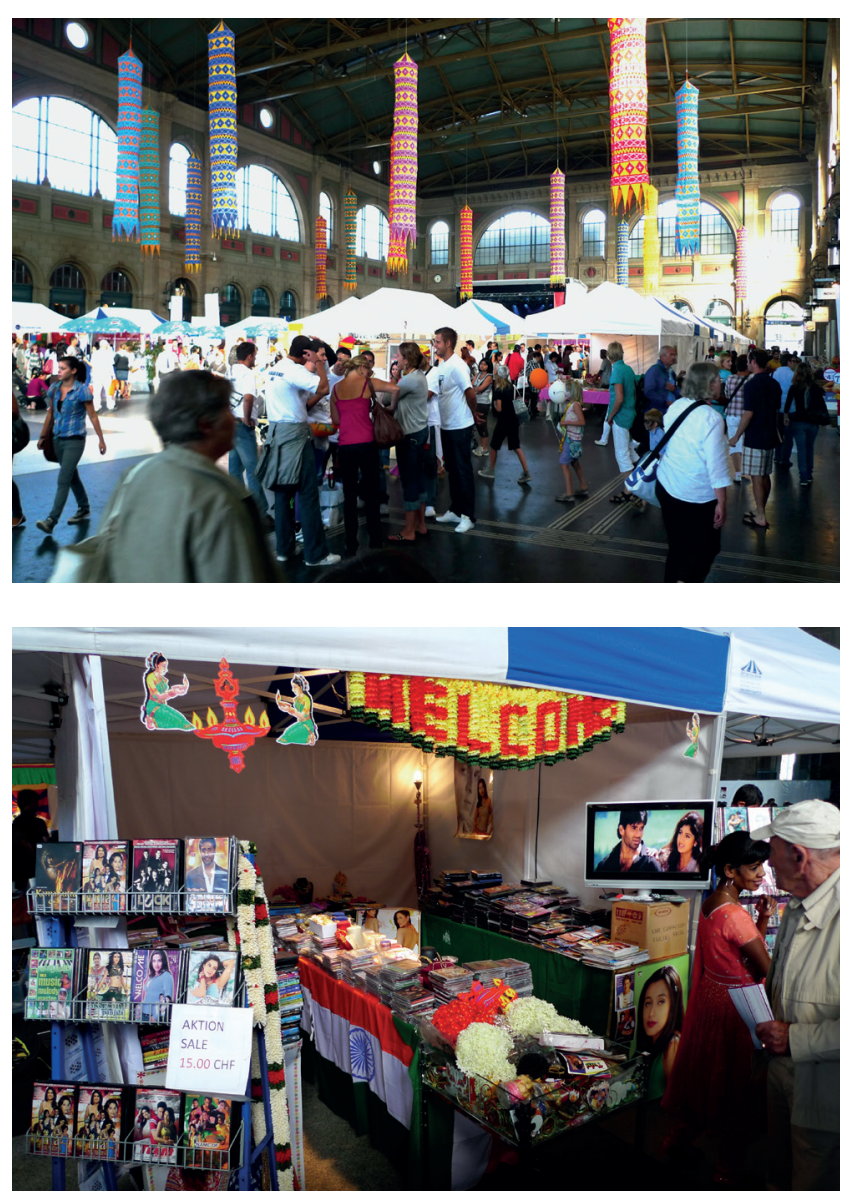

Abbildung 11a) und 11b): Neue indische Präsenz auf dem grössten öffentlichen Platz der Schweiz. Mega Mela im Zürcher Hauptbahnhof zur Feier des 60-jährigen Jubiläums des Schweizerisch-Indischen Freundschaftsvertrages (Quelle: Autor)

Wie kam es dazu, dass drei Tage lang eine derart spektakuläre Präsenz von „Indianness" und insbesondere von indischer Exotik - überhaupt von ethnischer Differenz - den meist frequentierten öffentlichen Raum der Schweiz erfüllen konnte? In den Zeiten der Assimilationspolitik zwischen den 1960er und den frühen 
1990er Jahren waren ethnische Selbstrepräsentationen von Migrant_innen in der Öffentlichkeit verpönt (von migrantischen Kundgebungen gegen die Schweizer Ausländer- und Migrationspolitik wie etwa den italienischen Protesten gegen die Schwarzenbach-Initiative in den 1970er Jahren ganz zu schweigen). Abseits von der nationalen Öffentlichkeit - und unsichtbar für die Dominanzgesellschaft gingen damals Anlässe migrantischer und nicht-christlicher Gemeinschaften und Organisationen vonstatten. Die südasiatischen Gemeinschaften versammelten sich zu Diwali-, Id-, Durga-Puja- und Onam-Feiern in den Kirchgemeindehäusern oder in den Quartiertreffs der städtischen Agglomerationen, in der Genfer Ramakrishna-Mission, in der indischen Botschaft oder in Privatwohnungen. Das öffentliche paternalistische Indienbild in der Schweiz zeichnete damals größtenteils ein Land von Armut und Unterentwicklung, von Aberglaube und Rückständigkeit. Ganz anders dagegen die Mega Mela von 2008: Nicht nur präsentierte sich die indische Diaspora stolz und selbstbewusst mitten in der Schweizer Öffentlichkeit. Auch wurde sie von der Zürcher Stadtverwaltung mit offenen Armen empfangen, um die multikulturelle Vielfalt und die Weltoffenheit Zürichs zu feiern. Und die Schweizer Außenministerin zollte dem ehemaligen Entwicklungsland Indien plötzlich Anerkennung als regionale Wirtschaftsmacht und bekräftigte damit das handfeste Interesse der Schweiz, an den Früchten der teilliberalisierten Märkte in Indien teilzuhaben. Und schließlich waren es nun nicht exzentrische Hippies und Alt-68er am Rande der bürgerlichen Öffentlichkeit, sondern die Masse mittelständischer Urbaniten, die die feilgebotenen indischen Exotika konsumierten.

Im Folgenden wird die Präsenz Indiens (und von indischer Exotik) an der Mega Mela als Assemblage innerhalb der einschneidenden Veränderungen in der globalen Kulturökonomie interpretiert, die landläufig als „Globalisierung“ bezeichnet werden. In davor ungekannter Dichte und Intensität verknüpften sich Stadtmarketing, Differenzkonsum und diasporische Anerkennungspolitik in der global city Zürich mit der Liberalisierungsreform in Indien und den globalen Aspirationen einer „neuen Mittelschicht“, wie sie paradigmatisch von der indischen IT-Industrie oder dem Bollywood-Kino repräsentiert werden. Angesichts der gesteigerten Verquickung globaler Prozesse und lokaler Räume, so die These, haben sich die Bedingungen von postkolonialer Repräsentationspolitik zwischen der Schweiz und Indien im Allgemeinen verändert - und somit auch die Strategien, wie „Inder_innen der zweiten Generation“ aus der Schweiz subjektive Erfahrungen in transnationalen Diskursen, Netzwerken und Räumen aushandeln.

Wie verschiedene Beiträge zur Globalisierungsforschung argumentieren, haben seit der Ölkrise in den 1970er Jahren neoliberale Reformen, neue Muster in der Kapitalakkumulation und in der internationalen Arbeitsteilung sowie neue Transport- und Kommunikationstechnologien die globale Zirkulation und Vernetzung von Menschen, Gütern, Daten und Imaginationen intensiviert und vervielfältigt (Sassen 1989; Harvey 1990a; Lash/Urry 1994; Massey 1994; Appadurai 1996; Castells 1996). Im Rahmen der Wirtschaftskrise der 1970er Jahre hatte die Dein- 
dustrialisierung westlicher Industrieländer und ihrer städtischen Metropolen eine Neuordnung internationaler Arbeitsteilung ausgelöst. Gleichzeitig verschob sich darin der Schwerpunkt der kapitalistischen Wertschöpfung von der Produktion hin zu Finanzwirtschaft, Dienstleistungen und Konsum (Harvey 1990b). Gemäß der global-city-Hypothese war der globale Strukturwandel dabei eng verknüpft mit der urbanen Konzentration von Unternehmen im Dienstleistungs- und Finanzsektor, die diese globalen Wirtschaftsprozesse steuerten (Sassen 1989). Diese massiven globalen Brüche schlugen sich auch in der Neuausrichtung der nationalen Modernisierungsprojekte Indiens und der Schweiz nieder:

1. Ab den 1980er Jahren „knackten“ neoliberale Strukturanpassungsprogramme und Freihandelsabkommen im Zuge des Zusammenbruchs des real existierenden Sozialismus die Märkte ehemaliger Schwellenländer wie etwa Argentiniens, Mexikos oder eben Indiens. 1991 hatte die indische Regierung auf dem Tiefpunkt einer einschneidenden Wirtschaftskrise ein Liberalisierungsprogramm eingeleitet, das die indischen Märkte zunehmend für ausländische Importe und Investitionen öffnete. Dies war sowohl politisch als auch ökonomisch eine deutliche Abkehr vom bisherigen, sozialistisch orientierten Wirtschaftsprogramm, das auf Importsubstitution und nationale Monopolunternehmen setzte (Menon/Nigam 2007; Rothermund 2008; Cross 2014). Diese Liberalisierungsreformen waren eingebettet in eine umkämpfte gesellschaftliche Transformation, die durch die Liberalisierung in eine spezifische Richtung beschleunigt wurde. Ab den 1980er Jahren hatte sich eine „neue Mittelschicht“ entwickelt, die sich durch Medien und diasporische Netzwerke zunehmend an einer westlichen Öffentlichkeit bezüglich Konsum und politischer Debatten orientierte und deren Status vor allem auf Zugang zu akademischer Bildung basierte (Verma 1998; Fernandes 2003). Gleichzeitig verfügte diese Schicht kaum über Privilegien in den bürokratischen Strukturen und sah die sozialen, politischen Aspirationen der unterprivilegierten Schichten und Kasten zunehmend als Gefährdung ihres Status (Menon/Nigam 2007). In den 1990er Jahre erwuchs im umkämpften Erziehungssystem eine Generation gut ausgebildeter Fachkräfte - namentlich in den technischen, medizinischen und wissenschaftlichen Berufen, sowie im IT- und Finanzbereich -, die den Anspruch des liberalisierten Indiens auf die Früchte des globalen Kapitalismus verkörperten. Neben den traditionellen Teeständen und Straßenmärkten entstanden in Indien immer mehr klimatisierte Filialen von Kaffeehausketten und Fastfood-Restaurants. Hochglanzmagazine, Satellitenfernsehen und Bollywood-Filme verbreiteten Bilder und Erfahrungen neuer Lebensstile in den urbanen Enklaven und den Diasporas des globalisierenden Indiens. Diese soziale Transformation war jedoch auch konstitutiv verbunden mit gewaltsamen Strukturen und Prozessen der Ungleichheit: Die Entwicklung urbaner und transnationaler Räume, Lebensstile und Identitäten einer globalen indischen Moderne standen dabei in kausaler Wechselbeziehung mit unmenschlichen Produktionsbedingungen in sweat shops und städtischen Slums, mit illegalen 
Enteignungen und land grabbing für Infrastrukturprojekte sowie für Sonderwirtschaftszonen in urbanen, ländlichen und indigenen Gebieten (Roy 2003; Gupta 2009; Cross 2014)

2. Das Schweizer Modernisierungsmodell wiederum war seit den 1960er Jahren angesichts der Deindustrialisierung in eine Akkumulations- und Regulierungskrise geraten. Aus der Sicht der Dominanzgesellschaft konnte die akute Krise sozial und politisch dadurch „abgefedert“ werden, dass temporären Verträge von Hunderttausenden ausländischer Arbeitskräfte nicht verlängert wurden. Strukturell wurde durch neoliberale Reformen und die Förderung von (multinationalen) Dienstleistungsbetrieben - insbesondere im Finanzbereich - reagiert. Es entstand eine headquarter economy mit entsprechenden Sekundärstrukturen von Zulieferern und Dienstleistern in den urbanen Großräumen Zürich, Genf und Basel, die durchaus als kleine, dezentrale global-cities-Strukturen verstanden werden können (Hitz et al. 1995). Die neoliberalen Reformen schufen durch Entlassungen und die Schwächung sozialer Sicherheitssysteme sowohl strukturelles soziales Leiden (Honegger/Rychner 1998) als auch eine neue Schicht von Professionellen, die sich die neue soziokulturelle Ökologie der global cities als hegemoniale Räume aneigneten. Diese waren dabei konstitutiv an Migration gebunden (Sassen 1991:315 ff.; Mollenkopf/Castells 1991; Glick Schiller/Caglar 2011). Zum einen zogen die Dienstleistungssektoren in global cities hochqualifizierte ausländische Kader und Fachleute an, die über das nötige Know-how in Technik und Management verfügten. Zum anderen waren diese Betriebe auf wenig qualifizierte Migrantinnen und Migranten angewiesen, die die physische Reproduktion der global orientierten Unternehmen - respektive der global city - gewährleisteten. Diese Arbeitsbereiche erstrecken sich bis heute von der Reinigungsbranche, der Gastronomie, der Bauindustrie, der Kulturindustrie bis zum Pflegesektor und beschäftigen grösstenteils niedergelassene Migrant_innen, Geflüchtete und illegaliserte Migrant_innen. Während hochqualifizierte Professionelle, Fachkräfte und Angestellte im städtischen Raum immer mehr kosmopolitische Freizeit- und Konsummöglichkeiten nachfragten, versorgten sich wenig qualifizierte Migrant_innen gegenseitig durch informell hergestellte Produkte aus ethnic businesses. Sowohl die Produktionsund Reproduktionsprozesse als auch der urbane öffentliche Raum in der Schweiz waren also seit den späten 1980er Jahren von einer zunehmenden und sichtbaren Internationalisierung gekennzeichnet. Dies schuf ab den 1990er Jahren eine neue spannungsvolle Konstellation im Modernisierungsmodell der Schweiz, das Wachstum und multikulturellen Differenzkonsum mit einer erneuten Vormacht des Rechtspopulismus verband.

Teil B dieser Ethnografie untersucht unter dem Titel „Exotik und globale indische Moderne“, wie sich ab den 1990er Jahren im Kontext dieser globalen Umbrüche und Verflechtungen die Bedingungen und Praktiken der Subjektivierung von „In- 
der_innen der zweiten Generation"verändert haben. Der Fokus von Kapitel 4 und 5 liegt auf der Genealogie und Ethnografie einer neuen multikulturell-exotisierenden Subjektivierungslogik, die sich in der Schweiz ausgehend von der neoliberalen Rekonstruktion in den urbanen Räumen entwickelt hat. Sie hat die assimilatorische Subjektivierungslogik nicht etwa abgelöst, sondern ist sowohl aus ihr und im Widerstand dagegen entstanden und markiert eine Pluralisierung der Aushandlung des „Eigenen“ und des „Anderen“ in der Schweizer Öffentlichkeit. Während die Assimilationslogik „die Anderen“ in die privaten Räume der „Migrationsfamilie“ und der Migrationsorganisationen projizierte, ermöglicht die neue Repräsentationslogik, Differenz öffentlich sichtbar zu machen, ja, fordert manchmal geradezu dazu auf und verspricht - unter bestimmten Bedingungen - Anerkennung und Räume der Selbstrepräsentation. Die ostentative indische Präsenz, die sich in der Mega Mela verdichtete, markierte diese Verschiebung der assimilatorischen Grenze zwischen dem Privaten und Öffentlichen respektive dem „Anderen" und dem „Eigenen“. Bevor in Kapitel 5 anhand der Fallbeispiele von Sonia, Maya, Raj und Aftab und weiterer Protagonist_innen dargelegt wird, wie „Inder_innen der zweiten Generation“ diese multikulturell-exotisierende Subjektivierungslogik in ihren Lebenswelten und in ihren Biografien aushandeln, wird in Kapitel 4 deren Genealogie und Wirkungsweise erläutert. In Kapitel 6 wird schließlich wieder anhand von Fallbeispielen darauf eingegangen, wie „Inder_innen der zweiten Generationen" neue Handlungs- und Anerkennungsräume im liberalisierten Indien ausbedingen. Wenn auch Kapitel 4 und 5 vor allem die Bedingungen und die Praxis transnationaler Lebensführung von schweizerisch-indischen Second@s in der Schweiz fokussieren und Kapitel 6 diejenigen in Indien, müssen die genealogischen Analysen, theoretischen Erläuterungen, ethnografischen Beschreibungen und biografischen Narrative im Teil B vor dem Hintergrund der zunehmend rhizomatischen transnationalen Verflechtungen der letzten Jahrzehnte gelesen werden. Diese globalen Prozesse manifestierten sich auf einschneidende Weise in den transnationalen Subjektivierungprozessen von „Inder_innen der zweiten Generation. Langsam aber sicher schienen die sogenannten „zwei Welten“ näher ineinanderzugreifen; die eigene (erahnte) Normalität von Mehrfachzugehörigkeit und kultureller Übersetzung wurde normaler für die Welt. Gleichzeitig entstanden unter diesen Bedingungen transnationaler Subjektivierung neue Widersprüche zwischen Privilegien und Armut, Anerkennung und Rassismus, kosmopolitischen Freiheiten und globaler Ungerechtigkeit.

Der Fokus auf die transnationalen Aushandlungen der biografischen Projekte von Maya, Sonia, Aftab, Raj und vielen anderen erlaubt, ethnografisch in die Nischen und Zwischenräume dieser globalen Umbrüche vorzudringen und $\mathrm{zu}$ verstehen, wie Globalisierungsprozesse in ihren Ambivalenzen und existenziellen Konsequenzen „on the ground" stattfinden. Sie verweisen auf eine postkoloniale Welt, in der Dichotomien wie "the West and the Rest" oder Moderne und Tra- 
dition nicht mehr adäquat scheinen, aber auch noch nicht klar ist, welche neuen Ordnungen am Entstehen sind.

Die spektakuläre Präsenz Indiens an der Mega Mela veranschaulicht, wie sich die öffentliche Repräsentation von ethnischer Differenz im Vergleich zu den 1970er und 1980er Jahren des Assimilationismus verändert hat. Es lässt sich erahnen, dass die angedeuteten globalen Veränderungen auch die institutionellen und diskursiven Bedingungen verändert haben, in denen Subjektivierungsprozesse von „Inder_innen der zweiten Generation“ stattfinden.

Aber wie und warum genau hatte sich das öffentliche Repräsentationsregime von kultureller Differenz seit dem Assimilationismus verändert? Welche Diskurse, politischen Kräfte und ökonomischen Interessen waren es, die dazu führten, dass in diesem historischen Moment eine so spektakuläre Präsenz Indiens mitten in der Schweizer Öffentlichkeit stattfinden konnte? Und welche Artikulationen des „Eigenen“ und des „Anderen“ erlaubt diese öffentliche Präsenz von Differenz - und insbesondere von Exotik - sowohl in der Dominanzgesellschaft als auch in der indischen Migrationsbevölkerung?

Diese Kapitel liefert eine ethnografische Genealogie eines - wie ich es nenne kommerziellen Multikulturalismus, der sich in der Schweiz seit den 1990er Jahren entwickelt hat, und innerhalb dem sich ab dem neuen Millennium ein vorübergehender Indien-Hype etablieren konnte. Die folgenden Ausführungen dienen zum einen als Voraussetzung für das Verständnis neuer Subjektivierungsprozesse von „Inder_innen der zweiten Generation“ im Spannungsfeld von Exotisierung und Anerkennung. Zum anderen bietet dieses Kapitel aber auch ein eigenständiges Argument, um zu verstehen, wie sich postkoloniale Repräsentationspolitiken in der Schweiz an der Schnittstelle von Migrationspolitik, Stadtentwicklung und Populärkultur gewandelt haben und wie sie ausgehandelt werden. ${ }^{47}$ Um diese Debatte zu befördern, werden empirische Daten aus Archivforschung, Diskursanalyse, Experteninterviews und ethnografischer Feldforschung mit Debatten um eine multikulturelle Anerkennungspolitik (Taylor 1992; Mitchell 1997; Povinelli 2002) mit der Literatur zu global cities (Sassen 1991; Harvey 1990b; Hitz et al. 1995) sowie mit den anthropologischen und kulturwissenschaftlichen Studien zur globalen Kommodifizierung von Ethnizität und Exotik (Hall 1991; Ong 1999; Huggan 2001; Ha 2005; Comaroff/Comaroff 2009) in Beziehung gesetzt.

1. In einem ersten Teil wird aufgezeigt, wie sich in der Schweiz aus der Kritik am Assimilationsregime und an der „Überfremdungs“-Bewegung der 1970er Jahre Ansätze eines politischen Multikulturalismus entwickelten, die jedoch in den 1990er Jahren auf nationaler politischer Ebene angesichts des wachsenden Rechts-

47 | Ansätze zu diesem noch wenig beforschten Feld in der Schweiz lieferten Arbeiten aus unterschiedlichen Disziplinen der Geschichtswissenschaft, Stadtsoziologie und der Anthropologie (Maiolino 2010; Schmid/Weiss 2004; Wessendorf 2007). 
populismus scheiterten. Hingegen vermochte sich im Zuge der Restrukturierung Zürichs zu einer global city ein kommerzieller Multikulturalismus im öffentlichen Raum einzuschreiben. Am Beispiel der Mega Mela wird ethnografisch vertieft, wie sich in diesem Kontext eine warenförmige Anerkennungslogik von Differenz herausbildete, innerhalb der die Stadt Zürich, die diasporischen Organisator_innen der Mega Mela sowie die mediale Öffentlichkeit ihre Beziehungen aushandelten. Paradigmatisch manifestiert sich diese warenförmige Anerkennung in einer zeitgenössischen ästhetischen Form der Exotisierung Indiens.

2. In einem zweiten Teil versuche ich, das schweizerische Begehren nach indischer Exotik ab dem Millenniumswechsel vor dem Hintergrund der Verschiebungen der postkolonialen Machtverhältnisse zwischen der Schweiz und Indien zu verstehen. Ich argumentiere, dass der Konsum indischer Populärkultur insbesondere einer urbanen Mittelschicht in der Schweiz ermöglicht, das „Phänomen der Globalisierung" auf sinnhafte, wenn auch ambivalente Weise, auszuhandeln. Einerseits vermittelt er das Gefühl einer kosmopolitischen Teilhabe am globalen Kapitalismus. Andererseits erlaubt der Konsum des exotisierten - d. h. nicht-modernen - Indiens eine Selbstvergewisserung des schweizerischen Wohlstandmodells angesichts der aufsteigenden Weltmacht Indien.

3. Schließlich werde ich darauf eingehen, wie in der Schweiz im Kontext der Integration in den dezentralen Kapitalismus eine Spaltung in der Repräsentation der „Zweiten Generation“ stattfindet. Während „gut integrierte“ Angehörige der „zweiten Generation“ aus der Mittelschicht als exotische, kosmopolitische Bereicherung im nationalen Projekt gelten können, werden Angehörige der „Zweiten Generation" aus der Unterschicht und insbesondere ex-jugoslawischer und islamischer Zugehörigkeit als „unassimilierbare Andere“ dargestellt. Diese Spaltung verweist auf das ambivalente Zusammenspiel von Assimilationsforderung und multikulturellem Begehren, das die Subjektivierungsprozesse von „Inder_innen der zweiten Generation“ seit dem Millenniumswechsel prägt. Durch ihre Zugehörigkeit zur Mittelschicht eröffnen sich dadurch für sie neue, wenn auch ambivalente Anerkennungsräume, neue professionelle und biografische Opportunitäten sowie neue Bedingungen der Subjektivierung.

\subsection{Kurze Genealogie eines KommerzielLen Multikulturalismus in DER (URBANEN) SCHWEiz}

Der Philosoph Charles Taylor hat in seinem einflussreichen und kontrovers diskutierten Aufsatz „The Politics of Recognition“ von 1992 den Begriff der Anerkennung verwendet, um eine normative Politik des Multikulturalismus zu begründen. Er argumentierte, dass Menschen Identität und Selbstwert erst durch die Aner- 
kennung durch andere entwickeln können: "Nonrecognition or misrecognition can inflict harm, can be a form of oppression, imprisoning someone, in a false distorted, and reduced mode of being." (1992:25) Ergo: "Due recognition is not just courtesy we owe people. It is a vital human need." (1992:26) Angesichts der Tatsache, dass immer mehr Gesellschaften mehr als nur eine „kulturelle Gemeinschaft" umfassen, so Taylor weiter, bestehe die Gefahr, dass das Selbstverständnis von Angehörigen von ethnischen oder indigenen Minderheiten geleugnet werde (1992:61). "The idea is that it is precisely this distinctness that has been ignored, glossed over, assimilated to a dominant or majority identity. And this assimilation is the cardinal sin against the ideal of authenticity." (1992:38, Hervorhebungen R. J.) Anerkennung besteht gemäß Taylor demnach darin, dass die Dominanzgesellschaft die Leistungen der Minderheiten als kulturell eigenständig und authentisch wahrnimmt, ihnen einen positiven Wert zubilligt und schließlich Selbstbestimmung über die Aushandlung der Differenz erlaubt. Um dies zu gewährleisten, sollte Multikulturalität als staatsbürgerliche Verfasstheit der Gesellschaft angesehen werden, die sich in politischen, sozialen und ökonomischen Rechten niederschlagen soll (Kymlicka 1995). Vor allem im angelsächsischen Raum wurde eine Politik des Multikulturalismus einerseits im Rahmen von sprachlichen und kulturellen Kollektivrechten für indigene und ethnische Minderheiten und andererseits in der Bildungspolitik diskutiert, in der multikulturelle Universitätscurricula und Schulpläne sowie Maßnahmen der affirmative action etabliert wurden. Die Schweiz wurde prägnant und zu Recht als „multikulturelles Land ohne multikulturelle Politiken" bezeichnet, wonach in der nationalen Politik der Schweiz für Migrantinnen und Migranten keine umfassenden multikulturalistischen Politiken nach angelsächsischem Modell Fuß fassen konnten (D’Amato 2010). Der Migrationsforscher Gianni D'Amato bezieht sich in seiner Analyse auf eine doppelte Bedeutung von Multikultur in der Schweiz: Einerseits setzt sich die Schweiz seit ihrer Gründung 1848 aus vier Sprachregionen zusammen, deren kollektive Rechte in Kulturpolitik, in der Bildung, in Verwaltung und Politik rechtlich oder politisch verankert wurden. Andererseits existieren kaum multikulturalistische Ansätze in Bezug auf die ausländische Bevölkerung, die im 20. Jahrhundert durchschnittlich 12,8 Prozent umfasste. Stattdessen herrsche in der Schweiz seit dem Beginn des 20. Jahrhunderts ein starker Assimilationsgedanke im Staatsbürgerschaftsrecht (ius sanguinis) vor, der sich, wie in Kapitel 2 erläutert, in einer restriktiven Einbürgerungspraxis und Integrationspolitik niederschlägt. Ich argumentiere, dass trotz der fehlenden rechtlichen und politischen Verankerung ein Topos der multikulturellen Anerkennung die urbane Schweizer Öffentlichkeit durchzieht. Wie in der Vignette der Mega Mela angedeutet, äußert die indische Diaspora mit der öffentlich zur Schau gestellten „Indianness“ den Wunsch, nach den Jahren der Assimilation von der schweizerischen Dominanzgesellschaft öffentlich wahrgenommen zu werden. Zum anderen erkannte die Stadt als Schirmherrin der Veranstaltung explizit dieses Bedürfnis an und förderte es. Mit der Mega Mela, ließe sich mit 
Taylor argumentieren, hat eine anerkennungspolitische Beziehung zwischen Dominanzgesellschaft und indischer Minderheit stattgefunden. Es stellt sich jedoch die Frage nach der Natur dieser soziomoralischen Anerkennungsbeziehung, die zwar kulturell greifbar ist, sich aber kaum politisch oder rechtlich manifestiert. Im Gegenteil: Die öffentliche Geste der Anerkennung und die populärkulturelle Sichtbarkeit von Differenz ging mit einer zunehmenden Verschärfung der Ausländer- und Asylpolitik in der Schweiz einher.

Ein policy-orientiertes und normatives Verständnis von Multikulturalismus reicht nicht aus, um die gesellschaftliche Aushandlung einer selektiven, ambivalenten Anerkennungsbeziehung in der urbanen Schweiz, wie sie an der Mega Mela stattgefunden hat, im Detail analysieren und verstehen zu können. Lois McNay argumentiert in ihrem Buch „Against Recognition“ (2008), dass Taylor normative und analytische Bedeutung von Anerkennung vermische und dadurch die Beziehung von Subjektformation und Machtverhältnissen simplifiziere.

The normative "redemptive" force that resides in the ideal of mutual recognition constrains the ways it is used as an analytical tool to explain how power creates unequal identities. In order to render recognition plausible as an ideal of self-realization and equality, sociological barriers to its possible implementation must necessarily be diminished or constructed as contingent, secondary effects of power. [...] This is achieved through the disconnection of an understanding of subject formation from an analysis of power relations, with the consequence that the ideal of recognition fails to grasp some important dimensions of the reproduction of social inequality. (McNay 2008:8, Hervorhebung im Original)

Nach McNay finden Anerkennungsprozesse in spezifischen historischen Machtverhältnissen statt, in denen sowohl die Subjektpositionen des „Eigenen“ und des „Anderen“ als auch der Topos der Anerkennung selbst diskursiv, institutionell und praktisch hergestellt und ausgehandelt werden. Gemäß dem hier verfolgten genealogischen Ansatz verstehe ich unter Topoi der Multikulturalität daher spezifische Politiken, Semantiken und Praktiken, die im Rahmen historischer Machtverhältnisse die öffentliche Anerkennung, d. h. eine Sichtbarkeit kultureller Differenz, deren positive Bewertung sowie eine gleichberechtigte Aushandlung dieser Anerkennungsbeziehung einfordern und ermöglichen sollen. In Bezug auf die Mega Mela stellt sich demnach die Frage, welche politischen, ökonomischen und populärkulturellen Prozesse die Sichtbarkeit und Aufwertung von Differenz beförderten und welche Repräsentations- und Anerkennungsbeziehungen des „Eigenen“ und des „Anderen“ sich dadurch ergaben. Um diese Frage beantworten zu können, wird im Folgenden zunächst die Entstehung und Entwicklung des Topos der Multikulturalität in der Schweiz ab den 1970er Jahren analysiert. 


\section{Zaghafte Ansätze eines politischen Multikulturalismus in der Schweiz}

Als historischer Ausgangspunkt eines Topos der Multikulturalität in der Schweiz können die politische Kritik und der Widerstand gegen das staatliche Assimilationsregime - sowie gegen den explizit kulturrassistischen „Überfremdungsdiskurs“ - angesehen werden. Aufgerüttelt von der „Überfremdungs“-Bewegung drangen ab den späten 1960er Jahren italienische Gewerkschaften und Migrant_ innenorganisationen in die politische Öffentlichkeit (Maiolino 2011). Sie kämpften für den Familiennachzug und die Aufhebung von Diskriminierungen auf dem Arbeits- und Wohnungsmarkt. Aus Solidarität mit den italienischen Arbeitskräften formierte sich gleichzeitig eine migrationspolitische Allianz christlicher Organisationen, der Drittweltbewegung, von Teilen der Gewerkschaften und radikaler linker Parteien und Organisationen, die im Jahr 1974 die „Mitenand-Initiative“ lancierte. Statt der omnipräsenten Problematisierung von Migration betonten sie das Potenzial eines „harmonischen Zusammenlebens schweizerischer und ausländischer Bevölkerungen“" (Niederberger 2004:102).

Ab dem Jahr 1970 waltete zudem die vom Bundesrat einberufene Eidgenössische Konsultativkommission für das Ausländerproblem (EKA), um wissenschaftliche und politische Grundlagen für eine aktive Eingliederungspolitik zu entwickeln. ${ }^{48}$ Neben der „rechtlichen Gleichstellung“, die der Bundesrat auf völkerrechtlichen Druck in Gang gebracht hatte, sollte die EKA die „Betreuung“ von Ausländer_innen auf dem Arbeits- und Wohnungsmarkt und im Bildungssystem und damit deren erfolgreiche kulturelle Assimilation und schließlich die Einbürgerung fördern. ${ }^{49}$

Trotz der nur mäßigen politischen Erfolge der italienischen Gewerkschaften und der EKA sowie der haushohen Niederlage der „Mitenand-Initiative“ im Jahr 1981 kann in diesen Institutionen und Netzwerken der Keim eines multikultu-

48 | Die Kommission war aus Delegierten der Arbeitgeber- und Arbeitnehmerverbände, christlichen Organisationen sowie der Nationalen Aktion und der Neuen Helvetischen Gesellschaft zusammengesetzt. Symptomatischerweise durften Ausländer-Organisationen nicht Einsitz nehmen, da sie nicht den politischen Willen der Schweiz repräsentierten.

49 | Die EKA baute ein Netz von kantonalen und städtischen „Kontaktstellen“ für Ausländerinnen und Ausländer auf, gab Empfehlungen an Schulen für integrationsfördernde Maßnahmen und setzte sich für die politische Mitsprache in Gemeindeorganen ein. Ab den 1980er Jahren baute die EKA ein Netzwerk von migrantischen Medien auf und versuchte insbesondere fremdsprachige Sendungen für Migrant_innen in den öffentlich-rechtlichen Radio- und Fernsehprogrammen einzurichten, einerseits, um deren Selbstrepräsentation zu fördern, andererseits, um die staatliche Kommunikation mit den Migrationsgemeinschaften zu vereinfachen. 
ralistischen Gegendiskurses gesehen werden. Wurde in den 1970er Jahren mit den Paradigmen der christlichen Nächstenliebe, der Menschenrechte, des Klassenkampfes und der Gleichberechtigung argumentiert, vermischen sich diese kritischen Diskurse ab den frühen 1980ern zunehmend mit der Rhetorik eines politischen Multikulturalismus aus dem angelsächsischen Raum, die explizit die vielfältige, rechtliche Verfasstheit der Nation proklamierte (Sancar 2003; Wicker 2003:47 f.; D’Amato 2010). Wegen der Nähe zu alternativen politischen Kreisen und wegen der zunehmenden integrationspolitischen Aktivitäten von Gemeinden und Kirchen wurden multikulturelle Semantiken vermehrt in parastaatlichen Kontexten wie der Sozialarbeit oder der Pädagogik verwendet, wobei dies eher in einem Alltagsverständnis ohne notwendige wissenschaftliche, professionelle Reflexivität geschah (Radtke 1992; Sancar 2003). In den 1990er Jahren wurde zudem eine explizit multikulturalistische Debatte um Minderheitenrechte und kulturelle Vielfalt relevant (Kälin 2000)..$^{50}$ In der Arbeit der Ausländerkommission EKA wurde nun kulturelle Assimilation explizit abgelehnt, weil sie - ganz im Sinne Taylors „zum Identitätsverlust und zur Preisgabe des eigenen Selbstwertgefühls, allenfalls begleitet von Störungen des psychischen Gleichgewichts" führen könnte (Schweizerischer Verband der Bürgergemeinden und Korporationen 1989:22; Sancar 2003; Suter Reich 2013).). Neben der multikulturellen Semantik verfolgte die EKA auch die Förderung einzelner multikultureller Maßnahmen, wie etwa den sogenannten Unterricht in Heimatlicher Kultur und Sprache (HSK). Denn die Schule sei ein Ort, „an dem die angestammte kulturelle Eigenart des Ausländerkindes nicht verdrängt werden darf. Vielmehr bringt das Zusammentreffen verschiedener Kulturen für alle, Ausländer und Einheimische, eine Bereicherung" (Schweizerischer Verband der Bürgergemeinden und Korporationen 1989: EKA-Info 5). ${ }^{51}$

50 | Das Bundesgericht hatte in einem paradigmatischen Entscheid von 1993 ein türkisches Mädchen vom Schwimmunterricht dispensiert, weil dieser ihrer "strenggläubigen Auffassung des Islam" widersprach (Urteil der II. öffentlich-rechtlichen Abteilung des Bundesgerichtes vom 18. Juni 1993, BGE 119 la 18). Diese Handhabe wurde jedoch 2008 durch einen anderen, von juristischen und migrationswissenschaftlichen Experten als "schlampig" disqualifizierten Entscheid mit der Forderung nach "Integration" revidiert.

51 | In ihrer Analyse der Vergabe des Integrationskredites (VIntA vom 13. September 2000) an alevitische Organisationen in der Periode von 2001 bis 2004 zeigt Virginia Suter Reich, dass bei der Vergabe in den ersten Jahren neben der Qualität der Projekte auch die Anerkennung der ehrenamtlichen Arbeit der alevitischen Organisationen für die Sprachförderung ihrer Mitglieder sowie für die Förderung der Toleranz ausschlaggebend war. In der zweiten Förderungsperiode verschwand der Anerkennungstopos zugunsten des neo-assimilatorischen Konzepts des "Förderns und Forderns", das auf Eigenverantwortung und Sprachkompetenz basiert (Suter Reich 2013:296 f.). 
Zusammenfassend lässt sich feststellen, dass dezidiert multikulturalistische Aspekte auch in der Arbeit der EKA (und weiterer parastaatlicher Institutionen) stets selektiv und marginal blieben. Sie blieben eingebettet in ein neues Integrationsparadigma, das neben dem neuen Fokus auf institutionelle und soziale Teilhabe - trotz gegenteiliger Aussagen - weiterhin stark von assimilationistischen Konzepten geprägt war. Sowohl im Ratgeber "Ausländer in der Gemeinde“ (Schweizerischer Verband der Bürgergemeinden und Korporationen 1989) als auch in den „Umrissen zu einem Integrationskonzept“ (Riedo 1996) wird der „Zweiten Generation" angesichts eines drohenden „Kulturkonflikts" große Sorge entgegengebracht. Dieser „Kulturkonflikt“ werde zudem durch die „kulturelle Distanz“ gesteigert, weshalb auch die EKA das so genannte Dreikreisemodell unterstützte, eine migrationspolitische Strategie, wonach außereuropäische Migrantinnen und Migranten aus nicht-westlichen Ländern nur in Ausnahmefällen Niederlassungsbewilligungen erhalten sollten. Trotz der Pluralisierung der migrationspolitischen Narrative und Strategien wurde die „Kultur der Anderen“ im staatlichen Migrationsdispositiv der späten 1980er und der 1990er Jahre grundsätzlich weiterhin als Assimilationshindernis angesehen. Kurz: Die zaghaften multikulturalistischen Semantiken führten dazu, die Bedeutung von „Kultur“ als essenzialistisches Konzept zu stärken. Neben der assimilatorischen Sprache der Problematisierung wurde jedoch gleichzeitig eine multikulturalistische Sprache der Anerkennung und der Aufwertung kultureller Differenz in den sozioethischen und affektiven Beziehungen zwischen den „Eigenen“ und den „Anderen“ eingeführt.

Aber auch diese schwachen Ansätze eines politischen Multikulturalismus verpufften auf nationaler Ebene schließlich vollständig. Im Zuge der politisch und medial äußerst wirksamen "neuen Überfremdungsbewegung“ unter der Ägide des rechten Zürcher Flügels der Schweizerischen Volkspartei (SVP) ab den frühen 1990er Jahren war das Bestreben nach politischer multikultureller Anerkennung von Migrantinnen und Migranten in der affirmativen Politik der Mitte kaum durchsetzbar (Skenderovic/D’Amato 2008; Buomberger 2004). Trotz der kaum namhaften Bemühungen für einen (wirklichen) politischen Multikulturalismus in der Schweiz verkündete schließlich Eduard Gnesa, der damalige Chef des Bundesamtes für Migration, 2007 das endgültige "Scheitern des Multikulturalismus“.52 Stattdessen hatte sich auf nationaler Ebene ein Integrationskonsens eines „Fördern und Forderns" herausgebildet, der assimilatorische Ansätze im Namen eines Verfassungspatriotismus wieder einführte und die neoliberale Messung und Bewer-

52 | Zum gesamteuropäischen „Backlash gegen den Multikulturalismus" vgl. Vertovec/ Wessendorf (2010). Zur Theoretisierung dieser Tendenz im Sinne eines „Post-Multikulturalismus" vgl. Strasser (2014). 
tung von "guten“ und „schlechten“ Migrant_innen in selektiven Integrationsmaßnahmen und Bewilligungskriterien institutionalisierte (Piñero al. 2009). ${ }^{53}$

\section{Zürichs Aufstieg zur "Weltstadt", Mediterranisierung des öffentlichen Raums und Indienhype}

Während die Ansätze zu einem politischen Multikulturalismus auf nationaler Ebene verpufften, befanden sich die Schweizer Städte ab den 1990er Jahren in einem anderen politischen, ökonomischen und sozialen Kräftefeld, das es erlaubte - ja sogar erforderte -, den Topos der Multikulturalität im Sinne der Sichtbarkeit und Aufwertung von kultureller Differenz zu inkorporieren. Gemäß dem Sozialanthropologen Rudolf Wicker waren die Städte maßgeblich dafür verantwortlich, in den 1990er Jahren eine aktiv Integrationsmaßnahmen mit entsprechenden multikulturellen Nuancen einzuführen, die schließlich auch zu einer nationalen Integrationspolitik beitrugen (Wicker 2009:23 f.). Da Migrant_innen überproportional häufig in den Städten lebten, sahen sich die lokalen Behörden mit konkreten interkulturellen Kommunikationsproblemen in der Verwaltung, der Sozialarbeit und der Schulbildung konfrontiert. Broschüren in mehreren Sprachen, interkulturelle Übersetzer_innen, Unterricht in Sprache und Kultur der Herkunftsländer und die Zusammenarbeit mit religiösen Organisationen und Migrationsvereinen waren notwendige, situative multikulturalistische Maßnahmen innerhalb der städtischen Verwaltungslogik. Im Folgenden möchte ich am Beispiel von Zürich zeigen, dass es neben diesem Verwaltungsethos weniger migrationspolitische Entscheidungen als vielmehr die Anpassung an globale strukturelle Wirtschaftsprozesse waren, die die städtische Aneignung des multikulturellen Topos nachhaltig beförderten.

Hitz et al. haben argumentiert, dass sich Zürich seit den 1970er Jahren zunehmend zu einer global city entwickelte (Hitz et al. 1995). Die exportorientierte Zürcher Industrie war mit ihren hohen Lohnkosten schlecht auf die Wirtschaftskrise der 1970er Jahre vorbereitet und reagierte durch Rationalisierung, Spezialisierung, Auslagerung sowie durch die Nichtverlängerung von Arbeitsbewilligungen von Zehntausenden von Gastarbeiter_innen. Zürich etablierte sich in diesem Struk-

53 | Es ist eine Ironie der Geschichte, dass die anti-essenzialistische Kritik am Multikulturalismus von linken Kreisen und insbesondere auch von Ethnolog_innen die positiven Aspekte des politischen Multikulturalismus angelsächsischer Prägung aus dem Diskurs gedrängt hat. Mit dem strukturellen Integrationsbegriff wurde eine kritische Auseinandersetzung mit Differenz in der Form von Anti-Rassismus oder einer multikulturellen Verfasstheit der Nation aus dem Diskurs der Migrations- und Integrationspolitik verdrängt. Der Integrationsbegriff mit seiner differenzpolitischen Leere und seiner interventionistischen Stoßrichtung eignete sich schließlich zur neo-assimilationistischen Re-Interpretation im heutigen Integrationsregime des „Förderns und Forderns". 
turwandel zum Inbegriff einer Schweizer "headquarter economy, die vor allem auf die Organisation der transnationalen Produktion und die Steuerung der globalen Kapitalkreisläufe spezialisiert ist." (Hitz et al. 1995:215) Die Entwicklung Zürichs zu einer global city war jedoch keineswegs linear, geplant oder zwangsläufig. Noch in den 1960er Jahren setzte die Zürcher Stadtregierung zusammen mit den liberalen Wirtschaftskreisen auf eine städtische Modernisierungsstrategie, die von umfangreichen Verkehrsinfrastrukturprojekten, Gentrifizierung und der Funktionalisierung des öffentlichen Raumes geprägt war. Dieser technokratische Versuch, Zürich an die globale Wirtschaft anzukoppeln, führte jedoch in eine „Krise der Stadt“: „Die forcierte Globalisierung kollidierte mit dem provinziellen politischen und kulturellen Klima Zürichs, mit einer bornierten kleinstädtischen Enge, einem eklatanten Mangel an städtischen Lebensformen“ (Hitz et al. 1995:244). Angesichts wachsender Wohnungsnot, fehlender kultureller Freiräume und zunehmender Verkehrsbelastung entstand zuerst mit der 68er- und später mit der 80er-Bewegung eine heterogene Gegenkultur aus linken, ökologisch orientierten und spontaneistischen Kreisen, die für gesellschaftliche Veränderungen, alternative urbanistische Visionen und für kulturelle Freiräume kämpfte. In dieser entstehenden urbanen Gegenkultur verkehrten und vernetzten sich auch Teile der oben erwähnten migrationspolitischen Allianz. Der Slogan der 80er-Bewegung, "Nieder mit den Alpen, freie Sicht aufs Mittelmeer", verdichtet die Forderung nach urbaner Weltoffenheit und vielfältigen soziokulturellen und ethnischen Lebensstilen, die nicht den Vorstellungen der kleinbürgerlichen Provinzialität der Schweiz entsprachen.

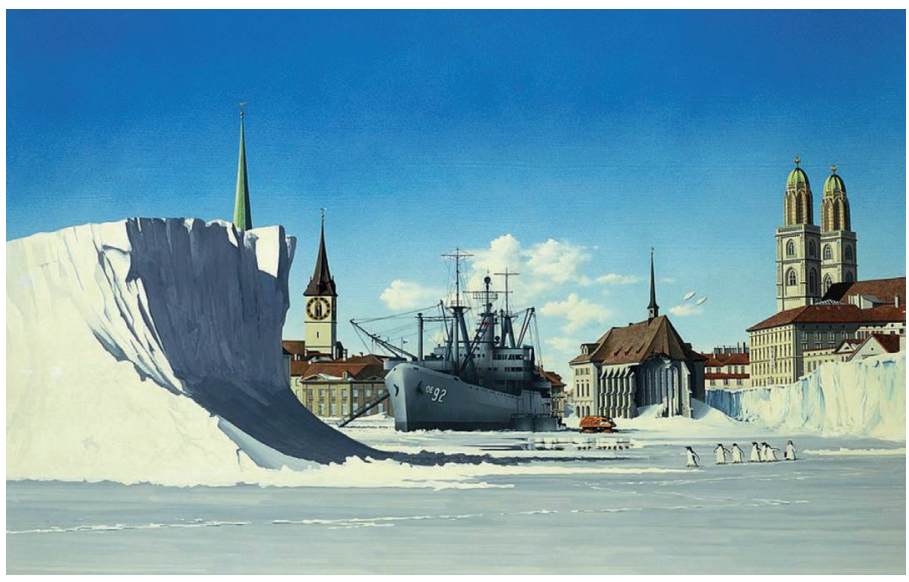

Abbildung 12: Das Bild "Zürich Eiszeit" von Giuseppe Reichmuth aus dem Jahr 1975 etablierte das Bild der Kälte für das Lebensgefühl in der Schweiz (Quelle: Giuseppe Reichmuth) 
Italienische Gastarbeiter_innen waren in dieser gegenkulturellen Imagination nicht - wie für die bürgerliche Dominanzgesellschaft - gefährliche Kommunisten und Anarchisten, sondern auch vorbildliche Lebenskünstler, Genießer und Rebellen. Als Reaktion auf den gegenkulturellen Widerstand förderte die Stadt Zürich ab Anfang der 1980er Jahre Viertel mit urbanem Flair sowie kulturelle Freiräume wie die Rote Fabrik, das Theaterspektakel oder das Theater Gessnerallee. Diese kulturpolitische Kursänderung war sowohl auf einen generationellen Wechsel in der Regierung und der Verwaltung zurückzuführen als auch auf einen Schulterschluss von Sozialdemokratie und Freisinn im Stadtzürcher Parlament der 1980er und 1990er Jahre. Gleichzeitig war er auch eingebettet in ein größeres politisches Projekt der Restrukturierung Zürichs im Kontext des globalen Kapitalismus. Unter der Ägide einiger Chefbeamter im Präsidialamt entwickelte sich eine strategische Planung des Stadtmanagements als Verbindung von Stadtentwicklung, Standort- und Wirtschaftsförderung sowie Kulturpolitik. Paradoxerweise ermöglichte, so Hitz et al., die politische Inkorporation des Widerstands gegen die bürgerliche Hegemonie langfristig die Restrukturierung Zürichs zur global city.

Im Spannungsfeld von Widerstand und Integration wurde die von der 80er-Bewegung geforderte und gelebte Öffnung so selbst zu einem Faktor der ökonomischen Attraktivität Zürichs. Die neuen Archipele der „alternativen Kultur“ machten Zürich zur „Weltstadt“, die sie allein mit der distinguierten Monokultur von Banken und Multis nie geworden wäre. (Hitz et al. 1995:247)

Ausgehend von den alternativen und multikulturalistischen Milieus und gefördert von der städtischen Kulturpolitik manifestierte sich ab den späten 1980er Jahren eine „Mediterranisierung“ des öffentlichen Raumes (Maiolino 2010). Restaurants und Bars entdeckten nach dem Vorbild der italienischen Piazza die Straße als Lebens- und Konsumraum und die lokale Schweizer Bevölkerung begann, wie früher die italienischen Gastarbeiterfamilien, die Seepromenade zu bevölkern. Ab den 1990er Jahren wurde „Weltoffenheit“ zur programmatischen Leitidee des Zürcher Stadtmarketings. Öffentliche Spektakel waren wichtige Räume, in denen sich Zürich als global city inszenieren und der Konsum von Kultur und Vielfalt als urbaner Lifestyle inkorporiert werden konnte. ${ }^{54} 1992$ wurde die erste „Streetparade“ als „Demonstration für Liebe, Frieden, Freiheit, Großzügigkeit und Toleranz“ bewilligt. 1995 fand mit dem „Caliente“ zum ersten Mal das größte Latin-Festival der Schweiz statt. Und auch das Theaterspektakel etablierte sich als kosmopolitische Plattform, wie etwa 1993 für Peter Brooks Inszenierung des hinduistischen Epos „Mahabharata“.

54 | Zur Restrukturierung der Zentren von global cities zu Konsumzonen, in denen authentische Erfahrungen als Spektakel inszeniert werden vgl. Zukin (2010), Harvey (1990b). 


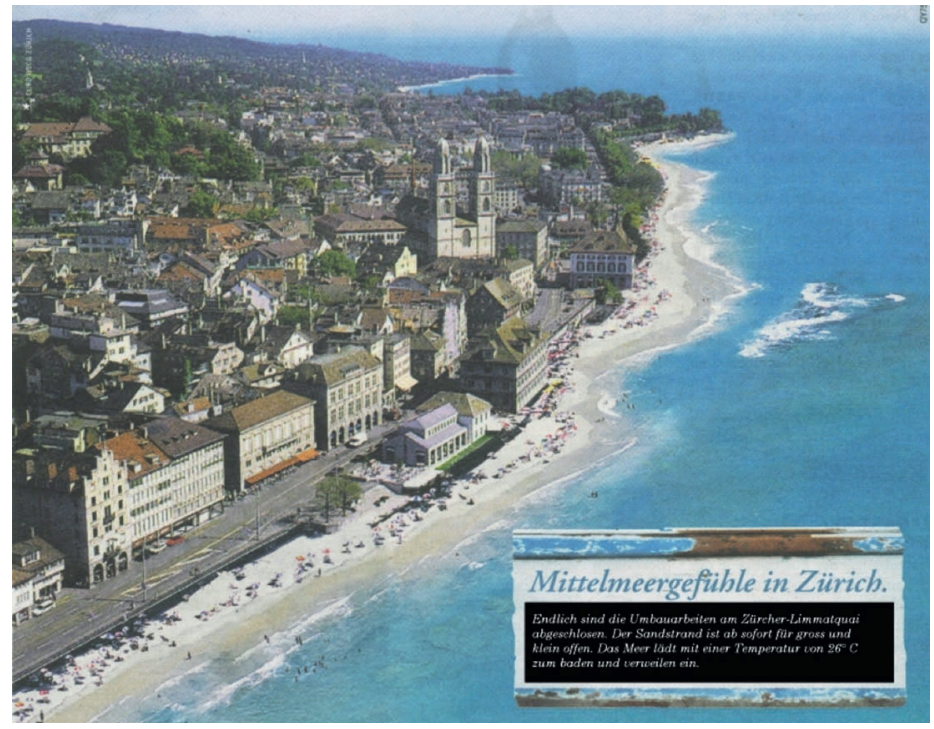

Abbildung 13: „Nieder mit den Alpen, freie Sicht aufs Mittelmeer": Inkorporation der 80er Bewegung führte zu einer kulturökonomischen Mediterranisierung in der global city statt zu politischer Teilhabe von Migrant_innen. Zeitungsartikel mit stadtbekanntem Sujet. (Quelle: Autor)

Während also in den 1990er Jahren der politische Multikulturalismus auf nationaler Ebene verpuffte, wurde seine Semantik der öffentlichen Anerkennung von Differenz in Zürich gemäß der Verwertungs- und Verwaltungslogik der global city inkorporiert. Die in den urbanen Raum eingeschriebene soziokulturelle und ethnische Vielfalt bestätigte Zürichs Status als global city und wurde selbst zu einem unverzichtbaren symbolischen und ökonomischen Wert. Die Aneignung der multikulturellen Gegenkultur in das Projekt der global city war jedoch geprägt von einer strukturellen Neutralisierung des Politischen. Während die politischen Kämpfe der italienischen Migrant_innen in den 1970er Jahren größtenteils abgeblockt wurden, tauchte „Italianità “ in den 1990er Jahren als kulturelle und ökonomische Ressource in der Reartikulation des urbanen Raums im globalen Kapitalismus wieder auf. Während kulturelle Differenz als Ware im öffentlichen Raum anerkannt wurde, blieben die politischen Subjekte von den Aushandlungen der Bedingungen dieser Anerkennungspolitik ausgeschlossen. Salopp formuliert, forderte die Schweiz von den italienischen Gastarbeitern Pizza statt Klassenkampf. ${ }^{55}$

55 | Symptomatisch gelten "die Italiener" heute als angepasste Lieblingsausländer in der (Deutsch-)Schweiz, ein Narrativ, das die strukturelle Gewalt und den Rassismus in den Arbeitsverhältnissen und im Alltag ausblendet, die Gastarbeiter_innen, Saisonniers und deren Kinder erdulden mussten. Den Status als Lieblingsausländer haben 
Die Analyse, dass der Multikulturalismus, der aus politischen Bürgerrechtsbewegungen entstanden ist, von Nationalstaaten im Zuge ihrer Inkorporation in den globalen Kapitalismus reinterpretiert wurde, wird von anderen anthropologischen Forschungen bestätigt. Die konkreten Strategien betreffen zum Beispiel die Liberalisierung von Staatsbürgerschaftsregelungen zur Attraktion von Investitionen in Kanada (Mitchell 1997) und auch staatliche multikulturelle Programme zur Sühne kolonialer und rassistischer Vergangenheit in Australien (Povinelli 2002). Gargi Bhattacharya hat in ihrer Analyse der Entwicklung des Multikulturalismus in Großbritannien dargelegt, dass sich sowohl dessen politisch-institutionelle Praxis als auch dessen explizite Rhetorik in ständiger, gesamtgesellschaftlicher Aushandlung befinden. So verschwand die politische Sprache des Multikulturalismus in den 1990er Jahren fast vollständig aus der britischen Öffentlichkeit. Gleichzeitig wurde die multikulturelle Logik in der heritage industry der Stadtplanung wieder aufgenommen, um Quartiere wie Chinatown zu touristischen und kulturellen Erlebniszonen umzunutzen. Bhattacharya schreibt: „Some versions of multicultural thinking have sifted into various areas of life" (Bhattacharya 1998:252) - also aus der Politik in die Ökonomie, in die Stadtplanung oder in die Konsumkultur. In solchen vielfältigen Prozessen haben sich auch die Bedeutung und Wirkung multikultureller Topoi in der Schweiz verändert. In diesem Sinne möchte ich von einem kommerziellen Multikulturalismus in der urbanen Schweiz sprechen. Darunter verstehe ich ein Regime staatlicher Praktiken, ökonomischer Prozesse und populärkultureller Narrative, in dem öffentliche Sichtbarkeit und Anerkennung von kultureller Differenz im Akt der ökonomischen Verwertbarkeit hergestellt und ausgehandelt wird, ohne jedoch rechtlich sanktioniert zu sein oder formale politische Teilhabe zu erlauben.

Im Kontext dieses kommerziellen Multikulturalismus nahm ab dem Millenniumswechsel in Zürich die Präsenz von „Indianness“ im öffentlichen Raum und in der Populärkultur derart zu, dass getrost von einem „Indienhype“ gesprochen werden kann. ${ }^{56}$ Ausgangspunkt des „Indienhypes“ war die Rezeption des indischen

sich "die Italiener" also durch das Schweigen auf den politischen Druck des Assimilationssystems erlitten. Pikanterweise taucht die Rolle migrantischer Kämpfe für die 80er Bewegung, die Stärkung der Gewerkschaften sowie die progressive Migrationspolitik auch in linken erinnerungspolitischen Diskursen kaum mehr auf. Auch in der wichtigen Analyse von Hitz et al. (1995) zur Entwicklung Zürichs zur global city wird weder die Rolle migrantischer Akteure in der 80er Bewegung erwähnt noch die Rolle von Migration, um die global city zu re-/produzieren und als weltoffene, vielfältige Stadt zu vermarkten (Schmid/Weiss 2010; Jain 2017).

56 | Eine solche Kommodifizierung indischer Exotik wurde in Großbritannien und den USA schon ab 1998 festgestellt. Ausgangspunkt war Madonnas Video zum Stück "Frozen" (1998), in dem sie klassisch indische Rhythmen, hinduistische Textfragemente und Henna-Tattoos verwendete (Maira 2000; Kalra/Hutnyk 1998). 
Bollywood-Kinos in der Schweiz, das bis anhin fast vollständig unbekannt war. Durchbruch war der Publikumspreis für den Film „Lagaan“ („Steuer“, 2001) von Ashutosh Gowariker beim Filmfestival von Locarno 2001. 2002 wurde Bollywood im Zürcher Museum für Gestaltung die erste Ausstellung in der Schweiz gewidmet. Parallel zeigte das alternative Zürcher Kino Xenix die Reihe „Bollywood - Populäres Hindi-Kino von den 30er Jahren bis heute - die (unbekannte) Schweiz indischer Kinoträume“. Seither werden ausgewählte Bollywood-Filme immer wieder in den normalen Programmen von - meistens alternativen, urbanen - Kinos gezeigt. Daneben sind Bollywood-Blockbusters als eigenes Genre in DVD-Geschäften etabliert und in urbanen Zentren sind Bollywood-Tanzkurse und -Partys gang und gäbe. Einen besonderen Boom erlebte auch die indische Kulinarik: Indisches Essen war im vegetarischen Restaurant Hiltl in Zürich schon ab 1951 erhältlich. $\mathrm{Ab}$ den 1960er Jahren eröffneten indische Migrantinnen und Migranten einzelne Restaurants, insbesondere in den Städten, die jedoch nur von einer spezialisierten Klientel von Indientourist_innen, kosmopolitischen Gourmets, Neugierigen und indischen Migrant_innen selbst frequentiert wurden. Um den Millenniumswechsel entstand eine Vielzahl neuer Restaurants und Take-away-Buden mit regionaler Spezialisierung und urbanem Flair, die neue Kundensegmente anzogen. Auch kleine Lebensmittelläden begannen sich zu etablieren. Ab 2005 bot zudem auch die größte schweizerische Lebensmittelkette Migros ein indisches Sortiment mit Gewürzen und Fertiggerichten an, die von der Restaurantkette King's Kurry aus Zürich kulinarisch gestaltet wurde. Auch Yoga konnte sich vom Ruf einer kuriosen Körperpraxis von Spät-Hippies befreien und sich als urbane Selbsttechnologie etablieren, die Gesundheit, Fitness und Individualismus verknüpft (Strauss 2005). In Zürich existieren Dutzende Yoga-Schulen mit unterschiedlichen Ausrichtungen für unterschiedliche Bedürfnisse, und seit 2010 findet jährlich ein Yoga-Festival nach kalifornischem Vorbild statt. Ab den 1990er Jahren fanden auch neue indische Klänge den Weg in die urbane Populärkultur. Zuerst wurden in der Clubszene Asian underground - eine musikalische Adaptation klassischer indischer Musik und Electronica (vor allem Drum'n'Bass) - und British Asian bhangra - ein Remix aus Volksmusik aus Punjab, Hip-Hop, Pop oder elektronischen Elementen - rezipiert, die in der britisch-südasiatischen Subkultur entstanden waren (Sharma et al. 1996; Banerjea 2000). Mit dem Bollywood-Boom wurde in der Öffentlichkeit vermehrt die Film-Popmusik bekannt. Schließlich sind in den letzten Jahren indische Designs und Textilien wie Seidenschals, Tuniken, Hemden, Sandalen, Schmuck usw. nicht mehr nur auf Wochenmärkten, sondern in multinationalen Modehäusern wie H\&M oder Zara sowie in hippen Kleidergeschäften zu finden. Indische Alltagsgegenstände - insbesondere Einkaufstaschen, Filmplakate oder Buchstabentafeln mit Devanagiri- oder Tamil-Schriftzeichen -, hinduistische Statuen, Kalender und Sticker werden in urbanen Lifestyle-Geschäften als Kitsch-Objekte verkauft, die zunehmend die Wände und Kommoden nicht mehr ausschließlich alternativer Wohngemeinschaften schmücken. 

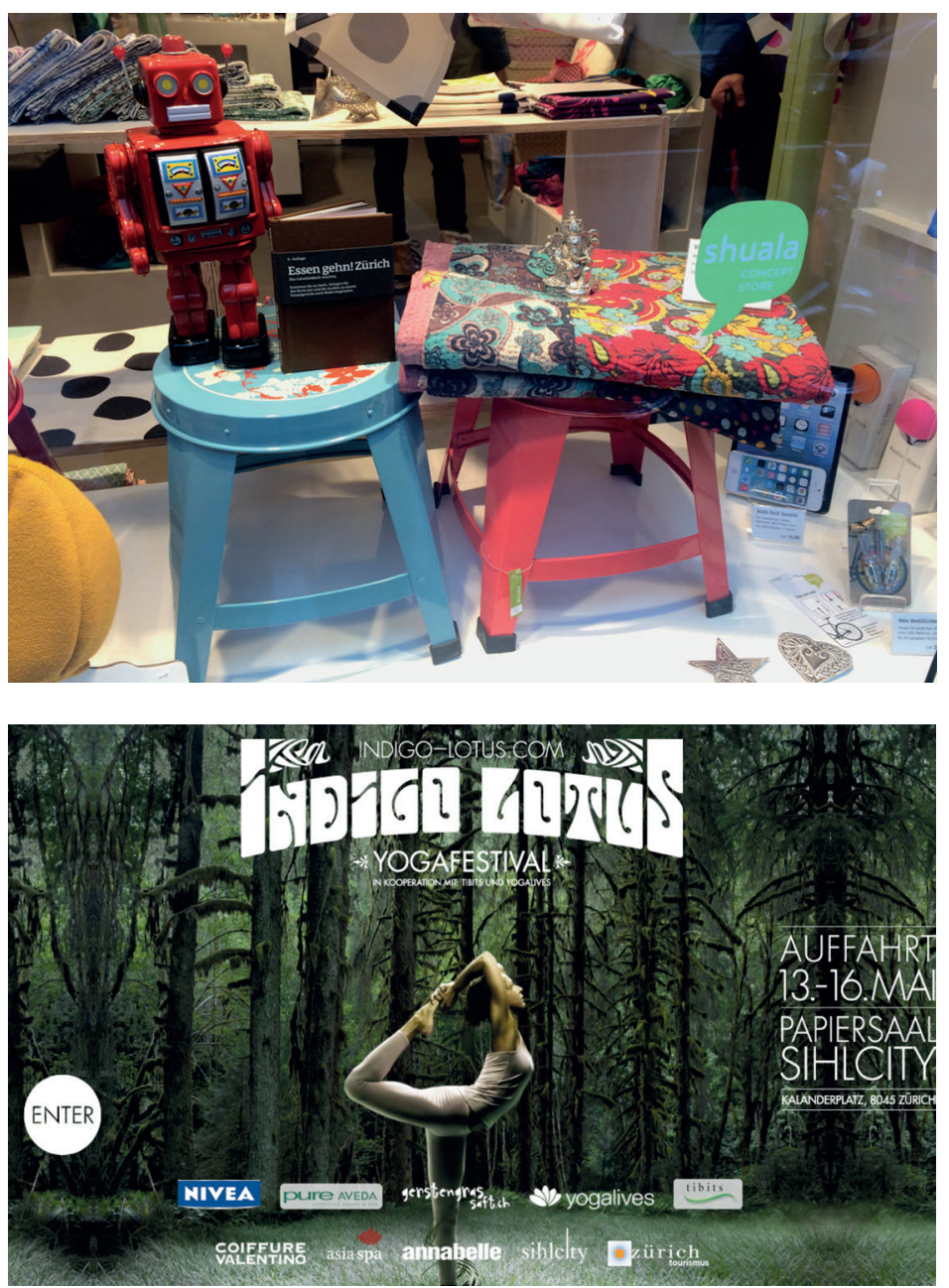

Abbildungen 14a) und 14b): Indien ist omnipräsent in der feinmaschigen, ästhetischen Textur der global city. Flyer Yogafestival und Auslage Boutique mit Textilien, Hockern und Ganesha-Statue (Quelle: Autor)

\section{"Showcase India" - warenförmige Anerkennung in der urbanen Schweiz}

Die Geschichte der Mega Mela 2008 bot geradezu eine ideale ethnografische Forschungsarena, um die Dynamik, Mikropolitik und Semantik herauszuarbeiten, in der die Anerkennungsbeziehungen zwischen Akteuren der indischen Diaspora, der Stadt Zürich und der schweizerischen Öffentlichkeit im Kontext von kommerziellem Multikulturalismus und Indienhype ausgehandelt wurden. Im Sinne 
Lois McNays zeigen sich darin die machtvollen Bedingungen, innerhalb derer bestimmte Formen der Anerkennung und Repräsentation entstehen und andere ausgeschlossen werden.

Der Indische Verein Zürich (Indian Association Zurich, IAZ), der das „Grüezi India Festival" organisiert hatte, wurde 1954 von einer kleinen Gruppe indischer Studierender der ETH Zürich mit dem Ziel gegründet, sich gegenseitig im Alltag zu unterstützen, kulturelle und religiöse Feste zu feiern sowie den schweizerisch-indischen Dialog zu fördern. Der seit 2004 amtierende Vorstand des Indischen Vereins Zürichs hatte dieses Streben ambitioniert und visionär weitergeführt, und bediente sich darin zunehmend einer multikulturalistischen Rhetorik. Im Editorial der zweisprachigen Publikation „indialogue“, die im selben Jahr zum 50. Jubiläum des Indischen Vereins Zürich erschien, schreibt der Herausgeber:

Wichtig ist es ihnen [den Frauen, Männern und Kindern in diesem Buch], ihrer kulturellen Eigenart und deren Veränderbarkeit Ausdruck zu geben. Sie möchten es sich dann und wann leisten können, vor den durchschimmernden Vorhang zu treten, in den Kleidern ihrer Wahl, um ihren Dialog mit den individuellen und kollektiven Identitäten anderer Menschen zu führen. (Indischer Verein Zürich 2005:7, Hervorhebung R. J.)

In diesem Zitat wird der (implizite) Bezug zum multikulturellen Anerkennungsdiskurs im Sinne Taylors deutlich: Der Vorhang ist eine Metapher für die assimilatorische Grenze, die die ethnische Selbstrepräsentation ins Private verbannt. Das auf Deutsch geschriebene Editorial formuliert dabei den Anspruch, dass die betroffenen Menschen vor den Vorhang treten und die „Kleider ihrer Wahl“ tragen - als Metapher für Authentizität und Selbstbestimmung - sowie „ihren eigenen Dialog" führen können. Dieser Wunsch nach Selbstrepräsentation wurde dadurch begünstigt, dass im selben Jahr eine Kooperation mit der Stadt Zürich entstand, als diese im Rahmen einer Ausstellungsreihe zu Weltreligionen die Ausstellung „Hinduistisches Zürich " organisierte, die die religiöse Vielfalt der Zürcher Bevölkerung dokumentieren und den interkulturellen Dialog fördern sollte. Im Vorwort zum sogenannten „Hindu-ABC“, dem Katalog der Ausstellung, schrieb der damalige Stadtpräsident Elmar Ledergerber:

Es ist schon beinahe eine Plattitüde, von einer globalisierten Welt zu sprechen. Begriffe wie Multikulturalität gehören in unsere Welt, und Begegnungen mit fremden Kulturen und Religionen sind nichts Aussergewöhnliches mehr. Wir [sic!] müssen nicht mehr ins Flugzeug steigen, um hinduistische Tempel aufzusuchen. Es gibt heute in und um Zürich einige hinduistische Tempel, mit Priestern, Zeremonien und Tempelfesten. Indische Geschäfte bieten alles an, was man für ein echtes Ritual benötigt. Die Liste der Yoga-Schulen ist lang, noch länger als die der tamilischen Restaurants [...]. Mit 
der Ausstellung „Hinduistisches Zürich“ möchten wir einen Einblick in die Lebenswelt der Zürcher Hindus geben. (Beltz 2004: Vorwort)

Im Zitat fällt die zeitliche Markierung Zürichs als weltoffene Stadt auf: Zwar habe es einmal eine Zeit gegeben, in der Begegnungen mit fremden Kulturen und Religionen etwas Außergewöhnliches gewesen seien. Das heutige Zürich sei jedoch so global vernetzt und so kulturell vielfältig geworden, dass diese Zeiten kaum mehr der Rede wert seien. Aber diese „Weltoffenheit“ erweist sich bei genauerem Lesen nur als performative Inszenierung respektive als politisches Programm, da Multikulturalität zwar als „Begriff“ und Imagination omnipräsent sind, aber nicht als Praxis. Die Rede des Stadtpräsidenten, die Ausstellung selbst und auch das „Hindu-ABC“ sind die pädagogischen Mittel des Staates, um diese Weltoffenheit im urbanen Zusammenleben zu fördern. Die Ausstellung „Zürcher Hindus“ und das „Hindu-ABC“ sollen erlauben, diese „Anderen“ zu sehen und kennenzulernen, sich sowohl Wissen über sie anzueignen als auch ihnen zu begegnen. Der „Reiseführer" verspricht eine lehrreiche und genussvolle Horizonterweiterung, die aber letzlich auf dem musealen und touristischen Konsum der exotischen „Anderen“ im urbanen Raum basiert. Im Projekt der Ausstellung „Hinduistisches Zürich“ verband sich eine multikulturelle Pädagogik mit der Inszenierung der „Weltoffenheit Zürichs“, in der sowohl die lokale schweizerische Bevölkerung „sensibilisiert“ als auch Migrant_innenorganisationen „einbezogen“ werden sollten. Im Rahmen der Ausstellung „Hinduistisches Zürich“ wurde deshalb der Indische Verein Zürich angefragt, eine Diwalifeier im Stadthaus zu organisieren. Entgegen allen Erwartungen war der öffentliche Ansturm überwältigend und wirkte auch für die Organisator_innen als totale Überraschung, wie Rupa Ramakrishnan, Event-Managerin und Mitglied des Organisationskomitees, in einem Interview erzählte:

We said, let's have the Puja [hindustisches Ritual, R. J.] at five o'clock, that will be for the Indians, they will come and do the Puja, and after that we had a cultural programme with food and everything. But, at five o'clock the hall was full of Swiss people waiting for the Puja to start, no Indians to be seen, it was an eye opener for us, what all we can do to showcase India to the Swiss, to involve the Swiss.

Das Begehren nach indischer Exotik und interkultureller Begegnung in der urbanen Schweizer Bevölkerung spiegelt sich auch in der medialen Öffentlichkeit, wie der Artikel „Eine Zeremonie der Freude und des Lichts“ in der „NZZ“ am nächsten Tag belegt:

Durch die Menschenmenge wieseln Frauen mit langen schwarzen Haaren und mit Augen, die so dunkel sind wie die Nacht. Die Frauen sind in Kleider aus edlen Stoffen gehüllt, die mit Perlen und kunstvollen Stickereien besetzt 
sind. Dazu tragen sie funkelnden Festtagsschmuck aus Gold mit glitzernden Steinen. Auf der Bühne tanzen kleine Inderinnen anmutig zu traditionellen Klängen oder zu Songs aus den Bollywood-Filmfabriken. Derweil wird das Publikum mit klebrigen, wohlschmeckenden Süssigkeiten verwöhnt. Bei manchen wird dadurch der Hunger nach mehr geweckt, der sich glücklicherweise an Ort und Stelle bestens stillen lässt: In den oberen Stockwerken rühren indische Köche in grossen Kochtöpfen, aus denen es göttlich gut riecht. ${ }^{57}$ („NZZ“ vom 15.11.04)

In der medialen Darstellung der „NZZ“-Redaktorin rutscht der durch die Stadt angestrebte zwischenmenschliche Dialog endgültig in die Repräsentation indischer Exotik ab. In der kurzen Meldung taucht fast das gesamte exotisierende Repertoire auf, das die lange orientalistische Repräsentationsgeschichte Indiens in Europa kannte: Mysteriöse Frauen, der sagenhafte Reichtum der Maharadschas, der kulinarische Zauber der Gewürze und die Assoziation mit einem außerweltlichen polytheistischen Pantheon. Der Riesenerfolg der Diwali-Feier 2004, die guten Beziehungen zur Stadt und das zunehmende öffentliche Interesse an indischer Exotik motivierten den Vorstand des Indischen Vereins dazu, zum 60-jährigen Jubiläum des schweizerisch-indischen Freundschaftsvertrages 2008 das Indienfestival „Grüezi India“"zu veranstalten, in dem die Mega Mela im Bahnhof Zürich der Höhepunkt sein sollte. Die Mega Mela sollte die Ankunft der indischen Diaspora im Herzen der Schweizer Öffentlichkeit markieren, nachdem im Assimilationsregime "Indianness" in den privaten Raum verbannt war. Jedoch verwendeten Organisator_innen der Mega Mela nicht eine politische Sprache der Anerkennung, die auf die Missachtung von Rechten oder auf Diskriminierung referiert hätte. ${ }^{58}$ Aber auch der anerkennungspolitische Anspruch, „einen eigenen Dialog“ zu führen, wurde in der neoliberalen Stadt zunehmend zugunsten einer kommerziellem Logik abgeschliffen, die sich um die Praxis des Verkaufs, des Konsums und des ästhetischen Genusses von „Indianness“ drehte, wie in Rupa Ramakrishnas Aussagen in einem Interview mit dem Autor deutlich wird:

For example the restaurants, we give them an opportunity, to showcase themselves. [...] So people know what Indians are doing here, what is going on in the Indian community. And it is not blatantly said, but through all these things people realise that there is an Indian community here, that this [the

57 | Gemäß dem Artikel „Eine Zeremonie der Freude und des Lichts“ vom 15. November 2004. Online: http://www.nzz.ch/aktuell/startseite/article9ZRUF-1.334720 (gesichtet am 4. Oktober 2012).

58 | Dies wäre zweifellos möglich gewesen, da sich zu dieser Zeit viele Angehörige der hoch qualifizierten indischen Mittelschicht in der Schweiz über Diskriminierung auf dem Wohnungsmarkt und über Alltagsrassismus beklagten. 
Mega Mela] is happening [...] just for the sake to make India known, giving Indians the opportunity to show themselves here in Switzerland. So through that the Indian community benefits from it. Of course, I would even say that eighty percent of our audience is Swiss, or local people who are interested, but not Indians.

In dem omnipräsenten Motiv der „Sichtbarkeit“ („to showcase India“, „Einblicke geben“, etc.) verknüpfen sich die multikulturelle Sprache der Anerkennung und die Praxis des Differenzkonsums, die beide an einer möglichst prägnanten und positiven Präsenz in der Öffentlichkeit orientiert sind. Die unterschiedlichen Perspektiven und Interessen von Migrantenorganisation, der Stadtverwaltung und der Medien treffen sich aus unterschiedlichen Gründen in der Sichtbarkeit von „Indianness" und insbesondere von indischer Exotik. Das eröffnet einen spezifischen soziomoralischen Raum für die Aushandlung zwischen „Eigenen“ und „Anderen“ in der global city. Der kommerzielle Multikulturalismus verbindet die Suche nach Anerkennung mit einer globalen Kommodifikation von Ethnizität. Wie die Sozialanthropolog_innen Jean und John Comaroff in ihrem Buch „Ethnicity Inc.“ argumentieren: "Identity, from this vantage, resides in recognition from significant others, but the kind of recognition specifically expressed in consumer desire." (Comaroff/Comaroff 2009:10). Statt die politischen und ethischen Bedingungen des Anerkennungsverhältnisses selbst zu thematisieren und darin zu intervenieren, wird die kommerzielle Matrix von Authentizität von allen Seiten akzeptiert, um ein Nebeneinander des „Eigenen“ und des „Anderen“ im öffentlichen Raum zu inszenieren. Im kommerziellen Multikulturalismus konnte sich der Konsum von Authentizität - in der Form von Exotik - als spezifisches normatives Medium herausbilden, um Anerkennungsverhältnisse auszuhandeln. ${ }^{59}$

Es wäre zu kurz gegriffen, in dieser Re-Exotisierung Indiens in der urbanen Schweiz einfach eine Popularisierung der Hippie-Subkultur aus den 1970er Jahren zu sehen. Für die Angebotsseite stellt sich die Frage, wo und wie die spezifischen Bilder und Waren des Indienhypes produziert wurden und wie sie zirkulieren. Im Hinblick auf die Nachfrageseite stellt sich die Frage, wie sich das plötzliche Begehren nach indischer Exotik in der urbanen Mittelschicht entwickeln konnte und was der Konsum damit zu tun hat. Im Folgenden wird davon die Rede sein, wie die Re-Exotisierung Indiens innerhalb der dominanten Öffentlichkeit dazu dient, den Aufstieg Indiens zu einem ökonomischen und politischen global player und eine damit verbundene postkoloniale Verunsicherung auszuhandeln.

59| Im Begriff Mega Mela verdichtet sich diese kommerzielle Sprache der Anerkennung: Mega Mela bedeutet die superlative Vermischung von Spektakel, Unterhaltung und Markt. 


\subsection{DAS „NEUE INDIEN“ IM SCHWEIZER BLICK: EXOTISIERUNG ZWISCHEN ÖKONOMISCHER EXPANSION UND POSTKOLONIALER VERUNSICHERUNG}

Als die Außenministerin Micheline Calmy-Rey in ihrer Festrede auf der Mega Mela „Indien“ begrüßte, bezog sie sich wahrscheinlich nicht auf das exotische und populärkulturelle Indien. Auch wollte sie als Außenministerin kaum ihre Anerkennung für die indische Diaspora in der Schweiz aussprechen, wie dies die Stadt Zürich tat. In ihrer Rede begrüßte sie stattdessen ein „neues Indien“, das sich seit den 1990er Jahren von einem Schwerpunktland der Schweizer Entwicklungszusammenarbeit zu einer regionalen Supermacht gewandelt hatte. Wie auch schon das schweizerisch-indische Freundschaftsabkommen von 1948, in dem die Schweiz ihre kolonialen ökonomischen Interessen in der Ära der indischen Unabhängigkeit abzusichern versuchte, diente auch das Jubiläum sechzig Jahre später einer Neuaushandlung der schweizerisch-indischen Beziehungen und Hierarchien im Kontext eines globalen Umbruchs (Jain 2015). Der Indienhype in der Schweiz und auf der Mega Mela - war nicht nur ein lokales Phänomen, sondern bezog sich in vielfältiger Weise auch auf den sozialen, ökonomischen und kulturellen Wandel, den Indien durch die Integration in den globalen Kapitalismus durchgemacht hat. Für die meisten Diaspora-Angehörige vermittelten Bollywood-Tanzvorführungen am Zürcher Hauptbahnhof oder der Konsum indischer Populärkultur auf mannigfaltige Weise Anerkennung, Stolz oder Nostalgie. Angehörige der Schweizer Dominanzgesellschaft interpretierten die beschriebene Präsenz Indiens jedoch auf oft selbstverständliche Weise exotisierend. ${ }^{60}$ Es ist also wichtig zu betonen, dass Exotik nicht eine Eigenschaft ist, die etwa dem Bollywood-Kino, Saris oder Currys innewohnt. Stattdessen lässt sich unter Exotisierung eine spezifische Form der Repräsentation verstehen, in der ein „Fremdes“ anhand spezifischer ästhetischer

60 | Gemäß dem hier angenommenen Verständnis ist es psychologisch nicht möglich, eine exotisierende Position zu sich selbst einzunehmen, da das Exotische in ein hierarchisches Verhältnis von "Eigenen" und "Anderen" eingeschrieben ist. Das heißt nicht, dass es nicht möglich, sich Exotisierungsdispositive und -technologien anzueignen und daraus Praktiken der Selbst-Exotisierung abzuleiten - mit unterschiedlichen Zielen und Folgen. In nationalistischen Kontexten werden exotisierende Momente in folkloristische Mythen aufgenommen, die jedoch oft Beziehungen des "Eigenen" und des "Anderen" innerhalb der Nation widerspiegeln, wie etwa zwischen Stadt und Land im Falle der alpinen Mythologie der Schweiz (Schetzer 2009; Schär 2012). Auch in postkolonialen Zusammenhängen ist es durchaus möglich (und üblich), Selbst-Exotisierungen und Selbst-Orientalisierungen in Praxis und Subjektivierung vorzunehmen (Huggan 2001; Maira 2002). Diese sind aber keineswegs gleichbedeutend mit einer hegemonialen Form der Exotisierung, wenngleich sie auch darin eingebettet sind. 
Formen und Bewertungen in einem vertrauten kulturellen System konstruiert und angeeignet wird.

Exoticism's "aesthetics of diversity" is manipulated for the purpose of channelling difference into areas where it can be attractively packaged and, at the same time, safely contained. What is at work here is a process, commodified of course, of cultural translation through which the marginalised other can be apprehended and described in familiar terms [...], a superimposition of a dominant way of seeing, speaking and thinking onto marginalised peoples and the cultural artefacts they produce. (Huggan 2001:14)

Die exotisierende Repräsentationsweise erlaubt(e) seit dem Kolonialismus das (nicht-europäische) „Fremde“ an der Grenze zum modernen „Eigenen“ als irrational und primitiv und gleichzeitig als authentisch und natürlich zu imaginieren. Die Ambivalenz im exotisierenden Blick erlaubt es, das „Fremde“ in einem kontrollierten Rahmen außerhalb der eigenen modernen Zeitrechnung als ursprünglich zu genießen und sich gleichzeitig der eigenen zivilisatorischen Überlegenheit zu vergewissern. Exotisierung als machtvolle Praxis erlaubt es dabei, durch die imaginäre Verankerung des „Fremden“, eine Ordnung aufrechtzuerhalten, die im Wandel ist. Exotisierung als sozial konstruierte Formation der ästhetischen Aneignung von „Anderen“ ist dabei keine Universalie, sondern wird durch die Interessen, Begehren und Imaginationen in historischen Machtverhältnissen angetrieben und organisiert. Welches Begehren und Interesse erlaubte also die Re-Exotisierung Indiens ab dem Millennium zu befriedigen?

Während sich die Exotisierung Indiens aus der gegenkulturellen Hippie-Subkultur in die Mitte der Schweizer Öffentlichkeit verschob, wurden ihre soziale Organisation, ihre kulturelle Bedeutung, ihre politische Ökonomie, ihre ästhetischen Formen und affektiven Effekte in der globalen Kulturökonomie maßgeblich verändert. In Vorwegnahme einer detaillierten Analyse in Kapitel 6 wird hier kurz auf die ökonomische, kulturelle und soziale Transformation Indiens seit den frühen 1990er Jahren eingegangen, die die Integration in den globalen Kapitalismus mit sich brachte.

\section{Exkurs: Bollywood und Indiens Anspruch auf den globalen Kapitalismus}

1991 hatte die indische Regierung auf dem Tiefpunkt einer schwerwiegenden Wirtschaftskrise ein Liberalisierungsprogramm eingeleitet, das die indischen Märkte zunehmend für ausländische Importe und Investitionen öffnete. Dies war sowohl politisch als auch ökonomisch eine einschneidende Abkehr vom bisherigen, sozialistisch orientierten Wirtschaftsprogramm, das auf Importsubstitution 
und nationale Monopolunternehmen setzte. ${ }^{61}$ Die Vision eines autonomen indischen Entwicklungsstaates fußte auf der Ideologie der antikolonialen Unabhängigkeitsbewegung, wonach Indien dem Westen zwar technologisch und ökonomisch unterlegen, jedoch moralisch und spirituell überlegen sei (Chatterjee 1989, 1993). Die nationale Doktrin beruhte darauf, die nachholende Entwicklung und Modernisierung Indiens zu fördern, ohne dem Hedonismus des Westens anheimzufallen. Entsprechend lehnte die staatstragende Mittelschicht zu dieser Zeit ostentativen Konsum größtenteils ab (Varma 1998). Seit den Liberalisierungsschritten ab 1992 wuchs die Wirtschaft Indiens von 266,5 Mrd. Dollar auf $2294 \mathrm{Mrd}$. Dollar im Jahr 2016, also jährlich durchschnittlich um ca. 6,5 Prozent. ${ }^{62}$ Als eine soziostrukturelle Konsequenz wurde die Entstehung einer „neuen Mittelklasse“ festgestellt, die ihre Aufstiegsaspirationen innerhalb der Strukturen und Repräsentationen des globalisierten Kapitalismus aushandelte (Deshpande 2003). Statt wie die Angehörigen der „alten Mittelklasse“ etwa sichere, staatliche Beamtenkarrieren anzustreben, nahm eine neue Generation transnationale Bildungswege und professionelle Karrieren in multinationalen Unternehmen der Privatwirtschaft ins Visier (Fernandes 2006). Als paradigmatisch dafür kann die IT-Industrie angesehen werden, die seit der Liberalisierung jährlich um durchschnittlich 30 Prozent gewachsen ist. Obwohl die Branche nur 7,5 Prozent des indischen Bruttosozialprodukts generiert und nur etwa 2,5 Millionen Personen beschäftigte (Rothermund 2008), repräsentierte sie sowohl in Indien als auch im Ausland die materiellen und transnationalen Aspirationen der neuen indischen Mittelklassen (Xiang 2007; Radhakrishnan 2008; Upadhiya 2008). Mit den wachsenden „neuen Mittelschichten“ hatte auch die indische Migration in die westlichen Industrieländer und Australien massiv zugenommen und die dortige Bevölkerung von Auslandsinder_innen betrug im Jahr 2016 gemäß Schätzungen der indischen Regierung ungefähr 9 Millionen von insgesamt 30,8 Millionen Auslandsinder_innen. ${ }^{63}$ Diese transnational mobilen Mittelschichten vor Augen, eigneten sich die Mittelschichten im urbanen Indien neue westliche Lebensstile und Konsumpraktiken und neue Formen nationaler Repräsentation an. In den neuen medialen und urbanen Populärkulturen wurde eine kulturelle Ideologie einer globalen „Indianness“ imaginiert und inkorporiert, die im Gegensatz zur Ideologie der „alten Mittelschicht“ sowohl dem Westen moralisch überlegen als auch materiell und technologisch zumindest ebenbürtig sei (Radhakrishnan 2008). Im Sinne des Historikers Arif Dirlik lässt sich diese Hal-

61 | Ab den späten 1980er Jahren hatte der Premierminister Rajiv Gandhi begonnen, gewisse marktwirtschaftliche Justierungen vorzunehmen, etwa in Bezug auf Luxusgüterimport und den IT-Sektor (Rothermund 2008).

62 | Diese Werte beruhen auf den Angaben der Weltbank (data.worldbank.org) (gesichtet am 21.08.2014).

63 | Diese Werte beruhen auf den Angaben des Ministry of Overseas Indian Affairs (MOIA) (Stand Dezember 2016). 
tung der neuen indischen Mittelschichten als „Anspruch auf den globalen Kapitalismus“ lesen, statt diesen, wie die „alte Mittelschicht“, bestenfalls zu imitieren:

Transnational capital is no longer just Euro-American, and neither is modernity. The complicated social and cultural composition of transnational capitalism makes it difficult to sustain a simple equation between capitalist modernity and Eurocentric cultural values and political forms. Others who have achieved success within the capitalist world system demand their voice for their values within the culture of transnational capital. (Dirlik 2003:354)

Das Bollywood-Kino kann als Leitmedium dieses indischen Anspruchs auf den globalen Kapitalismus gelesen werden. Während die Hindi-Filme der 1970er und 1980er Jahre neben Patriotismus und Familienwerten stets auch Kapitalismus als westliche Dekadenz geißelten, sind die Bollywood-Narrative seit den 1990er Jahren zunehmend auf Konsum und transnationale Mobilität ausgerichtet (Thomas 1995; Brosius/Yazgi 2007). Insbesondere die Reartikulation diasporischer Subjekte erlaubte es, die neue soziale Distinktion und Ästhetik einer globalen „Indianness“ zu etablieren und zu legitimieren. Non-Resident Indians (NRI) verkörperten in den 1970er und 1980er Jahren nationale Grenzgänger_innen zwischen dekadentem Reichtum im Westen und spiritueller und moralischer Reinheit in Indien (siehe Exkurs in Kapitel 3). In den 1990er Jahren wurden stattdessen neue diasporische Subjektivitäten konstruiert, die materiellen Überfluss und moralische Überlegenheit Indiens verbanden. Dies ist darauf zurückzuführen, dass die ökonomische Bedeutung der diasporischen Märkte mit der wachsenden Emigration für die Hindi-Film-Industrie immer mehr zunahm und sich die Produktionsbedingungen internationalisierten (Rajadhyaksa 2003; Ganti 2012). Viele Filme spielten vollständig in Europa, den USA oder Australien oder beinhalteten Episoden transnationaler Mobilität und boten Identifikationspotenzial und Anerkennung für diasporische Publika. Die Bollywood-Charaktere und -Stars - wie Kajol oder Sharukh Khan - verbanden auf davor unvorstellbare Weise indische Familienwerte und Patriotismus mit westlichem Lifestyle und wurden in den 1990ern zu Vorbildern für die neuen indischen Mittelschichten. Diese ideologische, narrative und ästhetische Hybridisierung sowie die Expansion nach Europa, Nordamerika und Australien wohnt dem Medium des Bollywood-Kinos inne und markiert den indischen Anspruch auf den globalen Kapitalismus.

Im Zuge der Integration Indiens in den globalen Kapitalismus nahm ab den 1990er Jahren die Präsenz von indischen Fachkräften im IT- oder Finanzbereich, von indischen Studierenden und Touristen auch in der Schweiz stark zu (Keller 2002). Der enorme wirtschaftliche, soziale und kulturelle Wandel Indiens sowie die zunehmende Präsenz hochqualifizierter indischer Migrant_innen und Tourist_innen aus der wachsenden Mittelschicht wurden jedoch in der Schweizer Öffentlich- 
keit kaum registriert. Interessanterweise war es stattdessen das Bollywood-Kino, durch das dieses "neue Indien“ in der Schweizer Öffentlichkeit wahrgenommen wurde: Ab Mitte der 1990er Jahren wurden Tanzszenen vieler Bollywood-Blockbusters in den Schweizer Alpen gedreht. Abseits der Schweizer Öffentlichkeit tummelten sich die millionenschweren Filmstars mit ihren Crews im Berner Oberland, in Graubünden oder bei Sehenswürdigkeiten in den größeren Städten (Schneider 2002). Ab dem Millenniumswechsel wurde diese Präsenz der weltweit größten Kinoindustrie entdeckt - noch bevor die Filme selbst auf Interesse gestoßen wären. ${ }^{64}$ In den Städten kursierten Geschichten von den improvisierten Dreharbeiten mit den schönen und arroganten indischen Filmdivas, deren gelangweilten Schirmträgern und den kuriosen Tänzen vor dem Berner Zytgloggeturm oder auf dem Zürcher Paradeplatz. Sowohl die Präsenz dieser Filmcrews in der Schweiz als auch das spezifische Musical-Genre des Bollywood-Kinos erschienen als exotische Kuriosität der Globalisierung. Die improvisierte Regelung des Verkehrs während der Dreharbeiten wurde beklagt oder bewundert. Die Tanzeinlagen und die romantischen Plots der Kunstmärchen wurden als unrealistisch und kitschig abgetan oder als schräg und erfrischend geliebt. Mit dem Bollywood-Kino drang eine bisher unbekannte und unvorstellbare Perspektive einer dezentralen Globalisierung in die Schweizer Öffentlichkeit ein und verstörte deren eurozentrische Selbstverständlichkeit. Nicht nur, dass im angeblichen Entwicklungsland Indien eine Filmindustrie existierte, die einen größeren Output hatte als Hollywood, sondern auch, dass diese sich der Schweiz als exotischer Kulisse bediente, war eine Inkommensurabilität sondergleichen. Die Erfahrung dieses postkolonialen indischen Blicks auf die Schweiz kann im Sinne von Dipesh Chakrabarty als Erfahrung der „Provinzialisierung" beschrieben werden (Chakrabarty 2000). Dadurch wurde die existenzielle Vorstellung deplatziert, dass der Westen alleiniges kulturelles, politisches und wirtschaftliches Zentrum der Welt darstelle. In diesem Moment der Irritation schimmerte eine kurze Ahnung des indischen „Anspruchs auf den Kapitalismus“ auf, der im Bollywood-Kino mittransportiert wird, der jedoch in der Schweiz bisher verborgen geblieben war.

64 | Im November 2000 - noch vor dem Publikumspreis für den Film "Lagaan“ ("Steuer", 2001) beim Filmfestival Locarno im Jahr 2001 - strahlte das Schweizer Fernsehen den Dokumentarfilm "Bollywood im Alpenrausch" aus, in dem die Präsenz der Bollywood-Industrie in der Schweiz als kuriose Globalisierungsgeschichte erzählt wurde (vgl. Keller 2002). 


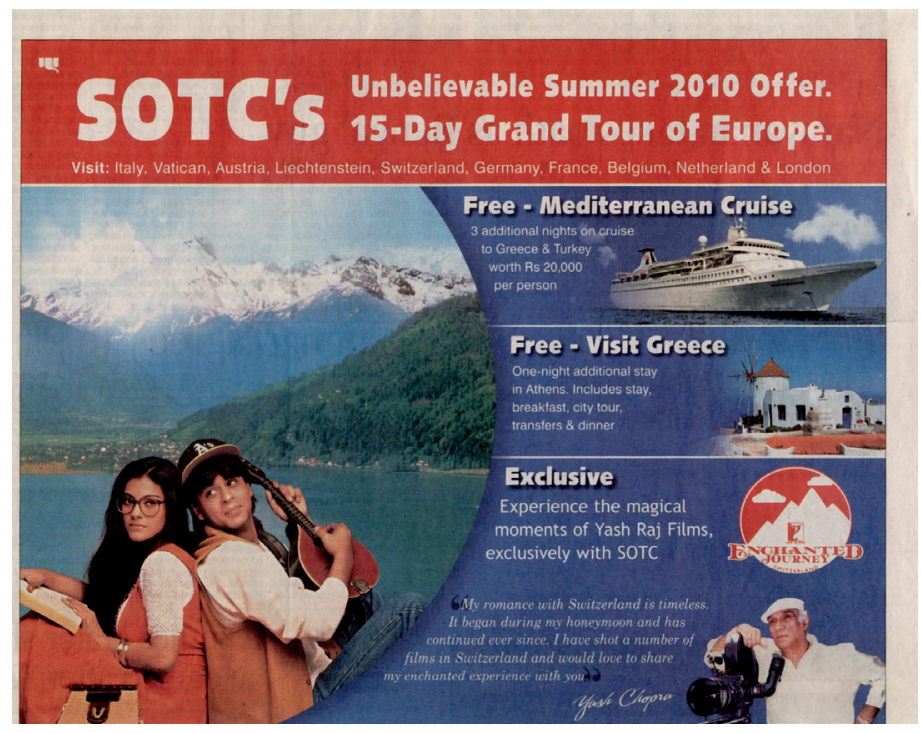

Abbildung 15: Die Schweiz ist für die wachsende indische Mittelschicht nur eine imaginäre Kulisse aus dem Bollywood-Film Dilwale Dhulanya Le Jayenge (1995). Werbung der Kuoni-Tochter SOTC für eine Europa-Reise mit dem Höhepunkt Schweiz (Quelle: Times of India, Autor)

Statt jedoch das Interesse an den Veränderungen in Indien und an den aktuellen dezentralen Globalisierungsprozessen zu wecken, wurde diese postkoloniale Irritation seit den 2000er Jahren in einer Exotisierung Indiens neutralisiert. Angesichts der (post-)kolonialen Unvorstellbarkeit, dass Indien von einem Entwicklungsland außerhalb der Temporalität der europäischen Moderne zu einem Player im globalen Kapitalismus wurde, erschien die Präsenz Bollywoods als krisenhafte Begegnung mit dem „realen Anderen“. Die Konstruktion und der Konsum eines exotisierten Indiens ab dem Millenniumswechsel erlaubte es, die Beziehung der Schweiz zu Indien in der sich wandelnden Hierarchie eines dezentralen globalen Kapitalismus“" zu kontrollieren und langsam neu zu imaginieren.

\section{Hybride Formensprache indischer Exotik und Aneignung von Globalisierung}

Angesichts der jahrhundertealten Tradition des romantischen Orientalismus und jüngst seit der Hippiezeit war die europäische Exotisierung Indiens eine bereits präsente kulturelle Formation. Die Re-Exotisierung Indiens an der Schnittstelle des globalen Aufstiegs Indiens und eines kommerziellen Multikulturalismus verschob jedoch die ästhetischen, kulturellen und politischen Aushandlungsbedingungen des „Eigenen“ und des „Anderen“. Im Kontext der globalen Kulturöko- 
nomie entstanden neue Narrative, neue Publika und neue affektive und ethische Beziehungen.

An einem regnerischen Frühsommerabend 2008 machte ich mich auf ins Zürcher Kongresshaus, um ein Konzert von Anoushka Shankar zu hören, das im Rahmen des „Grüezi India“-Festivals durchgeführt wurde. In den Wochen zuvor hatten Plakate mit dem Antlitz des Weltmusikstars den urbanen Raum geschmückt. Zu Beginn des Konzerts stellte die junge Frau mit amerikanischem Akzent, hellbraunem Teint und wallenden schwarzen Locken in einem eleganten indischen Kleid in Pink das Programm des Abends vor. Hinter ihr strahlte eine große, farbig auf den Hintergrund projizierte Lotusblüte. Sie sprach professionell, locker, sympathisch - nichts von der unnahbaren, ernsten Pose der weißhaarigen männlichen Künstler, die ich bisher aufklassischen indischen Konzerten erlebt hatte. Zuerst spiele Anoushka Shankar, wie sie ausführte, drei Lieder, die ihr Vater Ravi Shankar für sie komponiert hatte, wobei sie gewisse Neu-Interpretationen der traditionellen Stile vornehmen werde. Im Verlauf des Konzerts kombinierte sie die klassischen indische Ragas mit Flamenco, Jazz und Pop. Nach dem Konzert ließ ich meinen Blick schweifen, suchte jedoch fast vergebens nach indischen Migrant_innen, geschweige denn nach „Inder_ innen der zweiten Generation“. Das Publikum dieses Spektakels war größtenteils aus hellhäutigen, allenfalls braungebrannten Männern und Frauen in eleganten dunklen Anzügen respektive in Abendkleidern zusammengesetzt. Besonders stachen die distinguierten Saris und Salwar Kameez einzelner Frauen hervor, die diese vielleicht auf Reisen gekauft oder als Geschenk erhalten haben mögen.

Sowohl der Bezug zu ihrem Vater Ravi Shankar als auch die kosmopolitische musikalische Reise waren bei Anoushka Shankar Realität und Inszenierung, Programm und Biografie zugleich: Die performative Betonung des genetischen als auch das kulturellen Bandes zwischen Vater und Tochter, Lehrer und Schülerin versicherte das Publikum der Authentizität und Qualität ihrer Musik, die aus der Verankerung in einer jahrhundertealten Tradition stammte. Gleichzeitig repräsentierte Anoushka Shankar die transnationalen Flüsse und Übersetzungen, die die indische Musik seit Woodstock erlebt hatte. Da schon Ravi Shankar als Ikone der Hippie-Bewegung in Indien und in den USA lebte, wuchs Anoushka zwischen Kalifornien, London und New Delhi auf. Nachdem sie seit ihrer Kindheit an der Seite ihres Vaters klassische Musik gespielt hatte, nahm sie 2005 - 24 Jahre alt eigenständige künstlerische Projekte in Angriff, wie sie auf der Website beschreibt:

"It was the first record that I composed and envisioned, so it made sense that it should represent more of the types of music I've listened to in my personal life. Before, they had always been separate from my role as a classical sitar player. But they didn't have to be so separate." - Fusing East and West, em- 
ploying both acoustic and electric instrumentation, the album marked a new departure for Anoushka. ${ }^{65}$

Die Vermarktung und die Performanz der Ikone Anoushka Shankar kombiniert den Genuss kultureller Authentizität mit den Versprechungen kosmopolitischer Mobilität und Freiheit. Sie und ihre Musik verkörpern sowohl die authentische Tradition des Vaters als auch den Aufbruch in eine globale Welt. Ihre Darbietung passte daher perfekt in das Setting des Kongresshauses in der global city Zürich:

Das Kongresshaus ist ein Zürcher Traditionshaus mit nationaler und internationaler Ausstrahlung. [...] Vielfalt ist hier Programm: mit Kongressen, Messen, Ausstellungen sowie wirtschaftlichen, gesellschaftlichen und kulturellen Events aller Art - inklusive Highlights von Weltformat. ${ }^{66}$

Entsprechend der Eintrittspreise zwischen 50 und 120 Franken und dem Darbietungsort erschien der Anlass als kultureller Leckerbissen eines bildungsbürgerlichen Publikums, leidenschaftlicher Fans von Anoushka Shankar oder einiger Aficionados von World Music und Fusion. Im Vergleich zu Ravi Shankars Auftritt in Woodstock 1968 bedeutete ein Konzert von Anoushka im Jahr 2008 für das Publikum jedoch weder eine soziale Provokation der bürgerlichen Gesellschaft, noch erforderte sie eine politisch-ethische Transformation der Lebensweise. Mit dem Besuch des Konzerts von Anoushka Shankar im Kongresshaus Zürich konnte viel eher eine gebildete und kulturell versierte, bürgerliche Mittelschicht körperlich und affektiv an einer aufregenden, kosmopolitischen Welt teilhaben.

Die zeitgenössische Re-Exotisierung Indiens nimmt zwar ästhetische Imaginationen und Affekte früherer romantisch-orientalistischer Schübe auf, wie sie seit der deutschen Romantik, in der Reformbewegung um 1900 und dann in der Hippie-Bewegung immer wieder stattgefunden haben, um die bürgerliche Moderne infrage zu stellen. Jedoch haben sich die Bedeutungen, die Ästhetiken und die Räume indischer Exotisierung im Kontext eines dezentralen globalen Kapitalismus maßgeblich verschoben:

1. Wie das Beispiel von Anoushka Shankars kosmopolitischer Inszenierung, aber auch die neue Ästhetik der Bollywood-Filme zeigen, hat im globalen Kapitalismus eine zunehmende Hybridisierung der kulturellen Konstruktion indischer Exotik stattgefunden. Was in der Exotisierung Indiens bei den Hippies oder großbürgerlichen Sammlern indischer Klassik als inauthentisch gegolten hätte, weckte im zeitgenössischen Indienhype gerade das spezifische Begehren. Rupa Ramakrishnan, die Organisatorin der Mega Mela und Event-Managerin für indische Anlässe, hat

65 | http://www.anoushkashankar.com (gesichtet am 9. September 2014)

66 | http://www.kongresshaus.ch/de/ueber-uns/kongresshaus-zuerich.html (gesichtet am 28. Oktober 2016). 
die Passung von hybrider Formensprache und heutigem Begehren nach der Exotisierung Indiens in einem Interview prägnant und ironisch beschrieben:

I have realized that when we do a Bahratnatyam piece or a Odissi piece [klassische indische Tanzstile, R. J.], people really don't get it. Of course, they say, oh, it is so beautiful, look, how she is moving her eyes, how she is moving her hands, oh, we can never do the way you are doing it. [...] But if you do it into a little bit contemporary, if you use the music differently, you use the costume differently, if you use not such a strong Abhinaya [künstlerische Gebärde, R. J.] in it, then it becomes much more approachable for people, and they enjoy that much more [...]. And basically Bollywood is a mixture of classical, folk and contemporary, and it takes Hip Hop and it takes a lot from the West.

Wie schon seit jeher wird in dieser Exotisierung Indiens ein Begehren nach gegenmoderner Authentizität und spiritueller Tradition befriedigt. Jedoch wird diese Sprache der Authentizität heute stärker denn je durch den komplexen Einsatz technischer Reproduktion, ästhetischen Remixes und kultureller Hybridisierung hergestellt. Paradoxerweise vermögen die komplexen Mischprodukte und Kopien das Begehren nach Authentizität im Kontext des globalen Kapitalismus effektiv zu wecken, zu befördern und zu stillen, ohne dadurch Gefahr zu laufen als ,inauthentisch“ zu gelten (Bruner 1994; Gallini 1996; Comaroff/Comaroff 2009). Hybridität erscheint in diesem Kontext nicht zwangsläufig als subversive Kritik an einer kultessenzialistischen Hegemonie, wie etwa von Homi Bhabha postuliert, sondern als spezifische „kulturelle Logik im postmodernen Kapitalismus“ (Jameson 1989). So betont Kien Ngi Ha Hybridität als Signatur in einer Kulturökonomie, in der lokale und globale Prozesse immer stärker verbunden werden: „Hybride Kulturprodukte [können] als ökonomischer Reflex auf die fortschreitende Transnationalisierung und Flexibilisierung eines glokalisierten Kapitalismus gesehen werden, der aus dem Zusammentreffen von lokalen und globalen Kontexten Neues generiert“ (2005:78). Im globalen Kapitalismus erlaubt die wechselseitige Konstruktion von Authentizität und Hybridität sowohl die maximale Verbreitung von Gütern als auch die Herstellung einer sinnhaften Sprache der Aushandlung von „Eigenem“ und „Anderem“.

2. Die Hybridisierung indischer Populärkultur eröffnet im Westen eine spezifisch kosmopolitische Distinktions- und Aneignungspraxis, die sich von früheren, gegenkulturell-exotisierenden Imaginationen Indiens unterscheidet. Der Hybriditätskonsum macht für unterschiedliche Segmente einer urbanen, bürgerlichen Mittelschicht den „Mythos Globalisierung“ (Bourdieu 1998) greifbar. Dadurch können sie sozial, affektiv und körperlich am globalen Kapitalismus teilhaben und einen kosmopolitischen Habitus demonstrieren und sich gleichzeitig von anderen sozialen Schichten abgrenzen, die aus ihrer Sicht weder das ökonomische noch das 
kulturelle Kapital aufweisen, um diese Weltoffenheit zu verkörpern. Ein Konzert von Anoushka Shankar, ein Essen beim „Inder“ oder der wöchentliche Yoga-Unterricht ist eine kontrollierte Begegnung mit einem gleichzeitig „authentischen“ und „globalen Anderen“.

Zur Hybridität verschmolzene Differenz tritt heutzutage als verkäufliches Kulturprodukt und aneigenbare Lifestyle-Technik in einer transkulturellen Konsumwelt auf, in der sie ebenso fortschrittlich wie exotisch bereichernd wirkt. [...] Dadurch wird exotisierte Hybridität im Alltag in erster Linie als ästhetisierende Kulturtechnik zur Erweiterung jenes Selbst eingesetzt, das seine dominante Position durch eine selektive und kontrollierte Aneignung des Anderen aufwerten kann. (Ha 2005:179)

Dieser Neigung zum Irrationalen scheint jedoch eine starke Ambivalenz eingeschrieben zu sein. Der urbane Exotikkonsum bezeugt sowohl ein Streben nach dem „authentischen“ und „globalen Anderen“ als auch eine Selbstvergewisserung der eigenen Kontrolle und Überlegenheit. Indem (vor allem) Angehörige der urbanen Mittelschicht sich eines kosmopolitischen Lebensstils vergewissern, wird das Phantasma eines zeitlosen, unmodernen, authentischen Indiens repetiert - eines so nahe am spirituellen Ursprung der Menschheit, wie es schon immer war. Die schlichte Tatsache der Präsenz des Bollywood-Kinos mit seinen transnationalen, diasporischen Vertriebsstrukturen und seiner Konsumästhetik einer hybriden globalen „Indianness“ offenbart aber gleichzeitig den historischen geopolitischen Anspruch Indiens, das nun in die Zeitrechnung der europäischen Moderne eingetreten ist und diese herausfordert. Der ritualisierte Konsum von indischer Opulenz von Farben, Formen und Mythos lässt die unerwartete Nähe der aufsteigenden Supermacht Indien und die damit verbundene postkoloniale Verunsicherung aufscheinen und verdeckt sie zugleich. Die ambivalente Repräsentationsstruktur von Exotik - zwischen kosmopolitischer Distinktion und orientalistischem Phantasma - gibt dieser tiefgreifenden und krisenhaften Erfahrung im postkolonialen Kontext des globalen Kapitalismus kulturellen Ausdruck und eine soziale Form.

\section{"Der Aufstieg des indischen Elefanten" - zur Ambivalenz des neuen Indiendiskurses in der Schweiz}

Mit der Zeit öffnete sich hinter dem schillernden Fetisch des Bollywood-Kinos, das erlaubte hatte, die Begegnung mit dem „realen Anderen“ zu verzögern, der Blick auf die wirtschaftlichen, kulturellen und sozialen Veränderungen in Indien. Zuerst fiel in öffentlichen Debatten der IT-Boom Indiens auf, danach wurden die indischen Call-Center thematisiert, die vor allem für amerikanische Firmen Kundenberatungen durchführten. Wie schon der Bollywood-Boom wurden diese Topoi zuerst größtenteils als Kuriositäten der Globalisierung thematisiert, weil sie 
die in der Schweiz vorherrschenden Bilder von Indien als armes, unterentwickeltes Land irritierten. Erst mit der Zeit etablierten sich der Aufstieg Indiens, seine neuen Mittelschichten und insbesondere die Versprechungen der neuen Märkte im öffentlichen Bewusstsein (Schoettli 2009). Um Bollywood, indischen IT-Kapitalismus, Armut und Spiritualität arrangierte sich nun ein neuer Indiendiskurs. Die in der Exotisierung verdichtete Ambivalenz zwischen Furcht und Kontrolle einerseits und Bewunderung und Begehren andererseits setzt sich jedoch auch in diesem neuem Indiendiskurs fort: Einerseits stellt die „asiatische Renaissance“ eine Herausforderung für das schweizerische, ja, das westliche Wohlstandsmodell dar - oder gar eine Gefahr, etwa wenn der ehemalige „Spiegel“-Journalist Gabor Steingart in seinem Bestseller von einem „Weltkrieg um Wohlstand“ (2006) spricht. Andererseits ermöglichen die „neuen Märkte“ eine wirtschaftliche Expansion und die Vermehrung des schweizerischen Wohlstandes. Angesichts dieser Ambivalenz zwischen postkolonialer Verunsicherung und dem Begehren nach dem (orientalischen) Reichtum wurden in der Schweizer Wirtschaft gerade exotisierende Bilder und Praktiken zu einer imaginativen, affektiven und sozialen Ressource, um die Chancen und die Probleme des Markteintritts in Indien vorstellen und ausrechnen zu können. Interessanterweise waren ein großer Teil der Klienten von Rupa Ramakrishnas Event-Agentur entweder multinationale Konzerne oder Schweizer kleine und mittelständische Unternehmen, die den Markteintritt in Indien suchten oder in Indien billiger produzieren wollten. Eine Bollywood-Tanzshow, Yoga-Kurse oder ein indisches Buffet machen das Fremde vertraut und zugänglich und fördern die Lust auf die neuen Projekte und Abenteuer in der Ferne. Sie schaffen unverbindliche Gesprächs- und Imaginationsräume für Geschäftspartner, Teams, Familienmitglieder und Bekannte, die auch in die Praxis der kapitalistischen Expansion eingebunden sind. ${ }^{67}$ Gleichzeitig erlaubt die Ambivalenz in der Exotik auch, die Ängste bezüglich der unsicheren Zukunft der Projekte in Indien respektive des Wohlstandsmodells der Schweiz in Zeiten des globalen Umbruchs auszudrücken. Diese Repräsentationsweise schafft nicht nur eine psychische Verankerung, indem das „Andere“ imaginierbar und kontrollierbar wird. Die Imagination der anachronistischen und rückständigen Traditionen Indiens in der Exotik erlaubt gleichzeitig, sich der bestehenden hierarchischen Ordnung des modernen „Eigenen“ und des traditionellen „Anderen“im globalen Kapitalismus zu vergewissern. Wegen dieser postkolonialen Verunsicherung wurde im neuen Indiendiskurs die eurozentristische Kritik an sozialen, politischen und kulturellen Missständen in Indien umso lauter und prägnanter geäußert. Die moralische Panik angesichts

67 | Nicht selten haben mir männliche Schweizer Expats erzählt, dass ihre Ehefrauen Indien dem anderen, noch größeren Wachstumsmarkt China vorziehen. Nicht nur ist Indien durch das exotische Narrativ viel positiver konnotiert und zugänglicher. Auch ganz konkret erlauben zum Beispiel die Yoga-Industrie sowie Englisch als öffentliche Sprache viel mehr Aktivitäten für Familienangehörige. 
der Terroranschläge in Mumbai im Jahr 2008, um Korruptionsaffären oder um Massenvergewaltigungen im Jahr 2012 bieten die postkoloniale Vergewisserung, dass das westliche, ja, das schweizerische Modernisierungsmodell - wenn allenfalls nicht ökonomisch, so doch politisch, moralisch und kulturell - überlegen ist. Die postkoloniale Verunsicherung wird umso grösser, wenn die Aushandlungen vor der eigenen Haustür stattfinden, wie in der Debatte um Lohndumping und Entlassungen bei Banken angesichts von IT-Outsourcing oder in der Zunahme des indischen Tourismus in der Schweiz.

\section{Man spricht Indisch hinter CS-Bildschirmen}

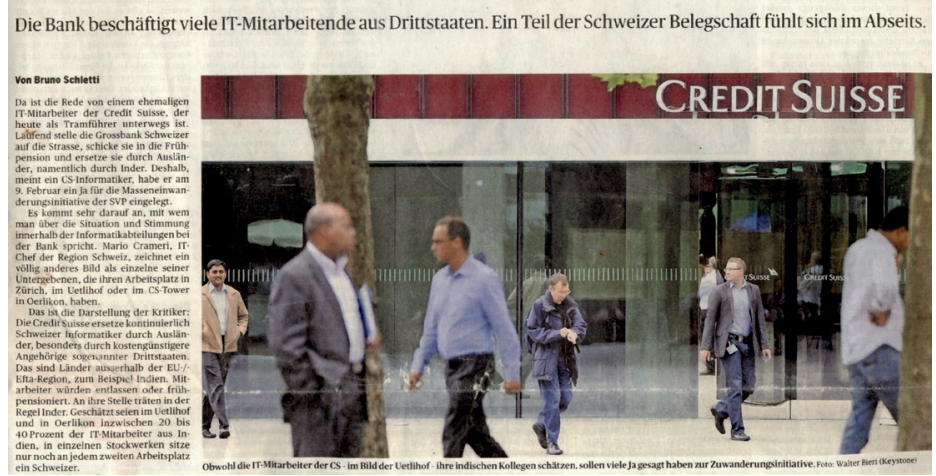

Abbildung 16: Angst vor Arbeitsplatzverlust durch IT-Outsourcing befeuerte unter Schweizer Informatikern die Zustimmung für die restriktive Masseneinwanderungsinitiative von 2014 (Quelle: Tagesanzeiger 26. März 2014)

Im Diskurs über ein kapitalistisches Indien ist also eine starke Ambivalenz zwischen ökonomischem und kosmopolitischem Begehren einerseits und postkolonialer Verunsicherung andererseits eingeschrieben. Diese Ambivalenz von Öffnung und Abschottung innerhalb neuer Machtverhältnisse im dezentralen Kapitalismus strukturiert in der Schweiz die Aushandlungen des „Eigenen“ und des „Anderen“, so auch die Repräsentation der „Zweiten Generation“ im Allgemeinen und von „Inder_innen der zweiten Generation“im Speziellen. 


\subsection{Fazit: Die Spaltung deR „ZWeiten Generation“ IN "KOSMOPOLITISCHE EXOT _ INNEN" UND „UNASSIMILIERBARE ANDERE"}

Das 60-jährige Jubiläum des schweizerisch-indischen Freundschaftsvertrags - mit der Mega Mela als Höhepunkt - stellte eine in dieser Form bisher ungekannte öffentliche und offizielle Sichtbarkeit von "Indianness“ mitten in der Schweiz dar. Ich habe argumentiert, dass sich diese Präsenz Indiens an der kulturökonomischen Schnittstelle der Entwicklung Zürichs zu einer global city und dem Aufstieg Indiens zu einer regionalen Supermacht im globalen Kapitalismus herauskristallisiert hat. Im Rahmen von warenförmiger Anerkennung und Indienhype hat dabei eine multikulturell-exotisierende Subjektivierungslogik Form angenommen, die im Gegensatz zum Assimilationsregime die spezifische öffentliche Repräsentation kultureller Differenz erlaubt und sogar positiv bewertet. Gleichzeitig setzt sie den Konsum von Authentizität, namentlich von Exotik, als Rahmen, um Anerkennungsverhältnisse auszuhandeln. Dabei reproduziert sie tendenziell das Begehren der Dominanzgesellschaft als repräsentationspolitische Norm. Denn die affektive Erfahrung und der spektakuläre Genuss von kultureller Differenz zum Beispiel auf der Mega Mela erfordern zumindest partiell und temporär die exotisierende Fixierung des Objekts respektive des Subjekts und die Ausblendung des Kontexts und der Prozesse, die diese spezifische Austauschbeziehung ermöglichen. Eine kritische Verhandlung dieser asymmetrischen Bedingungen würde daher die Aufgabe des Genusses erfordern und zwar für diejenigen Personen, die Anerkennung gewähren und diejenigen, denen sie zuteil wird.

Wie beeinflusst nun die multikulturell-exotisierende Subjektivierungslogik die Konstruktion der „Zweiten Generation“ und insbesondere die Subjektivierungsprozesse von „Inder_innen der zweiten Generation“? Und wie sind die multikulturell-exotisierende und assimilatorische Subjektivierungslogik miteinander verknüpft?

Auf paradigmatische Weise spiegelte der Wahlkampf zur Initiative über die erleichterte Einbürgerung der „Zweiten und dritten Generation“ von 2004 das komplexe Zusammenspiel von assimilatorischer und multikulturell-exotisierender Repräsentation der „Zweiten Generation“ in der Schweiz seit den 1990er Jahren wider. Der Vorstoß zur Verfassungsänderung forderte, dass Angehörige der „Zweiten Generation“ erleichtert und Angehörige der „dritten Generation“ per Geburt eingebürgert werden können (ius soli) - eine weit restriktivere Regelung als das französische und deutsche ius soli kennen. Wie in Kapitel 2 dargelegt, durchzieht dieses Anliegen einer erleichterten Einbürgerung der „zweiten Generation“ die schweizerische Migrationspolitik seit über hundert Jahren. Bei der erneuten Auflage kämpfte das Netzwerk Second@s wacker für die Anerkennung und Aufwertung der „Zweiten Generation“ und eine multikulturelle und weltoffene Schweiz 
(Wessendorf 2008). ${ }^{68}$ Mit dem Slogan „Ohne Migranten keine Pizza“ spielte das Netzwerk Second@s humorvoll auf die Aufwertung der „Italianità “ seit den späten 1980er Jahren im kommerziellen urbanen Raum an. Auf der anderen Seite inszenierte die rechtspopulistische Schweizerische Volkspartei (SVP) die Staatsbürgerschaft als letzte Bastion in einem ethnodemografischen Untergangsszenario der kulturellen und rassischen Vermischung. Ihr kam eine laufende mediale Hetzkampagne gegen Autoraser aus Kosovo zu Hilfe, in der Angehörige der „zweiten Generation“ in der Primetime und mit Millionenauflage als potenziell unassimilierbare, kriminelle, ethnische „Andere“ dargestellt wurden. Schließlich wurde die Initiative, die zwar von allen großen Parteien unterstützt wurde, mit 56,7 Prozent abgelehnt. Nicht nur eine erleichterte Einbürgerung, sondern auch ein ius soli für die „dritte Generation“ erschien der Schweizer Stimmbevölkerung schließlich als zu großes assimilatorisches Risiko.

Der Wahlkampf zur erleichterten Einbürgerung von 2004 offenbarte prägnant eine Spaltung in der öffentlichen Repräsentation der „zweiten Generation“: Auf der einen Seite wurden Jugendliche aus Ex-Jugoslawien und Muslim_innen, die oft bildungsfernen Schichten angehören, als „unassimilierbare Ausländer“ Gegenstand des öffentlichen Zorns und eines sicherheitspolitischen Disziplinarregimes. Auf der anderen Seite galten „Second@s“ aus der Mittelschicht und aus den z. B. südeuropäischen Modellminderheiten, die zudem erfolgreiche Bildungsbiografien vorweisen konnten, als "gut integriert“ und als „kosmopolitische Exoten“, die eine weltoffene und globale Schweiz zu repräsentieren vermochten. Mit den „kosmopolitischen Exot_innen“ und „un/assimilierbaren Andere“ standen sich zwei Subjektpositionen der „Zweiten Generation“ gegenüber, die innerhalb desselben hegemonialen Kontexts der Positionierung der Schweiz im globalen Kapitalismus funktionierten. Statt nach einer essenzialistischen nationalen Homogenität zu streben, wie im Assimilationsregime der 1960er bis 1980er Jahre, wird heute die öffentliche Bewertung von Migration und Integration viel selektiver und situativer vorgenommen. Dies wird weiterhin im Umgang mit der „zweiten Generation“ als der zentralen strategischen bevölkerungspolitischen Plattform ausgehandelt. Die hegemonialen Diskurse und Dispositive des „Eigenen“ und des „Anderen“ verbinden nun unterschiedliche Fantasien und Technologien des Hybriden und

68 | Der Begriff "Second@“ wurde ursprünglich durch die italienische Migrationsnachfolgeneration geprägt. 1993 wurde der Begriff im Film „Babylon 2" über die "zweite Generation" im Migrationsland Schweiz vom damals noch unbekannten Lausanner Rapper Carlos Leal öffentlich verwendet. 2001 bezichtigte Esther Maurer, damalige Vorsteherin des Zürcher Polizeidepartements, Secondos an den Krawallen rund um die 1.-Mai-Kundgebungen von 2001 beteiligt gewesen zu sein. Das Netzwerk Second@s wurde 2002 als Widerstand gegen dieses Statement und im Hinblick auf die eidgenössische Abstimmungsvorlage für die erleichterte Einbürgerung der "zweiten und dritten" Generation gegründet. 
des Transgressiven, die entweder die erfolgreiche Integration der Schweiz in den Weltmarkt bezeugen und bewerkstelligen sollen oder umgekehrt den Untergang des kulturellen und ökonomischen Erfolgsmodells der Schweiz besiegeln. Während also Mehrsprachigkeit im Falle von gut qualifizierten Second@s als Potenzial oder als interkulturelle Kompetenz gewertet werden kann, wird diese im Falle von Second@s aus bildungsfernen Familien als Assimilationsrisiko gewertet. Die assimilatorische und die multikulturell-exotisierende Subjektivierungslogik konstituieren sich gegenseitig, indem sie in der politischen Imagination, aber auch in den biografischen Integrationsverläufen von Angehörigen der „Zweiten Generation“ gemäß einer strukturierten Matrix von Klasse, Herkunft, Religion und Geschlecht aufeinander verweisen. Erst vor dem Hintergrund der einen wird die andere sozial wirksam. Sie sind ineinander verwickelt und müssen ständig ausgehandelt werden. Das heißt, dass gewisse öffentliche Repräsentationen und Praktiken von ethnischer Differenz in einem bestimmten Kontext Anerkennung bewirken können, in einem anderen jedoch Sanktionierung und Ausschluss.

Die Pluralisierung der Repräsentation durch den kommerziellen Multikulturalismus macht also einerseits die hegemoniale Ordnung des „Eigenen“ und des „Anderen“ fit für den globalen Kapitalismus und verdrängt respektive überschreibt gleichzeitig andere politische Sprachen von Vielfalt. Nichtsdestotrotz bietet die transnationale Überlappung öffentlicher Räume für spezifische Gruppen und Individuen situativ auch Handlungsspielräume der Anerkennung, neue professionelle Kanäle und biografische Opportunitäten der Selbstrepräsentation. „Inder_innen der zweiten Generation", die in der Schweiz aufgewachsen sind, gehören größtenteils der Mittelschicht an. Im Zuge des Indienhypes in der Schweiz und des darin eingeschriebenen Topos der Multikulturalität sind einerseits Chancen der öffentlichen Aushandlung von Mehrfachzugehörigkeit entstanden. Andererseits sind diese angesichts der Warenförmigkeit der Anerkennung beschränkt und selektiv. In gewissen Kontexten können „Inder_innen der zweiten Generation“ wie Anoushka Shankar als kosmopolitisch und cool gelten. In anderen Kontexten werden sie zu „unassimilierbaren Anderen“, wie Sonia, die unter dem Verdacht stand, sich für eine arrangierte Heirat entschieden zu haben. Wiederum eröffnet sich für sie eine hybride Repräsentationspolitik in einem öffentlichen Raum, in dem sich transnationale Diskurse und Lebenswelten überlappen und neue Identifikationen stattfinden können - so, wenn etwa das Bollywood-Kino einen postmigrantischen Diskurs unter Second@s aus der Türkei, Kosovo und Indien eröffnet. Gleichzeitig ist ihre Anerkennung als kosmopolitisches Potenzial strukturell immer auch verknüpft mit der Disziplinierung von „unassimilierbaren Anderen“. 

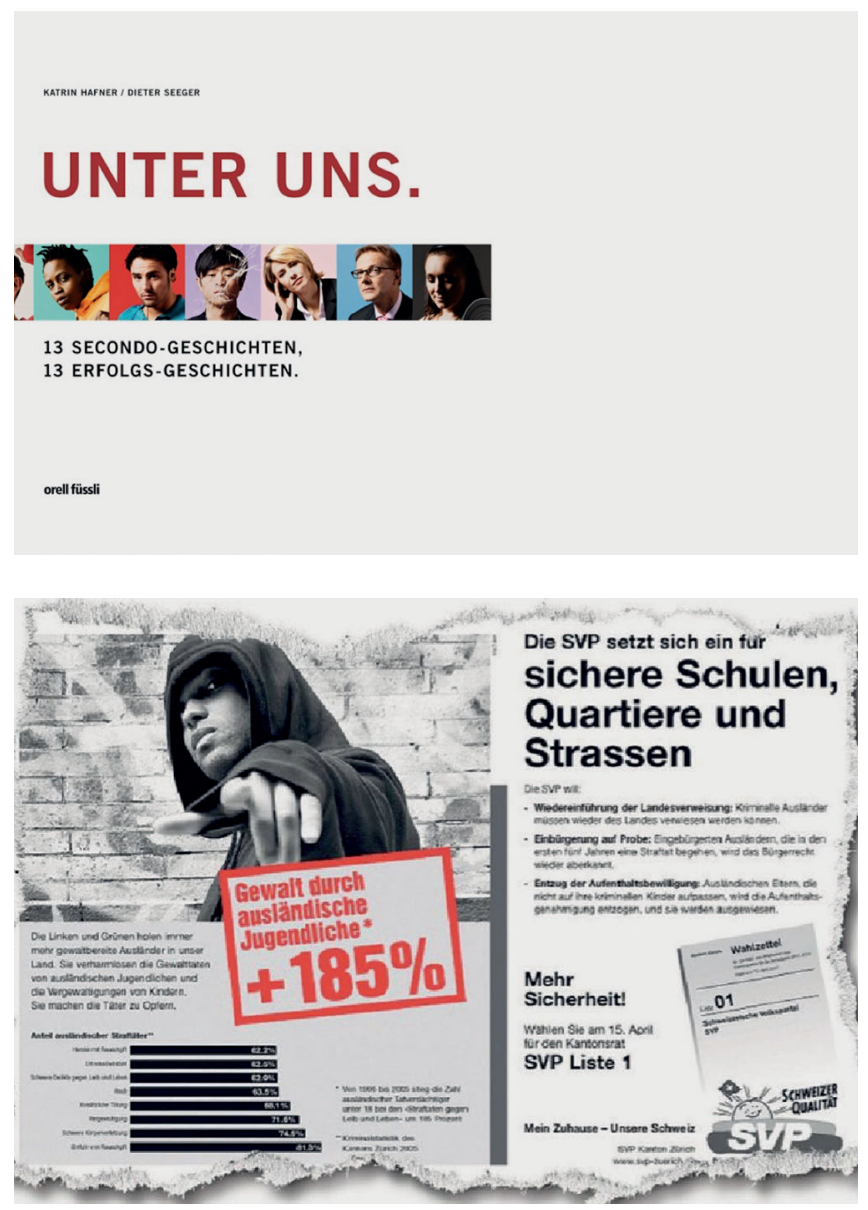

Abbildung 17a) und 17b): Die Spaltung der "zweiten Generation" in kosmopolitisch-coole Integrationsheld_innen und "unassimilierbare Andere". Buchcover "Unter uns.13 Second@-Geschichten.13 Erfolgsgeschichten" (Hafner / Seger 2007) und reisserische Wahlwerbung Schweizerische Volkspartei (Quelle: Autor)

Den neuen Anerkennungsräumen wohnen also starke Ambivalenz, Situativität und Fluidität inne. Mit dem Transfer des multikulturalistischen Topos aus der Migrationspolitik in die städtische Standortpolitik im Kontext der Globalisierung war eine Verschiebung im ethischen Verständnis von Anerkennung verbunden. Statt durch politische Rechte verspricht der urbane Multikulturalismus Anerkennung durch Teilhabe an der Kommodifikation von Differenz in dem neuen nationalen Modernisierungsmodell im Kontext eines dezentralisierten Kapitalismus. Im Vergleich zum Assimilationismus erlaubt diese warenförmige Anerkennungsweise zwar eine öffentliche Selbstrepräsentation, wobei die Definitionsmacht über 
die repräsentationspolitischen Bedingungen zu einem großen Teil bei der Dominanzgesellschaft verbleibt.

Mit der Ethnisierung und Exotisierung steigt das Bedürfnis nach authentischen Repräsentanten der Hybridisierung. Dieser Effekt hat zur neuen Sichtbarkeit von Migrantinnen beigetragen, da dadurch gesellschaftliche Bedürfnisse befriedigt werden [...]. Ihre bereichernde Präsenz auf der massenmedialen Repräsentationsebene beschränkt sich vornehmlich auf die Darstellung von Formenvielfalt, trifft aber nur in begrenztem Maße auf die Festlegung und Vermittlung von Inhalten und Perspektiven zu. Noch seltener führt die Repräsentation des Anderen in solchen Kontexten zur Sichtbarmachung von Macht- und Verteilungsfragen. (Ha 2005:81)

Am Beispiel der Kampagne des Netzwerks Second@s in der Abstimmungsvorlage zur erleichterten Einbürgerung von 2004 wird dies deutlich: Die Second@s-Bewegung konnte angesichts der Aufwertung von Differenz im kommerziellen Multikulturalismus zwar ihren Wunsch, in der Schweizer Öffentlichkeit als politische Subjekte anerkannt zu werden, selbstbewusst äußern. Mit dem selbst-exotisierenden Slogan „Ohne Migranten keine Pizza“ hatte die Bewegung jedoch die dominanzgesellschaftliche Perspektive des kommerziellen Multikulturalismus akzeptiert und befördert, statt sie etwa infrage zu stellen. Der Anspruch auf Anerkennung stützt sich demnach auf dem multikulturellem Genuss des „Anderen“ und nicht etwa auf ein „Rechte auf Rechte“ für diejenigen 20\% der Bevölkerung, die vom demokratischem Prozess ausgeschlossen sind, nur weil sie keinen Schweizer Pass besitzen. Die Kampagne bewies zwar die assimilatorische Fähigkeit der „Zweiten Generation“, die dominanzgesellschaftliche Perspektive zu verstehen und zu akzeptieren, aber auch die Unfähigkeit, diese zu konfrontieren. 


\section{Yoga, Bollywood und IT - ethnic entrepreneurship, Identitätskonsum und neue Gemeinschaften}

In den späten 1990er Jahren begannen Sonia, Aftab, Raj und Maya und viele andere schweizerisch-indische Second@s ihre biografisch-ethischen Projekte des Andersseins immer mehr in öffentlichen Räumen auszuhandeln. Vor dem Hintergrund eines kommerziellem Multikulturalismus und eines Indienhypes in der urbanen Schweiz wurden Hobbys zu beruflichen Projekten und intime Aushandlungen von Herkunft und Zugehörigkeit nahmen in sozialen Beziehungen und kulturellen Lebensstilpraktiken öffentliche Gestalt an. Diese neuen Praktiken gingen auch einher mit einem Perspektivenwechsel auf die eigene Biografie und auf die Bewertung von Mehrfachzugehörigkeit und von transnationalen Lebenswelten. Es ist symptomatisch für die globale Umbruchzeit der 1990er und 2000er Jahren, dass die Praktiken und biografischen Prozesse dieser Pionier_innen in ihrer Bedeutung oszillierten. Je nach Perspektive in einer zunehmend multifokalen Welt konnte eine arrangierte Ehe aus einer assimilatorischen Perspektive verurteilt werden oder als kosmopolitische Praxis reinterpretiert werden. Der Konsum von Bollywood-Filmen konnte je nach lebensweltlicher Verankerung und postkolonialer Verortung als Kitsch, als postmigrantische Subversion oder als hindu-nationalistische Ermächtigung gesehen werden - oder als Mischung von alle dem. Eine Mehrstimmigkeit, die sich in den transnationalen Lebenswelten schon immer subtil abgezeichnet hatte, fand zunehmend eine soziale Entsprechung - unter spezifischen glokalen Bedingungen eines dezentralisierten globalen Kapitalismus. In diesem Kapitel werden ethnografisch die performativen Strategien untersucht, mit denen schweizerisch-indische Second@s Zwischenräume und Unstimmigkeiten inmitten von Assimilationsregime und multikultureller Kommerzialisierung ausmarchen und daraus autonome Formen der Lebensführung und Subjektivierung entwickeln. Knüpfen wir also an den Biografien von Sonia, Maya, Raj und Aftab dort an, wo wir am Ende von Kapitel 3 aufgehört hatten. 
Sonia hatte 1998 mit ihrem Betriebswirtschaftsstudium begonnen und zunehmend den Kontakt zu ihrem indischen Verlobten vertieft. Die Hochzeit löste in ihrem Umfeld Unverständnis und den Verdacht auf eine arrangierte Eheschliessung aus. Die in der urbanen Schweiz aufkommende südasiatische Populärkultur sowie der gute Ruf von indischen Finanzfachleuten in der globalen Bankenwelt eröffneten ihr und ihrem Ehemann jedoch die Möglichkeit einer transnationalen Karriere und eines kosmopolitischen Lebensstils, was das Stigma einer angeblich arrangierten Ehe zusehends relativierte - für sie selbst und ihr Umfeld.

Maya hatte Mitte der 1990er Jahre im Yoga ein spirituelles Projekt der Selbstverwirklichung entdeckt, in dem sie sich sowohl von assimilatorischen Anrufungen als auch von elterlichen Erwartungen befreien konnte. Im Yoga-Boom nach dem Millenniumswechsel konnte sie sich in der Schweiz als Yoga-Lehrerin selbstständig machen und sich zunehmend selbstbewusst als transnational vernetzte Yogini und indische Seconda positionieren.

Raj hatte seine Sehnsucht nach Indien, die im Spannungsfeld von Rassismuserfahrung ohne gleichzeitige ethnische Sozialisierung erwuchs, vor allem durch individuelle Reisen bearbeitet. Durch die Präsenz Indiens im kommerziellen Multikulturalismus konnte er zusammen mit anderen indischen Second@s im Rahmen eines expressiven Konsums von Bollywood-Filmen oder indischem Essen eine freundschaftlich-ironische Form der Auseinandersetzung mit Rassismus und Herkunft entwickeln. Daraus entstanden neue Formen legitimer Selbstrepräsentation von „Indianness“ und Mehrfachzugehörigkeit.

Aftab wiederum vermochte sich nach langen Wanderjahren in den aufstrebenden indischen Märkten als interkultureller Unternehmensberater mit Südasienschwerpunkt zu etablieren. Er machte seine intellektuelle und ironische Vermittlung „Zwischen den Welten“, die seine Biografie und Subjektivität seit der Jugend prägte, zum Geschäftsmodell.

Im Zentrum der folgenden Ausführungen steht das Argument, dass sich im kommerziellen Multikulturalismus, durch die Vervielfältigung der (assimilatorischen) Grenze von Privatem und Öffentlichen, neue Räume für die Äußerung von Subjektivität, Zugehörigkeit und kultureller Differenz herausbildeten. Ordnungen der Bedeutung und Bewertung von Differenz waren in Bewegung geraten. In sich überlappenden transnationalen Öffentlichkeiten konnten Mehrfachzugehörigkeiten plötzlich als kulturelle Ressourcen eingesetzt und entwickelt werden, etwa als kosmopolitischer Lifestyle, als interkulturelle Kompetenz oder als diasporisches Kapital in einer zusehends globalen (indischen) Moderne.

Unter diesen historischen Bedingungen eröffnete sich für schweizerisch-indische Second@s zunehmend ein „dritter Raum“ in den bestehenden Repräsentati- 
onsregimes des „Eigenen“ und des „Anderen“, wie dies Homi Bhabha formulierte. Eine Hybridisierung des „Lebens zwischen den Welten“ schien sich anzubahnen, in denen sich neue berufliche Möglichkeiten, multiple Identitäten, soziomoralische Texturen und repräsentationspolitische Horizonte entwickelten.

The importance of hybridity is not to be able to trace two original moments from which the third emerges, rather hybridity to me is the "third space" which enables other positions to emerge. This third space displaces the histories that constitute it, and sets up new structures of authority, new political initiatives, which are inadequately understood through received wisdom [...]. The process of cultural hybridity gives rise to something different, something new and unrecognisable, a new area of negotiation of meaning and representation. (Bhabha 1990:211)

$\mathrm{Zu}$ recht wurde eine Verwendung des Begriffs der Hybridität bei Homi Bhabha vielfältig kritisiert (z. B. Young 2005; Ha 2008). Insbesondere wurde bemängelt, dass Bhabha Hybridisierung zu einseitig als widerständige Praxis kultureller Grenzüberschreitung interpretierte. Denn zu Recht wurde in Anschlag gebracht, dass Prozesse und Praktiken der Hybridisierung in historische Machtverhältnisse eingebettet sind, die die Bedeutung, Handlungsmacht und Potenziale regulieren, die diesen innewohnt. Wie ich im letzten Kapitel zum Beispiel am Bollywood-Kino gezeigt habe, sind Prozesse und Ästhetiken der Hybridisierung im Kontext des dezentralisierten Kapitalismus konstitutiv für einen hegemonialen Globalismus, der sich in öffentlichen Räumen gemäß lokaler und nationaler Logiken äußert (García-Canclini 1995; Ha 2008). Eine kritische (Analyse von) Repräsentationspolitik anhand des Hybriditätsbegriffs wird dadurch erschwert - aber nicht etwa obsolet. Der Begriff der Hybridität bietet gerade eine spannende Grundlage, um empirisch und kulturpolitisch zu verstehen, wann Prozesse der kulturellen Übersetzung und der Transgression Hegemonien entweder verstärken oder aber Autonomie und Subversion ermöglichen. Dies erfordert jedoch, den Zusammenhang des spezifischen lebensweltlichen Einsatzes hybrider Sprache und Praktiken analytisch in Verbindung zu setzen mit den machtvollen diskursiv-institutionellen Bedingungen ihrer Produktion und Aushandlung.

Es lässt sich also für die Analyse der Subjektivierungsprozesse von Sonia, Maya, Raj, Aftab und anderen schweizerisch-indischen Second@s ethnografisch fragen, wie sie inmitten hegemonialer Logiken der Hybridität alternative Prozesse der Lebensführung und der transnationalen Ethiken des guten Lebens entwickeln. Die repräsentationspolitische Qualität von Hybridisierung ist dabei grösstenteils unabhängig von der kulturell-ästhetischen Form, sondern hängt von den repräsentationspolitischen und sozioethischen Bedingungen ab, in die sie eingebettet sind und in denen sie eingesetzt werden. Der Begriff der Äußerung kann helfen, eine performative Theorie der Transformation anzudenken. 
[Der] „dritte Raum“ konstituiert [...] die diskursiven Bedingungen der $\ddot{A} u ß e$ rung, die dafür sorgen, dass die Bedeutung und die Symbole von Kultur nicht von allem Anfang an einheitlich und festgelegt sind und dass selbst ein und dieselben Zeichen neu belegt, übersetzt, re-historisiert und gelesen werden können. (Bhabha 2000:57)

Während Bhabha den Begriff der Äußerung eher universalistisch in den Raum stellt, eignet er sich auch für eine genealogisch-ethnografische Analyse neuer Subjektivierungsprozesse in einem Kontext historischer Transformation des öffentlichen Raums. Angesichts einer assimilatorischen Erziehung zum Schweigen waren für „Inder_innen der zweiten Generation“ die „plötzliche“ Möglichkeit, Notwendigkeit, ja Aufforderung, Erfahrungen des Andersseins zu äußern, neu. Angesichts von Indienhype und kommerziellem Multikulturalismus mussten oder konnten sie die durch Scham, Unsicherheit oder Unwissen belagerte Grenze „zwischen den Welten" überwinden und sich zunehmend aktiv und selbstbewusst - statt defensiv und beschwichtigend - über sich selbst, über „Indianness“ und Mehrfachzugehörigkeiten äußern. In diesem historischen Moment verschoben sich die soziethischen Bedingungen der Anrufung und der Subjektivierung, was wiederum die Entwicklung neuer kultureller Techniken der Äußerung und andere Erfahrungen des Selbst- und Andersseins beförderte. Die folgende Analyse fokussiert daher auf das performative Moment der verbalen oder körperlichen öffentlichen Äußerung, der gesellschaftliche und subjektive Transformationsprozesse verbindet. Aus dieser Perspektive lassen sich drei analytische Ebenen unterscheiden, wie sich Subjektivierungsprozesse von schweizerisch-indischen Second@s im Kontext eines kommerziellen Multikulturalismus verändert haben:

Erstens sind mit neuen Anerkennungsräumen auch neue berufliche Möglichkeiten, neue kulturelle Praktiken, neue Handlungsspielräume und neue Subjektivierungsprozesse entstanden. Zweitens entwickelten sich je nach Zusammenspiel der inkorporierten biografischen Logik des Andersseins und der diskursiv-institutionellen Bedingungen unterschiedliche Äußerungsweisen. Drittens hat sich der Kampf um die Definitionsmacht, wer unter welchen Bedingungen über die Repräsentation subjektiver Erfahrungen und kultureller Differenz verfügen kann, verändert. Wie ich zeigen möchte, haben Maya, Sonia, Aftab und Raj durch den kommerziellen Multikulturalismus eine größere Repräsentations- und Handlungsmacht über sich selbst, ihre Herkunft und die Welt gewonnen - wenn auch unter spezifischen und weiterhin asymmetrischen Bedingungen.

Die neuen kommerziell-multikulturellen Repräsentationsräume eröffnen dabei keineswegs eine lineare Form der „Befreiung“ im Sinne eines normativen multikulturellen Paradigmas. Sie erlauben nicht, eine - wie auch immer authentische - kulturelle Substanz zu äußern, wie dies in Taylors Konzept der multikulturellen Anerkennung impliziert wird (Markell 2003; McNay 2008). Gerade umgekehrt produziert der kommerzielle Multikulturalismus als soziales, institutionelles und 
diskursives Repräsentationssystem ein machtvolles und spektakuläres Begehren nach (indischer) Authentizität, die im eigentlichen Moment der warenförmigen Anerkennung und des Konsums fixiert werden muss, um Befriedigung zu vermitteln. So beschreiben Comaroff/Comaroff in ihrem Buch „Ethnicity Inc.“ (2009) die zeitgenössische Bedeutung - sowie die Ambivalenz - der Kommodifikation von Ethnizität folgendermaßen:

Ethnicity Inc. has, without doubt, opened up new means of producing value, of claiming recognition, of asserting sovereignty, of giving affective voice to belonging, this, not infrequently, in the all-but-total absence of alternatives. [...] Ethno-commodities are queer things: their mass marketing is as likely to animate cultural identities as to devalue the difference on which they are founded - although, in the process, they may reformulate identity sui generis in important respects. But those commodities are also vulnerable to the vagaries of commerce, which demands that the alienation of heritage ride a delicate balance between exoticism and banalization - an equation that often requires "natives" to perform themselves in such a way as to make their indigeneity legible to the consumer of otherness. (Comaroff/Comaroff 2009:142)

Die erwähnte Ambivalenz und die Kontingenz sind entscheidend: Denn weder kann Massenexotisierung nur als rassistische oder kulturessenzialistische Ausgrenzung durch die Kulturindustrie angesehen werden, die eine nicht-entfremdete, autonome Subjektivität der „Anderen“ verunmöglicht, wie dies in der marxistischen Tradition oft dargestellt wird (Kalra et al. 2005; Hutnyk 2000). Noch können Praktiken der Hybidisierung als Fest der Anerkennung oder der Vielfalt zelebriert werden, wie es in einem naiven kommerziellen Multikulturalismus geschieht. Die Aushandlung neuer Subjektivitäten und Repräsentationsräume geschieht stattdessen im Spannungsfeld zwischen einer Politik der Authentizität und der Hybridität, zwischen Exotisierung und Selbstrepräsentation (Maira 2002): Einerseits werden „Inder_innen der zweiten Generation“ in diesen Räumen immer wieder dazu aufgerufen, das Begehren nach spektakulärer Authentizität Indiens zu erfüllen, das der kommerzielle Multikulturalismus generiert, und sich dadurch der Logik der Dominanzgesellschaft unterzuordnen. Andererseits öffnet der kommerzielle Multikulturalismus ihnen (transnationale) Handlungsspielräume, um individuelle Erfahrungen des Andersseins und von Mehrfachzugehörigkeit legitim zu äußern oder um sich eindeutigen Zuschreibungen oder Anrufungen zu entziehen.

Die Argumentation in diesem Kapitel orientiert sich daher an folgenden Fragen:

- Welche Verschiebungen in den Subjektivierungsprozessen und Biografien von „Inder_innen der zweiten Generation“ entstanden innerhalb der Logik des kommerziellen Multikulturalismus? 
- Welche Äußerungsweisen und ethischen Spielräume, aber auch welche Ausschlussprozesse und Widersprüche haben sich angesichts neuer Anerkennungsräume, beruflicher Möglichkeiten und biografischer Chancen ergeben?

Zur Beantwortung dieser Fragen führe ich die vier Fälle von Sonia, Maya, Raj und Aftab weiter aus, die ich anhand teilnehmender Beobachtung, biografischer Interviews und diskursiver Dokumentenanalyse rekonstruiert habe. Die ergänzende Kombination dieser Fälle liefert eine dichte Beschreibung einer widerspenstigen Politik von Authentizität und Hybridität von „Inder_innen der zweiten Generation“ im Kontext des kommerziellem Multikulturalismus. Eingebettet sind diese Prozess in neue soziale Praktiken, die sich im Rahmen des kommerziellen Multikulturalismus herausgebildet haben: ethnic entrepreneurship, Identitätskonsum und affektive Vergemeinschaftung. Während der Feldforschung war ich immer wieder fasziniert und erstaunt, wie indische Second@s ihre intimen biografischen Projekte des Andersseins (die ich in Kapitel 3 beschrieben habe) in unternehmerische Selbstständigkeit oder in professionelle Projekte und Aspirationen ummünzten. Genauso eröffneten die neuen Konsummöglichkeiten in einer wachsenden südasiatischen Subkultur neue Lebensstilpraktiken und neue soziale und ethnische Netzwerke. Innerhalb dieser Prozesse, die mehr oder weniger von der Kommerzialisierung von kultureller Differenz geprägt sind, entstanden aber stets auch neue sozioethische Beziehungen der Sorge und der Freundschaft, in denen die Anerkennung von Mehrfachzughörigkeit gepflegt und neue Formen des $\mathrm{Zu}$ sammenlebens (conviviality) erprobt wurden. ${ }^{69}$

\subsection{SONIA: "GLOBALE INDISCHE Frau“ UND KOSMOPOLITISCHER LEBENSSTIL}

Sonia hatte sich seit jeher in transnationalen Netzwerken bewegte und sich zumindest implizit an den Geschlechterrollen einer „neuen indischen Mittelschicht“ orientiert, die professionelle Karriere, westliche Konsumorientierung, traditionelle

69 | Im Gegensatz zu den in den entsprechenden Subfeldern der Migrationsforschung relevanten Fragestellungen und Konzepten interessiere ich mich im Folgenden für ethnic entrepreneurship und Identitätskonsum als performativ-biografische Strategien zur öffentlichen Aushandlung assimilationistischer und multikulturell-exotisierender Subjektivierungslogiken. Zu ethnic entrepreneurship, Netzwerken und Identitätskonsum bei Angehörigen der "zweiten Generation“ in der Schweiz existieren einige spannende Studien, die sich mit biografischen Verläufen der Selbstständigkeit (Juhasz 2005; Hettlage 2007 et al.), den sozialen und politischen Bedingungen der Netzwerkbildung (Wimmer 2003, Wessendorf 2013) sowie mit subkulturellen Lebensstilpraktiken (Wessendorf 2007; Ritter et al. 2010) beschäftigen. 
Familiensinn und respektable Weiblichkeit verbanden. Diese Verschiebungen der Geschlechterrollen verdichteten sich im Narrativ einer "globalen indischen Frau“ (Radhakrishnan 2008:11), und ergänzte im Kontext des Aufstiegs Indiens zu einer globalen Wirtschaftsmacht ältere, patriarchalische Weiblichkeitsideale (s. detaillierter Kapitel 6). Diese transnationale Subjektivität ließ sich in den späten 1990er Jahren kaum repräsentieren. Im dominanten Narrativ der „arrangierten Ehe“ und der „orientalischen Familie“ erschien Sonia entweder als Opfer patriarchaler Strukturen oder als konservative und unberechenbare „Verräterin“, die einen Teil ihres Selbst gegenüber Schweizer Öffentlichkeit und Peers geheim gehalten habe. Sonia reagierte auf diese assimilationistischen Anrufungen mit einem romantischen Narrativ einer diasporischen Liebesgeschichte, wonach die standesgemäße Liebe, die schon in der Kindheit angelegt war, schließlich über die Hindernisse von Raum und Zeit obsiegte. Damit fand sie für sich selbst eine legitime Sprache für ihr Verständnis von Ehe als Teil eines transnationalen familiären Projektes, in dem sich familiäre Werte, romantische Liebeserwartungen und soziale Aspirationen verbinden ließen. Diese Haltung entsprach einer Strategie innerhalb der „neuen indischen Mittelschicht“, die sowohl die Wünsche der Eltern nach einer standesgemäßen Ehe als auch die eigenen Bedürfnisse nach Individualismus und Romantik zu verbinden suchte (Uberoi 2006; Brosius 2010). Mit ihrem Narrativ wies sie, ohne zu widersprechen, die Anrufung einer arrangierten Ehe zurück. Sie schwieg über die intimen familiären Aushandlungen und konnte sich trotzdem selbst repräsentieren.

Im Zuge des populärkulturellen Indienhypes, der Internationalisierung der Arbeitswelt sowie der wachsenden südasiatischen Mittelschichtsdiaspora in der urbanen Schweiz erschienen Sonias kulturelle Praktiken und Zugehörigkeitsmuster zunehmend in einem neuen Licht. Im Kontext ihrer Arbeit in einem multinationalen Unternehmen und durch den kommerziellen Multikulturalismus gewannen diese - für sie selbst, aber auch in ihrem Umfeld - neue Bedeutung, Legitimität und Anschlussmöglichkeiten.

\section{„Indian brain“ und weibliche Respektabilität in der Bankenwelt}

Ab 2004 arbeitete Sonia in einer internationalen Bank im Investmentbanking und wohnte mit ihrem indischen Mann in einer großen Schweizer Stadt. Der Job in der internationalen Bank entsprach Sonias Lebensentwurf. Neben dem damit verbundenen Status, der beruflichen Herausforderung und dem Wissenszuwachs gefiel Sonia die internationale Ausrichtung der Bank. Zwar bestand ihr Team mehrheitlich aus Schweizer_innen und einigen Mitarbeiter_innen aus europäischen Ländern. Aber wie auch andere Firmen im Rahmen globaler Arbeitsteilung herrscht auch in Sonias Bank die Atmosphäre eines corporate multiculturalism. Darunter kann die Verwendung multikulturalistischer Imaginationen und Semantiken in Organisationen verstanden werden, um den Erfolg und die Wettbewerbsfä- 
higkeit in einem globalen Markt aufrechtzuerhalten (Chicago Cultural Studies Group 1992). Sind darin zwar Arbeitsbeziehungen von professionellen Standards (westlicher Prägung) dominiert, spielen Herkunft und kulturelle Differenz für die sinnhafte Aushandlung der kollegialen und freundschaftlichen Bindungen eine tragende Rolle. Im sozialen Setting der internationalen Bank wurde für Sonia die öffentliche Aushandlung von kultureller Differenz zum selbstverständlichen Aspekt ihrer Subjektivierung. Sie erzählte den Kolleg_innen viel von ihrem indischen Hintergrund und ihrer Familie. Manchmal gingen sie gemeinsam indisch oder asiatisch essen und Sonias Angewohnheit, das Essen scharf nachzuwürzen, war ein stereotyper running gag. Diese alltägliche Anerkennung von Differenz wurde dadurch verstärkt, dass „Indianness“ auch in die Konstruktion von Sonias Position in der Bank eingeschrieben war.

Als ich mich eben für die Bank bewarb, haben wir so mathematische Tests gehabt, und so language tests. Bei meinen mathematischen Tests haben dann wirklich viele gesagt, das ist also ein Indian brain. In der Mathematik bin ich eigentlich ganz normal, aber viele sagen halt auch, Inder haben dieses mathematische Denken, das sei wahrscheinlich geerbt.

Dieses Narrativ des „Indian brain“ war nicht nur in alltäglichen Gesprächen präsent, sondern spiegelte sich laut Sonia auch in der Personalstruktur und Arbeitsteilung der Bank: „Wir haben in London extrem viele indische traders. Und traders sind die, die wirklich das beste mathematische Denken haben müssen, sie entwickeln alle unsere quantitativen Modelle für Derivate. Also es sind wirklich Genies - und achtzig Prozent sind Inder. ${ }^{\text {"70 }}$ Wenn auch die alläglichen ethnischen Stereotypisierungen im corporate multiculturalism sowie affirmative diversity policies eine kritische Auseinandersetzung mit Diskriminierung konterkarieren mögen (Ahmed 2013), so eröffneten sie für Sonia Räume öffentlicher Selbstrepräsentation. Im Rahmen ihrer Arbeit absolvierte Sonia regelmäßige Geschäftsreisen und Weiterbildungen in London und konnte auch beruflich südasiatische Netzwerke aufbauen, in denen sie mit den britisch-asiatischen Öffentlichkeiten sowie mit kritischen Diskursen über Rassismus in Kontakt kam, die in der Schweiz kaum verbreitet sind. Eingebettet in diese vielfältigen transnationalen Netzwerke vermochte Sonia sich selbst noch nuancierter und selbstbewusster über die Werte als

70 | Diese Ethnisierung professioneller Aktivitäten im globalen Kapitalismus ist im Falle von Inder_innen insbesondere in der IT-Branche üblich (Xiang 2007). Analog zur Finanzbranche wird auch dort auf die mathematischen und technologischen Fähigkeiten Bezug genommen. Diese haben jedoch eher mit dem Bildungssystem zu tun, das technologische und naturwissenschaftliche Disziplinen seit der Unabhängigkeit an Elite-Schulen fördert. Daher besteht nicht nur ein großer Wettbewerb in diesen Disziplinen, sondern sie genießen auch einen hohen Status in Indien. 
moderne indische Frau zu repräsentieren, die Karriere und Familie, Erfolg und Mäßigung zu verbinden vermochte. Dies wurde vor allem spürbar als mit der Finanzkrise seit 2008 plötzlich der Ruf der Bankenwelt ins Wanken geriet und Sonia - wie alle ihrer Kolleg_innen - um den sozialen Status als Bankerin fürchten musste. Sie grenzte sich vom übermäßigen Konsumismus und einer wachsenden Gier in der Bankenwelt ab, die sie oft bei Männern beobachtete. Noch dezidierter war ihre Kritik an Bankerinnen, die ihrer Karriere weibliche Respektabilität und Familiensinn opferten - gerade wenn sie aus aus der südasiatischen Diaspora stammten. Sie hingegen sei noch eine „normale Frau“, sie gehe „immer noch nach Hause und koche für ihren Mann, statt nach Hause zu kommen und zu sagen, koch jetzt was, ich habe auch gearbeitet" (Jain 2010). Die Bewahrung dieser aus ihrer Sicht indischen Familienwerte, die ihre Eltern sie gelehrt haben, unterschiede sie von gierigen Anlageberatern, arroganten Bankern aber auch von maskulinen Karrierefrauen sowohl europäischer als auch südasiatischer Herkunft. Die Immersion in die internationale Bankenwelt und die Aushandlung der moralischen und strukturellen Bankenkrise 2008 verhalfen Sonia dazu, ihre Subjektivität als "globale indische Frau" weiter zu profilieren, die eine professionelle Karriere mit Familienwerten, Emanzipation mit moralischer Respektabilität verbindet.

\section{Zwischen Diasporakultur und kosmopolitischem Lifestyle}

Nach der Hochzeit 2005 hatte Sonias Ehemann Rahul eine Stelle als private banker in der Schweiz gefunden. Die Entscheidung, einen Job in der Schweiz zu suchen, fiel aufgrund Sonias Wunsch, bei ihrer Bank zu bleiben und in der Nähe ihrer Familie zu wohnen. Der gute Ruf des Bankenplatzes Schweiz versprach zudem gute Arbeitsbedingungen. Angesichts dieser transnationalen Biografie fühlte Rahul sich im internationalen Berufsumfeld seiner Bank wohl, für die er Privatvermögen aus Südamerika und dem Mittleren Osten verwaltete. Der Indienhype in der urbanen Schweiz und die wachsende südasiatische Subkultur boten Sonia und Rahul spannende private und berufliche Handlungs- und Anerkennungsräume. Sie besuchten mit Freunden, mit Bekannten oder Kunden neben anderen kosmopolitischen urbanen Angeboten insbesondere auch indische Restaurants und Bollywood-Partys oder schauten sich Hindi-Filme im Kino an. Insbesondere für Sonia entstanden damit südasiatische Öffentlichkeiten in der Schweiz, die sie sonst nur aus Indien, London oder Dubai kannte. Dadurch konnte sie ihren Lebensentwurf als „globale indische Frau" auch vermehrt in der Schweiz öffentlich und legitim repräsentieren und äußern.

Ich traf Sonia und Rahul zufällig auf einer Bollywood-Charity-Party, die von einem indischen IT-Mitarbeiter einer Schweizer Bank organisiert worden war. Dessen Partys hatten seit einigen Jahren einen guten Ruf gewonnen und über E-Mail-Verteilerlisten und digitale Plattformen einige Hundert Leute mobilisiert. Da der Anlass in 
den Expat-Kontext eingebettet war, inszenierte der Veranstalter die Party zu Beginn als Spektakel der Völkerverständigung. Zuerst informierte er unter Applaus, dass der Erlös der Charity-Veranstaltung an eine NGO fließe, die er gegründet hatte und die Bildungsprojekte in Indien unterstütze. Danach fand ein Bhangra-Crash-Kurs statt, in dem eine professionelle Tänzerin den zahlreichen nicht-indischen Gästen die wichtigsten Schritte dieses nordindischen Volkstanzes zeigten, der seit den 1990er Jahren die globale südasiatische Clubszene dominierte. Nach einer Weile trafen Sonia und Rahul mit einem befreundeten indischen Paar ein. Sie hatten sich trotz eines langen Arbeitstags entschieden, sich noch ein bisschen zu amüsieren. Rahul trug Jeans und ein sportliches Trainerjackett, Sonia ein schwarz-weißes Tigertop, ein schwarze Hose und gleichfarbige Pumps. Ihre Bekannten und die anderen Angehörigen der südasiatischen Diaspora kannten alle Bollywood-Gassenhauer auswendig, wie etwa den Hit „Jai Ho" (Hindi etwa: der Sieg sei dir; du schaffst es) aus dem Soundtrack der britisch-indischen Ko-Produktion "Slum Dog Millionaire“ (2008). Der Film - und dessen indischer Musikproduzent A. R. Rahman - waren im Jahr davor mit einem Oscar für die beste Musik geehrt worden und der Song „Jai Ho“ verkörperte den Stolz des „neuen Indiens“. Obwohl Sonia die Lieder und die Choreografien nicht fließend beherrschte, nahm sie voller Freude am Gruppentanz teil, scherzte und sang, so gut es ging, mit. Sie kannte zwar die kulturellen Codes dieser neuen globalen indischen Partykultur nicht vollständig, konnte aber performativ einen sicheren Platz in der globalen indischen Diaspora einnehmen.

Einige Wochen zuvor hatte ich Sonia und Rahul auch auf dem Konzert von Anoushka Shankar gesehen, das im Rahmen des „Grüezi India“-Festivals 2008 stattfand (s. Kapitel 4.2). Nach dem Konzert hatte ich mich im Publikum umgesehen und war erstaunt gewesen, kaum Personen indischer Herkunft zu sehen. Stattdessen waren viele elegant gekleidete weiße Männer und Frauen in der Halle des Zürcher Kongresshauses. Plötzlich entdeckte ich Sonia und Rahul in Begleitung zweier Schweizer Pärchen. Wie ich vermute, handelte es sich um Kunden oder Arbeitskolleg_innen von Rahul oder Sonia. In Abendkleid und Anzug verkörperten Sonia und Rahul sowohl eine eloquente und feierliche Eleganz als auch die Seriosität des beruflichen Anlasses. Wie schon auf der Bollywood-Charity-Party erlaubte der Besuch des Konzertes Sonia eine mehrfache performative Selbstrepräsentation. Einerseits konnte sie sich in Anoushka Shankars musikalischer Fusion von Ost und West, Tradition und Moderne, mit der Mehrfachzugehörigkeit des Weltstars identifizieren. Andererseits konnte sie auch einen kosmopolitischen Lebensstil inszenieren, der transnationale Mobilität und soziale Distinktion mit dem Zugang zur Elite verband.

Die Arbeit bei einer multinationalen Bank und die Ehe mit einem Finanzfachmann aus der südasiatischen Diaspora eröffneten Sonia im globalen Kapitalismus neue transnationale Anerkennungs- und Handlungsräume. Das multikulturelle Setting der Bank, das Expat-Umfeld an der urbanen Bollywood-Disco sowie die internationalen Milieus der bürgerlichen Schweizer Elite boten für Sonia einen 
polysemischen Subjektivierungsraum, in dem sie sich virtuos bewegte. Sonias Aneignung des Familienprojektes erscheint - übersetzt in die illustre internationale Finanzwelt, in die Netzwerke der wachsenden südasiatischen Diaspora und in den kommerziellen Multikulturalismus der urbanen Schweiz - nicht mehr als traditionell oder gar rückständig, sondern als erfolgreicher, selbstbewusster kosmopolitischer Lebensentwurf in einem globalen Kapitalismus. Durch die gute Ausbildung, die Berufswahl, die standesgemäße Ehe und die transnationalen familiären Netzwerke hat sie ihre sozialen Aspirationen in globale Opportunitäten und Perspektiven übersetzen können. Zwar muss sich Sonia gegen die aus ihrer Sicht allenfalls konservativen Normen und Erwartungen ihrer Verwandten oder gegen assimilationistische Anrufungen ihrer lokalen Peers in der Schweiz positionieren. Aber angesichts der ökonomischen, sozialen und kulturellen Ressourcen und ihrer transnationalen Lebenswelt verfügt sie über eine gewisse Autonomie, um diese Spannungen auszuhalten.

\section{Exkurs: Das Scheitern indischer Wunschbiografien, amor fati und die Kontinuität des "Lebens zwischen den Welten“}

Sonias beruflicher und privater Werdegang kann geradezu als Wunschbiografie vieler indischer Eltern bezeichnet werden, die aus der Mittelschicht stammen und die durch die Migration eine intergenerationelle soziale Mobilität anstrebten. Die Arbeit in einem internationalen Unternehmen entspricht einem oft gehegten Ideal, da dies erstens erlaubt, Anerkennung innerhalb der transnationalen indischen Statushierarchien zu gewinnen, wogegen sich die Arbeit in einer unbekannten Schweizer Firma kaum in transnationalen Statusgewinn übertragen ließe. ${ }^{71}$ Zweitens können „Inder_innen der zweiten Generation“ in internationalen beruflichen Kontexten ihre transnationale Biografie und Mehrfachzugehörigkeit pflegen und assimilationistische Diskriminierung zumindest teilweise vermeiden. Auch die Heirat ihrer Kinder mit einem indischen Mann oder einer indischen Frau ist für viele Eltern eine ideale Möglichkeit, Status und Familienwerte innerhalb der Diaspora aufrechtzuerhalten und den Vorwurf des „kulturellen Verlusts“ zu vermeiden. In den 1990er Jahren machten sich jedoch Gerüchte in den transnationalen Netzwerken breit, dass Ehen zwischen Frauen aus der Diaspora und indischen Männern sehr problematisch seien. Es wurde insinuiert, dass Bildungsunterschiede, aber auch Verschiebungen in den Geschlechterrollen oft zu Konflikten innerhalb der patriarchalen Logik führten. Daher etablierte sich bei indischen Secondas und ihren Familien in der Schweiz die Strategie, indische Männer aus der Diaspora zu finden, die die westlichen Lebensbedingungen kannten und selbst eine trans-

71 | Zur Übersetzung von kulturellen und sozialen Kapitalien in transnationalen Netzwerken - als Erweiterung der Bourdieu'schen Theorien zu sozialer Ungleichheit s. Weiss 2005; Berger/Weiss 2008; Nieswand 2011; Nohl et al. 2014. 
nationale Karriere verfolgten - wie eben Rahul. Die Erfüllung der Idealbiografie, wie im Falle von Sonia, war jedoch äußerst voraussetzungsvoll. Wenn die Ausbildung nicht von Erfolg gekrönt war, die intergenerationelle Tradierung der Familienwerte nicht wie erhofft funktionierte oder Ehepläne scheiterten, wurde dies von indischen Second@s und ihren Familien oft als krisenhaft erfahren. Diese Krisen erforderten es, biografische Aspirationen innerhalb der Familie neu zu definieren und soziale Werte umzulagern. So etwa bei Anil, einem 38-jährigen Kundenberater:

Anils Eltern stammten aus der Mittelschicht einer mittelgroßen nordindischen Stadt. Sein Vater hatte ab den 1970er Jahren als promovierter Naturwissenschaftler für die Bundesverwaltung gearbeitet und sich seit einigen Jahren als Unternehmer in der Import-Export-Branche selbstständig gemacht. Anils Mutter ist Hausfrau, sein älterer Bruder Informatiker. Von Beginn an hatte Anil stets Mühe in der Schule und seine Leistungen und seine Disziplin wurden immer wieder als unterdurchschnittlich eingestuft. Viel lieber vergnügte er sich bei Sport und Spiel mit Peers in einer der kinderreichen Siedlungen in einer Agglomerationsgemeinde. Obwohl er sich grundsätzlich akzeptiert und integriert fühlte, wurde er als Kind auch Opfer eines gewalttätigen, alltagsrassistischen Übergriffs, der sich ihm als verstörende Urerfahrungen des Andersseins einschrieb. Da der Erfolg ausblieb, verlor er weitgehend das Interesse an der formalen Bildung und investierte mehr Zeit, Ehrgeiz und Energie in seine sportlichen Aktivitäten, worin ihn die Eltern unterstützten. Im Gegensatz zur Schule erschien ihm der Sport als (wirklich) meritokratisches System, in dem Bemühungen, Leistungen und Erfolg in einem nachvollziehbaren und fairen Verhältnis standen. Da der Zeitaufwand für den Sport die Ausbildung jedoch stark gefährdete, musste er diese Hobbys zeitweise zurückstellen. Obwohl er sich im Sportmilieu wohlfühlte, blieb auch dort ein nennenswerter Erfolg aus, woraufhin er sich auf Traineraktivitäten im Jugendbereich konzentrierte. Der Übergang in den Beruf gestaltete sich schwierig: Beim zweiten Anlauf gelang ihm der kaufmännische Abschluss und er arbeitete in unterschiedlichen Betrieben als Außendienstmitarbeiter oder Kundenberater. Eine Zeit lang arbeitete er in einem multinationalen Informatikunternehmen, in dem auch sein Bruder arbeitete. Dies verschaffte ihm vorübergehend gegenüber der indischen Familie und im Bekanntenkreis eine gewisse Anerkennung, aber eben nur vorübergehend. Als junger Erwachsener hatte Anil eine Liebesbeziehung mit einer Schweizerin gehabt, die aber in die Brüche ging, worunter er sehr gelitten hatte. Daher hatte er sich mit der in Indien verbreiteten Sichtweise angefreundet, wonach westliche Frauen keine Kompromisse eingehen könnten und nicht zu ihm passten. Als ich Anil traf, offenbarte er mir sichtlich peinlich berührt, dass er gerade nach Indien auf „Brautschau“ fahre. Ehen von Männern aus der Diaspora mit Frauen aus Indien schienen nicht problematisch, weil diese die bestehende patriarchale Asymmetrie nicht infrage stellten (Thapan 2005; Palriwala/Uberoi 2008). Anils Bruder hatte schon einige Jahre vorher eine Familie mit einer indischen Frau gegründet, die 
er über familiäre Netzwerke und Heiratsannoncen in Indien kennengelernt hatte. Anil meinte, er wolle aber eine „moderne indische Frau“ suchen und diese vor der Heirat richtig kennenlernen - im Gegensatz zu seinem Bruder. Zurzeit wohnen er und seine Frau mit seinen Eltern, seinem Bruder und dessen Familie im eigens für die patrilokale Großfamilie (joint family) konzipierten Haus, in der jede Partei ein Stockwerk bewohnt. Seit einigen Jahren arbeitet er nun im familieneigenen transnationalen Handelsunternehmen und treibt daneben weiterhin voller Leidenschaft und intensiv Freizeitsport. Anil genießt den kommerziellen Indienhype. Der Konsum von Bollywood-Filmen, indischem Essen und indischer Musik ist für ihn sehr wichtig und definiert sein Selbstverständnis als indischer Secondo. Dieser „Identitätskonsum" findet jedoch vor allem zu Hause statt und kaum in öffentlichen Anerkennungsräumen des kommerziellen Multikulturalismus. Die Verbindung zu diasporischen Kreisen neuer indischer Migrant_innen ist nur schwach, da er sich doch zu schweizerisch fühlt und ihm die distinguierte Weltläufigkeit fehlt. Und der Kontakt zu den anderen indischen Second@s ist seit der Jugend größtenteils abgebrochen und ließ sich trotz Versuchen nicht mehr einfach auffrischen. Anil erlebt die Situation ambivalent. Einerseits fühlt er sich oft eingeengt und erfährt seine Wohnform als unpassend im Vergleich zu Schweizer Standards. Andererseits genießt er die enge Familiensolidarität und die nostalgische Heimatverbundenheit, die zu Hause - nicht zuletzt dank der Kochkünste seiner Mutter - herrscht.

Im Sinne von Bourdieus Begriff des amor fati hat Anil gelernt, sein Schicksal, wenn nicht zu lieben, so doch hinzunehmen. Angesichts des Misserfolgs in der Ausbildung und im Berufsleben, dem trotz großer sportlicher Anstrengungen begrenzten „natürlichen Kapital“ und der deswegen ausbleibenden Perspektiven, orientierte sich Anil zunehmend am Lebensmodell seiner Eltern. Das Wohnen bei seinen Eltern nach der Lehre versprach ihm in den unsicheren Zeiten soziale und finanzielle Sicherheit. Analog bestätigte für Anil das Scheitern der Beziehung mit einer Schweizerin im jungen Erwachsenenalter den elterlichen Wunsch einer Ehe mit einer indischen Frau. Zwar ist er selbst irritiert über seine „Brautschau“, doch nimmt er sie trotzdem hin, um einen Familie gründen zu können und damit den sozialen Normen der (indischen und schweizerischen) Mittelschicht möglichst zu genügen. Als männlicher Non-resident Indian im patriarchal geprägten Statussystem der indischen Diaspora konnte er so schließlich eine legitime Rolle als Sohn und Ehemann einnehmen. Für Anil und für seine Eltern wurde also die diasporische joint family zu einem Modell, um den unerfüllten Wunsch der transnationalen sozialen Mobilität zu reartikulieren, ja zu kompensieren.

Sowohl Sonia als auch Anil haben ihre Biografie weitgehend im Familienidiom ausgehandelt. Durch ihre gute schulische Ausbildung konnte sich Sonia im Gegensatz zu Anil jedoch eine gewisse Autonomie innerhalb des Familienprojektes in Bezug auf Berufswahl und Aushandlung der Partnerschaft ausbedingen. Gleichzeitig erlaubte ihr die Arbeit als Bankerin, sich in einem transnationalen beruflichen Umfeld und einem kosmopolitischen Milieu zu bewegen. Gute Aus- 
bildung, guter Job, transnationale Kanäle eröffneten ihr viele öffentliche Anerkennungs- und Gestaltungsräume jenseits des „Lebens zwischen den Welten“. Anils schulischer und beruflicher Hindernislauf und die damit verbundene Unsicherheit verstärkten in ihm die Orientierung an der „indischen Familie“, ohne dass er Anschluss an Räume der Anerkennung von Mehrfachzugehörigkeit hätte finden können. In seinem Fall hat sich das „Leben zwischen den Welten“ fortgesetzt, in dem er täglich zwischen Indien und der Schweiz, der Familie und der Schweizer Öffentlichkeit, Nostalgie und Assimilation hin- und herpendelt.

\subsection{Maya: SelbstVerWirkLichung UND KULtURELLE ÜBERSETZUNG IM Yoga-BOOM}

Die 42-jährige Yogalehrerin Maya hatte während Kindheit und Jugend im Gegensatz zu Sonia und Anil unter der sozioräumlichen Undurchlässigkeit von „indischer Familie" und Schweizer Öffentlichkeit gelitten und einen eigenen biografischen Weg jenseits dieser assimilatorischen Erfahrung gesucht. Nach Abschluss des Gymnasiums Mitte der 1990er Jahre entdeckte Maya auf einer Indienreise ihre Faszination für Yoga. In dem darin eingeschriebenen Ethos der Selbsttransformation ließ sie den wahrgenommenen kulturellen Konflikt zwischen den Erwartungen der ,indischen Migrationsfamilie“ und den Normen der assimilatorischen Öffentlichkeit hinter sich, indem sie ihr Leben als Prozess der spirituellen, körperlichen und psychischen Entwicklung des Selbst re-interpretierte. Nach dem Abschluss ihres Studiums 2004 reiste Maya mit erspartem Geld nach Indien und dann nach Thailand, wo ihr mehrjähriger Yogalehrer eine neue Schule eröffnet hatte. Durch die ständige Auseinandersetzung mit westlichen Yogis und Yoginis in Indien und durch ihre subjektiven Erfahrungen als Auslandsinderin eignete sich Maya eine transnationale Lebensweise an, in der sie räumlich und kulturell „Zwischen Ost und West“ übersetzte. Als sie in dieser intensiven Phase ethischer Selbsttransformation von einer Bekannten angefragt wurde, in der Schweiz als Yoga-Lehrerin zu arbeiten, wirkte diese Anfrage als geradezu schicksal- und krisenhafte Offenbarung.

Und dann, eineinhalb Jahre oder fünfzehn Monate war ich schon in Thailand und Indien unterwegs, hat mich meine ehemalige Tanzlehrerin aus der UniZeit gefragt, ob ich an ihrer Schule Yoga unterrichten würde. Und dann habe ich zum ersten Mal so gedacht: Wow, das wäre ja eine Möglichkeit, dass ich das, was ich am liebsten mache auch da in der Schweiz machen kann. Das ist irgendwie - ich bin ihr extrem dankbar - ich wäre selbst nie auf diese Idee gekommen. 
Bis dahin hatte Maya Yoga als persönliche und intime Erfahrung und ethische Praxis der Selbsttransformation praktiziert. Sie überlegte, dass die Vermittlung von Yoga Verantwortung und Selbstvertrauen als Lehrerin erforderte, die sie eventuell nicht aufbringen würde. Auch befürchtete sie, dass die Bindung des Yoga an organisatorische und ökonomische Fragen die Wahrhaftigkeit und Unbeschwertheit ihrer Yoga-Praxis beeinträchtigen könnte. Es fällt auf, dass Maya nie selbst darauf gekommen wäre, in der Schweiz Yoga zu unterrichten, was für viele Europäer_innen, die eine Yoga-Ausbildung absolvieren, eine offensichtliche Option, wenn nicht gar das Ziel ist. Ich argumentiere, dass für Maya die Vorstellung, in der Schweiz Yoga zu lehren, krisenhaft war, weil dies erforderte, „Indianness“ - durch das Symbol Yoga und aber auch durch ihre Person selbst - öffentlich zu repräsentieren. Dies mochte in Indien, dem Herkunftsland des Yoga sowie ihrer Eltern, in der globalen Yoga-Community und angesichts der biografischen Grenzerfahrung des Reisens stimmig wirken. Aber in der Schweiz, wo sie während Kindheit und Jugend die assimilatorische Forderung internalisiert hatte, Ethnizität möglichst als private und intime Angelegenheit zu behandeln, erschien die Möglichkeit und die Aufforderung, die Grenze „zwischen den beiden Welten“ zu überschreiten, also „Indianness" öffentlich und selbstbewusst zu repräsentieren, als existenzielle Paradoxie. Nach langer Überlegung nahm Maya schließlich die Anfrage als Fügung an und entschied sich dazu, in der Schweiz in Teilzeit als Yoga-Lehrerin zu arbeiten.

\section{Chancen und Grenzen des Yoga-Universalismus}

Yoga hatte sich als wichtige Ressource für Maya entpuppt, um einen subjektiven Erfahrungsort jenseits eines angeblichen biografischen „Kulturkonfliktes“ zu etablieren. Es war ihr dabei wichtig zu betonen, dass sie Yoga nicht als Lebensweg gewählt hat, weil sie indischer Herkunft ist:

Für mich war und ist das Yoga primär ein persönlicher Entwicklungsweg, der sehr wenig mit meiner äußeren Identität und „Indianness“ zu tun hat. Ich würde Yoga auch studieren, wenn ich Chinesin wäre. Und hätte ich nicht Yoga zuerst kennengelernt, hätte mich wahrscheinlich Qi Gong maßgeblich beeinflusst. Der Beweggrund Yoga auszuüben war einfach: Ich lernte da erstmals, mich wirklich zu entspannen.

Diese universalistische Interpretation von Yoga erstaunt historisch gesehen nicht sonderlich, da diese eng verflochten ist mit der modernen Geschichte dieser Philosophie und Praxis. Im Kern des Yoga-Universalismus steht eine Methode, wonach alle Menschen unabhängig von kulturellen oder ethnischen Unterschieden psychische, spirituelle und gesundheitliche Erfüllung finden können, indem sie durch Praxis immer tiefer in die Weisheit des Yoga eintauchen. Das moderne Yoga hatte sich seit dem späten 19. Jahrhundert im Kontext kolonialer Wissenszirkulation von 
einer meditativen Geheimlehre indischer Eremiten und Mönche zu einem umfassenden globalen Denk- und Heilsystem gewandelt, das in einem transnationalen Netz von internationalen Schulen organisiert und finanziert wurde. Der Erfolg des modernen Yoga im Westen ab dem Fin de Siècle wurde darauf zurückgeführt, dass es in der Tradition des romantischen Orientalismus eine Imagination, eine Sprache und ein Ethos für eine „alternative Moderne“ bot, um das „stählerne Gehäuse" der europäischen Moderne zu durchbrechen (Strauss 2005). Wie Joseph Alter zudem argumentierte, erlaubte die naturwissenschaftliche Modernisierung des Yoga in der antikolonialen Bewegung des frühen 20. Jahrhunderts, dieses als empirisch fundierte Heilslehre in einer globalen Wissensgesellschaft zu etablieren (Alter 2004). Der Fokus auf den Körper als experimenteller und spiritueller Ort der Wahrheitsfindung sowie als Objekt der sportlichen und gesundheitlichen Selbsttechnologie erlaubte seither, das mystische Wissen des Yoga in der globalen Moderne anschlussfähig zu machen. Trotz ihrer performativen Affirmation des Yoga-Universalismus ist Maya als Person und als Lehrerin mit der omnipräsenten Imagination Indiens als kulturellem und geografischem Ursprung des Yoga konfrontiert. Unabhängig davon, ob für sie ihre Herkunft eine Rolle bei der Faszination für Yoga gespielt haben mag, wird ihre Herkunft in ihrer Tätigkeit als Yoga-Lehrerin implizit oder explizit immer wieder Thema. Diese Herkunftsanrufungen erfordern von Maya im Alltag als Yoga-Lehrerin spezifische Techniken der Selbstrepräsentation.

An einem lauen Sommerabend nach einer Yoga-Lektion beschlossen Maya und ich, etwas trinken zu gehen. Karin, eine Schülerin im mittleren Alter, deren Heimweg in die gleiche Richtung führte, begleitete uns. Wir sprachen über Mayas anstehende berufliche Selbstständigkeit sowie über ihre geplante Indienreise und über Kindheitserinnerungen in der indischen Gemeinschaft. Völlig fasziniert schaltete sich Karin ein und erzählte, dass sie als Kind indische Tempeltänzerin hatte werden wollen. Ein bisschen perplex wollte ich sagen, dass indische Tempeltänzerinnen ursprünglich Prostituierte waren, verkniff mir aber diesen Kommentar. Zweifellos war Maya auch ein bisschen überrumpelt von dieser Offenbarung orientalistischer Phantasie und zweifellos wusste sie um den historischen Hintergrund des klassischen Tempeltanzes. Trotzdem antwortete sie ehrlich und ohne Ironie, wie schön sie diesen kindlichen Wunsch finde. Nicht nur konnte Maya sich wohl mit Karin identifizieren, weil der klassische indische Tanz auch sie selbst seit der Kindheit faszinierte, wie sei betonte. Gleichzeitig vermittelte sie damit auch eine wahrhaftige und empathische Anerkennung der subjektiven Erfahrungen und Wünsche ihrer Schülerin. Nichtsdestotrotz war die kurze Antwort auch eine Möglichkeit, die lancierte exotistische Schwärmerei abzublocken. Daraufhin fragte die Schülerin, wie Maya Yoga kennengelernt habe und Maya erzählte, wie sie als Gymnasiastin unter dem indischen Sternenhimmel zum ersten Mal Yoga praktiziert habe. Karin war fasziniert und meinte: „So schön, so jung dieses Geschenk zu erhalten." Damit meinte sie wahrscheinlich 
vor allem das Geschenk des Yoga, aber gleichzeitig verwies die Aussage im Kontext des Gespräches über Kindheit, Nostalgie und Indienschwärmerei auch auf die kulturelle Nähe oder Privilegiertheit Mayas im Zugang zur spirituellen Quelle Indiens. Sie habe schon viel Yoga gemacht, meinte Karin, finde jedoch Mayas Unterricht so gut, weil er so ruhig und meditativ sei und eine tiefe Erfahrung erlaube. Diese Aussage bezog sich zwar auf den Stil der Yogapraxis, war jedoch auch anschlussfähig an ein Ursprungsnarrativ, wonach Menschen indischer Herkunft einen privilegierteren Zugang zu Yoga hätten. Symptomatisch (er)klärte Maya im Sinne des Universalismus, dass Yoga zwar in Indien entstanden sei, aber grundsätzlich alle Menschen das Potenzial hätten, gemäß Yoga sich selbst zu entwickeln. Sie nannte das Beispiel des Schweizer Gurus Reinhard Gammenthaler, des letzten Schülers des berühmten Yogis Dhirendra Bhramachari, der sich in langen Jahren als Eremit im Himalaya ins Yoga vertieft hatte. Karin nickte zustimmend. Nach einer Weile verabschiedete sie sich dann und Maya wandte sich zu mir: "Ich konnte das zwar vor ihr nicht sagen. Aber ich finde schon, dass es in Indien generell viel mehr weise Leute gibt als hier, das merkt man einfach. Die Leute sind näher bei der Weisheit als hier, wo die Leute eher Kopfmenschen sind."

In diesem vielfältigen Gespräch zeigen sich die Chancen und Grenzen von Mayas Yoga-Universalismus. Erstens zeigt dieses Gespräch exemplarisch, wie Indien im globalen Yoga-Diskurs als spiritueller und geografischer Ort der Authentizität eingeschrieben ist, der jeglichen Universalismus stets auch untergräbt. Sowohl die orientalistische als auch die antikoloniale Konstruktion haben in der Yoga-Gemeinschaft, in der Populärkultur und im westlichen Alltag die Sehnsucht nach Indien als Stätte spiritueller Befreiung und moralischer Überlegenheit zutiefst verankert. Nicht nur Karin, sondern auch Maya selbst können sich dieser Spannung in der imaginären Geografie des Yoga nicht entziehen. Wenn oft auch implizit, wird im Gespräch immer wieder eine tief verankerte quasi-essenzialistische Kontinuität von Yoga und „Indianness“ angedeutet. Während Karin zwar stets über Yoga generell spricht, deutet sie immer auch eine Faszination dafür an, dass Maya dieser Kultur so nah sei, diese besitze. Als Reaktion auf Karins Exotisierung wählt Maya zunächst eine Strategie des Schweigens. Erst als das Thema ihrer eigenen Herkunft aufkommt, interveniert sie mit der Expertise als Lehrerin und belegt den Universalismus des Yoga am Beispiel Gammenthalers. Obwohl Maya versucht, sich vor allem durch Professionalität und universalistische Narrative zu repräsentieren, ist sie selbst nicht frei davon, in Indien eine besondere, authentische Qualität des Yoga zu verankern. Dies möchte sie jedoch Karin gegenüber nicht äußern, entweder um ihre Professionalität nicht infrage zu stellen, die auf dem Universalismus beruht, oder um keine kulturelle Hierarchie zwischen ihr und ihrer Schülerin zuzulassen. 


\section{Die Konstruktion kultureller Übersetzung als Expertise und die Krise der Repräsentation}

Während Maya meistens versuchte, sich als Person und als Lehrerin durch die universalistische Yoga-Philosophie zu positionieren, bot ihr die Tätigkeit als Yoga-Lehrerin auch die Möglichkeit, ihre biografischen Erfahrungen des eines diffusen Gefühls des Andersseins in der Schweiz zu rahmen - und auch zu äußern. Innerhalb der globalen Geschichte des Yoga bietet ihr dazu die Methode der „kulturellen Übersetzung“ einen legitimen Rahmen, um ihre subjektiven Erfahrungen in der universalistischen Philosophie des Yoga zu verorten. Als ich an einem Yoga-Wochenende in den Schweizer Alpen teilnahm, erzählte Maya bei einem Spaziergang, wie konstitutiv die Übersetzung „zwischen West und Ost“ in ihrer Yoga-Biografie gewesen sei. Sie hatte zwar Yoga nach dem Gymnasium in Indien bei einem indischen Arzt kennengelernt und sie war fasziniert von dem Charisma des Mannes, der Kraft des Ortes und der Intensität der Erfahrung. Trotz dieser Faszination konnte sie jedoch die, wie sie sagte, wirklich „tiefen Erfahrungen“ erst machen, als sie einen rumänischen Lehrer einer Schule kennenlernte, in der das mystische Yoga-Wissen aus einer naturwissenschaftlichen - in Mayas Worten: westlichen - Logik erklärt wurde. Erst dadurch konnte sie das Potenzial von Yoga verstehen, nachvollziehen und schließlich in seiner Tiefe erfahren.

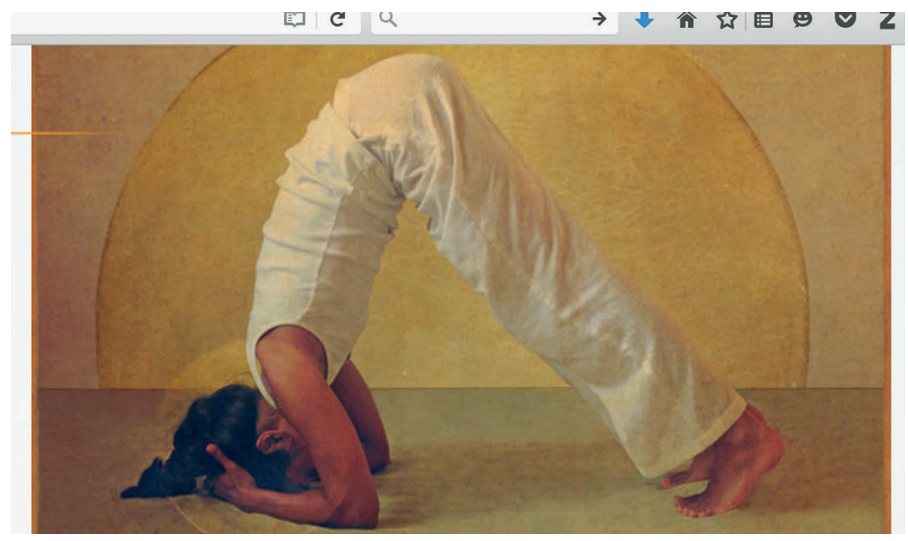

Abbildung 18: Suche nach einer Ästhetik und Spiritualität zwischen Ost und West. Selbstrepräsentation auf Website (Quelle: Autor)

Diese historische Geste der Übersetzung manifestierte sich auch in Mayas Lizentiatsarbeit, worin sie körperpsychotherapeutisches, neurowissenschaftliches und „klassisches“ Yoga-Wissen über die menschliche psychische Entwicklung verglich. In dieser Arbeit zeigt sich nicht nur die intensive und inspirierende persönliche Auseinandersetzung Mayas mit Yoga, sondern auch der Versuch, durch kulturelle 
Übersetzung unterschiedlicher Wissenstraditionen eine universalistische Wissensform und Subjektivität zu finden, in der sich westliche und östliche Weisheit verbinden lassen. So schreibt sie auf ihrer Homepage:

Immer wieder ergeben sich aufgrund meiner Verwurzelung in zwei Kulturen Dialoge, in welchen traditionelles Wissen aus dem Yoga und dem indischen Kontext auf die Wissenschaft und das Wissen der westlichen Kultur treffen. So übersetzte ich beispielweise in Rishikesh (Indien) die Fragen von europäischen Personen, die Yoga praktizierten, für einen indischen Yogi, der viele Jahre weit weg von der Zivilisation gelebt hat. Eben solchen Austausch zu ermöglichen, ist ein wesentlicher Teil meiner Arbeit.

Wie wir gesehen haben, stellt diese Beschreibung zweifellos eine wahrhaftige Selbstrepräsentation ihrer Reisen in Indien und ihres Selbstverständnisses als Yogini dar. Aber die Beschreibung transkultureller Subjektivierung auf der Homepage generiert im Kontext des kommerziellen Multikulturalismus zwangsläufig auch andere Bedeutungen. In Broschüren und auf der Homepage, die neben Selbstrepräsentation und Information auch eine Werbeplattform darstellen, können diese Aussagen auch das Begehren nach Authentizität im kommerziellen Multikulturalismus mobilisieren. Aus dieser Perspektive gelesen deutet der Homepage-Text eine doppelte Expertise an: Erstens verspräche Mayas Yoga-Unterricht durch ihr Leben in „beiden Kulturen“ einen privilegierten Zugang zum alten indischen Wissen, das sich durch eine kulturelle Kontinuität bis heute auszuzeichnen scheint. Zweitens erlaubte Mayas doppelte Herkunft, dieses Wissen dem heutigen und hiesigen Denken angepasst zu vermitteln. Mayas Versuch, ihre persönliche transkulturelle Erfahrung zu äußern, offenbart im diskursiven Kontext des kommerziellen Multikulturalismus einen problematischen Widerspruch: In einer ersten, verbreiteten Lesart essenzialisiert und legitimiert die Semantik der Authentizität Mayas „Verwurzelung in beiden Kulturen“, die sie geradezu genetisch oder über kulturelle Tradition an die Kontinuität indischer Zivilisation bindet. Diese Interpretation fixiert Mayas oszillierende und fluide Performanz ständiger Übersetzung. Und insbesondere wird dadurch ihre langjährige Yoga-Ausbildung und ständige Arbeit an einem guten Unterricht ausgeblendet. In der zweiten oft vorgenommenen Lesart wird Mayas Selbstrepräsentation im Yoga-Markt „lediglich“ als Vermarktungsstrategie gelesen, in der die „kulturelle Übersetzung“ "zu einer spezifischen Leistung wird. Diese verbreitete Interpretation einer Instrumentalisierung von Ethnizität zu Vermarktungszwecken verweigert ihr jedoch die Anerkennung für die persönlichen Erfahrungen kultureller Übersetzung sowie für ihre Erfahrungen des Andersseins, die Maya durch die öffentliche Kommunikation dieser biografischen Perspektive implizit einfordert.

Das in den Differenzkonsum eingeschriebene Phantasma der Authentizität schränkt Mayas Spielraum der Anerkennung von Mehrfachzugehörigkeit ein. 
Maya spürt intuitiv diese repräsentationspolitischen Tücken: Sie versucht, ihre Biografie und ihre Tätigkeit als Yoga-Lehrerin - außer im Homepage-Text und in den Broschüren - möglichst zu trennen und in einer universalistischen Weltanschauung und ihrer Qualifikation aufzulösen: „Die Leute, die sich zu mir hingezogen fühlen, tun das, weil ihnen diese Art des Unterrichts entspricht und sie in anderen Yogastunden das, was sie in dieser Praxis erfahren, nicht erfahren." Mayas Versuch, ihre eigene Biografie und Herkunft möglichst aus der öffentlichen Aushandlung herauszuhalten und sich durch Professionalität zu profilieren, repetiert dabei ein assimilationistisches Schweigen, weil sie ihre Erfahrungen des Andersseins weiterhin nicht öffentlich äußert. Die Repräsentationskrise ist aber nicht individuell, sondern diskursiv. Denn Mayas subjektive Erfahrung der ständigen kulturellen Übersetzung ist in der hiesigen, repräsentationspolitischen Grammatik sprachlich und performativ weiterhin kaum zu vermitteln.

Trotzdem vergrößerte der Yoga-Boom für Maya einen öffentlichen und sozialen Handlungsraum, um ihre subjektiven Erfahrungen einer transkulturellen Übersetzung zu äußern. Durch die Weiterentwicklung ihrer Yoga-Schule, die Beziehungen zu ihren Schüler_innen und anderen Yoginis, die eigene Praxis und Weiterbildung konnte sich Maya in einem transnationalen sozialen Feld bewegen und etablieren, in dem sie ständig zwischen westlichem und östlichem Wissen, zwischen Mystik und Naturwissenschaft sowie zwischen Vergangenheit und Gegenwart übersetzen kann. Dadurch hat sie eine äußere und soziale Entsprechung für ihre subjektiven Erfahrungen gefunden, statt sich wie im Assimilationismus als „anders“ wahrzunehmen und sich an öffentliche Normen anzugleichen.

Innerhalb dieser neuen transnationalen Räume sind Schweigen und Nicht-Repräsentation von Anderssein jedoch weiterhin sehr verbreitet: Einmal, als wir uns trafen, meinte Maya, dass ihr der kurta (langes Hemd) gefiele, den ich trug. Sie freue sich, in Indien auch wieder solche Kleider tragen zu können, ohne aufzufallen. Da fragte ich sie, warum sie eigentlich in der Schweiz keine indischen Kleider trage. Sie meinte erstaunt, das sei eine gute Idee, daran habe sie noch gar nicht gedacht. Und tatsächlich trug sie, als wir uns nach ihrer nächsten Indienreise trafen, ein salwar kameez (weibliche Kombination von langem Hemd und Hose), die im Sinne eines kosmopolitischen Lebensstils perfekt in den multikulturellen Raum Zürichs passten. Mayas legitime und öffentliche Aushandlung Indiens als Yoga-Lehrerin zwischen kommerziellem Multikulturalismus und Indienreisen verändert ihre subjektive Erfahrung von Biografie und Zugehörigkeit. Neben dem professionellem Yoga-Universalismus stimulierte die Logik warenförmiger Anerkennung bei ihr auch subtile nostalgische Äußerungsformen des Andersseins. Als wir uns das erste Mal zu einem Interview trafen - sie war eineinhalb Jahre davor von ihrer Indien- und Thailandreise zurückgekehrt - erzählte sie begeistert davon, dass sie auf der Straße in der Schweiz nun Menschen Hindi sprechen höre. Das habe es in unserer Kindheit nicht gegeben. Nach den langen Indienaufenthalten und angesichts dieser unerwarteten öffentlichen indischen Präsenz habe sie das 
Bedürfnis, die Erfahrungen und Kontakte ihrer Kindheit wieder stärker zu pflegen, die sie lange vernachlässigt habe. In den subtilen Repräsentationspraktiken angesichts des Indienhypes und ihrer transnationalen biografisch-professionellen Aushandlung Indiens zeigt sich bei Maya eine gewisse Nostalgie, aber auch ein emanzipatorischer Schritt in Richtung der Überwindung des (assimilationistischen) Schweigens, hin zur Schaffung von Räumen der Mehrfachzugehörigkeit.

\subsection{Raj: Offenbarung, IDENTITÄTSKonsum UND IRONIE UNTER "INDIAN BROTHA'S AND SISTA'S"}

Beim 49-jährigen Pflegefachmann Raj war Nostalgie seit seiner Jugend eine wichtige Ausdrucksweise, um Anderssein und Herkunft im Kontext des Assimilationismus auszuhandeln. Die Suche nach den „eigenen Wurzeln“ war das Produkt aus dem Zusammenspiel der Zuschreibung eines „Lebens zwischen den Welten“ und fehlender korrespondierender „indischer Migrationsfamilie“. Sein indischer Vater war wegen der Arbeit als Monteur oft abwesend und blieb Raj ein Mysterium - wie seine Herkunft. Er reiste in den späten 1980er Jahren und in den 1990er Jahren mehrmals als Backpacker nach Indien, las Bücher und eignete sich Wissen über das Heimatland seines Vaters an. Trotz dieses biografischen Projektes der „Indianness“, das er mit seinen Freunden, seiner Frau und seinen Kindern teilte, blieb Raj jedoch weitgehend allein in dieser Aushandlung des Andersseins.

Dies änderte sich vor einigen Jahren, als er mit Jasmin und Tara zwei schweizerisch-indische Secondas kennenlernte, die mit ihren jungen Familien im selben Quartier wohnten wie er. Die 46-jährige Jasmin, Innendekorateurin und Leiterin einer Tagesschule, lebte bis zu ihrem siebten Lebensjahr in prekären Verhältnissen in Indien, als sie von einer Schweizer Familie adoptiert wurde. Im Spannungsfeld von Rassismus- und Ausschlusserfahrungen in einer ländlichen Umgebung zog sie sich zunehmend in sich selbst zurück und versuchte einen „eigenen Weg“ zu gehen. Sie versuchte sich zu assimilieren und gleichzeitig Orte und Milieus zu suchen, in denen sie (wirklich) nicht auffiel. Die urbane linksalternative Subkultur bot ihr seit den späten 1980er Jahren gegenkulturelle Räume, in denen kulturelle Differenz als Bereicherung verstanden wurde. In einem damals betriebenen Treffpunkt für people of colour fand sie auch das erste Mal Menschen, mit denen sie sich identifizieren konnte, weil sie, ähnliche Erfahrungen des rassialisierten Andersseins hatten. Jasmin bildete sich in dieser Zeit zur Innendekorateurin aus und gründete zusammen mit ihrem Partner mit knapp 25 Jahren eine Familie, in ihren Worten: ein „eigenes Nest“, in dem sie sich zum ersten Mal aufgehoben fühlte. Hatte sie sich schon in ihrer Malausbildung mit ihren Kindheitserfahrungen und ihrer Herkunft auseinandergesetzt, löste schließlich die Geburt ihrer ersten Tochter einen Prozess aus, in dem sie sich nun bewusst mit ihrer Herkunft auseinandersetzte. Einerseits aus Verantwortung gegenüber ihrer Tochter, andererseits auch als Versuch, einen Teil 
ihres (Innen-)Lebens für sich und andere zu öffnen, entwickelte sie eine reflexive und spielerische Auseinandersetzung mit ihrer Biografie und ihrer Herkunft. Sie begann, ihre Wohnung in einem indischen anmutenden Stil einzurichten und lernte indisch zu kochen. In den 1990er Jahren begab sie sich mit ihrem Partner und ihrer älteren Tochter nach Indien auf die Suche nach ihren Brüdern, nach den „Wurzeln, von denen sie abgeschnitten wurde“, wie sie es ausdrückt.

Während Jasmin wie Raj angesichts fehlender ethnischer Sozialisierung und Netzwerke ein sehr intimes und nostalgisches biografisches Projekt der „Indianness"verfolgten, hatte die 45-jährige Projektleiterin Tara ganz andere biografische Bedingungen für die Aushandlungen kultureller Zugehörigkeit. Tara ist Tochter eines Schweizer Journalisten und einer indischen Psychologin, die aus einer Industriellenfamilie aus Mumbai stammt. Die Eltern hatten sich in der Schweiz kennengelernt, als Taras Mutter hier studierte und arbeitete. War sie zwar auch wie Raj Kind aus einer binationalen Familie, boten ihr die internationalen beruflichen Pfade und das transnationale soziale und kulturelle Kapital der Eltern die Bedingungen für eine im bürgerlichen Sinne kosmopolitische Biografie. Sie verbrachte einen Teil ihrer Jugend in Indien, wo ihr Vater als Diplomat arbeitete, und studierte später in London an einer renommierten Universität. Seit ihrer Geburt reist sie jährlich und selbstverständlich nach Indien, wo neben ihrer erweiterten Familie mütterlicherseits seit einigen Jahren auch ihre Eltern leben.

Die Bekanntschaft mit Tara und Jasmin seit dem Millenniumswechsel veränderte für Raj die sozioethischen Bedingungen, unter denen er sich mit seinen Erfahrungen des Andersseins auseinandersetzen und wie er darüber sprechen konnte. Zum ersten Mal konnte er sich intensiv mit Menschen austauschen, mit denen er sich identifizieren konnte, das heißt, gegenüber denen er sich nicht „anders“ fühlte. Über die Jahre sind freundschaftliche und vertraute Beziehungen zwischen Raj, Tara und Jasmin entstanden, die sich durch alltägliche Aushandlung von $\mathrm{Zu}$ gehörigkeiten und Lebensentwürfen auszeichnet. Wie Susanne Wessendorf für Netzwerke von italienischen Second@s in der Schweiz argumentiert, erfordern solche „starken Bindungen“ neben gemeinsamer Herkunft eine zusätzliche Gemeinsamkeit, einen sogenannten „double-tie“ (Wessendorf 2013). Demnach war die als gemeinsam wahrgenommene Herkunft für Raj mit Tara und Jasmin nur zusammen mit der ähnlichen soziokulturellen Lage als junge Eltern in einem ähnlichen linksalternativen Milieu sowie durch die Position am Rande der südasiatischen Netzwerke bedeutsam und wirkungsvoll. Sowohl Raj als auch Jasmin - und auf eine andere Weise auch Tara - waren nicht oder nur sehr schwach in die Netzwerke der südasiatischen Diaspora in der Schweiz eingebunden und nahmen sich tendenziell als illegitim oder als nicht zugehörig zu diesen Kreisen wahr und grenzten sich davon ab. Während sich für Raj die ohnehin vorhandene Erfahrung nicht zu diesen Kreisen dazuzugehören durch die Scheidung der Eltern noch verstärkte, war die Zugehörigkeit für Jasmin durch die fehlende kulturelle Bindung zu Indien und die Unkenntnis indischer Netzwerke in der Schweiz noch existenzieller infra- 
ge gestellt. Für Tara wiederum muteten die kulturellen Praktiken in der südasiatischen Gemeinschaft in der Schweiz angesichts ihrer kosmopolitischen Familie oft konservativ und gar folkloristisch an.

Im freundschaftlichen Rahmen einer ethnischen Vergemeinschaftung entstanden für Raj und Jasmin - und teilweise auch für Tara - ein neuer Äußerungsund Aushandlungsraum von Anderssein und Zugehörigkeit.

\section{"Indian sista's and brotha's": Offenbarung, Intimität und performative Vergemeinschaftung}

In den Beziehungen von Raj, Tara und Jasmin spielt die Suche, Offenbarung und Vermittlung der „eigenen Geschichte“ eine konstitutive Rolle. Die Freundschaft „auf den ersten Blick“ von Tara und Jasmin basierte darauf, einander die eigene Biografie erzählen zu können und zu wollen. Die „eigene Geschichte“ erzählen zu können und zu wollen steht im Kontrast zum Erzählen-Müssen oder zum Schweigen, die in den assimilatorischen Erfahrungen seit der Kindheit und Jugend vorherrschten. Wie etwa Jasmin sich erinnert, war für sie seit der Kindheit die Frage nach der Herkunft, diese Neugier nach ihrer Geschichte, der Inbegriff der Ohnmacht und des Ausschlusses. Die Frage markierte die Erfahrung der Illegitimität des dunkelhäutigen Mädchens, Mitglied einer weißen Schweizer Familie zu sein. Sie sagt, sie sei „als Bild und nicht als Mensch“ erfahren und dadurch zu einem Objekt degradiert worden. Die Erfahrung, entweder in ihrer Malerei, im Treffpunkt für schwarze Menschen in ihrer Adoleszenz der späten 1980er Jahre oder eben in den Beziehungen mit Raj und Tara, ihre „eigene Geschichte“ zu entdecken und selbst darüber verfügen zu können, eröffnete für sie eine neue ethische und performative Ebene von Identität und der Sozialität. ${ }^{72}$ Die Offenbarung der eigenen Geschichte etabliert eine intime Beziehung zum Gesprächspartner, in der sich sowohl die Verletzlichkeit angesichts der biografischen Erfahrungen spiegeln als auch die reflexiven und praktischen Bemühungen, eine eigene Geschichte erarbeitet zu haben und darüber verfügen zu können. Durch die Bezeichnungen „Indian brotha“ und "Indian sista“ signalisieren sich Raj, Jasmin und Tara, dass sie qua Erfahrung des Andersseins und qua Herkunft, sowie durch die Möglichkeit, ihre „Geschichte erzählen“ zu können, zu einer rituell-familiären Gemeinschaft geworden sind.

72 | Diese Praxis der Offenbarung zeigte sich immer wieder in meiner Forschung. Insbesondere das biografische Interview gab indischen Second@s Raum, intime Erfahrungen des Andersseins zu äußern, die sie noch nie jemandem erzählt hatten, respektive durch Rückfragen an mich einen Vergleich mit sich selbst zu haben. Zwar beinhaltet das biografische Interview immer diese Möglichkeit der Offenbarung, jedoch möchte ich argumentieren, dass bei vielen indischen Second@s, mit denen ich gesprochen habe, das Schweigen, das durch die Offenbarung überwunden werden sollte, im spezifischen assimilationistischen Dispositiv hervorgebracht worden war. 
Während rituelle Verwandtschaften - wie etwa in der nordindischen Tradition des rakshabandhan - bei Jugendlichen in der südasiatischen Diaspora verbreitet sein mögen und durch entsprechende indische Terminologien bezeichnet werden, verweist die Rhetorik der „,brotha's and sista's“ explizit auf afroamerikanische Subkulturen und anti-rassistische Bewegungen, die schon auf den erwähnten Jasmins Besuchen im Treffpunkt für people of colour zurückgeht. Angesichts der prekären Zugehörigkeit sowohl zur schweizerischen Dominanzgesellschaft als auch zur indischen Gemeinschaft in der Schweiz konstituieren sich die Beziehungen von Raj, Jasmin und Tara in dieser familiären Rhetorik auf eine neue Weise. Vor allem für Raj und Jasmin war die Gründung einer „eigenen Familie“ ein existenzieller Moment der Geborgenheit und Zugehörigkeit, da sie durch Adoption und zerrütteten Familienverhältnissen die Erfahrung internalisiert hatten, dass sie keine in der Schweiz anerkannte soziale Herkunft vorweisen zu können. Die performative ethnische Gemeinschaft von Raj, Jasmin und Tara erweiterte die schon durch die „eigenen Familien“ geschaffenen Milieus von Vielfalt und Anerkennung um einen teilöffentlichen Raum, in dem sie die eigenen intimen Erfahrungen des Andersseins explizit und legitim im Topos der „Indianness“ austauschen konnten. Durch ihre freundschaftlichen Beziehungen untereinander vermittelten sie diese Aushandlungen von „Anderssein“ und „Indianness“ auch über die Generationen an ihre Kinder weiter. Dadurch entstand ein erweitertes Netzwerk von Familien, rituellen Verwandtschaften und Freundschaften, in denen sie sich zunehmend gleichzeitig anders und „heimisch“ fühlen können (Brah 1996).

\section{Identitätskonsum und Ambivalenz der Kommerzialisierung}

Während diese performativen, ethnischen Beziehungen zu einer stärkeren Präsenz Indiens im Alltag von Raj und Jasmin beigetragen haben, ist die Form dieser neuen Sozialität nur vor dem Hintergrund des populärkulturellen und medialen Indienhypes zu verstehen. „Indianness“ war zwar seit der Hippie-Zeit durch Kleider und Schmuck auf Straßenmärkten oder religiöse Paraphernalien in der alternativen Populärkultur (zum Beispiel in der Goa-Szene) stets präsent. Schon früher war für Raj und Jasmin der Konsum von „Indianness“ durch die Aneignung von Kleidern oder Haushaltgegenständen eine Praxis, um die genealogische Verbindung zu Indien auszudrücken. Aber der Indienhype und die Räume des kommerziellen Multikulturalismus eröffneten diesem „doing Indianness“ eine neue Dimension. Wie Urmila Goel argumentiert, schuf das urbane Angebot an südasiatischer Populärkultur gerade für Personen an den Grenzen diasporischer Netzwerke neue Räume, um sich legitime Zugehörigkeit anzueignen und diese auszudrücken (Goel 2008). Der Konsum von Bollywood, Asian Underground, Bhangra und indischen Lebensmitteln markierten für Raj und Jasmin sowohl die Identifikation mit Indien als auch eine fragile, mithin trotzige Inszenierung und Repräsentation des Andersseins. Zu Hause, im privaten Raum, bedeutete dieser 
Identitätskonsum eine intime ästhetische Praxis, in der „die Außenwelt stärker der Innenwelt angeglichen“ wird, wie Raj und Jasmin das nennen. Während Raj seine indische Innenwelt so beschreibt, dass „etwas“ anklingt oder ein „Film abgeht“, wenn er mit Indien konfrontiert wird, beschreibt Jasmin, dass die „Farben Indiens“ in ihrem Inneren stets vorhanden gewesen seien. Seit der Geburt ihrer ersten Tochter, noch bevor sie Tara kannte, hatte sie begonnen, „ihr Nest“ stärker indisch zu gestalten. Die ästhetische Konstruktion des eigenen Indiens durch Gestaltung des eigenen Wohnraums ermöglichte, die inneren Erfahrungen des Andersseins ästhetisch auszudrücken und sozial - und gleichzeitig kontrolliert - zu äußern. Während Raj zeitweise einen persönlichen Schrein mit hinduistischen Götterstatuen, Fotos und Schmuck pflegte, dominieren bei der Innendekorateurin Jasmin indische Textilien, Möbel und Bilder.

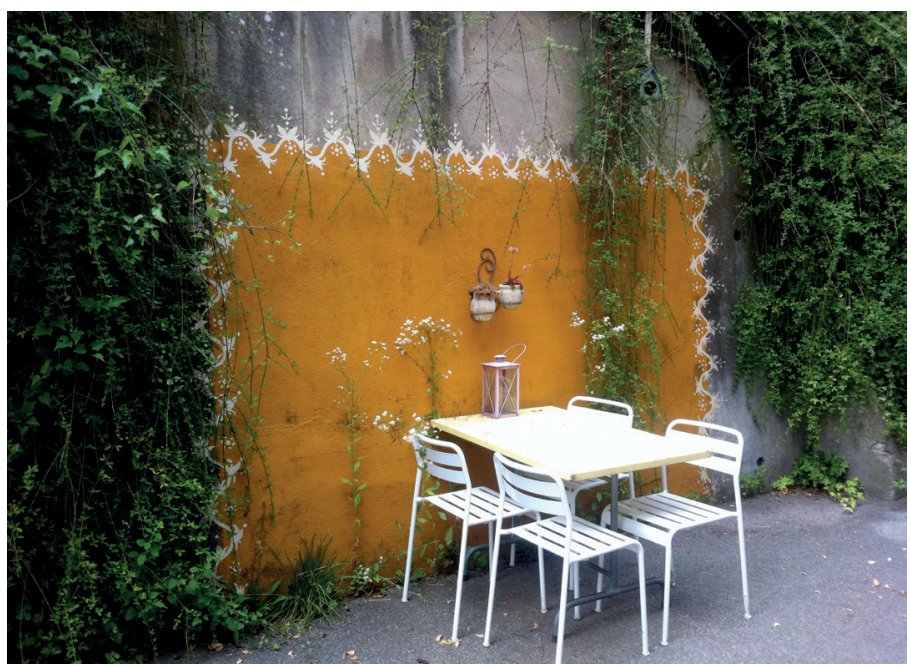

Abbildung 19: Sublime Selbstrepräsentation und neue Freundschaften schaffen Nischen des Heimisch-Werdens (Quelle: Autor)

Die performative, familiäre Vergemeinschaftung von Raj, Jasmin und Tara förderte und legitimierte diese Form von Identitätskonsum zusätzlich. Umgekehrt wurden ihre freundschaftlichen Beziehungen durch die Konsumpraktiken und "Indianness“ als alltägliche Dimension in dieser Freundschaft verstärkt. Für Jasmin und Raj bieten Indienhype und kommerzieller Multikulturalismus wichtige, neue Ressourcen und Räume für eine autonome Aushandlung von Anderssein und Zugehörigkeit. Sie fördern eine nostalgische Verankerung des Herkunftstopos, aber auch eine legitime Repräsentation von prekärer Mehrfachzugehörigkeit. Tara nutzt zwar diese Möglichkeiten des Indienhypes auch, sieht hingegen darin eher 
einen oberflächlichen Kommerz und eine postmoderne Beliebigkeit, ohne Subs$\operatorname{tanz}$ und Tiefe. Während etwa in den Indienwochen in einem bekannten Kaufhaus vor dreißig Jahren hohe Qualität geboten wurde, weil die Einkäufer in Indien selbst die besten Anbieter aufgesucht hatten, sei heute bei ähnlichen Aktionen nur noch Massenware zu finden, sagt sie. Als Produkt des globalen Kapitalismus leiste der kommerzielle Indienhype einem kulturellen Einheitsbrei Vorschub, dessen Symbole und Markierungen kulturell wertlos werden. In der kapitalismuskritischen und kulturpessimistischen Einschätzung Taras kommt die privilegierte $\mathrm{Zu}$ gehörigkeit zu einer transnational vernetzten Familie der bürgerlichen Elite zum Ausdruck. Erstens hat Tara den transnationalen Konsum indischer Güter sowohl als Identitätskonsum als auch als soziale Distinktion so stark inkorporiert, dass er kaum eine explizite Anerkennungspraxis mehr darstellt wie etwa bei Raj und Jasmin. Zweitens wird bei Tara in der kulturpessimistischen Kritik an der globalen Kommerzialisierung indischer Alltagskultur auch eine nostalgische Klage um eine Authentizität Indiens laut, die wie ihre Kindheit und Jugend im präliberalisierten Indien der 1980er Jahre angesiedelt ist. Das „neue Indien“ erscheint in dieser Erzählung vor dem Hintergrund des grassierenden Kapitalismus, der soziale Beziehungen zerstört und Ungleichheit vergrößert, auch als verwestlichte Fratze, in dem die Vergangenheit als ein sozialromantisches Korrektiv aufblitzt.

Der Identitätskonsum im Rahmen der globalen Kulturökonomie nimmt also für Tara, Raj und Jasmin, die alle in einem linksalternativen Milieu verankert sind, eine ambivalente Bedeutung an. Einerseits bietet er für Raj und Jasmin eine Möglichkeit, ihre Erfahrung des Andersseins im Topos von „Indianness“ auf eine spielerische Weise zu äußern und warenförmige Anerkennung zu gewinnen. Andererseits ist der kommerzielle Indienhype aus ihrer Sicht Teil eines künstlichen Netzes von Kopien im globalen Zeitalter der technischen Reproduzierbarkeit, in dem das angeblich „wahre Indien" ausgeblendet wird. Auf paradoxe, aber trotzdem produktive Weise wird die Authentizität, die der Identitätskonsum zu inszenieren erlaubt, gleichzeitig infrage gestellt.

\section{Ironie und Parodie: Chancen und Tücken experimenteller Authentizität}

In diesem ambivalenten Spannungsfeld stellt die Inszenierung von „Indiannes“" durch Konsum und Vergemeinschaftung ein ambivalentes und ironisches Spiel mit dem Topos der Authentizität und Hybridität dar. Unter den „sista's and brotha's“ ist es etwa eine übliche Praxis, durch die Parodie von Indian English, das Erzählen von grotesken Erlebnissen oder die theatralische Imitation von Körpergesten wie etwa dem Kopfwackeln, „Indianness“ in einem komischen Register darzustellen. In der internalisierten Assimilationslogik beinhaltet diese performative Äußerung des Andersseins - wie auch der Identitätskonsum - einen trotzigen Anspruch auf Selbstrepräsentation und Anerkennung. Die Selbstrepräsentation erfordert 
die Überwindung einer Scham angesichts der aus ihrer Sicht illegitimen und inauthentischen ethnischen Performanz, die zwar offensichtlich biologisch markiert ist, aber nicht durch Sozialisation in Fleisch und Blut übergegangen ist. Die komische Performanz von „Indianness“ erlaubt, diese vorübergehend Widersprüche aufzuheben und die sublimen Erfahrungen von Anderssein und Zugehörigkeit zu äussern. Wie Darja Klingenberg argumentiert, hilft Komik als spezifische soziale und rhetorische Praxis, inkongruente Sphären zu verbinden sowie gesellschaftliche Widersprüche und Brüche im Migrationskontext auszuhandeln.

Im Vergleich zur ernsten Rede ermöglicht das Sprechern im Scherz ein temporäres Außerkraftsetzen von gesellschaftlichen Verhältnissen und Begrenzungen. Dies erlaubt eine gewisse Distanz und die Artikulation von schwierigen, nicht ganz durchdachten oder radikalen Perspektiven. Diese scherzhaft wahrgenommenen Widersprüche und Begrenzungen können verbal überschritten und spielerisch neutralisiert werden. (Kotthoff et al. 2013:242)

In der ironischen Rede oder in der theatralischen Parodie spiegelt sich Rajs und Jasmins Ambivalenz gegenüber ihrer angeblich illegitimen Zugehörigkeit. Denn in den komischen Praktiken, wie etwa in der Parodie des Indian English, inszenieren sich Raj oder Jasmin als „richtige“ Inder_innen und grenzen sich gleichzeitig von diesen ab. Darin wird ein Widerstand sowohl gegen die Dominanzgesellschaft sichtbar, die ihnen eine Selbstrepräsentation des Andersseins immer wieder verweigert(e), als auch gegen Repräsentanten der Diaspora, aus deren Sicht ihre Zugehörigkeit als illegitim erscheinen mag. So führte Raj, wie er mir erzählt hatte, nach einer Indienreise eine Dia-Show für seine Mitarbeiter vor. Er hatte einen indischen kurta angezogen, den er in Indien gekauft hatte. Er faltete die Hände und begrüßte seine Kolleg_innen mit einem herzhaften „Namaste“ und einigen Floskeln in einem parodierten Indian English. Danach erzählte er zum Teil informativ und immer wieder mit einem komischen Seitenhieb auf sich selbst oder "die Inder" von seiner Reise. Diese offensive öffentliche Parodie von „Indianness“ durch die Verwendung des Indian English sprengt durch die Übertreibung auf subversive Art die immer noch gültige assimilationistisch Forderung, dass der Fremde seine Differenz nicht selbst repräsentieren soll. Dadurch enthält diese ironische Praxis einen geradezu monströsen Anspruch auf Anderssein und eine karnevaleske Nonchalance, die immer wieder Irritation und Gelächter auslöst. Wenn auch einige indische Second@s diese Parodien ihrer Eltern, Verwandten oder Bekannten schon seit ihrer Kindheit betrieben, wird dies heute verstärkt im Rahmen von Medienkonsum und Populärkultur ausgehandelt. Britische Sendungen wie Goodness Gracious Me, The Kumars from Number 42 oder die Aufführungen des Komödianten Russell Peters aus Kanada haben südasiatische Parodien in der Diaspora seit den 1990er Jahren im TV-Genre der ethnic comedy populär gemacht. In diesen ironischen und humoristischen Formaten positionierten sich südasiatische Komödiant_innen der 
„Zweiten“ oder „dritten Generation“ in der öffentlichen Repräsentationspolitik. Sie konnten sich dadurch gleichzeitig sowohl als spezifische Akteure gegenüber der Elterngeneration darstellen als auch gegen rassistische Strukturen des Othering anlachen. ${ }^{73}$ Auch in der Schweiz hatten indische Second@s in den letzten Jahren begonnen, diese Sendungen übers Internet zu konsumieren, die sowohl eine transnationale Identifikation als „zweite Generation“ beförderten als auch neue Äußerungsmodi und Subjektpositionen des Andersseins im Alltag einführten. Im Gegensatz zum multikulturalistischen Großbritannien wurde jedoch die stereotype Parodie von „Indianness" und insbesondere des Indian English in der Schweiz in einem implizit rassistischen Diskurs durch die Fernseh-Comedy-Figur Rajiv populär, die der Komiker Viktor Giacobbo zwischen 1998 und 2002 in seiner LateNight-Show im Schweizer Fernsehen darbot. ${ }^{74}$ Wie ich andernorts argumentiert habe (Jain 2012), kommt das Lachen über die Comedy-Figur Rajiv und sein charakteristisches Indian English im „weissen“ und von Assimilationismus geprägten Schweizer Kontext einem „Spektakel des Fremden“ gleich (Hall 1997), in dem die Dominanzgesellschaft ihre moralische, politische und ethnische Deutungshoheit behaupten kann. Da die Performanz des Indian English in der landläufigen Assoziation mit Rajiv als beliebtes infantilisierendes Stereotyp von "Indianness“ verwendet wird, bedeutet Gelächter oder Zuspruch im Falle von Rajs Parodien auch eine Zuschreibung als Clown in einem hierarchischen Drehbuch des „Eigenen“ und des "Anderen“, das nicht umgeschrieben wird. Es bleibt unklar, ob Raj in dieser Situation mit der Dominanzgesellschaft über sich selbst lachte oder ob er mit dieser über „richtige“ Inder_innen lachte. Vor einem dominanzgesellschaftlichen Publikum läuft eine alltägliche Parodie von „Indianness“ entweder Gefahr, ins Lächerliche überzuschwappen und eine Selbst-Exotisierung festzuschreiben, oder sie kann gar einen „kathartischen Rassismus" in der Dominanzgesellschaft legitimieren und reproduzieren (Jain 2012).

73 | Durch die Komik etablierten sie eine neue Strategie gegenüber antirassistischen Diskursen der 1980er Jahre, in denen people of colour oft als passive Opfer von Rassismus dargestellt wurden. Gleichzeitig fanden sie eine breite Nachfrage in den neuen multikulturellen Programmen der Fernsehstationen (Malik 2002).

74 | Durch die Figur von Rajiv verbreitete sich Indian English als populäre Parodie von "Inder_innen" also kurz bevor die neue Migrationswelle von IT-Ingenieur_innen oder Finanzspezialist_innen in der schweizerischen urbanen Öffentlichkeit präsent wurde. In diesen alltäglichen Parodien wird Indian English als unverständlich, falsch und dümmlich, aber durchaus auch als sympathisch und lustig dargestellt. Die humoristische Überdeterminierung führt im Alltag oft dazu, "Inder_innen“ als nicht ebenbürtige Gegenüber zu stigmatisieren. Während man über Indian English als unverständliches Kauderwelsch lachte, wurde ignoriert, dass in Indien öfter Englisch als Muttersprache oder fließende Zweit- oder Drittsprache gesprochen wird als in der Schweiz oder Europa. In der Diaspora gilt dies angesichts eines Mittelschichtsbias noch viel stärker. 
Unter den "Indian sista's and brotha's“ jedoch erlauben Ironie und Parodie durchaus eine Praxis des "laughing back“ (Kotthoff et al. 2013), um den Rassismus oder die Ignoranz in der weißen Dominanzgesellschaft lächerlich zu machen. Vor allem Raj und Jasmin inszenieren immer wieder Begegnungen, in denen sie sich aufgrund ihrer Hautfarbe oder ihrer Herkunft herabgewürdigt fühlten: Ein Running Gag ist etwa der allbekannte Ausspruch: „Jetzt schau mal, wie es [das Mädchen] herzig Schweizerdeutsch spricht." In einer Parodie über eine solche Begegnung mokierte sich Jasmin über die eigentlich aus ihrer Sicht tragische Leugnung ihrer legitimen Zugehörigkeit zur Schweiz. In der hegemonialen Sicht auf die Schweiz erschienen Schweizerdeutschkompetenz und dunkle Haut als inkongruent und provozierten unmittelbares Erstaunen und wohlmeinende Sympathie. In der Parodie verschob Jasmin jedoch die Inkongruenz und machte damit klar, dass nicht ihr eigenes Leben unwirklich sei, sondern dass die hegemoniale Wahrnehmung eigentlich unfassbar dümmlich, ja surreal ist, wenn darin ihre Schweizerdeutschkompetenzen als außergewöhnlich erscheinen. Indem sie diese herrschende Schweizer Position parodiert, macht sie sowohl die ignorante Stereotypisierung sichtbar als auch ihre eigene Wirklichkeit als indische Seconda respektive als dunkelhäutige Schweizerin. Die uneigentliche Rede kehrt den Wirklichkeitsanspruch um und appropriiert Deutungshoheit gegenüber einer auf tragische Weise rückständigen und ignoranten Dominanzgesellschaft in einer zunehmend globalisierten Welt. Die Praxis der Ironie ist dabei auch eine engagierte Kritik am Alltagsrassismus in der Schweiz und markiert eine andere, utopische Wirklichkeit, die die „sista's and brotha's “ für sich geschaffen haben.

\subsection{Aftab: Das Management „INTERKultureller Probleme" IM GLOBALEN Kapitalismus}

Der 51-jährige Unternehmensberater Aftab strebte im Gegensatz zu Maya, Sonia und Raj schon in Kindheit und Jugend an, die Erfahrungen des Andersseins im Assimilationsregime aktiv durch die Aneignung von Wissen über Indien und eine erklärende und argumentative Haltung gegenüber der Dominanzgesellschaft zu kontern. Während er zwar den Dialog mit seinen Peers suchte, war er gleichzeitig ein Eigenbrötler und Improvisator. In den 1990er Jahren jobbte Aftab zuerst im Kulturjournalismus, als Assistent und Projektleiter in der Marketing- und Grafikbranche und schließlich als Software-Ingenieur. Trotz der vielseitigen Arbeitserfahrung reizte den unkonventionellen Individualisten Aftab der Journalistenberuf am meisten, der intellektuelles Prestige, kreative Selbstverwirklichung und organisatorische Selbstständigkeit verhieß. Mitte der 1990er Jahre schrieb er aufs Geratewohl eine Rezension der Geschichtensammlung „East, West“ (1994) von Salman Rushdie, die prompt gedruckt wurde. Der britisch-südasiatische Schriftsteller Salman Rushdie war seit der Publikation seines Romans „Die satanischen Verse“ 
(1988) und der darauf folgenden Fatwa durch den iranischen Ayatollah Khomeini der Inbegriff südasiatischer Literatur im Westen geworden (Huggan 2001). Salman Rushdie war wie Aftabs Eltern in Indien geboren, wanderte dann nach Pakistan aus und emigrierte schließlich nach Europa. Die Auseinandersetzung mit den Geschichten über Migration und Asyl, die öffentliche Politisierung der Figur Salman Rushdies und die westliche Kritik am Islam war ein geradezu ideales Betätigungsfeld für Aftabs Strategie der aufklärerischen Übersetzung zwischen Südasien und Europa. Immer stärker begann er den „südasiatischen Nexus“, wie er es nennt, zu pflegen und zu nutzen. Er schrieb für Tageszeitungen und Magazine über südasiatische Kultur, Politik und Wirtschaft und reiste dafür immer wieder nach Indien und Pakistan. Da er den IT-Boom in Indien mitverfolgt hatte und aufmerksam auf die Sorgen der schweizerischen Unternehmen wegen des Y2K-Problems ${ }^{75}$ wurde, nutzte er die Gunst der Stunde und begann er in den späten 1990er Jahren indische IT-Ingenieure an Schweizer Firmen zu vermitteln.

\section{Von der Biografie zum Geschäftsmodell an den Schnittstellen des globalen Kapitalismus}

Wie im vorangehenden Kapitel erläutert, waren der indische IT-Boom und das Wachstum der indischen Wirtschaft in der schweizerischen Öffentlichkeit der späten 1990er Jahre kaum bekannt und Aftabs Unterfangen wurde als höchst exotisch wahrgenommen. Indien galt in der breiten öffentlichen Wahrnehmung immer noch als unterentwickeltes Land mit einer antiken und durchaus faszinierenden Zivilisation, kaum jedoch als Ausbildungsstätte von Hunderttausenden von IT-Spezialisten. Einige große multinationale Konzerne und Banken jedoch, die entweder schon in Indien tätig waren oder sich global orientieren mussten, interessierten sich für Aftabs Vermittlungsdienste. Die Nachfrage bei den Unternehmen für billige IT-Arbeitskräfte war laut Aftab zwar groß, aber auch die Konsternation: „Die Kunden haben gesagt, das sind super Leute, aber wir verstehen ihre Mentalität einfach nicht, und da habe ich begonnen interkulturelle Seminare zu entwickeln." Aufbauend auf diesen ersten Arbeitserfahrungen übernahm Aftab die Leitung eines indisch-schweizerischen Joint Ventures im IT-Outsourcing. Die Widersprüche der Massenentlassungen der 1990er Jahre, der Auslagerungsprozesse und der Großfusionen, die die bisherige soziale und wirtschaftliche Organisation des Wohlstandsmodells der Schweiz infrage stellten (Honegger/Rychner 1998), zeigten sich auch in diesem Unternehmen. Das Software-Outsourcing nach Indien

75 | Y2K (Year 2 Thousand = K= kilo) bezeichnete ein Problem in der Informatikbranche Ende der 1990er Jahre. Viele Jahresindizes in Computersystemen waren nur mit 2 Ziffern programmiert, weshalb beim Wechsel von 1999 zu 2000 ein endemischer Zusammenbruch der IT-Infrastruktur befürchtet wurde. Bei vielen Unternehmen und Institutionen entstand daraufhin große Nachfrage nach günstigen IT-Dienstleistungen. 
löste firmenintern eine große Verunsicherung aus, die sich durch den Konkurs der traditionellen Schweizer Mutterfirma im Jahr 2001 und die dadurch bedingte Übernahme durch eine amerikanische Finanzierungsgesellschaft noch verstärkte. Im globalen Kapitalismus bekamen die bekannten Ordnungen und Hierarchien Risse und produzierten starke eurozentrische Ambivalenzen: Einerseits waren die indischen Software-Ingenieure, wie auch die amerikanische Finanzierungsgesellschaft, Retter in der Not, die die strukturelle Krise der Schweizer Unternehmung auffingen. Gleichzeitig erschienen sie der schweizerischen Mittelklasse auf ihre je eigene Weise als unzivilisierte Invasoren in die europäische Moderne. Während den Amerikanern unterstellt wurde, außer der Profitgier keine Unternehmenskultur zu kennen, waren die Inder im Verständnis der schweizerischen Mittelklasse noch „unvollständig modern“: Sie wussten nicht, so die Meinung, wie moderne Organisation und soziale Ordnung funktionierte, galten als unpünktliche, unzuverlässige und unselbstständige Neulinge. In dieser vorurteilsgeladenen Krisensituation konnte Aftab - mit seiner verinnerlichten Kompetenz, die „zwei Welten“ zu verbinden - als Vermittler einspringen.

Meine Aufgabe war es dafür zu sorgen, dass mehr Arbeit nach Indien gegeben wird, weil man dadurch Kosten sparen konnte, aber auch, dass unsere Leute in der Schweiz gern mit den Indern zusammenarbeiten. Ich habe da ein schwieriges Erbe übernommen, weil viele Leute nicht gerne mit den Indern zusammengearbeitet haben.

Innerhalb der postkolonialen Umbrüche sowie der neuen globalen Wertschöpfungsketten und Hierarchien entstand unter den Schweizer Akteuren die Konstruktion „interkultureller Probleme“, die einer entsprechenden Beratung und eines entsprechenden Managements bedurften. An diesen transnationalen Schnittstellen des globalen Kapitalismus verbanden sich Aftabs biografische und professionelle Subjektivierung auf sinnhafte und produktive Weise. Durch interkulturelle Seminare, die Etablierung von „sauberen Prozessen“ und besserer Kommunikation konnte Aftab das transnationale Vertrauen im Unternehmen wiederherstellen und so die Effizienz des Unternehmens - und des globalen Kapitalismus - steigern. Wie er selbst in einem Interview pointiert formulierte: „Ich habe meine Biografie zu meinem Geschäftsmodell gemacht.“ Umgekehrt hat die „interkulturelle Problematik“ im globalen Kapitalismus seine Selbstwahrnehmung als „Brückenbauer“ geprägt. ${ }^{76}$ Nach einigen Jahren gründete Aftab seine eigene Firma, die sich weiterhin auf die Durchführung von interkulturellen Seminaren sowie auf die Beratung schweizerischer Firmen beim Markteintritt in Indien spezialisierte. Aftabs Ver-

76 | Siehe dazu Aihwa Ongs Beschreibung, wie sich im chinesischen Diasporakapitalismus Angehörige der "zweiten Generation" als "Brückenbauer" inszenieren, respektive als solche wahrgenommen werden (Ong 1999:187 f.). 
mittlung interkultureller Kompetenz wurde in diesen Schnittstellen des globalen Kapitalismus zu einer Ware, deren Kauf ihm sowohl persönliche als auch professionelle Anerkennung verschaffte. Diese Konstellation eröffnete ihm einen sozialen, kulturellen und ethischen Raum, in dem er seine bisherigen Aushandlungen von Mehrfachzugehörigkeit noch stärker öffentlich und professionell artikulieren konnte.

\section{Der indische Business-Knigge}
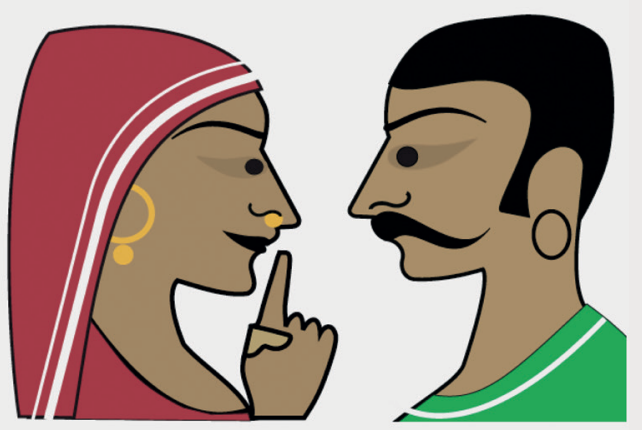

\section{Für alle, die in Indien}

\section{selbstsicher und kompetent} auftreten wollen.
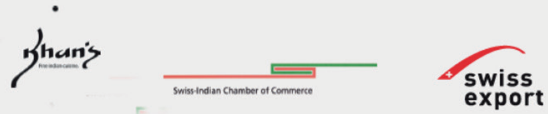

Abbildung 20: „Die Biografie zum Geschäftsmodell gemacht”.

Flyer zu interkulturellem Seminar (Quelle: Autor)

\section{Rationale Expertise über die Irrationalität Indiens}

Auf seiner Homepage schrieb Aftab als Teaser für seine interkulturellen Seminare:

Indien ist ein faszinierendes Land. Reich an Traditionen und Spiritualität, voller Gegensätze und aufgeladen mit einer pulsierenden Energie. Doch seine kulturellen Unterschiede zum Westen sind groß, oft irritierend und überfordernd! Interkulturelle Kompetenz ist der Schlüssel für jeden, der in Indien erfolgreich sein will. [...] Sie profitieren von unserer zehnjährigen Erfahrung 
in der Vermittlung der indischen Kultur und Mentalität und unserer persönlichen Verankerung sowohl in der westlichen als auch in der indischen Kultur. $^{77}$

In Aftabs Argumentation in Artikeln und Vorträgen hat die zunehmende Liberalisierung in den 1990er Jahren in Indien zwar zu einer Modernisierung des Alltags und zu einer Teilhabe am globalen Kapitalismus geführt, in dem jedoch die antiken Werte aus der Philosophie und der spirituellen Lehre lebendig geblieben waren. So leiten sich etwa die Art und Weise, wie Vorgesetzte und Mitarbeiter zusammenarbeiten und kommunizieren, von spirituellen Kernelementen der brahmanistischen Kultur ab, wie er in einem Artikel in einem Buch zu interkultureller Führung schrieb.

Die Vorstellung der vier Lebensabschnitte und der vier Kasten unterstreicht den hierarchischen Führungsstil, den man in den meisten indischen Firmen heute noch antrifft [...]. Indische Mitarbeiter neigen oft dazu, sich in diesem hierarchischen System nicht nur anzupassen, sondern sich sogar überanzupassen. Dies wird von westeuropäischen Geschäftsleuten als „yes culture“ beschrieben. Es wird zu allem ja gesagt, doch die darauf folgenden Handlungen stehen dazu nicht im Einklang.

Aber auch weitere in den Kreisen des Outsourcing-Kapitalismus wahrgenommene „interkulturelle Probleme“ wie Unterschiede in Zeitmanagement, Verhandlungspraxis und sozialen Beziehungen liessen sich in Aftabs Kommunikationsstrategie oft auf diese antiken Werte zurückführen: Indien erscheint in dieser Sprache als monolithisches kulturelles System, in dem die Menschen einerseits in einem von außen undurchsichtigen und unveränderten Universum von Kastenhierarchie, Wiedergeburt, Yoga und Kamasutra leben, gleichzeitig aber durchaus am modernen Geschäft des globalen Kapitalismus teilhaben wollen und können. Durch die ständige Konstruktion Indiens als Mysterium, das jedoch durch einen rationalen und ethischen Lernprozess verstanden werden kann, legitimierte Aftab seine professionelle und persönliche Expertise als Unternehmensberater, Selfmademan und indischer Secondo. Die essenzialistische Argumentation kann dabei als Repräsentationsstrategie gesehen werden, um Expertise im Feld des globalen Business empfehlen und legitimieren zu können. Mit der indologischen Authentifikation der irrationalen, lokalen Kultur erwächst eine doppelte Authentifikation von Aftabs Expertise als interkultureller Vermittler: Erstens bestätigt die Konstruktion des „interkulturellen Problems“ auf der Basis einer indologischen Essenzialisierung Indiens eine rationale, wissenschaftliche Autorität von Aftabs Wissen. Dieses

77 | Die Quellen der folgenden Zitate werden aus Gründen der Anonymisierung nicht genannt. Die Dokumente liegen im Archiv des Autors. 
Wissen lässt sich zudem in einfach zu vermittelnde Häppchen aufteilen, die sich in pragmatische unternehmerische Handlungsanweisungen transformieren lassen. Zweitens legitimiert die Essenzialisierung die Methode und die Glaubwürdigkeit des interkulturellen Brückenbauers als Person. Denn die interkulturelle Kompetenz Aftabs ist nicht nur eine formale, wissenschaftliche Qualifikation, sondern ist sowohl inkorporiert in der persönlichen Verankerung in der uralten indischen und in der schweizerischen Kultur als auch im persönlichen Erfahrungsschatz des transnationalen Selfmademans.

\section{Markteintritt als postkoloniales Abenteuer und ironische Kritik des Eurozentrismus}

Es wäre jedoch verfehlt, Aftabs Repräsentation als reine Vermarktungsstrategie oder als reine Essenzialisierung anzusehen. Während die Authentifikationsstrategie und die damit verbundene orientalistische Sprache gewisse offene Deutungsprozesse schließen, eröffnen sie sowohl persönliche Anerkennungsräume für Aftabs Erfahrung der Mehrfachzugehörigkeit als auch Räume für eine subtile Kritik der postkolonialen Machtverhältnisse. In einem Zeitungsartikel zum Thema „Indien im Aufbruch" aus dem Jahre 2007 schrieb Aftab:

Da steigt eine Nation zur Wirtschaftsmacht auf und wir wundern uns: Ist Indien nicht das Land siechender Bettler, geknechteter Kinder, heiliger Kühe und verbrannter Witwen? Das große Land mit den nach Märchen und Magie klingenden Namen, das markant in das Arabische Meer und in den Indischen Ozean ragt, verändert sich. Indische Softwareprogrammierer und der glamouröse Auftritt am letztjährigen Weltwirtschaftsforum waren nur die Vorboten dafür, dass mit dem Land, wo die duftenden Curries und die akrobatischen Liebeskünste herkommen, zu rechnen ist.

In diesem Text reartikulierte Aftab den hegemonialen Indiendiskurs, der von der Spaltung des traditionellen und armen Indiens und des modernen, industrialisierten Westens ausgeht: Statt Armut und Spiritualität repräsentiert ein neues Indien nun auch Hochtechnologie sowie ökonomische und politische Stärke. Die Modernisierung und Liberalisierung reduzieren nicht etwa die orientalistische Opazität und Exotik Indiens, sondern steigern sie noch, weil die klare Dichotomie zwischen der modernen Schweiz und dem traditionellen Indien verschwimmt. In dieser Unübersichtlichkeit ist gleichzeitig ein neuer Markt entstanden, den zu verpassen sich niemand im Westen leisten kann. Aftabs orientalistische Sprache produzierte daher noch eine weitere Bedeutungsebene, die nicht die Kultur Indiens, sondern die kapitalistische Erschließung des indischen Marktes als irrationales und faszinierendes Projekt erscheinen lässt. Genauso wie sich das europäische Selbst seit der Romantik nach der spirituellen Erneuerung sehnte, strebt die schweizerische 
Unternehmung, ja das westliche Kapital, heute nach seiner wunderbaren Erneuerung in den neuen Märkten Indiens. Die Verquickung von kapitalistischer und orientalistischer Rede vermittelt das Begehren nach dem Eldorado der neuen indischen Märkte. Gemäß Aftab imaginieren viele Akteure im Outsourcing-Kapitalismus den Markteintritt in Asien mit einem neuen Goldrausch, als Frontierkapitalismus im „Wilden Osten“. Wie es in einer geläufigen Wendung in Anlehnung an Frank Sinatras „New York, New York“ heißt, die Aftab gerne zitierte: “If you can make it there [in India], you can make it anywhere." Die Verdichtung von indischer Exotik und Kapitalismus als postkoloniales Abenteuer manifestierte sich im Programm von Aftabs interkulturellen Seminaren. Darin verband er Information über Kultur, Geschichte, Wirtschaft und Politik Indiens mit konkreten Hinweisen für Geschäftspraktiken wie Verhandlungsstrategien oder Smalltalk-Regeln auf Empfängen oder bei Geschäftsessen. Diese Seminare beinhalten ein wunderbares indisches Mittagessen in einem renommierten Restaurant, bei dem gleichzeitig die exotische Imagination eines Lebens in Indien und das Üben von Tischsitten bei einem business lunch vermittelt werden. Die Reartikulation exotischer Narrative in der heutigen ökonomischen Praxis verweist dabei auf die Notwendigkeit im globalen Kapitalismus, die Bewegungen von Kapital, Personen und Gütern auch kulturell und affektiv auszuhandeln. Sie lassen koloniale und orientalistische Imaginationen wiederaufleben, die Schweizer Akteure einerseits nutzen, um sich die Ambivalenzen eines risikoreichen Projekts vorstellen zu können. Andererseits erlauben sie eine Selbstvergewisserung und ein Überlegenheitsgefühl im Kontext sich wandelnder Machtverhältnisse zwischen Indien und der Schweiz (s. Kapitel 4; Jain 2015).

Aftabs orientalistische Stereotypisierung ist daher zweifellos ein intelligentes Marketingmittel, das einer spezifischen Nachfrage nach indischer Exotik und kultureller Differenz im globalen Kapitalismus entgegenkommt. Sie offenbart aber auch eine spöttische und ironische Kritik an der europäischen Überforderung mit dem sich wandelnden Indien und den neuen globalen Machtverhältnissen. Ähnlich wie Salman Rushdie verwendet Aftab orientalistische Stereotype, um die postkolonialen Unsicherheiten und Begehren seiner westlichen Adressaten zu entlarven und infrage zu stellen. So schreibt er am Schluss des oben zitierten Artikels:

Gerade als Schweizer kann es sein, dass man sich vor dem großen, sich aufdrängenden Indien besonders klein fühlt. Man sorgt sich um seine eigene Größe, um seine Identität. Man möchte sich daran erinnern, was der Inhalt des eigenen kulturellen Gepäcks ist, das uns in den Augen des Fremden zum Fremden macht. [Das] macht die Begegnung mit Indien zu einer Auseinandersetzung mit uns selbst. Mit unseren eigenen Widersprüchen und Extremen. Mit all dem, worin wir zahm und korrekt sind, aber auch mit all jenem, wo wir vielleicht doch noch wild und frei sind. 
Was in der leichten, ironischen Sprache zum Schmunzeln veranlasst, enthält jedoch auch eine leise Drohung, dass mit der neuen Supermacht handfest zu „rechnen“ ist - auch für die Schweiz. Angesichts der Veränderungen der globalen ökonomischen und kulturellen Machtverhältnisse insinuiert Aftab eine Schweizer Identitätskrise. Der Markteintritt in Indien und Geschäftsbeziehungen in Indien erlauben daher nicht nur eine ökonomische, sondern auch eine persönliche - je geradezu spirituelle - Suche nach dem Schweizer Selbst, so die ironische Suggestion. Das kapitalistische Engagement im „Wilden Osten“ mit dessen bürokratischem Labyrinth, Infrastrukturproblemen und eigener kultureller Überforderung, aber auch mit den Schlupflöchern und Privilegien, verspricht dabei eine kathartische Befreiung von der überregulierten und überkorrekten Schweiz. Durch das grammatikalische Subjekt "Wir" deutet der Erzähler sowohl Identifikation als auch Zugehörigkeit an. Gleichzeitig wird diese Solidarität durch die ironische Rede und die interkulturelle Autorität wieder aufgehoben, durch die er diese Analyse überhaupt vollziehen kann. Als all- oder wenigstens besserwissender ironischer Erzähler, der seine Schweizer Klienten über ihre interkulturelle Selbstverwirklichung aufklärt, ist er ihnen jedoch immer einen Schritt voraus. Dadurch kann er als interkultureller Vermittler nicht nur auf der geschäftlichen Ebene, sondern auch auf der persönlichen Ebene intervenieren, unterhalten - und kritisieren.

Mit der Mischung von Wissensvermittlung und Ironie stößt er für schweizerische Expats und Geschäftsleute einen offenen ethischen Prozess des interkulturellen Lernens an, der an den Orten von Markt und Handel vertieft werden soll. Seine interkulturelle Didaktik leistet dabei einem liberalen Universalismus Vorschub, wonach der Markt per se die Kraft hat, Menschen zu verbinden - sofern sie nicht von Stereotypen geblendet sind. In diesem Sinne kombiniert Aftab seine seit der Kindheit verfolgten Aufklärungsbestrebungen mit einem erfolgreichen Geschäftsmodell direkt an den Schnittstellen des globalen Kapitalismus.

\section{Authentifikation und Verdacht}

Während die Authentizitätsstrategie Aftab ermöglichte, biografische und professionelle Repräsentationsspielräume zu gewinnen, sind damit aber auch spürbare Widersprüche verbunden: Als Aftab sich im Rahmen der 60-jährigen Jubiläumsfeier zum schweizerisch-indischen Freundschaftsvertrag als Kommunikationsberater für die schweizerische Agentur für Landeskommunikation „Präsenz Schweiz“ engagierte, wurde er von verschiedenen Seiten der lokalen indischen Gemeinschaft in der Schweiz verunglimpft. In Rundbriefen, in Zeitungsberichten und in der Gerüchteküche wurde verbreitet, dass Aftab nicht die geeignete Person für die öffentliche Repräsentation Indiens sei, weil er ja gar kein Inder, sondern geborener Pakistani sei. Während die einen daraus schlossen, dass er sich öffentlich fälschlicherweise als Inder ausgebe, um von der Geschäftsopportunität angesichts des indischen Wachstums zu profitieren, gingen andere nationalistische Kommen- 
tatoren weiter und sahen darin eine Verschwörung des pakistanischen Geheimdienstes oder einfach eine nationale Schande. Diese Sichtweisen delegitimierten Aftabs professionelle Praxis und seine subjektive Zugehörigkeitserfahrung.

Vor diesem Hintergrund erscheint Aftabs genealogische Erzählung, die er in seiner intellektuellen Auseinandersetzung mit der Erfahrung des Andersseins ausgiebig recherchiert hatte, in einem neuen Licht (s. Kapitel 3.1). Aftab betonte stets, dass alle seine Vorfahren aus dem heutigen Gujarat stammen und vor mehreren Generationen zum Islam konvertiert seien. Wegen gewalttätiger anti-islamischer Übergriffe und politischer Verfolgung musste seine Familie nach der Teilung Indiens nach Pakistan flüchten. Mit dieser familiengenealogischen Argumentation macht er seine Herkunft nicht nur geografisch in Indien, sondern kulturell und religiös neben dem Islam auch im Hinduismus fest. Durch die Betonung dieser doppelten Authentizität konnte Aftab den Versuch der Delegitimierung subjektiv und professionell abblocken - und hätte sich sogar rechtlich gegen üble Nachrede schützen können. Dieses Spiel mit der Authentizität erscheint jedoch auch als ungenaue Anpassung an eine essenzialistische Zugehörigkeitspolitik in der Schweiz und in der südasiatischen Diaspora, die der historischen und familienbiografischen Komplexität im Kontext des kolonialen Südasien nicht gerecht wird. Denn mit einer auf Authentizität basierenden Repräsentationsstrategie lassen sich die vielschichtigen familienbiografischen, politischen und historischen Verflechtungen südasiatischer Geschichte und Zugehörigkeit nicht repräsentieren. Dies zeigt sich frappant in der Darstellung Indiens in Aftabs Publikationen zur interkulturellen Unternehmensberatung: In seinen kulturalistischen Modellen weicht die ethnische, religiöse und kulturelle Vielfalt Südasiens einem brahmanisch-hinduistischen Idealbild. Insbesondere der Islam, mit dem Aftab aufgewachsen ist und der die Familienbiografie seit der Konversion seiner Vorfahren und seit der Emigration nach Pakistan geprägt hat, erscheint kaum als Teil dieses Indiens. Dies mag verschiedene Gründe haben: Allenfalls würde die Komplexität der Information das Geschäftsmodell behindern oder es erscheint allenfalls nicht relevant, weil höchstwahrscheinlich die meisten der indischen Geschäftspartner seiner Kunden wegen der überproportionalen Unterschichtszugehörigkeit der Muslime in Indien Hindus sein dürften. Aber vielleicht ist es auch eine Reaktion auf einen anti-muslimischen Rassismus, der seit den Terroranschlägen in New York im Jahr 2001 auch in der Schweiz zugenommen hat und der Aftab, wie er selbst sagt, als gebürtigen Schweizer Muslim stark verunsichert.

Auf jeden Fall liegt in der Authentifikationsstrategie im kommerziellen Multikulturalismus für Aftab eine Spannung zwischen Wettbewerbsvorteil und Delegitimation, warenförmiger Anerkennung und partieller, persönlicher Verleugnung. Nichtsdestotrotz erlaubt ihm die Praxis als interkultureller Unternehmensberater den Gegensatz zum „Leben zwischen den Welten“, zwischen der indisch-pakistanischen Familie und der schweizerischen Öffentlichkeit, aufzuheben und aktiv mitzugestalten: 
Ich fühle mich, wenn man das psychologisch betrachtet, heute vollständiger, als es vor zehn Jahren der Fall gewesen ist oder vor zwanzig Jahren. Aus heutiger Perspektive würde ich sagen, vor zwanzig Jahren war ich innerlich mehrfach gespalten und heute nehme ich diese Friktionen nicht mehr wahr.

Aus der intimen Aushandlung von Anderssein „zwischen den Welten“ ist eine komplexe und vielseitige Repräsentationspolitik geworden, mit der Aftab Indienbilder und interkulturelle Prozesse an den Schaltstellen des „Outsourcing“-Kapitalismus selbstbewusst und schlau aushandelt.

\subsection{FazIT: (UN-)DoING "INDIANNESS" - ANERKENNUNG, Nostalgie Und Authentizität}

Wie die Fallanalysen von Sonia, Maya, Raj und Aftab zeigen, haben seit deren Kindheit und Jugend im Kontext des Assimilationsregimes maßgebliche Transformationen stattgefunden. Ethnic entrepreneurship und Identitätskonsum boten vor dem Hintergrund eines kommerziellen Multikulturalismus und eines Indienhypes Zugang zu neuen translokalen Räumen des Heimisch-Werdens. An der Schnittstelle biografischer Logik und institutionell-diskursiver Bedingungen fanden Maya, Sonia, Raj und Aftab Möglichkeiten und Umfelder, um eine öffentliche Repräsentation ihrer Erfahrung des Andersseins und der Mehrfachzugehörigkeit vorzunehmen und Deutungsmacht über ihre Subjektivität einzufordern:

Für Sonia brachte ein corporate multiculturalism in ihrer Bank sowie der Zugang zur Subkultur hochqualifizierter indischer Migrant_innen und zu Expat-Kreisen eine Lebenswelt hervor, in der sie ihre Subjektivität als indische Seconda und "globale indische Frau" öffentlich aushandeln konnte. Sonia konnte implizit und performativ unterschiedliche Narrative von legitimer „Indianness“ und Mehrfachzugehörigkeit bespielen, ohne sich exponieren, erklären oder rechtfertigen zu müssen. Die Aneignung des Familienprojektes der ,(konservativen) indischen Familie" erschien dadurch auch in der Schweizer Dominanzgesellschaft nicht mehr nur als Stigma, sondern auch als erfolgreicher Lebensentwurf in einem globalen Kapitalismus.

Maya konnte sich im Yoga-Boom in der urbanen Schweiz als selbstständige Yoga-Lehrerin etablieren. Während sie dadurch einerseits ihren individualistischen Lebensentwurf institutionalisieren konnte, beförderte dies auch eine öffentliche Aushandlung von Herkunft und Zugehörigkeit. Maya repräsentiert sich daher gegenüber ihren Schüler_innen vor allem in einem Diskurs des Yoga-Universalismus, in dem sie die öffentliche Repräsentation ihrer Herkunft möglichst vermeidet. Diese Strategie ließe sich als Weiterführung eines assimilatorischen Schweigens 
interpretieren. Aber angesichts ihrer regelmäßigen Indienreisen und ihrer ständigen Auseinandersetzung mit Indien in ihrer Praxis und Lehre des Yoga kann Maya ihre transkulturellen Erfahrungen in ihrem Alltag performativ äußern und gestalten. Innerhalb ihrer transnationalen Lebenswelt zeigen sich bei Maya trotz der universalistischen Repräsentationsstrategie immer wieder nostalgische Imaginationen und Praktiken, in denen sie positiv an Kindheit und Herkunft anknüpft.

Raj konnte durch die Freundschaft mit Jasmin und Tara sein biografisches Projekt des Andersseins in einer rituell-familiären Gemeinschaft von „Indian brotha's and sista's" vertiefen und ausdifferenzieren. Die Offenbarung biografischer Erfahrungen, Identitätskonsum und Ironie ermöglichen Raj - und auch Jasmin - Erfahrungen illegitimer Zugehörigkeit zu äußern, ohne sich anders zu fühlen. Dadurch können sie sich spielerisch als „Inder_innen“ inszenieren und gewinnen öffentliche Anerkennung und eine legitime Zugehörigkeit. Ihnen ist zwar bewusst, dass diese performative Authentizität auch eine kommerzielle Illusion ist, sie nutzen jedoch diesen multikulturellen Raum für eine widerspenstige und trotzige Ethik des Andersseins. Damit können sie zwar das assimilatorische Schweigen überwinden, laufen jedoch Gefahr, „Indianness“ und ihr Anderssein im hegemonialen Narrativ eines „Spektakels des Fremden“ und der „Exotik“ festzuschreiben. Diese in den Identitätskonsum und in die Ironie eingeschriebene Ambivalenz bezeugt die Fragilität dieser öffentlichen Selbstrepräsentationen des Andersseins im kommerziellen Multikulturalismus, in dem das Begehren nach Authentizität sowohl legitime Räume der Mehrfachzugehörigkeit eröffnet als auch essenzialistische Differenzen perpetuiert.

Aftab hat sein biografisches Projekt der Vermittlung „zwischen den Welten“ zu einem Geschäftsmodell im globalen Kapitalismus gemacht. Als interkultureller Unternehmensberater mit Indienschwerpunkt legitimiert er seine Expertise neben seiner betriebswirtschaftlichen Qualifikation und Erfahrung auch durch seine südasiatische Herkunft. In einer Mischung von Kulturrelativismus und unternehmerischem Universalismus kann Aftab sein biografisches Projekt in einer pragmatischen Ethik im globalen Kapitalismus weiterführen. Aftabs kulturessenzialistische Authentifikation im Rahmen einer warenförmigen Anerkennung stößt jedoch an Grenzen, weil er in diesem Rahmen seine transnationale südasiatische Familienbiografie und die multireligiöse Zusammensetzung Indiens nicht vollständig repräsentieren kann.

Zusammenfassend lässt sich feststellen, dass durch den kommerziellen Multikulturalismus und den Indienhype in der urbanen Schweiz eine Pluralisierung der Subjektivierungsprozesse stattgefunden hat. Neben den assimilatorischen Räumen sind Institutionen und Diskurse entstanden, in denen indische Second@s subjektive Erfahrungen des Andersseins und der Mehrfachzugehörigkeit öffentlich 
und legitim reartikulieren können. Multinationale Unternehmen, diasporische Subkulturen und Expat-Zirkel, urbane Konsumkultur und linksalternative Milieus haben Narrative und Räume generiert, in denen kulturelle Differenz und Mehrfachzugehörigkeiten sowohl sichtbar sind als auch positiv bewertet werden. Als Indian brain in der internationalen Bankenwelt, als „Brückenbauer“ bei interkulturellen Problemen im globalen Kapitalismus, als kulturelle Übersetzerin in der globalen Yoga-Industrie, als erfrischende, multikulturelle Stimme in der urbanen Öffentlichkeit oder einfach als Second@s können Sonia, Maya, Raj und Aftab ihre biografischen Aushandlungen des Andersseins - entgegen der assimilationistischen Subjektivierungslogik - zunehmend in legitimen Narrativen aushandeln. Diese öffentlichen Aushandlungen des Andersseins im kommerziellen Multikulturalismus sind jedoch eingebettet in asymmetrische Machtverhältnisse und ökonomische Logiken, die diese Anerkennungsräume regulieren. Dies schlägt sich sowohl auf der formalen Ebene von Zugang und Äußerungsstrategien als auch auf der inhaltlichen Ebene von Narrativen und Subjektivitäten nieder:

1. Die Spielräume für eine Aushandlung von Mehrfachzugehörigkeit entstehen nur, wenn Second@s überhaupt Zugang zu öffentlichen und legitimen Räumen der Dominanzgesellschaft - etwa im kommerziellen Multikulturalismus - erhalten. Erst als Objekte dieses dominanten, ökonomisch regulierten Begehrens nach Authentizität und Vielfalt können sie die Spielräume erringen, in denen sie ihre biografischen Projekte, Interessen und Bedürfnisse artikulieren können. Die Regulierung des Zugangs zu diesen Anerkennungs- und Repräsentationsräumen hängt stark von spezifischen kulturellen, sozialen und ökonomischen Ressourcen ab. So hatte etwa der Kundenberater Anil angesichts seiner soziokulturellen Vernetzung und seiner Bildungsbiografie weder Zugang zu linksalternativen Milieus oder zu einem corporate multiculturalism noch $\mathrm{zu}$ den diasporischen Gemeinschaften hochqualifizierter Inder_innen und Südasiat_innen. Die Aushandlung seines Andersseins oder seiner Herkunft findet weitestgehend im ethnisierten Rahmen der joint family oder des assimilatorischen Narrativs der Dominanzgesellschaft statt. Anils Aushandlungen von Anderssein werden zwar auch durch Narrative des Indienhypes oder des kommerziellen Multikulturalismus beeinflusst. Er kann sich zwar nun ganz legitim als indischer Secondo darstellen, aber er hat nur wenig Deutungsmacht und wenig Gestaltungsfreiheit. Es ist seine Assimilation, die seine Zugehörigkeit zur Schweiz legitimiert, wogegen sein Anderssein weiterhin in die Familie projiziert wird.

2. Aber auch innerhalb der Räume, die ethnic entrepreneurship respektive professionelle Indienprojekte und Identitätskonsum eröffnen, findet die Selbstrepräsentation nicht vollständig autonom statt. Sie werden weiterhin in asymmetrischen sozialen Beziehungen ausgehandelt, in denen Angehörige der Dominanzgesellschaft indische Second@s als „Andere“ mit multikulturell-exotisierenden Narrativen 
anrufen und befragen. An dieser Schnittstelle entstehen spezifische Äußerungsstrategien, um diese Anrufungen zu verhandeln. In den Fällen von schweizerisch-indischen Second@s sind professionelle Expertise, Offenbarung und Ironie die wichtigsten verbalen und expliziten Äußerungsstrategien jenseits des assimilatorischen Schweigens.

Die professionelle Expertise, wie etwa bei Aftab und Maya und in geringerem $\mathrm{Maß}$ bei Sonia, legitimiert sich durch die ökonomische Logik des Nutzens und der Nachfrage. Sie muss innerhalb der Regeln des professionellen Feldes konstruiert werden und dessen Standards genügen, um Anerkennung hervorzurufen. Die Kommerzialisierung von Differenz - respektive die Funktion kultureller Differenz für die sinnhafte Aushandlung globaler Prozesse - erfordert dabei oft Strategien der Authentifikation. Diese Strategien sind jedoch ambivalent oder gar prekär: Zum einen können sie so interpretiert werden, dass Herkunftsrepräsentationen in einem unlauteren (oder geschickten Sinn) genutzt werden, um „bessere Geschäfte“ zu machen. Zum anderen wird die Qualität der Arbeit dabei oft auf die Herkunft umgangssprachlich auf die „Gene“, „Blut“ oder „Wurzeln“ - reduziert, was sowohl die Qualifikation als auch die Erfahrung der Mehrfachzugehörigkeit infrage stellt.

Offenbarung ist eine Strategie, die Vorstellungen von Authentizität als subjektive Wahrhaftigkeit mobilisiert, um Anerkennung einzufordern. Sie bedingt spezifische ethische Techniken der Selbstreflexion und der Äußerung und schafft eine intime soziomoralische Vergemeinschaftung. Während Raj und Jasmin sich diese Techniken im nonkonformistischen Milieu aneigneten, konnte Maya ihre biografische Selbstreflexion in der Yoga-Philosophie vertiefen. Während die Offenbarung zwar anschlussfähig an multikulturelle Anerkennungsdiskurse ist, besteht in der öffentlichen Äußerung das Risiko der erneuten Verletzung durch hegemoniale Disziplinierung subjektiver Erfahrungen. Deswegen wird sie größtenteils im privaten Raum - sowohl mit anderen indischen Second@s als auch mit Freund_innen und in der Familie - eingesetzt. Die performative Offenbarung nutzt sozioethische Prozesse, in der auf intuitive und affektive Weise Wissen und Erfahrungen vermittelt werden können, für die die Akteure respektive hegemoniale Öffentlichkeiten keinen etablierten sozialen Ausdruck (zum Beispiel keine Sprache oder Ästhetik) kennen. Diese intimen sozioethischen Prozesse bieten dabei oft eine affektive Grundlage für selbstbewusste Formen der Repräsentationspolitik.

Die Strategie der Ironie ist eine subtile, indirekte Form der Aushandlung und der Kritik, die zwar eine Selbstrepräsentation zulässt, aber gleichzeitig hegemoniale Muster des Ausschlusses nicht explizit anspricht. Sie artikuliert und kritisiert implizit und situativ widersprüchlichen Narrative, Werte oder Subjektivitäten innerhalb der Gesellschaft und lässt alternative Wirklichkeiten aufscheinen. Die Parodie als institutionalisierte komische Form im kommerziellen Multikulturalismus ist für indische Second@s zwar anschlussfähig für öffentliche Äußerungen des Andersseins, birgt jedoch auch die Gefahr, als infantile Clowns oder als besonders 
glaubwürdige Kritiker einer belächelten political correctness von der hegemonialen Ausschlusslogik vereinnahmt zu werden (Jain 2012). Sarkastische Formen des Humors, wie etwa Aftabs Spott über die Repräsentationskrise der Schweiz angesichts des „neuen Indiens“, mögen sich dieser hegemonialen Vereinnahmung wegen der Vieldeutigkeit und der expliziten Adressierung der Dominanzgesellschaft als „Andere" und der Strategie des laughing back eher zu entziehen. Wie auch die Strategie der Offenbarung vermögen Ironie und Humor auf intuitive und affektive Weise Erfahrungen zu äußern, die sich aus einem marginalisierten Gegenwissen speisen, die noch kaum institutionalisiert sind (Terkessidis 2004).

Neben diesen drei Formen expliziter Äußerung erscheint jedoch weiterhin das Schweigen, ein inkorporiertes Überbleibsel der assimilatorischen Subjektivierungslogik, eine der wichtigsten Strategien im Umgang mit dem hegemonialen Begehren nach Authentizität im kommerziellen Multikulturalismus. Während aber das Schweigen im Assimilationismus inkorporiert waren und oft automatisch geschahen, wird es nun oft bewusst und reflektiert eingesetzt. Die Pluralisierung der (transnationalen) Räume der Anerkennung und Selbstrepräsentation erlaubt, angesichts von Disziplinierungen oder Verletzung „anders zu schweigen“ - und zwar mit dem Wissen darum, diese Erfahrungen in anderen Räumen aktiv kompensieren, überschreiben oder neue produktive Praktiken entwickeln zu können.

Diese Analyse der Subjektivierungsprozesse indischer Second@s und ihrer ÄuBerungsweisen offenbart den kommerziellen Multikulturalismus in der Schweiz weiterhin als „Souveränität der Mehrheit“, wonach die Dominanzgesellschaft politisch, ökonomisch und kulturell definiert, welche Narrative, Äußerungsweisen und Bevölkerungen des Andersseins legitim sind und welche nicht (Markell 2003). Da kein breiter politischer Diskurs und wenig institutionelle Politik zu Multikulturalismus oder zu Antirassismus existiert, kritisieren indische Second@s diese Machtverhältnisse jedoch kaum öffentlich. Stattdessen nutzen sie die neuen Spielräume im kommerziellen Multikulturalismus oft eher performativ und implizit, indem sie die intime und private Gestaltung ihrer Subjektivierungsprozesse weiterführen, ohne öffentlich gegen bestehende hegemoniale Narrative und Anrufungen aufzubegehren. Die situative und - wie noch zu sehen sein wird - transnationale Verwendung unterschiedlicher performativer Äußerungsstrategien sichert ihnen nichtsdestotrotz eine gestalterische Freiheit.

3. Die beschriebenen Subjektivierungsprozesse sind geprägt von einer Spannung zwischen performativer Aushandlung kosmopolitischer Mehrfachzugehörigkeit einerseits und einer Nostalgie und Ethnisierung andererseits. Gerade der Versuch, Mehrfachzugehörigkeiten zu repräsentieren, befördert angesichts des Begehrens nach Authentizität im kommerziellen Multikulturalismus auch selbst-exotisierende und nostalgische Imaginationen Indiens. In diesem Sinne können diese Subjektivierungsprozesse und kulturellen Praktiken von indischen Second@s mit Herbert Gans als „symbolische Ethnizität" bezeichnet werden (Gans 1979; Waters 
1990). Damit bezeichnete Gans Praktiken „ethnischer Identifikation“ vor allem in der „dritten Generation“, in der ethnische Netzwerke zur sozialen und beruflichen Unterstützung nicht mehr nötig und auch nicht mehr vorhanden sind, weil eine größtenteils erfolgreiche Assimilation stattgefunden hat. Durch die expressive Verwendung von Symbolen wird eine Zugehörigkeit propagiert, die jedoch rein emotional ist und die strukturelle Assimilation nicht in Frage stellt. Tatsächlich können Phänomene wie ethnic entrepreneurship und Identitätskonsum bei schweizerisch-indischen Second@s als Praktiken einer solchen symbolischen Ethnizität angesehen werden. Denn bei ihnen finden Praktiken symbolischer Ethnizität, wie von Gans argumentiert, tatsächlich nach einer erfolgreichen Assimilation und einer Etablierung in der Mittelschicht der Dominanzgesellschaft statt. Bei Maya, Raj und Aftab - und mit Einschränkungen auch bei Sonia - sind es sowohl die inkorporierte kulturelle Kenntnis der hegemonialen Normen und Begehren als auch der Zugang zu Ressourcen der Dominanzgesellschaft, die ihnen erlauben, Anerkennung durch doing Indianness zu gewinnen. Die Notwendigkeit von Assimilation und sozialem Mittelschichtstatus für den Zugang zu warenförmiger Anerkennung wird auch durch die wenigen Arbeiten zu ethnic entrepreneurship (Juhasz 2005; Hettlage et al. 2007) sowie zum Identitätskonsum in der zweiten Generation bestätigt (Wessendorf 2007; Ritter et al. 2010). Demnach unterscheiden sich ethnic entrepreneurs der „Zweiten Generation“ von solchen der „ersten Generation“ durch eine höhere institutionelle Bildung und den Einstieg in Dienstleistungsbranchen. Zudem verfolgen die zweite Generation mit einer Selbstständigkeit öfter Ziele der sozialen Anerkennung oder der Selbstverwirklichung, als der primären Versorgung der Familie. Dazu nutzen sie „ethnische Symbole“ für Marketing, Produktgestaltung oder strategische Ausrichtung. Bezüglich des Identitätskonsums und ethnischer Netzwerke hat Wessendorf für italienische Second@s in der Schweiz argumentiert, dass Angehörige der Unterschicht eher eine „Italianità “als innerethnische Vergemeinschaftung pflegen, indem sie wie die Eltern die italienische Populärkultur in der Schweiz nachleben. Second@s hingegen, die entweder durch die soziale Lage der Eltern oder durch soziale Mobilität der Mittelschicht angehören, versuchen sich als kosmopolitische Second@s zu repräsentieren, indem sie auch Ressourcen und Werte der Dominanzgesellschaft einsetzen, um ihre Repräsentationsmacht zu steigern.

Während also das Konzept der „symbolischen Ethnizität“ sich rein deskriptiv zu eignen scheint, um die in diesem Kapitel beschriebenen Praktiken der ethnic entrepreneurship und den Identitätskonsum bei Second@s zu beschreiben, müssen noch einige konzeptionelle Ergänzungen angebracht werden. Gans verstand „symbolische Ethnizität“ als Phänomen, das im Assimilationsprozess automatisch stattfindet, einerseits aus familiärer Nostalgie, andererseits als Ausdruck hegemonialer Ausschlussprozesse. Ich konstatiere jedoch, dass in der Schweiz ethnische Selbstrepräsentationen - anders als in den USA mit dem Nationalmythos des mel- 
ting pot - vollständig verpönt war. Für die Etablierung von öffentlichen Praktiken und Imaginationen „symbolischer Indianness“ waren demnach der kommerzielle Multikulturalismus - und die dahinterstehenden migrantischen Kämpfe der 1960er und 1970er Jahre - sowie der Indienhype als lokale Momente in einem globalen Kapitalismus konstitutiv. In diesem Sinne sind ethnic entrepreneurship und Identitätskonsum bei indischen Second@s aus der Schweiz sowie die damit verbundenen nostalgischen $u$ ud kosmopolitischen Verschiebungen in den Subjektivierungsprozessen in transnationale Prozesse einer globalen Kulturökonomie eingebettet. Der Indienhype in der Schweiz und die dadurch veränderten Subjektivierungsweisen von „Inder_innen der zweiten Generation“ waren demnach nur vor dem Hintergrund der marktwirtschaftlichen Teilliberalisierung Indiens und des damit verbundenen sozialen Wandels seit den frühen 1990er Jahren möglich. Bollywood, Chicken Curry und IT schrieben sich seither in den öffentlichen Raum der Schweiz ein und gewährten eine beschränkte - warenförmige - Anerkennung. Es war jedoch nicht nur die exotisierende Aneignung des „neuen Indiens“ im kommerziellen Multikulturalismus in der urbanen Schweiz, die die Subjektivierungsprozesse von „Inder_innen der zweiten Generation“veränderten. Durch ihre mehr oder weniger ausgeprägte transnationale Vernetzung kamen sie auch direkt mit den Veränderungen im „neuen Indien“, der wachsenden neuen Mittelschicht, deren global orientierten urbanen Konsumpraktiken und -räumen, und den darin verhandelten neuen Repräsentationen der indischen Nation in Kontakt. Wie die konkreten subjektiven Aushandlungen von Nostalgie, Anerkennung und kosmopolitischem Lebensstil von „Inder_innen der zweiten Generation“ verknüpft sind mit ihren transnationalen Praktiken und Projekten im „neuen Indien“ seit den wirtschaftlichen Liberalisierungsprozessen der frühen 1990er Jahre, ist Gegenstand des nächsten Kapitels. 


\section{6. "Swiss Indian Dreams" - diasporische Subjektivitäten, globaler Kapitalismus und soziale Ungleichheit im "neuen Indien"}

Es war in einem Indienurlaub Anfang der 1990er Jahre, als ich, ein 14-jähriger Teenager, zwei ältere Kusinen und meine Mutter zum Sarojini Nagar Market in Süd-Delhi begleitete. Der Markt war schon damals bekannt für günstige Textilien und Kleider - oft Ausschussware aus der Exportproduktion. Meine Kusinen waren aufgeregt, weil meine Mutter ihnen versprochen hatte, ihnen ihre ersten Jeans $z u$ kaufen. Durch geliehene Hollywood-Blockbuster aus der Videothek oder illegal kopierte Musikkassetten von Madonna, George Michael und Michael Jackson war die westliche Konsumkultur in ihrem Leben sehr präsent. Trotz der Präsenz des Westlich-Imaginären und der ansteigenden Exportproduktion hatte sich bisher in der lokalen öffentlichen Kultur jedoch kein Markt für Jeans etabliert. ${ }^{78}$ Sie symbolisierte für meine Kusinen und ihre Peers daher eine spannungsvolle Ambivalenz zwischen unsittlicher Dekadenz und rebellischer Coolness, zwischen Indien und dem Westen. Mit dem Kauf der ersten Jeans schien also eine Veränderung in der Luft zu liegen, die ich zwar wahrnahm, aber trotzdem nicht ganz verstand. Ich freute mich zwar, an diesem feierlichen Moment teilzuhaben, und ich war stolz, dass meine Mutter als Non-resident Indian (NRI), eine entscheidende Rolle in dieser gewichtigen Transaktion spielen sollte. Jedoch relativierte ich die Aufregung innerlich, da es sich auf dem Sarojini Nagar ja nur um gefälschte Jeans, also um (wertlose) Imitationen der westlichen Originale handeln konnte. Ich war zwar fasziniert von der aus meiner Sicht kindlichen Freude meiner Kusinen, die sich auch von der Authentizitätsfrage

78 | Die indische Jeans-Revolution hatte in den frühen 1980er Jahren begonnen (Wilkinson-Weber 2011). Damals hatte das traditionelle indische Textilunternehmen Arvind Limited begonnen, Jeans für den lokalen Markt zu produzieren. Heute ist das Unternehmen zu einem der größten Jeanshersteller avanciert und produziert für verschiedene lokale und globale Marken wie etwa Wrangler. 
nicht trüben ließ. Gleichzeitig bestätigte diese aus meiner Sicht naive Begeisterung nur meine eurozentrische Interpretation, dass es sich hier um eine Form der Mimikry handeln konnte. Im Rückblick schienen meine Kusinen und ich auf diesem Gang zum Sarojini Nagar Market - aus unseren je eigenen Perspektiven - das Gefühl des kapitalistischen Aufbruchs in Indien zu spüren, das die transnationalen indischen Mittelschichten erfasst hatte.

Seit diesem Erlebnis vor über 20 Jahren hat sich die öffentliche Kultur im metropolitanen Indien im Zuge der Liberalisierungspolitik und der damit verbundenen Integration des Landes in den globalen Kapitalismus rasch verändert. In den 1990er Jahren entstanden die ersten Malls, in denen sich die Oberschicht und die etablierten oberen Mittelschichten westliche Markenprodukte - inklusive Jeans - zu überteuerten Preisen kauften, statt sich wie davor die Güter von ihren Verwandten aus dem Ausland bringen zu lassen. Mit der Zeit wurden diese Produkte immer günstiger und für diejenigen aufsteigenden Segmente der Mittelschicht erschwinglich, die sozioökonomisch von der Ansiedelung multinationaler Konzerne und den Outsourcing-Industrien - wie etwa der IT-Branche oder Callcenter - profitierten. Später eroberten sich die Jeans als „authentische Reproduktionen“ (Bruner 1994) die urbanen Straßenmärkte. Neben den Teeständen und Straßenmärkten entstanden immer mehr klimatisierte Filialen nationaler Kaffeehausketten und internationaler Fastfood-Restaurants sowie Supermärkte. Riesige Werbetafeln mit Motorrädern, Waschmaschinen und strahlenden Konsument_innen begannen die Straßen zu säumen. Hochglanzmagazine, Satellitenfernsehen und Bollywoodfilme verbreiteten Bilder und Erfahrungen neuer Lebensstile in den urbanen Enklaven des sich global ausrichtenden Indiens.

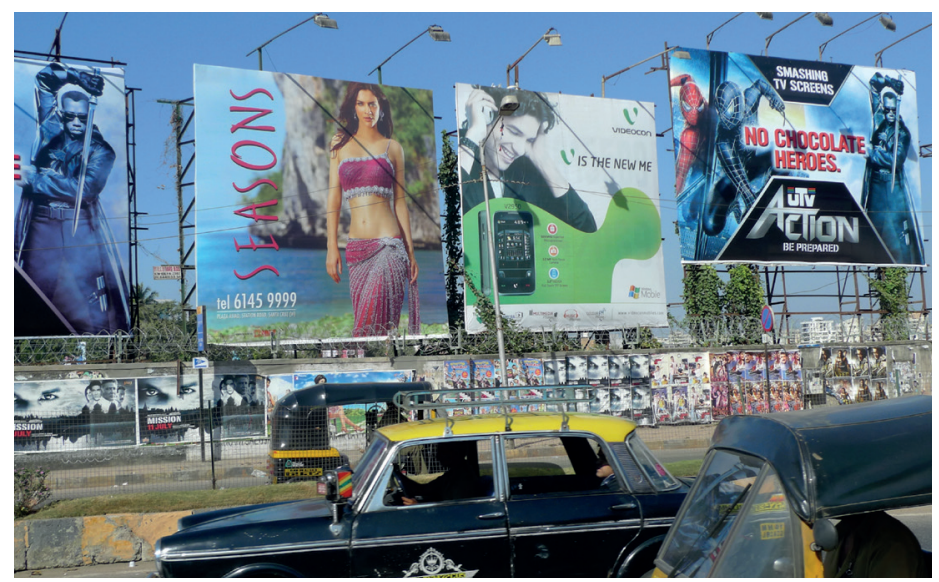

Abbildung 21: Werbebanner präsentieren neue Identitäten, Begehrlichkeiten und Lebensstile im globalisierenden, urbanen Indien (Quelle: Autor) 
In diesem kulturellen und sozialen Wandel manifestierte sich eine massive wirtschaftliche Transformation, die Indien ab den 1990er Jahren erfuhr: Nachdem das Bruttosozialprodukt durch die Wirtschaftskrise von 326,6 Mrd. im Jahr 1990 auf 274,8 Mrd. Dollar im Jahr 1991 gesunken war, betrug es im Jahr 2000 wieder 476,6 Mrd. In den nächsten zehn Jahren stieg das Bruttosozialprodukt auf 1 708,4 Mrd. Dollar im Jahr 2010 und betrug im Jahr 20162264 Mrd. Dollar, also gut sieben Mal mehr als noch vor der Krise 1990. In den 1990er Jahren wuchs das BSP durchschnittlich um ca. 6,5 Prozent und in den 2000er Jahren um 6,9 Prozent. In den Boomjahren ab 2006 und 2007 lag der Wert nur knapp unter der 10-Prozent-Marke und 2010 sogar knapp drüber. Die ausländischen Direktinvestitionen waren wegen der Krise 1990 von 236,6 Mio. Dollar auf 73,5 Mio. Dollar gefallen. Im Jahr 2003 betrugen sie dann 3,6 Mrd. Dollar, im Jahr 2010 27,4 Mrd. Dollar und im Jahr 2016 44,5 Mrd. Dollar - also knapp 200 Mal mehr als vor der Krise 1990. ${ }^{79}$

Wurden Wirtschaftswachstum sowie sozialer und kultureller Wandel Anfang der 1990er Jahre - wie in der Eingangsvignette des Kapitels beschrieben - eher implizit erfahren, gefühlt und erlebt, entwickelte sich mit den Jahren ein expliziter Diskurs über ein „neues Indien“ (Chowdhury 2011). In Beststellern wie „India Unbound“ (2000) des ehemaligen Direktors von Procter \& Gamble, Gurucharan Das, oder „Superstar India“ (2008) der Life-Style-Verlegerin und Schriftstellerin Shobha Dé, sowie in öffentlichen Leitmedien wurden die Transformationen als neue Ära der indischen Nation interpretiert, die als direkte Folge der Liberalisierungsreform dargestellt wurde. Paradigmatisch schrieb im Jahr 2005 etwa Aroon Purie, der damalige Verleger des größten englischsprachigen Politmagazins „India Today“:

For many years, to India and Indians, independence meant political freedom but no more. Today as we look around us, we see a rapidly changing nation. India is on the brink of one of its most dramatic periods in its post-independence history and it has little to do with politics. It is as if India has been freed, again, from the shackles of the past [...] With all its traditions and heritage, India has become a forward-looking nation. When Indians now travel overseas they see more like them, doing business with the world, engaging with tomorrow [...] in an increasingly polarised world, India's position as an Asian giant with nuclear capabilities can be undermined no longer [...]; freed of the license raj, India Inc. has bloomed in a new economic climate, as it has always promised. (Purie in Brosius 2010:4)

In diesem Zitat zeigte sich ein gängiger Gründungsmythos eines „neuen Indiens“. Demnach vermochte die Liberalisierungsreform die Potenziale der Nation zu befreien, die davor von der Staatswirtschaft beschränkt wurden. Durch die Integra-

79 | Die Werte beruhen auf den Angaben der Weltbank (data.worldbank.org) (abgerufen am 21.08.2017). 
tion in den globalen Kapitalismus konnte sich Indien demnach nach jahrhundertelanger islamischer und britischer Herrschaft als neue Supermacht etablieren und endlich die Anerkennung gewinnen, die ihm qua zivilisatorischer Größe zusteht. Wie argumentiert wurde, ist diese wirtschaftsnationalistische Erzählung des "neuen Indiens“ jedoch selbst Ausdruck einer Verschiebung des nationalen hegemonialen Projektes seit den frühen 1990er Jahren (Fernandes/Heller 2006; Bhatt et al. 2010; Chowdhury 2011). Das neue nationale Projekt, das sich seit den 1990er Jahren herauskristallisierte, war konstitutiv mit der sozialen Etablierung einer „neuen Mittelschicht“ verbunden, die seither als politische Kraft, aber auch als kollektives Subjekt das „neue Indien“ verkörpert (Varma 1998; Mazzarella 2003; Fernandes 2006; Brosius 2010; Chowdhury 2011). Während die staatstragende „alte“ Mittelschicht im Entwicklungsstaat die antikapitalistische Politik Nehrus und die Gandhi'sche Bescheidenheit internalisiert hatte, sollte die „neue Mittelschicht“ auch westliche Konsumkultur und transnationale Mobilität repräsentieren. So analysierte die Politikwissenschaftlerin Leela Fernandes:

Policies of economic liberalization initiated since the 1990s have been accompanied by an array of visual images and public discourses that have centred on a shifting role of the middle class and their attitudes, lifestyles, and consumption practices [...] The growing visibility of this new middle class embodies the emergence of a wider political culture, one that has shifted from older ideologies of state-managed economy to a middle-class-based culture of consumption. (Fernandes 2006:xv)

Diese „neue Mittelschicht“ wurde als historische Agentin einer neuen hegemonialen Wirklichkeit konstruiert: durch staatliche Statistiken und Berichte von Finanz- und Unternehmensberatungsfirmen (Fernandes 2006:76 ff.; Wansleben 2013), durch neue Repräsentationen in Werbung und öffentlicher Populärkultur (Mazzarella 2003; Fernandes 2006) sowie durch Restrukturierungen und Redefinitionen im urbanen Raum (Favero 2003; Waldrop 2004; Fernandes 2006; Chowdhury 2011). ${ }^{80}$ In diesem hegemonialen Projekt eines „neuen Indiens“ wurde die

$\mathbf{8 0}$ | Fernandes zeigt, wie staatliche und privatwirtschaftliche statistische Schätzungen und Berichte das hegemoniale Narrativ der neuen Mittelschicht als grundlegend konsumorientierte Klasse hervorbrachten (Fernandes 2006). Statt der kolportierten Zahl von 200 bis 300 Millionen Personen waren jedoch eher 50 bis 80 Millionen Personen finanziell in der Lage, einen konsumistischen Lebensstil zu pflegen (Deshpande 2003; Ganguly-Scrase/Scrase 2009; Gupta 2009). Wansleben, argumentiert, dass die Konstruktion der Kategorie der "BRIC-Staaten“ durch die Investement-Bank Goldmann-Sachs im Bericht "Dreaming with BRIC's" aus dem Jahr 1999 den "aufstrebenden indischen Markt" und das Potenzial der konsumierenden Mittelschichten in der Finanzwelt sichtbar und zugänglich machte (Wansleben 2013). 
Figur der „neuen Mittelschicht“ zu einem umkämpften sozialen und politischen Feld und kollektiven Subjekt, das spezifische Subjektivitäten, Praktiken, Distinktionen und Aspirationen sowohl repräsentierte als auch tatsächlich hervorbrachte.

Ich argumentiere im Folgenden, dass die Herstellung des hegemonialen Projektes des „neuen Indiens“ und der neuen Mittelschichten, die dieses verkörpern, konstitutiv mit einer Konstruktion der „Diaspora“ und deren Integration in dieses „neue Indien“ einherging. Die Reartikulation der nationalmoralischen Grenzgänger_innen der NRI versprach es, westlichen Materialismus und indische Werte auf der Projektionsfläche einer global orientierten Mittelschicht sinnhaft zu verknüpfen.

[An] increasing prominence of the (Western) NRI subject, especially since the mid-1990s, has effectively blurred the inside/outside gap between nation and diaspora - both in cultural and financial terms. [...] The dominant view of the new Indian subject, an idealized middle-class national citizen produced by the influx of capital, is often a reflection of his successful diasporic cousin. (Chowdhury 2011:13)

Noch in den 1990er Jahren fand diese Integration der Diaspora eher implizit in der Alltagskultur und in den transnationalen Netzwerken der Mittelschichten statt. Ab Mitte der 1990er Jahre folgte die Konstruktion der Diaspora in der Bollywood-Populärkultur und ab 2003 begründete der indische Staat eine explizite diasporapolitische Konstruktion einer „global Indian family“ (Vajpayee in Mani/ Varadarajan 2005). Die zunehmende kulturelle, politische und ökonomische Verflechtung des „neuen Indiens“ mit „seiner Diaspora“ beförderte eine Konfiguration, die ich basierend auf den theoretischen Erläuterungen in der Einleitung als globale indische Moderne bezeichnen möchte.

Diese Konfiguration einer globalen indischen Moderne bot schweizerisch-indischen Second@s aus der Schweiz eine neue Subjektivierungslogik, um sich legitim und öffentlich als Teil einer indischen Nation zu identifizieren und zu repräsentieren. Nicht nur zirkulierten in Indien und in den wachsenden transnationalen Netzwerken staatlich sanktionierte, populärkulturelle und alltägliche Narrative über die Diaspora und insbesondere auch über „Inder_innen der zweiten Generation“. Vielmehr wurde das „neue Indien“ selbst - mit seinen neuen urbanen Räumen und den darin eingeschriebenen Narrativen und Subjektivitäten von global orientierter "Indianness“ - zugänglicher und kompatibler für schweizerisch-indische Second@s, als dasjenige Indien, das viele vor allem aus Familienferien aus den 1980er Jahren oder davor kannten. Robin, ein 42-jähriger Eventmanager und Betriebswirt, brachte diesen Wandel in der Erfahrung Indiens pointiert zum Ausdruck: 
Ich hatte in den 1980er Jahren in Indien bei meiner Mutter gelebt, die hier als Journalistin arbeitete. Indien war am Anfang aufregend und anders, aber ich war ein Skater und orientierte mich an der Subkultur in der Schweiz. Hier gab es nichts für mich und mit der Zeit wurde es langweilig. Indien war für mich gestorben und ich zog zu meinem Vater in die Schweiz. Als ich dann Ende der 1990er Jahre wieder einmal nach Indien kam, haute es mich aus den Socken: Überall Leuchtreklamen, Malls, tolle Klamotten, die neuesten Autos! Es war eine andere Welt. Sowohl westlich als auch indisch. Extrem aufregend.

In der kleinen, heterogenen und verstreuten indischen Gemeinschaft in der Schweiz, die kaum über diasporische Öffentlichkeiten verfügte, waren Narrative des „neuen Indiens" oder des Diasporabewusstseins im Vergleich zu anderen diasporischen Orten wie etwa in den USA, Kanada oder Grossbritannen viel fragmentarischer und daher schwieriger zugänglich. Die Formierung von Räumen, Narrativen und Diskursen einer globalen indischen Moderne ab den 1990er Jahren mag die intimen Aushandlungen von Zugehörigkeit von indischen Second@s in individuellen Indienferien oder im Rahmen der transnationalen Familie beeinflusst haben. Jedoch ist ein wichtiges Argument dieser Arbeit, dass erst das produktive Zusammenspiel der Veränderungen im „neuen Indien“ mit dem Indienhype in der Schweiz die institutionellen und diskursiven Bedingungen schuf, um bei schweizerisch-indischen Second@s neue transnationale Subjektivitäten und diasporische Lebensstile zu befördern. In der mehrjährigen Überlappung der Veränderungen in Indien und in der Schweiz verdichteten sich bei „Inder_innen der zweiten Generation" ihre transnationalen Lebenswelten. Dies schlug sich in vielfältigen für sie neuen Praktiken nieder, die von beruflicher und familiärer Remigration, über kulturelle, wissenschaftliche und humanitäre Projekte, intergenerationelle Familienferien und Immobilienprojekte bis zu schweizerisch-indischen Traumhochzeiten im Bollywood-Stil reichten. Dadurch konnten sie sich zunehmend in einer globalen indischen Moderne positionieren und ihre transnationalen Subjektivierungsprozesse in neuen und anerkannten Handlungs- und Imaginationsräumen aushandeln.

Die globale indische Moderne versprach schweizerisch-indischen Second@s, die größtenteils aus der Mittelschicht stammen, eine privilegierte, wenn auch fragile Teilhabe am Wachstums- und Konsumprojekt der "neuen Mittelschichten“. Das "neue Indien“ bot ihnen kosmopolitischen Lifestyle, transnationale Karrieren, globale Anerkennungsräume, Nostalgie und Abenteuer zugleich und ermöglichte ihnen, den privaten Raum ihrer transnationalen Familie zu verlassen und sich eine neue Subjektposition innerhalb der familiären Netzwerke auszuhandeln. Dadurch verschob sich die Bedeutung von Familienbeziehungen als neue Ressource, aber sie brachte auch neue Zwänge in die transnationalen Lebenswelten.

Die Faszination für dieses „neue Indien“ und die damit verbundenen Zugehörigkeits- und Freiheitsoptionen war eingebettet in die Aushandlung des sozialen 
Wandels an der diskursiven Schnittstelle von „altem“ und „neuem“ Indien. Exotisierung und humanitäre Armutskritik waren prägende westliche Blickregime gewesen, die „Inder_innen der zweiten Generation“ seit ihrer Kindheit internalisiert hatten. Die neuen Subjektivierungsprozesse in den privilegierten und kosmopolitischen Freiräumen im „neuen Indien“ sind daher auch geprägt von einer starken Ambivalenz im Umgang mit Armut und sozialer Ungleichheit sowie einem nostalgischen Begehren nach einem „authentischen Indien“ vor der sogenannten Verwestlichung und Modernisierung.

In diesem Kapitel möchte ich zuerst die diasporische Subjektivierungslogik in der globalen indischen Moderne genauer analysieren. Nach einer historischen Herleitung des hegemonialen Projektes eines „neuen Indiens“ soll die Konstruktion der „Diaspora“ und vor allem der „Zweiten Generation“ in der Bollywood-Populärkultur sowie in der indischen Diasporapolitik dargelegt werden. Danach untersuche ich in ethnografisch-biografischen Fallanalysen, wie die Subjektivierungsprozesse von „Inder_innen der zweiten Generation“ während Aufenthalten im „neuen Indien“ ausgehandelt wurden.

Erstens interessiert mich, welche transnationalen Praktiken angesichts der neuen Verflechtungen zwischen der Schweiz und Indien entstanden sind. Zweitens geht es mir darum zu untersuchen, wie schweizerisch-indische Second@s diasporische Teilhabe an der indischen Nation konkret aushandelten. Drittens möchte ich diskutieren, welche ethischen Widersprüche sich in den Subjektivierungs- und Repräsentationsprozessen durch die Verschiebungen in den postkolonialen Machtverhältnissen zwischen der Schweiz und Indien ergeben. Konkret diskutiere ich den Umgang von „Inder_innen der zweiten Generation“ mit Armut und Exotik in Indien vor dem Hintergrund transnationaler Privilegien und kosmopolitischer Freiheiten.

\section{1 "THE GLOBAL INDIAN FAMILY" - DIE SUBJEKTIVIERUNG DER „ZWEITEN GENERATION" IM „NEUEN INDIEN"}

In diesem Unterkapitel rekonstruiere ich die ökonomische, politische und kulturelle Artikulation eines „neuen Indiens“ vor dem Hintergrund der Integration des Landes in den globalen Kapitalismus. Ich argumentiere, dass die neue globale Konfiguration indischer Moderne konstitutiv mit der Konstruktion der „Diaspora“ und deren Integration in eine sich globalisierende indische Mittelschicht verbunden ist. Wie ich am Beispiel des Bollywood-Kinos und der staatlichen Diasporapolitik zeige, diente die ,indische Diaspora“ als politisches, soziales und kulturelles Bindeglied in der nationalistischen Konstruktion einer "globalen indischen Familie“, in der westlicher Materialismus und indische Werte nach neuen Mustern und Normen von Klasse, Geschlecht und Position verknüpft werden konnten. 


\section{Die neuen Mittelschichten als Trägerschaft der hegemonialen Konstruktion eines "neuen Indiens"}

Das Nehru'sche Projekt, wonach sich Indien wirtschaftlich selbstständig und kulturell autonom modernisieren sollte, hatte seit den 1970er Jahren zu bröckeln begonnen. Der Ausnahmezustand unter Indira Gandhi von 1967 bis 1971, die frühen Annäherungsversuche an den Kapitalismus unter Rajiv Gandhi ab den 1980er Jahren, der demokratische Druck der unterprivilegierten Schichten und Kasten sowie die zunehmende Politisierung religiöser Spannungen markierten die wirtschaftliche und politische Krise des säkularen Entwicklungsstaates (Menon/Nigam 2007). Die Liberalisierung der Märkte im Jahr 1991 durch den Premierminister der Kongresspartei P. V. Narasimha Rao traf in der Imagination der unabhängigen indischen Nation einen wunden Punkt. Der drohende Staatsbankrott und die Währungskrise zeigten einerseits die Grenzen des bisherigen wirtschaftspolitischen Modells des Entwicklungsstaates auf. Andererseits erschien die Abhängigkeit von den Weltbank- und IWF-Krediten als Verlust der nationalen Souveränität und damit auch als politische Bankrotterklärung des antikolonialen Indiens. Die politische Legitimation der Liberalisierungsreform, die von bestimmten Kräften - etwa der industriellen Führungselite - unterstützt wurde, erforderte daher eine weitreichende Reartikulation des hegemonialen nationalen Projektes (Fernandes/ Heller 2006; Chowdhury 2011).

Im Kräftezentrum dieser politischen Verschiebung standen diejenigen Fraktionen der Mittelschichten, die entweder von Statusverlustängsten geplagt oder deren Aspirationen im Nehru'schen Konsens enttäuscht worden waren. Sie hatten weder die Privilegien der staatstragenden Beamten noch das Kapitel der industriellen Elite. Und auch konnten sie nicht auf die Unterstützung staatlicher Wohlfahrtsprogramme hoffen. 1989 hatten Angehörige dieser Schichten gegen die Umsetzung der Forderungen der Mandal-Kommission protestiert, die höhere Quoten für Angehörige der unterprivilegierten Kasten und Gemeinschaften in der Verwaltung und an Universitäten vorsah. Vor dem Hintergrund der drohenden affirmative action und der Wirtschaftskrise versprach die Liberalisierungspolitik in unterschiedlichen Fraktionen der Mittelschicht vorhandene Statusängste zu beschwichtigen respektive globale Aspirationen zu erfüllen. Wegen ihres relativ hohen kulturellen Kapitals profitierten die „neuen Mittelschichten“ überdurchschnittlich von den neuen outgesourcten Dienstleistungsindustrien wie Business Process Operations (Callcenter) oder IT, aber auch von Leitungspositionen und administrativen Stellen in den neuen indischen oder den angesiedelten multinationalen Konzernen und ihren lokalen Zulieferfirmen (Fernandes 2006). Zusammen mit den Oberschichten und denjenigen Teilen der „alten Mittelschichten“ (Varma 1998), die durch ihr soziales und kulturelles Kapital die Kaderstellen der neuen Dienstleistungsbranchen eingenommen hatten, steigerten sie die Nachfrage in der wachsenden Konsumkultur. Bedeutete Konsum als Inbegriff des Westens bis da- 
hin vor allem moralische Dekadenz, verkörperte er im neuen Paradigma Status und Lebensstandard sowie das Potenzial sozialer Gerechtigkeit. Denn gemäß der neoliberalen Doktrin, die die Regierung seit den Reformen verkündete, könne die globale Wirtschaft Entwicklungsaufgaben besser erfüllen als der Nehru'sche Staat. Diese neoliberale Botschaft gewann jedoch nicht vor allem durch den politischen Diskurs an Überzeugungskraft, sondern auch durch die öffentliche Kultur, etwa in der Werbung oder im Bollywood-Kino (Mazzarella 2003; Fernandes 2006; Deshpande 2005). In der medialen Bilderwelt sowie in den neuen urbanen Lebensstilen wurde ein ideales indisches Subjekt konstruiert und legitimiert, das durch die Aneignung des globalen Kapitalismus den individuellen und den nationalen Lebensstandard erhöhen könne. Wie William Mazzarella in seiner Ethnografie über die Werbebranche im „neuen Indien“ argumentierte:

The [language of aspiration] attempted to equate the generality of consumer desire with the particular norms and forms of the nascent middle-class imaginary. It introduced an alternative temporality with its own language of progress and evolution [...] The aspirational comsumer was being exhorted to individual and collective self-fulfillment by means of pleasure rather than sacrifice. (Mazzarella 2003:101)

Vermochte zwar das omnipräsente Konsumversprechen die Aspirationen breiter Schichten anzufeuern, so erforderte das Projekt eines „neuen Indiens“ gleichzeitig, die Ängste um kulturelle Autonomie und Reinheit, die in der antikolonialen Kapitalismuskritik eingeschrieben waren, zu beschwichtigen. Zwischen Verheißung zukünftigen Konsums und Angst vor Verwestlichung klaffte weiterhin ein grosser Widerspruch. Noch in den frühen 1990er Jahren beklagte die hindunationalistische Bhatriya Janata Party BJP (Indische Volkspartei) - im Einklang mit ihrer ideologischen Mutterorganisation Rashtriya Swayamsevak Sangh RSS (Nationale Freiwilligenorganisation) und in Anlehnung an die antikoloniale Boykottpolitik des swadeshi (Autonomie, Unabhängigkeit) - die kulturelle Korruption durch die Präsenz westlicher Konsumgüter und -praktiken in Indien. ${ }^{81}$

Im Hinblick auf die Wählerstimmen in den verschiedenen Fraktionen der Mittelschicht begann die hindunationalistische BJP ab Mitte der 1990er Jahre ihre Berührungsängste mit der Liberalisierungspolitik der Kongresspartei aufzugeben (Fernandes/Heller 2006). Der medienwirksame hindunationalistische Populismus, der zur Zerstörung der Babri Masjid im Jahr 1992 und seither zu mehreren

81 Zusammen mit der chauvinistischen Partei Shiv Sena (Armee Shivas) aus Bombay forderten RSS-Mitglieder in ebenso spektakulären wie respektlosen Aktionen das Verbot von sogenannt unhinduistischen Anlässen wie der Miss-World-Wahl 1996 in Bangalore oder der Veröffentlichung des queeren Films "Fire" der indisch-kanadischen Regisseurin Deepa Mehta im Jahr 1998. 
Pogromen vor allem in der muslimischen, aber in der hinduistischen Bevölkerung führte, hatte der BJP großen Zulauf in den urbanen Mittelschichten beschert (van der Veer 1994; Hansen 1999; Rajagopal 2001). Die Unterstützung der Liberalisierungsreform ermöglichte es der BJP, diese urbanen, hochkastigen Wählerschaften an sich zu binden. Sie konnte sowohl die Umverteilung an die tieferen Kasten und Schichten drosseln als auch eine hindunationalistische Vision eines aufsteigenden Indiens im Kontext des globalen Kapitalismus propagieren. Gemäß dem neuen Paradigma bedeutete swadeshi nicht mehr ökonomische und kulturelle Autarkie, sondern ein starker und kompetitiver hinduistischer Staat im globalen Kapitalismus. Dieser Anspruch wurde durch die Nuklearbombentests von Pokhran-II im Sommer 1998 bestätigt, die zwar von der Kongresspartei vorbereitet, aber von der neu gewählten BJP-Regierung unter Atal Bihari Vajpayee im selben Jahr schnell implementiert wurden.

Diese in den 1990er Jahren akzentuierte hegemoniale Verbindung von Nationalismus und globalem Kapitalismus wurde 2004 in der Kampagne „India Shining" deutlich, die die regierende BJP vor den Wahlen lancierte. Die Kampagne präsentierte Plakate mit strahlenden Gesichtern von Cricket spielenden urbanen Müttern oder ländlichen Kleinunternehmern. Auf den Plakaten fand sich etwa der Slogan „There was never a better time to be Indian“. Die zynisch wirkende Kampagne vermochte jedoch die soziale Ungleichheit nicht zu verhehlen, die mit der Liberalisierung verbunden war, und die BJP wurde abgewählt. Unabhängig vom politischen Misserfolg ist jedoch die Aussage des gestalterischen Leiters der Kampagne besonders interessant, dass er für die Kongresspartei die genau gleiche Kampagne gemacht hätte (Mid-Day, 15. Februar 2004). Diese Aussage unterstützt die hier vertretene These, dass spätestens ab Mitte der 1990er Jahre - trotz innenpolitischer Unterschiede zwischen Kongresspartei und BJP - ein hegemonialer Konsens unter den führenden politischen Blöcken in Bezug auf die Liberalisierungspolitik und den damit verbundenen Nationalismus vorherrschte. Was also zu Beginn der 1990er Jahre mit einer tiefgreifenden, nationalen Krise begann, wurde in wenigen Jahren zu einem neuen hegemonialen Projekt Indiens, das den Anspruch auf den globalen Kapitalismus mit einem starken Nationalismus hinduistischer Prägung verband.

\section{„Diasporaisierung" und globale indische Moderne}

Das hegemoniale Projekt, das seit den 1990er Jahren Gestalt gewann, war eng verknüpft mit der Konstruktion einer „Diaspora“ als organisches Element im Wachstumsprojekt der Nation. Wie Brubaker nahelegt, ist die öffentliche Präsenz des Begriffs, des Phänomens und der sozialen Gruppe der ,indischen Diaspora“ ab den 1990er Jahren selbst in machtvolle Prozesse der "Diasporaisierung" eingeschrieben, die aus einer ethnografisch-genealogischen Perspektive analysiert werden müssen: 
We should think of diaspora in the first instance as a category of practice, and only then ask whether, and how, it can be fruitfully used as a category of analysis. As a category of practice, "diaspora" is used to make claims, to articulate projects, to formulate expectations, to mobilize energies, to appeal to loyalties. It is often a category with strong normative change. It does not so much describe the world as seek to remake it. (Brubaker 2005:12)

Die (Re-)Konstruktion eines „diasporisch Imaginären“ (Axel 2002) diente so gesehen etwa dem indischen Staat, der Bollywood-Industrie sowie den transnationalen Mittelschichten als kulturelle, ökonomische und politische Ressource, um sich im hegemonialen Projekt des neuen Indiens zu positionieren. Wie im Exkurs in Kapitel 4 angedeutet, herrschte im antikolonialen Nehru'schen Konsens eine moralische Ambivalenz gegenüber Emigrant_innen vor, die nach der Unabhängigkeit zunehmend in den Westen auswanderten; zuerst nach Großbritannien, ab 1965 auch in die USA und zunehmend nach Kanada, Europa und Australien. Die oft gut ausgebildeten Fachkräfte und Akademiker_innen aus der Mittelschicht galten als Fahnenflüchtige, die sich aus eigennützigen Interessen der Aufgabe des Wiederaufbaus Indiens entzogen und die Solidarität in Indien schwächten. Konsum, fehlende Familienwerte und sexuelle Freizügigkeit im Westen würden die Bindung der NRI zum Mutterland schwächen. Gleichzeitig verfügten diese Auslandinder_ innen über einen hohen Status, weil mit ihnen ökonomischer Erfolg und Reichtum assoziiert wurden. In den 1990er Jahren verschoben sich die Beziehungen Indiens zu seinen NRI dramatisch (Mani/Varadarajan 2005:63). Im neuen nationalistischen Projekt erschien die ökonomische, politische und kulturelle Integration der davor skeptisch beäugten NRI als stimmige, ja notwendige Folge. ${ }^{82}$

Moving away from the anticolonial alliance that characterized the post-independence Indian state, the new globally oriented India of the early twenty-first century needed national subjects who would legitimize its new path and potentially consolidate its economic and symbolic power. (Mani/Varadarajan 2005:65)

Die NRI hatten gute ökonomische, politische und kulturelle Netzwerke im globalen Kapitalismus und vor allem im Westen geknüpft, und zum Beispiel in der IT-Branche in den USA ein erfolgreiches und fortschrittliches Image von Indien verbreitet. In der Reartikulation des hegemonialen nationalen Projektes wurden diasporische Subjekte zu narrativen und ästhetischen Schablonen und Projekti-

82 Obwohl in Indien die Währungskrise auch den NRI angelastet wurde, weil diese ihre in Indien investierte Fremdwährung abzogen statt den Rupienkurs mit noch mehr Investitionen zu stützen, waren in den Liberalisierungs- und Wachstumspaketen von Anfang an wirtschaftliche Zugeständnisse für NRI vorgesehen. 
onsflächen für die Konstruktion von Lebensstilen in den „neuen indischen Mittelschichten". Geradezu paradigmatisch verkörperten demnach NRI eine Subjektivität, die materielle Konsumkultur des Westens mit den Werten der indischen Zivilisation zu einer kulturpolitischen Imagination einer „global Indianness" verband.

As urban India experiences the optimism of an economic upswing, and the diaspora increasingly engages in it, and ideology of "global Indianness" has crystallized - a set of beliefs and practices that act at once tied to a global lifestyle and to a deep sense of belonging to the Indian nation. Where previously, Indianness and westerness were opposed to one another, a discourse of "global Indianness" makes them compatible. (Radhakrishnan 2008:9)

Global orientierte urbane und mediale Konsumkulturen und transnationale Karrierewege und soziale Netzwerke verwischten zunehmend die Grenzen zwischen den lokalen, neuen Mittelschichten und den bisherigen NRI im Westen. Daraus wurden zunehmend Räume und Narrative einer hegemonialen globalen indischen Öffentlichkeit geschaffen (Breckenridge 1995), in denen indische Subjektivitäten nach neuen Mustern von Klasse, Religion, Geschlecht und Herkunft ausgehandelt wurden.

Auch die nationalen Normen von „weiblicher Respektabilität“, die im antikolonialen Nationalismus als Sanktum von spirituellen und moralischen Werten galten (Chatterjee 1989), wurden durch die Integration von Frauen in den globalen Kapitalismus als Arbeitnehmerinnen und Konsumentinnen radikal infrage gestellt und verschoben. Wie Smitha Radhakrishnan in ihrer Ethnografie über indische IT-Spezialistinnen im Silicon Valley zeigte, galten diese als Pionierinnen in der Aushandlung neuer globaler indischer Weiblichkeiten.

Previously existing ideals of domesticity and nationhood have fused with contemporary notions of the global Indian nation to shift gendered ideals of middle-class respectability. Whether in India or the diaspora, professional IT women feel their professional achievements to be indicative of the progress of India, and also experience the benefit of an added respect for their professional lives, even compared to middle-class housewives, who were the embodiment of respectability for a previous generation (Radhakrishnan 2008:16).

Nicht nur als professionelle Trägerinnen des Wachstums und des sozialen Wandels, auch als Konsumentinnen wurden Frauen aus der neuen Mittelschicht öffentlich angerufen und repräsentiert. Die Rezeption von Modemagazinen (Thapan 2004; Uberoi 2006), Werbungen (Mazzarella 2003), Fernsehserien (Mankekar 1999) und Bollywood-Filmen (Uberoi 2006) vermittelte neue Geschlechternormen und markierte zudem die mittelständische Distinktion im Umgang mit diesen 
neuen global orientierten Konsumpraktiken. ${ }^{83}$ Gleichzeitig beförderte dieselbe Konsumkultur Narrative einer weiblichen Respektabilität, wonach professionelle Karrieren oder konsumorientierte Lebensstile weder auf Kosten der Rolle als Mutter, Ehefrau und Schwiegertochter verfolgt werden, noch die männliche Dominanz infrage stellen sollten.

The new discourses of belonging to India is a fundamentally gendered one that relies on the ability of professional women to make delicate balances between an "Indian" home life and a "global" professional life. (Radhakrishnan 2008:7)

Die Konstruktion einer globalen indischen Moderne, die indische Werte und westlichen Materialismus verbinden soll, hat durch die Verschiebung der Grenze zwischen privater und öffentlicher Sphäre zu einer Pluralisierung von Geschlechterrollen geführt. Frauen aus der transnationalen Mittelschicht sind darin angerufen, eine Balance von Aufopferung und Ausgelassenheit, von Respektabilität und Lifestyle, Disziplinierung und Autonomie, von patriarchalen Geschlechternormen und neoliberalen Lebensstilen zu verkörpern und zu repräsentieren.

Ich argumentiere, dass der Konstruktion der „Diaspora“ eine wichtige Bedeutung innewohnte, um das hegemoniale Projekt des „neuen Indiens“ umzusetzen. In Indien wurde damit ein legitimer globaler Horizont geschaffen und umgekehrt wurde eine Integration der Diaspora in die "globale indische Familie“ vollzogen. Im Folgenden zeige ich zuerst die konkreten klassen- und geschlechtspezifischen Konstruktionen der „Diaspora“ in der Bollywood-Populärkultur auf, um danach die Institutionalisierung dieser Narrative in der neuen staatlichen Diasporapolitik ab 2003 nachzuzeichnen. Die Analyse zeigt auf, wie darin Angehörige der „Diaspora“ insbesondere Angehörige der „Zweiten Generation“ gemäß klassen- und geschlechtspezifischen Abstufungen als Teil der Nation imaginiert und einbezogen respektive ausgeschlossen wurden.

\section{Bollywood als Leitmedium der globalen indischen Moderne: Diasporische Narrative von Rückkehr und Konsum}

Wie die Eingangsvignette zu diesem Kapitel zeigte, waren Aushandlungen von Konsum und Zugehörigkeit in den transnationalen familiären Beziehungen zwischen NRI und Inder_innen in den 1980ern und den frühen 1990ern gang und gäbe. Die Bollywood-Populärkultur war geradezu prädestiniert, diese alltäglichen

83 | Paradigmatisch standen die omnipräsenten Miss-World-Wahlen in den 1990er Jahren, die von feministischer Seite und von hindunationalistischer Seite bekämpft wurden, für die Konstruktion individualistischer, konsum- und global orientierter indischer Weiblichkeit in der hegemonialen Öffentlichkeit (Oza 2001; Dewey 2008). 
kulturellen Prozesse aufzunehmen und als Teil einer transnationalen öffentlichen Kultur zu verarbeiten und zu vertreiben. ${ }^{84}$ Das Hindi-Kino war schon seit den 1950er Jahren international verbreitet, insbesondere in Regionen, in denen viele südasiatische Arbeitsmigrant_innen lebten, wie im Nahen Osten oder in Südostasien, aber auch in der Sowjetunion. Mit dem Aufkommen von Videorekordern ab den frühen 1980er Jahren und einer florierenden Piraterie wurde das Hindi-Kino noch vor der Liberalisierung der Märkte auch unter NRI im Westen populär. Durch diese transnationale Verbreitung unter NRI im Westen und als Leitmedium öffentlicher indischer Kultur wurde Bollywood zu einer privilegierten Plattform "for the articulation of Indian identity in a globalized world“ (Uberoi 2006:184 f.). Ab Mitte der 1990er Jahre fand im Bollywood-Kino die Re-Imagination diasporischer Subjekte als transnationale Agenten zwischen Indien und dem Westen sowie zwischen Konsum und Moral ihren narrativen und ästhetischen Niederschlag (Inden 1999; Deshpande 2005; Brosius/Yazgi 2007).

Im paradigmatischen Film „Purab aur Paschim“ (1970) (s. Kapitel 3) wurden NRI als Grenzgänger in einer dichotomen moralischen Ordnung zwischen Indien und dem Westen repräsentiert. NRI erschienen als zigarettenrauchende Frauen in Miniröcken, Pseudo-Hippies und melancholische Nostalgiker, die von materiellen Aspirationen und Orientierungslosigkeit getrieben wurden. Im Kult-Film „Dilwale Dhulanya Le Jayenge“ („Der Beherzte gewinnt die Braut“, 1995, abgekürzt als DDLJ bekannt) von Aditya Chopra wurde diese moralisch-territoriale Ordnung zwischen Indien und dem Westen maßgeblich reartikuliert.

Der Film erzählt die Geschichte von Raj (Shahrukh Khan) und Simran (Kajol), die beide als Kinder von indischen Migranten in London aufgewachsen sind. Während Simran in der Familie des Cornershop-Besitzers Baldev (Om Puri) lebt, der sich in England fremd fühlt und sich nach seiner Heimat Punjab sehnt, ist Raj Sohn des erfolgreichen Selfmademans Dharamvir (Anupam Kher), der in London zum Millionär geworden ist und einen westlichen Lebensstil pflegt. Die Geschichte beginnt mit dem Bachelorabschluss von Raj und Simran, den beide - unabhängig voneinander und ohne sich zu kennen - auf einer Eurorail-Tour mit Freunden und Freundinnen feiern wollen. Um die Reise antreten zu können, muss Simran ihrem Vater versprechen, eine schon arrangierte Heirat einzugehen. Auf der Europreise, die zu einem großen Teil in der Schweiz spielt, kreuzen sich die Wege von Raj und Simran immer

$\mathbf{8 4} \mid$ Der Begriff Bollywood für das kommerzielle Hindi-Kino wurde zwar schon in Filmmagazinen der 1970er geprägt, war aber damals noch kaum gebräuchlich. Erst ab Mitte der 1990er Jahre löste "Bollywood" Begriffe wie masala movies oder ganz simpel hindi movies als dominante Bezeichnung für Hindi-Filme respektive für die ganze Industrie ab. Die populäre Bezeichnung selbst steht für eine zunehmende Internationalisierung und weitere Kommerzialisierung dieser Filmindustrie (Rajadhyaksa 2003; Vasudevan 2011:334 ff.; Ganti 2012:12 f.). 
wieder. Der karnevaleske Lebenskünstler Raj verstrickt sich und Simran durch seine Scherze und Missgeschicke immer wieder in Abenteuer, wodurch sich die beiden näherkommen. Als die Reise zu Ende und sie zurück in London sind, merken beide, dass sie sich ineinander verliebt haben. Als Simrans Vater dies realisiert, fliegt die Familie unverzüglich nach Indien, um die arrangierte Hochzeit von Simran unter Dach und Fach zu bringen. Unterstützt von seinem Vater reist Raj ebenfalls nach Indien, um Simrans Vater zu überzeugen, dass er selbst der richtige Bräutigam für Simran sei. Als Simran ihn trifft, fleht sie ihn an, mit ihr gemeinsam abzuhauen. Indem er sich in die Hochzeitsgesellschaft einschleust, will Raj hingegen den Segen von Simrans Vater gewinnen. Als Simrans Vater diesen Trick entdeckt, lässt er Raj brutal verprügeln. Schließlich lässt der Vater Simran trotzdem mit Raj ziehen, als er bemerkt, dass niemand seine Tochter wird glücklicher machen können als Raj.

DDLJ erzählt zwar eine für das melodramatische Hindi-Kino typische Heiratsgeschichte, in der der Widerspruch zwischen Liebe und familiären Interessen ausgehandelt wird (Thomas 1995). Indem die Geschichte in der Diaspora angesiedelt ist, macht der Film zudem die Grenze zwischen Nation und Diaspora, Indien und Westen, sowie zwischen Tradition und Moderne explizit zum Thema. Die Geschichte handelt davon, wie Familienhierarchien und Geschlechternormen im Kontext von westlicher Kultur und sozialem Wandel intergenerationell ausgehandelt werden sollen. Vor diesem Hintergrund repräsentieren die beiden Väter zwei Grundhaltungen, die im Film einander gegenübergestellt werden - mit klarer Sympathie-Verteilung: Der Vater von Simran wird als melancholischer und realitätsfremder Patriarch dargestellt, der an seiner alten Heimat und den Werten seiner Jugend festhält und seine Ehre über das Glück der Tochter stellt. Rajs Vater hingegen stellt den erfolgreichen Selfmademan dar, der sich (auch) ohne Schulabschluss für ein gutes Leben seines Sohnes abgerackert hat. Dharamvir genießt seinen Erfolg, wohnt in einer Villa mit Swimmingpool, finanziert den opulenten Lebensstil seinen Sohnes und stößt mit diesem auf die wohl verdienten Europaferien an, obwohl Raj den Abschluss vermasselt hat. Trotz seines westlichen Lebensstils vermag Dharamvir seine indischen Familienwerte in einer humorvollen, freundschaftlichen und engen Beziehung an seinen Sohn weiterzugeben.

Eine besondere erzählerische Funktion nehmen Ironie und Humor ein, mit denen Raj und sein Vater dargestellt werden. Rajs Charakterisierung als Taugenichts und seine ständigen karnevalesken Scherze während der Europareise lassen sich in die Tradition der Karikatur von verwestlichten und identitätslosen indischen Subjekten einordnen, die seit dem frühen Nationalismus am Ende des 19. Jahrhunderts den antikolonialen Diskurs prägen. ${ }^{85}$ Und tatsächlich beschreibt Simrans

85 | Die Karikatur des babu, des Typus des anglophilen bengalischen Beamten, Landlords oder Dandys, wie sie von Bankim Chandra Chattopadhyay (1838-1894) literarisch popularisiert wurde, war ein wichtiges Genre des Nationalismus in der bengalischen 
Vater Raj nach einer Begegnung in London als typischen „Wäscherhund, weder im Haus noch am Fluss“. Und auch das ehrenhafte indische Mädchen Simran nimmt Raj auf der Reise zuerst lediglich als Taugenichts wahr, der sich nur für Frauen und Partys interessiert und für den alles nur ein Spiel oder ein Witz ist. Rajs Karneval generiert jedoch im Film und in der Rezeption nicht nur die unmittelbare Erfahrung von Spaß und Abenteuer als Teil eines neuen Lebensstils, sondern auch die Möglichkeit, den Tabubruch zu inszenieren und dadurch eine neue moralische Ordnung zu definieren:

Als Simran nach einem Alkoholrausch im Bett von Raj erwacht, gaukelt er ihr vor, sie hätten die Nacht zusammen verbracht. Erst als Simran in Tränen ausbricht, weil sie um ihre Jungfräulichkeit fürchtet, beteuert plötzlich Raj - bar jeglicher Ironie -, dass er keineswegs der Taugenichts sei, den sie in ihm sehe. Er sei ein „Inder“, auch wenn er in England geboren sei, und wisse daher die Ehre einer „indischen Frau“ zu respektieren. In diesem Moment patriarchaler Offenbarung erscheint Rajs westlich konnotierter Lebensstil von Promiskuität, Party und Alkohol als spielerische Fassade. Von da an vertraut Simran Raj und sie weiß, dass unter der clownesken Oberfläche eine solider moralischer Kern, ein „indisches Herz“ steckt. In der Figur des diasporischen Clowns, der zwischen westlichen Lebenstil und indische Werte, Spaß und Moral „switcht“, wird „Indianness“ sowohl vom indischen Territorium als auch von äußerlichen Symbolen losgelöst und stattdessen zu einem portablen inneren Wert umgedeutet. Als Rajs Vater in seinen ulkigen westlichen Kleidern in der Hochzeitsgesellschaft im Punjab auftaucht, gewinnt er mit seiner Heimatverbundenheit sofort die Gunst von Simrans Vater. Als Letzterer erläutert, dass er ihm diese Heimatliebe angesichts der Kleider auf den ersten Blick nicht zugetraut hätte, antwortet Rajs Vater: „Glauben Sie etwa an dieses Theater mit den Kleidern? Ich trage Indien im Herzen." Durch die Entkoppelung von indischen Familienwerten und äußerlichen und klischeehaften Traditionen und Symbolen erscheinen westlicher Konsum und Lebensstil sowie transnationale soziale Mobilität nicht als a priori verwerflich wie etwa in „Purab aur Paschim“. Die humorvolle und erfolgreiche Konstruktion innerer indischer Werte, die im Herzen eingeschrieben sind, lassen stattdessen die äußerlichen und formalen Symbole von „Indianness“ - etwa bei Simrans Vater - als unecht, starr und heuchlerisch erscheinen. Sie verhindern Sensibilität gegenüber dem sozialen Wandel, Empathie gegenüber der eigenen Tochter und schließlich auch den Spaß am Leben.

DDLJ vermag durch den diasporischen Plot, den ironischen Erzählstil sowie angesichts der transnationalen Verbreitung des Bollywood-Kinos die sich wandelnde indische Gesellschaft und NRI gemeinsam zu adressieren:

Renaissance (Sartori 2008). Diese Karikatur wird etwa in "Purab aur Paschim" von Shyam verkörpert, der in seinen Hippie-Kleidern, durch die verwestlichten Namen und seinen prominenten Englischakzent als identitätslose Karikatur erscheint. 
With DDLJ, their problems of being Indian in a foreign setting are projected as our problems of identity as well. Conversely, our problems of constituting a "moral universe" of family relations are seen to be their problems as well. That is, the challenge of being (and, more important, remaining) Indian in a globalized world is one that has to be met by those who stay at home and those who live abroad. (Uberoi 2006:186)

Zusammenfassend lassen sich folgende Punkte festhalten:

1. Die Ansiedlung der Geschichte in der Diaspora und insbesondere auf einer Ferienreise erlaubte die explizite Aushandlung tabuisierter Themen wie voreheliche Sexualität, Alkoholkonsum von Frauen und die Darstellung westlicher Lebensstile. In diesem transgressiven Raum konnte mit neuen Erzählungen, Werten und Subjektivitäten einer „global Indianness“ experimentiert werden, in denen sich die „neue Mittelschicht“ erfinden konnte. Durch die Identifikation mit Raj, dem „consumable hero of globalized India“ (Deshpande 2005), konnte sich die Mittelschicht vom ländlichen und diasporischen Patriarchat abgrenzen. Gleichzeitig reartikulierte sie patriarchale Werte im Kostüm eines konsumorientierten und emanzipatorischen Lebensstiles. Denn auch wenn Simran schließlich die erträumte Liebesheirat durchsetzte: Ihre befreite Weiblichkeit ist abhängig vom patriarchalen Kampf zwischen ihrem Vater und Raj. Somit lieferte das Bollywood-Kino die affektiven, ästhetischen und narrativen Ressourcen im hegemonialen Projekt des „neuen Indiens“, um die Widersprüche zwischen globaler Aspiration und „Indianness" sowie zwischen Konsum und Moral zu minimieren - und dadurch eine größere Transformation patriarchaler Geschlechterverhältnisse im Kern aufzuschieben.

2. Zum anderen adressierte der Film die Diaspora, die in DDLJ erstmals als legitimer, ja sogar vorbildlicher Teil der Nation repräsentiert wurde. Das Anfangslied „Ghar aaja pardesi, tera desh bula raha hai“ („Komm nach Hause, Fremder, dein Land ruft dich"), das einen nostalgischen Tagtraum von Simrans Vater untermalt, in welchem ihm am Trafalgar Square die Rapsfelder des Punjabs erscheinen, etablierte zwar ein Rückkehrnarrativ. Der Film erteilte jedoch dieser starren Form der Melancholie eine ironische, aber klare Absage und schrieb stattdessen die $\mathrm{Zu}$ gehörigkeit zur Nation in das transnationale „indische Herz“ - zumal der Film offenlässt, ob Simran, Raj und dessen Vater nach London zurückkehren oder im neuen urbanen Indien leben werden. „Indianness“ wurde damit als transnational flottierendes Ethos etabliert, das sich im Kontext eines globalen Kapitalismus von einen Territorium und starren Praktiken losgelöst hat und sich in flexibilisierten Formen von Konsum und Mobilität verändern muss. 
Mit DDLJ etablierte Bollywood den bis dahin impliziten und informellen Topos der Diaspora in der öffentlichen Kultur und löste die Entstehung eines eigenen Genres aus, in dem die Konstruktion der Diaspora als Erneuerung der indischen Nation weiter ausdifferenziert wurde.$^{86}$ Durch die Popularität und die wachsende Diaspora im Westen entstanden internationale Distributions- und Finanzierungsstrukturen, die zunehmend auf einem professionalisierten Vertriebsnetzwerk von Kinos in Großbritannien und in den USA basierten. Angesichts der hohen und stabilen Auslandseinnahmen in einem Geschäft mit hohem Risiko wurden die in der Diaspora lebenden Inder_innen immer mehr explizit als Zielgruppe mit entsprechenden Narrativen und Genres beliefert. ${ }^{87}$ Umgekehrt bot das Bollywood-Kino der Diaspora eine transnationale öffentliche Kultur, in der sie als Angehörige der Nation nicht vergessen wurden, ja Anerkennung fanden.

Fand die „Diasporaisierung“ ab den 1990er Jahren vor allem in einer transnationalen öffentlichen Kultur statt, begann auch der indische Staat diese in seine nationale Kulturpolitik einzubeziehen. 1998 erkannte die neue BJP-Regierung unerwartet das kommerzielle Kino als Industrie an und erlaubte dadurch eine bessere finanzielle Förderung und einen größeren Einfluss auf die Filmindustrie. 1999 wurde dieses kulturpolitische Engagement weiter institutionalisiert, als der Staat seine Diasporapolitik lancierte, die 2003 in Kraft trat.

86 | Weitere Blockbuster aus diesem Genre sind "Pardes” („Ausland“, 1997), "Kabhie Khushi Kabhie Gham" („In guten wie in schlechten Tagen“, 2001), "Kal No Na Ho“ („Denke nicht an morgen", 2003), "Swades" ("Heimat", 2004), "Namastey London“ (2007) oder "Dilli 6" (2009).

$\mathbf{8 7} \mid$ Es wurde argumentiert, dass Indiens Integration in den globalen Kapitalismus selbst die Transformation des Hindi-Kinos in eine "Bollywood"-Industrie bewirkt habe, die sich durch internationale Vertriebs- und Finanzierungsstrukturen, Narrative über familiäre Werte, Konsumorientierung im Produktionsdesign, staatliche Förderung und den Fokus auf ein Mittelschichtspublikum, insbesondere auch in der Diaspora im Westen, auszeichnet (Rajadhyaksa 2003; Vasudevan 2011; Ganti 2012). Diese „Bollywoodisierung" des indischen Kinos begann sich gerade zu institutionalisieren, als Mitte der 1990er Jahre die ersten diasporischen Subjekte in der öffentlichen Kultur wie etwa in DDLJ auftauchten. 

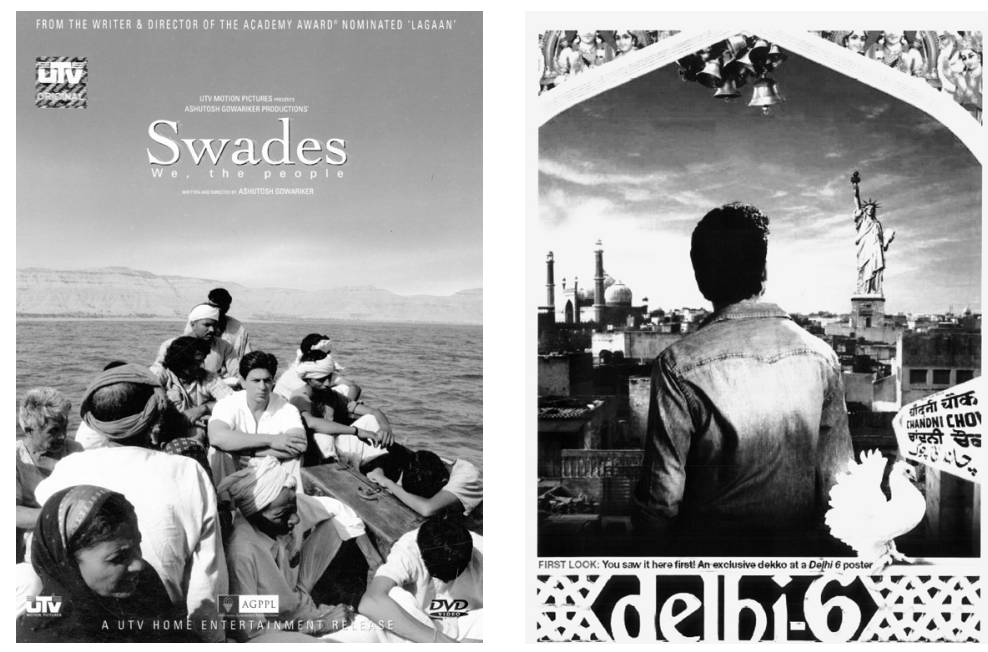

Abbildung 22a und 22b: Filme wie "Swades" (2004) oder "Dilli 6" vermitteln Rückkehrnarrative von Angehörigen der "zweiten Generation" (Quelle: Autor)

\section{"The sun never sets on the Indian diaspora" - die Nation und ihre Diaspora}

Hatte die Kongressregierung unter P. V. Narasimha Rao die NRI noch durch Anreizpakete in der Liberalisierungsreform insbesondere als ökonomische Akteure angesprochen, lag der BJP-Regierung unter Attal Bihari Vajpayee, die 1998 an die Macht kam, die Thematik der Diaspora noch stärker am Herzen. Die Verknüpfung von globalen kapitalistischen Aspirationen und der Ideologie der hindutva (Sanskrit für „Hinduness") fand ihre Entsprechung in den engen Beziehungen der BJP-nahen hindunationalistischen Bewegungen, VHP und RSS, mit Kreisen hochqualifizierter amerikanischer Hindus. Die finanzielle Unterstützung des Hindunationalismus durch die amerikanisch-hinduistische Diaspora wie auch deren Lobby-Arbeit nach den Atombomben-Tests von 1998 etablierten eine transnationale, politische Allianz (Bhatt/Mukta 2000; Mathew/Prashad 2000; Rajagopal 2001). ${ }^{88}$ Innerhalb des Projektes, Indien als neue Supermacht in den globalen Ka-

$\mathbf{8 8}$ | Wie argumentiert wurde, war ein Grund für den Erfolg von hindutva bei hochqualifizierten Inder_innen die Erfahrung von Rassismus und institutioneller Diskriminierung in den USA. In der stark rassialisierten Sozialstruktur der USA bot hindutva eine Sprache, um sich in Abgrenzung zu anderen - etwa afro- und hispanoamerikanischen - Bevölkerungen als liberale Modellminderheit zu repräsentieren und gleichzeitig Rassismus abzuwehren. Der vordergründige Fokus auf Kultur statt auf Politik sowie das positive Image des Hinduismus in den USA erlaubten dann eine Inklusion in einen liberalen Multikulturalismus. Nach den Terroranschlägen in New York im Jahr 2001 ver- 
pitalismus zu integrieren, strebte die BJP-Regierung daher zunehmend eine kohärente Diasporapolitik an. Im Jahr 2000 setzte sie mit diesem Ziel die High Level Commission for the Indian Diaspora unter der Leitung des ehemaligen Hochkommissars in Großbritannien, L. M. Singhvi, ein. Der Bericht der Kommission, der am 19. Dezember 2001 verabschiedet wurde, etablierte neue politische Narrative und Maßnahmen der „Diasporaisierung“ ${ }^{89}$ Nicht zufällig nennt der Bericht Israel und China als Vorbilder für die vorgeschlagene Diasporapolitik. In beiden Fällen verbindet die Diasporapolitik wirtschaftlichen Aufbau mit nation building. Insbesondere China als direkter und wichtigster Konkurrent Indiens um die wirtschaftliche und politische Vorherrschaft in Asien hatte die Diasporapolitik ab den 1980er Jahren eingesetzt, um die Integration in den Weltkapitalismus kulturell und ökonomisch zu vollziehen (Ong 1999). Anhand des Diasporadiskurses wurden im Singhvi-Report die indische Nation und ihre sozialmoralischen Bindungen zur Diaspora reartikuliert. Der Bericht beginnt mit dem vielsagenden Satz: “The Indian Diaspora spans the globe and stretches across all the oceans and continents. It is so widespread that the sun never sets on the Indian Diaspora." (High Level Comittee 2001:v) Dieser Einstieg rahmt die Geschichte der indischen Diaspora als Akteurin in einem globalen Epos und invertiert auf kecke Weise den kolonialen Anspruch des British Empires, die Welt zu beherrschen. Indem der Bericht alle Personen indischer Herkunft überall auf der Welt explizit als Teil einer indischen Diaspora konstruiert, schreibt er ihnen eine gemeinsame Identität und Heimat zu. Gemäß diesem nationalen Mythos wohnt allen Menschen, die vom indischen Territorium abstammen, eine Essenz inne, die der Staat nun sieht und anerkennt. "They live in different countries, speak different languages and are engaged in different vocations. What gives them their common identity are their Indian origin, their consciousness of their cultural heritage und their deep attachment to India." (High Level Comittee 2001:v) Ich argumentiere, dass die explizite Verwendung des Begriffs der „Diaspora“ diesen globalen Nationalismus auf spezifische Weise narrativ zu etablieren vermag. ${ }^{90}$ Denn, wenn auch der Samen (gr. sperma) über Grenzen gestreut (gr. diasporein) wird, so wohnt ihm doch weiterhin das Potenzial inne,

mochte die transnationale hindutva-Allianz eine antimuslimische Agenda in den Beziehungen zwischen den USA und Indien zu stärken. Dadurch wurde auch innerhalb der südasiatischen Diaspora die Religion zunehmend politisiert und als Markierung in den Aufstiegs- und Positionskämpfen verwendet (Therwath 2007).

89 | Der Bericht wurde auf der folgenden Website des Indischen Aussenministeriums veröffentlicht: http://indiandiaspora.nic.in/contents.htm (abgerufen am 21.8.2017).

90 | Wie in der Einleitung dargelegt, wurde ab den späten 1980er Jahren der Diasporabegriff in der akademischen Debatte zunehmend reartikuliert, um Migrationserfahrungen zu beschreiben, die nicht zwangsläufig durch Vertreibung oder Rückkehrorientierung gekennzeichnet sein müssen. Durch die politische und populäre Diffusion wurde er im indischen Kontext zu einer Herrschaftsstrategie des Staates. 
seine biologische Lebenskraft zu entfalten - wenn auch in einer neuen Umwelt und dadurch allenfalls in einer neuen Form. Der im griechischen in einer botanischen Semantik angesiedelten Begriffs der Diasporabegriff verbindet die Metaphorik von Grenzen und Brüchen mit einer der Einheit. Dadurch ermöglicht er eine Offenheit und Flexibilität von Hybridisierungen, die auf vielfältige Art und Weise gestaltet und ausgehandelt werden können. Im Gegensatz zum bisherigen Nationenbegriff erfordert er keine eindeutige Identifikation mit einem Territorium (Ius soli) oder mit äußerlichen oder formalen kulturellen Traditionen, so die Suggestion, sondern verbindet eine innere, lebendige Essenz mit der Naturalisierung in einem anderen Land. "The Indian Diaspora has spread far and wide [...] and it has gained universal recoginition for the unique contributions that its members have been making to their host societies, while at the same time acting as bridge between them and the land of their ancestors." (High Level Comittee 2001:v) Mit der Metapher der „Brücke“ wird - wie mit dem Diasporabegriff - eine weitere Metaphorik der Mehrfachzugehörigkeit konstruiert und anerkannt, die im ambivalenten Bild des NRI in der Nehru-Ära nicht vorstellbar gewesen wäre, da letztere auf der Logik eines Entweder-Oder beruhte. Nehrus Politik des Nicht-Engagements gegenüber NRI erscheint in dieser nationalistischen Familienrhetorik implizit als moralische Fehlleistung, da sie bestehende essenzielle moralische Bindungen leugnete. Wie der Bericht zitiert, hatte Attal Bihari Vajpayee als damaliger indischer Außenminister in einem Seminar im Jahr 1977 versprochen, dass, „though our sons and daughters have gone abroad to work or to reside there, India will not disown them or fail to appreciate and respect their essential loyalty to the culture and heritage of the mother country“ (High Level Comittee 2001:v). Mit der Diasporapolitik, die Vajpayee nun als Premierminister einführte, könne die moralische Beziehung zwischen der „Mutter Indien“ und ihren „verlorenen Söhnen und Töchtern“ wiederhergestellt werden und das historische Unvermögen gesühnt werden. 


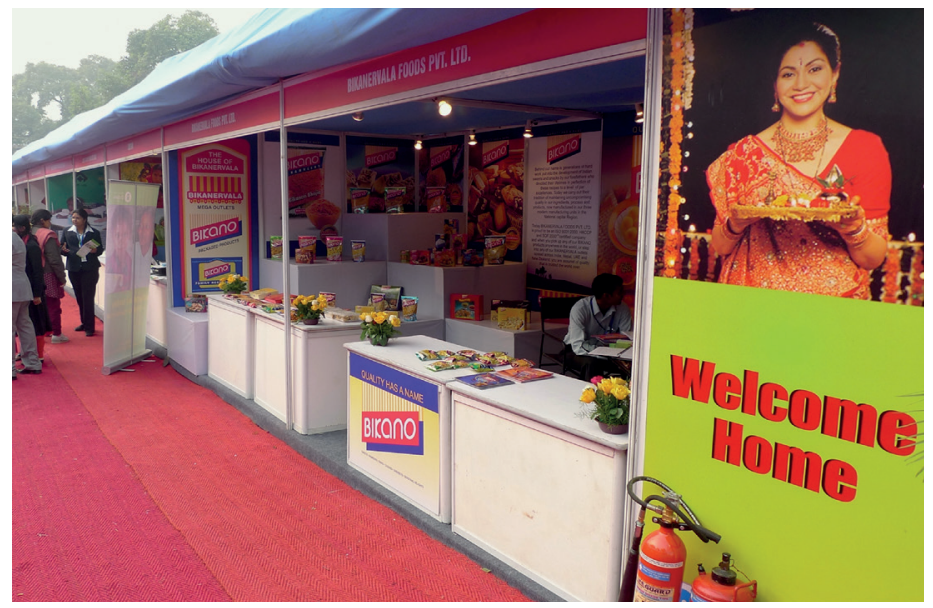

Abbildung 23: Der indische Staat heisst seine Diaspora feierlich willkommen zuhause, 8. Pravasi Bhartiya Divas, vom 7.-9. Januar 2009 (Quelle: Autor)

Diese Imagination einer "globalen indischen Familie“ war dabei auch verbunden mit neuen Bewertungen. Der Bericht erzählte dabei nicht etwa von moralisch korrumpierten Fahnenflüchtigen oder armen ehemaligen Plantagenarbeitern, sondern vielmehr von erfolgreichen, anerkannten und fleißigen Subjekten, die größtenteils der Mittel- und Oberschicht angehören.

The Indian Diaspora has transformed the economies and has come to occupy a pride of place in the life of those countries. Its members are found as entrepreneurs, workers, traders, teachers, researchers, inventors, doctors, lawyers, engineers, managers and administrators. [...] By playing a leading role in the global technological revolution, it has transformed India's image abroad. While it continues to flourish in different countries and in different walks of life, it continues to be rooted in its ancient cultural heritage. (High Level Comittee 2001:vi)

In diesem Zitat verknüpfte die diasporapolitische Sprache der Regierung explizit globale Aspiration, ökonomischen Erfolg und kulturelle Bindung. Indien könne also ökonomisch (nur) wachsen, wenn sich die "globale indische Familie“ auf ihre Wurzeln besänne. "The contemporary Indian state recruited its diasporic populations into an expansive national body that asserted Indian's prominence in the twenty-first century as a leading free-market destination within a capitalist economy." (Mani/Varadarajan 2005:49) Diese metaphorischen Verknüpfungen von Kapitalismus und Biologie, von Geld und Blut spannten den diskursiven Rahmen und das transnationale Netzwerk einer globalen indischen Wirtschaftsnation auf, 
in der wirtschaftliche Produktivität und Zugehörigkeit zur Nation zunehmend verknüpft wurde.

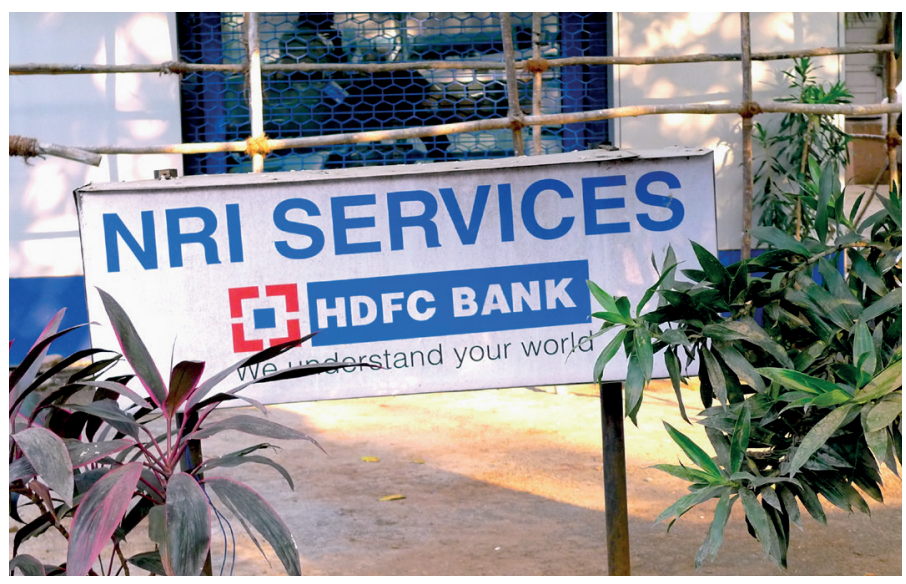

Abbildung 24: Liberalisierungsschritte und Diasporapolitik beförderten spezifische Investitionsmodelle für NRI (Quelle: Autor)

Diese Stoßrichtung wurde auf Empfehlung der Kommission im Jahr 2003 beim ersten Pravasi Bhartiya Divas in Delhi im Overseas Citizenship of India Scheme umgesetzt, der rechtlich auf dem Citizenship Amendment Act von 2003 basiert. Während davor die Kategorie Person of Indian Origin (PIO) Visaerleichterungen für Personen ermöglichte, deren Urgroßeltern in Indien niedergelassen waren, war die OCI eine spezielle Staatsbürgerschaftskategorie für diejenigen Personen, die entweder einmal die indische Staatsbürgerschaft nach Inkrafttreten der Verfassung innehatten oder vor der Unabhängigkeit auf indischem Territorium gelebt hatten sowie für Kinder und Kindeskinder solcher Personen. Während OCI als „dual citizenship“ lanciert und kommuniziert wurde, wurden jedoch politische Rechte ausgenommen. Neben dem lebenslangen Visum waren mit dem OCI-Status im Vergleich zum PIO-Status stattdessen zusätzliche wirtschaftliche Rechte wie etwa Investitionen, Kontoinhaberschaft, Rechte auf Immobilieneigentum und so weiter verbunden. Der rechtliche Fokus auf die wirtschaftliche Mobilisierung der Diaspora war umso deutlicher, als der OCI-Status im Gesetz von 2003 nur für die „highly industrialized countries“ Australien, Kanada, Finnland, Frankreich, Griechenland, Irland, Israel, Italien, Holland, Neuseeland, Portugal, Zypern, Schweden, die Schweiz, Großbritannien und die USA galt. Alle diese Länder waren Ziel von Angehörigen einer größtenteils hochqualifizierten indischen Mittelschicht, die nach der Unabhängigkeit ausgewandert war. Das „OCI Scheme“ sollte hingegen nicht für diejenigen Millionen von Personen indischer Herkunft gelten, deren Vorfahren schon im 19. Jahrhundert oder frühen 20. Jahrhundert als 
Schuldknechte (indentured labour) auf britischen Plantagen in der Karibik oder Afrika oder als Beamte, Händler oder technisches Personal im Empire gearbeitet hatten. Die wirtschaftsliberale und gleichzeitig hindunationalistische Handschrift der Diasporapolitik wurde zudem darin ersichtlich, dass pakistanische Staatsangehörige und Bangladeshi weder PIO noch OCI werden konnten und können, auch wenn sie bei der Teilung aus Indien flüchten mussten. ${ }^{91}$ Die im Bericht erörterte narrative Verbindung von ökonomischem Wachstum und kultureller Essenz fand also ihre Entsprechung in einer "graduellen Staatbürgerschaftslogik“ (Ong 1999). Die ethnische und ökonomische Logik der Diasporapolitik der Regierung zielte darauf $\mathrm{ab}$, der indischen Diaspora im Westen einen privilegierten Zugang zum „neuen Indien“ zu gewähren, sie zu binden und zu mobilisieren. Während auf der narrativen Ebene der Diasporabegriff die Einheit der „globalen indischen Familie“ mit einem territorialen und kulturellen Zentrum betonte, wurden die dadurch geschaffenen Subjekte in den rechtlichen Kategorien gleichzeitig moralisch, kulturell und ökonomisch bewertet. Der Diasporadiskurs erlaubte demnach legitime und weniger legitime, produktive und unproduktive Zugehörigkeiten zu unterscheiden und im Sinne „flexibler Staatsbürgerschaften“ für das nationale Wachstumsprojekt einzusetzen. $^{92}$

91 Wie Roy plausibel darlegt, ist die staatsbürgerrechtliche Konstruktion der indischen Nation von einem zunehmenden Illiberalismus charakterisiert (Roy 2008). Denn gleichzeitig mit der Gewährung der $\mathrm{OCl}$, der Staatzugehörigkeit nach Herkunft (ius sanguinis), wurde die Kategorie illegaler Migrant_innen eingeführt, die vor allem auf muslimische Migrant_innen aus Bangladesh abzielte. Weiter wurde die Einbürgerung für Kinder von Immigrant_innen weiter erschwert. Damit hat seit dem ersten Staatsbürgerschaftsgesetz von 1955 sowohl eine Verschiebung von einem weitgehenden ius soli zu einer ethnisch definierten Staatsbürgerschaft als auch zu einer klassenverzerrten Staatbürgerschaftslogik stattgefunden.

92 | In der expliziten Kritik an dieser "economic citizenship" mag auch mit ein Grund liegen, warum 2005 eine neue Erweiterung des Staatsbürgerschaftsgesetzes erfolgte, in dem die $\mathrm{OCl}$ unabhängig von der spezifischen Region zugesprochen wurde (Mani/ Varadarjan 2005). Jedoch ermöglichte die Unterscheidung von PIO und OCI weiterhin - über die Korrespondenz von Generationenabfolge und historischen Migrationswellen -, dass eine rechtlich graduelle Staatsbürgerschaft und eine indirekte Diskriminierung aufrechterhalten wurde, die die ökonomische Macht der verschiedenen historischen Diasporagemeinschaften grosso modo sanktionierte. Wie Roy argumentiert, könnte der Ausschluss der Länder der ersten kolonialen Auswanderungswelle aus dem $\mathrm{OCl}$-Scheme auch so interpretiert werden, dass damit die koloniale Vergangenheit geleugnet werden soll, wie dies ja zu Beginn des Berichts auch durch die Inversion "the sun never sets on the Indian Diaspora" geschieht (Roy 2008). Diese graduelle Sanktionierung zwischen verschiedenen Diasporas wurde angesichts zunehmender Proteste 
Gemäß dieser generationellen Wachstumslogik einer "globalen indischen Familie“ existierte auch ein spezifisches Interesse an der Bindung der „Zweiten“ und „dritten Generation“ an die Nation, weshalb die Singhvi-Kommission erfolgreich auf die Gewährung des OCI-Status für die „zweite Generation“ pochte. ${ }^{93}$

The emphasis on continuity paves the ground for bringing the second generation of overseas Indians, those who were not born in India, also into the purview of overseas citizenship, for perpetuating and cementing the links of the younger generation of the diaspora with India as they will be keen to keep in touch with their elders in India as well as relate to their roots [...] The members of the Indian diaspora are naturally keen to pass on their value systems, which have been a reason of their success to coming generations, and they would welcome our country's support in this endeavour. India should also initiate measures to ensure that the diaspora's pride and faith in it are strengthened, which would inter-alia revitalise its internal development. (High Level Comittee 2001:511)

Ich habe in diesem Unterkapitel argumentiert, dass das Bollywood-Kino und die indische Diasporapolitik wichtige Plattformen sind, um Auslandsinder_innen als Teil eines hegemonialen Projektes eines „neuen Indiens“ zu konstruieren. Sowohl in der öffentlichen Kultur als auch in der diasporapolitischen Imagination des Staates und in den staatsrechtlichen Bestimmungen seit 2003 wird nationale Zugehörigkeit deterritorialisiert und von äußerlichen und formalen Traditionen entkoppelt. Stattdessen wird eine Essenz konstruiert, die eine moralische und emotionale Bindung herstellt und die intergenerationell reproduziert werden kann und soll. Die Entkoppelung von Essenz und äußerlicher Lebensweise ermöglicht eine Pluralisierung und Hybridisierung der Nation im Kontext des globalen Kapitalismus. Dadurch sind neue legitime Subjektivitäten, Praktiken und Räume einer "global Indianness“ entstanden, in der westliche Lebensstile mit indischen Werten verbunden werden können. Der kulturelle, politische und ökonomische Fokus auf die mittelständische Diaspora im Westen offenbart dabei eine Aufsplitterung dieser „globalen indischen Familie“ sowie einen selektiven Zugang zum „neuen

aufgehoben. 2015 wurde Menschen mit PIO-Karte abgeschafft und der Zugang zu OCI erleichtert.

93 | Diesbezüglich ist auch die Lancierung des Know India Programme interessant, das Nachkommen indischer Migration in einer zweiwöchigen Tour einen privilegierten VIP-Blick in die Kultur, Politik und Wirtschaft Indiens bieten soll. 2017 fand der Pravasi Bhartiya Divas (PBD, Tag der Indischen Diaspora) mit einem Fokus auf die Jugend statt, mit einer eigenen eintägigen internationalen Konferenz. 
Indien“ gemäß Klasse, Geschlecht und historisch-geografischer Verortung der Migrationsgeschichte. ${ }^{94}$

Diese hegemoniale und selektive Konstruktion legitimer Zugehörigkeit zum „neuen Indien“ ist in die Konstruktion einer exklusiven urbanen und medialen Konsumkultur eingeschrieben, zu der „Inder_innen der zweiten Generation“ aus der Schweiz qua ökonomischem und kulturellem Kapital einen privilegierten $\mathrm{Zu}$ gang haben. Im Gegensatz zu Angehörigen der unteren indischen Mittelschichten, zu Nachfahren von indischen Schuldknechten oder auch zu Schweizer Touristen können sie in diesen Räumen legitime, wenn auch nicht unbedingt gleichwertige Zugehörigkeiten aushandeln. Haben allenfalls „Inder_innen der zweiten Generation“ aus der Schweiz diese neuen Subjektivierungsmöglichkeiten und Anerkennungsräume in den 1990er Jahren schon individuell erfahren, schuf und legitimierte der Indienhype in der Schweiz Bedingungen für neue transnationale Praktiken und Projekte. In den folgenden ethnografisch-biografischen Fallanalysen möchte ich darlegen, wie schweizerisch-indische Second@s transnationale Subjektivierungsprozesse im „neuen Indien“ aushandeln. Dabei interessiert mich insbesondere, wie sie das „neue Indien“ und ihre Zugehörigkeit dazu konstruieren. Es stellt sich die Frage, wie sie soziale Ungleichheit und Modernisierung vor dem Hintergrund früherer Indienerfahrungen sowie exotisierender und humanitaristischer Indiendiskurse in der Schweiz in ihre Lebenswelten und Subjektivierungsprozesse integrieren.

\subsection{Akash: Karriere, Nostalgie und Freiheit ALS „SWISS INDIAN DREAM"}

Während meiner Feldforschung in Indien war ich in regelmäßigem Kontakt mit dem 39-jährigen Manager Akash. Er war in der Schweiz aufgewachsen und lebte zwischen 2006 und 2013 als Expat einer multinationalen Schweizer Industriefirma in Indien. An einem Oktoberabend nahm mich Akash nach einem Abendessen bei einer Schweizer Journalistin in Delhi mit zu einer Party. Auf dem Weg trafen wir den 42-jährigen schweizerisch-indischen Betriebswirt und Event-Manager Robin,

94 | Wie etwa die Analyse des Films DDLJ zeigte und weiter unten in der letzten Fallanalyse thematisiert wird, ist die kulturelle Regulierung legitimer und illegitimer $\mathrm{Zu}$ gehörigkeit und Mobilität in der "globalen indischen Familie" stark geschlechtsspezifisch. Jedoch habe ich diese Machtdimension in Bezug auf die staatliche Diaspora- und Staatsbürgerschaftspolitik nicht systematisch untersucht und in den $\mathrm{OCl}$-Bestimungen keine explizit geschlechtsspezifischen Unterschiede festzustellen sind. Die Frage wäre in Bezug auf erleichterte Einbürgerung, Heiratspraktiken, transnationale Scheidungen, Mitgiftrückerstattungen, Kindersorgerechtsfälle, Adoptionen und Leihmutterschaft aber zweifellos höchst relevant. 
der auch gerade in Indien weilte. Der Klub, in dem die Party stattfand, befand sich in einer Mall in Süd-Delhi, einer dieser Konsumpaläste des „neuen Indiens“, die in den letzten Jahren aus dem Boden geschossen waren. Nach der Sicherheitskontrolle fuhren wir auf den Rolltreppen durch die leere Mall bis ins Dachgeschoss. Auf der Dachterrasse tanzten Partybesucher_innen zwischen Sonnenschirmen und Palmen $z u$ dröhnender elektronischer Musik und dem Rap eines $M C$, während andere sich auf Rattanmöbeln räkelten. Wir bestellten Drinks und genossen das Gefühl der Freiheit, das in der lauen Herbstluft unter dem Sternenhimmel aufkam. Nach der ausgelassenen Party fuhr uns Akashs Chauffeur zu Akash nach Hause in ein nobles Viertel. Im Salon des Hauses unterhielten wir uns noch ein wenig über das Leben in Indien und die wirtschaftlichen Möglichkeiten. Während Akash als Manager einer multinationalen Firma beruflich in Indien etabliert war, versuchte Robin gerade mit unterschiedlichen Geschäftsideen im indischen Markt Fuß zu fassen. Mit ehrlicher Bewunderung für Akash meinte Robin: „Er lebt den Swiss Indian Dream - er lebt in Indien mit einem Schweizer Lohn. Wir sind die neue Generation, nicht der alte Filz. Komm doch auch zurück", schlug er mir vor.

Akash studierte ab Mitte der 1990er Jahre Betriebswirtschaft und später Recht an einer renommierten Schweizer Universität. Schon damals hatte sich Akash von den Chancen im aufstrebenden „neuen Indien“ angezogen gefühlt. Auf der Grundlage seines privilegierten familiären und professionellen Blicks hatte er mit einer Gruppe von Studierenden begonnen, sich mit Indien als Wachstumsmarkt auseinanderzusetzen. 1998 machte er ein kurzes Praktikum in einer multinationalen Firma in Indien, noch bevor die Öffentlichkeit oder kleine und mittelständische Unternehmen in der Schweiz das liberalisierte Indien als Absatzmarkt oder Produktionsstätte wahrgenommen hatten. Die ökonomische Dynamik Indiens versprach eine spannende Karriereoption im Herkunftsland seiner Eltern. Nach Ende des Studiums im Jahr 2004 bewarb er sich auf der Suche nach einer beruflichen Perspektive unter anderem auch in Indien. Er hätte jedoch lediglich einen lokalen indischen Lohn erhalten, was eine Senkung seines Lebensstandards bedeutet hätte. Da er nach dem Studentenleben nach finanzieller Selbstständigkeit und nach Statusgewinn strebte, entschied er sich stattdessen für einen Job als strategischer Unternehmensberater bei einer Consulting-Firma in der Schweiz und verschob die Indienpläne auf später. Tatsächlich bot sich ihm dann im Jahr 2006 eine Gelegenheit, als er von einem Kollegen gefragt wurde, ob er sich für eine Stelle bei einem Schweizer Unternehmen in der Maschinenindustrie in Indien interessiere. Nachdem Akash nach Beratung mit seinem Vater einen Vertrag unter Schweizer Arbeitsbedingungen ausgehandelt hatte, nahm er das Indienprojekt kurz entschlossen in Angriff.

In der Rekrutierung Akashs spiegelt sich das Bestreben vieler Akteure der Schweizer Wirtschaft, möglichst organisch - das heißt effizient - in die wachsenden Märkte Indiens zu expandieren. Akashs Firma hatte schon vor der Unabhän- 
gigkeit Indiens Produkte in Indien abgesetzt und konnte diese Stellung nach der Unabhängigkeit durch ein Joint Venture erhalten. In den 1990er Jahren stieg der Absatz enorm an, sodass das Management jemanden suchte, der oder die den Indienmarkt entwickeln konnte. Zweifelten die Entscheidungsträger in den 1990er Jahren noch an der Stabilität des Wachstums und am Reformwillen der Regierung, schien ab 2003 bei Wachstumsraten von über sieben Prozent die Zeit reif für eine strategische Neubearbeitung des Marktes. Wie Akashs Vorgesetzter mir erläuterte, war Akash sehr gut qualifiziert, jedoch vervollständigten seine indische Herkunft sowie seine Kenntnisse sowohl der indischen Bedingungen als auch auch der Schweizer Unternehmenskultur sein Profil. Wie der interkulturelle Unternehmensberater Aftab stellte auch Akash als „Inder der zweiten Generation“ in der Imagination des expandierenden Schweizer Kapitalismus im „Wilden Osten“ den perfekten Brückenbauer dar. ${ }^{95}$ Neben der Aussicht, dass Akash sich in Indien kulturell besser werde durchschlagen können, vereinfachte sein Status als Overseas Citizen of India (OCI) seine Anstellung als Expat. Neben den rationalen Kostenargumenten erlaubte Akashs Position als Grenzgänger sowohl aus kulturellen als auch administrativen Gründen eine stimmige und günstige Bewirtschaftung der wachsenden Märkte Indiens.

Diese unternehmerische Einschätzung spiegelte sich in den Worten des Betriebswirten Akash:

Indien ist total am Boomen. Das finde ich schon sehr spannend, alles wächst, es ist alles im Aufbau, und das ist spannender, als wenn alles stagniert. Wenn $\mathrm{du}$ wachsen willst, musst du, ökonomisch gesehen, einem Konkurrenten den Marktanteil nehmen. In Indien wächst der Markt natürlich. Das ist ein wahnsinnig spannendes Zeitfenster, in dem sich Indien gerade befindet, und an dem ich in diesem Alter durch spezifische Fähigkeiten teilhaben kann.

In seinem ökonomischen Narrativ verbindet Akash das Wachstum der Märkte mit der Möglichkeit, sich selbst persönlich und beruflich zu entwickeln. In diesem Umfeld und Zeitfenster verfügte Akash über einen „natürlichen Vorteil“, wie er es nannte, weil er sowohl die lokalen rechtlichen Bewilligungen als OCI nicht benötigte als auch als Mitarbeiter einer Schweizer Firma einen für indische Verhältnisse enorm hohen Lohn erhielt sowie sozialversicherungsrechtlich besser abgesichert war. Die Stelle in Indien erlaubte ihm, sowohl berufliche Auslandserfahrung zu sammeln als auch das bekannte Leben in den Schweizer Finanz- und Unternehmerkreisen gegen ein Abenteuer in der dynamischen und aufregenden Heimat seiner Eltern einzutauschen. Schon seit seinem ersten Praktikum in Indien deutete er eine Arbeit in Indien als Chance, „Indien besser kennenzulernen“, wie

95 | Ong beschreibt eine gleiche Logik der Repräsentation diasporischer chinesischer Unternehmer als „Brückenbauer" (Ong 1999:187f.). 
er es nannte. In seinem nostalgischen Bildungsstreben hatte er zwar viel gelesen über Indien und das Land mit seinen Eltern bereist. Doch erst durch die Arbeit in Indien konnte er Land und Kultur im Alltag und aus einer eigenen Perspektive erfahren.

Als Grenzgänger in der transnationalen kapitalistischen Verflechtung zwischen Indien und der Schweiz konnte sich Akash nicht nur als „Brückenbauer" eines schweizerischen Kapitalismus positionieren, sondern auch innerhalb der Narrative einer globalen indischen Moderne. Im Lichte des indischen Diasporadiskurses hatte Akash durch seinen Job als Expat, durch den damit verbundenen Lohn sowie durch seine westlichen Konsumgewohnheiten direkten Zugang zum „neuen Indien“, das westliche und indische Lebensstile, Ästhetiken und Werte verband. Sein Status als OCI und als Expat erlaubten ihm auf geradezu paradigmatische Weise eine diasporische Subjektivierung als global Indian, der materiellen Wohlstand und „Indianness“, Fortschritt und Nostalgie verband. Im Folgenden möchte ich Akashs vielfältige Aushandlungen als diasporisches Subjekt an der Schnittstelle seiner transnationalen Familie, seines Lebensstils in der kosmopolitischen Oberschicht und seiner Position als Manager einer multinationalen Firma analysieren.

\section{Das letzte gemeinsame Diwali? - Feier der transnationalen indischen Familie}

Akash stammt aus einer Familie aus der Elite eines nordindischen Bundesstaates. Sein Großvater war leitender Beamter in einer regionalen Infrastrukturbehörde und war darauf bedacht, den sozialen Status durch strenge Erziehung und gezielte Ausbildung seiner vier Söhne zu erhalten. Akashs Vater wurde mit 18 Jahren in die Schweiz geschickt, um an der Eidgenössischen Technischen Hochschule in Zürich (ETH) eine Ausbildung zum Maschinenbauingenieur zu machen. Als er sich als Ingenieur bei einem Schweizer Unternehmen etabliert hatte, heiratete er Akashs Mutter, die auch aus einer angesehenen Ingenieursfamilie aus der gleichen Region stammte und später in der Schweiz als Englischlehrerin arbeitete. Die intergenerationelle, transnationale Strategie der Statuserhaltung hatte sich markant in die Familienkultur eingeschrieben. Akashs Eltern versuchten dabei ihren drei Kindern - Akash und seinen beiden Schwestern - weniger kulturelle oder religiöse Symbole zu vermitteln als vielmehr Familienzusammenhalt, professionelle Ambitionen sowie Statusbewusstsein. Durch die Remigration Akashs verschoben sich auch die sozialen innerfamiliären Bindungen und Beziehungen. Als ich in Indien weilte, war Akash gerade in eine Wohnung im Haus seiner Großeltern mütterlicherseits eingezogen. Durch seinen Aufenthalt in Indien hatten sich Akashs Beziehungen zu den Eltern vertieft, die nun vermehrt nach Indien reisten. Der schweizerische-indische Secondo hatte die Funktion eines Brückenkopfes in ihrer transnationalen Lebenswelt inne und er kümmerte sich um die Großeltern sowie um die baulichen 
und finanziellen Angelegenheiten im familieneigenen Haus. Durch seine unmittelbaren Erfahrungen mit den lokalen Lebensbedingungen und sein professionelles und persönliches Wissen über den Wandel in Indien konnte er gegenüber den Eltern eine eigene, neue Perspektive einnehmen und mit Indienexpertise auftreten, was insbesondere die Autorität des Vaters regelmäßig infrage stellte. Gleichzeitig überließ er den Eltern den ihnen gebührenden Raum, wenn sie sich in Indien aufhielten. Er spielte Golf mit seinem Vater und nahm Ratschläge für seine Karriereentscheidungen an. Akashs Remigration war dabei auch eingebettet in das Spannungsfeld der transnationalen Familie zwischen Nostalgie und Statusprojekt:

An einem lauen Herbstabend begab ich mich zu Akash, um an einer Diwalifeier im engeren Kreis teilzunehmen. Als ich eintraf, stellte sich heraus, dass sich das Puja, also das hinduistische Ritual, das Akashs Großmutter durchführen wollte, verzögern würde. Akashs Mutter und deren Schwester beschlossen darauf, dass sie noch einen Sari anziehen wollten, worauf Akash, sein Vater und ich uns in den Salon begaben. Die Möbel waren alt und edel, die Einrichtung bestand aus alten, ausgewählten Nippes und Familienfotografien. In Bezug auf die Verzögerung meinte Akashs Vater theatralisch, er sei bei diesem Anlass nicht der decision maker, worauf Akash schmunzelnd antwortete, dass das manchmal zweifellos besser sei. Demonstrativ bestellte Akashs Vater einen Drink. Als Akash ihn ironisch daraufaufmerksam machte, dass dies vor dem Puja kaum angemessen sei, meinte der Vater, Tee sei auch immer gut. Darauf meinte Akash, dass er auch eine Nespresso-Maschine habe, falls ich Kaffee bevorzugte. Nebenbei erwähnte er, dass Nespresso-Kaffee in Indien eine Marktlücke sei. Wenn man Kapital habe, lasse sich hier zur Zeit viel machen. Nachdem wir Tee getrunken hatten, wurden wir zum Puja gerufen. Wir setzten uns zum Schrein, den die Großmutter vorbereitet und mit Girlanden geschmückt hatte. Akashs Vater gab seinen demonstrativen Widerstand gegen das Ritual auf und begann, die Ölkerzen anzuzünden. Die Großmutter begann mit dem Puja. Akashs Mutter signalisierte Akash, dass er mitsingen solle, was dieser auch tat. Nach dem Puja klingelte das Telefon. Zuerst rief Akashs Schwester aus den USA an, die dort gerade ein Marketing-Praktikum machte. Danach rief Akashs Mutter ihre älteste Tochter in der Schweiz an, die selbst wiederum drei Töchter hat. Das Mobiltelefon wurde herumgereicht und alle plauderten in ausgelassener Stimmung. Nach dem Essen bat uns die Mutter, nach draußen zu gehen, um das Grande Finale der Diwali-Feier zu genießen: Akashs Cousin hatte mithilfe der Angestellten einen massiven Vorhang aus Lichtgirlanden an der ganzen Fassade montiert und eine Stereoanlage mit Boxen arrangiert, aus denen laute Bollywood-Musik tönte. Auf Aufforderung von Akashs Mutter begann der Cousin Feuerwerksraketen zu zünden, die in den Lärm- und Lichtreigen einstimmten, der den Himmel über dem Quartier schon erfüllte. Akash spottete, wann denn die 500 anderen Gäste kämen. Trotzdem begannen er und ich damit, die Unmengen von Feuerwerkskörpern in die Luft zu jagen. Zwischen dem Lichterteppich an der Fassade, dem Feuerwerk und dem Bollywood-Sound strahlte 
Akashs Mutter ob des machtvollen spektakulären Ausdrucks von Freude, Familie und Status.

Aus der Sicht von Akashs Mutter bot dieses Jahr, angesichts des schlechten Gesundheitszustandes ihres Vaters und der zerstreuten transnationalen Biografien ihrer Kinder, allenfalls die letzte Möglichkeit zu einer annähernd gemeinsamen Diwali-Feier in Indien. Während sie den Anlass managte, ihre Schwester mit ihrem Sohn die technische Infrastruktur organisierte und die Großmutter als religiöse Autorität fungierte, waren Akash, sein Vater, sein Großvater und ich einfach Teilnehmende. Der Anlass verdichtet sich unter der Regie der Mutter zu einer von Nostalgie geprägten Inszenierung der transnationalen indischen Familie: Die Disziplinierung der Männer am Puja, die Telefonate mit den Töchtern im privaten Raum sowie der Teppich der Leuchtgirlanden und der opulente Feuerwerksreigen drückten gleichzeitig Freude und Status aus. Wenn auch die Männer über die chaotische Organisation und die aus ihrer Sicht zu traditionelle Inszenierung spotteten, trugen sie die familiären Feier im Kern mit. In den ironischen Distanzierungen von der mütterlichen Performanz des „letzten Diwali“ und der gleichzeitigen Unterstützung zeigte sich bei ihnen zwar eine ambivalente Haltung gegenüber der Bedeutung religiöser und kultureller Symbolik. Das in die Feier der Familie eingeschriebene transnationale Statusprojekt trugen sie aber zweifellos und tatkräftig mit.

\section{Konsum, Bildung und Distinktion - das Ethos des kapitalistischen Kosmopoliten}

Als ich in Indien war, hatte Akash gerade die Leitung einer Fabrik des gleichen Schweizer Konzerns übernommen, bei dem er schon in der Strategieentwicklung gearbeitet hatte. Die Arbeit als Fabrikmanager bedeutete einen noch intensiveren Arbeitsalltag und eine noch stärkere Transnationalisierung seiner Lebenswelt. Neben den mehrstündigen Autofahrten zur Fabrik musste er regelmäßig in die Schweiz, nach China oder Südostasien fliegen, um Fabriken zu besichtigen oder um an Strategiesitzungen teilzunehmen. Daneben konnte er jedoch seinen statusorientierten Lebensstil und seine Bildungsinteressen weiterverfolgen. Akash verfügt in seinem Leben zwischen transnationaler kapitalistischer Klasse und "globaler indischer Familie“ über einen privilegierten Zugang zum „neuen Indien“. Durch seine sozioökonomische Lage bewegte er sich in einem illustren Zirkel von Expats und Angehörigen der indischen Oberschicht und führte ein exklusives Leben in den urbanen Enklaven. Mit seinen Freunden und Bekannten besuchte er Discos und teure Restaurants, die in Malls, in Fünfsternehotels oder in neuen urbanen Szenequartieren entstanden waren. Daneben hatte er begonnen, Golf zu spielen und sein Interesse an Kunst und Kultur zu vertiefen. Akash hatte damals gerade aufgrund von Tipps von Schweizer Bekannten begonnen, indische Antik- 
möbel und Kunst an internationalen Messen zu kaufen, um die Wohnung im Haus seiner Großeltern einzurichten. Neben der Arbeit oder in Kombination mit seinen Geschäftsreisen besuchte er Indien und die Nachbarländer, um das kulturelle Erbe kennenzulernen und die besten Etablissements des internationalen Tourismus zu genießen. In diesem Lebensstil verschwand für Akash aus seiner Sicht die Relevanz seines NRI-Status in Indien. Akash inszenierte sich weder als Expat noch als Inder, sondern als „global Indian“, der sowohl aus der oberen Mittelschicht oder der Diaspora stammen als auch ein westlicher Expat hätte sein können.

Vor diesem Hintergrund lässt sich Akashs Haltung gegenüber Indien weniger als nostalgische Identifikation denn zunehmend als diejenige eines „kosmopolitischen aficionados“im Sinne des Anthropologen Ulf Hannerz beschreiben.

Cosmopolitanism [...] includes a stance towards diversity itself, towards the coexistence of cultures in the individual experience. [...] It is an intellectual and aesthetic stance of openness toward divergent cultural experiences, a search for contrasts rather than uniformity. To become acquainted with more cultures is to turn into an aficionado, to view them as art work [...] There is a cultural competency, a built-up skill in manoeuvering more or less expertly with a particular system of meanings and meaningful forms. (Hannerz 1990:239).

Durch Konsum, seine regelmäßigen Reisen und sein Streben nach Bildung eignete sich Akash faszinierendes kulturelles Wissen an und macht die Vielfalt der Welt dadurch zu einem Teil seines transnationalen Selbst. In der ökonomischen Rationalität des Managers Akash erschienen Konsum und Bildung als situative und verbundene Praktiken, um sich kulturelle Partikularitäten und deren Faszination in einem kosmopolitischen Lebensstil anzueignen, um Status und Distinktion zu beweisen sowie um sich intellektuell weiterzubilden. Darin verbanden sich die wahrhaftige Kennerschaft und die Faszination des aficionado mit der Autorität einer transnationalen Klasse, die sich lokale kulturelle Phänomene durch ökonomisches und kulturelles Kapital aneignen und für ihre Projekte nutzen konnte. Die Remigration nach Indien hatte die Wirkung, dass Akash innerhalb des familiären Statusprojekts Nostalgie als nationale oder kulturelle Identifikation zunehmend zugunsten eines kosmopolitischen Klassenethos überwand.

Nichtsdestotrotz wurde in lokalen Kontexten eine kulturelle Differenz auf ihn projiziert, die sowohl Karriere und Anerkennung als auch Status zu versprechen schien - wie etwa als Vermittler im globalen Kapitalismus für seine Firma oder als "global Indian“ in den urbanen Enklaven des „neuen Indien“. Diese Zuschreibungen nutzte und genoss er, ohne sie explizit selbst zu bedienen. Stattdessen positionierte er sich oft mit Ironie, Zynismus oder Theatralität gegenüber diesen ethnischen, nationalen oder kulturellen Zuschreibungen - wie etwa im „letzten Diwali“. Dieses Bündel von kosmopolitischen Strategien lässt Akash geradezu als 
schillernde Mimesis des transnationalen Kapitals erscheinen, das überall die lokale Form annehmen kann, ohne sich zu identifizieren, weil es global ist.

\section{Armut und Macht im NRI-Zirkel}

Akashs Leben in den exklusiven urbanen Enklaven waren eng verknüpft mit sozialer Ungleichheit und mit Armut, die zwar das „neue Indien“ strukturieren und ermöglichen, aber darin gleichzeitig ausgeblendet werden.

Im Januar 2010 veranstaltete Akash einen Geburtstags- und Neujahrs-Apéro bei sich zu Hause. Außer dem Möbelhändler Shiva waren vor allem Freunde und Bekannte aus Akashs Schweizer Zirkel eingeladen. Akash und seine Schweizer Freundin hatten sich Mühe gegeben, einen bürgerlichen Anlass zu organisieren, der sowohl einen schweizerischen als auch einen indischen Touch hatte. Das Buffet bot Käse, Salami, Pakora und Samosa, Weißwein und Whisky. Akash war sichtlich unzufrieden mit seinem Diener Hero. Als alle am Glastisch saßen und Wein tranken, befahl Akash Hero streng, Untersetzer für Gläser zu bringen. Der Junge suchte hektisch, Akash herrschte ihn auf Hindi an und erklärte ihm entnervt, was er wolle und wo es zu finden sei. Eingeschüchtert von den kryptischen Anweisungen in holprigem Hindi und den regelmäßigen Zurechtweisungen erstarrte Hero zusehends. Schließlich meinte Akash beiläufig: „Es ist sowieso sein letzter Tag." Als wir nach dem Apéro in einer kleineren Gruppe in ein Restaurant fuhren, verwickelte Akash den Chauffeur in ein lockeres Gespräch. Der Fahrer stieg auf den lockeren Ton von Akash ein und lachte immer wieder. Akash schien sich jedoch an der vorlauten Art des Fahrers zu stören. Immer wieder beklagte er sich, dass der Fahrer anscheinend bessere Wege kenne, aber am Schluss doch falsch fahre. In theatralisch-autoritärem Ton fragte er „Aap music kyo nahi laga rahe hain?" [Wieso stellen Sie die Musik nicht an?] Als die Musik lief, kommandierte Akash: „Volume up, no, down, ok.“ Dabei droht er auf Deutsch: „Ich entlasse ihn sowieso gleich."

Die Beschäftigung von Diener und Chauffeur markiert den idealen Lebensstandard im „neuen Indien“. Wie etwa Shiva, ein indischer Bekannter von Akash, der durch Möbelimport aus China reich geworden ist, meinte, kann er im „neuen Indien“ alles haben, was der Westen bietet, und gleichzeitig einen Diener, der ihm die Kohle für die Wasserpfeife holt. Akashs Beziehungen zu seinem Diener und Chauffeur waren daher wichtige Prozesse der Grenzziehung und der Zugehörigkeitskonstruktion im „neuen Indien“. Einerseits erhielten Diener und Chauffeur den Lebensstil und den hektischen Berufsalltag im „neuen Indien“ aufrecht. Andererseits zwang die Herstellung dieses Lebens zur ständigen Inszenierung von kultureller Überlegenheit und Autorität gegenüber den Angestellten (Ray/Qayum 2009). Angesichts seiner rationalen ökonomischen Sicht der Dinge sowie seines kosmopolitischen Ethos versuchte der Manager Akash die hierarchischen Bezie- 
hungen mit Angestellten privat und in der Firma durch eine vertragliche Logik zu organisieren, die zwar seine Überlegenheit, aber auch eine faire Chance der $\mathrm{Zu}$ sammenarbeit oder der Verhandlung ermöglichte (Bhatt et al. 2010:143 f.). Seine theatralische Aggression erschien dabei als Ausdruck davon, dass diese rationale Verständigung nicht funktionierte und seine Ansprüche trotz fairer Chancen nicht erfüllt wurden. Aus einer machtkritischen Perspektive macht jedoch die ständige Konfrontation mit dem Diener am Geburtstag die affektive, körperliche und soziale Arbeit sichtbar, mit der Akash seine exklusiven Räume des „neuen Indiens" ständig herstellen musste.

Die Aggression offenbarte also die strukturelle Gewalt in der Konstruktion des "neuen Indiens", die Akashs ökonomische Rationalisierung von Ungleichheit infrage stellte und geradezu körperliche Herrschaft erforderte. Akashs Ärger zeigte jedoch auch, dass er die in Indien als naturgegeben angesehene Rolle als Patron, wie sie etwa Shiva verkörperte, nicht einzunehmen vermochte, da er sich auf andere Legitimationsstrategien von Hierarchie bezog. Dies wurde auch in der Beziehung zum Fahrer deutlich, mit dem er täglich mehrere Stunden verbrachte. Während er auch ihm gegenüber eine autoritäre Position einnahm, herrschte zwischen ihnen nolens volens eine Art joking relationship vor. Akashs ambivalente herrisch-kollegiale Art konnte stets auch als theatralisch und ironisch verstanden werden. Wenn er etwa fragte, warum der Fahrer keine Musik spielte, tat er dies nicht als Befehl, der keine Antwort duldete, sondern als strenge Frage. Akashs holpriger Hindi-Akzent und die Tatsache, dass der Fahrer ihn in unterschiedlichen Situationen erlebt hatte, wie etwa nach Klubbesuchen, unterliefen dabei seine Inszenierung von glaubwürdiger Autorität. Für den Fahrer scheint Akash ein anderes Herrschaftsverhalten an den Tag zu legen als andere Angehörige der Oberschicht, die oft keine Beziehung jenseits des Kommandos und der Ignoranz eingehen wollen. Daraus ergab sich ein routiniertes Machtspiel, in dem der Fahrer stets auch sprach, antwortete und handelte, was Akashs Autorität wieder infrage stellte. Die Drohung, es sei dessen letzter Arbeitstag, war in dieser Beziehung ein Ritual, in dem Akash seine Wut und seine Frustration ob des ständigen Scheiterns seiner Autorität und ob seiner Abhängigkeit von subalternen Anderen zum Ausdruck brachte. Das exklusive Leben im „neuen Indien“ machte stärker als etwa in der Schweiz die strukturelle Gewalt und die soziale Ungleichheit sichtbar und erforderte eine ständige Legitimation und Reproduktion. Gerade für Schweizer Expats, die in der egalitären Ideologie der Schweiz heimisch sind, ist diese Erfahrung, die postkolonialen Privilegien sichtbar machte, moralisch und affektiv eine große Herausforderung.

Akash und ich besuchten eine Schweizer Journalistin in ihrer neuen Wohnung in einem noblen, metropolitanen Quartier. Sie war gerade erst nach Indien gekommen, hatte sich aber schon recht gut eingelebt. Sie hatte ein gutes Netzwerk aufgebaut, die Wohnung eingerichtet und schon einige sozialkritische Berichte veröffentlicht. Als sie 
erfuhr, dass Akash Golf spielt, begann sie von jenem höchst exklusiven Golfclub zu schwärmen, in dem er Mitglied war. Sie meinte, dass sie dort gerne einmal schwimmen gehen würde. Akash entgegnete, dass es das einzige Naherholungsgebiet sei. Er genieße es sehr beim Golfen im Grünen zu sein, das sei in einer indischen Metropole noch wichtiger als in der Schweiz. Provoziert von diesem Statement, meinte die Journalistin, die Frage sei nur: Naherholungsgebiet für wen? Es sei ja auch sehr dekadent. Aufgebracht meinte Akash, dass er sich seinen Lebensstil kaum vorwerfen lassen müsse, wenn er sich ihre Wohnung so ansehe. Bezug nehmend auf den jüngsten Bericht der Journalistin sagte ich, dass die Problematik beim Golfplatz insbesondere der Wasserverbrauch sei. Darauf beklagte sich Akash darüber, dass die Millionen von Rupien, die für die Reinigung der städtischen Gewässer aufgewendet würden, spurlos versickerten.

Offensichtlich waren wir alle in den Widersprüchen des „neuen Indiens“ gefangen. Unabhängig von unserer politischen Position profitierten wir alle beruflich und persönlich von den Versprechungen und Angeboten des exklusiven Lebens im „neuen Indien“. Während die Journalistin oder ich in diesem Lebensstil die soziale Ungleichheit moralisch beklagten, ließ Akash diesen aus seiner Sicht heuchlerischen Vorwurf nicht gelten. Als die Debatte durch meine Bemerkung auf eine strukturelle Ebene wechselte, verschob er den Fokus gemäß einer liberalen Logik auf die Korruption beim Staat, durch die das Wasser knapp sei und dadurch das Wasser des Golfklubs überhaupt wertvoll werde. Die Journalistin nahm im Feld der Schweizer Expats eine sozialkritische Position ein, wogegen andere explizit die Rückständigkeit Indiens kritisierten. Ein mit Akash befreundeter Diplomat beklagte sich kurz nach seiner Ankunft in Indien, dass der Umbau seines Hauses nicht funktioniere, die Straßen dreckig, die Leute nicht vertrauenswürdig seien und sein Sohn auf der Straße mitansehen musste, wie ein Huhn geköpft wurde. Ein anderer Expat war geradezu wütend über die Korruption in Indien und die Ausschlusslogik der Mittelschichten, welche die Armut der Massen hervorbringen würden. Jedoch schien er überhaupt nicht mit einzubeziehen, dass die Liberalisierungsanstrengungen in Indien, die er als Beamter unterstützte, als Kehrseite des Wachstums und des Profits auch Armut und soziale Ungleichheit hervorbrachten (Gupta 2009; Chowdhury 2011). Im Kontext der Annehmlichkeiten im „neuen Indien" und der expliziten Aufgabe von Expats oder Diplomaten, diese für Schweizer Interessen verfügbar zu machen, wohnt diesen Positionen zwangsläufig auch ein eurozentrischer Überlegenheitsgestus inne, der nur zu oft eine neokoloniale Note annimmt. Akash legte weder - wie die meisten Expats - eine Ambivalenz zwischen eurozentristischem Überlegenheitsgefühl und humanitärer Kritik an den Tag, noch hatte er die lokalen Machtverhältnisse inkorporiert wie etwa der Möbelhändler Shiva. Angesichts seiner rationalen und neoliberalen Argumentation sowie der kosmopolitischen Distanziertheit von den moralischen lokalen Bedingungen konnte er Machtverhältnisse und soziale Ungleichheiten größtenteils als 
conditio humana abtun. Aber auch er war über das menschliche Elend im Alltag immer wieder entsetzt. Dies war für ihn auf einer individuellen Ebene moralisch schwer zu ertragen, weshalb er versuchte das Elend als Patron zu lindern. So hatte er in seiner Fabrik mehrmals durch einzelne Maßnahmen wie Lohnerhöhungen oder soziale Unterstützung interveniert. Während er zwar das Elend wahrnahm, konnte er die strukturelle Gewalt, die dem zugrunde lag, durch Korruptionsvorwürfe gegen den Staat oder moralische Interventionen ausblenden. Diese sozialen Widersprüche im „neuen Indien“ schrieben sich bei Akash trotzdem zunehmend in seine Subjektivität ein. Wie seine Eltern reflektierten - und er selbst anerkannte -, war er in Indien ungeduldiger und aufbrausender geworden. Die Aggression gegenüber seinen Hausangestellten und seinem Chauffeur oszillierte zwischen dem Scheitern der neoliberalen Legitimation von Ungleichheit eines Schweizers Managers und der Verkörperung der Macht eines indischen Patrons.

Im Leben zwischen transnationaler kapitalistischer Klasse und „globaler indischer Familie" entwickelte Akash einen kosmopolitischen Habitus, für den lokale Partikularitäten zu ästhetischen Bildungsfragmenten und Konsumgütern in einer aufregenden globalen Lebenswelt wurden. Das „neue Indien“ war für ihn zwar mit Privilegien behaftet und mit nostalgischen Gefühlen verbunden, wie das „letzte Diwali“"zeigte, jedoch schien es für Akash vor allem ein Ort zu sein, an dem er das transnationale familiäre Statusprojekt durch die Bildung eines kosmopolitischen Ethos weiterführen konnte. Akash konnte sich in die vielfältigen schweizerischen Expat- und indischen Mittelklasse-Diskurse einfügen. Er war fast vollständig in einer exklusiven Lebenswelt des „neuen Indiens“ eingetaucht und hatte sich einen Blick angeeignet, der das „andere Indien“ nicht mehr wahrnimmt. Gleichzeitig konnte er die Widersprüche und die strukturelle Gewalt nicht vollständig ausblenden, die dem „neuen Indien“ innewohnen. Die Konfrontation mit moralischen Vorwürfen und der sozialen Ungleichheit in seiner Fabrik, in seinem Alltag mit Diener und Chauffeur sowie durch seine Konsumpraktiken in den urbanen Enklaven erforderten eine ständige Aushandlung seines Status und seiner Autorität sowie die Herstellung und Legitimation des exklusiven Lebens im „neuen Indien“.

\section{3 „INCREDIBLE INDIA“96 - EIN FAMILIÄRES BILDUNGSPROJEKT: RAJ UND KRISH}

Ich lernte den 49-jährigen Pflegefachmann Raj im Herbst 2009 in Indien kennen, als er mit seinem damals zehnjährigen Sohn Krish eine mehrwöchige Reise machte. Wir trafen uns in der Nähe der Kleinstadt Kumta, im Bundesstaat Karnataka

96 | "Incredible India“ ist seit 2002 der Slogan der indischen Regierung, um den Tourismus im Sinne des hegemonialen Projektes eines "globalen Indiens" zu fördern (Geary 2013). 
südlich von Goa. Heinz, ein väterlicher Freund Rajs, der schon knapp 30 Jahre - mit Unterbrechungen - in Indien lebte, baute dort mit einem jungen indischen Arzt eine Ayurveda-Klinik auf. Raj und Krish waren von Delhi über Agra, Rajasthan und Varanasi nach Kolkata gereist, wo sie eine Woche bei Rajs Vater verbrachten, der jährlich mehrere Monate in Indien lebt. Dort hatten sie Krishs zehnten Geburtstag und das hinduistische Volksfest Durga Puja gefeiert. Danach reisten sie über Goa nach Kumta, um Heinz zu besuchen. Ich traf sie dort und nach einigen Tagen in Kumta fuhren wir nach Mumbai, von wo aus Raj und Krish zurück in die Schweiz flogen.

\section{Indien - ein intergenerationelles Bildungsprojekt}

Krish hatte für diese Reise die Schule unter der Bedingung aussetzen können, dass er mit Raj den Schulstoff bewältigen und er einige zusätzliche Bildungsprojekte übernehmen würde. Einerseits schrieb der Junge ein Tagebuch über seine Erlebnisse und Erfahrungen. Zweitens bereitete er einen Vortrag über Mahatma Gandhi vor. Raj nahm die Einhaltung dieses Programms sehr ernst, da er seinem Sohn eine gute schulische Erziehung bieten sowie ein präsenter und unterstützender Vater sein wollte - beides Erfahrungen, die er als Kind immer wieder schmerzlich vermisst hatte. Die Indienreise war aber auch insofern ein intergenerationelles Bildungsprojekt, als Raj seinen persönlichen Bezug und seinen Zugang zu Indien an seinen Sohn weitergeben wollte. Wie Raj trug auch Krish einen Talisman (taweez) am Oberarm, den sie beide von Rajs Großmutter erhalten hatten und der die Erfahrung des Anderssein in der Schweiz in den Körper einschrieb (s. Kapitel 5). Zudem war eine gemeinsame Indienreise von Raj und seiner Partnerin Rosa im Jahr 1992 Teil des familiären Erzähl- und Erinnerungskorpus und belebte bei Krish und seiner jüngeren Schwester den Mythos Indien. Der nostalgische Fluchtpunkt war jedoch auch mit Unsicherheit und Abenteuer besetzt, war doch Rosa auf der einjährigen Indienreise lange krank gewesen, weshalb sie zuerst entschieden hatten, die Kinder dieser Gefährdung nicht auszusetzen. Für Raj und Krish bedeutete die erste gemeinsame Reise also einen biografischen Einschnitt und ein spektakuläres Abenteuer: Für Raj versprach die Reise, sein individuelles Indienprojekt an seinen Sohn weitergeben und die transnationale Konstruktion der „eigenen Familie“ weiterführen zu können. Krish wiederum konnte sich endlich die legendären Erzählungen seiner Eltern über Indien aneignen und - gerade weil seine Schwester nicht an der Reise teilnahm - eine spezifisch männliche Verantwortung für familiäre Aushandlungen des Andersseins übernehmen.

Als ich sie in Kumta antraf, waren Raj und Krish sehr entspannt. Die bisherige Reise in den massentouristischen Hochburgen war zweifellos schön und aufregend, aber auch anstrengend gewesen. Die politisch-ökonomische Asymmetrie im Massentourismus zwängte die beiden in eine Rolle als „wandelnde Geldautomaten“, wie Raj es nannte. Dadurch nahmen sie Indien durch einen Außenblick 
wahr, der nicht-standardisierte soziale Beziehungen kaum zuließ. Vor diesem Hintergrund entwickelten sie ein Ethos einer Schicksalsbeziehung, das sie durch familienbiografische Tradierungsprozesse, spielerische Männlichkeitsrituale, touristische Bildungspraktiken, sozialkritische Diskussionen und humoristische Indienparodien aushandelten. Auch den Aufenthalt in Kolkata hatten sie ambivalent erfahren. Die Feier von Krishs 10. Geburtstag sowie das religiöse Massenvolksfest Durga Puja mit Rajs Vater und der erweiterten Familie waren zweifellos ein symbolischer Höhepunkt der Reise. Die Beziehung zum Vater war seit Rajs Jugend zwar dadurch gediehen, dass er als wichtiger intergenerationeller Vermittler von Rajs Indienreisen fungierte. Trotz der regelmäßigen Besuche in Indien war es für Raj immer noch schwierig, die familiären Beziehungen, in die auch sein Vater verstrickt war, zu durchschauen. Während die Begegnungen bei den Familienessen auch dieses Mal herzlich und vertraut verliefen, blieb aus Rajs Sicht ein Blick auf die „Familienprobleme“, ja der „der Blick hinter die Kulissen“ verschlossen. Zurück blieb das ambivalente Gefühl, zwar zur Familie dazuzugehören, aber in Bezug auf Deutungs- und Handlungsmacht kein gleichberechtigtes Mitglied zu sein. Durch Parodien, offene Gespräche über die Familie und über kulturelle Differenz konnten Raj und Krish diese ambivalenten Erfahrungen im Rahmen des gemeinsamen familiären Bildungsprojektes einordnen. Eine Woche später meinte Raj zurückblickend: „Bezüglich der ständigen Einladungen zum Essen war Kolkata die Hölle. Es war nett gemeint und ich habe meine Verwandten ja sehr gern. Aber wir konnten einfach nicht mehr essen. Aber es hört ja niemand zu. Irgendwie gehen die Beziehungen nicht tiefer." Vor dem Hintergrund der erfahrenen Ambivalenz zwischen beschränkter Zugehörigkeit und Ausschluss - sowohl im Massentourismus als auch in der indischen Familie - offenbarte die Weiterreise nach Kumta einen maßgeblichen Perspektivenwechsel: Als ich Raj anrief, damit wir uns in Kumta treffen konnten, meinte er entspannt: „Ich sage dir, hier bei Heinz ist das Paradies.“

\section{Kumta: Das „echte Indien“ zwischen Paradies und Armut}

Heinz' intime Erfahrung Indiens war für Raj und vor allem für Krish kulturell und sprachlich viel zugänglicher. Heinz war in den 1970er Jahren nach Indien gereist, statt den erfolgreichen elterlichen Käsereibetrieb zu übernehmen. Er hatte Yoga studiert und geholfen, verschiedene Schulen im heutigen Yoga-Mekka Rishikesh aufzubauen. Nun hatte er begonnen, mit einem jungen indischen Arzt ein Ayurvedaspital einzurichten. Dieser väterliche Freund und profunde Indienkenner Heinz verkörperte mit seiner radikal-individualistischen Biografie sowie mit seinen politischen und religiösen Erläuterungen die gegenmoderne Verflechtungsgeschichte zwischen Indien und der Schweiz. Heinz' Zugang zu Indien war geprägt von einem romantischen Orientalismus, mit dem er einen spirituellen, hinduistischen Weg eines authentischeren Lebens jenseits der zivilisatorischen Dekadenz 
sucht. In seinem politisch-spirituellen Ethos stellte er sich immer auf die Seite der Menschen, die aus seiner Sicht in den indischen gesellschaftlichen Machtverhältnissen marginalisiert waren: insbesondere Kastenlose (dalits) und Frauen. Die Lebenswelt Aussteigers Heinz bot Raj und Krish eine Gelegenheit, Indien durch eine intime und alternative Innensicht zu erfahren, die sich zutiefst von der familiären und der massentouristischen unterschied und gleichzeitig gut anschlussfähig an ihr intergenerationelles Bildungsprojekt war.

Eines Morgens beschlossen Raj, Krish und ich, nach Kumta auf den Markt zu fahren, um einige Souvenirs zu kaufen und um diese Kleinstadt kennenzulernen. Wir warteten auf den Bus - vergeblich. Plötzlich hielt ein Minivan, in dem eng zusammengerückt ein gutes Dutzend Menschen saßen. Der Fahrer rief aus dem offenen Fenster „Kumta, Kumta, Kumta ...!". Raj und ich sahen einander unsicher an. Schließlich rief ich: „Kommt, den nehmen wir." Und wir quetschten uns lachend zu den Passagieren, die ebenfalls lachten. Ich erkundigte mich in Hindi, wo der Markt sei. Unsere Mitfahrer_innen fragten zurück, ob wir aus Mumbai kämen und nickten wissend, als wir erklärten, dass wir in der Schweiz leben: „Ah, NRI." Es entwickelte sich eine längere Konversation in einer Mischung aus Hindi, Englisch und dem lokalen Kannada und nach einer Weile wurden wir abgesetzt. Wir flanierten durch die nur schwach frequentierten Gässchen des Marktes, deren erdiger Boden sich durch den Regen in ein Archipel kleiner Inseln zwischen Schlammpfützen und Bächen verwandelt hatte. Abfall und ein altes Motorradwrack säumten den Weg. Zwischen Palmen standen alte Ziegelhütten und Marktstände aus Holz. Plötzlich meinte Raj: „Das liebe ich auf den Indienreisen, wie es riecht, wie es aussieht, dieses Nass-Sein. Diese Läden, die Busfahrt, das ist das echte Indien. "In Wanderhosen und Trekkingsandalen sowie beladen mit Rucksäcken zogen wir die Blicke der wenigen Menschen auf dem Markt auf uns. Raj machte Krish auf eine Gruppe von Mädchen in dessen Alter aufmerksam, die in blauen Schuluniformen, mit umgehängten Trinkflaschen und gebundenen Schleifen in den Haaren an uns vorbeigingen: „Schau, Krish, die Kinder kommen von der Schule nach Hause. Sie tragen eine Schuluniform, damit man nicht merkt, wer reich ist und wer arm. Bei euch in der Schule ist es ja auch blöd, wenn einige teure Markenjeans tragen und andere sich diese nicht leisten können." Krish nickte. Die Kinder schauten einander gegenseitig an. Eine schwarze Kuh stand bei einem roten Telefon, das auf einer Metallkonstruktion befestigt war. Wir lachten über das Bild der „telefonierenden Kuh" und steckten damit die Frauen an, die uns amüsiert zugeschaut hatten. Krish und ich fotografierten die kuriose Szene. An einem Stand nebenan kaufte Raj nach kurzen Preisverhandlungen einige blau-grün karierte dhotis (Wickelröcke) und meinte: „Die sind super im Sommer nach einem kurzen Bad im Fluss." Krish begann das Geld in seinem Portemonnaie zu zählen. Er wusste jedoch nicht, was er mit dem verbleibenden Geld noch kaufen sollte. Wir rechneten gemeinsam indische Rupien in Schweizer Franken um. Zu Krish gewandt meinte Raj in theatralischem Indian English: „I make you a very good price, only two 
thousand Rupees." Krish grinste. Nach dem Kauf einiger Souvenirs entschlossen wir uns einen Kannada-Film im lokalen Kino anzusehen, bevor wir zurück in unsere Unterkunft ins Ayurveda-Retreat fuhren.

In der kindlichen Begeisterung und der väterlichen Ernsthaftigkeit, mit der Raj seinen Sohn Krish auf das „echte Indien“ aufmerksam machte, verdichteten sich unterschiedliche - touristische, familiäre und humanitäre - Elemente von Rajs und Krishs Bildungsprojekt: Im Gegensatz zu den touristischen Hochburgen Agra oder Varanasi erschien das Straßenleben in Kumta als einfacher Alltag in Indien, den Raj als langjähriger Rucksackreisender zu schätzen gelernt hatte. Die Taxireise und das Bild der „telefonierenden Kuh" konstruierten Indien als das kuriose und nicht-moderne Andere, das bekannte Routinen aufbricht und dadurch einen Blick auf sich selbst ermöglicht. Statt als „wandelnder Geldautomat" zu fungieren, erlaubte das „einfache Indien“ für Raj - trotz sprachlicher Barrieren und der klaren Asymmetrie - eine intime Interaktion zwischen Touristen und lokaler Bevölkerung. Der Markt in Kumta erschien aus dieser Perspektive bar kapitalistischer Korruption, wie sie in der Schweiz, im Massentourismus oder in der mittelständischen indischen Familie in Kolkata vorherrscht, die sich von diesem kleinstädtischen Indien zu distinguieren versuchte. Das „echte Indien“ erschien aus diesem touristischen Blick aber auch als ärmliches und nur wenig modernisiertes Indien, in dem die Kuh auf der Straße oder das überfüllte Taxi das Andere einer reichen und reinlichen Schweiz markieren. Dieses Indien war für Raj auch deshalb „echt“, weil Armut eine Ausprägung einer realen globalen Ungleichheit darstellt. Schon als Kind war er schockiert von den Bildern von Kindern mit amputierten Beinen am Flughafen von Kolkata und durch seine Verankerung in der linksalternativen Szene hat er die antiimperiale Haltung der Drittweltbewegung aus den 1980er Jahren kennengelernt. Eingebettet in die gemeinsamen Diskussionen über Mahatma Gandhis Kampf um Unabhängigkeit, konnten Raj und Krish die hautnah erlebte Armut in Indien auch als Geschichte kolonialer Ausbeutung diskutieren, die in den heutigen globalen Machtverhältnissen reproduziert wird. Im Kontext des intergenerationellen Bildungsprojektes bemühte sich Raj, seinem Sohn sowohl seine nostalgischen Erinnerungen als Rucksacktourist als auch die Mechanismen globaler sozialer Ungleichheit und Armut zu vermitteln.

Vor diesem touristisch-pädagogischen Hintergrund nahm die eingespielte Praxis, dass Krish sein eigenes Budget verwaltete, um Souvenirs und Geschenke einzukaufen - eine zweifellos altersgerechte Erziehungsmethode -, eine mehrfache Bedeutung an. Krish war ständig damit beschäftigt, Währungen umzurechnen und war fasziniert vom Kaufkraftunterschied, der ihm Schnäppchen versprach, aber gleichzeitig auch immer wieder seine widersprüchliche Macht als Tourist vor Augen führte. Zudem vermittelte Raj mit dem Running Gag „I make you a very good price" der Schweizer Comedy-Figur Rajiv, dass Feilschen eine typisch indische kulturelle Praxis sei und hielt ihn dazu an, dies zu üben und sich nicht übers 
Ohr hauen zu lassen. Im intergenerationellen Bildungsprojekt nahmen der Kauf als Praxis, das Geld und die Waren die Funktion ein, sowohl kulturelle Differenz als auch Ungleichheit zwischen der Schweiz und Indien sowie zwischen Touristen und locals auszuhandeln. Der Konsum als touristische Praxis konstruierte Indien als arm und unmodern, aber auch als aufregend und freier. Der Konsum war dabei gleichzeitig die privilegierte Weise schlechthin, die Welt der „Anderen“ zu erfahren, anzueignen und zu inkorporieren. Der Kauf von dhotis in Kumta erlaubte einerseits einen Kontakt mit der lokalen Bevölkerung. Gleichzeitig geschah der Kauf auch im Hinblick auf die nostalgisch-subversive Performanz von Mehrfachzugehörigkeit im Schweizer Alltag. Für Raj und Krish wurde Konsum zum fundamentalen Element der Reise und der transnationalen Subjektivierung selbst.

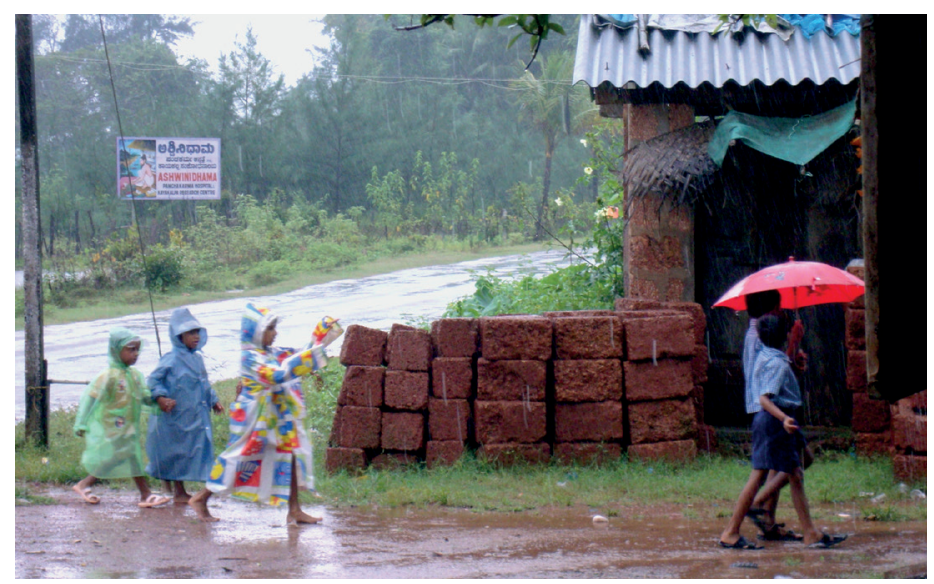

Abbildung 25: Impressionen des „echten Indiens" zwischen Nostalgie und politischer Bildung (Quelle: Autor)

Die touristisch-humanitäre Haltung macht Raj jedoch immer wieder bewusst, dass er gerade deswegen von einer ,authentischen“ kulturellen und sozialen Zugehörigkeit zu Indien ausgeschlossen blieb. Diese Enttäuschung war allerdings nicht nur dem paradoxen touristischen Begehren nach Authentizität unter den Vorzeichen politisch-ökonomischer Asymmetrie geschuldet, sondern auch der biografischen Aushandlung seiner fragilen diasporischen Zugehörigkeit zu Indien. Dies wurde in Rajs Bedauern ersichtlich, dass er keine lokale Sprache beherrschte und daher aus seiner Sicht nicht auf gleiche Weise am indischen Alltag teilhaben konnte wie ich. Die Indienparodien - wie etwa das „I make you a very good price, only two thousand Rupees“ - erlaubten ihm, sich über dieses unzugängliche Indien lustig zu machen und gleichzeitig sein Begehren auszudrücken, Teil davon zu sein. Umso mehr schätzte er die Möglichkeit, durch meine Sprachkenntnis sowie durch Heinz' profundes Indienwissen in einen engeren Austausch mit den Menschen vor Ort 
treten zu können und stärker eine Innensicht auf das Mysterium Indien einnehmen zu können.

\section{Fabindia und Arundhati Roy: zwischen Teilhabe, Sozialkritik und Nostalgie}

Nach dem Aufenthalt in Kumta fuhren wir im Auto nach Goa, um von dort nach Mumbai zu fliegen. Wegen einer Überschwemmung waren die Eisenbahnlinie und die Hauptstraße unterbrochen und wir mussten einen Umweg über die Bergkette machen, um den Flug nicht zu verpassen. Raj hatte sich schon sehr auf diese letzten Tage in Mumbai gefreut. Zum einen wollte er unbedingt das Trendcafé Leopold's ${ }^{97}$ in Colaba besuchen, in dem Angehörige der lokalen Oberschicht und Touristen ein- und ausgingen. Als er 1992 mit seiner jetzigen Ehepartnerin Rosa zum ersten Mal im Leopold's Bier trank und Kebabs aß, war dies ein regelrechter Kulturschock gewesen. Vor dem Hintergrund der ärmlichen Verhältnisse in Kolkata und der Erfahrungen als Rucksackreisender hatte er dieses moderne, metropolitane Indien nicht gekannt. Das Leopold's nahm daher eine wichtige Bedeutung im familiären Indienmythos ein und belebte für Raj und Krish das Interesse an einem „neuen Indien“, das jenseits familiärer, sprachlicher oder touristischer Einschränkungen war.

Raj freute sich aber auch auf Mumbai, weil seine „Indian sista“ Tara die Stadt sehr gut kannte und ihm eine Liste mit Shopping- und Sightseeing-Tipps mitgegeben hatte, die er unbedingt abklappern wollte. Taras persönlicher Mumbai-Reiseführer erlaubte Raj aus einer ihm unbekannten privilegierten bildungsbürgerlichen Perspektive eine Innensicht in dieses „neue Indien“. Seit seiner ersten Erfahrung der metropolitanen, indischen Moderne jenseits des orientalistischen, touristischen Blicks vor knapp zwanzig Jahren hatte sich das „neue Indien“ gewandelt, und Raj wollte diese Transformation weiter kennen lernen und Krish näher bringen.

An einem sonnigen Tag streunten Raj, Krish und ich durch South Central Mumbai, um die letzten Mitbringsel und Andenken zu kaufen. Auf dem Einkaufszettel standen indisches Blechgeschirr, handgemachtes Papier aus einem Laden, den Tara vorgeschlagen hatte, und eine zusätzliche Reisetasche. Als wir an einem Nike-Geschäft vorbeigingen, vor dem Straßenhändler saßen, machte Raj Krish auf die enormen Veränderungen in Indien aufmerksam, in der „Armut und Reichtum, Tradition und Moderne so nah" sind. Wir gingen in das Geschäft, wo Krish sich erhoffte, mit erspartem Geld günstige Fußballschuhe zu kaufen. Jedoch waren die Preisunterschiede bei Luxusgütern zwischen der Schweiz und Indien nicht wirklich groß. Hingegen gefie-

97 | Das Leopold's Café wurde Ende des 19. Jahrhunderts von Parsis gegründet und war seit dem kolonialen Fin de Siècle ein bekannter Treffpunkt im kosmopolitischen Süd-Mumbai. 
len Raj die Retro-Leibchen der indischen Cricket-Nationalmannschaft, die statt aus Kunststoff aus dichter Baumwolle gefertigt und in einem schlichten Design gehalten waren. Er konnte den zweifelnden Krish davon überzeugen, dass diese T-Shirts mit der Aufschrift "India“ unter seinen Freunden und Schulkollegen als „cool“ gelten würden. Auf unserer Shopping-Tour in Süd-Mumbai kleideten wir uns schließlich noch bei Fabindia ein, dem Marktführer in sozial verantwortlich und ökologisch produzierter ethnic wear. Als wir im Fabindia-Restaurant Panini aßen, glaubte Raj plötzlich in einer Frau am Nebentisch die Schriftstellerin und Aktivistin Arundhati Roy zu erkennen. Elektrisiert ging er zur Frau, um seine Ahnung tatsächlich bestätigt zu finden, und kam mit der Booker-Prize-Gewinnerin ins Gespräch. Nach einer Weile kehrte er begeistert mit einem Autogramm zurück.

Das „neue Indien“ mit seinen global vernetzten urbanen Räumen erschien als äußerst anschlussfähig für Rajs transnationale Subjektivierungsprozesse. Im Gegensatz zu den Erfahrungen als Außenstehender bei seiner Familie in Kolkata oder als Tourist vor allem in Agra, aber auch in Kumta, traf er hier auf Inderinnen und Inder aus der Mittel- und Oberschicht, mit denen er kulturelle und sprachliche Praktiken und Wissensbestände gemeinsam hatte - wenn sie auch unterschiedliche Positionen und Subjektivitäten einnehmen mochten. Das Café Leopold's und insbesondere der Nike-Shop verkörperten ein „globales Indien“, an dem Raj qua kulturellem und ökonomischem Kapital teilhaben und zu dem er sich zugehörig fühlen konnte. Der Kauf von Cricket-T-Shirts und Blechgeschirr, kurtas von Fabindia und handgemachtem Papier verwies auf einen Rahmen einer transnationalen indischen Mittelschicht. Die Kombination dieser Objekte und die damit verbundenen kulturellen Praktiken dienten sowohl der distinguierten Performanz von "global Indianness“ in privilegierten Segmenten der Mittelschicht als auch dem Anspruch auf eine legitime Mehrfachzugehörigkeit im schweizerischen Alltag des kommerziellen Multikulturalismus. In kurtas von Fabindia und Trekking-Sandalen auf Shopping-Tour in South Central Mumbai hätte er genauso gut ein lokaler Angehöriger der Mittelschicht wie ein Schweizer Tourist indischer Herkunft gewesen sein können.

Der Kauf von kurtas sowie das Gespräch mit Arundhati Roy bei Fabindia versinnbildlichen eine spezifische Spannung innerhalb der globalen indischen Moderne. Fabindia ist ein international tätiges, indisches Textil- und Modeunternehmen, das 1960 begann, zusammen mit indigenen und lokalen Produzentinnen und mit traditionellen Färbe- und Drucktechniken ethnic fabric sozial verantwortlich und ökologisch herzustellen und zu vermarkten. Paradigmatisch verkörperten Fabindia-Kleider die hybride Identifikation urbaner Mittelschichten mit indigenen Traditionen und westlicher Schlichtheit und Eleganz. Wenn auch Fabindia zu einem Statussymbol und einem Geschäftsmodell geworden war, steht es trotzdem für eine sozialkritische Perspektive im „neuen Indien“. Die Autorin und Aktivistin Arundhati Roy hatte mit ihrem Erstlingswerk „The God of Small Things“ von 1995 
gleich den Bookerpreis gewonnen und eine neue indische Schriftstellergeneration geprägt, die aus der „transnationalen neuen Mittelschicht" stammte und sich im internationalen englischsprachigen Buchmarkt etablieren konnte. Danach hatte sich Roy jedoch als politische Aktivistin engagiert, um die soziale Ungleichheit und strukturelle Gewalt zu bekämpfen, die sich in Indien seit der Liberalisierung verstärkt hatten. Sie wurde zum Aushängeschild einer intellektuellen und sozialkritischen Mittelschicht, die sich gegen die Konsumversprechen im „neuen Indien" stellen und stattdessen sowohl Nehru'sche, kommunistische als auch alternative gesellschaftliche Visionen verfolgte. In Rajs Freude über die Begegnung mit Arundhati Roy bei Fabindia wurde gewissermaßen eine diasporische Perspektive sichtbar, die den Widerspruch zwischen einer Sehnsucht nach dem „echten Indien“ und dem Zugang zu einem kapitalistischen "neuen Indien“ in einer globalen sozialkritischen Perspektive aufzulösen versprach. Eingebettet in die linksalternative Szene eignete sich dieses junge, mittelständisch-sozialkritische Milieu geradezu ideal für eine transnationale Identifikation. Die Ikone Arundhati Roy erlaubte Raj, sowohl Teil des „neuen Indiens“ zu sein als auch eine sozialkritische Position einzunehmen, die sich mit dem „echten Indien“ der kleinen Leute vom Land solidarisiert.

In seinem Bildungsethos nimmt Raj als aktiver und kritischer Beobachter an der Transformation Indiens teil, ohne in eine Ablehnung des neuen indischen Kapitalismus aufgrund eines sozialkritischen westlichen oder indischen Blickes zu verfallen. Seine Indienreisen, so auch die diejenige mit Krish, sind offene ethische Projekte und Praktiken, in denen er sich immer mehr Wissen und Erfahrungen über Indien aneignet und mit seinem sozialen Umfeld teilt. Darin kann Raj seinen Bildungsprozess vorantreiben und immer stärker auf eine öffentliche Weise eine eigene legitime Zugehörigkeit zu Indien aushandeln. Zwischen der Teilhabe am „neuen Indien“ und dem kommerziellem Multikulturalismus in der urbanen Schweiz kann Raj zunehmend eine transnationale Lebenswelt und eine „eigene indische Familie" ausbilden. Der Besuch bei Heinz und die Treffen in der Schweiz, der transnationale Austausch von Geschenken, Erfahrungen und Reisetipps mit Tara und Jasmin sowie die Bildungsreise mit Krish schaffen einen immer dichteren, transnationalen lebensweltlichen Zusammenhang, der über seine ,indische Familie" und eine rein genealogische Konstruktion von Zugehörigkeit hinausgeht. Obwohl er aus seiner Sicht weiterhin einen Blick von außen einnimmt, erfährt er gleichzeitig eine stärkere und legitimere Zugehörigkeit zu Indien.

Diese Verschiebungen der Aushandlung diasporischer Zugehörigkeit im „neuen Indien"verdichteten sich in Rajs und Krishs Besuch des Taj Mahal. Der Eintritt ins Taj Mahal kostete damals für Ausländer_innen (inkl. OCI und PIO) $750 \mathrm{Ru}$ pien, für indische Staatsbürger_innen indes nur 20 Rupien. Dies war - vor allem unter Auslandsinder_innen - ein Riesenpolitikum, zumal gemunkelt wird, dass ein großer Teil der Einnahmen nicht für die Erhaltung des Tajs eingesetzt wird, sondern in der angeblich korrupten Bürokratie versickert. Als Raj und Krish bei 
der Kasse des Tajs Schlange standen, meinte ein Officer streng, dass sie sich bitte in die Schlange der Ausländer stellen sollen. Da zückte Raj seinen OCI-Pass und proklamierte, sie seien Inder. Der Officer verwies auf die Erläuterungen an der Preistafel, als plötzlich alle Inder_innen in der Schlange der Einheimischen riefen: „Hey, die beiden sind Inder.“ Sie beteuerten, Raj und Krish sollen zu ihnen kommen und ließen den protestierenden Officer stehen. Auf geradezu ironische Weise hatte die lokale Bevölkerung den Trick der Regierung subvertiert, OCI als „doppelte Staatsbürgerschaft“ zu vermarkten, ohne politische Rechte zu gewähren. Für Raj und Krish war dies eines der symbolischen Highlights der Reise, zumal ich erzählte, dass ich als „Ganzinder“ mit Hindi-Kenntnissen bei meinem letzten Besuch des Tajs vor drei Jahren trotz Protest und versuchter Irreführung den Preis für Ausländer und NRI hatte bezahlen müssen.

\subsection{Sonia, Gayatri und Asha: Verwerfungen von GESCHLECHT UND KLASSE IN DER „GLOBALEN PATRILINAREN FAMILIE"}

Sowohl Akashs professionelle Karriere als auch Rajs touristisches Bildungsprojekt waren verknüpft mit der Reartikulation der Bedeutung und Funktion der transnationalen Familiennetzwerke. Einerseits boten diese eine wichtige rechtliche, soziale, kulturelle und moralische Ressource in den transnationalen Subjektivierungsprozessen. Andererseits erlaubte nur das Heraustreten aus der Familie und ihrer sozialmoralischen Normen, eigene Perspektiven auf Indien zu entwickeln und sich alternative diasporische Räume von Mehrfachzugehörigkeiten anzueignen.

Die disziplinierende Macht transnationaler Familiennetzwerke zeigt sich insbesondere im Falle einer Heirat innerhalb der „globalen indischen Familie“. Nationalmoralische Geschlechternormen betreffen zwar sowohl Männer als auch Frauen (Uberoi 2006; Chopra et al. 2004). Jedoch sind Frauen als Schwiegertöchter, Ehefrauen und (potenzielle) Mütter in einem besonderen Maße in die Verschiebungen der heteronormativen mittelständischen Geschlechterordnung eingebunden. Tagtäglich vollziehen sie die neue hegemoniale Verknüpfung zwischen Familiensolidarität und Kapitalismus, zwischen neoliberalen Lebenswürfen und patriarchalen Werten, um ihren Mittelschichtsstatus und den ihrer Familie zu reproduzieren. Die folgenden Beispiele dreier indischer Secondas aus der Schweiz, die in der "globalen indischen Familie“ geheiratet haben, zeigen die Verwerfungen von Klassenprivilegien und patriarchaler Logik in der Konstruktion von diasporischen und mittelständischen Subjektivität im sich globalisierenden Indien. Leider basieren sie nur auf Interviews und einzelnen Gesprächen und nicht auf teilnehmender Beobachtung, weil entweder die Forschungsteilnehmerin (im Falle von Sonia), ihre Angehörigen (im Falle von Asha) dies nicht wünschten oder es aus 
zeitlichen Gründen (im Falle von Gayatri) - also aus feldspezifischen Gründen nicht möglich war.

\section{Sonia: Kinderwunsch und Karriere}

Die Investmentbankerin Sonia hatte sich durch ihre transnationale Karriere und durch die Heirat mit einem Inder aus der Diaspora mitten in einer globalen indischen Moderne eingefunden, ohne dass dies in der Schweiz erkannt worden wäre (s. Kapitel 5). Durch die Aushandlung ihrer Subjektivierungsprozesse im Familienprojekt der Statusrehabilitation sowie angesichts der jährlichen Reisen nach Indien war sie seit ihrer Jugend mit Veränderungen der Lebensstile und Geschlechterdiskurse in den „neuen indischen Mittelschichten“vertraut. In dieser transnationalen Situation zwischen Indien und dem Westen entwickelte sie - symptomatisch und kreativ zugleich - einen Lebensentwurf als "globale indische Frau“, die in ihren Worten „das Beste aus beiden Welten“ - Moral und Lifestyle, Familienwerte und professionelle Karriere - verbunden hatte (Radhakrishnan 2008). Innerhalb der transnationalen Lebenswelt zwischen der Schweiz, London, Mumbai und Dubai war Sonia unterschiedlichen Geschlechternormen ausgesetzt. Durch die Heirat mit Rahul wurde sie auch in neue und größere transnationale Familiennetzwerke eingebunden, in denen sie sich mit diesem Lebensentwurf positionieren musste:

Einige entfernte Verwandte von Rahul sind in Dubai und die sind sehr konservativ. Das hast du in den Familien, in denen nur die Männer gearbeitet haben und Frauen nie etwas gemacht haben. Das sind alles Leute, die genug Geld haben und die das Gefühl haben, wenn eine Frau arbeiten muss, dann stimmt es finanziell nicht. So denkt vor allem die ältere Generation, nicht die junge. Also seine Großmutter hatte mir einmal gesagt [parodierend]: „Du musst doch sicher nicht arbeiten, beti [Tochter], geht es noch, also wir haben genug. Du musst für uns [!] nicht arbeiten.“ Da habe ich gefunden: „Ja ich weiß es, aber ich arbeite für mich, oder.“

In dieser Szene, aber auch in der Erzählung selbst, markierte Sonia nachdrücklich ihren Lebensentwurf als emanzipierte und berufstätige indische Frau, den sie - in ihrem eigenen biografischen Verständnis - durch das Leben in der Schweiz erst fassen konnte. Neben der transnationalen Familie war sie auch in andere assimilatorische und diasporische Öffentlichkeiten sowie in korporative Multikulturalismen eingebunden, in denen sie Mehrfachzugehörigkeiten gemäß anderen kulturellen Narrativen und disziplinierenden Normen aushandelte. Genauso wie sie sich in der Schweiz gegen Vorwürfe einer „arrangierten Heirat“ positionierte, musste sie sich in der transnationalen Familie von konservativen Geschlechternormen und in London von „maskulinen“ Karrierefrauen abgrenzen. Durch die Balance zwischen diesen Geschlechternormen konnte sie sich in all diesen unterschiedlichen 
Kontexten einen hohen Lebensstandard und einen hohen Status aufrechterhalten. Das vielseitige Narrativ einer "globalen indischen Frau“, ihre hohe transnationale Mobilität und ihr Leben im unabhängigen Haushalt mit Rahul boten ihr viele Ressourcen und eine nicht unbeträchtliche Flexibilität und Autonomie. Nicht zufällig hatte Sonias Autonomie damit zu tun, dass sie und Rahul (bis jetzt) keine Kinder haben. Zwar machte sich Sonia Gedanken über die Familienplanung. Und tatsächlich übten die Verwandten in dieser Frage einen beträchtlichen Druck aus. Aber trotz elektronischer Kommunikationsmittel sind diese weiterhin geografisch und moralisch relativ weit entfernt. Jedoch bereitete sich Sonia in Gedanken auf eine allfällige neue biografische Phase als Mutter und als Mutter von Enkeln ihrer Schwiegereltern vor. Für sie kam mittelfristig eine Migration nach Dubai infrage, wo Rahul aufgewachsen war und wo seine Eltern wohnen. Neben dem beherrschenden Wunsch nach Enkeln stand für Sonias Schwiegervater das Familienunternehmen im Vordergrund und er hoffte darauf, dass Rahul - und allenfalls auch Sonia - dieses eines Tages weiterführen würden. Im Sinne der neuen Subjektposition der "globalen indischen Frau“ war für Sonia klar, dass sie sich als Mutter ganz für die Familie einsetzen werde (Donner 2008; Radhakrishnan 2008). Ob sich dies mit einer Arbeit im Familienunternehmen verbinden ließe, war eine offene Frage - auch für Sonia selbst.
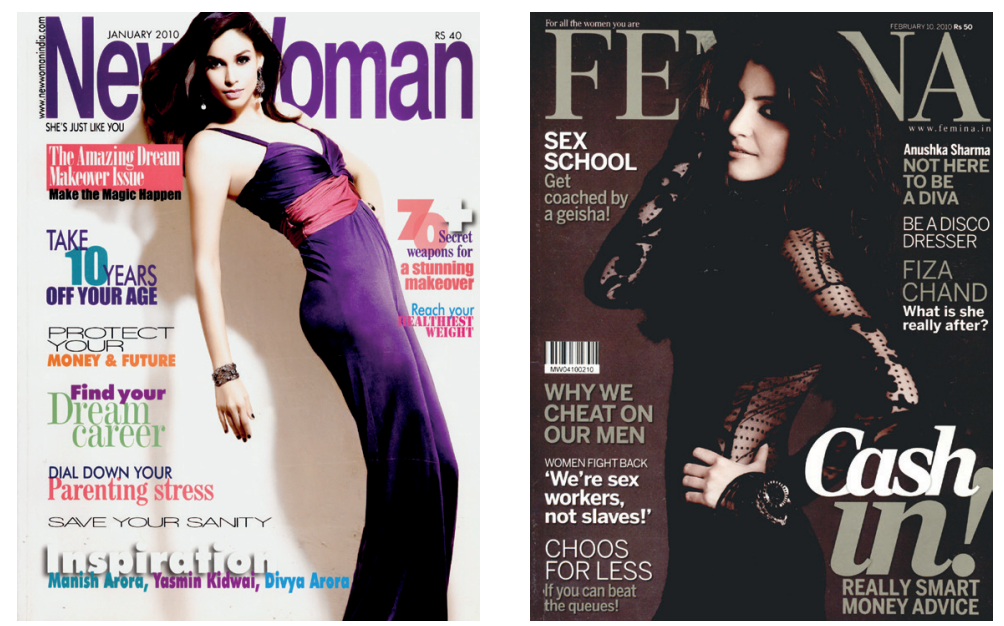

Abbildung 26a und 26b: Frauenmagazine verbreiten nach westlichem Vorbild Wissen und Bilder "der neuen indischen Frau" (Quelle: Autor)

Im Folgenden möchte ich zwei Beispiele von indischen Secondas schildern, die nach der Heirat stärker als Sonia mit der Forderung oder dem Wunsch konfrontiert waren, in einer patrilokalen joint family im „neuen Indien“ zu wohnen. Während sich zwar Familienformen - genauso wie Geschlechternormen und Hei- 
ratsregeln - durchaus pluralisiert haben, konnte sich die joint family auch in den metropolitanen Räume als Ideal und als Standard erhalten, um finanzielle, soziale und kulturelle Sicherheit zu gewährleisten (Mody 2008). Neben den hohen Immobilienpreisen haben der zeitliche Aufwand für Ausbildung und Erziehung der Kinder und „kin-work“ (Donner 2008), Haushaltsführung und Betagtenpflege (Dickey 2000; Bhatt et al. 2010) sowie neue Lebensstilpraktiken (Brosius 2010) dazu geführt, die joint family als Modell im neoliberalen Kontext des „neuen Indien“ zu reproduzieren. Während Frauen und Mütter in unterschiedlichen Segmenten der Mittelschichten in Bezug auf Mobilität, berufliche Tätigkeiten und Lebensstilpraktiken einen gewissen Freiraum aushandeln konnten und können (Ganguly-Scrase/Scrase 2009:104), sind sie weiterhin für die sozialmoralische, kulturelle und oft auch finanzielle Reproduktion eingebunden und müssen gleichzeitig ihre „weibliche Respektabilität“ unter den neuen Bedingungen der Konsumgesellschaft neu aushandeln. Während die Inkorporation konsumorientierter Weiblichkeit aus Modemagazinen, Bollywood-Filmen und Werbungen die Distinktion als mittelständische Frauen garantiert, erfordert der Alltag in der joint family weiterhin Sparsamkeit, die Erfüllung sozialer und religiöser Verpflichtungen und insbesondere das Schulmanagement der Kinder in einem höchst kompetitiven privaten Bildungswesen (Donner 2008).

Die folgenden kurzen Fallanalysen zeigen die Möglichkeiten und die Grenzen für „Inderinnen der zweiten Generation“ auf, sinnhafte und autonome Subjektivitäten im Hinblick auf ein Leben in einer patrilinearen joint family im „neuen Indien“ zu entwickeln.

\section{Gayatri: Promotion, familiäre Solidarität und Sozialkritik im „neuen Indien“}

Gayatri ist eine 38-jährige promovierte Sozialwissenschaftlerin und stammt aus einer traditionellen brahmanischen Familie aus Südindien. Ihr Vater wuchs in einem Dorf auf und konnte dank guter schulischer Leistungen als erster seiner Familie einen universitären Abschluss machen. Ihre Mutter ist mit ihrer Familie aus einem Dorf in die Stadt gezogen, wo sie nach dem Tod ihres Vaters für die Familie sorgte, schließlich einen Bachelor-Abschluss machte und heiratete. Ein Jahr nach Gayatris Geburt migrierte die junge Familie für das Doktorat des Vaters in die Schweiz. Statt wie geplant nach Indien zurückzukehren, nahm er nach der Promotion eine Stelle als Elektroingenieur an und unterstützte seine Brüder mit Rimessen bei der Ausbildung. Gayatri hatte das familiäre Solidaritäts- und Mobilitätsprojekt und dessen kulturelle Reproduktion stark internalisiert. Sie war stets eine gute Schülerin und brachte den elterlichen kulturellen Normen und religiösen Praktiken großen Respekt entgegen. Sie mochte die soziomoralische Solidarität der transnationalen Familie sowie die sinnlich-andächtigen hinduistischen Zeremonien, die ihre Mutter durchführte. Seit der Jugend versuchte aber Gayatri, 
wie auch Sonia, einen biografisch-ethischen Freiraum im „Leben zwischen den Welten“ auszuhandeln, indem sie die elterlichen Geschlechternormen und die adoleszenten Freizeitrituale miteinander zu vereinbaren suchte. Jedoch kristallisierte sich heraus, dass Liebesbeziehungen für sie wegen der elterlichen Erwartungen „keine Zukunft“ hatten. Stattdessen entwickelte sie ein Ethos platonischer Freundschaften und engagierte sich umso stärker bei kulturellen und sozialen Aktivitäten. Während sie den elterlichen Rahmen grundsätzlich akzeptierte, versuchte sie innerhalb davon, eine selbstständige und kritische Perspektive darauf zu entwickeln. Sie interessierte sich immer mehr für Indien, um die elterlichen Normen zu reflektieren und zu hinterfragen. Nach dem Gymnasium setzte sie durch, dass sie mit einer Freundin und zwei Freunden ihrer Schule durch Nordindien reisen durfte, um das westliche Initiationsritual des Rucksack-Tourismus zu erleben sowie um ihr Wissen über das Land zu erweitern. Danach blieb sie noch ein halbes Jahr bei ihren Verwandten in Südindien, machte eine Ausbildung in klassischer indischer Musik und schaffte es, ihren Radius außerhalb des „goldenen Käfigs“ der Familie zu erweitern. Insbesondere die Erfahrungen von Armut, der „haarsträubenden Ignoranz in den Mittelschichten“ gegenüber sozialer Ungleichheit sowie der „patriarchalen Strukturen“ in Indien motivierten sie nach dem Zwischenjahr Gesellschaftswissenschaften mit Fokus Sozialarbeit zu studieren. Sie wollte die Mechanismen von Ungleichheit verstehen und ändern, die in der Welt, in der indischen Gesellschaft und insbesondere auch zwischen den Geschlechtern herrschten. Damit Gayatri sich besser auf das Studium konzentrieren und sozial integrieren konnte, erfüllten ihre Eltern ihr den Wunsch, in einer Frauen-WG in der Stadt zu wohnen, in der sie studierte. Dort arbeitete sie in Studentenjobs und entwickelte durch Praktika bei der UNO und soziales Engagement ein wissenschaftlich-sozialkritisches berufliches Profil. Wie Sonia konnte sich Gayatri also gegenüber ihren Eltern Freiheiten ausbedingen, indem sie deren Normen sozialer Mobilität und kultureller Reproduktion akzeptierte. Und umgekehrt war für Gayatri klar, dass sie im Austausch für dieses elterliche Vertrauen auch deren Wünsche erfüllen würde, soweit sie dafür nicht ihre persönlichen Ideale aufgeben müsste. Während ihres Studiums lernte sie den indischen Software-Ingenieur Rupam kennen, der als temporärer Projektmitarbeiter in Europa weilte und dem weiteren Bekanntenkreis ihrer Familie angehörte. Während zwischen ihnen einerseits große Sympathie und großer Respekt bestanden, war Gayatri andererseits auch klar, dass Rupam, der sowohl aus der gleichen Stadt und derselben Kaste stammte wie ihre Familie, eine „gute Partie“ darstellte. Über E-Mail-Kontakt, Chats und Treffen wuchs über drei Jahre eine Freundschaft zwischen Gayatri und Rupam, in der auch die Perspektive einer Heirat besprochen wurde. Ihr früheres Bedauern, selbst keine adoleszenten Liebesbeziehungen geführt zu haben, hatte sich mittlerweile durch Erfahrungen von Schweizer Freundinnen in ein kritisches Mitleiden an der "romantischen Utopie“ (Illouz 1997) verwandelt, gegen die sie ein Beziehungsethos von Pragmatismus, Freundschaft, Liebe und Familienwerten setzte. Aus den langen Gesprächen 
wusste Gayatri, dass Rupam einen pflegebedürftigen Bruder hatte, den er und seine Eltern intensiv betreuten, und sie war bereit, nach der Heirat mittelfristig nach Indien zu ziehen, um sie dabei zu unterstützen. Während laut Gayatri ihre eigenen Eltern angesichts dieser „guten Partie“ wie erwartet „auf Wolke 7“ waren, wie sei sagte, war die Nachricht für Rupams Eltern zuerst „ein Schock“. Gayatri entsprach als NRI nicht deren Vorstellungen einer idealen Schwiegertochter und sie bezweifelten, dass Gayatri den moralischen Anforderungen angesichts der Betreuungssituation für Rupams Bruder gewachsen sein werde. Schließlich konnte genug Vertrauen zwischen allen Parteien geschaffen werden. Durch die langjährigen freundschaftlichen Dialoge hatte sich ein affektiv-ethischer Raum zwischen Gayatri und Rupam entwickelt, der sich in einer "companionate marriage“ (Parry 2001; Fuller/Narasimhan 2008) fortsetzte, in der die Bedürfnisse des Gegenübers ernst genommen werden und man sich gegenseitig unterstützt. Gayatri hatte ihren zukünftigen Ehemann und dessen Familie davon überzeugen können, dass er zuerst in der Schweiz arbeitet, damit sie fertig studieren und er ihr Leben in der Schweiz kennenlernen konnte. Umgekehrt war für sie klar, dass sie in transnationale familiäre Verpflichtungen eingebunden war und dem Wunsch ihres Mannes mit seiner Familie in Indien zu leben, Folge leisten würde. Vor diesem Hintergrund und nach der Geburt ihrer Tochter bewarb sie sich erfolgreich auf eine sozialwissenschaftliche Stelle als Doktorandin und Assistentin an der Universität. In Gayatris Familienbiografie nahm die Promotion des Vaters einen hohen Stellenwert ein. Als Sohn eines brahmanischen Dorflehrers boten für ihn die naturwissenschaftliche Ausbildung und der Doktortitel eine biografische Perspektive, um den transnationalen sozialen Aufstieg in einem kastenspezifischen Familienidiom zu verfolgen. Die Teilzeitstelle als Doktorandin und Assistentin passte zwar gut in ihre Lebenssituation als junge Mutter. Gayatris mittelfristige Perspektive war jedoch, in Indien bei ihren Schwiegereltern zu leben und ihren familiären Pflichten nachzukommen, ein wesentlicher Grund für die Entscheidung gewesen, zu promovieren. Sie entwickelte deshalb ein wissenschaftliches Projekt über Anerkennungs- und Mobilisierungspolitik in indischen Slums. Dadurch konnte sie sich während der Feldforschungen in Indien aufhalten. Zudem versprach sie sich davon Möglichkeiten, als selbstständige Beraterin in Fragen der Entwicklungspolitik in Indien zu arbeiten, einer Thematik, die sie seit dem Zwischenjahr und dem Studium moralisch und wissenschaftlich intensiv beschäftigt hatte.

Meine Dissertation mache ich auch mit dem Pragmatismus, dass wir vielleicht nach Indien ziehen und ich schon ein Netzwerk aufbauen kann. Also in X. [der Heimatstadt ihrer Eltern und Rupams] kann ich es mir schon gut vorstellen zu leben, weil ich es gut kenne, die Sprache spreche. Und es ist sehr kosmopolitisch. Da triffst du Leute, die aus dem hintersten indischen Dorf kommen und Leute, die wie in Manhattan leben. Einfach der Verkehr und die soziale Kontrolle der Familie sind ein bisschen penibel. Es wird viel geredet. 
Aber man muss einfach ein bisschen strikt sein, dann kann man schon ein eigenes Leben haben.

Gayatris Entscheidung zu einer Dissertation über indische Stadtentwicklungspolitik war eingebettet in komplexe Verflechtungen von professioneller Ambition, transnationalen familiären Verpflichtungen und sozialkritischen Idealen. Gleichzeitig war die südindische metropolitane Stadt, in der ihre Schwiegereltern und die meisten ihrer Verwandten lebten, eine Hochburg der indischen IT-Industrie und zu einem Inbegriff der Konsumkultur der neuen indischen Mittelschichten geworden. Die neuen urbanen Räume boten ihr als Frau nicht nur Bewegungsfreiheit und eine westlich kompatible und aufregende Freizeitkultur, sondern auch den idealen wissenschaftlichen Hintergrund für die Erforschung urbaner Verdrängungs- und sozialer Polarisierungsprozesse im „neuen Indien“ (vgl. Roy/Ong 2011; Chowdhury 2011).

Gayatri und ich waren etwa zur gleichen Zeit auf Feldforschung in Indien und obwohl sich ein Treffen aus terminlichen Gründen nicht ergab, telefonierten wir oder tauschten uns per E-Mail aus. Ihre Arbeit und ihre Feldforschung wurden von den Familienangehörigen respektiert, weil sich dadurch die sozialmoralischen Beziehungen vertieften und weil das Projekt einer Dissertation in urbanen Slums anschlussfähig an die bildungsorientierte und philanthropische brahmanische Familientradition war. Die Familie war für sie einerseits eine wichtige Ressource für die Forschung, da ihr Onkel sie im Feld vernetzte und ihr Zugänge verschaffte und sich ihre Schwiegereltern um ihre Kinder kümmerten. Trotz der spannenden Erfahrungen in diesem komplexen familiären, wissenschaftlichen und ethischen Projekt war Gayatri aber auch immer wieder frustriert. Trotz ihrer positiven Einstellung und ihrer Selbstdisziplin war sie von den "Dynamiken der joint family“ überrumpelt worden. Zum einen war ihr Mann gleichzeitig in seinen jährlichen Indienferien und es war klar, dass er auch seine Freunde treffen sollte und sie sich neben der Forschung auf die Kinderbetreuung konzentrieren musste. Zum anderen hielten sich die Schwiegereltern nicht an Abmachungen, verwöhnten die Kinder und diese fielen aus dem Ess- und Schlafrhythmus - was sie dann wieder zu korrigieren versuchte, aber mit einem Rückstand in der Forschung bezahlte. Angesichts ihres Aufwandes, um den transnationalen familiären Verpflichtungen nachzukommen, empfand sie die Situation insgesamt als unausgeglichen.

Trotz dieser Spannungen und Widersprüche kann Gayatri ihre professionellen Ambitionen, ihren kritischen Geist und das Leben als "gute Schwiegertochter“ in der transnationalen Familie in einem umfassenden biografischen ethischen Lebensentwurf verbinden. Durch Selbstdisziplin, Flexibilität und Opferbereitschaft kann sie einen allfälligen Autonomieverlust kompensieren und ihren bisherigen Lebensentwurf im Hinblick auf ein Leben in einer joint family im „neuen Indien“ sinnhaft reartikulieren. Jedoch war für sie nach der Feldforschung klar: „Im gleichen Haushalt mit den Schwiegereltern leben geht für mich nicht. Neben-, über-, 
untereinander wohnen ist ok, aber nicht miteinander." Mit diesen Vorstellungen bewegte sie sich angesichts der Pluralisierungen der Familienformen im „neuen Indien" keineswegs außerhalb der Normen weiblicher mittelständischer Respektabilität, sondern mitten im Trend.

\section{Asha: Weibliche Flexibilität zwischen neoliberaler Ressource und konservativer Disziplinierung}

Asha, 44-jährige Familienfrau, ist in der Schweiz aufgewachsen und lebt seit knapp zwanzig Jahren in Indien. Der Vater hatte in den 1990er Jahre seine Stelle als Informatiker in der Schweiz verloren. Begünstigt durch das indische Wirtschaftswachstum und den IT-Boom, versuchte er dann eine Rekrutierungsfirma für indische Software-Ingenieure aufzubauen und lebte jeweils mehrere Monate pro Jahr in Indien. Durch die zirkuläre Migration der Eltern und deren einstweiligen Rückkehrpläne hatte Asha einen guten Einblick in die kulturellen Veränderungen in den neuen Mittelschichten Indiens. Nach dem Abschluss der Handelsschule zog sie - zur Freude der Eltern - nach Indien, um ein College zu besuchen und ein Leben in Indien zu versuchen. Ohne das College abzuschließen, heiratete sie, 21-jährig, einen Mitstudenten und zog zu dessen Familie. Ihr Mann wollte sich nicht von seinen Eltern trennen und sie gab nach, um eine "gute indische Ehefrau zu sein“ und „alles richtig zu machen“. Nach der Heirat arbeitete sie in einer Deutschschule und unterstützte die Familie im Unternehmen. Im Rahmen des Wirtschaftswachstum hatte die Familie einen mittelständischen, konsumorientierten Lebensstandard erarbeitet und kämpft seither darum, diesen zu erhalten. Statt Diener wie bei Akash, leistete das solidarische Netz der patrilokalen Familie die Reproduktionsarbeit - mithilfe von sporadischen Haushaltshilfen. Seit der Geburt ihrer beiden Kinder konzentrierte sich Asha auf die Rolle als Mutter und Familienfrau. Neben Haushalt und familiären Verpflichtungen fiel ihr vor allem das Schulmanagement der Kinder im kompetitiven privaten Bildungssystem zu. Durch Haushaltsmanagement, Aufgabenhilfe und Shuttledienste für die Kinder trug sie tagtäglich zur Reproduktion zum Mittelschichtsstatus ihrer Familie bei.

Ich traf Asha in einem Café in einem edlen Quartiermarkt zu einem Gespräch. Wie sie am Telefon erzählt hatte, war ihre Familie geschäftlich gerade mit einem Großauftrag wegen Diwali beschäftigt. Gerne würde sie mich nach den Festivitäten zum Essen einladen und mir ihre Familie vorstellen. Nach einem ersten Kennenlernen stellte sich jedoch heraus, dass sie sich mit mir in einem Café treffen wollte, weil sie gerade verhindern wollte, dass ihr Mann und dessen Eltern von diesem Interview erfuhren. Ihr Leben in der joint family war seit einiger Zeit schwierig geworden, nachdem ihr Mann und seine Eltern Asha vorgeworfen hatten, eine Affäre mit dem Kinderarzt der Familie gehabt zu haben. Sie hatte dies nachdrücklich und glaubwürdig bestritten, was jedoch die Vorwürfe nicht entkräftete - eher im Gegenteil. Weil Asha in der Schweiz aufgewachsen war, nahmen ihr Mann und 
dessen Eltern an, dass sie potenziell) ein „loose girl“ sei. Dieses Narrativ über diasporische Frauen, das in den früheren NRI-Diskursen - etwa im Film „Purab aur Paschim“ - explizit beschrieben wurde, lebte in den neuen Mittelschichten in neuen Ausprägungen weiter. Während Asha sich durch diesen Konflikt eingestehen musste, dass ihr Mann und dessen Familie sehr konservativ waren, musste sie seither umso mehr ihre Rolle als „gute indische Frau“ legitimieren. Gerne hätte sie vorgeschlagen, mit ihrem Mann und ihren Kindern in die obere Wohnung des Hauses zu ziehen, um den Konflikt zu entschärfen. Stattdessen wartete sie, bis die Eltern dies selbst vorschlugen, um nicht erneut als respektlos und egoistisch dargestellt zu werden.

Ihre Eltern, die wieder in der Schweiz leben, versuchten sie zu überzeugen, sich scheiden zu lassen und in die Schweiz zurückzukehren. Asha wollte aber noch einmal versuchen, die Wogen zu glätten. Sie fände es unfair, so ihre Worte, den Kindern den Vater zu entziehen. Die rechtliche Situation war jedoch wahrscheinlich gerade umgekehrt: Ein Anspruch auf ein Sorgerecht würde Asha nach indischem Zivilrecht und Hindu-Familienrecht kaum gewährt werden. Weder würde ein indisches Gericht zulassen, dass sie mit den Kindern in die Schweiz zieht, weil deren Lebensmittelpunkt - Familie und Schule - in Indien sei. Auch könnte Asha kaum als alleinerziehende Mutter mit ihren Kindern in Indien leben, da gemäß herrschender Meinung ihr Mann den Kindern finanziell und sozial ein besseres Umfeld bieten könnte. In diesem Dilemma zwischen moralischer Disziplinierung und drohendem Verlust des Sorgerechts, war für sie klar, dass sie sich noch stärker den familiären Disziplinierungen und Geschlechternormen unterwerfen musste. Gleichzeitig nutzt sie ihren massiv geschrumpften Spielraum, um bei ihren Kindern zu sein und sich in der Familie als respektable mittelständische Ehefrau und Schweigertochter zu rehabilitieren. Allerdings hat sich ihre Evaluation der biografischen Entscheidungen, ein Leben in Indien zu versuchen und früh zu heiraten, verändert. Im Nachhinein sei ihr klar geworden, dass „dies alles zu früh gewesen sei“ und dass sie „hätte warten sollen mit all dem“. „Es sei einfach nicht fair“, wie ihr Leben verlaufen sei, hatte sie doch immer versucht „alles richtig zu machen“ und hatte sie doch „so viel für diese Familie aufgegeben“.

Nach diesem Treffen beantwortete Asha meine SMS nicht mehr. Stattdessen antwortete bei einem Anruf ihr Mann und teilte mir mit, dass Asha nicht interessiert sei, weiterhin an der Forschung teilzunehmen. Weiterhin schaue ich mir auf Facebook die von ihr hochgeladenen Familienfotos von ihr und ihren Kindern an und lese die geposteten Lebensweisheiten: „A healthy relationship will never require to sacrifice your friends, your dreams or your dignity.”

Die drei Beispiele von Sonia, Gayatri und Asha beschreiben verschiedene Aushandlungen diasporischer Subjektivierung von indischen Secondas aus der Schweiz in transnationalen Familiennetzwerken. Sonia, Gayatri und Asha verstanden die Heirat sowohl als Teil eines intergenerationellen Mobilitätsprojektes als auch eines 
sinnhaften biografisch-ethischen Projekts. Indem sie die Familienwerte der Eltern in ihre eigenen Biografien integriert hatten, bot für sie die Heirat in eine indische Familie eine durchaus sinnhafte transnationale Perspektive eines nicht-essenzialistischen Lebensentwurfes in einem Netz familiärer Solidarität. Im Kontext globaler indischer Moderne hatten sich Geschlechternormen, Heiratsregeln und Familienformen pluralisiert, wodurch neue Spielräume für die Aushandlung beruflicher Ziele, familiärer Erwartungen und persönlicher Ideale der Lebensführung entstanden waren. Zudem versprach das „neue Indien“ kulturelle Dynamik, berufliche Perspektiven sowie kosmopolitische Lebensstile.

Die Fallanalysen zeugen jedoch auch von den Verwerfungen in der globalen indischen Moderne, in denen traditionelle Familienformen mit konsumorientierten Lebensstilen kombiniert werden, um den Kampf um Status und Lebensstandard innerhalb der neuen Mittelschichten zu bestehen. Die Widersprüche in der hegemonialen Reartikulation der Nation zwischen westlichem Materialismus und indischen Familienwerten zeigen sich auf spezifische Weise in den Subjektivierungsprozessen von Frauen, Müttern und Schwiegertöchtern der Mittelschichten. Als wichtige Akteurinnen der Reproduktion von mittelständischem Lebensstandard und Status bewegen sie sich flexibel und versiert an der Grenze von Familie und öffentlicher Konsumkultur, zwischen „altem“ und „neuem Indien“. Gleichzeitig ist diese Flexibilität eng verbunden mit einer Selbstdisziplinierung im soziomoralischen Spannungsfeld zwischen kapitalistischer Bestätigung und patriarchalen Normen. Vor allem bei Asha, aber auch bei Gayatri zeigen sich die Tücken des Lebens in der patrilokalen mittelständischen joint familiy. In diesem hierarchischen System müssen sie sich als diasporische Schwiegertöchter immer wieder besonders bewähren, um Narrative fehlender Respektabiliät und mangelnder Aufopferung zu entkräften. Sonia, Gayatri und Asha handeln innerhalb dieser Konstellationen unterschiedliche Spielräume aus, um ihre biografisch-ethischen Lebensentwürfe verfolgen zu können. Sonia konnte durch transnationale Distanz am meisten Autonomie bewahren und ihren Lebensentwurf zwischen Karriere, transnationaler Familie und kosmopolitischem Lebensstil pflegen. Offen bleibt, wie sie ihren Lebensentwurf angesichts des Kinderwunsches und der kommenden Pensionierung ihres Schwiegervaters in Zukunft reartikuliert.

Auch Gayatri hat sich einen beträchtlichen Freiraum ausgehandelt, innerhalb dessen sie bereit ist, familiäre Verpflichtungen zu übernehmen. Das Leben in der joint family zeigte jedoch auch die Grenzen ihrer sinnhaften Verknüpfung von transnationaler Familie, professionellen Ambitionen und persönlichen Idealen. Asha hatte mit ihrer fragilen Ausbildungssituation und im Leben in der joint family beträchtlich weniger Autonomie. Als sie sich dem moralischen Vorwurf des Ehebruchs gegenübersah, offenbarte sich ihre strukturelle Verletzlichkeit als (diasporische) Frau in den umkämpften und unübersichtlichen Geschlechterordnungen der neuen Mittelschichten. Diese moralische Disziplinierung in der joint 
family stellt ihren bisherigen sinnhaften Lebensentwurf radikal infrage, ohne dass eine klare Alternative aufschiene.

Die Auswahl der Fälle suggeriert allenfalls eine zu starke geschlechtliche Trennung zwischen freiheitlicher Mobilität von männlichen Touristen und Managern und familiärer Disziplinierung von schweizerisch-indischen Frauen. Auch indische Secondas verfolgen berufliche Projekte, bewegen sich in der urbanen Konsumkultur und - abseits davon - auf touristischen Entdeckungstouren. Und auch schweizerisch-indische Männer - wenn nicht sogar öfter als Frauen - sind Ehen mit Personen indischer Herkunft eingegangen und sind einer starken moralischen familiären Disziplinierung ausgesetzt - wie etwa Anil (s. Exkurs Kapitel 5). Jedoch zeigt sich besonders bei der Heirat klar eine patriarchale Geschlechterordnung, die von Frauen trotz Flexibilisierungen eine strukturell stärkere moralische Selbstdisziplinierung erfordert - insbesondere in der patrilokalen joint family.

\subsection{Fazit: Privilegien UNd Ungleichieit IM „NEUEN INDIEN"}

Die Liberalisierungspolitik ab den 1990er Jahren hatte die Abkehr von einer Nehru'schen Modernisierung des Landes und von Gandhi'schen Werten der Bescheidenheit befördert. Stattdessen basierte das neue hegemoniale Projekt auf dem Versprechen von Wachstum und einer konsumstarken neuen Mittelschicht, die einen ureigenen indischen Anspruch auf den Kapitalismus und globale Macht verkörperte. In der populärkulturellen, politischen und sozialen Konstruktion der Nation als "globale indische Familie“ stellten diasporische Subjekte eine ideale Projektionsfläche für die Verknüpfung von „westlichem Materialismus“ und „indischen Werten“ dar. „Inder_innen der zweiten Generation“ aus der Schweiz hatten mit ihrem relativ großen ökonomischen und kulturellen Kapital einen privilegierten und äußerst kompatiblen Zugang zu den metropolitanen Räumen dieser neuen Mittelschichten.

Im Kontext des Indienhypes in der Schweiz ab dem Millenniumswechsel und des sich globalisierenden Indiens haben die Verflechtungen zwischen den Ländern stark zugenommen. Während der Feldforschung war es auffällig, wie viele „Inder_innen der zweiten Generation“ in den letzten zehn bis zwanzig Jahren transnationale Praktiken intensiviert oder Projekte lanciert haben: Yogakurse, Tanzprojekte, Traumhochzeiten, Forschungen, Heirat, Praktika, Jobs, Familienferien, Ferienwohnungen oder Entwicklungsprojekte sind nur einige der Projekte, die „Inder_innen der zweiten Generation“ aus der Schweiz vorantrieben. Zwischen warenförmiger Anerkennung in der Schweiz und diasporischer Teilhabe am „neuen Indien“ vermochten viele schweizerisch-indische Second@s die diffuse Erfahrung des Andersseins und die damit verbundenen biografischen Projekte zunehmend in transnationalen Lebenswelten zu verwandeln. 
Akash konnte sich angesichts der Expansion des Schweizer Kapitalismus in den „wilden Osten" als idealer interkultureller Brückenbauer für eine Schweizer Firma in Indien empfehlen. Damit konnte er einen spannenden Karrieresprung mit einem exklusiven kosmopolitischen Lebensstil und einem nostalgisch-intellektuellem Bildungsprojekt verknüpfen. Er entwickelte durch diese Erfahrungen zunehmend ein Ethos eines „kapitalistischen Kosmopoliten“, für den lokale Kulturen zu spannenden und wertvollen Objekten, Waren und Wissensbeständen in einer exklusiven und transnationalen Lebenswelt wurden. Die alltägliche Interaktion mit Dienern, Kellnern oder Arbeitern in der Fabrik erforderte jedoch eine ständige Legitimierung und Reproduktion des exklusiven Lebensstiles und offenbarte immer wieder aufs Neue die strukturelle Gewalt im „neuen Indien“.

In seinem touristischen Bildungsprojekt konnte Raj die biografisch-nostalgische Auseinandersetzung mit Indien mit seinem Sohn teilen sowie diesem eine kritische Auseinandersetzung mit globaler Ungleichheit vermitteln. Während sich Raj als Tourist und Familienmitglied früher immer außen vor gefühlt hatte, boten ihm das "neue Indien“ und die ethnische Vergemeinschaftung mit anderen Second@s in der Schweiz zunehmend eine kompatible und legitime diasporische Zugehörigkeit in einer globalen indischen Moderne.

Die drei Kurzbeispiele von Sonia, Gayatri und Asha nehmen die Bedeutung der Heirat von schweizerisch-indischen Secondas in der "globalen indischen Familie" in den Blick. Da sich die Geschlechternormen, Heiratsregeln und Familienformen in den "neuen Mittelschichten“ pluralisiert haben, versuchten sie allefamiliäre Erwartungen mit ihren professionellen Ambitionen und persönlichen Idealen verbinden. Die Fälle zeigen jedoch auch, dass Frauen und insbesondere Schwiegertöchter in der transnationalen Familie - und insbesondere in der patrilokalen joint family - einem beträchtlichen moralischen Druck ausgesetzt sind. Im Spannungsfeld von Selbstdisziplinierung und Flexibilität konnten sie Spielräume für die eigenen Lebensentwürfe aushandeln und gleichzeitig den eigenen mittelständischen Status in einer transnationalen Lebenswelt reproduzieren. Im Fall von Asha brachte jedoch gerade die Zuschreibung als NRI die strukturelle Verletzlichkeit von Frauen in den Mittelschichten zum Vorschein, die auf unterschiedliche Weise neoliberale Aspirationen mit konservativen Normen kombinieren müssen.

Die Fallanalysen haben mit Fokus auf Beruf, Tourismus und Familie gezeigt, dass „Inder_innen der zweiten Generation“ in der globalen indischen Moderne zunehmend transnationale Lebenswelten - wenn auch unterschiedlicher Dichte - etablieren. Diese Lebenswelten spannen komplexe hierarchische Räume und soziomoralische Beziehungen auf, die folgende analytische Schlüsse zulassen:

1. Die diskursiv-institutionelle Anerkennung der Zugehörigkeit zur indischen Nation befördert die biografisch eingeschriebene Suche nach nicht-essenzialitischen Subjektivitäten vor einem globalen Horizont. Transnationale Mobilität und neue Räume der Anerkennung von Mehrfachzugehörigkeit in Indien und der Diaspora 
erlauben, die assimilationistischen und exotisierenden Disziplinierungen in der Schweiz durch transnationale Praktiken und Imaginationen zu unterwandern. Diese Subjektivierungsprozesse sind eingebettet in transnationale Netzwerke, Organisationen und Diskurse - etwa das multinationale Unternehmen, den internationalen Tourismus, die globale Konsumkultur oder die transnationale Familie -, die ihrerseits hierarchisch gegliedert sind, disziplinierend wirken sowie neue Formen der Lebensführung ermöglichen oder erfordern.

2. In diesen transnationalen Lebenswelten verschieben sich die Positionen und Hierarchien innerhalb der eigenen „Migrationsfamilie“. Die institutionellen und diskursiven Räume der globalen indischen Moderne erlauben, die „Migrationsfamilie" als soziomoralische Ordnung zu überwinden und durch eigene Aushandlungen zu ergänzen. Gleichzeitig dient das soziale Kapital der Eltern und Verwandten als Ressource in den eigenen Vorhaben und Projekten. Dadurch werden die soziomoralischen familiären Bindungen verstärkt und gleichzeitig relativiert. Im Falle einer Heirat innerhalb der "globalen indischen Familie“ wird die soziomoralische Macht der Familie besonders deutlich. Während sie einerseits als Solidaritätsnetz fungiert und Geborgenheit verspricht, ist sie auch hierarchisch gegliedert und wirkt disziplinierend. Insbesondere für schweizerisch-indische Frauen erfordert dies eine intensive Selbstdisziplinierung, um persönliche Ideale, professionelle und familiäre Ziele sinnhaft zu verbinden.

3. Die Teilhabe an der globalen indischen Moderne ist eingebettet in die strukturelle Aushandlung sozialer Ungleichheit und postkolonialer Hierarchien. Die Integration Indiens in den globalen Kapitalismus wird von „Inder_innen der zweiten Generation" in einer besonderen Ambivalenz und Sensibilität erfahren, weil sie oft sowohl schweizerische als auch indische Diskurse oder Positionen kennen und weil sie die postkolonialen Veränderungen seit der Kindheit erlebt haben. Ihre transnationalen Lebenswelten stellen geradezu ein Prisma dar, das die politischen, kulturellen und ethischen Widersprüche auffächert, die mit den Verschiebungen postkolonialer Hierarchien im globalen dezentralen Kapitalismus verbunden sind. Während ihnen das „neue Indien“ neuerdings einen privilegierten und kompatiblen diasporischen Zugang gewährt, sind sie dadurch stärker in die Konstruktion sozialer Ungleichheit und die Reproduktion von Armut eingebunden. Zum einen erfahren sie das "neue Indien“ als kulturell dynamisch, zum anderen sehen sie darin auch eine Verwestlichung und einen Verlust von Authentizität, die sie aus Kindheitserfahrungen und (auto-)orientalistischen Diskursen imaginieren. Die Teilhabe an der globalen indischen Moderne erfordert eine ständige affektive und moralische Positionierung innerhalb dieser postkolonialen Verwerfungen - zwischen eurozentrischem Humanitarismus, familienspezifischen Privilegien und Kapitalismuskritik. Es ist symptomatisch für die Verschiebungen in den globalen Hierarchien, dass die bestehenden Diskurse, Subjektivitäten und Institutionen 
keine eindeutigen Positionen ermöglichen - weder im Westen noch in Indien noch mittendrin. 


\section{Schlusswort: Kosmopolitische Ethiken in einem dezentralen globalen Kapitalismus}

Die vorliegende Ethnografie behandelt die Subjektivierungsprozesse von „Inder_innen der zweiten Generation“" aus der Schweiz innerhalb einer sich wandelnden postkolonialen Welt. Ich habe insbesondere argumentiert, dass Subjektivierungsprozesse von „Inder_innen der zweiten Generation“ aus der Schweiz innerhalb des Kräftefeldes von Assimilation, kommerzieller Exotik und globaler indischer Moderne stattfinden. Ein biografisch-genealogischer Ansatz erlaubte dabei die historische Tiefe sowie die intime Natur aufzuzeigen, die diesen Prozessen zugrunde liegen. Zudem eröffnet sich durch die gewählte Herangehensweise ein kritischer und explorativer Blick auf die institutionellen und diskursiven Verhältnisse, innerhalb derer diese transnationalen Lebenswelten ausgehandelt werden.

Der erste Teil untersuchte, wie die assimilatorische Projektion eines „Lebens zwischen den Welten“, die die nationalstaatliche (und koloniale) Epistemologie von Nation und Migration prägt, in die Subjektivierungsprozesse von „Inder_innen der zweiten Generation“ eingeschrieben wurde. Diese omnipräsente Metapher diente sowohl als Imaginäres in der staatlichen Assimilationspolitik als auch als biografische Ressource von „Inder_innen der zweiten Generation“. Die rassialisierte Grenze von „migrantischer Familie“ und „nationaler Öffentlichkeit“ wurde ihnen zu einer zentralen lebensweltlichen Orientierung, was die Aushandlung von Räumen der Mehrfachzugehörigkeit maßgeblich erschwerte. Viele Protagonist_ innen dieser Ethnografie internalisierten stattdessen die assimilatorische Subjektivierungslogik und repräsentierten sich in der Öffentlichkeit nicht selbst als von der Norm abweichend. Ich habe dies in einem doppelten Sinne ein assimilatorisches Schweigen genannt, da erstens kaum anerkannte öffentliche Sprachen existierten, um die eigenen Erfahrungen des Andersseins zu äußern, und weil zweitens diese Erfahrungen kaum - weder im Sinne von Ausschluss noch von transnationaler Vielfalt - thematisiert wurden, geschweige denn öffentlich und gemäß eigener Definitionsmacht. Wenn auch „Inder_innen der zweiten Generation“ keine soziale Gruppe oder gar eine ethnische Gemeinschaft bildeten oder bilden, setzte die po- 
litische Konstruktion und intime Erfahrung des Andersseins vergleichbare und geteilte Subjektivierungsprozesse bei ihnen in Gang. Ich habe „Inder_innen der zweiten Generation“ insofern als „unmögliche Subjekte“ bezeichnet, als sie zwar machtvolle, biopolitische Erfahrungen des Andersseins erlebten, aber angesichts eines assimilatorischen Schweigens ihre Erfahrungen nicht-essenzialistischer und nicht-normativer Zugehörigkeit in intime biografisch-ethische Projekte kanalisierten. Innerhalb dieser Prozesse zeigte sich die Fähigkeit der interkulturellen Übersetzung, der sozialen Imagination sowie der kritischen Reflexion von Ausschlussprozessen als wichtige Ressource einer kosmopolitischen Selbstsorge.

Der zweite Teil behandelte, wie „Inder_innen der zweiten Generation“ diesen fragilen Formen der Lebensführung im Kontext der (Re-)Positionierung Indiens sowie der Schweiz im dezentralen globalen Kapitalismus immer mehr soziale Gestalt verliehen. Die wachsende Präsenz von Bollywood, indischer Kulinarik, Yoga oder indischer IT-Expertise in der urbanen Öffentlichkeit der Schweiz beförderten ab den späten 1990er Jahre Räume einer warenförmigen Anerkennung für schweizerisch-indische Second@s. Die Liberalisierung der indischen Märkte und eine neue Diasporapolitik boten „Inder_innen der zweiten Generation“ wiederum einen privilegierten Zugang zum urbanen Indien der „neuen Mittelschichten“. Diese Konfigurationen eröffneten neue biografische Optionen, professionelle Kanäle, soziale Netzwerke und öffentliche Repräsentationsräume. Sowohl der kommerzielle Multikulturalismus in der urbanen Schweiz als auch die globale indische Moderne in den urbanen Metropolen des Subkontinents beförderten Narrative, Bilder und Räume der Mehrfachzugehörigkeit und Hybriditäten, die für schweizerisch-indische Second@s neu und anschlussfähig waren, wenn auch gemäß bestimmten machtvollen Intersektionen von Geschlecht, Klasse und postkolonialer Position. Dies führte zu einer sozialen Ausdifferenzierung und Institutionalisierung ihrer biografisch-ethischen Aushandlungen des Andersseins.

Wie die Fallanalysen verdeutlichen, sind die individuellen Subjektivierungsprozesse innerhalb des erwähnten Kräftefeldes zwischen Assimilation, Exotik und globaler indischer Moderne sehr unterschiedlich verortet. Entsprechend möchte ich nicht den Anspruch erheben eine repräsentative oder abschließende Beschreibung von Fällen oder Typen präsentiert zu haben. Und doch, so die Hauptthese, stecken diese Subjektivierungslogiken das Kräftefeld ab, innerhalb dessen „Inder_innen der zweiten Generation" aus der Schweiz als spezifische Subjekte angerufen werden und sich als solche erfahren. ${ }^{98}$ In allen Fällen greifen diese Subjektivierungslogiken auf unterschiedliche und oft widersprüchliche Weise ineinander und schaffen Be-

98 | Eine wichtige Ausnahme könnten queere Positionen sein, die horizontale Formen der Solidarität stärken mögen (Gopinath 2005). Auch zu kurz kommen mögen postkoIoniale, politische und künstlerische Positionen, die sich aber auch gemäß intim-biografischer Projekte äußerten und sich in der Schweiz erst in der jüngeren antirassistischen Bewegung in horizontalen Allianzen zu artikulieren beginnen. 
dingungen für spezifische Strategien und Formen einer transnationalen Lebensführung, die Anerkennung und Ausschluss, Freiheit und Unterordnung sowie Mobilität und Lokalität verbinden: Die Investmentbankerin Sonia handelte ihre Bedürfnisse als emanzipierte Frau im Rahmen eines transnationalen Familienprojektes aus, wenn sie auch zweitweise die assimilatorische Stigmatisierung ihrer Peers aushalten musste, dass sie eine „arrangierte Hochzeit“ eingegangen sei. Der Unternehmensberater Aftab reagierte auf die Zumutung der Fremdzuschreibung, indem er als Junge seine Peers mit seinem interkulturellen Wissen konfrontierte, was ihm vielleicht das Etikett eines Besserwissers einbrachte, aber auch den Weg als Südasienkorrespondent und als Unternehmensberater im IT-Outsourcing ebnete. Maya wählte in einem spannungsvollen Prozess einen nonkonformistischen Lebensentwurf als Yoga-Lehrerin, um sich von ihren Eltern und von der Assimilationsgesellschaft abzugrenzen. Raj wiederum hatte als Jugendlicher im prekären Spannungsfeld zwischen Rassismuserfahrung und einem „abwesenden indischen Vater" ein nostalgisches Interesse an seiner indischen Herkunft entwickelt, das er mit Reisen und kultureller Bildung verfolgte. Durch freundschaftliche Beziehungen in seiner Wahlfamilie von "Indian sista's and brotha's" sowie durch Identitätskonsum in multikulturellen urbanen Szenen hat er gelernt, die Frage nach seiner Herkunft selbstbewusst auszuhandeln. Die Subjektivierungslogiken können sich auch im biografischen Verlauf verfestigen, aufweichen oder neu überlappen, wie etwa bei Bruno Ziauddin, dem Autor des Buches „Curry-Connection“ (s. Einleitung): Über vierzig Jahre lang hatte er versucht, das Assimilationsversprechen zu erfüllen und einzufordern. Nach dem Tod seines Vaters machte er sich auf die transnationale Suche nach „seinen Wurzeln“ und nutzte mit der Publikation des besagten Buches die Räume warenförmiger Anerkennung dafür, seine Mehrfachzugehörigkeit zu repräsentieren.

Im Zentrum dieser Ethnografie stand die Frage, welche transnationalen Lebensweisen „Inder_innen der zweiten Generation“ pflegen. Gemäß dem Ansatz einer genealogischen Ethnografie stand zudem das Interesse, wie an der Schnittstelle von Nationalstaaten, Kapitalismus und transnationaler Familie neue machtvolle Prozesse entstehen, die diese Subjektivierungen regulieren. Während die multilokale Ethnografie Subjektivierungsprozesse im Kontext von Assimilation, kommerzieller Exotik und globaler Moderne in den Blick nimmt, ist sie im Sinne von George Marcus gleichzeitig auch eine Fallstudie des „Weltsystems“ (Marcus 1995). Vor dem Hintergrund einer schweizerisch-indischen Verflechtungsgeschichte beleuchtet die Ethnografie daher auch, wie sich Diskurse, Institutionen, Netzwerke und Räume zwischen den 1990er und 2010er Jahren durch zunehmende globale Interdependenzen verändert haben. Sowohl in der Schweiz als auch in Indien wurden während der Forschung die umkämpften Prozesse und Widersprüche sichtbar, die in dieser historischen Phase mit der Repositionierung der lokalen Ökonomien in den globalen Kapitalismus verbunden waren. In Indien und in der Schweiz war und ist dieser Prozess verbunden mit einer sozial- 
strukturellen Verschiebung, in der sich urbane, global orientierte Mittelklassen zunehmend gegen „unten“ abgrenzen. Städtische Räume werden zunehmend für einen Dienstleistungskapitalismus und die Reproduktion dieser Mittelschichten umgebaut. Aufbauend auf diesen urbanen Knotenpunkten entstehen zunehmend transnationale Netzwerke, Institutionen und Ökonomien, die den dezentralen Kapitalismus steuern und die durch lokale, prekarisierte und oft migrantische Arbeiter_innenschichten aufrechterhalten werden.

Im Zug einer zunehmenden Dezentralisierung des Kapitalismus nach dem Kalten Krieg setzte der Aufstiegs Indiens und der anderen BRIC-Staaten die in den 1980er Jahre noch relativ machtvolle Unterscheidung von "Moderne" und "Tradition“ oder "West against the Rest" maßgeblich in Bewegung, pluralisierte und deplatzierte diese imaginäre Geografie. Dies zeigt sich ganz plastisch in den transnationalen Lebenswelten der Protagonist_innen dieses Buches: Die meisten erfuhren in ihrer Kindheit „Indien“ und die "Schweiz“ als zwei geografische Einheiten, die höchstens in der Familie, in Migrationsvereinen oder in religiösen Stätten temporär lebensweltlich verschmolzen. Internationale Telefongespräche waren teuer und statt Informationen auszutauschen, zählte es, die Stimmen der Angehörigen zu hören. Reisen nach Indien erschien immer auch als „Zeitreise“ in ein Entwicklungsland. Dieses „Leben zwischen den Welten“ spiegelte sich in den nationalen Mythen und der öffentlichen Kultur wider, wonach die Schweiz ein neutrales, humanitäres Land ohne koloniale Geschichte sei, und sich gegen Migration abschotten müsse, um den hart erarbeiteten Wohlstand zu bewahren. Indien wiederum war ein antikoloniales Projekt, das auf Importsubstitution setzte, den Westen kritisch beäugte und eine überlegene Moral von Säkularismus, Entwicklung und Tradition inszenierte. Die Versuche der Kinder indischer Migrant_innen, die eigene transnationale Normalität in Worte zu fassen und auszudrücken, mussten angesichts dieser hegemonialen Geografien regelmäßig scheiterten. Aber vor dem Hintergrund der neoliberalen Globalisierung schien sich die Welt ihrer Normalität zunehmend anzupassen: Die transnationale Spurensuche anhand der Biografien und Praktiken von schweizerisch-indischen Second@s zeigt sowohl in Erzählungen, Dokumenten aber auch on the ground (wie etwa an der Mega Mela), wie in den letzten zwanzig Jahren zwischen Indien und der Schweiz (und weiteren diasporischen Orten wie Großbritannien, Dubai oder den USA) immer mehr transnationale Netzwerke, Institutionen, Diskurse und Infrastrukturen entstehen, die lokale Prozesse und Strukturen verbinden. Diese Arbeit der transnationalen Artikulation und Übersetzung, die im Kontext der Globalisierung in beachtlicher Geschwindigkeit zunimmt, markierte seit jeher den lebensweltlichen Horizont von schweizerisch-indischen Second@s. Die kosmopolitische Selbstsorge, mit der sie versuchten, die Realität „hier" und die Realität „dort" respektive Selbst- und Fremdrepräsentation im eigenen Leben ineinander zu übersetzen und aufeinander zu beziehen, entspricht vor dem Hintergrund des dezentralen Kapitalismus immer mehr der geteilten Realität. Aus einem „Leben zwischen zwei Welten“ entstanden 
langsam veritable transnationale Lebenswelten. Aus „unmöglichen Subjekten“ wurden zunehmend „kosmopolitische Pioniere“.

\subsection{Kosmopolitische Subjekte: Zwischen Aspiration UND DISZIPLINIERUNG}

Seit den späten 1990er Jahren, also in der gleichen Zeit, in der sich auch die transnationalen Lebenswelten schweizerisch-indischer Second@s auszudifferenzieren begannen, entwickelte sich eine Debatte über einen „neuen Kosmopolitismus“ (Brennan 1997; Cheah/Robbins 1998; Beck 2000; Breckenridge et al. 2002; Appiah 2006; Gilroy 2006: Werbner 2008; Bhambra 2011; Römhild/Westrich 2013). Ein neuer globaler Horizont des Zusammenlebens war durch Migration, globalen Kapitalismus, Fundamentalismus und nationalistische Konflikte notwendig geworden und der Begriff des Kosmopolitismus bot einen Ansatzpunkt „for our need to ground our sense of mutuality in conditions of mutability, and to learn to live tenaciously in terrains of historic and cultural transition" (Breckenridge et al. 2002:4). Diese Debatte unterschied sich explizit vom philosophisch-normativen Projekt einer demokratischen Weltregierung im Sinne der europäischen Aufklärung. „We were interested to see, what new archives might be brought to bear on the analysis of cosmopolitanism; to discover whether the historical and, what is equally important geocultural perspective on the problem could be extended beyond the singular, privileged location of European thought and history." (Breckenridge 2001: 9f.).

Zum Einen drehte sich die Debatte also um eine postkoloniale Kritik an eurozentrischen Ansätzen, die Kosmopolitismus in einer Genealogie von griechischer Antike, Aufklärung und Europäischer Union ansiedeln (z.B. Beck 2000, 2006). Eine solche Perspektive auf das Konzept verschleiere die Rolle kolonialer und postkolonialer Verflechtungen, die die europäische Moderne und aufklärerische Konzepte erst hervorgebracht haben (Bhambra 2011; Buck-Morss 2011). Statt eines Universalismus, sei eine Provinzialisierung angesagt, die erst erlaube, die historischen (kolonialen) Bedingungen eines kosmopolitischen Europas wahrzunehmen und mit (nicht-europäischen) „Anderen“ in (kosmopolitischen) Kontakt zu treten: "The task now is a provincialized cosmopolitanism, that can learn from others, where we recognize that what they contribute is not a confirmation of what we already know, but the bringing into being of a new understandings relevant to the worlds we inhabit together." (Bhambra 2011:10)

Zum Anderen - und eng damit verbunden - beförderten die Debatten um einen „neuen Kosmopolitismus“ statt einer normativ-universalistischen Setzung ein empirisches Interesse für die vielfältigen Aushandlungsprozesse von „actually existing cosmopolitanisms“ an verschiedenen Orten der Welt (Robbins 1998) das heißt von „trans-ethnic, collectively emergent ,worlds' and shared discourses 
that transcend cultural boundaries and parochial lifestyles" (Werbner 2008: 50). Aus anthropologischer und postkolonialer Perspektive gelte es den Begriff insbesondere von einem elitären Verständnis zu befreien, wonach er eingebettet sei in einen kolonial-bürgerlichen und männlichen Habitus des Reisens und Forschens (Clifford 1997; van der Veer 2002), respektive in einen neuen Globalismus, personifiziert im transnationalen, professionellen "Vielflieger" (Brennan 1997; Calhoun 2002). Mit dem Fokus auf „vernacular cosmopolitanisms“ (Werbner 2006) sollten stattdessen empirische Grundlagen für neue Ethiken des Zusammenlebens im Kontext globaler Ungleichheit und postkolonialer Geografien erforscht werden.

Trotz der kontroversen Debatte um den Begriff des Kosmopolitismus erscheint er in seinem anthropologischen und postkolonialen Verständnis als treffend, um dem Material aus der Forschung und den vielen Begegnungen im Sinne eines ethnografischen Ausblicks noch eine weiterführende Bedeutung zu geben. Als doppelte Subjektivierung, das heisst als Lebensführung und Disziplinierung, durchzieht aus meiner Sicht ein kosmopolitischer Topos die transnationalen Lebenswelten von „Inder_innen der zweiten Generation“:

Einerseits entwickelten sie als Subjekte am Rande der Nation(en) (zwangsläufig) Praktiken individueller Lebensführung, in denen sie nicht-essenzialistische und nicht-normative kulturelle Zugehörigkeiten aushandeln (mussten). Die biografisch-intime Suche nach einem Umgang mit dem angeworfenen Anderssein äußerte sich immer auch als kosmopolitische Selbstsorge. Diese verband ein Wissen um Ausschluss und Fremdsein mit dem Wunsch, heimisch zu sein, und schrieb sich als Ressource und als Aspiration in die untersuchten Subjektivitäten ein.

Andererseits sind „Inder_innen der zweiten Generation“ in ihren transnationalen Lebenswelten als Akteur_innen beteiligt in der machtvollen Konstruktion von Diskursen, Institutionen, ethischen Räumen, Narrativen und Praktiken, in denen sich ein kosmopolitisches Versprechen manifestiert.

Im Sinne Arjun Appadurais (2013) lässt sich formulieren, dass die Protagonist_innen dieses Buches eine Aspiration nach einem guten Leben hegen, das auch kosmopolitisch sein soll. Unter „capacity to aspire“ würde dabei ihre Fähigkeit verstanden, sich das Wissen, die Metaphern, die Netzwerke, die Strategien, die Ressourcen und Imaginationen anzueignen, um die dominanten Machtverhältnisse im Sinne eines eigenen guten Lebens zu ändern. Im Versuch, die eigene „capacity to aspire" mit entsprechenden diskursiv-institutionellen Bedingungen in Kongruenz zu bringen, und sich dadurch Anerkennung und Definitionsmacht für das eigene Leben zu verschaffen, wäre also das Streben nach einem guten Leben bei "Inder_innen der zweiten Generation" angelegt.

Angesichts des hegemonialen assimilationistischen Regimes und der kleinen, heterogenen und verstreuten indischen Gemeinschaft in der Schweiz verfügten „Inder_innen der zweiten Generation" während ihrer Kindheit und Jugend kaum über kulturelle Räume für den Ausdruck solcher kosmopolitischer Aspirationen. Trotzdem experimentierten sie mit vorgefundenen Fragmenten und Artefakten, 
die ihnen versprachen, ihre Aspirationen umzusetzen, die sich immer wieder in konkreten kulturellen Praktiken äußerten: als Hippie mit ihren nonkonformistischen Peers wie Maya, als interkultureller Aufklärer wie bei Aftab, wie bei Raj als Fußballspieler mit anderen Secondos oder wie Sonia in Indienferien.

Die Herausbildung eines kommerziellen Multikulturalismus in der urbanen Schweiz beförderte ab den späten 1990er Jahren öffentliche Räume, in denen Mehrfachzugehörigkeit zunehmend sichtbar wurden. Zwar nutzten „Inder_innen der zweiten Generationen“ diese neuen repräsentationspolitischen Räume für erste professionelle Projekte oder für die Performanz kosmopolitischer Lebensstile. Jedoch widersetzten sie sich den exotisierenden Zumutungen der Dominanzgesellschaft kaum öffentlich, sondern eher in privaten Räumen. Trotz der selektiven Flexibilisierung assimilatorischer Normen ab den 1990er Jahren und einer wachsenden rassismuskritischen Migrationsrechtsbewegung existierte in der Schweiz noch keine kritische politische Kultur, die eine „interkulturelle Öffnung“ der Gesellschaft hätte durchsetzen können (Terkessidis 2010). Stattdessen kanalisierten die schweizerisch-indischen Second@s, die ich getroffen habe, ihre kosmopolitischen Aspirationen ab den 1990er Jahren oft anderweitig: Angesichts des neuen legitimen und kompatiblen Zugangs zu einer globalen indischen Moderne und vor dem Hintergrund eines Indienhypes entwickelten „Inder_innen der zweiten Generation“ transnationale Strategien, um ihre Aspiration zu erfüllen. Durch diesen „Transnationalismus von unten“ konnten viele die assimilatorischen und exotisierenden Zuschreibungen in der Schweiz relativieren, ja provinzialisieren, und sich im „neuen Indien“ oder an anderen diasporischen Orten den Zugang zu neuen öffentlichen Arenen kosmopolitischer Anerkennung eröffnen.

Diese Realisierung kosmopolitischer Aspirationen wird jedoch nicht im luftleeren Raum vollzogen, sondern im Rahmen spezifischer transnationaler Institutionen, Netzwerke, Diskurse und Normen: in der Familie, in multinationalen Organisationen, in der globalen Populärkultur, im Tourismus. Trotz mannigfaltiger Unterschiede sind diese verschiedenen transnationalen Institutionen durch kosmopolitische Normen und Narrative geprägt, die die Überschreitung nationaler und ethnischer Grenzen postulieren und daher „Inder_innen der zweiten Generation“ versprechen, ihre Aspirationen erfüllen zu können. Die „Assimilation in transnationale Institutionen“ (Bommes 2005) eröffnet dabei zwar legitime Räume des Andersseins und der Mehrfachzugehörigkeit, erfordert jedoch gleichzeitig die Aneignung neuer Disziplinierungen, Normen und Ethiken. So konnte Maya ihren Lebensentwurf der Selbstverwirklichung in der globalen Yoga-Gemeinschaft vollziehen, musste sich dazu aber gleichzeitig ein moralisches und körperliches Regime der Askese sowie die Bedingungen des Yoga-Marktes in der neoliberalen global city verhandeln. Akashs Ethos als „kapitalistischer Kosmopolit“ war eingebettet in die Hierarchien, Diskurse und Normen seines transnationalen Unternehmens. Zur Erhaltung des Status' und zur Förderung seiner Karriere musste er geografisch und zeitlich höchst flexibel sein, und er musste nolens volens Diener, 
Chauffeure und Mitarbeiter managen. Sonia war in die sozialmoralischen Räume der multinationalen Unternehmung und der transnationalen Familie eingebettet und versuchte, kosmopolitischen Lifestyle, lange Arbeitszeiten und weibliche Respektabilität in der Familie aufrechtzuerhalten. Für sie, Gayatri und Asha verspricht die Perspektive eines Lebens in der joint family eine soziomoralische Verankerung in einem System der Solidarität, erfordert aber auch eine starke Selbstdisziplinierung und Flexibilität - und im Falle von Asha möglicherweise existenzielle Formen der Selbstverleugnung. Schweizerisch-indische Männer, die wie Anil in der joint family leben, sehen sich neben dem Segen mütterlicher Sorge auch den präskriptiven Zwängen im Hinblick auf Männlichkeitsnormen und patriarchale Hierarchien ausgesetzt.

Die kosmopolitischen Ethiken und Aspirationen, die „Inder_innen der zweiten Generation“ in diesen machtvollen transnationalen Organisationen und Netzwerken aushandeln, verweisen dabei konstitutiv auf ihre Positionierungen in einer transnationalen Mittelschicht, die unausweichlich eine Auseinandersetzung mit den Prozessen und Strukturen globaler Ungleichheit mit sich bringen.

\subsection{Das „Kosmopolitische” als hegemoniale Signatur EINES DEZENTRALEN KapitalismuS}

Ein kritischer Blick auf die Räume, in denen die Subjektivierungsprozesse von „Inder_innen der zweiten Generation“ stattfinden, offenbart eine spezifische Verwertbarkeit von Hybridität und Authentizität in einem flexibilisierten, dezentralen Kapitalismus. Dies wird besonders deutlich im Falle von ethnic entrepreneurship und bei Karrieren im Umfeld multinationaler Unternehmen. Bei Akash und Aftab erschien die indische Herkunft für Schweizer Unternehmen als Schlüsselqualifikation im Hinblick auf deren Expansion nach Indien. Wurden indische Migrant_innen in der Schweiz vor dreißig Jahren aufgefordert, je nach Sprachregion Deutsch, Französisch oder Italienisch mit ihren Kindern zu sprechen, gelten nun Sprachkenntnisse, interkulturelle Kompetenz und kulturelles Wissen als unbezahlbare soft skills in der transnationalen Allokation und Akkumulation von Kapital. In der global city wiederum verspricht der Konsum von indischen Exotika einer urbanen Mittelschicht einen kosmopolitischen Lifestyle und dadurch die performative Teilhabe an einer ungleichen Globalisierung. Im Falle von Maya wird dabei ihre Herkunft - ohne dass sie das will - durch die multikulturelle Kommerzialisierung des Yogas immer auch zu einer Markierung von Authentizität und Expertise.

Vor diesem Hintergrund muss das im Topos des Kosmopolitischen repräsentierte utopische Versprechen „of reaching out across cultural difference with dialogue, aesthetic enjoyment and, respect“ (Werbner 2008: 2) auch als kulturelle Signatur einer dezentralen kapitalistischen Globalisierung gelesen werden. Kosmopolitische Semantiken und Strategien in staatlichen Institutionen, in den ex- 
pandierenden Gefilden der Wirtschaft und in der globalen Populärkultur ermöglichen es, erstens verschiedene Lokalitäten sinnhaft zu verknüpfen und zweitens durch die Verwertung von Hybridität - als Semantik und als Qualität von Humankapital - neue Akkumulationsmöglichkeiten zu etablieren (Ha 2005). Demnach wird in den kapitalistischen Institutionen und in der Konsum- und Populärkultur und im Alltag einer globalen Mittelschicht ein hegemoniales, kosmopolitisches Imaginäres perpetuiert, das machtvoll suggeriert, dass Freiheit, transnationale Mobilität und Humanismus eine Funktion von frei fließendem Kapital darstellen, und umgekehrt, dass der transnationale Fluss des Kapitals im Rahmen eines liberalen Konsenses stattfinde (Brennan 1997).

Ein Blick auf die Möglichkeitsbedingungen der transnationalen Subjektivierungsprozesse von „Inder_innen der zweiten Generation“ offenbart diese kosmopolitische Signatur jedoch als Markierung von sozialer Ungleichheit und verweigerter Repräsentation im Kontext neoliberaler Globalisierung (Cheah 2006). Zweifellos verfügten „Inder_innen der zweiten Generation“ angesichts des Assimilationsregimes und über ihre postkoloniale Positionierung lange über beschränkte Möglichkeiten der Selbstrepräsentation. Aber Mittelschichtszugehörigkeit, ein positives Image von „Indianness“ im Westen sowie der globale Aufstieg Indiens erlauben ihnen zunehmend eine vorteilhafte Position innerhalb einer globalen, postkolonialen Moderne einzunehmen. Während indische Second@s in der Schweiz als „coole oder exotische Kosmopoliten“ gelten, werden Migrant_innen aus der Unterschicht - vor allem mit ex-jugoslawischem Hintergrund und/oder islamischer Religionszugehörigkeit - als „unassimilierbare und ethnische Andere" kriminalisiert, diszipliniert und ausgegrenzt. Auch im Sinne einer selektiven Staatsbürgerschaftslogik versuchte der indische Staat mit seinem Overseas Citizenship of India Scheme nur diejenigen, „neueren“ Teile der Diaspora im Westen zu gewinnen, die zum großen Teil aus der Mittelschicht stammen und Investitionen versprechen. Den Angehörigen der „älteren“ Diaspora in Afrika, der Karibik oder im Indischen Ozean mit meist ländlichem Hintergrund wurden diese Rechte erst auf massiven Protest hin gewährt. Darüber hinaus wird der kosmopolitische Lebensstil in den urbanen Enklaven der indischen Mittelschicht ermöglicht durch die Arbeit von Diener_innen, Chauffeuren, Kindermädchen und Kellner_innen, die oft in den Slums leben und der ständigen Drohung ausgesetzt sind, den zukünftigen Malls, Restaurants und Siedlungen des „globalen Indiens“ weichen zu müssen. „Inder_innen der zweiten Generation“ eröffnet diese als kosmopolitisch markierte öffentliche Kultur zweifellos Räume der Anerkennung, neue berufliche Opportunitäten und exklusive Lebensstile. Gleichzeitig manifestieren sich in ihren Lebenswelten dadurch die mannigfaltigen Kämpfe um Teilhabe an Wohlstand, Freiheiten und Rechten im dezentralen globalen Kapitalismus.

Die kosmopolitischen Aspirationen von „Inder_innen der zweiten Generation" markieren dabei familiäre Strategien, um an einer privilegierten und mobilen globalen Mittelschicht teilzuhaben, die sich seit dem Kolonialismus entwickelt hat 
und sich im dezentralen Kapitalismus vergrößert und ausdifferenziert. Die Migration in die Schweiz war für die Eltern der Protagonist_innen eine Strategie, um transnationale soziale Mobilität zu erreichen und ihre Aspirationen nach einem guten Leben für sich und ihre Kinder zu erfüllen. Ihr Ziel war es in den meisten Fällen, das Mobilitätsprojekt innerhalb der Familiennormen zu perpetuieren, was im Falle von Sonia oder Akash gelang. Das soziale Mobilitätsprojekt kann jedoch auch zu prekären Ergebnissen führen, wenn insbesondere die Bildungsanforderungen nicht erfüllt werden (wie bei Anil), ein College-Abschluss zugunsten konservativer Geschlechternormen geopfert wird (wie bei Asha). Maya wiederum verfolgte ihren Weg in die globale Mittelschicht auf Wegen einer globalen Gegenmoderne und Raj schaffte es ohne soziales und kulturelles Kapital der Eltern auf eigene Faust.

Die Positionierung im Westen bietet zwar weiterhin strukturelle Privilegien beim Zugang zur globalen Mittelschicht. Jedoch hat sich die Ausgangslage im dezentralen Kapitalismus verändert. Wirtschaftliche Integration, Medien, Migration und Telekommunikation haben sowohl globale soziale Statussysteme und eine hegemoniale globale Kultur hervorgebracht, in welchen die aufstrebenden Mittelschichten aus der ganzen Welt ihre Aspirationen geltend machen (Dirlik 2003). Die Ethnografie eröffnet dabei einen Blick auf eine werdende, globale Klassengesellschaft, in der Teilhabe an Ressourcen und Anerkennung zwar weiterhin gemäß Klasse, Geschlecht und der Positionierung in einer postkolonialen Hierarchie reguliert werden, aber in der der Unterschied zwischen dem „Westen“ und dem „Rest" abnimmt. Anja Weiss bettet in ihrer Forschung über hochqualifizierte Inder_innen - in Anlehnung an Pierre Bourdieus Kapitaltheorie - deren Statusaspirationen und Mobilitätsprojekte in einen globalen Rahmen ein (Weiss 2005). Transnationales Kapital erlaube es, kulturelles, soziales und ökonomisches Kapital in globalen Netzwerken innerhalb der postkolonialen Geografie zu verwandeln. Boris Nieswand spricht in seiner Studie über ghanaische Migrant_innen von einem "Statusparadox“, um auf die komplexen Übersetzungsprozesse von unterschiedlichen Kapitalien zwischen zwei lokalen Statussystemen zu beschreiben (Nieswand 2011). In diese Statussysteme sind „Inder_innen der zweiten Generation" eingebettet und in Anlehnung an Bourdieu können kosmopolitische Lebensstile als spezifische Praktiken der Distinktion verstanden werden, durch die Positionen in einer globalen Mittelschicht - und zwischen unterschiedlichen Segmenten davon - erkämpft werden.

Während sich in diesen globalen Mittelschichten zwar gemeinsam referenzierte globale Kulturen und Statussysteme herausbilden, werden darin weiterhin postkoloniale Verwerfungen sichtbar, in denen sich die Interessen ihrer aufstrebenden Mittelschichten (in Indien) oder ihren etablierter Mittelschichten (in der Schweiz) angesichts der Verschiebungen in den globalen Hierarchien zeigen. 


\subsection{Postkoloniale Verwerfungen: Ausblick auf REPRÄSENTATIONSPOLITIK UND ETHIK IN EINER GLOBALEN ÄRA}

Am Phänomen des Bollywood-Kinos, das sich als "Swiss-Indian Love-Story“ durch diese Arbeit zieht, zeigen sich diese postkolonialen Verwerfungen im dezentralen globalen Kapitalismus sehr anschaulich. Während die Präsenz und der Konsum der Bollywood-Industrie sowohl in den urbanen Räumen im „neuen Indien" als auch im kommerziellen Multikulturalismus der Schweiz die Integration in einen dezentralen globalen Kapitalismus markieren, sind die damit verbunden affektiven Politiken unterschiedlich. Im „neuen Indien“ artilkulieren die hybriden Ästhetiken und diasporischen Narrative, die das Bollywood-Kino ab den 1990er Jahren hervorgebracht hat, den euphorischen wirtschaftsnationalistischen Anspruch auf den „globalen Kapitalismus“. In der Schweiz wiederum wurde das Bollywood-Kino - im Gegensatz zum angeblich „realistischen“ Hollywood-Kino - als exotischer Kitsch rezipiert, was einerseits die westliche Überlegenheit bestätigte und andererseits eine orientalistische Faszination auslöste. In dieser Exotisierung zeigt sich eine Spannung zwischen "postkolonialer Verunsicherung“ (postcolonial anxiety) und einer kapitalistischen Expansion in die „neuen“ Märkte Indiens (Jain 2015): Der Aufstieg Indiens von einem Entwicklungsland zu einem global player vollzieht sich nicht nur auf einer politisch-ökonomischen sondern genauso konstitutiv auf einer kulturellen Ebene. Genauso wie in Indien eine neue hegemoniale Konstruktion der Nation notwendig wurde, um die Integration in den globalen Kapitalismus sinnhaft zu machen und zu legitimieren, erfordert der dezentrale Kapitalismus angesichts der Verschiebung postkolonialer Hierarchien eine ähnliche kulturelle und politische Repositionierung der Schweiz. Die Dichotomien eines materiell armen, politisch korrumpierten, aber spirituell reichen Indien einerseits eines materiell reichen, politisch rationalen und spirituell verkümmerten Westens andererseits, auf dem die schweizerisch-indischen Beziehungen lange Zeit basierten, sind ins Wanken geraten. Die politischen Narrative, affektiven Bewegungen und ethischen Haltungen, die diese generiert haben - wie etwa Eurozentrismus und Humanitarismus - korrespondieren nicht mehr sinnhaft mit den Erfahrungen historischer Ereignisse: Armut und IT-Ingenieure, Gurus und Wolkenkratzer erscheinen als monströse Widersprüche, welche die postkolonialen Geografien und Hierarchien sprengen.

Die sinnhafte Reartikulation dieser postkolonialen Hierarchien und der mit ihnen verbundenen Diskurse, Narrative, Identitäten und Imaginationen wird durch die Komplexität der Information und der multiplen Perspektiven, die die zirkuläre Dynamik in der globalen Öffentlichkeit auszeichnen, zusätzlich erschwert. Dies wurde in der globalen Rezeption des britisch-indischen Filmes „Slumdog Millionnaire“ (2008) des britischen Regisseurs Danny Boyle deutlich, der acht Oscars gewann (u.a. für den besten Film, den besten Regisseur und die beste Filmmusik). 
Der Film beschreibt in einem ironischen Genre-Mix aus Pulp, Gangsterfilm und Bollywood, die Geschichte des Kellners Jamal, der im Slum und als Straßenjunge aufgewachsen ist und unerwartet die bekannteste TV-Quizshow des Landes gewinnt. Durch seine Präsenz im Fernsehen kann er seine Kindheitsfreundin Latika wiederfinden. Gemeinsam schaffen sie es, gegen die Interessen von Gangstern und der Fernsehindustrie ein neues Leben zu beginnen. Während der Erfolg des Films in den englischsprachigen Medien der indischen Mittelschicht wegen des Oscar-Segens (unter anderem für den Bollywood-Komponisten A.R. Rahman) zuerst eine nationale Euphorie auslöste, wurden mit der Zeit auch kritische Stimmen laut. Erstens wurde debattiert, ob der Film eine indische oder eine britische Produktion darstelle, da er zwar in Indien spiele, aber von einem britischen Regisseur stamme. Nicht zu Unrecht wurde bemängelt, dass Filme von indischen Regisseuren, wie etwa „Lagaan“ im Oscar-Wettbewerb in der Kategorie „fremdsprachiger Film“ beurteilt würden. Zweitens wurde mit grosser Unterstützung aus der Diaspora aus Europa und Nordamerika kritisiert, dass der Slum-Topos im Film ein ethnozentrisches Bild von Indien als armem Land verbreite und den Wandel des „neuen Indiens“ ausblende. Diese transnationale Debatte wurde wiederum dadurch kompliziert, dass Bewohner_innen des Slums Dharavi gegen den Film mit dem Slogan „We are no dogs“ protestierten und dadurch öffentliche Sichtbarkeit erlangen konnten. Damit machten sie deutlich, dass sowohl die westliche Ästhetisierung des Slum-Topos als auch die Fragen postkolonialer Repräsentationspolitik eigentlich realitätsferne Debatten einer globalen Mittelschicht darstellten, deren Distinktion und Wohlstand sich durch Ausbeutung und Ausschluss der Menschen in Slums konstituieren. Die Konsequenz in der Schweiz war wiederum, dass das Schweizer Fernsehen - aufgrund einer Kombination aus Bollywood-Hype und Humanitarismus - eine sozialromantische Sommerserie sendete, in der die beliebte Nachrichtensprecherin Susanne Wille direkt aus dem Mega-Slum Dharavi in Mumbai berichtete, wo der Film „Slumdog Millionnaire“ unter anderem gedreht wurde.

Die Widersprüche, die im Film „Slumdog Millionnaire“ und in dessen Rezeption zum Vorschein kamen - und die ich hier nicht einmal ansatzweise durchdringen konnte (Gehlawat 2013) -, verweisen auf die moralischen und politischen Verwerfungen in den postkolonialen Machtverhältnissen: Der Film nutzt die Widersprüche des „neuen Indiens“ als spannende Kulisse für einen unkonventionellen, ästhetisch hybriden Film, der sowohl die kosmopolitischen Bedürfnisse der Mittelschichten im Westen wie in der globalen indischen Moderne anspricht. Segmente indischer Mittelschichten begehrten gegen den Westen auf und genossen trotzdem dessen Aufmerksamkeit. Angehörige der Slums gewannen Sichtbarkeit mit ihrer Kritik, worauf sie die Solidarität sozialkritischer, mittelständischer Segmente in Indien und der sozialromantischen Schweizer Öffentlichkeit erfuhren. Wer hat in dieser postkolonialen Repräsentationspolitik die Definitionsmacht über das Bild „Indiens“, respektive des „Slums“? Wie hängen eine postkoloniale 
Repräsentationspolitik und die Frage globaler Ungleichheit zusammen? Und, wie sind Kritik und Solidarität über globale Klassengrenzen und postkoloniale Verwerfungen hinweg möglich? Angesichts der Komplexität dieser globalen, multiperspektivischen Öffentlichkeit, aber auch weil für diese Fragen die Ressourcen und Räume einer globalen Ethik und Repräsentationspolitik sich erst entwickeln, sind eindeutige Positionen in der Debatte, die der Film eröffnete, kaum möglich.

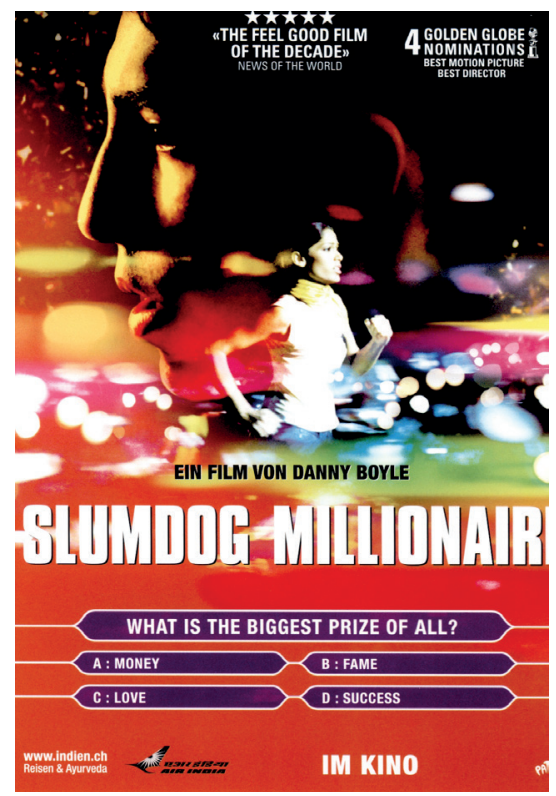

Abbildung 27: Testfeld für eine kommende postkoloniale Repräsentationspolitik, Postkarte „Slumdog Millionaire“ (Quelle: Autor)

Transnationale Subjektivierungsprozesse von „Inder_innen der zweiten Generation" sind auf eine spezifische Weise mitten in diese postkolonialen Verwerfungen einer schweizerisch-indischen Verflechtungsgeschichte eingebettet. In ihren kosmopolitischen Ethiken und Aspirationen sind „Inder_innen der zweiten Generation" bestrebt, die eigenen Erfahrungen des Andersseins legitim zu repräsentieren und sich eine passende Nische in einer globalen Mittelschicht zu erarbeiten. In diesen transnationalen Prozessen sind sie mit Widersprüchen zwischen Anerkennung und Exotisierung (in der Schweiz) oder mit Privilegien und Armut (in Indien) konfrontiert. Sie müssen sich ethische und politische Positionen erarbeiten, um der globalen, sozialen Ungleichheit in ihren Lebenswelten begegnen $\mathrm{zu}$ können, und artikulieren dafür neue Argumente, Narrative und Praktiken. Andererseits müssen sie eine Repräsentationspolitik entwickeln, wie sie selbst über sich als postkoloniale Subjekte, aber auch über Indien oder den Westen sprechen 
wollen. Wie durch ein Prisma fächern daher die transnationalen Subjektivierungsprozesse von „Inder_innen der zweiten Generation“ die gegenwärtigen ethischen und politischen Widersprüche und Fragen in einem dezentralen Kapitalismus auf. Im Geiste dieser Ethnografie ist anzunehmen, daß sich in den lebensweltlichen "Archiven“ dieser „kosmopolitischen Pioniere“ schon die Fragen der Zukunft abzeichnen. 


\section{Bibliografie}

Ahmed, Sara (2012): On Being Included: Racism and Diversity in Institutional Life. Durham/London: Duke University Press.

Alexander, Claire E. (2000): The Asian Gang: Ethnicity, Identity, Masculinity. Oxford: Berg.

Allenbach, Brigit (2011): „Made in Switzerland“: Erzählungen über Religion und Zugehörigkeit von Secondos / Secondas aus Südosteuropa. In: Allenbach, Brigit/ Goel, Urmila/ Hummrich, Merle/ Weissköppel Cordula (Hrsg.): Jugend, Migration und Religion - Interdisziplinäre Perspektiven. Baden-Baden: Nomos. S. 199-224.

Alter, Joseph (2004): Yoga in Modern India: The Body Between Science and Philosophy. Princeton: Princeton University Press.

Anderson, Benedict (1996): Die Erfindung der Nation: Zur Karriere eines folgenreichen Konzepts. Frankfurt/New York: Campus.

Anthias, Floya (1998): Evaluating „Diaspora“: Beyond Ethnicity? In: Sociology 32(3), S. 557-580.

Anthias, Floya (2001): New hybridities, old concepts: the limits of. In: Ethnic and Racial Studies 24(4), S. 619-641.

Apitzsch, Ursula (1990): Migration und Biographie. Zur Konstitution des Interkulturellen in den Bildungsgängen junger Erwachsener der 2. Migrantengeneration. Habilitationsschrift Unversität Bremen.

Apitzsch, Ursula (2006): Die Migrationsfamilie: Hort der Tradition oder Raum der Entwicklung interkultureller biografischer Reflexivität? In: Badawia, Tarek/ Luckas, Helga/ Müller, Heinz (Hrsg.): Das Soziale gestalten. Über Mögliches und Unmögliches der Sozialpädagogik. VS Verlag für Sozialwissenschaften.

Appadurai, Arjun (1996): Modernity at Large. Cultural Dimensions of Globalization. Minneapolis: University of Minnesota Press.

Appadurai, Arjun/Breckenridge, Carol A. (1995): Public Modernity in India. In: Breckenridge, Carol A. (Hrsg.): Consuming Modernity. Public Culture in a South Asian World. Minneapolis/London: University of Minnesota Press. S. $1-22$. 
Appaduari, Arjun (2013): Future as Cultural Fact: Essays on the Global Condition. London: Verso.

Appiah, Anthony (2006): Cosmopolitanism: Ethics in a World of Strangers. New York: W.W. Norton \& Co.

Argast, Regula (2007): Staatsbürgerschaft und Nation: Ausschliessung und Integration in der Schweiz 1848-1933. Göttingen: Vandenhoeck \& Ruprecht.

Argast, Regula (2010): „Wenn er aber Vogelfallen aufstellt, so bleibt er ein Fremder“: Kategorien von Ungleichheit und Gleichheit im schweizerischen Assimilationsdiskurs 1919-2000. In: David, Thomas/Groebner, Valentin/ Schaufelbuehl Janick/ Studer, Brigitte (Hrsg.): Die Produktion von Ungleichheiten = La production des inégalités. Zürich: Chronos. S. 183-194.

Augé, Marc (1994): Orte und Nicht-Orte: Vorüberlegungen zu einer Ethnologie der Einsamkeit. Frankfurt a. M.: Fischer.

Aumüller, Jutta (2009): Assimilation. Kontroversen um ein migrationspolitisches Konzept. Bielefeld: Transcript.

Axel, Brian Keith (2002): The Diasporic Imaginary. In: Public Culture 14(2), S. 411-428.

Bach, Olaf (2013): Die Erfindung der Globalisierung: Entstehung und Wandel eines zeitgeschichtlichen Grundbegriffs. Frankfurt a. M.: Campus.

Bacon, Jean (1996): Life Lines: Community, Family, and Assimilation among Asian Indian Immigrants. New York: Oxford University Press.

Balibar, Étienne/Wallerstein, Immanuel (1990): Rasse - Klasse - Nation: Ambivalente Identitäten. Hamburg/Berlin: Argument.

Ballard, Roger (1994): Desh Pardesh: The South Asian Presence in Britain. London: C. Hurst and Co.

Banerjea, Koushik (2000): Sounds of Whose Underground? The Fine Tuning of Diaspora in an Age of Mechanical Reproduction. In: Theory, Culture \& Society 17(3), S. 64-79.

Barth, Fredrik (Hrsg.) (1969): Ethnic groups and boundaries. The social organization of culture difference. Bergen/London: Universitetsforlaget, Allen \& Unwin.

Bates, Crispin (Hrsg.) (2001): Community, Empire and Migration. South Asians in Diaspora. New Delhi: Orient Longman.

Bauböck, Rainer/Faist, Thomas (2010): Diaspora and Transnationalism: Concepts, Theories and Methods. Amsterdam: Amsterdam University Press.

Bauman, Zygmunt (1998): Moderne und Ambivalenz. In: Bielefeld, Uli (Hrsg.): Das Eigene und das Fremde: Neuer Rassismus in der alten Welt? Hamburg: Junius. S. 23-49.

Baumann, Gerd (1996): Contesting Culture. Discourses of Identity in Multi-Ethnic London. Cambridge et al.: Cambridge University Press.

Beck, Ulrich (2000): The cosmopolitan perspective: sociology of the second age of modernity. In: British Journal of Sociology 51(1), S. 79-105. 
Beck, Ulrich (2004): Der kosmopolitische Blick oder: Krieg ist Frieden. Frankfurt a. M.: Suhrkamp.

Beltz, Johannes (Hrsg.) (2004): Hindu-ABC. Zürich: Verlag Museum Rietberg.

Berlin, Isaiah (1997): Nationalism: Past Neglect and Present Power. In: Hardy, Henry/Hausheer, Roger (Hrsg.): The Proper Study of Mankind: An Anthology of Essays. London: Chatto \& Windus. S. 581-604.

Bhabha, Homi K. (2000): Die Verortung der Kultur. Tübingen: Stauffenburg Verlag.

Bhabha, Homi K./Rutherford, Jonathan (1990): The Third Space. Interview with Homi Bhabha. In: Rutherford, Jonathan (Hrsg.): Identity: Community, Culture, Difference. London: Lawrence \& Wishart. S. 207-221.

Bhachu, Parminder (1985): Twice migrants: East African Sikh settlers in Britain. London/New York: Tavistock Publications.

Bhambra, Gurminder K. (2007): Rethinking modernity: postcolonialism and the sociological imagination. Basingstoke: Palgrave Macmillan.

Bhambra, Gurminder K. (2011): Cosmopolitanism and Postcolonial Critique. In: Rovisco, Maria/ Novicka, Magdalena (Hrsg.): Ashgate Research Companion to Cosmopolitanism. Aldershot: Ashgate, S. 313-28.

Bhambra, Gurminder K. (2014): Connected Sociologies. London/New York: Bloomsbury.

Bhatt, Amy/Murty, Madhavi/Ramamurthy, Priti (2010): Hegemonic Developments: The New Indian Middle Class, Gendered Subalterns, and Diasporic Returnees in the Event of Neoliberalism. In: Signs 36(1), S. 127-152.

Bhatt, Chetan/Mukta, Parita (2000): Hindutva in the West: Mapping the Antinomies of Diaspora Nationalism. In: Ethnic and Racial Studies 23(3), S. 407-441. Bhattacharyya, Gargi (1998): Riding Multiculturalism. In: Bennett, David (Hrsg.): Multicultural States: Rethinking Difference and Identity. London/New York: Routledge. S. 252-266.

Billig, Michael (1995): Banal Nationalism. London/Thousand Oaks: Sage.

Boissier, Edmond (1909): Denkschrift über die Assimilation der Ausländer in der Schweiz. o.A.

Bojadžijev, Manuela (2008): Die windige Internationale: Rassismus und Kämpfe der Migration. Münster: Westfälisches Dampfboot.

Bojadžijev, Manuela/Römhild, Regina (Hrsg.) (2014): Vom Rand ins Zentrum. Perspektiven einer kritischen Migrationsforschung (Berliner Blätter 65). Berlin: Panama Verlag.

Bolzman, Claudio/Fibbi, Rosita/Vial, Marie (2003a): Secondas - Secondos: le processus d'intégration des jeunes adultes issus de la migration espagnole et italienne en Suisse. Zurich: Seismo.

Bolzman, Claudio/Fibbi, Rosita/Vial, Marie (2003b): Was ist aus ihnen geworden? Der Integrationsprozess der jungen Erwachsenen mit Migrationshintergrund. In: Wicker, Hans-Rudolf/Fibbi, Rosita/Haug, Werner (Hrsg.): Migration und 
die Schweiz. Ergebnisse des Nationalen Forschungsprogramm „Migration und interkulturelle Beziehungen “. Zürich: Seismo. S. 453-480.

Bommes, Michael (2005): Transnationalism or Assimilation? In: Journal of Social Science Education 4. Online: http://www.jsse.org/index.php/jsse/article/ view/977.

Bonilla-Silva, Eduardo (2006): Racism without Racists. Color-Blind Racism and Persistence of Inequality in the United States. Lanham, MD: Rowman \& Littlefield.

Bouquet, Mary (1996): Family Trees and Their Affinities: The Visual Imperative of the Genealogical Diagram. In: The Journal of the Royal Anthropological Institute 2(1), S. 43-66.

Bourdieu, Pierre (1998): Gegenfeuer: Wortmeldungen im Dienste des Widerstands gegen die neoliberale Invasion. Konstanz: UVK Verlagsgesellschaft.

Brah, Avtar (1996): Cartographies of Diaspora: Contesting Identities. London/ New York: Routledge.

Brändle, Rea (2013): Wildfremd, hautnah: Zürcher Völkerschauen und ihre Schauplätze 1835-1964. Zürich: Rotpunktverlag.

Breckenridge, Carol A. (Hrsg.) (1995): Consuming Modernity. Public Culture in an South Asian World. Minneapolis/London: University of Minnesota Press.

Breckenridge, Carol A. et al. (2002): Cosmopolitanism. Durham/London: Duke University Press.

Breckner, Roswitha (2005): Migrationserfahrung - Fremdheit - Biographie. Zum Leben in polarisierten Welten in Ost-West-Europa. Wiesbaden: VS Verlag für Sozialwissenschaften.

Brennan, Timothy (1997): At Home in the World: Cosmopolitanism Now. Cambridge: Harvard University Press.

Brosius, Christiane (2010): India's Middle Class: New Forms of Urban Leisure, Consumption and Prosperity. London/New York: Routledge.

Brosius, Christiane/Yazgi, Nicolas (2007): „Is there no place like home?“: Contesting cinematographic constructions of Indian diasporic experiences. In: Contributions to Indian Sociology 41(3), S. 355-386.

Brown, Judith (2006): Global South Asians: Introducing the Modern Diaspora. Cambridge: Cambridge University Press.

Brubaker, Rogers (2001): The Return of Assimilation? Changing Perspectives on Immigration and Its Sequels in France, Germany, and the United States. In: Ethnic and Racial Studies 24(4), S. 531-548.

Brubaker, Rogers (2003): Neither Individualism nor 'Groupism' A Reply to Craig Calhoun. In: Ethnicities 3(4), S. 553-557.

Brubaker, Rogers (2004): Ethnicity without Groups. Cambridge / London: Harvard University Press.

Brubaker, Rogers (2005): The 'diaspora' diaspora. In: Ethnic and Racial Studies 28(1), S. 1-19. 
Bruner, Edward (1994): Abraham Lincoln as Authentic Reproduction: A Critique of Postmodernism. In: American Anthropologist 96(2), S. 397-415.

Bryceson, Deborah Fahy/Vuorela, Ulla (2002): The Transnational Family. New European Frontiers and Global Networks. Oxford/New York: Berg.

Buck-Morss, Susan (2011): Hegel und Haiti. Frankfurt a. M.: Suhrkamp.

Bundesrat (1899): Kreisschreiben des Bundesrates an sämtliche Kantonsregierungen, betreffend Erleichterung der Einbürgerung von Ausländern (vom 28. März 1899). In: Bundeblatt, Jahrgang 51, Band 2, Heft 14, S. 438-441.

Bundesrat (1967): Bericht des Bundesrates an die Bundesversammlung über das Volksbegehren gegen dee Überfremdung (Vom 29. Juni 1967). In: Bundesblatt Jahrgang 119, Band 2, S. 69-118.

Buomberger, Thomas (2004): Kampf gegen unerwünschte Fremde: Von James Schwarzenbach bis Christoph Blocher. Zürich: Orell Füssli.

Burckhardt, Walther (1913): Einbürgerung der Ausländer. In: Politisches Jahrbuch der Schweizerischen Eidegnossenschaft 27, S. 3-114.

Butler, Judith (1993): Bodies that Matter: On the Discursive Limits of „Sex“. New York: Routledge.

Butler, Judith (2001): Psyche der Macht: Das Subjekt der Unterwerfung. Frankfurt a. M.: Suhrkamp.

Calhoun, Craig (2002): The Class Consciousness of Frequent Travelers: Toward a Critique of Actually Existing Cosmopolitanism. In: South Atlantic Quarterly 101(4), S. 869-97.

Castells, Manuel (1996): The Rise of the Network Society. Malden: Blackwell.

Chakrabarty, Dipesh (2000): Provincializing Europe. Postcolonial Thought and Historical Difference. Princeton: Princeton University Press.

Chatterjee, Partha (1989): Colonialism, Nationalism, and Colonialized Women: the Contest in India. In: American Ethnologist 16(4), S. 622-633.

Chatterjee, Partha (1993): The Nation and its Fragments. Colonial and Postcolonial Histories. Princeton: Princeton University Press.

Cheah, Pheng (2006): Cosmopolitanism. In: Theory, Culture \& Society 23(2-3), S. 486-496.

Cheah, Pheng/Robbins, Bruce (Hrsg.) (1998): Cosmopolitics: Thinking and Feeling Beyond the Nation. Minneapolis/London: University of Minnesota Press.

Chibber, Vivek (2013): Postcolonial Theory and the Specter of Capital. London: Verso.

Chicago Cultural Studies Group (1992): Critical Multiculturalism. In: Critical Inquiry $18(3)$, S. 530-555.

Chopra, Radhika/Osella, Caroline/Osella, Filippo (Hrsg.) (2004): South Asian Masculinities: Context of Change, Sites of Continuity. New Delhi: Kali for Women \& Women Unlimited.

Chowdhury, Kanishka (2011): The New India: Citizenship, Subjectivity, and Economic Liberalization. New York: Palgrave Macmillan. 
Clifford, James (1994): Diasporas. In: Cultural Anthropology 9(3), S. 302-338.

Clifford, James (1997): Traveling Cultures. In: (ders.): Routes. Travel and Translation in the Late Twentieth Century. Cambridge/London: Harvard University Press, S. 17-46.

Cohen, Robin (1997): Global Diasporas: An Introduction. London: Routledge.

Coleman, Simon/Von Hellermann, Pauline (2011): Multi-Sited Ethnography: Problems and Possibilities in the Translocation of Research Methods. New York: Routledge.

Comaroff, Jean/Comaroff, John (Hrsg.) (2001): Millennial capitalism and the culture of neoliberalism. Durham: Duke University Press.

Comaroff, John/Comaroff, Jean (2009): Ethnicity, Inc. Chicago: University of Chicago Press.

Conrad, Sebastian/Randeria, Shalini (2002): Einleitung: Geteilte Geschichten Europa in einer postkolonialen Welt. In: Conrad, Sebastian/Randeria, Shalini (Hrsg.): Jenseits des Eurozentrismus. Postkoloniale Perspektiven in den Geschichts- und Kulturwissenschaften. Frankfurt/New York: Campus. S. 9-49.

Coronil, Fernando (2000): Towards a Critique of Globalcentrism: Speculations on Capitalism's Nature. In: Public Culture 12(2), S. 351-374.

Crul, Maurice/Vermeulen, Hans (2003): The Second Generation in Europe. In: International Migration Review 37(4), S. 965-986.

D’Amato, Gianni (2010): Switzerland: A Multicultural Country Without Multicultural Policies? In: Vertovec, Steven/Wessendorf, Susanne (Hrsg.): The Multiculturalism Backlash: European Discourses, Policies and Practices. London/ New York: Routledge. S. 130-151.

Dahinden, Janine (2016): A plea for the 'de-migranticization' of research on migration and integration. In: Ethnic \& Racial Studies 39(13), S. 2207-25.

Dausien, Bettina/Kelle, Helga (2005): Biographie und kulturelle Praxis. Methodologische Überlegungen zur Verknüpfung von Ethnographie und Biographieforschung. In: Völter, Bettina/Dausien, Bettina/Rosenthal, Gabriele/Lutz, Helma (Hrsg.): Biographieforschung im Diskurs. Wiesbaden: VS Verlag für Sozialwissenschaften. S. 189-212.

Dausien, Bettina/Mecheril, Paul (2006): Normalität und Biographie. Anmerkungen aus migrationswissenschaftlicher Sicht. In: Bukow, Wolf-Dietrich/Ottersbach Markus, Tuider, Elisabeth/Yildiz, Erol (Hrsg.): Biographische Konstruktionen im multikulturellen Bildungsprozess. Wiesbaden: VS Verlag für Sozialwissenschaften. S. 155-175.

Dejung, Christof (2013): Die Fäden des globalen Marktes: eine Sozial- und Kulturgeschichte des Welthandels am Beispiel der Handelsfirma Gebrüder Volkart 1851-1999. Köln: Böhlau.

Delaquis, Ernst (1921): Der neueste Stand der Fremdenfrage. Öffentlicher Vortrag, gehalten in St. Gallen am 22. Oktober 1921. Bern: Stämpfli. 
Deshpande, Satish (2003): Contemporary India: A Sociological View. New Delhi/ New York: Viking.

Deshpande, Sudhanva (2005): The Consumable Hero of Globalised India. In: Kaur, Raminder/Sinha, Ajay J. (Hrsg.): Bollyworld. Popular Indian Cinema Through a Transnational Lens. New Delhi et al.: Sage. S. 186-203.

DeWalt, Kathleen Musante/DeWalt, Billie R. (2002): Participant Observation: A Guide for Fieldworkers. Walnut Creek: Altamira.

Dewey, Susan (2008): Making Miss India Miss World: Constructing Gender, Power, and the Nation in Postliberalization India. Syracuse: Syracuse University Press.

Dhawan, Nikita (2007): Can the Subaltern Speak German? And Other Risky Questions. Migrant Hybridism versus Subalternity. In: translate, webjournal of eipcp. Online: http://translate.eipcp.net/strands/03/dhawan-strands01en.

Dickey, Sara (2000): Permeable Homes: Domestic Service, Household Space, and the Vulnerability of Class Boundaries in Urban India. In: American Ethnologist 27(2), S. 462-489.

Dirlik, Arif (2003): Global Modernity? Modernity in an Age of Global Capitalism. In: European Journal of Social Theory 6(3), S. 275-292.

Donner, Henrike (2008): Domestic Goddesses: Maternity, Globalization and Middle-Class Identity in Contemporary India. Aldershot/Burlington: Ashgate. Donzelot, Jacques (1980): Die Ordnung der Familie. Frankfurt a. M.: Suhrkamp.

Dümmler, Kerstin (2014): Symbolische Grenzen: zur Reproduktion sozialer Ungleichheit durch ethnische und religiöse Zuschreibungen. Bielefeld: transcript.

El-Tayeb, Fatima (2015): Anders europäisch: Rassismus, Identität und Widerstand im vereinten Europa. Münster: Unrast.

Elkana, Yehuda/Krastev, Ivan/Macamo, Elisío/ Randeria, Shalini (Hrsg.) (2002): Unraveling ties: from social cohesion to new practices of connectedness. Frankfurt / New York: Campus.

Espahangizi, Kijan (2016): „Ankommen in der postmigrantischen Gesellschaft. Im Wartesaal der Geschichte“. Terra Cognita 27 (Thema: Potenzial), S. 104-109.

Espahangizi, Kijan (2017): Migrationsforschung und epistemische Teilhabe. Vier historische Schlaglichter auf die Zürcher „Fremdarbeitersoziologie“ in den 1970er Jahren. In: Morawek, Katharina/Krenn, Martin (Hrsg.): Urban Citizenship. Demokratisierung der Demokratie, S.

Espahangizi, Kijan, und Halua Pinto de Magalhães (2014): Vergesst 1291 und 1848! In: Die Zeit, Oktober 2014.

Esser, Hartmut/Friedrichs, Jürgen (Hrsg.) (1990): Generation und Identität: Theoretische und empirische Beiträge zur Migrationssoziologie. Opladen: Westdeutscher Verlag.

Fagerlid, Cicilie (2001): Beyond Ethnic Boundaries? British Asian Cosmopolitans. Unpulizierte Dissertation. Department of Sociology, University of Oslo. 
Falk, Francesca (2011): Eine gestische Geschichte der Grenze: Wie der Liberalismus an der Grenze an seine Grenzen kommt. München: Fink.

Falk, Francesca/Jenni, Franziska (2012): Indien im Blick. Schweizerische Imaginationen in vier Konfigurationen. In: Purtschert, Patricia/Lüthi, Barbara/Falk, Francesca (Hrsg.): Postkoloniale Schweiz. Formen und Folgen eines Kolonialismus ohne Kolonien. Bielefeld: transcript. S. 379-411.

Falzon, Mark-Anthony (2009): Multi-Sited Ethnography Theory, Praxis and Locality in Contemporary Research. Aldershot/Burlington: Ashgate.

Fanon, Frantz (1967): Black Skin, White Masks. New York: Grove Press.

Favero, Paolo (2003): Phantasms in a „Starry“ Place: Space and Identification in a Central New Delhi Market. In: Cultural Anthropology 18(4), S. 551-584.

Fernandes, Leela (2006): India's New Middle Class. Democratic Politics in an Era of Economic Reform. Minneapolis / London: University of Minnesota Press.

Fernandes, Leela/Heller, Patrick (2006): Hegemonic Aspirations. New Middle Politics and India's Democracy in Comparative Perspective. In: Critical Asian Studies 38(4), S. 495-522.

Fischer-Tiné, Harald (2014): Shyamji Krishnavarma: Sanskrit, Sociology and Anti-Imperialism. London/New Delhi: Routledge.

Foner, Nancy (1997): The Immigrant Family: Cultural Legacies and Cultural Changes. In: International Migration Review 31(4), S. 961-974.

Foroutan, Naika/Canan, Coskun (2016): Deutschland postmigrantisch III. Migrantische Perspektiven auf deutsche Identitäten. Einstellungen von Personen mit und ohne Migrationshintergrund zu nationaler Identität in Deutschland. Berlin: Berliner Institut für empirische Integrations- und Migrationsforschung.

Foroutan, Naika/Canan, Coskun/Schwarze, Benjamin/Beigang, Steffen/Kalkum, Dorina (2015): Deutschland postmigrantisch II. Einstellungen von Jugendlichen und jungen Erwachsenen zu Gesellschaft, Religion und Identität. Berlin: Berliner Institut für empirische Integrations- und Migrationsforschung.

Foroutan, Naika/Canan, Coskun/Schwarze, Benjamin/Beigang, Steffen/Kalkum, Dorina (2014): Deutschland postmigrantisch I. Gesellschaft, Religion, Identität. Erste Ergebnisse. Berlin: Berliner Institut für empirische Integrations- und Migrationsforschung.

Foucault, Michel (1977): Der Wille zum Wissen. Frankfurt a. M.: Suhrkamp.

Foucault, Michel (1980): Truth and Power. In: Gordon, Colin (Hrsg.): Power/

Knowledge. Selected Interviews \& Other Writings, 1972-1977. New York: Pantheon. S. 109-133.

Foucault, Michel (1986a): The Subject and Power. In: Dreyfus, Hubert L./Rabinow, Paul (Hrsg.): Michel Foucault: Beyond Structuralism and Hermeneutics. Brighton Sussex: Harvester Press. S. 208-226.

Foucault, Michel (1986b): Der Gebrauch der Lüste. Frankfurt a. M.: Suhrkamp. 
Foucault, Michel (1993): Technologien des Selbst. In: Martin, Luther/Gutman, Huck/Hutton, Patrick (Hrsg.): Technologien des Selbst. Frankfurt am Main: Fischer.

Foucault, Michel (1999): In Verteidigung der Gesellschaft: Vorlesungen am Collège de France (1975-76), (herausgegeben vn Michaela Ott). Frankfurt a. M.: Suhrkamp.

Fox, Richard (Hrsg.) (1991): Recapturing Anthropology: Working in the Present. Santa Fe: School of American Research Press.

Fraser, Nancy (1995): From Redistribution to Recognition? Dilemmas of Justice in a 'Post-Socialist' Age. In: New Left Review 212(I), S. 68-93.

Friedman, Jonathan (1990): Being in the World: Globalization and Localization. In: Featherstone, Mike (Hrsg.): Global Culture: Nationalism, Globalization and Modernity. London et al.: Sage. S. 311-328.

Frigerio, Marina (2014): Verbotene Kinder. Die Kinder der italienischen Saisonniers erzählen von Trennung und Illegalität. Zürich: Rotpunktverlag.

Fuller, C. J./Narasimhan, Haripriya (2008): Companionate marriage in India: the changing marriage system in a middle-class Brahman subcaste. In: Journal of the Royal Anthropological Institute 14(4), S. 736-754.

Gandhi, Leela (2006): Affective Communities: Anticolonial Thought, Fin-De-Siècle Radicalism, and the Politics of Friendship. Durham: Duke University Press.

Ganguly-Scrase, Ruchira/Scrase, Timothy J. (2009): Globalisation and the middle classes in India: the social and cultural impact of neoliberal reforms. London/ New York: Routledge.

Gans, Herbert J. (1979): Symbolic ethnicity: the future of ethnic groups and cultures in America. In: Ethnic \& Racial Studies 2(1), S. 1-20.

Ganti, Tejaswini (2012): Producing Bollywood: Inside the Contemporary Hindi Film Industry. Durham: Duke University Press.

Gardner, Andrew (2010): City of Strangers. Gulf Migration and the Indian Community in Bahrain. Ithaca: ILR Press.

Geary, David (2013): Incredible India in a global Age: The Cultural Politics of Image Branding in Tourism. In: Tourist Studies 13(1), S. 36-61.

Gehlawat, Ajay (2013): The "Slumdog” Phenomenon: A Critical Anthology. London/New York: Anthem Press.

Gillespie, Mary (1995): Television, Ethnicity and Cultural Change. London/New York: Routledge.

Gilroy, Paul (2006): Postcolonial Melancholia. New York: Columbia University Press.

Glättli, Balthasar/Niklaus Pierre-Alain (2014): Die unheimlichen Ökologen. Sind zuviele Menschen das Problem? Zürich: Rotpunktverlag.

Glick Schiller, Nina/Basch, Linda/Blanc-Szanton, Cristina (1992): Transnationalism: A New Analytic Framework for Understanding Migration. In: Annals of the New York Academy of Sciences 645(1), S. 1-24. 
Glick Schiller, Nina/Çağlar Ayse/Gulbrandsen, Thaddeus C. (2006): Beyond the ethnic lens: Locality, globality, and born-again incorporation. In: American Ethnologist 33(4), S. 612-33.

Glick Schiller, Nina/Caglar, Ayse (2011): Locating Migration: Rescaling Cities and Migrants. Ithaca: Cornell University Press.

Goel, Urmila (2008): „Half Indians“, Adopted „Germans“ and „Afghan Indians“. On Claims of „Indianness“ and their contestations in Germany. In: Transforming Cultures eJournal 3. Online: http://epress.lib.uts.edu.au/journals/index. $\mathrm{php} / \mathrm{TfC} /$ issue/view/41/showToc.

Goel, Urmila (2011): Über das Sprechen über die Religion der Anderen. In: Allenbach, Brigit/Goel, Urmila/Hummrich, Merle/Weissköppel Cordula (Hrsg.): Jugend, Migration und Religion - Interdisziplinäre Perspektiven. Baden-Baden: Nomos. S. 289-318.

Goel, Urmila/Punnamparambil, Jose/Punnamparambil-Wolf, Nisa (Hrsg.) (2012): InderKinder: Über das Aufwachsen und Leben in Deutschland. Heidelberg: Draupadi.

Goldberg, David Theo (2009): The Threat of Race: Reflections on Racial Neoliberalism. Somerset: Wiley-Blackwell.

Gopinath, Gayatri (2005): Impossible Desires: Queer Diasporas and South Asian Public Cultures. Durham: Duke University Press.

Grillo, Ralph (2008): The Family in Question: Immigrant and Ethnic Minorities in Multicultural Europe. Amsterdam University Press.

Gschwend, Simone (2007): Aushandeln transnationaler und lokaler Beziehungen. Eine Fallstudie zu sozialen Netzwerken von Migranten und Migrantinnen aus Kerala, Indien. Lizentiatsarbeit Ethnologisches Seminar Zürich.

Gupta, Akhil/Ferguson, James (1992): Beyond "Culture”: Space, Identity, and the Politics of Difference. In: Cultural Anthropology 7(1), S. 6-23.

Gupta, Dipankar (2009): The Caged Phoenix: Can India Fly? New Delhi et al.: Penguin.

Ha, Kien Nghi (2005): Hype um Hybridität: Kultureller Differenzkonsum und postmoderne Verwertungstechniken im Spätkapitalismus. Bielefeld: Transcript.

Hahn, Alois (2000): Konstruktionen des Selbst, der Welt und der Geschichte: Aufsätze zur Kultursoziologie. Frankfurt a. M.: Suhrkamp.

Hall, Kathleen (2002): Lives in Translation: Sikh Youth as British citizens. Philadelphia: University of Pennsylvania Press.

Hall, Stuart (1990): Cultural Identity and Diaspora. In: Rutherford, Jonathan (Hrsg.): Identity: Community, Culture, Difference. London: Lawrence \& Wishart. S. 222-237.

Hall, Stuart (1991): The Local and the Global: Globalization and Ethnicity. In: King, Anthony D. (Hrsg.): Culture, Globalization and the World-System. Basingstoke/New York: Palgrave. S. 19-39. 
Hall, Stuart (1996): Who needs identity? In: Hall, Stuart/Du Gay, Paul (Hrsg.): Questions of Cultural Identity. London/Thousand Oaks: Sage. S. 1-17.

Hall, Stuart (1997): The Spectacle of the „Other“. In: Hall, Stuart (Hrsg.): Representation. Cultural Representations and Signifying Practices. London et al.: Sage. S. 223-290.

Hämmig, Oliver (2000): Zwischen zwei Kulturen. Spannungen, Konflikte und ihre Bewältigung bei der Zweiten Ausländergeneration. Opladen: Leske + Budrich. Hannerz, Ulf (1989): Notes on the Global Ecumene. In: Public Culture 1(2), S. 66-75.

Hannerz, Ulf (1990): Cosmopolitans and Locals in World Culture. In: Featherstone, Mike (Hrsg.): Global Culture: Nationalism, Globalization and Modernity. London et al.: Sage. S. 237-251.

Hannerz, Ulf (1996): Transnational Connections: Culture, People, Places. London/ New York: Routledge.

Hansen, Marcus Lee (1996): The Problem of the Third Generation Immirant (1938). In: Sollors, Werner (Hrsg.): Theories of Ethnicity: A Classical Reader. Basingstoke/London: Macmillan. S. 202-215.

Hansen, Thomas Blom (1999): The Saffron Wave: Democracy and Hindu Nationalism in Modern India. Princeton: Princeton University Press.

Harvey, David (1990a): The Condition of Postmodernity. An Enquiry into the Origins of Cultural Change. Malden et al.: Blackwell.

Harvey, David (1990b): Flexible Accumulation through Urbanization. Reflections on „Post-Modernism“ in the American City. In: Perspecta 26, S. 251-272.

Hettlage, Raphaela/Juhasz, Anne/Schubert, Renate/Suter, Christiane (2007): Selbstständig erwerbende Migrantinnen und Migranten:Gibt es Unterschiede zwischen den Generationen? In: Die Volkswirtschaft 7/8, S. 22-25.

Higham, John (1981): Integrating America: The Problem of Assimilation in the Nineteenth Century. In: Journal of American Ethnic History 1(1), S. 7-25.

Hirsch, Joachim/Roth, Roland (1986): Das neue Gesicht des Kapitalismus: Vom Fordismus zum Post-Fordismus. Hamburg: VSA-Verlag.

Hitz, Hansruedi/Schmid, Christian/Wolff, Richard (1995): Boom, Konflikt und Krise - Zürichs Entwicklung zur Weltmetropole. In: Lehrer, Ute/Keil, Roger (Hrsg.): Capitales Fatales: Urbanisierung und Politik in den Finanzmetropolen Frankfurt und Zürich. Zürich: Rotpunktverlag. S. 208-282.

Honegger, Claudia/Rychner, Marianne (1998): Das Ende der Gemütlichkeit: Strukturelles Unglück und mentales Leid in der Schweiz. Zürich: Limmat Verlag. Honneth, Axel (1992): Kampf um Anerkennung: Zur moralischen Grammatik sozialer Konflikte. Frankfurt a. M.: Suhrkamp.

Huggan, Graham (2001): The Postcolonial Exotic. Marketing the Margins. Oxon/ New York: Taylor \& Francis.

Huonker, Thomas/Ludi, Regula (2001): Roma, Sinti und Jenische. Schweizerische Zigeunerpolitik zur Zeit des Nationalsozialismus (Veröffentlichungen der Un- 
abhängigen Expertenkommission - Zweiter Weltkrieg, Bd. 23). Zürich: Chronos.

Hutnyk, John (2000): Critique of Exotica: Music, Politics, and the Culture Industry. London/Sterling: Pluto Press.

Illouz, Eva (1997): Consuming the Romantic Utopia: Love and the Cultural Contradictions of Capitalism. Berkeley: University of California Press.

Imhasly, Bernard (2008b): Colonial Encounters: On the „Pre-History“ of Relations between Switzerland and India. In: Imhasly, Bernard (Hrsg.): Friendship in Diversity. Sixty Years of Indo-Swiss Relations. Hyderabad: Universities Press. S. 3-9.

Imhasly, Bernard (Hrsg.) (2008a): Friendship in Diversity. Sixty Years of Indo-Swiss Relations. Hyderabad: Universities Press.

Imhof, Kurt (1996): Wiedergeburt der geistigen Landesverteidigung: Kalter Krieg in der Schweiz. In: Imhof, Kurt/Kleger, Heinz/Romano, Gaetano (Hrsg.): Konkordanz und kalter Krieg: Analyse von Medienereignissen in der Schweiz der Zwischen- und Nachkriegzeit. Zürich: Seismo. S. 173-248.

Inden, Ronald (1999): Transnational Class, Erotic Arcadia and Commercial Utopia in Hindi Films. In: Brosius, Christiane/Butcher, Melissa (Hrsg.): Image journeys: audio-visual media and cultural change in India. New Delhi/Thousand Oaks: Sage. S. 41-69.

Indischer Verein Zürich (Hrsg.) (2005): indialogue. Fifty Years of Indian Association Zurich. 50 Jahre Indischer Verein Zürich. Zürich: Indian Association Zurich/Indischer Verein Zürich.

Jäger, Siegfried (2004): Kritische Diskursanalyse: Eine Einführung. Münster: Unrast.

Jain, Rohit (2010): „Viele haben das Gefühl, sie müssten aggressiv sein - wie die Männer.“ (Sonia Raman, Investmentbankerin). In: Honegger, Claudia/Magnin, Chantal/Neckel, Sighard (Hrsg.): Strukturierte Verantwortungslosigkeit: Berichte aus der Bankenwelt. Frankfurt am Main: Suhrkamp. S. 146-151.

Jain, Rohit (2011): Negotiating Assimilation, Exoticism and Global Indian Modernity: Transnational Subject-Making of Second Generation Indians in Switzerland. In: Asiatische Studien/Études Asiatiques LXV(4), S. 1001-1027.

Jain, Rohit (2012): Die Comedyfigur Rajiv Prasad in Viktors Spätprogramm post_koloniales Phantasma und die Krise des „Sonderfalls Schweiz“. In: Patricia Purtschert/Lüthi, Barbara/Falk, Francesca (Hrsg.): Postkoloniale Schweiz. Formen und Folgen eines Kolonialismus ohne Kolonien. Bielefeld: transcript. S. $175-199$.

Jain, Rohit (2013): Migrationsforschung als transnationale, genealogische Ethnographie - Subjektivierungsprozesse von „InderInnen der zweiten Generation aus der Schweiz“. In: Mecheril, Paul/Thomas-Olalde, Oscar/ Melter, Claus/ Arens Susanne/ Romaner, Elisabeth (Hrsg.): Migrationsforschung als Kritik? 
Spielräume kritischer Migrationsforschung. Wiesbaden: Springer VS. S. 175191.

Jain, Rohit (2015): Bollywood, Chicken Curry - and IT: The public spectacle of the Indian exotic and contemporary global capitalism. In: Fischer-Tiné, Harald/ Purtschert, Patricia (Hrsg.): Colonial Switzerland. Rethinking Colonialism from the Margins. Basingstroke: Palgrave MacMillan, S. 133-153.

Jain, Rohit (2017): Die Schweiz, eine Bastard ${ }^{*}$ in - Reflexionen zu einer postkolonialen Praxis im Kontext von Urban Citizenship in Zürich. In: Morawek, Katharina/Krenn, Martin (Hrsg.): Urban Citizenship. Demokratisierung der Demokratie.

Jameson, Frederic (1991): Postmodernism, or, The Cultural Logic of Late Capitalism. Durham: Duke University Press.

Jenkins, Paul (1998): Die Basler Mission im kolonialen Spannungsfeld Indien. Eine Einladung zu Imperialismus- und Nationalismusforschung im Archiv der Basler Mission. In: traverse 1998(2), S. 41-55.

Jenkins, Richard (1997): Rethinking Ethnicity. London/Thousand Oaks: Sage.

Joshi, Sanjay (2001): Fractured Modernity: Making of a Middle Class in Colonial North India. New Delhi/New York: Oxford University Press.

Jost, Hans Ulrich (1992): Die reaktionäre Avantgarde: Die Geburt der neuen Rechten in der Schweiz um 1900. Zürich: Chronos.

Juhasz, Anne (2005): Autonomie und Risiko statt Unsicherheit. Die selbständige Erwerbstätigkeit als Weg zur Bearbeitung biographischer Unsicherheiten in der Migration. In: sozialer sinn 2005(1), S. 93-1009.

Juhasz, Anne/Mey, Eva (2003): Die zweite Generation: Etablierte oder Aussenseiter? Biographien von Jugendlichen ausländischer Herkunft. Wiesbaden: Westdeutscher Verlag.

Jureit, Ulrike (2006): Generationenforschung. Göttingen: Vandenhoeck \& Ruprecht.

Kälin, Walter (2000): Grundrechte im Kulturkonflikt: Freiheit und Gleichheit in der Einwanderungsgesellschaft. Zürich: NZZ Verlag.

Kalra, Virinder S./Hutnyk, John (1998): Brimful of Agitation, Authenticity and Appropriation: Madonna’s „Asian Kool“. In: Postcolonial Studies 3(1), S. 339355.

Kalra, Virinder S./Kaur, Raminder/Hutnyk, John (2005): Diaspora \& Hybridity. London/Thousand Oaks: Sage.

Karakayali, Juliane/Tsianos, Vassilis (2014): Rassismus und Repräsentationspolitik in der postmigrantischen Gesellschaft. In: Aus Politik und Zeitgeschichte 64(13-14), S. 33-39.

Karakayali, Nedim (2005): Duality and Diversity in the Lives of Immigrant Children: Rethinking the „Problem of the Second Generation” in Light of Immigrant Autobiographies. In: Canadian Review of Sociology/Revue canadienne de sociologie 42(3), S. 325-343. 
Kazaal, Russel (1995): The Rise, Fall, and Reappraisal of a Concept in American Ethnic History. In: American Historical Review 100(2), S. 437-471.

Keller, Urs (2002): Der indische Tourismus in der Schweiz. Eine empirische Untersuchung unter besonderer Berücksichtigung der Beziehung von Tourismus und Film. Masterarbeit Geographisches Institut Zürich.

Koller, Max (1915): Die Fremdenfrage in der Schweiz. Zürich: Verlag „Stimmen im Sturm“.

Kotthoff, Helga/Jashari, Shpresa/Klingenberg, Darja (2013): Komik (in) der Migrationsgesellschaft. Konstanz: UVK.

Kury, Patrick (2003): Über Fremde reden: Überfremdungsdiskurs und Ausgrenzung in der Schweiz, 1900-1945. Zürich: Chronos.

Küsters, Ivonne (2009): Narrative Interviews. Grundlagen und Anwendungen. Wiesbaden: VS Verlag für Sozialwissenschaften.

Kymlicka, Will (1995): Multicultural Citizenship: A Liberal Theory of Minority Rights. Oxford/New York: Clarendon Press/Oxford University Press.

Laidlaw, James (2010): Social Anhropology. In: Skorupski, John (Hrsg.): The Routledge Companion to Ethics. Oxon/New York: Routledge. S. 369-383.

Lash, Scott/Urry, John (1987): The End of Organized Capitalism. Madison: University of Wisconsin Press.

Lash, Scott/Urry, John (1994): Economies of Signs and Space. London et al.: Sage.

Lauer, Tina (2013): „Wir sind keine kleinen Dalai Lama““: Lebenswelten von Tibeterinnen und Tibetern der zweiten Generation in Indien und der Schweiz. Bern: Haupt.

Leimgruber, Walter/Meier, Thomas/Sablonier, Roger (1998): Das Hilfswerk für die Kinder der Landstrasse: Historische Studie aufgrund der Akten der Stiftung Pro Juventute im Schweizerischen Bundesarchiv. Bern: Schweizerisches Bundesarchiv.

Leonard, Karen (1992): Making Ethnic Choices: California’s Punjabi Mexican Americans. Philadelphia: Temple University Press.

Lessinger, Johanna (1995): From the Ganges $\mathrm{ft}$ he Hudson: Indian Immigrants in New York City. Boston: Allyn \& Bacon.

Levitt, Peggy/Glick Schiller, Nina (2004): Conceptualizing Simultaneity: A Transnational Social Field Perspective on Society. In: International Migration Review 38(3), S. 1002-1039.

Levitt, Peggy/Waters, Mary C. (Hrsg.) (2002): The Changing Face of Home: The Transnational Lives $\mathrm{ft}$ he Second Generation. New York: Russell Sage Foundation Publications.

Lindner, Rolf (1990): Die Entdeckung der Stadtkultur: Soziologie aus der Erfahrung der Reportage. Frankfurt a. M.: Suhrkamp.

Loftsdottir, Kirstin/Jensen, Lars (Hrsg.) (2012): Whiteness and Postcolonial in the Nordic Region. Exceptionalism, Migrant Others and National Identities. Farnham/Surlington: Ashgate. 
Lüdemann, Susanne (2004): Metaphern der Gesellschaft: Studien zum soziologischen und politischen Imaginären. München: Fink.

Lutz, Helma (2000): Migration als soziales Erbe. Biographische Verläufe bei Migrantinnen der ersten und zweiten Generation in den Niederlanden. In: Dausien, Bettina/Calloni, Marina/Friese, Marianne (Hrsg.): Migrationsgeschichten von Frauen. Beiträge und Perspektiven aus der Biographieforschung. Bremen: Universität Bremen. S. 38-61.

Lutz, Helma (2008): Biographieforschung im Lichte postkolonialer Theorien. In: Reuter, Julia/Villa, Paula Irene (Hrsg.): Postkoloniale Soziologie: Empirische Befunde, theoretische Anschlüsse, politische Intervention. Bielefeld: transcript. S. 115-136.

Maiolino, Angelo (2010): Überfremdung und Mediterranisierung der Schweiz: Identitäten im Spannungsfeld. In: Widerstand, S. 177-193.

Maiolino, Angelo (2011): Als die Italiener noch Tschinggen waren: Der Widerstand gegen die Schwarzenbach-Initiative. Zürich: Rotpunktverlag.

Maira, Sunaina (2000): Henna and Hip Hop: The Politics of Cultural Production and the Work of Cultural Studies. In: Journal of Asian American Studies 3(3), S. 329-369.

Maira, Sunaina (2002): Desis In The House: Indian American Youth Culture In New York City. Philadelphia: Temple University Press.

Malik, Sarita (2002): Representing Black Britain. A History of Black and Asian Images on British Television. London/Thousand Oaks: Sage.

Malkki, Liisa (1992): National Geographic: The Rooting of Peoples and the Territorialization of National Identity among Scholars and Refugees. In: Cultural Anthropology 7(1), S. 24-44.

Mani, Bakirathi/Varadarajan, Latha (2005): „The Largest Gathering ft he Global Indian Family“: Neoliberalism Nationalism, and Diaspora at Pravasi Bharatiya Divas. In: Diaspora 14(1), S. 45-74.

Mani, Lata (1987): Contentious Traditions: The Debate on Sati in Colonial India. In: Cultural Critique, S. 119-156.

Mankekar, Purnima (1999): Screening Culture, Viewing Politics: An Ethnography of Television, Womanhood, and Nation in Postcolonial India. Durham: Duke University Press.

Mannheim, Karl (2009[1928]): Das Problem der Generationen. In: Barboza, Amalia/Lichtblau, Klaus (Hrsg.): Schriften zur Wirtschafts- und Kultursoziologie. Wiesbaden: VS Verlag für Sozialwissenschaften. S. 121-166.

Marchal, Guy/Mattioli, Aram (Hrsg.) (1992): Erfundene Schweiz: Konstruktionen nationaler Identität $=$ La Suisse imaginée $:$ bricolages d'une identité nationale. Zürich: Chronos.

Marcus, George E. (1995): Ethnography in/of the World System: The Emergence of Multi-Sited Ethnography. In: Annual Review of Anthropology 24, S. 95-117. 
Marcus, George E. (1998): Ethnography Through Thick and Thin. Princeton: Princeton University Press.

Markell, Patchen (2003): Bound by Recognition. Princeton: Princeton University Press.

Mathew, Biju/Prashad, Vijay (2000): The Protean Forms of Yankee Hindutva. In: Ethnic and Racial Studies 23(3), S. 516-534.

Mayo-Smith, Richmond (1894a): Assimilation of Nationalities in the United States I. In: Political Science Quarterly 9(3). S. 426-444.

Mayo-Smith, Richmond (1894b): Assimilation of Nationalities in the United States II. In: Political Science Quarterly 9(4). S. 640-679.

Mazzarella, William (2003): Shoveling Smoke. Advertising and Globalization in Contemporary India. Durham/London: Duke University Press.

McClintock, Anne (1995): Imperial Leather: Race, Gender, and Sexuality in the Colonial Contest. New York/London: Routledge.

McNay, Lois (2008): Against Recognition. Cambridge: Polity Press.

Mecheril, Paul (2003): Prekäre Verhältnisse. Über natio-ethno-kulturelle (Mehrfach-)Zugehörigkeit. Münster et al.: Waxmann.

Menet, Joanna (2010): Von „halben Schweizerinnen“, „eingebürgerten Ausländern“ und „echten Eidgenossen“. Eine ethnographiosche Forschung mit jungen Erwachsenen zu Ethnizität und Mehrfachzugehörigkeit. Lizentiatsarbeit Ethnologisches Seminar Zürich.

Menon, Nivedita/Nigam, Aditya (2007): Power and Contestation: India since 1989. Halifax/Winnipeg, London/New York: Fernwood Publisher/Zed Books.

Mezzadra, Sandro/Neilson, Brett (2013): Border as Method, or, The Multiplication of Labor. Durham/London: Duke University Press.

Michel, Noémi Vanessa (2014): Quand les mots et les images blessent: postcolonialité, égalité et politique des actes de discours en Suisse et en France. Unpublizierte Dissertation. Universität Genf.

Michel, Noémi Vanessa (2016): Sheepology: The Postcolonial Politics of Raceless Racism in Switzerland. In: Postcolonial Studies 18(4), S. 410-26.

Mitchell, Katharyne (1997): Transnational subjects: Constituting the cultural citizen in the era of Pacific Rim capital. In: Ong, Aihwa/Nonini, Donald (Hrsg.): Ungrounded empires the cultural politics of modern Chinese transnationalism. New York: Routledge. S. 228-258.

Mody, Perveez (2008): The Intimate State: Love-Marriage and the Law in Delhi. New Delhi: Routledge.

Mollenkopf, John/Castells, Manuel (1991): Dual City: Restructuring New York. New York: Russell Sage Foundation.

Morawska, Ewa (2003): Immigrant Transnationalism and Assimilation: A Variety of Combinations and the Analytical Strategy it Suggests. In: Joppke, Christian/ Morawska, Ewa (Hrsg.): Toward Assimilation and Citizenship: Immigrants in Liberal Nation-States. New York: Palgrave. S. 131-176. 
Müller, Monika (2013): Migration und Religion. Junge hinduistische und muslimische Männer in der Schweiz. Wiesbaden: Springer VS.

Nauck, Bernhard (2005): Familienbeziehungen und Sozialintegration von Migranten. In: IMIS-Beiträge 27, S. 83-108.

Nauck, Bernhard/Kohlmann, Annette/Diefenbach, Heike (1997): Familiare Netzwerke, intergenerative Transmission und Assimilationsprozesse bei türkischen Migrantenfamilien. In: Kölner Zeitschrift fur Soziologie und Sozialpsychologie 49(3), S. 477-499.

Niederberger, Josef Martin (2004): Ausgrenzen, Assimilieren, Integrieren: Die Entwicklung einer schweizerischen Integrationspolitik. Zürich: Seismo.

Nieswand, Boris (2011): Theorising Transnational Migration: The Status Paradox of Migration. New York: Routledge.

Niranjana, Tejaswini (2006): Mobilizing India: Women, Music, and Migration between India and Trinidad. Durham: Duke University Press.

Nohl, Arnd-Michael/Schittenhelm, Karin/Schmidtke, Oliver/Weiß, Anja) (2014): Work in Transition: Cultural Capital and Highly Skilled Migrants' Passages into the Labour Market. Toronto: University of Toronto Press.

OECD/EU (2015): Indicators of Immigrant Integration 2015: Settling In. Paris: OECD Publishing.

Olwig, Karen Fog (2007): Caribbean Journeys: An Ethnography of Migration and Home in Three Family Networks. Durham: Duke University Press.

Ong, Aihwa (1999): Flexible Citizenship. The Cultural Logics of Transnationality. Durham: Duke University Press.

Ong, Aihwa (2001): Splintering Capitalism: Asian Immigrants and Zones of Autonomy in the American West. In: Comaroff, Jean/Comaroff, John (Hrsg.): Millennial capitalism and the culture of neoliberalism. Durham: Duke University Press. S. 257-275.

Oza, Rupal (2001): Showcasing India: Gender, Geography, and Globalization. In: Signs 26(4), S. 1067-1095.

Parekh, Bhikhu/Singh, Gurharpal/Vertovec, Steven (Hrsg.) (2003): Culture and Economy in the Indian Diaspora. London/New York: Routledge.

Park, Robert E. (1928): Human Migration and the Marginal Man. In: American Journal of Sociology 33(6), S. 881-893.

Park, Robert E./Burgess, Ernest W. (1970): Introduction to the science of sociology: including an index to basic sociological concepts. Chicago/London: University of Chicago Press.

Parnes, Ohad/Vedder, Ulrike/Willer, Stefan (2008): Das Konzept der Generation: Eine Wissenschafts- und Kulturgeschichte. Frankfurt a. M.: Suhrkamp.

Parry, Jonathan P. (2001): Ankalu's Errant Wife: Sex, Marriage and Industry in Contemporary Chhattisgarh. In: Modern Asian Studies 35(4), S. 783-820.

Peach, Ceri/Vertovec, Steven/Clarke, Colin (1990): South Asians Overseas: Migration and Ethnicity. New York: Cambridge University Press. 
Petievich, Carla (Hrsg.) (1999): The Expanding Landscape: South Asians and the Diaspora. New Delhi: Manohar Publishers.

Piñeiro, Esteban/Bopp, Isabelle/Kreis, Georg (Hrsg.) (2009): Fördern und Fordern im Diskurs. Leerstellen des schweizerische Integrationsdiskurses. Zürich: Seismo.

Portes, Alejandro (1996): The New Second Generation. New York: Russell Sage Foundation.

Portes, Alejandro/Guarnizo, Luis E./Landolt, Patricia (1999): The Study of Transnationalism: Pitfalls and Promise of an Emergent Research Field. In: Ethnic and Racial Studies 22(2), S. 217-237.

Portes, Alejandro/Zhou, Min (1993): The New Second Generation: Segmented Assimilation and its Variants. In: The Annals of the American Academy of Political and Social Science 530(1), S. 74-96.

Povinelli, Elizabeth A. (2002): The Cunning of Recognition: Indigenous Alterities and the Making of Australian Multiculturalism. Durham: Duke University Press.

Prashad, Vijay (2000): The Karma of Brown Folk. Minneapolis: University of Minnesota Press.

Pratt, Mary Louise (1992): Imperial Eyes: Travel Writing and Transculturation. London/New York: Routledge.

Purkayastha, Bandana (2005): Negotiating Ethnicity: Second-Generation South Asian Americans Traverse a Transnational World. New Brunswick: Rutgers University Press.

Purtschert, Patricia (2011): Chewing on Post_colonial Switzerland. Redigesting What has not yet been swallowed. In: Thal, Andrea (Hrsg.): Chewing the Scenery (im Auftrag des Bundesamtes für Kultur als Teil des offiziellen Beitrags der Schweiz an der 54. Kunstbiennale Venedig). Zürich: Edition Fink, S. 95100/121-126/149-154.

Purtschert, Patricia/Lüthi, Barbara/Falk, Francesca (Hrsg.) (2012): Postkoloniale Schweiz. Formen und Folgen eines Kolonialismus ohne Kolonien. Bielefeld: transcript.

Radhakrishnan, Smitha (2008): Examining the "Global“ Indian Middle Class: Gender and Culture in the Silicon Valley/Bangalore Circuit. In: Journal of Intercultural Studies 29(1), S. 7-20.

Radtke, Frank-Olaf (1992): Lob der Gleich-Gültigkeit. Zur Konstruktion des Fremden im Diskurs des Multikulturalismus. In: Bielefeld, Uli (Hrsg.): Das Eigene und das Fremde: Neuer Rassismus in der alten Welt? Hamburg: Junius. S. 23-49.

Raj, Dhooleka S. (2003): Where Are You From? Middle-Class Migrants in the Modern World. 1. Aufl. Berkeley: University of California Press.

Rajadhyaksa, Ashish (2003): The „Bollywoodization“ of the Indian cinema: cultural nationalism in a global arena. In: Inter-Asia Cultural Studies 4(1), S. 25-39. 
Rajagopal, Arvind (2001): Politics after Television. Religious Nationalism and the Reshaping of the Indian Public. Cambridge/New York: Cambridge University Press.

Ramsauer, Nadja (2000): „Verwahrlost“: Kindswegnahmen und die Entstehung der Jugendfürsorge im schweizerischen Sozialstaat 1900-1945. Zürich: Chronos.

Randeria, Shalini (1999a): Geteilte Geschichten und verwobene Modernen. In: Rüsen, Jörn/Leitgeb, Hanna/Jegelka, Norbert (Hrsg.): Zukunftsentwürfe. Ideen für eine Kultur der Veränderung. Frankfurt/New York: Campus. S. 87-96.

Randeria, Shalini (1999b): Jenseits von Soziologie und soziokultureller Anthropologie: Zur Ortsbestimmung der nichtwestlichen Welt in einer zukünftigen Sozialtheorie. In: Soziale Welt 50, S. 373-382.

Randeria, Shalini (2002): Entangled Histories of Uneven Modernities: Civil Society, Caste Solidarities and Legal Pluralism in Post-Colonial India. In: Elkana, Yehuda/ Krastev, Ivan/ Macamo, Elisío/ Randeria, Shalini (Hrsg.): Unraveling Ties. Form Social Cohesion to New Practices of Connectedness. Frankfurt/ New York: Campus. S. 284-311.

Randeria, Shalini/Fuchs, Martin/ Linkenbach, Anje (Hrsg.) (2004): Konfigurationen der Moderne: Diskurse zu Indien. Baden-Baden: Nomos.

Ray, Raka/Qayum, Seemin (2009): Cultures of Servitude: Modernity, Domesticity, and Class in India. Stanford: Stanford University Press.

Riedo, René (1996): Umrisse zu einem Integrationskonzept. Bern: Eidgenössische Ausländerkommission (EKA).

Riegel, Christine (2004): Im Kampf um Zugehörigkeit und Anerkennung: Orientierungen und Handlungsformen von jungen Migrantinnen: eine sozio-biografische Untersuchung. Frankfurt am Main: IKO-Verlag für Interkulturelle Kommunikation.

Riegel, Christine/Geisen, Thomas (Hrsg.) (2007): Jugend, Zugehörigkeit und Migration Subjektpositionierung im Kontext von Jugendkultur, Ethnizitätsund Geschlechterkonstruktionen. Wiesbaden: VS Verlag für Sozialwissenschaften.

Rietmann, Tanja (2014): „Liederlich“ und „arbeitsscheu“. Die administrative Anstaltsversorgung im Kanton Bern (1884-1981). Zürich: Chronos.

Ritter, Christian/Muri, Gabriela/Rogger, Basil (Hrsg.) (2010): Magische Ambivalenz: Visualität und Identität im transkulturellen Raum. Berlin/Zürich: Diaphanes.

Robbins, Bruce (1998): Actually Existing Cosmopolitanism. In: Cheah, Pheng/Robbins, Bruce (Hrsg.): Cosmopolitics: Thinking and Feeling Beyond the Nation. Minneapolis/London: University of Minnesota Press. S. 1-19.

Römhild, Regina/Westrich, Michael (2013): Kosmopolitismus an der Grenze. Der Mittelmeerraum als Laboratorium für transversalen Gemeinsinn. In: Zeitschrift für Kulturwissenschaften 7(2), S. 85-98. 
Rose, Nikolas (1996): Identity, Genealogy, History. In: Hall, Stuart/Du Gay, Paul (Hrsg.): Questions of Cultural Identity. London/Thousand Oaks: Sage. S. 128150 .

Rosenthal, Gabriele (2005): Interpretative Sozialforschung: eine Einführung. Weinheim/München: Juventa.

Rothermund, Dietmar (2008): Indien: Aufstieg einer asiatischen Weltmacht. München: Beck.

Rouse, Roger (1991): Mexican Migration and the Social Space of Postmodernism. In: Diaspora 1(1), S. 8-23.

Roy, Ananya/Ong, Aihwa (2011): Worlding Cities: Asian Experiments and the Art of Being Global. Chichester/Malden: Wiley-Blackwell.

Roy, Anupama (2008): Between encompassment and closure. The 'migrant' and the citizen in India. In: Contributions to Indian Sociology 42(2), S. 219-248.

Ruth, Max (1937): Das Schweizerbürgerrecht. Basel: Helbing \& Lichtenhahn.

Saar, Martin (2007): Genealogie als Kritik: Geschichte und Theorie des Subjekts nach Nietzsche und Foucault. Frankfurt/New York: Campus.

Safran, William (1991): Diasporas in Modern Societies: Myths of Homeland and Return. In: Diaspora 1(1), S. 83-99.

Said, Edward (1978): Orientalism. New York: Vintage.

Sancar, Annemarie (2003): Migranten und Migrantinnen im Blickfeld der Sozial Arbeit. Von Exotisierung zu Problematisierung zu Ausgrenzung oder: die Frage nach einem normalen Umgang mit zugewanderten Menschen. In: Verein zur Förderung der sozialen Arbeit als akademische Disziplin (Hrsg.): Symposium Soziale Arbeit 2001: Soziale Arbeit und Migration. Bern: Edition Soziothek. S. 3-13.

Sartori, Andrew (2008): Bengal in Global Concept History: Culturalism in the Age of Capital. Chicago: University of Chicago Press.

Sassen, Saskia (1991): The Global City: New York, London, Tokyo. Princeton: Princeton University Press.

Schär, Bernhard (2012): „Bauern und Hirten reconsidered. Umrisse der ,erfundenen' Schweiz im imperialen Raum“. In: Purtschert, Patricia/Lüthi, Barbara/ Falk, Francesca (Hrsg.): Postkoloniale Schweiz. Formen und Folgen eines Kolonialismus ohne Kolonien. Bielefeld: transcript, S. 315-32.

Schenini, Elio (Hrsg.) (2018): On the Paths of Enlightenment: The Myth of India in Western Culture, 1808-2017 (Katalog zur gleichnamigen Ausstellung MASI Lugano). Genève: Skira.

Schmid, Carl A. (1900): Unsere Fremdenfrage. Zürich: J. Leemann.

Schmid, Carl Alfred (1912): Die Schweiz im Jahre 2000. Zürich: J. Frey.

Schmid, Christian/Weiss, Daniel (2004): The New Metropolitan Mainstream. In: Paloscia, Raffaele/INURA (Hrsg.): The Contested Metropolis: Six Cities at the Beginning of the 21st century. Basel/Boston: Birkhäuser. S. 252-260. 
Schneider, Alexandra (Hrsg.) (2002): Bollywood: Das indische Kino und die Schweiz. Zürich: Museum für Gestaltung.

Schoettli, Urs (2009): Indien: Profil einer neuen Grossmacht. Paderborn et al.: Verlag Neue Zürcher Zeitung.

Schumann, Antje (2004): race_gender_class. Zur postkolonialen Kultur des Nationalen. Eine feministische Kritik. Dissertation Amerika-Institut, Ludwig-Maximilians-Universität, München.

Schwab, Andreas (2003): Monte Verita - Sanatorium der Sehnsucht. Zürich: Orell Füssli Verlag.

Schweizer, Peter A. (2008): The Indian-Swiss Treaty of Friendship and Establishment of 14 August 1948. In: Imhasly, Bernard (Hrsg.): Friendship in Diversity. Sixty Years of Indo-Swiss Relations. Hyderabad: Universities Press. S. 13-24.

Schweizerischer Verband der Bürgergemeinden und Korporationen (Hrsg.) (1989): Ausländer in der Gemeinde. Bern: Eidgenössische Kommission für Ausländerprobleme.

Shah, Priya J. (2004): Second-Generation Indian Americans and the Trope of Arranged Marriage. Online: http://escholarship.org/uc/item/854797t2.

Shankar, Shalini (2008): Desi Land: Teen Culture, Class, and Success in Silicon Valley. Durham: Duke University Press.

Sharma, Sanjay/Hutnyk, John/Sharma, Ashwani (Hrsg.) (1996): Dis-Orienting Rythms: The Politics of the New Asian Dance Music. London/Atlantic Highlands: Zed Books.

Shukla, Sandhya (2003): India Abroad: Diasporic Cultures of Postwar America and England. Princeton: Princeton University Press.

Simmel, Georg (2006): Die Großstädte und das Geistesleben. Frankfurt a. M.: Suhrkamp.

Skenderovic, Damir/D'Amato, Gianni (2008): Mit dem Fremden politisieren: Rechtspopulistische Parteien und Migrationspolitik in der Schweiz seit den 1960er Jahren. Zürich: Chronos.

Sklair, Leslie (2001): The Transnational Capitalist Class. Oxford/Malden: Blackwell.

Smith, Anthony D. (1986): The Ethnic Origins of Nations. Oxford/ Cambridge: Blackwell.

Smith, Michael/Guarnizo, Luis (1998): Transnationalism from Below. New Brunswick: Transaction Publishers.

Sollors, Werner (1986): Beyond Ethnicity: Consent and Descent in American Culture. New York: Oxford University Press.

Spradley, James P. (1980): Participant Observation. New York: Holt, Rinehart and Winston.

Steingart, Gabor (2006): Weltkrieg um Wohlstand: Wie Macht und Reichtum neu verteilt werden. München: Piper. 
Stocking, George W. (1987): Victorian Anthropology. New York/London: Free Press.

Stolcke, Verena (1995): Talking Culture: New Boundaries, New Rhetorics of Exclusion in Europe. In: Current Anthropology 36(1), S. 1-24.

Stonequist, Everett V. (1935): The Problem of the Marginal Man. In: American Journal of Sociology 41(1), S. 1-12.

Strasser, Sabine (2014): Post-Multikulturalismus und „repressive Autonomie“: Sozialanthropologische Perspektiven zur Integrationsdebatte. In: Nieswand, Boris/Drotbohm, Heike (Hrsg.): Kultur, Gesellschaft, Migration. Die reflexive Wende in der Migrationsforschung. Wiesbaden: Springer. S. 41-68.

Strauss, Anselm (1991): Grundlagen qualitativer Sozialforschung: Datenanalyse und Theoriebildung in der empirischen soziologischen Forschung. München: W. Fink.

Strauss, Sarah (2005): Positioning Yoga: Balancing Acts Across Cultures. Oxford/ New York: Berg.

Studer, Brigitte/Arlettaz, Gérald/Argast, Regula (2008): Das Schweizer Bürgerrecht: Erwerb, Verlust, Entzug von 1848 bis zur Gegenwart. Zürich: Verlag Neue Zürcher Zeitung.

Studienkommisssion (1964): Das Problem der ausländischen Arbeitskräfte: Bericht der Studienkommission für das Problem der ausländischen Arbeitskräfte. Bern: Schweiz. Bundesamt für Industrie, Gewerbe und Arbeit.

Suter Reich, Virginia (2013): Zwischen Differenz, Solidarität und Ausgrenzung: Inkorporationspfade der alevitischen Bewegung in der Schweiz und im transnationalen Raum. Zürich: Chronos.

Taylor, Charles (1992): The Politics of Recognition. In: Gutmann, Amy (Hrsg.): Multiculturalism and „The Politics of Recognition“. Princeton: Princeton University Press. S. 25-73.

Terkessidis, Mark (2004): Die Banalität des Rassismus: Migranten zweiter Generation entwickeln eine neue Perspektive. Bielefeld: Transcript.

Terkessidis, Mark (2010): Interkultur. Berlin: Suhrkamp.

Thapan, Meenakshi (2004): Embodiment and identity in contemporary society: Femina and the ,new“ Indian woman. In: Contributions to Indian Sociology 38(3), S. 411-444.

Therwath, Ingrid (2007): Working for India or against Islam? Islamophobia in Indian American Lobbies. In: South Asia Multidisciplinary Academic Journal. Online: http://samaj.revues.org/262

Thomas, Rosie (1995): Melodrama and Negotiation of Morality in Mainstream Hindi Cinema. In: Breckenridge, Carol A. (Hrsg.): Consuming Modernity. Public Culture in a South Asian World. Minneapolis/London: University of Minnesota Press. S. 157-182.

Thomson, Mark/Crul, Maurice (2007): The Second Generation in Europe and the United States: How is the Transatlantic Debate Relevant for Further Research 
on the European Second Generation? In: Journal of Ethnic and Migration Studies 33(7), S. 1025-1042.

Tölölyan, Khachig (1991): The Nation-State and Its Others: In Lieu of a Preface. In: Diaspora 1(1), S. 3-7.

Uberoi, Patricia (2006): Freedom and Destiny: Gender, Family, and Popular Culture in India. New Delhi/New York: Oxford University Press.

Upadhiya, Carol (2008): Rewriting the Code: Software Professionals and the Reconstitution of Indian Middle Class Identity. In: Jaffrelot, Christophe/ van der Veer, Peter (Hrsg.): Patterns of Middle Class Consumption in India and China. New Delhi: Sage. S. 55-87.

Varma, Pavan K. (1998): The Great Indian Middle Class. New Delhi/New York: Viking.

Vasudevan, Ravi (2011): The Melodramatic Public: Film Form and Spectatorship in Indian Cinema. New York: Palgrave Macmillan.

Veer, Peter van der (1994): Religious Nationalism. Hindus and Muslims in India. Berkeley: University of California Press.

Veer, Peter van der (2002): Colonial Cosmopolitanism. In: Cohen, Robin/Vertovec, Steven (Hrsg.): Conceiving Cosmopolitanism: Theory, Context, and Practice. Oxford et al.: Oxford University Press. S. 195-180.

Veer, Peter van der (Hrsg.) (1995): Nation and Migration. The Politics of Space in the South Asian Diaspora. Philadelphia: University of Philadelphia Press.

Velho, Astride (2010): Un-Tiefen der Macht. Subjektivierung unter den Bedingungen von Rassismuserfahrungen in der Migrationsgesellschaft. In: Mecheril, Paul/Broden, Anne (Hrsg.): Rassismus bildet. Bildungswissenschaftliche Beiträge zu Normalisierung und Subjektivierung in der Migrationsgesellschaft. Bielefeld: transcript. S. 113-137.

Vertovec, Steven (1999): Conceiving and researching transnationalism. In: Ethnic and Racial Studies 22(2), S. 447-462.

Vertovec, Steven (2000): The Hindu Diaspora: Comparative Patterns. London/ New York: Routledge.

Vertovec, Steven/Wessendorf, Susanne (Hrsg.) (2010): The Multiculturalism Backlash: European Discourses, Policies and Practices. London/New York: Routledge.

Virot, Marc (1968): Vom Anderssein zur Assimilation. Merkmale zur Beurteilung der Assimilationsreife der Ausländer in der Schweiz. Bern: Haupt.

Völter, Bettina/Schäfer, Thomas (2005): Subjekt-Positionen. Michel Foucault und die Biographieforschung. In: Völter,Bettina/ Dausien, Bettina/ Rosenthal, Gabriele/ Lutz, Helma (Hrsg.): Biographieforschung im Diskurs. Wiesbaden: VS Verlag für Sozialwissenschaften. S. 161-188.

Vora, Neha (2013): Impossible citizens: Dubai's Indian diaspora. Durham/London: Duke University Press. 
Waldrop, Anne (2004): Gating and Class Relations: the case of a New Delhi "colony". In: City \& Society 16(2), S. 93-116.

Wansleben, Leon (2013): 'Dreaming with BRICs'. In: Journal of Cultural Economy 6(4), S. 453-471.

Waters, Mary C. (1990): Ethnic Options: Choosing Identities in America. Berkeley: University of California Press.

Weber, Max (1972): Wirtschaft und Gesellschaft. Tübingen: Mohr.

Weingart, Peter/Bayertz, Kurt/Kroll, Jürgen (1992): Rasse, Blut und Gene: Geschichte der Eugenik und Rassenhygiene in Deutschland. Frankfurt a. M.: Suhrkamp.

Weiss, Anja (2005): The Transnationalization of Social Inequality: Conceptualizing Social Positions on a World Scale. In: Current Sociology 53(4), S. 707-728. Weissköppel, Cordula (2011): Die Kultur der Väter verstehen: Ethnoreligiöse Sozialisation von Jugendlichen im transnationalen Beziehungsgefüge der koptisch-orthodoxen Kirche in der Schweiz. In: Allenbach, Brigit/ Goel, Urmila/ Hummrich, Merle/ Weissköppel Cordula (Hrsg.): Jugend, Migration und Religion - Interdisziplinäre Perspektiven. Baden-Baden: Nomos. S. 159-195.

Wekker, Gloria (2016): White Innocence: Paradoxes of Colonialism and Race. Durham: Duke University Press.

Werbner, Pnina (2006): Vernacular Cosmopolitanism. In: Theory, Culture \& Society 23 (2-3). S. 496-98.

Werbner, Pnina (Hrsg.) (2008): Anthropology and the New Cosmopolitanism Rooted, Feminist and Vernacular Perspectives. Oxford/New York: Berg.

Wessendorf, Susanne (2007): Sushi-eating secondos and Casual Latins. Political movements and the emergence of a Latino counter-culture among second-generation Italians in Switzerland. In: Journal of Intercultural Studies 28(3), S. 345-360.

Wessendorf, Susanne (2008): Culturalist discourses on inclusion and exclusion: The Swiss citizenship debate. In: Social Anthropology/ Anthropologie Sociale 16, S. 187-202.

Wessendorf, Susanne (2013): Second-Generation Transnationalism and Roots Migration Cross-Border Lives. Farnham/Burlington: Ashgate.

Wicker, Hans-Rudolf (2003): Einleitung: Migration, Migrationspolitik und Migrationsforschung. In: Wicker, Hans-Rudolf/Fibbi, Rosita/Haug, Werner (Hrsg.): Migration und die Schweiz. Ergebnisse des Nationalen Forschungsprogramm „Migration und interkulturelle Beziehungen“. Zürich: Seismo. S. 12-62.

Wicker, Hans-Rudolf (2009): Die neue Schweizerische Integrationspolitik. In: Piñeiro, Esteban/Bopp, Isabelle/Kreis, Georg (Hrsg.): Fördern und Fordern im Fokus: Leerstellen des schweizerischen Integrationsdiskurses. Zürich: Seismo. S. 23-47. 
Wilkinson-Weber, Clare M. (2011): Diverting Denim: Screening Jeans in Bollywood. In: Miller, Daniel/Woodward, Sophie (Hrsg.): Global Denim. Oxford/ New York: Berg. S. 51-68.

Wimmer, Andreas (2002): Nationalist Exclusion and Ethnic Conflict. Shadows of Modernity. Cambridge/New York: Cambridge University Press.

Wimmer, Andreas (2003): Etablierte Ausländer und einheimische Aussenseiter. Soziale Kategorienbildungen und Beziehungsnetzwerke in drei Immigrantenquartieren. In: Wicker, Hans-Rudolf/Fibbi, Rosita/Haug, Werner (Hrsg.): Migration und die Schweiz. Ergebnisse des Nationalen Forschungsprogramm „Migration und interkulturelle Beziehungen“. Zürich: Seismo. S. 207-236.

Wimmer, Andreas/Glick Schiller, Nina (2002): Methodological Nationalism and Beyond: Nation-State Building, Migration and the Social Sciences. In: Global Networks 2, S. 301-334.

Xiang, Biao (2007): Global „Body Shopping“: An Indian Labor System in the Information Technology Industry. Princeton: Princeton University Press.

Young, Iris Marion (1990): Justice and the Politics of Difference. Princeton: Princeton University Press.

Young, Robert J.C. (1995): Colonial Desire. Hybridity in Theory, Culture and Race. London/New York: Routledge.

Yuval-Davis, Nira (1997): Gender and Nation. London: Sage.

Zangger, Andreas (2011): Koloniale Schweiz: ein Stück Globalgeschichte zwischen Europa und

Ziauddin, Bruno (2010): Curry-Connection. Wie ich zu fünf Tanten, 34 Cousins und einem neuen Namen kam. Reinbek bei Hamburg: Rowohlt.

Zukin, Sharon (2010): Naked City the Death and Life of Authentic Urban Places. Oxford/New York: Oxford University Press. 


\section{Soziologie}
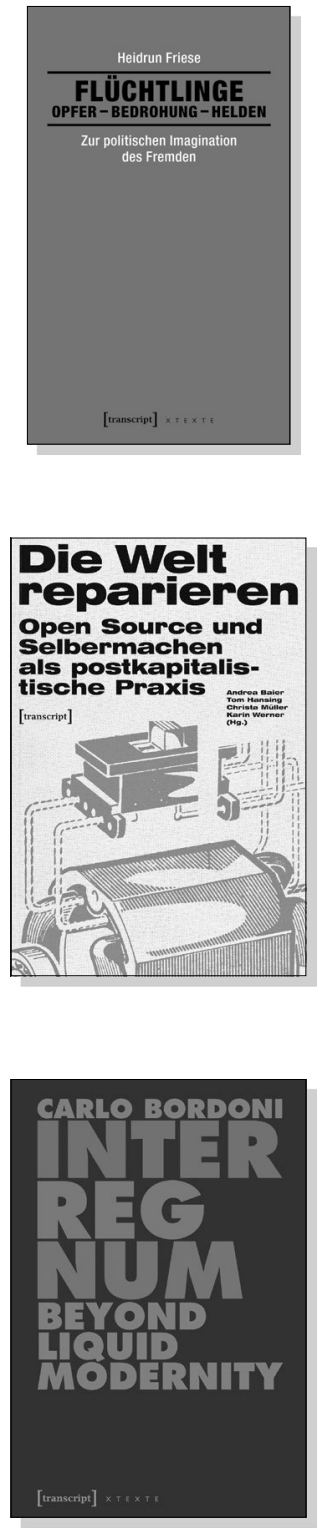

Heidrun Friese

Flüchtlinge: Opfer - Bedrohung - Helden

Zur politischen Imagination des Fremden

August 2017, 150 S., kart.

$14,99 €(D E), 978-3-8376-3263-7$

E-Book

PDF: $12,99 €$ (DE), ISBN 978-3-8394-3263-1

EPUB: $12,99 €(D E)$, ISBN 978-3-7328-3263-7

Andrea Baier, Tom Hansing, Christa Müller, Karin Werner (Hg.)

Die Welt reparieren

Open Source und Selbermachen

als postkapitalistische Praxis

2016, 352 S., kart., zahlr. farb. Abb. 19,99 € (DE), 978-3-8376-3377-1

E-Book: kostenlos erhältlich als 0pen-Access-Publikation ISBN 978-3-8394-3377-5

Carlo Bordoni

Interregnum

Beyond Liquid Modernity

2016, 136 p., pb.

$19,99 €(D E), 978-3-8376-3515-7$

E-Book

PDF: $17,99 €(D E)$, ISBN 978-3-8394-3515-1

EPUB: $17,99 €(D E)$, ISBN 978-3-7328-3515-7 


\section{Soziologie}
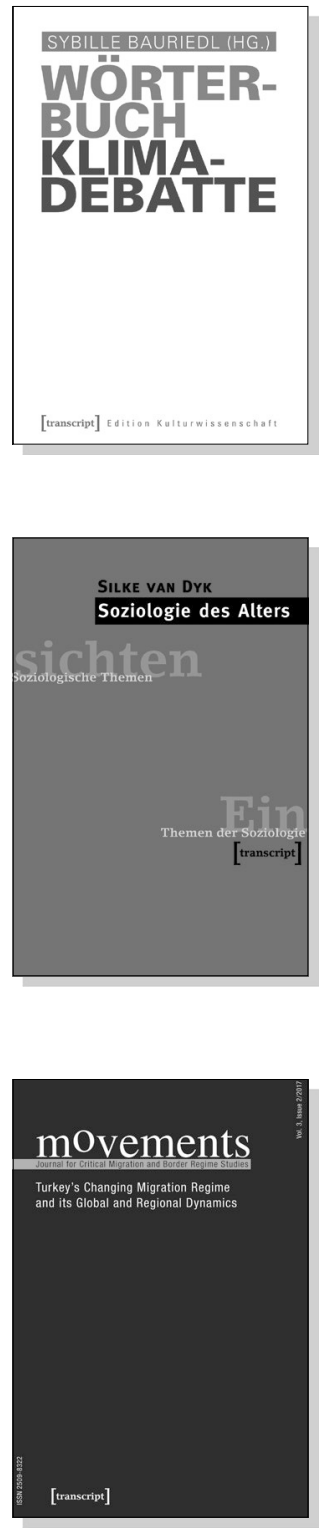

Sybille Bauriedl (Hg.)

\section{Wörterbuch Klimadebatte}

2015,332 S., kart.

$29,99 €(D E), 978-3-8376-3238-5$

E-Book: 26,99 € (DE), ISBN 978-3-8394-3238-9
Silke van Dyk

\section{Soziologie des Alters}

2015, 192 S., kart.

$13,99 €(D E), 978-3-8376-1632-3$

E-Book: $12,99 €(D E)$, ISBN 978-3-8394-1632-7
Ilker Ataç, Gerda Heck, Sabine Hess, Zeynep Kasli, Philipp Ratfisch, Cavidan Soykan, Bediz Yilmaz (eds.)

movements. Journal for Critical Migration and Border Regime Studies

Vol. 3, Issue 2/2017: Turkey's Changing Migration Regime and its Global and Regional Dynamics

November 2017, 230 p., pb.

$24,99 €(D E), 978-3-8376-3719-9$ 
